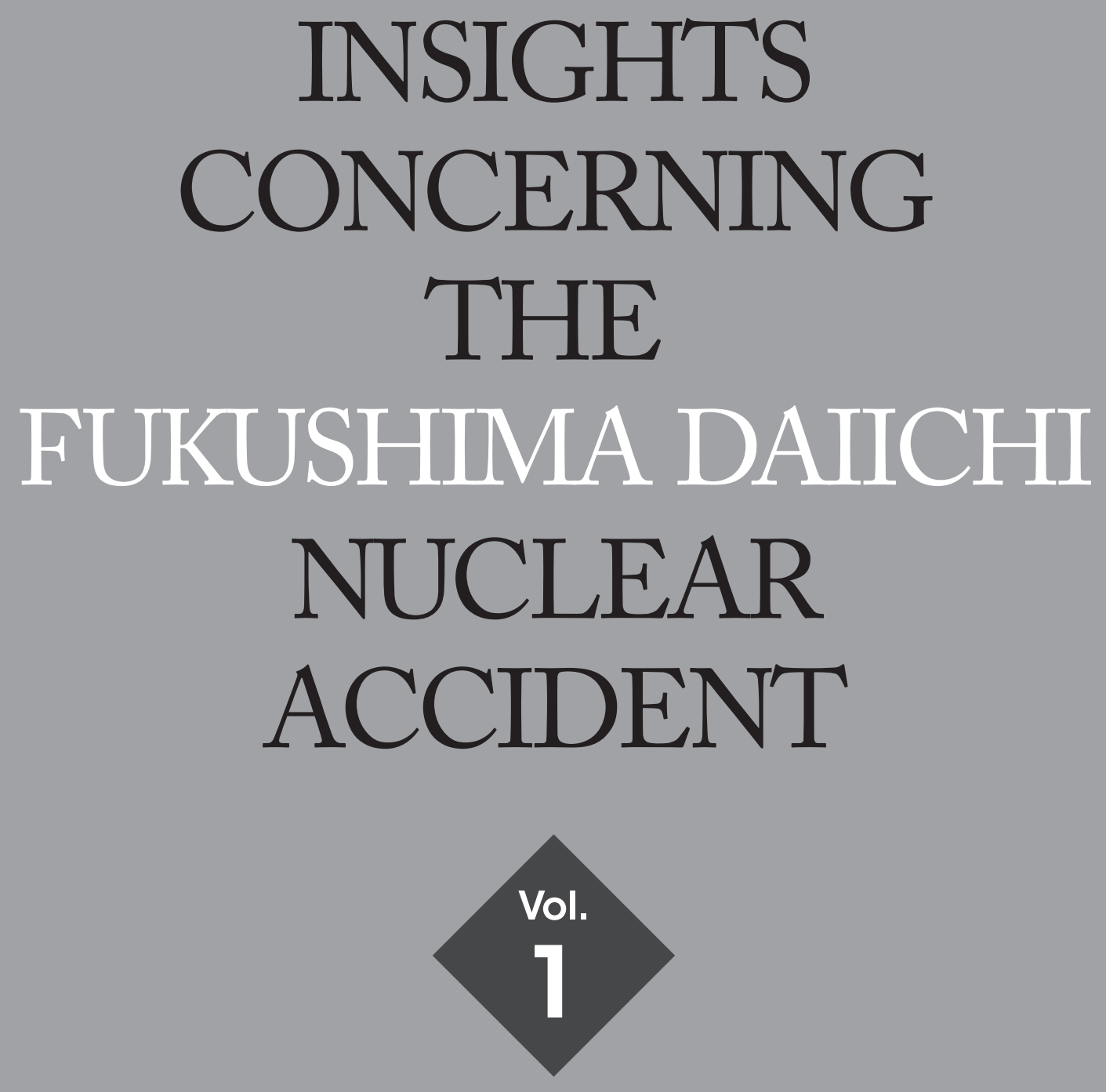

Fears and Concerns Just After the Accident, and Anxiety about Radiation Articles published in $A T O M O \Sigma$ within one year after the accident, and articles on radiation effects on human published in ATOMOE from April 2012 to 2016 


\section{Editor}

Editorial Committee, Atomic Energy Society of Japan

Editor-in-Chief: (Journal) Toyohiko Yano, (Bulletin) Tsutomu Sata

Associate Editor-in-Chief: (Journal) Toshihiko Ohnuki, Cheol Ho Pyeon

(Bulletin) Hidetoshi Okada, Masatoshi Kawashima

Special Working Group for this publication

Toshihiko Ohnuki, Toyohiko Yano, Naoki Yamano

PUBLISHED 2021

ISBN : 978-4-89047-180-5

DOI : 10.15669/fukushimainsights.Vol.1

Copyright @ Atomic Energy Society of Japan 2021. All right reserved.

Published by Atomic Energy Society of Japan

2-3-7, Shinbashi Minato-ku, Tokyo Japan

https://www.aesj.net

This book is not for sale.

This work is subject to copyright. All rights are reserved by the Atomic Energy Society of Japan whether the whole or part of the material is concerned, specifically the rights of translation reprinting reuse of illustrations, recitation, broad casting, reproduction on microfilms or in any other physical way, and transmission or information storage and retrieval, electronic adaptation computer software, or by similar or dissimilar methodology now known or hereafter developed. Exempted from this legal reservation are brief excerpt in connection with reviews or scholarly analysis or material supplied specifically for the purpose of being entered and executed on a computer system, for exclusive use by the purchaser of the work. Duplication of this publication or parts thereof is permitted only under the previsions of the Copyright Law of the Society's location, in its current version, and permission for use must always obtained from the Atomic Energy Society of Japan.

The use of general descriptive names, registered names, trademarks, service marks. etc. in this publication does not imply, even in the absence of a specific statement, that such names are exempt from the relevant protective laws and regulations and therefore free for general use.

While the advice and information in this book are believed to be true and accurate at the date of publication, neither the authors nor the editors can accept any legal responsibility for any errors or omissions that may be made.

Printed on acid-free paper

Printed by Sanbi Printing, Co. Ltd. 5-16-7, Nishi-Nippori, Arakawa-ku, Tokyo Japan https://www.sanbi.co.jp/company/corporate/ 


\section{Preface}

The March 11, 2011 off the Pacific coast of Tohoku Earthquake (also known as the Great East Japan Earthquake) and the severe nuclear accident that was initiated mainly by huge tsunami following the earthquake, inflicted enormous damage to a wide-spread area of Japan. The precious lives of nearly twenty thousand people were lost and a great number of residences and commercial buildings were destroyed by the 9.0 magnitude ( $\mathrm{Mw}$ ) earthquake, one of the greatest quakes in history, and its devastating tsunami. After almost a decade, a large number of people still continue to suffer because of this natural disaster and accident, and live in temporary housing as evacuees. Whereas reconstruction is proceeding in general, some areas have not been restored yet. The huge tsunami after the earthquake damaged equipment of the emergency core cooling systems such as diesel generators of the three nuclear reactors of Units 1 through 3 at the Tokyo Electric Power Company (TEPCO) Fukushima Daiichi Nuclear Power Plant. The subsequent failure of the reflooding resulted in multiple large-scale core meltdowns of Units 1 through 3 under station blackout. During these events, many kinds of radionuclides in large quantities including ${ }^{131} \mathrm{I}$ (estimated at about $150 \mathrm{PBq}$ ) and ${ }^{137} \mathrm{Cs}$ (13 PBq) were released into the atmosphere. This multiple large-scale core meltdown accident is one of the worst nuclear accidents in the world up to now.

After the accident, the Editorial Committee of the Atomic Energy Society of Japan published a large number of commentaries on the various aspects related to the accident through the Society's monthly Japanese language bulletin, Journal of the Atomic Energy Society of

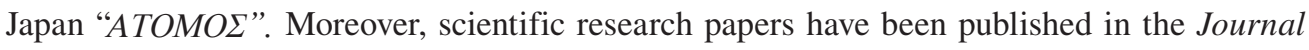
of Nuclear Science and Technology in English, and also in the Transactions of the Atomic Energy Society of Japan in Japanese; both are scientific journals of the Atomic Energy Society of Japan. Within these Fukushima Daiichi nuclear accident-related articles, those written in Japanese were crucial to understanding the situation at that time inside Japan, but they are not easily accessed and understood by persons worldwide. To remedy this situation, we as the Editorial Committee of the Atomic Energy Society of Japan decided to translate them into English and open them to researchers and the general public everywhere. We believe how the accident was tackled and the lessons learned from it are worth considering for preparing countermeasures against severe accidents and for pursuing safer and more secure nuclear power plants.

The collected commentaries and research articles were published in the five-year period beginning just after the accident. Each document has a "chronicle-like importance". What we thought, what we were anxious about, what we expected, what we believed, and what we should do to tackle the accident during that time line were recorded. Professionals in various academic fields were asked to provide these commentaries that represented the most up-todate information for the scientific community and the public. These records trace the recovery from this serious accident. Official reports on the nuclear accident at TEPCO's Fukushima Daiichi Nuclear Power Plant had been published by the Japanese Government, the IAEA, 
and the Atomic Energy Society of Japan; however it was not clear from these reports what we thought or what we were anxious about or what we wanted most to tackle at each time in Japan. Most of the commentaries were written not only for members of the Society but also for the public, including both those who were victims of the accident and those who were residents in Japan. The series of volumes that collected these articles has been entitled "Insights Concerning the Fukushima Daiichi Nuclear Accident, -Five Years' Comprehensive Archive Reports by Scientists and Engineers Published in Japanese from the Atomic Energy Society of Japan-". Each volume is entitled and includes selected articles as below.

\section{Volume 1: Fears and Concerns Just After the Accident, and Anxiety about Radiation}

Articles published in $A T O M O \Sigma$ within one year after the accident, and articles on radiation effects on human published in ATOMOS from April 2012 to 2016

Volume 2: Environmental Effects and Reconsideration of Nuclear Safety Articles on atmospheric dispersion, environmental remediation, decommissioning technology, nuclear safety and regulation published in ATOMO from April 2012 to FY2016

Volume 3: Impacts on the Public

Articles on social science published in ATOMOE from April 2012 to 2016

Volume 4: Endeavors by Scientists

Research and technical papers published in 2011-2016 in the Transactions of the Atomic Energy Society of Japan

Five years after the accident, many related articles still continued to be published. However, we thought that the situation during these first five years was more serious and, therefore it was more important to remember the articles appearing during this time. Many research papers published in the Journal of Nuclear Science and Technology (JNST) were written in English, and we have excluded them from these volumes. We ask interested readers to refer to these articles on the JNST journal web page, particularly in the special issues on the Fukushima Daiichi Nuclear Accident or papers identified as "Fukushima Daiichi NPP Accident related".

As we approach the end of the first quarter of the 21st century, populations are increasing rapidly in developing countries and improved living standards in those areas are sharply increasing energy consumption. At the same time, fears of great global environmental problems due to the consumption of fossil fuels are taking root, and there are also fears of food and safe water shortages. Among those issues, it is well accepted that an increase in atmospheric $\mathrm{CO}_{2}$ concentration is causing global warming and abnormal weather patterns that may cause serious damage to life as we know it on the Earth. To reduce emissions of greenhouse gases while securing the energy necessary for our life is a great challenge for all of us. Moreover, at present coronavirus COVID-19 is spreading worldwide rapidly, and more than 82 million people were suffered and 1.8 million people have passed away as of the end of 2020, and numbers still rapidly increasing. A higher quality of life supported by sufficient energy also can reduce susceptibility to unknown diseases. In these regards, there were great expectations 
for nuclear energy as well as renewable energies. The most dangerous aspect of nuclear energy was revealed to the public by the Fukushima Daiichi nuclear accident. We must humbly recognize the risks involved in the enormous energy release from the atomic nucleus, and then, reconstruct a safer nuclear system than ever before, in light of the important lessons learned from the 2011 accident. We believe the collected expertise in the volumes of this series forms an indispensable history for that purpose.

Finally, we would like to express our deep gratitude to Mrs. Kumiko Kishimoto of the Atomic Energy Society of Japan for her helpful assistance in all stages of this publication.

\author{
Toshihiko Ohnuki \\ Toyohiko Yano \\ Naoki Yamano
}

Note: The contents of Volumes 1 to 3 are only selected articles from the Journal Atomic Energy Society of Japan, ATOMOГ. Original Japanese articles can be accessed free of charge through J-STAGE website with color figures. Besides articles included into these volumes, so many commentaries/ opinions/technical reports related to the Fukushima Daiichi Nuclear Plant Accident were published in $A T O M O \Sigma$ from aftermath of the accident to date.

https://www.jstage.jst.go.jp/browse/jaesjb/63/2/_contents/-char/en

About the original Japanese papers in Volume 4, you can also access free of charge through web page of the Transactions of the Atomic Energy Society of Japan in J-STAGE.

https://www.jstage.jst.go.jp/browse/taesj/-char/en

Fukushima Daiichi Nuclear Plant Accident related papers already translated into English were excluded from this volume. 


\section{Administrative Map of East Part of Fukushima Prefecture}

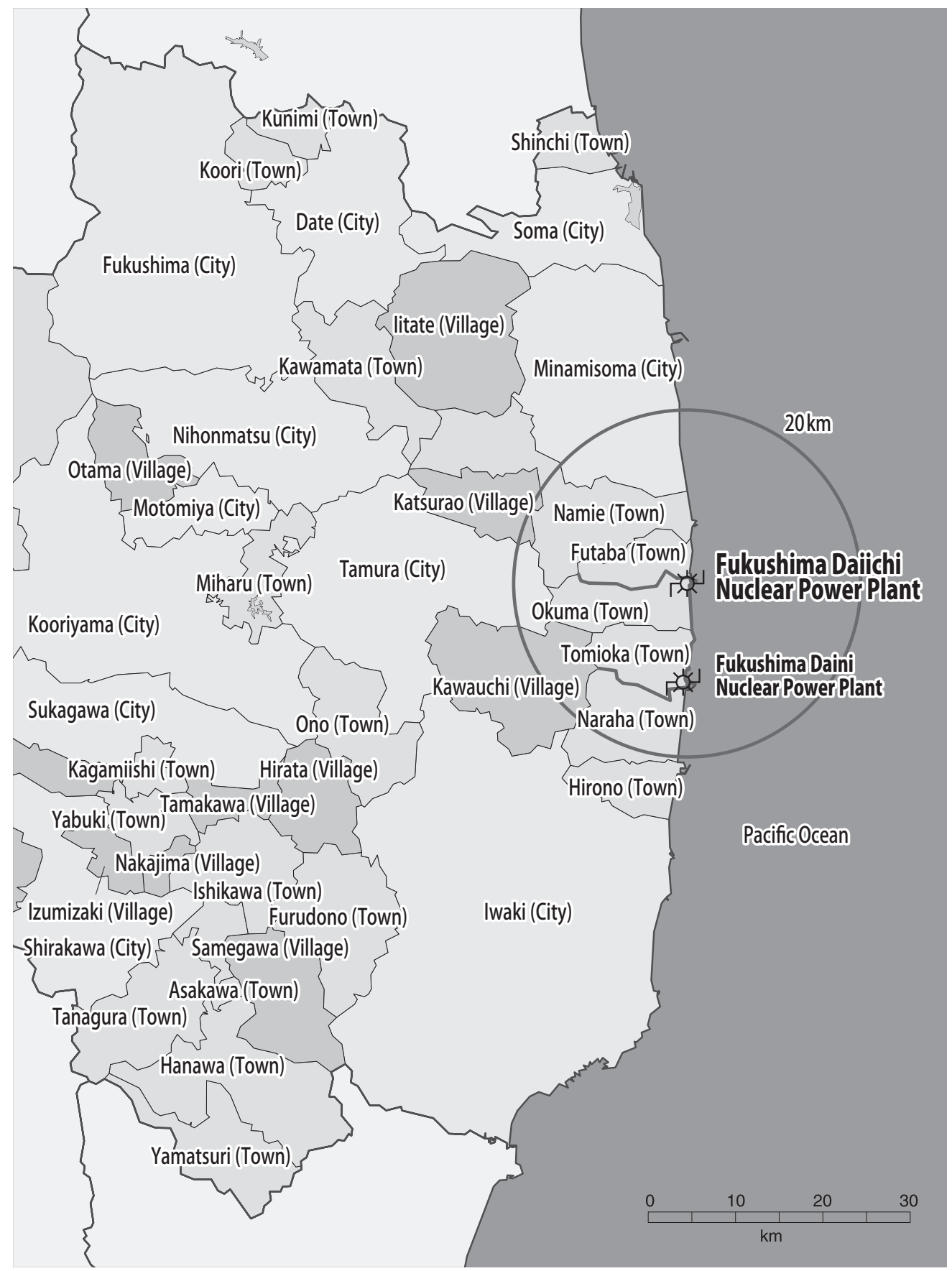




\title{
CONTENTS OF VOLUME 1
}

\section{Part I. Articles within One Year from the Accident}

\author{
Fukushima 1st NPPs Accidents and Disaster Caused by the Pacific Coast Tsunami of \\ Tohoku Earthquake \\ -Lessons from Evaluation of the Fukushima 1st NPPs Accidents-
}

-. Tadashi Narabayashi and Kenichiro Sugiyama

(June, 2011)*

The Disaster by the Fukushima Nuclear Power Plants and the Risk Science

Impacts of Fukushima Daiichi NPP Accident through Atmospheric Environment

-First Step Toward Grasping Comprehensive Overview of Environmental Impact-

Hiromi Yamazawa and Shigekazu Hirao

View of Environmental Monitoring in Emergency

-Based on the guide by Japan Nuclear Safety Commission-

Recent Nuclear Policy Trends in Major Countries Post Fukushima Accident

Lessons Learned from Fukushima Daiichi Nuclear Power Plant Accident

Hisashi Ninokata and Koji Okamoto

The Science and Technology Communication in a Post 3/11 World

-How Can the Public Have Trust in Nuclear Experts?-

Behavior of Spent LWR Fuel Decay Heat

-For Better Insight into Fukushima-Daiichi Accident-

\section{Long-term Impact on the Marine Environment}

-Simulation of the Marine Dispersion of Released Radionuclides from Fukushima-Daiichi Nuclear Power Plant and Estimation of Internal Dose from Marine Products- 
Close Look at the Accident in Fukushima Dai-ichi Nuclear Power Plant and What-if

Remediation of Contamination from Radioactive Material by the Fukushima Dai-ichi Nuclear Power Plant Accident

Mental Health in the Atomic Energy Research Institution

-From the Viewpoint of Occupational Physician-

The Circumstances of Severe Accident Measure Implementation and "The Residual Risk"

Waste Contaminated with Radioactive Material from the Fukushima Dai-ichi Nuclear Power Plant Accident

-Relation between Amount of Radioactive Material in Waste and Related Laws-

Lessons Learned from the Initial Response to Nuclear Disaster caused by Fukushima Nuclear Power Plants Accident

-Monitoring and Use of Radiation Information-

\section{Requirement for Qualification and Expertise of Nuclear Regulatory Body}

-To Prevent the Recurrence of the Fukushima Daiichi Nuclear Power Plant Accident-

Why was Introduction of Station Blackout Regulation Late?

-Failure to Apply Knowledge of Possible Major Tsunamis to Protect the Fukushima Daiichi Nuclear Power Plant-

\section{Discussion on Station Blackout}

For Promoting Remediation of Contaminated Area; Principle of Remediation Methods -From Tests at Date-city and Iitate-mura in Fukushima Prefecture-

Distribution of Dose-Rates and Deposition of Radioactive Cesium by the Airborne Monitoring Surveys 
Difficulties in Treatment of Contaminated Water in Fukushima-1 Nuclear Power Plant and Disposal of its Secondary Waste

-Proposal of Countermeasures with Focus on Disposal-

Isao Yamagishi, Hitoshi Mimura and Kazuya Idemitsu

(March, 2012)*

\section{Crisis Communication at the Fukushima Accident and the Concept of Crisis}

Management

-What is the information dissemination for?- 


\section{Part II. Effects of Radiation (Published from April 2012 to 2016)}

New Standard Limits for Radionuclides in Foods

Tomoyuki Takahashi

(September, 2012)*

The Effects of the Nuclear Disaster at Fukushima Daiichi Nuclear Power Station on Local Governments

Makoto Nakamura and Kinji Dake

(October, 2012)*

\section{Present Situation of Radioactivity Distribution}

-Summary of Initial Activity Situation-

Takashi Nakamura, Takuma Momose and Tetsuo Iguchi

(November, 2012)*

\section{Application of Reference Levels in the Existing Exposure Situations}

-Towards Stepwise Reduction of Radiation Dose Depending on Situations of Contamination-

- Haruyuki Ogino, Nobuyuki Hamada and Daisuke Sugiyama

(February, 2013)*

\section{Considering Risks of Food and Radiation}

-Cancer Risk Assessment-

Chikako Uneyama

(October, 2013)*

\section{Preventing a Second Chernobyl}

-The Results of Efforts to Eliminate the Effects of Fukushima's Low-dose Radiation Contamination-

The Reconsider Linear Non-Threshold (LNT) Hypothesis of Radiation Effect on Living Object

..--.--.- Yuichiro Manabe, Issei Nakamura, Hiroo Nakajima, Yuichi Tsunoyama and Masako Bando

(November, 2014)*

Low-dose Radiation Effects to Humans and the Importance of Eating Wisely

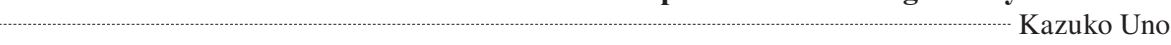

(April, 2015)*

Radiation and Children's Health

Yoko Ichikawa

(April, 2015)*

Radiation Dose Registration System for Decontamination Works and Dose Distribution of Workers

Kenjiro Miyabe, Atsuo Itoh, Tsuneo Yasutake and Tsubasa Ogawa

(August, 2015)*

Sheltering or Evacuation?

Role of Emergency Monitoring in Nuclear Disaster Control

Hiromi Yamazawa, Hideki Kimura, Yoshihiro Koyama and Toshiki Iwasaki

(February, 2016)*

* Original date of Publishing in ATOMO $\Sigma$ (in Japanese) 


\section{Part I}

Articles within One Year from the Accident 



\title{
Fukushima 1st NPPs Accidents and Disaster Caused by the Pacific Coast Tsunami of Tohoku Earthquake
}

\author{
-Lessons from Evaluation of the Fukushima 1st NPPs
} Accidents-

\author{
Hokkaido University, Tadashi Narabayashi and Kenichiro Sugiyama
}

The Fukushima Daiichi Nuclear Power Stations (NPSs) Accidents were an unprecedented severe accident that were triggered by the 2011 Off the Pacific Coast huge earthquake of magnitude 9.0 and a great tsunami, which occurred and progressed simultaneously in multiple units. This situation was reported in the mass media one by one, and many people experienced the devastation of the nuclear power station accident and the fear of radiation contamination. From the viewpoint of defense in depth, people involved in nuclear energy should conduct comprehensive inspection of the safety facilities available in nuclear power stations with a firm resolution to not cause any trouble to the residents regardless of the disaster type. The authors hope that the nuclear energy of Japan will recover based on these lessons.

\section{Introduction}

The 2011 Off the Pacific Coast of Tohoku Earthquake occurred at 14:46:18 on March 11, 2011, with epicenter at Japan's Sanriku off the Pacific Coast. It was a massive earthquake with a magnitude of 9.0, which generated a large tsunami on the Pacific Coast from Hokkaido to Chiba Prefecture, causing devastating damages, especially in northeastern area of Japan. This earthquake was named the 2011 Off the Pacific Coast of Tohoku Earthquake. Several thermal and nuclear power stations built on this coast were damaged and their operations tripped. Especially in Units 1-4 of Fukushima Daiichi Nuclear Power Station (NPS), which are operated by Tokyo Electric Power Company (TEPCO), both the external and emergency power units were lost, and after losing the core cooling function, the core melt down. Additionally, water supply to the spent fuel pools was stopped within a few days. As a result of core damage, radioactive materials were released into the atmosphere, which caused radioactive contamination not only on the surrounding area but also the water reservoirs even in the metropolitan area.

It was a serious accident that should not have occurred at a commercial nuclear power station. In the midst of unbearable situations reported in the media, such as the people whose

DOI : 10.15669/fukushimainsights.Vol.1.3

(C) 2021 Atomic Energy Society of Japan. All rights reserved.

Originally published in Journal of the Atomic Energy Society of Japan (ISSN 1882-2606), Vol. 53, No. 6, p. 387-400 (2011)

in Japanese. (Japanese version accepted: May 6, 2011) 
suffering from the tsunami damage was worsened by the forced emergency evacuation; disposal of contaminated vegetables, milk, and fishery; the slaughters of surviving livestock; and the damage caused by the rumors spread by media articles, the authors of this paper, who have been studying the nuclear safety and severe accident, followed the transition of the accident and conducted data analysis while hoping for an early convergence of the accident. In future, it is necessary to conduct detailed investigation of the accident and the analysis of its cause, and urgently take safety measures to avoid repeating the same situation. This commentary summarizes the research and analysis results obtained so far.

\section{Outline of the Fukushima Nuclear Power Station Accident}

\section{Outline of the Earthquake Disaster}

During this disaster, an earthquake of magnitude 9.0 triggered a large tsunami along the Pacific Coast, which stopped the operation of many large thermal and nuclear power stations along the Pacific Coast of northeastern Japan, except some thermal power plant and Kashiwazaki-Kariwa NPS of Japan sea side (Figure 1). This led to a loss in the external power over a wide area ${ }^{1,2)}$.

Since these nuclear power stations on the coast underwent seismic reinforcement work, their class A earthquake-proof reactor building (R/B) or the components inside the reactors were sound after even the severe earthquake. After losing the external power supplies, the scram and emergency diesel generator (EDG) were started immediately, followed by the emergency core cooling system (ECCS). However, the tsunami that hit the Pacific Coast about one hour later led to a serious situation. Especially at the Fukushima Daiichi Nuclear Power Station, which is operated by TEPCO, the loss in all the external and emergency power sources, i.e., station blackout, and the loss of cooling and heat removal of fuels in the core and water supply of spent fuel storage pool caused the core damage, resulting in the radioactive materials being released into the atmosphere and causing severe impacts of radioactive contamination on the surrounding area $\mathrm{a}^{3,4)}$.

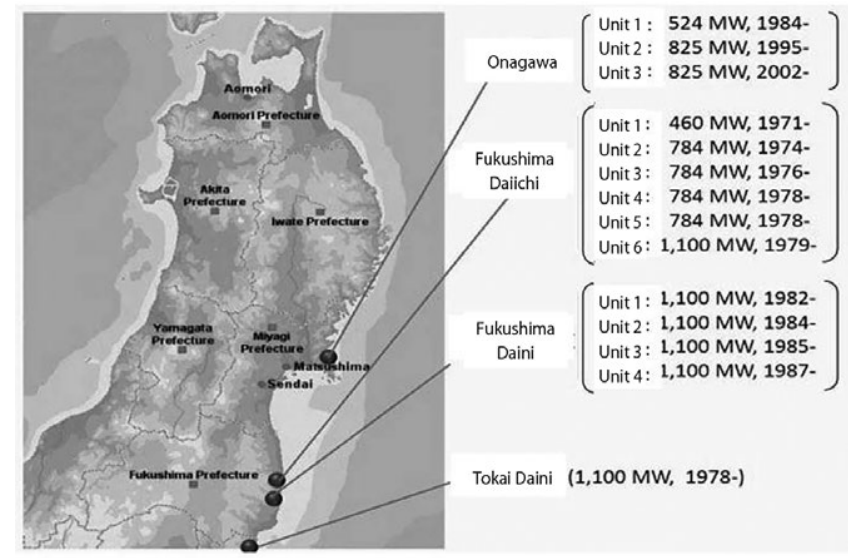

Figure 1 Nuclear power stations affected by the Great East Tohoku earthquake ${ }^{1)}$ 


\section{Impacts of the Earthquake and Tsunami on Fukushima Daiichi Nuclear Power Station}

The impact of the tsunami, which was a main cause of this accident, should be explained. The assumed maximum height of the tsunami (Japan Society of Civil Engineers, revised in 2002), was $5.7 \mathrm{~m}$ above the standard sea level, and the construction for the tsunami countermeasures had already been completed. However, the height of tsunami at this time was 14 $15 \mathrm{~m}$ above the standard sea level, hitting most of the R/B area, and the turbine building (T/B) was flooded with 4-5 $\mathrm{m}$ water. Therefore, some underground trench with an opening on the ground or the large component delivery entrance of the T/B was also partially damaged and became the route for seawater flowing into the R/B. It was possible to prevent the seawater flowing directly into R/B to some extent owing to its airtight structure; however, an onsite investigation of underground corridor between $\mathrm{R} / \mathrm{B}$ and $\mathrm{T} / \mathrm{B}$ needs to be conducted to ascertain this. There were also infiltration of seawater into a radioactive waste building ( $\mathrm{Rad}$ ) on the south side of Unit 1. According to Figure 2 (a), one of the two heavy oil tanks installed near the water intake of Unit 1 was swept away by the buoyancy of tsunami, whereas the other was carried to the road on the north side of Unit 1. The earthquake-proof class A equipments, such as the condensed water storage tank or the diesel fuel tank, were used for the EDG. On

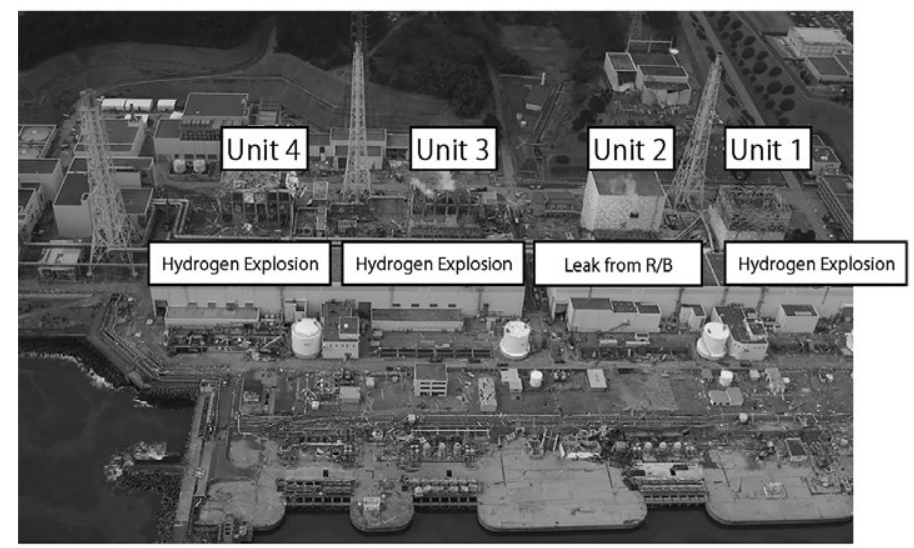

(a) Panoramic view of Fukushima Daiichi Nuclear Power Station (After hydrogen explosion) (Photograph by Air Photo Service)

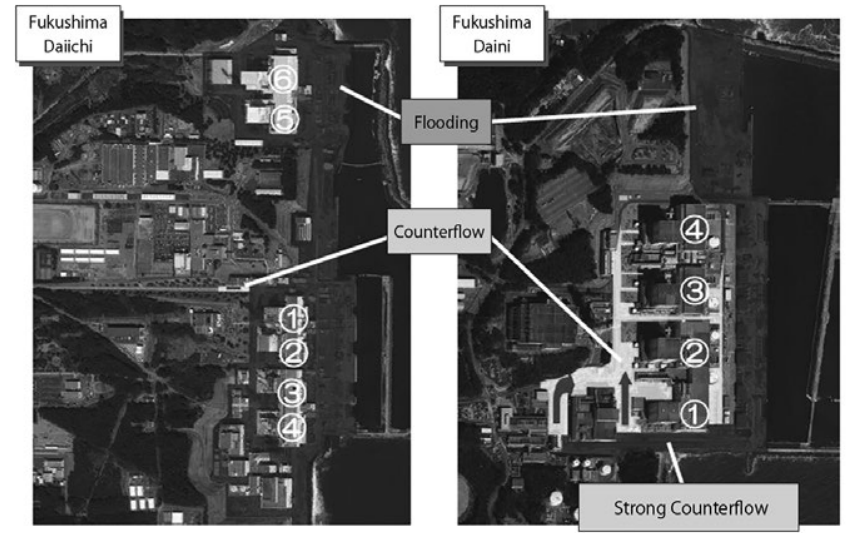

(b) Flooding and retroactive flow area after the tsunami (Fukushima Daiichi, Fukushima Daini) ${ }^{1)}$

Figure 2 Damage caused by the tsunami at Fukushima Daiichi and Daini Power Stations 
the other hand, extensive damage was caused in the seawater pump to supply cooling water for EDG and ECCS pump motors via heat exchanger. For instance, the motor of the seawater pumps that were under periodic inspection were swept away as far as near the seawater pump for Unit 2, as shown in Figure 2 (a).

Figure 2 (b) shows a comparison of the areas in Fukushima Daiichi and Daini Power Stations where flooding or retroactive flow was observed after the tsunami. The flooded area of Daiichi was larger, and as shown in Figure 3, it experienced station blackout caused by the loss of external power supplies and the unavailability of the EDG due to seawater infiltration.

Although the condensed water storage tank or the excess water of the waste processing tank was considered as the supply source of freshwater, most of the freshwater was injected into the reactor core. Meanwhile, there is 2.84 million tons of water in Sakashita Dam ${ }^{5}$, as shown in Figure 4, which was constructed during the construction of Daiichi Power Station to be used as a water source in the power station. Since there was a fresh water supply pipe from the dam to the sedimentation tank inside the power station premises, using this water was considered to be the most effective. However, the piping was damaged by the earthquake and repaired by the Self Defense Force. This water from the dam became usable only after more than 10 days since the start of seawater injection. During this time, securing freshwater was constantly an important issue; for example, the barges of the U.S. Army filled with freshwater came forward to provide water as help measures.

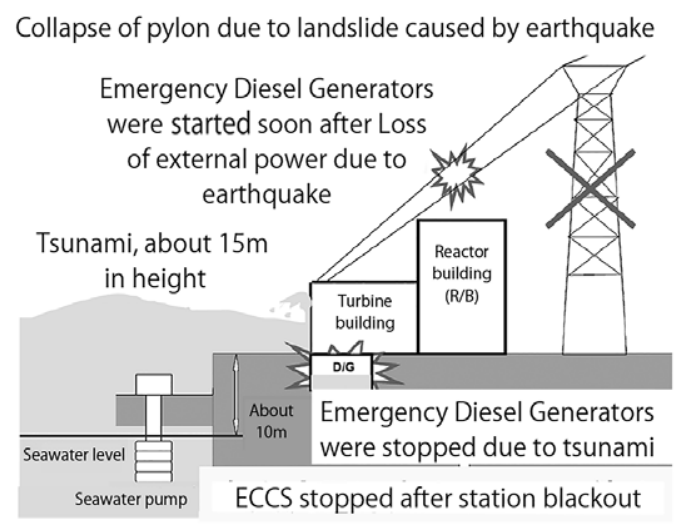

Figure 3 Station blackout caused by earthquake and tsunami ${ }^{1)}$

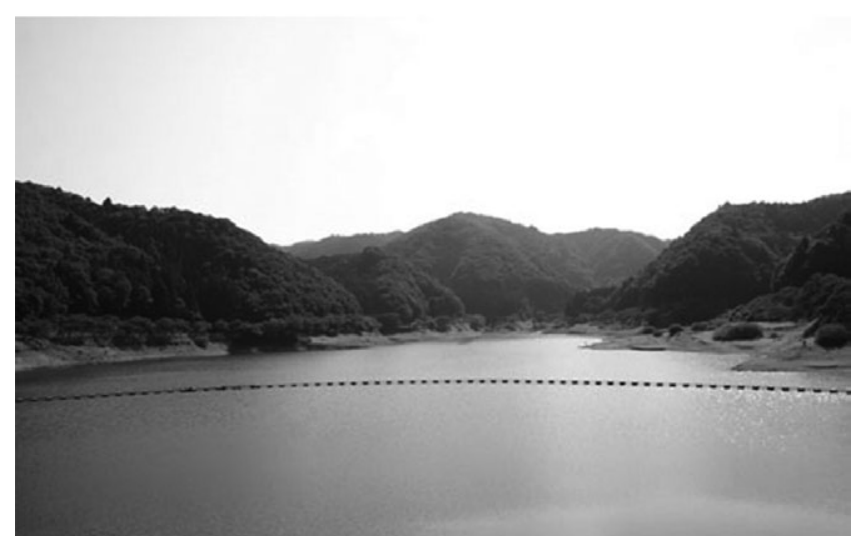

Figure 4 Sakashita Dam (Capacity 2.84 million ton) ${ }^{5)}$ 


\section{Safety System and Building Layout of Fukushima Daiichi Nuclear Power Station}

Figure 5 shows the system configuration of ECCS of BWR/4, which consists of a core spray (CS) and two low-pressure core injection (LPCI) systems. Each system is connected to its own EDG, which starts automatically when the external power supplies are lost. Moreover, it is equipped with a high-pressure core injection (HPCI) system driven by a steam turbine and reactor core isolation cooling (RCIC) system (nonsafety system). Unit 1 is BWR/3 and equipped with a passive isolation condenser (IC) instead of RCIC. It condenses the steam from the nuclear reactor and returns condensed water to the reactor core. Approximately 10 min after the IC starts, the steam generated from the secondary side of the pool is blown from the exhaust pipe of the R/B wall. When the HPCI or RCIC becomes unavailable, the main steam safety relief valve (SRV) is forced open; the main steam in reactor pressure vessel (RPV) is released into a doughnut-shaped suppression chamber, called torus (Figure 6), to reduce the pressure in the RPV, and water is injected using the LPCI. Besides the suppression chamber (S/C), the primary containment vessel (PCV) comprises flask-shaped drywell, S/C, and vent pipes that connect them. Headers are connected to the vent pipes and are attached to

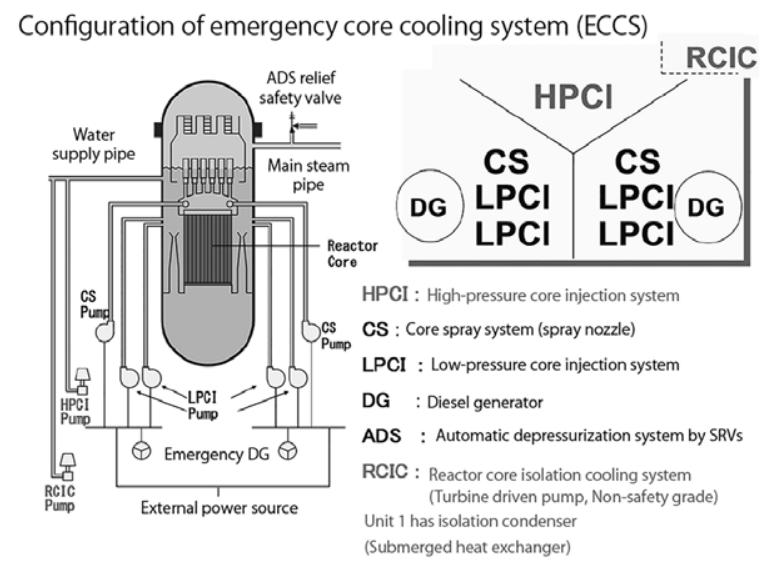

Figure 5 System configurations of ECCS of BWR/4 ${ }^{6)}$

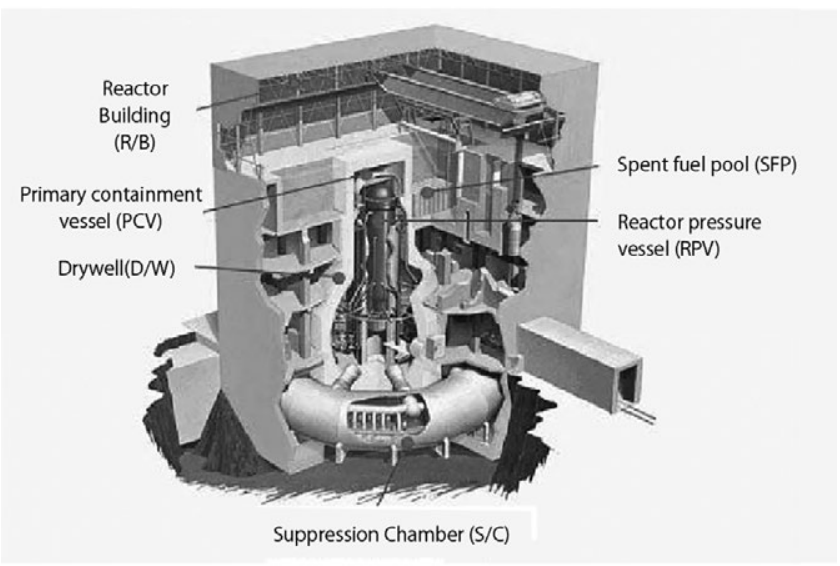

Figure 6 Mark-I Type PCV ${ }^{1)}$ 
many downcomer pipes. The downcomer pipes are submerged in the suppression pool (S/P) water and used to condense the drywell steam. Iodine and cesium contained in the steam are also filtered by this pool water.

Figure 7 shows the layout of the R/B of Unit 3 of Fukushima Daiichi NPS. It is crucial to remove the decay heat of core. Therefore, the residual heat removal (RHR) system was installed in the triangular corner of the four corners of the torus room on the first basement floor of $\mathrm{R} / \mathrm{B}^{7,8)}$. The decay heat is removed using RHR and seawater cooling systems into the sea water as an ultimate heat sink.

Figure 8 shows the bird's eye view of the overall layout of Unit 3 including the turbine building ${ }^{9)}$. The EDG is located on the first basement floor of the T/B. The main control room is located on the top floor of the control building next to R/B. The large component delivery gate on the first floor is used for hanging down fuels in a cask from the operating floor on top of R/B and loading them on trailers. The first basement floor is located-2.0 $\mathrm{m}$ above the standard sea level, the grand level of the first floor is at $10.2 \mathrm{~m}$, and the top of R/B is at $55.7 \mathrm{~m}$. Figure 9 shows the components layout inside the R/B of Unit $3{ }^{10)}$. The RPV is installed on a cylindrical plinth, called the pedestal, which extends over the reinforced concrete that covers the bottom of the drywell.

While exchanging the fuel in the reactor, a shield plug at the center of the operation floor is removed and PCV head flange is opened with an overhead traveling crane. The reactor,

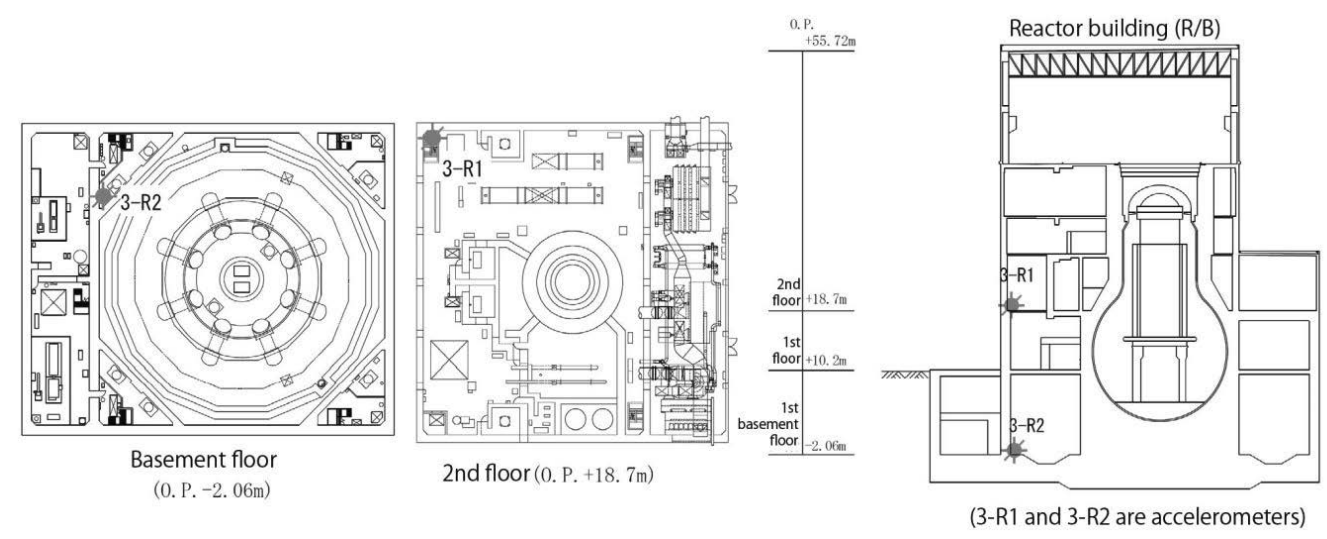

Figure 7 Layout of the R/B of Unit 3 of Fukushima Daiichi NPS ${ }^{7,8)}$

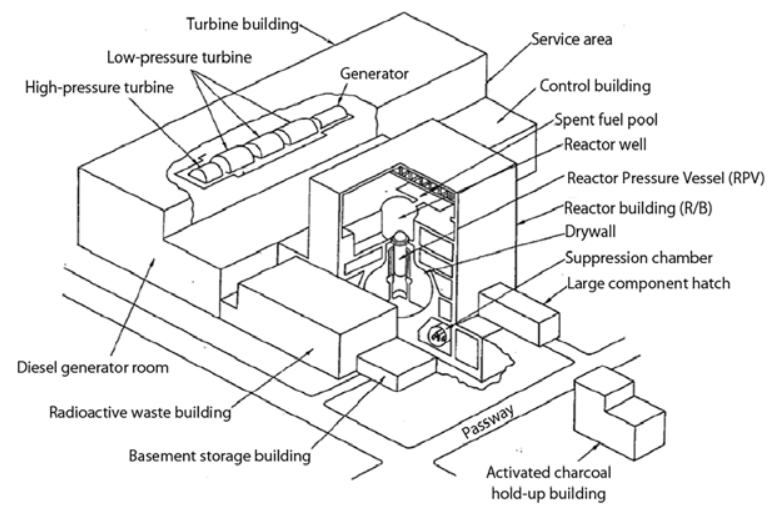

Figure 8 Bird's eye view of the overall layout of Unit 3 of Fukushima Daiichi NPS ${ }^{9)}$ 


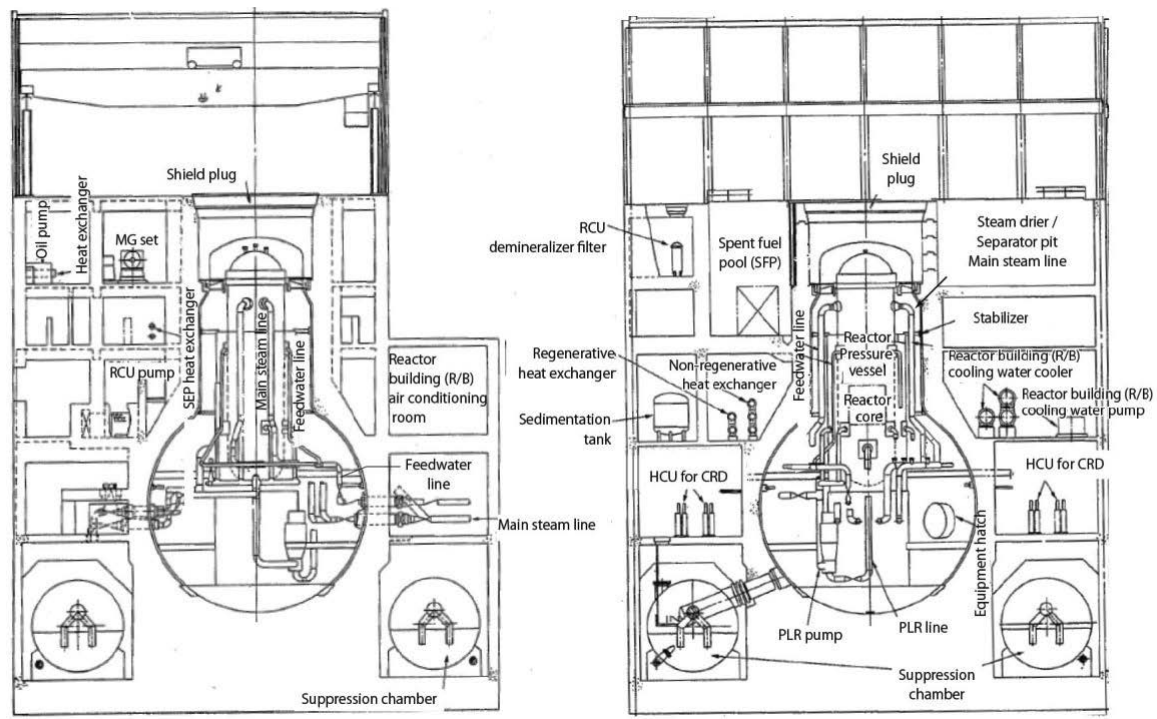

Figure 9 Component layout inside the R/B of Unit $3^{10)}$

which is well above the RPV, is filled with water and is connected with spent fuel pool. Then, RPV head flange is opened and the fuels in the core were exchanged. The spent fuel pool depth is $11 \mathrm{~m}$ and is stored in the lattice partition rack. The rack is attached to the pool bottom using anchor bolts. For natural convection, a hole is opened on the bottom of each fuel position (partition). Considering the lower tie-plate of the fuel, the active part of the fuel is about $50 \mathrm{~cm}$ from the pool bottom and about $7 \mathrm{~m}$ from the fuel top to the water surface (water shield for radiation protection). Without the volume of the fuels, the water quantity is about $1200 \mathrm{~m}^{3}$ in the case of Unit 4.

\section{Time Transition of the Fukushima Daiichi Nuclear Power Station Accident}

The time transition of the accident at Units 1-4 were as follows.

\section{(1) Unit 1}

This unit comprises one turbine-driven HPCI, two low-pressure CS as ECCS, and two ICs for RCIC, equipped in BWR/3. As shown in Figure 10 (b), soon after the scram by the earthquake, two EDGs were started by a loss in the external power and HPCI was also started. The decay heat removal and depressurization in RPV were conducted using two ICs that started automatically at $+7.1 \mathrm{MPa}$. Every cooling system was under good operation before the attack of tsunami. Unfortunately, cooling rate exceeded $55^{\circ} \mathrm{C} / \mathrm{h}\left(100^{\circ} \mathrm{F} / \mathrm{h}\right)$, and two ICs were stopped manually about $19 \mathrm{~min}$ after scram by an operator to meet the safety guide rule. Then, the operator adjusted the pressure near $7 \mathrm{MPa}$ by opening and closing the IC exit valve. When the tsunami came, the IC exit valve was closed, and the Unit 1 lost its entire cooling system.

The RPV pressure was kept as 7 MPa by SRV's safety mode, and steam was exhausted into S/P. Under such condition, water level should be decreased but the reactor water level (ם) increased at about 24:00 on March 11, as shown in Figure 11. This means that the temperature in PCV exceeded more than $300^{\circ} \mathrm{C}$ by core damage and water in a reference leg of water level measurement system decreased by vaporization. At the same time, PCV pressure increased and reached $750 \mathrm{kPa}$, near $2 \mathrm{Pd}$ (2 times the design pressure of $\mathrm{PCV})$ at 3:00 on March 


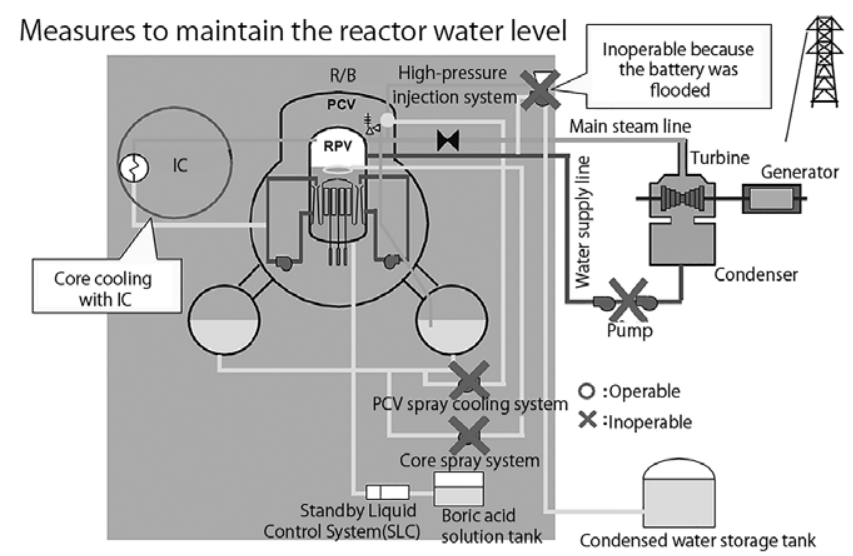

(a) Core cooling by IC during the station blackout immediately after the tsunami

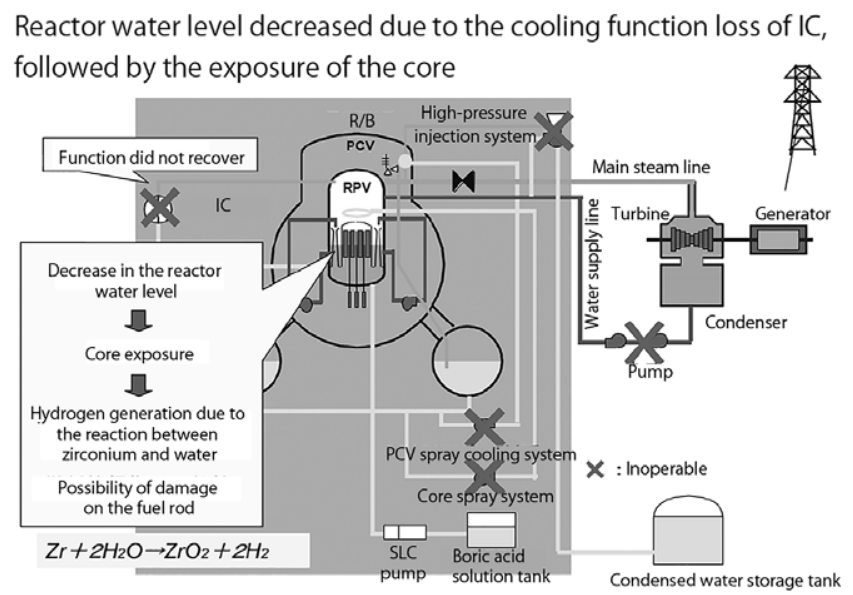

(b) Core exposure and hydrogen generation after IC stopped working

Figure 10 Loss of core cooling function and exposure of the core at Unit $1^{1)}$

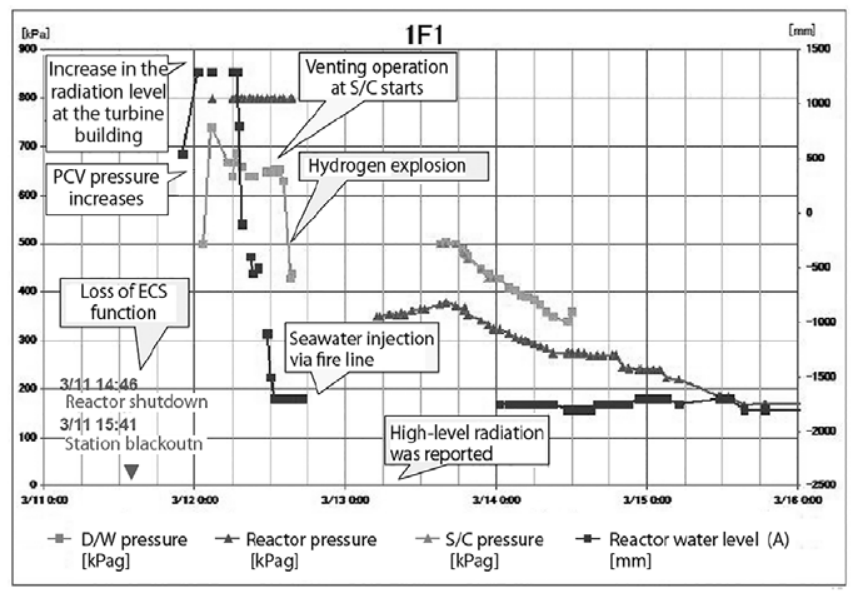

Figure 11 Time transition of the key parameters after the earthquake at Fukushima Daiichi Unit $1^{3)}$ 
12 (Figure 11). At 6:00, the PCV pressure decreased to $650 \mathrm{kPa}$. This means the leakage of vapor mixed with fission products (FPs) through top flange of PCV started. Indeed, the radiation level in the power station site started to increase, as shown in Figure 12. Moreover, the hydrogen from the zirconium water reaction was mixed in the steam. The hydrogen rose to the top floor in the $\mathrm{R} / \mathrm{B}$, where the shield plug, at the center of the operation floor, leaks the hydrogen through the gap around the circumference of the shield plug (about $20 \mathrm{~mm}$ ), and started to accumulate in the operation floor.

Meanwhile, at Unit 1, the severe accident mitigation measures stipulated in accident management (AM) were conducted (Figure 13). Water injection to core using mobile power generator and fire pump was conducted. First, fresh water injection was conducted using a CS system line connected to the firefighting system line and water from the firefighting tank while removing the vast amount of debris brought by the tsunami. At this point, it was necessary to conduct depressurization of RPV through the SRV used for the automatic depressurization system (ADS) because the discharge pressure of the fire pump, which was approximately $1 \mathrm{MPa}$, was not enough to inject water into the RPV of $7 \mathrm{MPa}$. Due to the station

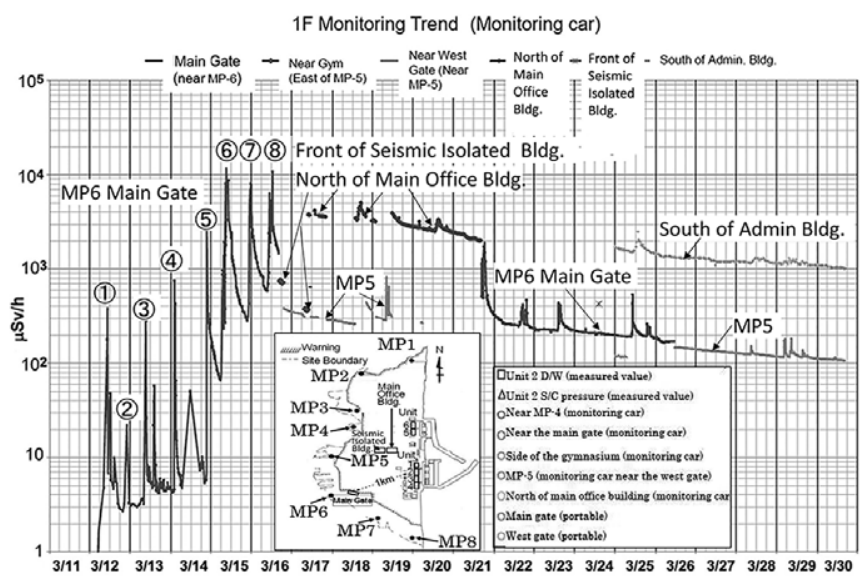

Figure 12 Radiation dose in the air dose rate in the Fukushima Daiichi NPS site ${ }^{2)}$

Seawater injection using Fire Pump

Venting was conducted via suppression chamber to reduce $\mathrm{PCV}$ pressure

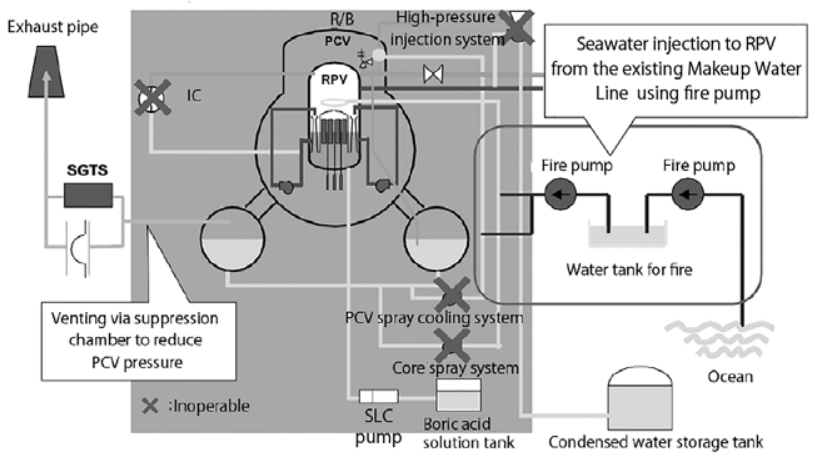

Figure 13 Severe accident mitigation measures at Unit $1^{1)}$ 
blackout, the elevator and lighting in the R/B, as well as the control panel in the main control room, were not working. Under such a situation, the batteries were brought in and connected to the solenoid valves attached to the SRV body to supply nitrogen gas to the actuator of the SRV and lift the valve shaft to open. After this operation, the reactor pressure decreased to $800 \mathrm{kPa}$ and water level was recovered to $1,300 \mathrm{~mm}$ after the injection of fresh water. However, the source of the freshwater ran out and the reactor water level significantly decreased to $-1,700 \mathrm{~mm}$, which is the level at which the fuel top became exposed (TAF standard). At 10:17 on March 12, venting operations such as manually opening the electric valve while the dose inside the building was already rising were conducted, and the PCV pressure started to decrease after 14:30. At this moment, the radiation dose level inside the NPS site (main gate) shown in Figure 12 rapidly increased to the peak of (1), that is, $400 \mu \mathrm{Sv} / \mathrm{h}$, and at $15: 36$, the hydrogen explosion that blew up the concrete wall above the operation floor of Unit 1 occurred during the live broadcasting by the media. AM stipulates that when freshwater is not available, seawater should be injected.

The seawater hose was manually installed down to the beach by going through the debris brought by the tsunami, which attached radioactive materials. It was considered as a difficult task, considering the emergency evacuation after the hydrogen explosion, among other things. In any case, following order from the Prime Minister's office, seawater injection using the CS line connected the fire pump started at 20:20. Following this seawater injection, steam was generated from the partially melted core and the radiation dose in the air increased again, as shown in Figure 12(2).

From the radiation ratio of $\gamma$-ray between the drywell and the wet well obtained from the $\gamma$-ray monitor installed inside PCV, called CAMS, at the morning of March 14, the core melting rate was estimated to be approximately $70 \%$. The time transition of the accident during the short period until the morning of March 14 is summarized in Table 1. After this time, the flow rate of the CS continued to decrease to $2 \mathrm{t} / \mathrm{h}$ while seawater injection continued, and from March 25, the pipe from Sakashita Dam was recovered and freshwater injection started, enabling switch from the fire-extinguishing line to the feedwater supply line. On March 29, the newly installed temporary external power cable from the transmission line from Tohoku Electric Power was connected and the water injection was switched to that using electric pumps. After the flow rate was increased to about $6 \mathrm{t} / \mathrm{h}$ and continued to inject water, the temperature of RPV and PCV that rose up to about $400^{\circ} \mathrm{C}$ started to decrease gradually. On April 7, nitrogen gas was injected into PCV because if the pressure inside PCV becomes negative and starts to suck in air, the hydrogen explosion can be prevented. Most of this outline is based on the published data by NISA and TEPCO, and addition/correction in response to the future investigation will be necessary for accuracy.

\section{(2) Unit 2}

As shown in Figure 14, at Unit 2, the steam turbine-driven RCIC continued its operation even after tsunami and water injection continued until around 11:00 on March 14. However, after RCIC stopped working, the water level in the reactor decreased rapidly. Seawater injection started at 16:34. However, they did not notice that the fuel of the firefighting pump was empty. During this time, the water level decreased to the bottom of active core (BAF) and fuel rod was completely exposed. When the seawater injection restarted again, high-temperature fuel rod reacted with water and significant amount of hydrogen mixed with stem was blown out into the S/P. At this time, the pressure in PCV started to increase rapidly due to steam and hydrogen. The dry vent was conducted before 24:00 on March 14 but it was failed by the loss of air of vent valve. This was accompanied by an increase in the radiation dose in 
Table 1 Accident progress of Unit 1 after the earthquake (short term)

\begin{tabular}{|c|c|c|c|c|}
\hline $\begin{array}{l}\text { Date } \\
\text { time }\end{array}$ & Reactor & $\begin{array}{c}\text { Primary containment vessel } \\
(\mathrm{PCV})\end{array}$ & Turbine building (T/B ) & 1F-1 NPS Site \\
\hline \multicolumn{5}{|l|}{$3 / 11$} \\
\hline \multirow[t]{2}{*}{$14: 46$} & Earthquake, Scram & & & \\
\hline & Loss of external power, IC & & HVAC Ventilation tripped & \\
\hline $15: 42$ & Station blackout, HPCI & & & \\
\hline \multirow[t]{2}{*}{$16: 36$} & Pressure control with SRV & & & \\
\hline & Reactor water level decrease & & & \\
\hline $17: 30$ & Core may have been exposed & & & \\
\hline $21: 30$ & $\begin{array}{l}\text { Decrease in reactor water } \\
\text { level drifted }(+450)\end{array}$ & & & \\
\hline $23: 00$ & & & High radiation level at T/B & \\
\hline \multicolumn{5}{|l|}{$3 / 12$} \\
\hline \multirow[t]{2}{*}{$0: 30$} & $\begin{array}{l}\text { Reactor water level increased } \\
(+1,300)\end{array}$ & & & $\begin{array}{l}\text { Fire engine prepared for } \\
\text { water injection }\end{array}$ \\
\hline & $\begin{array}{l}\text { Depressurization with ADS } \\
\text { manually opened }\end{array}$ & & & \\
\hline $0: 49$ & & Abnormally high D/W & & \\
\hline $2: 30$ & Reactor pressure $0.8 \mathrm{MPa}$ & $840 \mathrm{kPa}$ (TEPCO data) & & \\
\hline 4:00 & & & & $\begin{array}{l}\text { Radiation level at the main } \\
\text { gate increased }\end{array}$ \\
\hline $6: 00$ & IC stopped (Disclosed by METI) & & & \\
\hline $6: 17$ & $\begin{array}{l}\text { Reactor water level started to } \\
\text { decrease again }\end{array}$ & & & \\
\hline $8: 30$ & $\begin{array}{l}\text { Reactor water level } 0 \text { (Top of } \\
\text { core) }\end{array}$ & & & Radiation level increased \\
\hline \multirow[t]{2}{*}{$10: 17$} & & Venting started (NISA data) & & at the main gate \\
\hline & & (Pressure did not drop) & & (around 10:00) \\
\hline \multirow[t]{2}{*}{$12: 35$} & $\begin{array}{l}\text { Water level indicate at JP inlet } \\
\text { (Drifted error) }\end{array}$ & & & \\
\hline & $\begin{array}{l}\text { After this point, the water level } \\
\text { at the core is unclear }\end{array}$ & & & \\
\hline \multirow[t]{2}{*}{$14: 30$} & & Venting (S/C-Stack) & & $\begin{array}{l}\text { High radiation level at site } \\
\text { boundary }\end{array}$ \\
\hline & & $(540 \mathrm{kPa}$ after $1 \mathrm{~h})$ & & \\
\hline \multirow[t]{2}{*}{$15: 36$} & & & $\begin{array}{l}\text { Hydrogen explosion at R/B } \\
\text { operation floor }\end{array}$ & \\
\hline & $\begin{array}{l}\text { Injection of seawater/boric acid } \\
\text { started (CS injection line) }\end{array}$ & & & $\begin{array}{l}\text { Radiation level increased } \\
\text { again at the main gate } \\
(\sim 20: 00 ?)\end{array}$ \\
\hline \multirow[t]{2}{*}{$20: 20$} & $\begin{array}{l}\text { After this point, no order to } \\
\text { recover the reactor water level }\end{array}$ & & & \\
\hline & $\begin{array}{l}\text { Reactor pressure: Stabilized } \\
\text { around } 0.36 \mathrm{MPa}\end{array}$ & Pressure unknown & & \\
\hline $3 / 13$ & No change & & & \\
\hline $15: 00$ & Reactor pressure: $0.451 \mathrm{MPa}$ & $\mathrm{D} / \mathrm{W}$ and $\mathrm{S} / \mathrm{C}$ at $600 \mathrm{kPa}$ & & \\
\hline $3 / 14$ & Melting rate $70 \%$ (CAMS) & & & \\
\hline \multirow[t]{2}{*}{$7: 00$} & & D/W: $162 \mathrm{~Sv} / \mathrm{h}$ & & \\
\hline & & S/C: $26.6 \mathrm{~Sv} / \mathrm{h}$ & & \\
\hline
\end{tabular}


the NPS site, which reached its peak 5 shown in Figure 12. On the next morning at 6:14, the pressure in PCV decreased at once to atmospheric pressure, together with the sound of explosion near the S/C was reported. At 9:00 on March 15, white steam appeared from the blowout panel and the radiation dose level reached the peak of $10,000 \mu \mathrm{Sv} / \mathrm{h}$ shown in Figure 126), and a large quantity of volatile FPs was released into the atmosphere.

\section{(3) Unit 3}

As shown in Figure 15, steam turbine-driven RCIC and HPIS continued to function at Unit 3 after the tsunami. However, possibly due to the issue with the freshwater source, water injection became no longer possible at 5:00 on March 13. During this time, the water level decreased to $-3000 \mathrm{~mm}$ but temporally recovered after the depressurization operation of ADS. By 13:00 on March 12, the pressure in the suppression chamber reached approximately $780 \mathrm{kPa}$. It is assumed that this caused deformation of the top flange of PCV, which in turn led to a leakage of steam, which includes hydrogen that accumulated in the upper part of R/B for about 2 days. At 11:01 on March 14, a violent hydrogen explosion accompanied by black smoke blew up the upper part of R/B and caused the deformation of the walls of the operation floor and the steel frames of the roof to the extent that the original shape was unrecognizable.

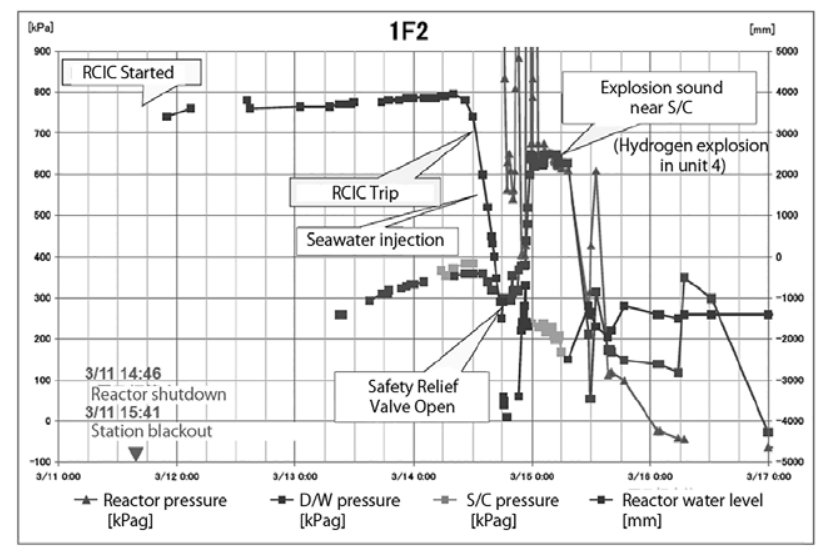

Figure 14 Time transition of Unit 2 after the accident ${ }^{1)}$

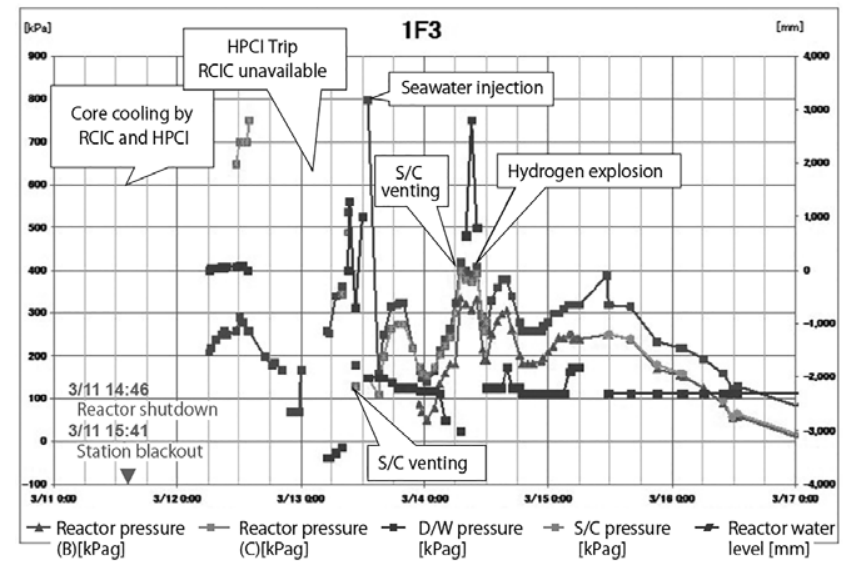

Figure 15 Time transition of Unit 3 after the accident ${ }^{1)}$ 
Table 2 Accident progress of Units 1-4 in Fukushima Daiichi NPS

\begin{tabular}{|c|c|c|c|c|}
\hline & Unit 1 & Unit 2 & Unit 3 & Unit 4 \\
\hline Output & $460 \mathrm{MW}$ & $784 \mathrm{MW}$ & $784 \mathrm{MW}$ & $784 \mathrm{MW}$ \\
\hline Start of its sales & March, 1971 & July, 1974 & March, 1976 & October, 1978 \\
\hline Manufacturer & GE & GE/Toshiba & Toshiba & Hitachi \\
\hline $\begin{array}{l}\text { Number of fuel rods } \\
\text { in the pool }\end{array}$ & Spent: 292, New: 100 & Spent: 587, New: 28 & Spent: 514, New: 52 & Spent: 1331, New: 204 \\
\hline $\begin{array}{l}\text { When the fuel was } \\
\text { put in the pool }\end{array}$ & March 2010 & September 2010 & June 2010 & November 30, 2010 \\
\hline Damage of R/B & $\times$ Hydrogen explosion & $\triangle$ Blowout panel opened? & $\times$ Hydrogen explosion & $\times$ Hydrogen explosion? \& Fire \\
\hline $\begin{array}{l}\text { Emergency Diesel } \\
\text { Generator }\end{array}$ & $x$ & $x$ & $x$ & \\
\hline $\begin{array}{l}\text { Fuel rods in the } \\
\text { core }\end{array}$ & $70 \%$ damaged & $33 \%$ damaged & $\begin{array}{l}32 \text { MOX fuels were installed in the } \\
\text { core from September } \\
2010\end{array}$ & none \\
\hline Mar. 11 (Fri) & $\begin{array}{c}\text { 14:46 Scram by Earthquake } \\
\text { 15:41 Station blackout by } \\
\text { Tsunami, IC tripped } \\
\end{array}$ & $\begin{array}{l}\text { 14:46 Scram by Earthquake } \\
\text { 15:41 Station blackout by } \\
\text { Tsunami, cooled by RCIC }\end{array}$ & $\begin{array}{l}\text { 14:46 Scram by Earthquake } \\
\text { 15:41 Station Blackout by } \\
\text { Tsunami, cooled by RCIC }\end{array}$ & $\begin{array}{l}\text { Under periodic inspection } \\
\text { 15:41 Station blackout by } \\
\text { Tsunami }\end{array}$ \\
\hline Mar. 12 (Sat) & $\begin{array}{l}\text { 15:36 Hydrogen explosion } \\
\text { Upper R/B was blown } \\
\text { off } \\
\text { 10:17 Wet venting } \\
\text { 20:20 Seawater injection }\end{array}$ & & & \\
\hline Mar. 13 (Sun) & & 11:00 Wet venting & $\begin{array}{l}\text { Cooling system stopped } \\
\text { 08:41 Wet venting } \\
\text { 13:00 Seawater injection }\end{array}$ & \\
\hline Mar. 14 (Mon) & & $\begin{array}{l}\text { 13:25 Cooling function lost } \\
\text { 16:34 Seawater injection } \\
\text { - Opening a hole on the } \\
\text { wall considered (not } \\
\text { carried out) } \\
\text { 18:22 } \\
\text { Total exposure of fuel rod } \\
\text { (pump fuel ran out but not } \\
\text { noticed) }\end{array}$ & $\begin{array}{l}\text { 05:17 Wet venting } \\
\text { 11:01 Hydrogen explosion }\end{array}$ & $\begin{array}{l}\text { 04:00 Water temperature of } \\
\text { spent fuel pool } 84^{\circ} \mathrm{C} \\
\text { (No data after this } \\
\text { time) }\end{array}$ \\
\hline Mar. 15 (Tue) & & $\begin{array}{c}\text { 00:02 Dry vent was tried (It was } \\
\text { failed by loss of air) } \\
\text { 06:14 Explosion sound near S/C } \\
\text { 12:00 PCV pressure decreased } \\
\text { to almost zero then went } \\
\text { up again up to } 300 \mathrm{kPa}\end{array}$ & $\begin{array}{l}\text { 10:00 } 400 \mathrm{mSv} / \mathrm{h} \text { detected on the } \\
\text { mountain side }\end{array}$ & $\begin{array}{l}\text { 06:14 Hydrogen explosion? } \\
\text { 8m square two holes } \\
\text { on all sides (4th and } \\
\text { 5th floors) } \\
\text { 09:38 Smoke observed } \\
\text { 11:00 Fire extinguished }\end{array}$ \\
\hline Mar. 16 (Wed) & & & $\begin{array}{l}\text { 08:30 White smoke observed } \\
\text { 10:40 Radiation level increased } \\
\text { rapidly, workers evacuated } \\
\text { 11:30 The information was false, } \\
\text { workers came back again } \\
(100 \mathrm{ft}, 250 \mathrm{mSv})\end{array}$ & $\begin{array}{l}\text { 05:45 Fire recured again } \\
\text { Fire splay abounded } \\
\text { by high radiation level, } \\
\text { the fire extinguished } \\
\text { Photograph was taken } \\
\text { from the sky by the } \\
\text { helicopter of Self } \\
\text { Defense Force } \\
\end{array}$ \\
\hline Mar. 17 (Thurs) & & $\begin{array}{l}\text { Preparation of external power } \\
\text { cable was completed } \\
\text { The work of next day planned } \\
\text { to be about } 10 \mathrm{~h}\end{array}$ & $\begin{array}{l}\text { 09:48 Water drained from Self } \\
\text { Defense Force helicopter } \\
\text { (7.5 } \mathrm{t} \text { by } 4 \text { times) } \\
300 \mathrm{ft} 87.7 \mathrm{mSv} \\
1000 \mathrm{ft} 4.13 \mathrm{mSv} \\
\text { Spent fuel pool volume } \\
1365 \mathrm{~m}^{3} \\
(9.9 \mathrm{~m} \times 12.2 \mathrm{~m} \times 11.3 \mathrm{~m}) \\
\text { 19:05 Riot Police water truck failed to } \\
\text { drain water into spent fuel pool } \\
\text { 19:35 Water sprayed from } 5 \text { fire } \\
\text { engines of Self Defense Force, } \\
\text { about } 30 \mathrm{t}\end{array}$ & $\begin{array}{l}\text { 21:45 Video shown water in } \\
\text { the pool was released } \\
\text { to press }\end{array}$ \\
\hline Mar. 18 (Fri) & $\begin{array}{l}\text { Preparation for external power } \\
\text { cable scheduled to be supplied } \\
\text { power on next day } \\
\text { Puddle of contaminated water } \\
\text { was discovered in the turbine } \\
\text { building. } \\
\text { Dose level was not measured }\end{array}$ & $\begin{array}{l}\text { Preparation of external } \\
\text { power cable } \\
\text { 22:00 Backup power panel was } \\
\text { supplied electricity from } \\
\text { external transmission line } \\
\text { Electricity for unit } 2 \text { will } \\
\text { be supplied on next day } \\
\text { Seawater injection } \\
5601 / \mathrm{min} \\
\text { A hole on the building } \\
\text { wall planned to be drilled } \\
\text { to protect hydrogen fire } \\
\sim 10: 30500 \mathrm{mSv} / \mathrm{h} \text { was recorded } \\
\text { (discovered on March } 23 \text { ) }\end{array}$ & $\begin{array}{l}\text { 13:55 Water sprayed from } 6 \text { fire } \\
\text { engines of Self Defense Force, } \\
\text { about } 40 \mathrm{t} \\
\text { U.S. Army water truck sprayed } \\
\text { about } 4 \mathrm{t} \\
\text { 24:30 Hyper rescue team of the } \\
\text { Metropolitan Fire Department } \\
\text { starts spraying water } \\
\text { 25:10 } 120 \mathrm{t} \text { of water was sprayed } \\
\text { Seawater core injection } \\
\text { 250 1/min } \\
\text { External power cable will be }\end{array}$ & $\begin{array}{l}\text { Temporary backup power } \\
\text { panel was installed } \\
\text { External power cable will be } \\
\text { connected by March } 20 \text { th }\end{array}$ \\
\hline Mar. 19 (Sat) & $\begin{array}{l}\text { External power cable } \\
\text { was connected via the } \\
\text { power center of Unit } 2 \\
\text { Radiation level at North } \\
\text { of the main office } \\
\text { 14:00 } 3443 \mu \mathrm{Sv} \\
\text { 17:00 } 3078 \mu \mathrm{Sv} \\
21: 002906 \mu \mathrm{Sv}\end{array}$ & $\begin{array}{l}\text { External power cable was } \\
\text { connected to the power panel } \\
1.5 \mathrm{~km} \text { cable was installed } \\
\text { Core cooling system will be } \\
\text { supplied power from tomorrow }\end{array}$ & $\begin{array}{l}\text { Total water injection by } \\
\text { Metropolitan Fire Department } \\
\text { was about } 2400 \mathrm{t} \\
\text { Water injection planned to be } 7 \mathrm{~h} \\
\text { (include unmanned injection) } \\
\text { From 14:05 the 19th to } 3: 40 \text { the 20th } \\
\text { 17:25 Osaka fire brigade departure }\end{array}$ & $\begin{array}{l}\text { Installing cable from MC } \\
\text { vehicle to the power panel }\end{array}$ \\
\hline
\end{tabular}


After this, the reactor pressure and drywell pressure varied in parallel in almost the same pressure curve. It is estimated that a drift occurred in the indicated value of the drywell pressure due to the impact of the hydrogen explosion. It is necessary to examine these measurement instruments to obtain the accuracy of the event analysis.

\section{(4) Unit 4}

As the exchange work of shroud in conjunction with a periodic inspection was undergoing, all 1331 spent fuels and new 204 fuels, which were planned to be installed, were inserted into the rack in the spent fuel pool. At 6:14 on March 15, hydrogen explosion occurred and blew up the earthquake-proof class A walls of the 3rd and 4th floors of R/B (reinforced concrete wall, $50 \mathrm{~cm}$ thick) as well as the concrete wall of the 5 th floor and roof. However, the yellow paint coating of the top flange of PCV and green paint coating of the fuel exchanger were not burned. Thus, it is assumed that a detonation where a shock wave passes through in an extremely short time occurred. After the accident, there was enough water in the spent fuel pool to cover the fuel, which is supposed to be in the state as shown in Figure 16. However, it has

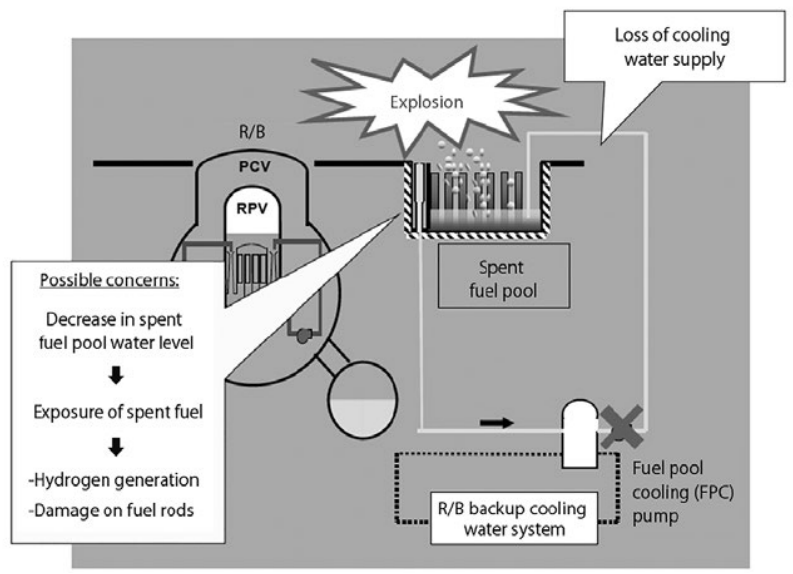

Figure 16 Concerns for spent fuel pool when external power source is lost ${ }^{1)}$

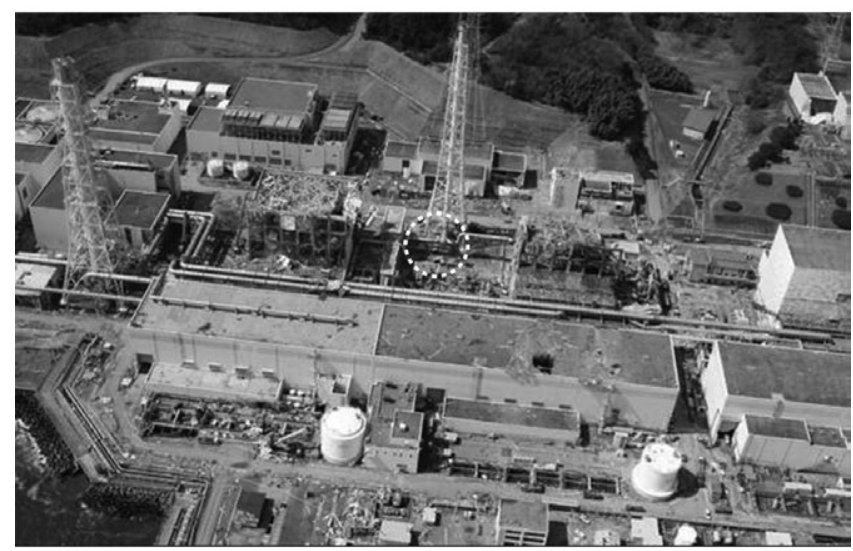

Figure 17 Damaged R/Bs of Units 4 and 3 and T-shape connected vent pipe at the lower end of stack.

(Photo: Air Photo Service) 
not been quantitatively explained. Since the reactor and equipment wells were filled with water, we assume that the partition panel between the spent fuel pool and reactor well came off due to an impact of the hydrogen explosion, which caused the water to flow from the reactor well to spent fuel pool. However, examination and verification are required to check whether the water in the spent fuel pool is sufficient to cool all the spent fuels after the earthquake.

\section{Lessons from the Three Mile Island Unit 2 Accident and Chernobyl Unit 4 Accident}

\section{Accident at Unit 2 of Three Mile Island NPS ${ }^{11)}$}

At the predawn on March 28, 1979, there was an accident at Unit 2 (power output 960 MW) of Three Mile Island NPS (TMI) located in Pennsylvania in the U.S., which caused a severe damage to the reactor core. The reactor of the TMI Nuclear Power Station was PWR (made by Babcock \& Wilcox). Its characteristics were small water volume in a steam generator (SG) and SG generate superheated steam. Following is its explanation with reference to Figure $18^{12)}$.

The accident occurred when the main feedwater pump, which supplied water from the condenser to SG, tripped. The axial feedwater pump immediately started automatically at a rated speed after $30 \mathrm{~s}$. However, the two discharge valves for the pump were closed; therefore, the water was not supplied to the SG. At this time, a sign plate that says "keep closed" was on the valve control switch in the control room. This should have been changed to "open" after the maintenance but they did not notice it during the patrol. It was already 8 min since the accident when an operator noticed it and opened the valves. At the reactor, the temperature and pressure of the primary system rose because water was not flowing to the SG, the pressure relief valve on the upper part of the pressurizer opened automatically, and the control rod was inserted to the core. The reactor shut down as it was designed to do so. However, the pressure relief valve did not close automatically; it was stuck open due to the damage on the pilot valve and could not be closed again, and caused the loss of coolant for the primary system and the pressure to become too low. This signal triggered the ECCS to start automatically, which started injecting the cooling water into reactor vessel. However, the operator stopped the valve of one system 4 min after the accident and after $10 \mathrm{~min}$, the valve of the other ECCSs

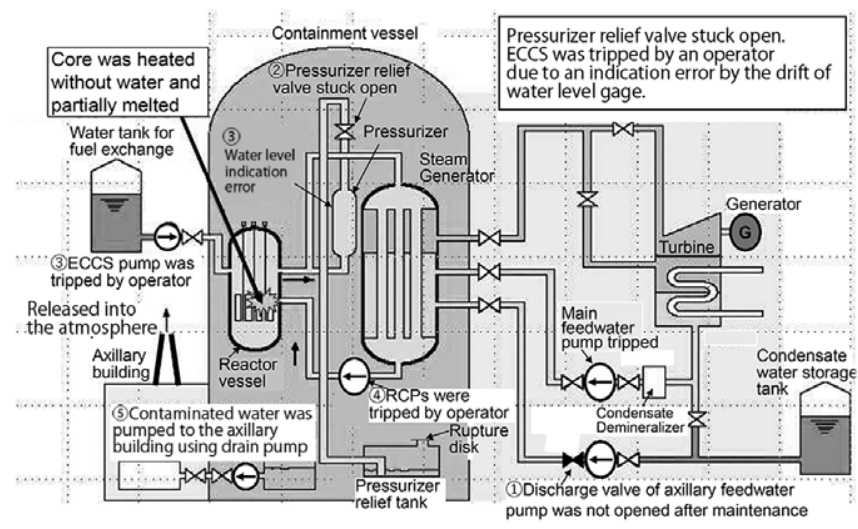

Figure 18 Accident at Unit 2 of Three Mile Island ${ }^{12)}$ in the U.S. 
of ECCS were also closed. This is because the drift in the water level in the pressurizer indicated full, and the operator was afraid that the pressure control would become difficult when the pressurizer was seemed to be full of water. However, after $12 \mathrm{~min}$, the operator was concerned about the fact that there was no cooling water route and he restarted ECCS. However, he was still concerned about the reactor vessel being full and pressure increasing, thus keeping the injection rate extremely low. Thus, leak flow rate was higher than that of injected into core and water level in the reactor decreased gradually. At the same time, the steam was blown down into the pressurizer relief tank in the containment vessel (CV) through the pressure relief valve that was kept stuck open. After some time, this tank became full and the water overflowed and started to accumulate in the sump at the bottom of CV. As the water level of this sump became too high, the radioactive water was sent to the auxiliary building by the drain pump. Furthermore, since there was a leakage path in the system, the FP gas that contains iodine 131 in the transferred water leaked into the building and was released to atmosphere through the ventilation system in the auxiliary building.

After the ECCS was restarted, the operator tripped the reactor coolant pump because it started to vibrate. As a result, the small amount of coolant circulation that somehow had managed to keep the core temperature in the state of remittance stopped. Due to this, the water in the core was evaporated and water level decreased, causing the fuel rod to be dry out and fuel rod to become heated. This led the fuel cladding tube start to damage. Then, the zircaloy of the cladding tube reacted with the steam under high temperature, oxidized, and generated a large amount of hydrogen. This hydrogen gas formed a large volume of non-condensable gas together with FP gas and started to accumulate in the upper part of the core.

Meanwhile, the fuel cladding became brittle due to the oxidization collapse and formed a large cavity on the central upper part of the core. The debris formed a thick pile in the bottom of the cavity and worsened the obstacle to the cooling; in addition, part of the heated fuel melted, flowed, and fell down to the bottom of the pressure vessel. Around this time, the operator finally noticed the leakage from the relieve valve and closed the stop valve and increased the flow rate of ECCS. This halted further progress of the core meltdown. However, the gas accumulated in the upper part of the pressure vessel prevented from the flow of coolant through the SG, which made the cooling of the primary system impossible, and then, the operation of ECCS for cooling continued. Thus, the stop valve connected with the relief valve was opened again to depressurize the primary system, and then closed again and started one of the primary cooling water pumps. This started circulation, and the thermometer at the hot and cold legs, which showed abnormal high temperature, returned to the normal temperature, while the cooling water started to flow through the core and the water that was heated in the core started being cooled by the SG. Thus, the stable cooling of the core was secured $16 \mathrm{~h}$ after the accident.

Though the accident itself was converged by the evening of March 28, an incorrect measurement which showed that a large amount of radioactive materials released from the stack was communicated to the U.S. Nuclear Regulatory Commission (NRC) on March 30, which triggered a discussion on various possibilities, leading the governor of Pennsylvania to issue an evacuation order for all pregnant women and pre-school age children within the 5 miles radius. As this was during a weekend, people followed one another in evacuation, and in the end, $40 \%$ of the residents within 10 miles radius evacuated outside the affected area. During this time, the streets were full of cars, while towns seemed like ghost towns. Regarding the exposure dose of the residents after this accident, the chairman of the Nuclear Safety Commission testified on the radiation level in the living environment at the Congress on April 4, saying that "even if one continues to stand on a point that is 0.6 miles from the power station, 
the exposure dose amount is maximum 80 mrem $(1 \mathrm{mrem}=0.01 \mathrm{mSv})$, in other words, equivalent to the dose of one or two times of X-ray examination of the chest." Moreover, the exposure dose amount of 2 million residents within $80 \mathrm{~km}$ radius around the power station is assessed to be on average $1.5 \mathrm{mrem}$, meaning that there was practically no exposure to the public.

The lesson of this accident can be learned from the social confusion and the psychological effect on the residents who were in panic. The report of the President's Special Investigation Commission created for this accident stated in the section on "Seriousness of the accident" that "according to our research on the health effect of the accident, our conclusion is that the impact of radioactive materials on a person's health was minute despite the significant damage on the power station because most of the radioactive materials were confined. The serious effect on the health of the accident was the psychological stress."

Immediately after this accident, NRC set up an accident research committee to examine its causes. Meanwhile, in response to the considerable social effect of the accident, President Carter created the President's Special Investigation Commission on April 11, two weeks after the accident, chaired by Dr. John G. Kemeny, the President of Dartmouth College. The commission consisted of 12 people including the state governor, specialists of various fields, and a representative of the local residents. They conducted a thorough investigation of not only the technical cause but also the background factors. This commission gathered public testimonies or conducted private interviews with over 150 people, and the materials they collected are said to reach $100 \mathrm{~m}$ when piled up.

This commission submitted its research result and improvement plan to the President, which stated that "based on the long years of experience in operating nuclear power stations, a mindset that nuclear power stations are perfectly safe was formed, which prevented from appropriate measures being taken in many aspects." In Japan, the Nuclear Safety Commission also suggested to immediately conduct a comprehensive review of each nuclear power station in the country, and that the Oi Nuclear Power Station currently in operation should stop its operation until it is verified that there is no concern about occurrence of such an accident. Moreover, the same commission established a special research commission to examine this lesson from various angles, and based on this examination, decided on the points to be reflected on future security measures that are categorized into "points related to design" and "points related to operation."

This most important lesson was not taken advantage of at the Fukushima Daiichi Nuclear Power Station. In other words, since it was based on an American layout design, the emergency $D / G$ was installed on the first floor of the basement of the turbine building without any protection against tsunami. Regarding this point, "Never Again," 13) the statement written by 16 famous international specialists in nuclear safety regulation, stated that "all the power was lost after a historically massive earthquake and equally historical large tsunami. Low-probability phenomena occurred simultaneously in an impossible manner, and the Fukushima site did not have a sense of danger." It appeals that instead of being content only with satisfying the initial safety standard, it is necessary to possess the latest knowledge and maintain the sense of immediacy and tension, and continue/strengthen the security effort. In other words, it strongly admonishes the negligence coming from a fixed mindset.

Furthermore, it demands from the aspect of research and development, (1) research to deepen the knowledge on the behavior of a nuclear reactor when its core is damaged, (2) research on the relation between human and machine, or the man-machine interface, (3) research on the system to support the operator's work, and (4) development of robots that can work in place of humans during accidents, to be prioritized. We believe that the academic 
society should verify that how the results of these researches helped understanding and convergence of the progress of the accident, and what was missing.

\section{Accident at Unit 4 of Chernobyl Nuclear Power Station ${ }^{11)}$}

On April 26, 1986, a nuclear accident occurred at Unit 4 of Chernobyl Nuclear Power Station located at approximately $100 \mathrm{~km}$ from capital Kiev of today's Republic of Ukraine (at the time, a part of the Soviet Union). The accident occurred late night at 01:23 AM. The operator in the control room said that he had heard the second explosion 2-3 s after the first one. The first explosion is deemed to have occurred because the fuel melted; the melted uranium dioxide became micro particles and diffused in the pressure tube and caused steam explosion. Though there are various interpretations of the cause of the second explosion, the theory that it was caused by the generated hydrogen and carbon monoxide is considered most likely. As a result, a quarter of the core was released into outside the reactor, and R/B was severely damaged such that it could not retain its shape to serve its purpose.

As shown in Figure 19 ${ }^{12}$, this reactor was a light water-cooled graphite moderated reactor (RBMK-type) developed in the former Soviet Union. The reactor core consists of a large piece of graphite with many vertically placed thick pressure pipes (1700 pipes). The fuel assembly is inserted into each pipe. Cooling water is run through them to heat/boil it and generates steam. This steam is separated from water in a steam-water separator (steam drum), which is then collected and sent to the turbine. This reactor is a thermal neutron reactor, and therefore, requires a neutron moderator, for which graphite is used. The light water flowing around the fuel in the pressure pipes mostly plays the role of heat transportation. When a core is designed with the concept of "graphite for moderation, light water for cooling," as in this reactor, there is a possibility of positive feedback due to the void generated during low output, unlike the light-water reactor system with the concept of "light water for both moderation and cooling" that is used in the power generation in Japan.

To counter this issue, the magnitude of the output and percentage of increase were monitored by measurement devices and scram device that automatically inserts more than 200 control rods on receiving an abnormal signal was attached. The test plan was to produce electricity for the station itself using the mechanical rotational energy (inertia) of the turbine with $20 \%-30 \%$ output. However, the output decreased to $1 \%$ due to the xenon effect. Because of

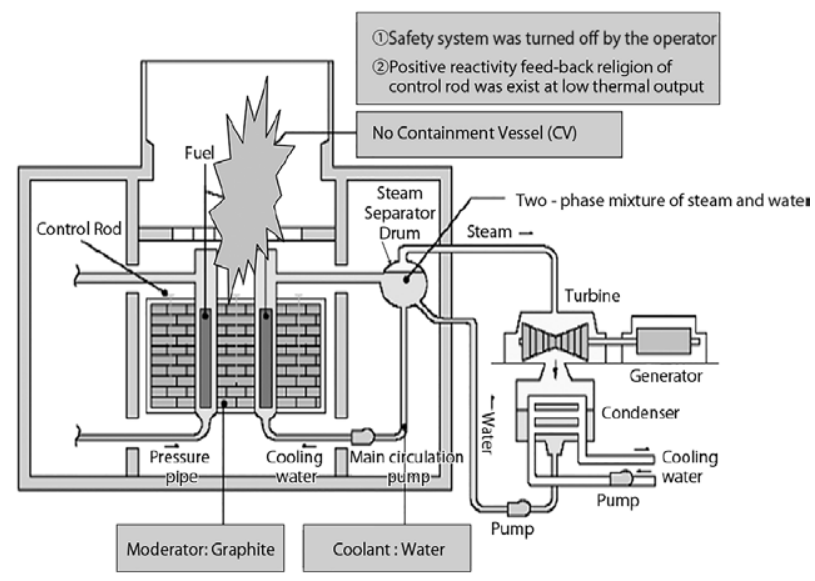

Figure 19 Factors of Chernobyl Nuclear Power Station Accident ${ }^{12)}$ 
this, despite the regulation (operation procedure) that forbade normal operation with less than $20 \%$ output, operators tried to recover the output by removing the safety device and pulling out many control rods. As a result, void was generated, accompanied by the reactor core instability at approximately $7 \%$ output, leading to the loss of control. As it has characteristic to temporally increase the output when the control rod is inserted in this situation, the nuclear fission energy reached $300 \mathrm{GW}$, which is about 100 times the rated output, in a few seconds after pressing the scram button, causing the nuclear runaway.

As discussed above, two explosions within a few seconds were followed by the nuclear runaway, steam explosion, and explosive burning of the hydrogen and carbon monoxide produced by the reaction between high-temperature graphite and water. This caused blowing up of radioactive materials reaching the stratosphere and then falling to a wide area from Ukraine to Europe. The radioactive contamination levels of Belarus, Ukraine, and Russia that surround the accident site were severe and caused much human damage. However, most of these people were the workers who were not informed about the danger of the accident and forced to respond to the emergency without protection clothes or masks or the children who ate vegetable or drank milk from the contaminated area. One can refer to the information from 237 people who responded to the emergency of the Chernobyl Accident and the exposure victims from Belarus, Ukraine, and Russia for a concrete proof of this.

To extinguish a large-scale graphite fire, the emergency response workers, including the firefighters, were forced to respond to the emergency without even protection masks and clothes. As a result, 28 people from the group of 93 who were exposed to 16-2.2 Gy radiation died within about 3 months (Table 3) ${ }^{14}$. For more than 20 people, the main causes of death were burn and respiratory disorder. In other words, because they were working without protection masks and clothes, the main cause of death was the burn inside and outside their bodies caused by the $\beta$-ray emitting nuclide coming into contact with skins or being inhaled. Moreover, all but one victims of an acute radiation syndrome suffered from myelopathy and most of the deceased suffered from intestinal damage. This accident was significantly different from that of the Fukushima Daiichi Nuclear Power Station not only in the amount of release of radioactive materials but also in the number of the dead and their cause of death.

According to the UNSCEAR 2000 report by the United Nations Scientific Committee on the Effects of Atomic Radiation ${ }^{14)}, 14$ years after the accident, no increase in leukemia among the exposure victims was observed, including the 245 who responded to the emergency, which appeared among the bomb victims of Hiroshima and Nagasaki in the early stage. It is estimated that in Hiroshima and Nagasaki, the functions of sensitive hematopoietic organs were damaged by an instantaneous strong radiation, and leukemia was caused by the later disorder. On the other hand, this result suggests that the human restorative/immune system works in the case of a long-term exposure to weak radiation, such as the case in the contaminated area

Table 3 Condition of emergency workers during the Chernobyl Accident ${ }^{14)}$

\begin{tabular}{|c|c|c|c|c|}
\hline $\begin{array}{c}\text { Degree of acute } \\
\text { radiation sickness }\end{array}$ & $\begin{array}{c}\text { Radiation Exposure } \\
\text { Dose (Gy) }\end{array}$ & $\begin{array}{c}\text { Number of people } \\
\text { hospitalized }\end{array}$ & Deceased & Number of survivors \\
\hline Light & $0.8-2.1$ & 41 & 0 & 41 \\
\hline Medium & $2.2-4.1$ & 50 & 1 & 49 \\
\hline Serious & $4.2-6.4$ & 22 & 7 & 15 \\
\hline Extremely serious & $6.5-16$ & 21 & 20 & 1 \\
\hline Total & & 134 & 28 & 106 \\
\hline
\end{tabular}

*Note: No acute radiation sickness was observed by other 103 emergency workers. 
of the Chernobyl Accident, and damage does not appear. Similarly, no increase in cancer has been observed in the disaster area. Naturally, it is necessary to monitor the future development but people who died of cancer after 10 years increased among the survivors of Hiroshima and Nagasaki, who were instantaneously exposed to more than $1 \mathrm{~Gy}$ radiation. This phenomenon is also supposed to be caused by the damage on the restorative/immune system and the accumulation of that damage along with aging. If the exposure level in a contaminated area is at a level that allows normal functioning of the human restorative/immune system, a meaningful increase in cancer might not be observed in the future, and requires a long-term research.

As the residents of the surrounding area were not aware of the Chernobyl Accident, there were many children in the large area contaminated by radioactive materials who ingested milk or vegetable and absorbed radioactive iodine into their bodies. Thus, 1800 cases of children with thyroid cancer have been reported at the time of UNSCEAR 2000 report $^{14}$, and the number continues to increase. Thyroid tumor caused by $\gamma$-ray exposure normally has more than 10 years of latent period but in the case of the Chernobyl Accident, it increased rapidly 5 years from the accident. Some specialists claim that the latent tumor originated from the chronic iodine shortage common in the interior of the continent contributed to this situation. This view considers that the thorough examination and its increased number after the accident contributed to the increase in the reported number of tumors. Meanwhile, Japanese people consume enough iodine, and during the Fukushima Daiichi Nuclear Station Accident, an early evacuation was conducted even though it was immediately after an earthquake, in addition to the preparation of the iodine neutralizer. Therefore, it is predicted that the health damage caused by radioactive iodine like the ones observed during the Chernobyl Accident will not appear.

Regarding radioactive cesium, no health damage has manifested in the residents themselves, including among those who refused to move to the area outside the forced emigration area with more than $550 \mathrm{kBq} / \mathrm{m}^{2}$, or who returned there. The reasons for this include the biological half-life of radioactive cesium, which can easily be discharged from the body, being about 100 days, the fact that radioactive cesium becomes equally distributed among muscles inside the body in the same behavior as potassium, including the radioactive potassium in human body, and the fact that it cannot have a concentrated effect on a specific important organ.

Figure 20 shows the possibility of radioactive materials leaking from the decrepit stone

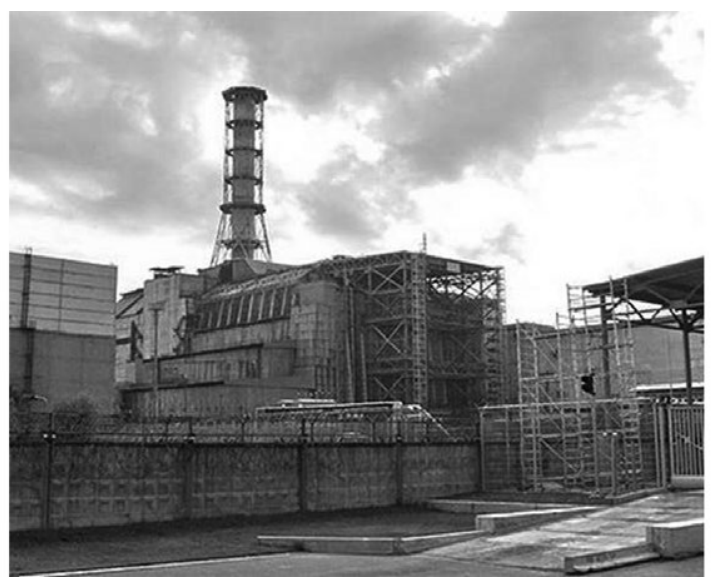

Figure 20 Chernobyl Nuclear Power Station after 25 years ${ }^{15)}$ 
coffin of Chernobyl Power Station after 25 years. However, the dose has been lowered to the point where sightseeing tour is possible. Based on the information of the contaminated areas within $400 \mathrm{~km}$ radius from the Chernobyl Power Station, Fukushima 25 years from now is predicted to have low contamination within $40 \mathrm{~km}$ radius. Moreover, we wish for a recovery to better future through measures such as soil exchange of schoolyards with high contamination level or active cultivation of plants that store radioactive cesium in their stalks or roots.

The health effect research result of the bomb victims from Hiroshima and Nagasaki whose exposure has already been 66 years ago are also precious data. A follow-up research on the mortality rate of a fixed group of 86,572 bomb survivors during 1950 was conducted in 1961 . This group was selected from the people who were within $10 \mathrm{~km}$ from ground zero of the atomic bombs; 8,500 people, $10 \%$ of the group, were exposed to $1-6 \mathrm{~Sv}$, and more than half of them were survivors from within $2.5 \mathrm{~km}$ from ground zero. In addition, 36,459 people assessed as with less than $5 \mathrm{mSv}$ exposure, who were deemed to practically have not been exposed, were selected as the comparison group to evaluate their difference from the group exposed to radiation.

According to the monitoring conducted until 1997, the number of people who died of cancer originating from the radiation exposure was 450 . It is predicted that when all 86,572 people are dead, the people who died of cancer originating from the exposure is predicted to be 800. Figure 21 shows the research result of the average age of death among the 86,572 atom bomb survivors. The data are the median value of the life expectancy of the survivor group whose exposure was up to $3 \mathrm{~Gy}^{16}$. Among the group exposed to $0.8 \mathrm{~Gy}$ or less radiation, while the person with shortest life displays dose dependency, among the people with median value or with the longest life, there is practically no difference with the group whose exposure was deemed zero. Though there are no data more detailed than this one, the following conclusion can be drawn. If the human body can withstand an instantaneous strong radiation, the human body function gradually recovers with time. However, the internal damage accumulated with age for people exposed to a high dose of radiation and the number of cases where they die of cancer originating through the so-called late effect increases. As a result, there was about 5-year difference between the median life expectancy of no exposure group and that of 3 Gy exposure group.

The Fukushima Daiichi Nuclear Power Station Accident did not cause an instantaneous high-dose exposure, as observed in Hiroshima and Nagasaki. Moreover, its exposure dose



The data of the joint Japanese/US study show no significant difference among groups from 0 to $0.8 \mathrm{Gray}$ at median age of life span. No genetic Effects were caused by radiation in the children born to the survivors.

Figure 21 Average age of death among 86,572 atom bomb survivors ${ }^{16)}$ 
was sufficiently low in comparison with that in the Chernobyl Accident. Among the people from the area with a relatively high dose, such as the planned evacuation area of Fukushima Daiichi Nuclear Power Station or Iitate village, prevention of discrimination, prejudice, and reputational damage that psychologically tormented the survivors of Hiroshima and Nagasaki, and needless to say, the prevention of health damage by the radiation disorder are extremely important issues.

In recent years, the repair mechanism of DNA is starting to become clear. There is a special article on this subject published in Nihon Keizai Shimbun ${ }^{17)} .<$ p53 gene $>$ is the gene called "guardian of genome" that restrains cancer cells. When there is damage on DNA, it repairs the damage and prevents the cell from becoming cancerous by working on $<\mathrm{p} 21$ gene $>$, which multiplies the cells. With $<$ p53 gene $>$ becoming active, the multiplication of cancer cells is restrained. When single strand of a DNA is broken, its repair rate is $99.99 \%$, and when the double strand is cut into two, the rate is $90 \%$, and the cell that cannot be repaired disappears. It is considered that cancer appears when this function is impaired with aging, and future development of this research is expected. As seen in this example, based on the DNA-level restoration/cancer prevention mechanism that organisms acquire through evolution, it is reasonable to think that if it is appropriately managed, the number of residents/workers who develop cancer due to the effect of radiation from an accident will be significantly reduced.

\section{Mitigation Measures for Severe Accidents in Europe}

The most important lesson from Fukushima Daiichi Accident is that once a large-scale accident occurs, the financial burden including compensation, decontamination cost, removal cost of radioactive materials or buildings, and security against reputational damage, among others, is extremely large.

Numerous diverse equipment to prevent the expansion of an accident are designed and installed as backup on a light-water reactor in case it occurs. However, simultaneous occurrence of disadvantageous events triggered by, for instance, an equipment defect or a tsunami goes beyond the situations expected by the design, and as a result, leads to a major damage such as the core meltdown, as was the case of Three Mile Island Accident or the Fukushima Daiichi Nuclear Power Station Accident. Such a situation is called a "severe accident." The nuclear reactor PCV was highly effective as the last "fortress" during the Three Mile Island Accident. The accident at Chernobyl Power Station, which did not have PCV, released radioactive material to all over the world.

However, at the Fukushima Daiichi Nuclear Power Station, leakage and breakage occurred due to an increase in the internal pressure. What was necessary before the major damage occurred due to an increase in pressure in PCV was measures such as preventing breakage by reducing the pressure by venting after removing radiation using a filter (filtered vent) ${ }^{18)}$ or a static cooling system that cools PCV with water or air in order to prevent excessive increase in pressure in PCV due to decay heat. The measures to prevent the expansion of a severe accident or actively mitigate its effect and prepare necessary methods for these measures are called AM.

At the below discussed Beznau Nuclear Power Station, which is located in Switzerland, 11 steps of the safety/reliability trustworthiness improvement plan, as shown in Table 4, were implemented after TMI 2 accident ${ }^{19)}$. Among these, the filtered containment venting system became the trump card for restarting nuclear power stations after the Chernobyl Accident in European countries. It is a venting system with a filter, as shown in Figure 22. An active usage of nuclear energy near residential areas is being promoted through the examination of 
Table 4 TMI-2 Safety and reliability improvement project after the accident ${ }^{19)}$

-New reactor pressure vessel relief system (Post TMI)

-Thermal $\mathrm{H}_{2}$-recomniners inside containment (Post TMI)

-Replacement of refueling water storage tanks

-Compact simulator

-Provision of a full-scope simulator located offsite in the USA

-Bunkered emergency heat removal system (NANO project)

-Seismic requalification of mechanical/electrical equipment

-Filtered containment venting system (SIDRENT project)

-Analysis for pressurized thermal shock of RPV

-Separation of station load transformer area

-Additional emergency feed water system (ERGES project)

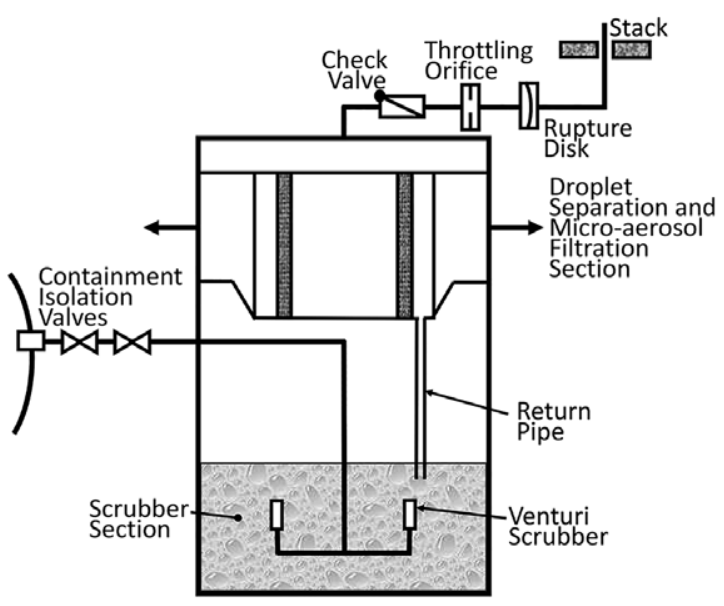

Figure 22 Filtered venting system ${ }^{18)}$

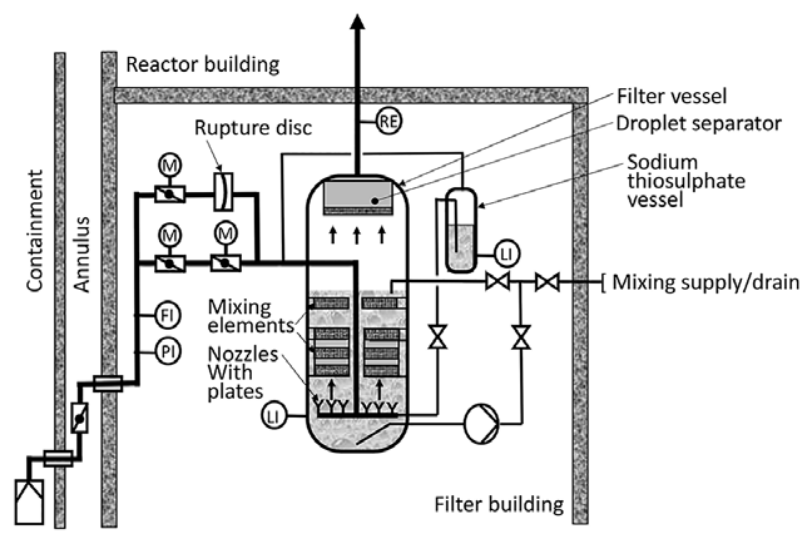

Figure 23 Venting system with filter in Switzerland ${ }^{19)}$ 
these measures and agreement with the population of a country of national referendums. Figure 23 shows the system diagram of the filtered venting facility of this power station. When a severe accident occurs, it starts this device with a highly efficient radioactive material removal function, which works without electricity before the pressure in PCV exceeds the designed pressure. If it is possible to release radioactive materials at a level that does not require evacuation, it is possible to both maintain the RPV and PCV integrity and prevent the health damage to the local residents and environmental damage without an evacuation. Even when there is an accident, there will be no trouble to the surrounding area. This should be the goal for the ultimate safety design of nuclear power stations.

Figure 24 shows Beznau Power Station and the surrounding residential area in Switzerland $^{20)}$. It is equipped with 2365 MWe reactors. This power station also engages with local nuclear power heat supply service shown in Figure $\mathbf{2 5}^{21}$. About 20,000 people living within $5 \mathrm{~km}$ radius from the power station, which is smaller than the emergency evacuation area in

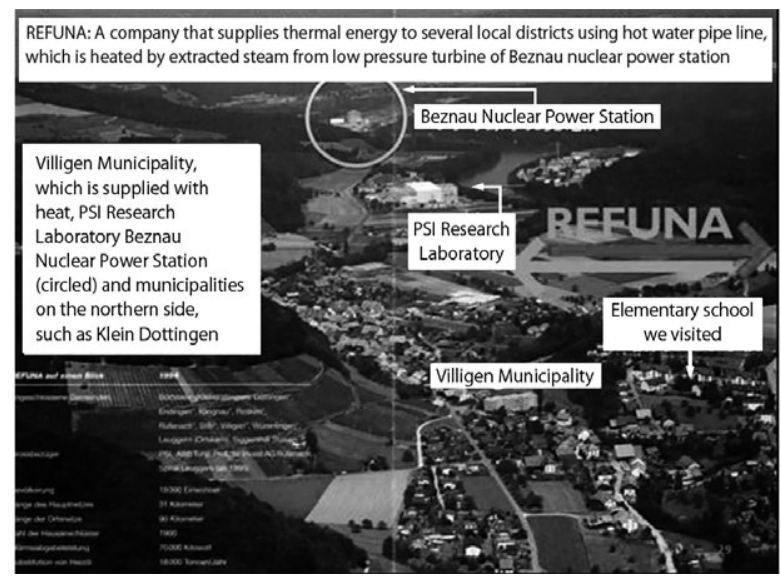

Figure 24 Regional symbiosis of Beznau Power Station in Switzerland ${ }^{20,21)}$

Districts Heat Supply Main Pipeline Network: Private homes, public facilities, commercial facilities, factories, research laboratories, and greenhouses for farming.

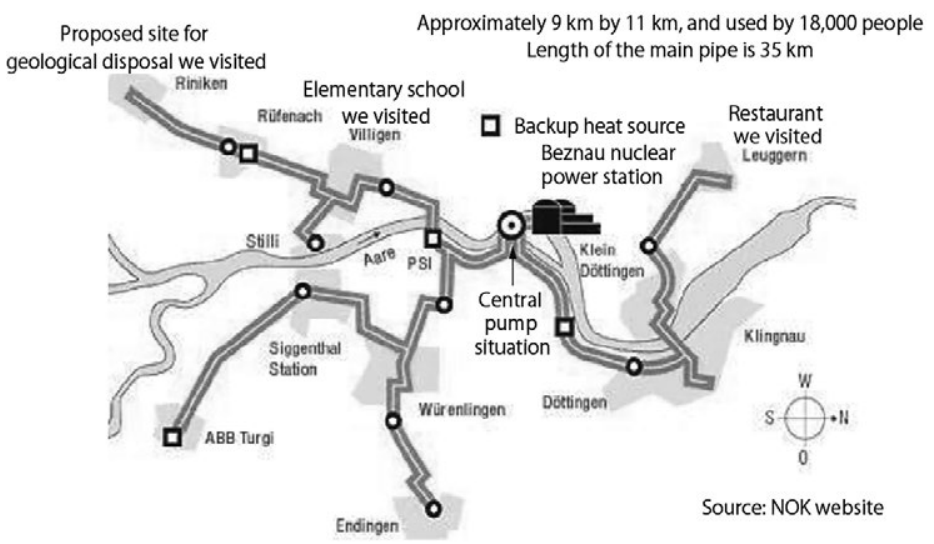

Figure 25 Local heat supply from Beznau Power Station ${ }^{20)}$ 
Japan, uses this system for the heating in winter and hot water throughout the year. $80 \%$ of the subscribers are private homes. With the economic stimulation of the area in view, public facilities such as schools and the like, commercial facilities, research laboratories, factory, and agricultural facilities (large-scale green house) are also actively using this service. The people of Switzerland, who maintains its neutrality since 1815 and was not involved in the First or Second World War and stayed peaceful, selected nuclear energy after discussing the measures and mental preparation for severe accidents and taking the energy security and environmental/carbon dioxide reduction measures into consideration.

\section{Provisional INES Level 7 Assessment}

The Nuclear and Industrial Safety Agency raised the assessment of the Fukushima Daiichi Accident to level 7 of International Nuclear Event Scale (INES), which is the most significant level. During the Chernobyl Accident, the reactor was destroyed by the explosion and a largescale graphite fire occurred, which led a large quantity of radioactive materials, including $3 \%-4 \%$ uranium in addition to iodine and cesium, to be spread across a wide area including European countries. Volatile nuclides, such as iodine and cesium, released from Fukushima were about $1 / 10$ of the Chernobyl Accident, and when it is evaluated with all the nuclides listed in INES, Fukushima, which did not release fuels such as uranium into the environment, released about $1 / 50$ of the Chernobyl Accident. Therefore, IAEA, which defined the standard of INES, objected the issuing of level 7 of INES. As per ROSATOM of Russia, level 7 assessed by the Nuclear and Industrial Safety Agency was excessive. Level 7 is for an accident that causes serious damage to the health of the local residents, which was not the case in Fukushima, where the exposure dose of the workers who were engaged in the recovery of the power station, was below the acceptable dose limit and did not cause health damage. From the extent of damage on the core, it was regarded that level 5 or level 6 was appropriate ${ }^{13)}$. Since it was assessed to be level 7, which was the same with Chernobyl, reputational damages such as the decrease in school trips and tourists in Aizuwakamatsu and sharp decrease in foreign students in the surrounding municipalities, are reported.

\section{Factor Analysis of the Fukushima Daiichi Power Station Accident and Future Measures}

\section{Accident Factor Analysis}

Although a detailed investigation is necessary in the future, when this accident is analyzed from the viewpoint of defense in depth based on the data published until this point, following are found to be the main factors of the accident.

(1) Loss of external power supplies for a long time: The nuclear and thermal power stations located on the large area of the eastern Japanese coast between Aomori Prefecture and Ibaraki Prefecture stopped due to the earthquake or the tsunami. In addition, the pylons in the premises of Fukushima Daiichi Power Station collapsed due to the earthquake. Therefore, recovery of external power took a long time, during which the batteries of the control panel or turbine-driven high-pressure water supply pump also ran out.

(2) Cooling systems that were dependent only on seawater failed together: Owing to the tsunami that went 4-5 $\mathrm{m}$ above the ground height of the premise, seawater entered the 
turbine building, flooded many electronic equipment and the emergency DG, and stopped them from functioning. In addition, the pump motor and other equipment of the seawater cooling system got flooded and failed.

(3) Occurrence of core cooling loss phenomenon: Due to the station blackout and breakdown of the IC or turbine-driven high-pressure injection pump, the injection cooling measures to the core were temporarily lost. This generated a large amount of hydrogen from the chemical reaction between the heated fuel cladding tubes and water. In addition, following the partial melting of the fuel pellet, the volatile components of nuclear FPs such as iodine and cesium were released in PCV, triggering a severe accident.

(4) Delay in the water injection to the core during severe accident countermeasures: Water should have been injected to the core promptly for severe AM (measures to mitigate severe accidents). Due to the delay in securing freshwater because freshwater in the premises ran out after long hours of injection and the pipe from the dam that was planned to be the water source was damaged, seawater was injected. However, because securing power supply vehicles and installing the hose to the fire-extinguishing pump while avoiding the debris from the tsunami took time, there were several hours of time loss to injecting water to the core.

(5) PCV overpressure and insufficient measures against hydrogen: Due to the venting conducted to prevent the internal pressure damage of PCV or the partial damage of PCV, iodine, cesium, and a large amount of hydrogen produced in (3) were released and caused hydrogen explosion. In addition, the emergency hydrogen processing system did not function due to the power loss.

(6) Cooling of the spent fuel pool: Water level could not be maintained at the spent fuel pool, and its fuel cladding tube might have been partially damaged.

\section{Basic Concept of Safety Measures}

As a nuclear reactor latently confines nuclear FPs in its reactor core, it is important to take multiple safety measures against external events such as earthquake or tsunami based on the following concept (defense in depth or multiple defense) : (1) Secure the cooling of the core. (2) Do not let an abnormality develop into an accident. (3) Even when there is an accident, keep its impact as small as possible.

If measures are to be taken for the abovementioned accident factors analysis from the perspective of defense in depth, it is necessary to plan the safety measures following the abovementioned concept of defense in depth. Specifically, following six points must be followed.

(1) Measures against loss of external power supplies for a long time: Strengthen the preparation for loss of external power supplies for a long time. Secure several power sources including hydropower and small-size thermal power. Take anti-earthquake/tsunami countermeasures for cabling, including the pylons in the premises.

(2) Prevent cooling systems that were dependent only on seawater from failing together: Install waterproof walls and doors to prevent seawater from entering the premises, important facilities for securing core cooling, and electric panel. In addition, prepare air-cooled emergency power source, power supply vehicles, and decay heat removal system as heat sink other than seawater.

(3) Prevent core cooling loss phenomenon: Prepare water injection with steam turbine-driven pump in order to prevent damage on fuel even when an important facility is damaged and power source or cooling function is lost. Attach a small generator to the steam turbine and make the butteries for control rechargeable. From the perspective of 
defense in depth, take measures for both piping rupture (LOCA) due to an earthquake and external power supplies/heat sink loss.

(4) Core water injection with speedy severe accident measures: Secure mobile power supply vehicles, partial permanent installation of cable connection to the emergency power source, maintenance of fire-extinguishing pump/water pump/fire hose, and conduct water injection training that follows the process of AM. Permanently install a part of water injection piping. Conduct trainings of water injection to the SG or the core, and extract and take measures against problems.

(5) Prevention of overpressure in PCV and measures against hydrogen: Strengthen the function to remove volatile iodine and cesium and take measures to prevent hydrogen explosion. We believe it is necessary to take medium- to long-term and fundamental safety measures such as employing the filtered vent used in Europe or a catalytic recombiner to install inside PCV.

(6) Cooling of spent fuel pool: Secure several water injection methods as well as mediumto long-term measures such as installation of air-cooling-type cooler or catalytic recombiner should be considered.

\section{Conclusions}

This accident at Fukushima Nuclear Power Station was an unprecedented event where severe phenomena occurred simultaneously at multiple units. Its situation was reported in detail by the mass media and many Japanese people experienced the devastation of the nuclear accident and the fear of radiation contamination. However, when the situation of each power station is analyzed with a calm mind, we can see a light of hope on the horizon. The Onagawa Nuclear Power Station, whose premises is located $14.8 \mathrm{~m}$ above sea level, managed to keep the damage of tsunami to minimal even though the town of Onagawa was heavily damaged by the same tsunami and achieved cold shutdown. A tsunami is an invasion of seawater, and we believe it is possible to physically stop it. Also, at the Fukushima Daini site, an emergency DG was installed in the R/B, and by changing the flooded seawater pump motor, cold shutdown was achieved.

During a severe accident, a filtered venting system that has a highly efficient radioactive material removal function that works without electricity is turned on before the pressure in $\mathrm{PCV}$ exceeds the design pressure. If radioactive materials can be released into the atmosphere at a level that does not require evacuation, it can both maintain the soundness of PCV and prevent health damage of the local residents and environmental damage without evacuation. How would this disaster have developed if such a facility had already been installed in Japan as the measures against external phenomena such as earthquake or tsunami? It is highly likely that the nuclear emergency could have remained minimal. From the perspective of defense in depth, the safety facility of nuclear power stations should be comprehensively reviewed with a strong will to not trouble the local resident near the power station no matter what disaster struck and even if the core is damaged. From the perspective of nuclear emergency mitigation/prevention, the Atomic Energy Society of Japan should urgently conduct various examinations for safety improvement with a strong will. With this reflection, we hope to regain the trust of local residents, develop world-class next-generation nuclear reactors, and the nuclear energy in Japan.

Finally, we would like to express our deepest gratitude to the people on ground who have 
been engaging in the recovery work of the nuclear power station since the immediate aftermath of the earthquake on March 11 during this unprecedented situation. Moreover, we offer our deepest condolences and goodwill as people who have been promoting the safety research of nuclear energy to the people who had to accept long-term evacuation and lost the foundation of life because of the tsunami and the nuclear power station accident. In the future, we will dedicate ourselves to the improvement in the safety of nuclear power stations, recovery of trust from the society, and the solutions to the future protection of the environment of this planet and securing energy for humanity.

We would like to acknowledge the suggestions from Takahisa Masuda, Yoshio Sunami, Yoshimori Hayashi, Yasuo Masuda, Masayoshi Kawai, Yasuhiko Fujii, Nobuaki Sato, Akira Kaneuji, and other members of the Fukushima recovery team F by the volunteers of a senior network of the Atomic Energy Society of Japan, which was published on March $28^{22}$. Moreover, Yasumasa Matsui of the nuclear power station team of TV Asahi supplied us with the time course of the media coverage of Fukushima Daiichi Nuclear Power Station, and Air Photo Service Co., Ltd. granted us permission to use their high-resolution aerial photos. We would like to express our gratitude to them here.

\section{References}

1) NISA, JNES. 2011 Earthquake off the Pacific Coast of Tohoku and the Earthquake Damage on Nuclear Power Station 2011 April. [in Japanese]

2) NISA, JNES. The 2011 off the Pacific coast of Tohoku Pacific Earthquake and the seismic damage to the NPPs.

3) Tokyo Electric Power Company. On the Impact of Nuclear Power Stations during 2011 Tohoku Earthquake and Their Current Situation, The Impact of Nuclear Power Stations during 2011 Tohoku Earthquake and Their Current Situation. 2011 April. [in Japanese]

4) Tokyo Electric Power Company. The Impact of Nuclear Power Stations during 2011 Tohoku Earthquake and Their Current Situation. 2011 April. [in Japanese]

5) Sakashita Dam: http://metalwings05.fc2web.com/dam/07_fukushima/sakashita/index.html [in Japanese]

6) Oka Y. TEPCO's Nuclear Power Plants suffered from big earthquake of March 11. 2011 March

7) Tokyo Electric Power Company. Issues to be reflected on the earthquake-proof safety evaluation following Unit 3 of Fukushima Daiichi nuclear power station and 2007 Niigata Prefecture Chuetsu offshore earthquake. 2010.June. [in Japanese]

8) Tokyo Electric Power Company. Earthquake-proof safety evaluation of Fukushima Daiichi power station Unit 3, buildings, structures and equipment important for safety and piping system. $2010 \mathrm{July}$. [in Japanese]

9) Kobayashi T, Yamaguchi K, Shimizu Y. Construction of Fukushima Daiichi Nuclear Power Station Unit 3 by Tokyo Electric Power Company Inc. Toshiba Rev. 1976; 31(12). [in Japanese]

10) Ichiki T. Layout plan of BWR power station. Toshiba Rev. 1969; 24(1). [in Japanese]

11) Ed. Atomic Energy Society of Japan. Century Opened by Nuclear Energy. 2004. [in Japanese]

12) Japan Atomic Energy Relations Organization. Collected Diagrams of Nuclear Power and Energy. 2011. [in Japanese]

13) Newspaper of Japan Atomic Industrial Forum. 2011 April; 2571th issue. [in Japanese]

14) United Nations Scientific Committee on the Effects of Atomic Radiation, UNSCEAR 2000 Report to the General Assembly with Scientific Annexes, Vol.II : Effects, http://www.unscear.org/unscear/ publications/2000_2.html

15) Wikipedia: http://ja.wikipedia.org/wiki/Chernobyl Accident, 2011. [in Japanese]

16) Lawson D. Engineering Disasters-Lesson to be learned.: ASME Press, New York; 2005.

17) Nihon Keizai Shimbun Prevent iPS Cell Turning into Cancer. Special article on iPS cell, Morning paper, 2009.9.20. [in Japanese]

18) Gavrilas $\mathrm{M}$ et al. Safety features of operating light water reactors of western design. CNES. 2000.

19) NOK AG. Beznau NPP Information Package. 2006 Edition.

20) REFUNA AG. REFUNA Pamphlet 1994 Edition. [in Japanese]

21) Sugiyama K. et al. Local nuclear energy heat supply, achievements in Switzerland. Nihon- 
Genshiryoku-Gakkai Shi (J. Atom. Energy Soc. of Jpn) 2006; 48(2). [in Japanese]

22) Narabayashi T. et al. Analysis and Proposal for Fukushima Daiichi Nuclear Power Plant Severe Accident-SNW Team F in AESJ, Genshiryoku Eye, Vol. 57, No. 6 , Nov. 2011, 10-13, [in Japanese]. https://iss.ndl.go.jp/books/R000000004-I11109113-00 


\title{
The Disaster by the Fukushima Nuclear Power Plants and the Risk Science
}

\author{
International Institute for Advanced Studies, Tomio Kinoshita
}

The author is a researcher in social psychology, having a long association with the world of nuclear power; however, his knowledge does not go beyond hearsay, and he has little expertise in the field. Thus, many of the following opinions may sound irrelevant to the nuclear energy experts. Bearing the above in mind, the author will discuss the problems of this accident from the perspectives of social psychology and risk studies.

\section{Nuclear Power Plant Accident that the World is Watching}

The Fukushima Nuclear Power Plant Accident caused by the Great East Japan Earthquake had a tremendous impact on the world. Because Japanese nuclear power plants were highly trusted so far, the public's reactions were also strong. At the citizen level, this shock mainly manifested itself in the form of panic toward radiation, reputational damage, the advancement of anti-nuclear organizations, and the general skepticism toward science and technology.

However, more serious issues are the national-level impacts such as the effect on the nuclear industry of the world, the resulting pressure on the energy demand and supply, and its impact on the world economy. If wrong responses are delivered regarding these issues, there is a possibility that the world will fall into confusion around energy security; moreover, the decline in Japan's power could trigger a major loss of balance in the world order.

Furthermore, major countries of the world are seriously observing this accident not only from such resource-based/economic perspectives but also from the perspective of government's comprehensive risk management abilities, field simulation of response to nuclear war, response to nuclear terrorism, review of emergency deployment capability of military forces and specialized equipment, and the reaction to emergency among their citizens. The world is observing because the state and potential of a nation becomes apparent in a big emergency.

While such cold logic of statecraft exists behind the warm support offered by other countries of the world, who in Japan is responsible for national security, which comprises advanced risk management that is beyond the problems of the earthquake and the nuclear power plants? To begin with, is the Japanese government capable of such risk management?

DOI : 10.15669/fukushimainsights.Vol.1.32

(C) 2021 Atomic Energy Society of Japan. All rights reserved.

Originally published in Journal of the Atomic Energy Society of Japan (ISSN 1882-2606), Vol. 53, No. 7, p. 465-472 (2011)

in Japanese. (Japanese version accepted: May 12, 2011) 


\section{The Impact of the Nuclear Power Plant Accident on Japan}

Public opinion will undoubtedly be stricter against nuclear energy. Not only will the construction of new nuclear power plants be more difficult, there may also be demands for decommissioning existing nuclear reactors. Until now, the majority of the public opinion agreed that "although nuclear power plants are dangerous, their operation should continue as nuclear energy is useful" ${ }^{1)}$; however, this risk/benefit trade-off relationship may be affected by this accident. Based on a recent opinion poll, the percentage of "people who promote nuclear power plants and people who support the status quo" was $56 \%{ }^{2)}$. Although this is $10 \%$ lower than the 2007 poll, its decrease was not as large as expected. If the accident resolves without any more deterioration, public opinion may not conclude that "nuclear power stations are dangerous and unnecessary, and therefore should be discontinued." However, public opinion may change quickly, depending on further developments of the situation.

In any case, the issue of energy security as the national policy is highly likely of triggering a major debate that will polarize the public opinion in future. There will be opinions to review the current basic energy plan, and the prospect of the so-called Nuclear Renaissance will be more distant for the near future. Most immediately, a reexamination of the safety of the FBR sodium-cooling system (which is considered a potential successor to the light water reactor) when it is damaged will be demanded.

The author believes it is imperative to remember that the energy security problem including the nuclear energy policy must be discussed from the global perspective of international strategy instead of the local Japanese perspective. What must be avoided is a debate that is driven by temporary emotional excitement and political speculation.

Finally, the most important concerns are the large number of nuclear energy researchers and engineers who are despondent and have lost confidence. Even though it might be a reversal of their previous overconfidence, this despondence is problematic for the Japanese people. Soul-searching is necessary after this accident, but the knowledge of these people is still indispensable for the maintenance of existing nuclear power plants and future development of safe nuclear power plants.

\section{Hardware Problems from the Risk Studies Perspective}

The accident has not yet been resolved (this paper was written in late April 2011), and the official work of elucidating the cause has not yet been conducted. Thus, it appears premature to discuss the cause of the accident. For this reason, it is possible that the following opinions are incorrect as they are based on predictions. Even if the opinions are correct, they may be criticized to be mere "afterthoughts." Nevertheless, the author will highlight some of the risk studies problems that have already become obvious without waiting for the official report.

\section{Station Blackout}

The loss of emergency power sources due to the tsunami is often deemed the cause of this accident. However, the author is more concerned about why the external main power source collapsed so easily, and why its recovery took so long. It is understandable to automatically shut down the circuit when a major earthquake hits to protect related equipment such as the 
generator. However, this external power supply's loss was beyond that level, including the collapse of transmission towers coupled with the absence of the supplementary circuit.

Meanwhile, from the perspective of the risk theory, it appears that the emergency power supply's preparation was insufficient despite being "for emergencies." As it will be discussed later, the reason for this is that the "defense in depth" arrangement that was required for emergency preparation was not implemented for some reason. Moreover, it is common in risk studies to always prepare machine or manual operation systems that do not require electricity for emergencies. Then, in the case of nuclear power plants, is it difficult to implement such an idea? ${ }^{3)}$. For instance, the emergency condenser or the isolation cooling (IC) system is present to realize such systems. So why did they not function during this accident? In any case, from the perspective of non-experts, it is too embarrassing for an electricity company to have suffered a total power loss. The author would like to know the type of unexpected events that led to such a situation.

\section{How Much Preparation Was Made in Advance Against the Shortcomings of the Reactor}

If the author is not mistaken, all reactors that caused this accident were BWR/Mark 1 type designed by General Electric (GE) (though the installer was different for each reactor and some had mediating consultants). The weakness of this reactor includes the possibility of the primary containment vessel (PCV) being overloaded more than the assumed pressure when the cooling function is lost, resulting in rupture. In addition, the PCV is too small and can easily cause problems during an accident; furthermore, the spent-fuel pool is positioned too high and thus cannot be appropriately managed. According to the report from the public hearing at the U.S. Congress, these shortcomings were found during the designing of Mark 2 and 3 .

These are all important problems that were also revealed during this accident, and in fact, the issues thus highlighted were resolved in the reactors constructed after Mark 2. Although GE informed all the owners of Mark 1 at that time and requested them to take measures against these weaknesses, judging from the result of this accident, it appears that Japanese electric companies did not take enough measures. For an outsider, it is not possible to know the reason behind this lapse.

\section{Disasters Attack the Weakest Point of a System}

From the perspective of risk theory, it is quite common that a system is fragile as a whole even if the individual machines that constitute the system are robust. This is because the weakness is often hidden in the interface connecting these machines, and the strength of the overall system is often determined by the strength of the weakest factor instead of the average strength of all factors constituting the system or the strength of the strongest part.

Importantly, disasters are known to precisely target the weakest point of a system. In other words, a disaster "bullies the weak". Therefore, risk management of a system requires deep knowledge of this characteristic of disasters ${ }^{3)}$.

This issue was in fact already highlighted at the time of the Great Hanshin Earthquake. For instance, the emergency information system normally comprises primary equipment such as a radio transceiver and a generator. However, many components of this system did not function. The reason was not the damage on the main equipment such as the transceiver or generator. Instead, it was the damage on the function of the peripheral equipment such as the 
damage to the water tank used for cooling the generator or the cutting of the pipe that connects them. Also in this case, the earthquake attacked the weakest point of the system.

To give an example from daily life, the same can be said about the members of a hiking trip. If one plans to go hiking in a group, one must plan his schedule while considering the member with the least physical strength. If the plan is made based on the average of the strengths of all participants, someone may drop out of the plan.

The malfunctioning of a transceiver or a hiking group is far less significant compared to the nuclear power plant disaster. However, when studied from the perspective of functionality, there are many similarities between them: a nuclear power plant is also a typical system, and while the main body of the reactor is extremely robust, other minor equipment and the interface connecting them (e.g., piping, connecting or welded parts of the equipment) are relatively weak $^{4)}$. It is common for a slight damage to these parts to stop the entire system. There are major concerns of non-experts regarding how many measures were taken against this risk in nuclear power plants, which are for such complex piping that they are called "piping monsters".

\section{Was the Defense in Depth Truly Multilayered?}

Thus far, technical explanations claimed that protection against radiation of a nuclear reactor is tightly conducted with a 5-layered "wall", and the probability of its safety is extremely high. However, this belief was easily broken by this disaster. The reason for this was the fact that each of the 5-layered walls was not independent. Moreover, the walls of the emergency power source or the spent-fuel pool were not multilayered to begin with.

Needless to say, to improve the probability of safety with defense in depth, the necessary precondition is that the individual protection system must be entirely independent ${ }^{3)}$. Regardless of the number of multiplexed walls, unless each wall is independent, the safety of the whole system cannot be obtained as the product of probability. This is why the brake system of an automobile is designed with entirely independent systems, namely, the hydraulic system and the wire system. This "entirely independent system" is literally independent from the beginning to the end. A famous example of failure is the 1985 Japan Airline accident.

As many people already know, there were several control systems in the tail of the crashed Japan Airline aircraft, and each of them was independent. However, these circuits were at the end gathered in one spot at the bulkhead of the tail. And when this bulkhead was damaged, the circuits for several systems fractured at once. Hence, the multiple systems in the circuit appeared independent, but in fact they comprised a single system at one point in the aircraft's tail. This nuclear power plant accident appears to be similar to this lesson from the Japan Airline aircraft's accident.

As can be observed, the 5-layered protection against radiation walls appear to be designed as independent, similar to the tail control circuit of the Japan Airline aircraft. However, similar to the way the circuit of the airline was gathered at one spot in the partition of the tail and lost independence, the walls of the nuclear plant also lost their independence when the assumption that the cooling function of the fuel rods is continuing collapsed.

Another point of concern regarding the independence is the location of the emergency generator. Here, emergency must include not only tsunamis such as this, but also many other cases such as fire or explosion. And when primary equipment is damaged during such emergencies, it implies a high possibility of the emergency generator installed nearby being damaged as well. Thus, to avoid such a risk, it is necessary to install at least one emergency generator at a safe location that is separated from the main equipment. For the same reason, a bank 
stores its client data, which is its lifeline, in a region far from the head office as a backup. It is difficult to understand why this design philosophy of risk distribution, which is the most basic logic in risk management, was not applied to the design of the nuclear power plant.

\section{Meaning of "Unexpected"}

The word unexpected is frequently used for this nuclear power plant accident: An earthquake of an unexpected M9.0 scale and the unexpected scale of the 15m-high major tsunami. Moreover, there are opinions that certain assumptions must be made to design equipment. However, from the perspective of the risk theory, this word unexpected is misunderstood because there are several levels in this assumption ${ }^{4}$.

The types of unexpected situations include: (1) an unexpected event whose probability of occurrence is objectively so low that it was removed from the list of expected events (e.g., the falling of a meteorite). (2) Events where there were people who brought the possibility to attention, but theirs were minority opinions, and because the consensus of the academic field exhibited low probability, such events were removed from the list of expected events (limit of academic standard or the issue of considering minority opinions). (3) Events whose probabilities are shown to some extent, yet removed from the list of expected events owing to subjective judgment that they are unlikely to occur (e.g., from misguided belief or overconfidence or the inability to face a difficult situation resulting in pushing the thought out of one's mind). These problems are faced in engineering ethics as well ${ }^{5)}$. (4) Events whose probabilities of occurrence are understood, yet removed from the list of expected events owing to trade-offs with external factors (e.g., the cost was too high or political consideration). (5) Events where despite being present, the possibilities of occurrence were not considered due to lack of imagination or information, leading to an unexpected result (the sin of ignorance, lack of study, or poor imagination). As can be seen, there are many types of unexpected events.

Moreover, in terms of the quality of prediction, there is not only the issue of the comprehensiveness of the assumed scope of risk of the probable events and the prediction of the risk's probability, but there is also the issue of total risk assessment in terms of how much consideration was given to the size of the damage when such events occurred. Regarding the quality of this risk prediction, the basic rule outside Japan is to begin with the "worst case scenario." However, for some reason, the Japanese do not wish to assume the worst case. The prediction-makers claim that this reluctance is because they do not wish to cause excessive concern. But that is a lie. Instead, it shows the mental weakness and inability to face the necessity of "thinking of the worst case."

In any case, only the first case among the 5 cases of "unexpected" discussed above is legitimate. All other unexpected events, especially the $3 \mathrm{rd}$ and the 5 th cases must not be allowed to occur. In the case of this disaster, were there such unexpected events? Although there are many media reports swirling around this issue, the author cannot verify the fact and this issue will be the focus of legal disputes. Therefore, no further comments regarding this will be given in this paper.

However, from the perspective of risk studies, the 4th case, the case where events were removed from the list of expected issues owing to the concern for cost, is problematic. In general, it is natural to consider the cost during design, and there is no objection to this point. The problem, however, is what standards and sense of values were used to evaluate the risk and cost trade-off. Cost includes not only the initial cost, but also the running cost, disaster cost during an emergency, and the disposal cost. Moreover, there are political, social, or psychological costs in addition to the economic cost. The author wonders whether much 
consideration was given to these other costs. Especially the disaster cost during an emergency tends to be given low priority because of its infrequency. However, there are countless examples of being stingy with this initial cost and ending up paying a lot more after a major disaster struck. Perhaps the same mistake was made during this accident? As it will be discussed later, such a misjudgment is known to happen often when the evaluation is performed with only an insular sense of value within an organization.

Furthermore, regarding this cost, there is a big difference between the cost for proceeding to the design of the actual facility/equipment and the monetary cost of conducting only thought simulation and thinking about the preparation of procedures in advance. Were the relevant people aware of this difference? For instance, the author does not insist that the abovementioned risk of a meteorite hitting the power plant should be considered when the real machine is designed. But it may be preferable to at least conduct a low cost thought simulation and be prepared. This logic is applicable to the unexpected events of case 2 as well.

Finally, there is the issue of whether the station blackout during this disaster was within the assumption or was unexpected. The possibility of power loss was brought to attention by some members of the administrative committee. Moreover, the scenario for preparing for it was at least discussed. Thus, it can be said that it was at least formally assumed. However, the real response was so inadequate that one cannot say that the administration was prepared. In that case, what was the content and scenario they assumed?

For instance, were they optimistically expecting some of the emergency power source to be functional even when the main power source is lost? Were they thinking that even if there is a station blackout, it will only be temporary and will recover quickly? Surely, the knowledge that the time until a core meltdown is short following total power loss was shared among them. So was there any special measure to ensure that the emergency power source will be available for a long time to prepare for such a situation? Regarding the three rules of "stop", "cool", "confine", there may be an optimistic thought that if the first step "stop" goes well, the following cooling process including ECCS will proceed smoothly. In any case, the author believes that the most important point in future examinations of the accident will be the issue of this assumption level and the number of measures taken in advance based on it.

\section{Problem of Software from the Risk Studies Perspective}

\section{Problem of Layout of the Structure}

In addition to the safety of the structure itself, the issue of the layout, in which how the structure as a whole is positioned, is involved in the safety of the structural system. The concern regarding the installation position of the emergency generator was already discussed in section III-4. Regarding Mark 1, the same could be said about the over-packed layout of the pipes and various equipment inside the PCV as well as about the layout of the spent-fuel pool, which was positioned high in the nuclear reactor building. However, this is a design-based issue for GE, and it will not be discussed further in this paper because these issues were improved in the reactors following Mark 2.

A more pressing issue is the fact that the four reactor buildings and turbine buildings are too close. Naturally, in normal times, it is more efficient for these buildings to be close to each other. However, this could worsen the damage during an emergency. For instance, when one reactor has an accident and generates abnormally strong radiation, there is a concern that the reactor next to it will be affected, and it will not be possible to even go close to the reactor, 
let alone repair it. This issue of "concentration and dispersion" has historically been discussed frequently in both risk studies and engineering fields. Was this issue sufficiently considered? However, there is no simple answer to this issue when one thinks of the trouble people have in working within many constraints attached to a site in a small country like Japan.

In addition, many nuclear reactors in Japan are built by the sea. For tsunami countermeasures, it appears that instead of building embankments more than $10 \mathrm{~m}$ high, building the reactor on land that is $10 \mathrm{~m}$ higher would be more effective. Why was there no design that considered layouts that utilized the topography? Furthermore, there are many pumps by the sea that did not have a building and were simply exposed. Why were buildings not built for them?

\section{Absence of Professionals Who Know the Whole System}

The response to this accident projects the impression that there was no professional who understood the system of the nuclear power plant as a whole down to the small details. Although there are many professionals for each component of the system, it appears that there is a serious shortage of professionals who have an overview of the entire system.

However, this issue did not become apparent only by this accident; rather, it has been discussed on the site for more than a decade. In fact, whenever a discussion was held with people responsible during a visit to the nuclear power plant, this issue was almost always raised. According to the people in charge, it sometimes happens that an experienced engineer who has been staring at a large design drawing for a long time points to somewhere in the drawing and says "I am not comfortable with this part," or "this part feels scary for some reason." Even though there is no real data, a problem was discovered when such a part was inspected just in case, allowing them to take measures in advance and avoid accidents. This is not simple "intuition." Instead it is "professional sense" acquired after long years of experience. These people intuitively know the basic fact that in a system, the simple sum of "parts" is not the "whole." Such extraordinary professionals have been the backbone of Japanese nuclear power plants.

However, when studying the response to this accident, one gets an idea of how the consequence of one measure leading to a certain type of chain reaction, especially during the early stage of the accident, was not sufficiently considered. If this lack of consideration was due to a decrease in the number of professionals capable of grasping the overall picture of the entire system, then what are the implications for future maintenance systems? Such staff cannot be trained in a short period of time.

\section{First-Rate Design and Third-Rate Construction?}

It has often been pointed out that while the design of Japanese nuclear reactors is firstrate, both the construction and the inspectors are third-rate ${ }^{6}$. As the author has no experience in this issue and consequently may have misunderstood something, the writing of Mr. Hirai, who does not support the anti-nuclear stand and has detailed field knowledge of the reactors, has some degree of persuasiveness. His writing also echoes the abovementioned lamentation of the people who are in charge of nuclear power plant sites that expert skills are not being passed on.

According to Mr. Hirai's opinions, the work at the frontline is facing the following problems: There are less "craftsmen" among the workers at nuclear reactors, and the number of workers who are not so different from amateurs is increasing. Even if one tries to train them, it is difficult to train the successors due to the issue of exposure. And many of the specialized 
operation management officers sent from the relevant ministries are also complete amateurs, and there is a shortage of people who can impart correct instructions. These anecdotes are not necessarily exaggerated. When talking to the technicians working at reactors, one often hears the same stories.

Regarding the specialized operation management officer, the necessity of establishing a third party organization that has solid specialized knowledge and skill, and can objectively and fairly conduct evaluations has been pointed out for some time, prior to the comment by Mr. Hirai. However, there are several variations of the function of a third party organization including giving advice, making inquiries, monitoring, evaluating, and providing information ${ }^{4,7)}$. Although what is required here is to mainly focus on monitoring and evaluation, which will not be discussed further in this paper because this issue also involves the issue of governmental administration reform.

\section{The Gap Between the Verification on Paper and the Real Situation on Site}

For the first step of a safety audit related to the abovementioned problems, it is common for the audit to be conducted through the inspection checklist supplied by the administration in advance and the papers the company prepared in response to the checklist. This checklist includes questions such as whether there is an emergency generator, a vehicle with a generator, and whether routine inspections are being conducted. Other such questions include, in case the telephone stops working, whether an alternative communication system is prepared; how many staff members are allocated for fire prevention, and whether training for emergencies is being conducted. On the whole, the checklist includes numerous questions.

This type of paper examination is not entirely meaningless, and not all its aspects are bad. The problem is the extent to which the numbers on the paper reflect reality. Even if every question in the checklist was answered as "yes," it does not necessarily reflect the reality because this practice is simply "matching the numbers," if stated negatively.

For instance, regarding the abovementioned generator vehicle, the problem is not whether they exist in number, but whether they are "active" and are maintained in a condition to be used at any time. To achieve this, every possible obstacle must be considered including whether the vehicle is always stored in a safe place, whether it is inspected daily, is its fuel secured, how long can it run continuously, whether an alternative vehicle is prepared when the primary vehicle is under inspection or in repair, if a driver is secured, and what are the measures when the road is blocked by debris. Such a consideration for complex and diverse risks is not possible unless one works at the site. It must be constantly repeated that risk management cannot be conducted only on paper. However, to begin with, is there a risk manager who can consider all these risks stationed at the site?

\section{Necessity of Accident Simulation Experiment}

It goes without saying that daily training is necessary to prepare for an accident (however, training that only follows the manual is not sufficient). What is equally important is a prior simulation of an accident. And it is desirable for this simulation to not only be a virtual simulation using a computer, but also an experimental simulation using real equipment, even if it is on a small scale. According to Dr. Itsuro Kimura of Kyoto University, such an experiment is already conducted in the U.S.

However, the author must admit that doing this is extremely difficult in reality, partly because of the issue of cost. Yet, the knowledge obtained from such an experiment will be much 
more realistic than that obtained from trainings, and it will be very advantageous to obtain such precious real data.

\section{Nuclear Energy Industry As a Closed System and Its Safety Culture}

The nuclear energy industry has been metaphorically compared to a "village" for a long time. That is because this industry is insular, and it does not often share or accept information from the outside. As this view is often voiced even by the staff or other departments of the electric company, who are colleagues of the nuclear energy staff, other related companies, government officials, and the staff of research institutes, the author believes that this impression of insularity is not merely a personal impression.

The possible reasons for the insularity of the industry is include how private use of nuclear energy rapidly progressed about 50 years ago, and nuclear energy was praised as the "dream energy" by the industry, government, academia, and public opinion, causing elites to enter this industry. Another reason is how the industry became inaccessible to outsiders because it is a technology that requires state-of-the-art and advanced specialization, and consequently, the internal group became united and lost the sense of necessity to absorb or share information with the outside world. There is a fierce criticism that says its insularity became an indirect cause to this accident.

To avoid misunderstanding, the author would like to clarify that the author is not claiming that nuclear specialists have been ignoring safety. They have been pursuing safety in their own ways. For instance, some intellectuals criticized the nuclear industry after this accident by saying that "the nuclear industry misled the people by propagating the safety myth." However, this comment is not necessarily correct. After the 1991 accident at the Mihama Nuclear Power Plant of the Kansai Electric Power Company, the company responded to the triggering of ECCS by significantly altering the claim in nuclear energy public relations (PR) magazines that said "accidents will never happen." Moreover, the content of the "White Papers on Nuclear Safety" published by the Nuclear Safety Commission in 2000 clearly suggests a "departure from the safety myth.” This was also widely reported in newspapers at the time ${ }^{8)}$.

This indicates the presence of the perspective that understands that there is no certainty in the safety of science and technology existing in the nuclear industry, at least on a philosophical level. The author also believes that this perspective was widely shared throughout the industry after 2000. However, upon studying this accident, it appears that this perspective did not lead to concrete and functioning actions. Why was that?

It may be due to a discrepancy between the standard for safety and that of the specialists outside the nuclear village. It is possible to wonder whether this discrepancy originated from the experts' overconfidence in their specialization, and whether the inability to notice the discrepancy or the overconfidence was due to the insularity of the village.

In short, even though they understood the concept of safety in theory, their response as an institution suddenly became an insular judgment, and they made an indulgent estimation or rejected external minority opinions and made themselves absolute. In other words, consciousness in terms of safety was not internalized by the organization. Such a negative aspect of organizational code has been one of the main research subjects of social psychology for a long time. The author hopes that the nuclear industry will consider such social psychological knowledge in their future organizational reviews, because wonderful knowledge also exists among the "outsiders" who are not part of the village.

In addition, the media is reporting several other problems around the insularity of the nuclear industry such as its collusion with politicians or the administration and the vested 
interest structure ${ }^{9}$. The author will not discuss this issue further owing to a lack of material or knowledge to discuss the validity of these reports. However, the author would like to highlight once more that generally, a system that cuts off its energy metabolism with the outside world always collapses. This is both a law of physics and a law of social science.

\section{Problem of Command/PR System from the Perspective of Risk Studies}

This nuclear power plant accident raised questions, beyond engineering problems such as how to handle the reactor, what type of team should be made to effectively cope with the major accident that occurred, what type of leadership is required in such circumstances, and what type of PR is required to explain the situation to the concerned people. Therefore, a major suggestion was made on the issues of social psychology. These questions will be discussed as follows.

\section{Problem of the Chain of Command}

There were many players who were involved in the response to this accident including the Tokyo Electric Power Company, the Nuclear Safety Commission, the Nuclear and Industrial Safety Agency of the Ministry of Economy, Trade and Industry, Toshiba, and Hitachi. However, what type of joint team was formed and who played the central role in leading the team is still unclear.

The author believes that when the JCO Accident occurred, the Nuclear Safety Commission played a central role in terms of implementing countermeasures and resolved the issue relatively smoothly. However, they did not play many visible roles this time. Was there a special reason for it?

What is more important than such an inquiry is the fact that what type of organization should take a leading role in the response to such a major accident was not clarified beforehand in normal times. It is commonly known that setting up an organization in haste after the occurrence of an event will not result in a functional organization.

Moreover, many other countries naturally have such an organization. Although Japan also has what is called the Government Nuclear Emergency Response Headquarters, its technical leadership was not very visible during this accident. There are many other similar organizations being established. However, they are not unified, and it is difficult not to form an impression of "too many cooks spoil the broth." What creates the most confusion in an organization is a person who only has "enthusiasm" without specialized knowledge tries to lead the organization.

According to the knowledge of social psychology, it is known that the ideal style of an organization or a group is strongly dependent on the task environment they are in. In a highly specialized task environment with significant urgency such as the situation of this accident, it is imperative to create a task-oriented organization. It can also be described as a type of task force.

To achieve this, it is important to unify the very best professionals of each specialized field, create a headquarters with a small group that controls the whole including support groups (the type of staff discussed in Section IV-2 is needed for precisely this type of task), select a leader who can see the big picture and make judgments accordingly, unify the group 
under strong leadership, provide that leader with sufficient authority (some countries grant the leader authority equal to the prime minister under certain conditions), and above all value decisiveness and speed. A good example of such a task force is the "Hayabusa" Asteroid Probe mission that returned safely despite many unexpected dangers ${ }^{10)}$.

Note that, for such task force members who are requested to possess highly professional knowledge, it is unacceptable for politicians with poor knowledge to interfere in the process or technical discussions. However, this does not mean that politicians must be ignored. Broadly speaking, they have two roles. One is to instruct the direction of problem solving, and the other is to make the final decision.

The first case is when the progress of the occurred situation includes socially complex factors, and the staff on site is not sure where to begin; it is the role of politicians to instruct the directions to proceed and the priority of tasks. However, to perform this role, it is a prerequisite for the politician to possess high-level judgment that can view the bigger picture in such a situation.

The second case is of taking responsibility and making decisions as the situation progresses, facing a difficult scenario where every option will likely lead to a negative consequence. That is because these two cases are highly political decisions rather than technical decisions.

\section{The Issue of PR System}

At the beginning of this accident, PR was handled by the Chief Cabinet Secretary and the staff of the Safety Agency. Later, TEPCO joined, and PR is currently handled by these three parties. What is hard to understand is why PR is not being unified. In risk studies, it is common sense to unify the PR system during such an emergency, similar to the abovementioned chain of command. Indeed, the existence of three information sources leads to the repetition of information or discrepancies between the claims of the three sources, causing misunderstanding and confusion.

There is of course the advantage of increased information when there are three sources. However, instead of conducting press conferences separately, the three parties should join in support, convert the information of all three sources into one, and then speak at any time depending on the topics. This may be a normal arrangement, but the problem in PR is not related to only its system but also to its contents.

First, there is a problem in the level of information disclosure. Information disclosure has generally been too passive or too careful. The reason for that is because relevant people may claim that "disclosing uncertain information will cause unnecessary concern to the people." However, this is an amateur's view with no knowledge of the communication theory of social psychology. If an uncertain piece of information is disclosed with careful explanation, the people will accept it without misunderstanding. Withheld information will lead to speculations that important information is hidden from the people, which will in turn cause more concerns ${ }^{8,11,12)}$. PR does not demand strict accuracy in terms of presentation in an academic society. And it must be understood that the people are not as ignorant as the persons involved believe they are.

Another misconception of the persons involved is that they seem to think "Correct PR is to ease the concern of the people". However, this is wrong. While it is good to correct the people when they are concerned about something that is objectively safe, it is in fact more dangerous to convince them that something dangerous is safe. They must understand what is required is to help the people to adapt the attitude to "fear what is dangerous, but fear it correctly" 13).

It is also important to know that there is no experiential data of panic occurring after a 
natural disaster, including earthquakes. This is common knowledge among sociologists and psychologists around the world. The term earthquake panic is merely a word coined by the media. However, in the case of this nuclear power plant disaster caused by an earthquake, there is a possibility of panic caused by distorted information.

Another problem the author would like to discuss is the quality of provided information. Seen from the perspective of social psychology, the current spokesperson unfortunately does not have basic academic knowledge of PR techniques toward the general public. The author can understand that the spokesperson is attempting to speak as simply as possible, but the problem is that the explanation is not in accordance with the recognition structure of the citizens.

Take the example of the radiation exposure problem, which the citizen is highly interested in. The average thinking pattern of the citizens is probably at the level of radiation = atomic bomb $=$ Chernobyl $=$ scary, and they hardly have knowledge in radiobiology or radiation protection science related to the danger of exposure. Although it is understandable that they do not know units such as $\mathrm{Sv}$ or $\mathrm{Bq}$, it can be speculated that the number of citizens who have basic knowledge on radiation, such as how the dose-response relation of radiation is studied, the difference between risk measurement and risk assessment, the transition of the temporal and spatial distribution of radiation, the meaning of stochastic effect, the meaning of tolerable risk or regulation value, or the meaning of precautionary principle, is extremely small.

And without some of this basic knowledge, it is not possible to understand why the radius of evacuation area was different between Japan and the U.S., why spinach was the first to be restricted, and why vague expressions such as do not go outside "for the time being" were used.

It is however wrong to criticize the citizens for being ignorant of these concepts, because they do not need this knowledge in daily life, and the citizens are too busy to study unnecessary subjects.

If that is the case, the persons involved must approach the citizens and make an effort to reconstruct the concept to suit the recognition level of the citizens and communicate them. Without such an effort, the meaning of radiation risk will be difficult to convey. To achieve this, a cooperation of professionals in both communication and radiation seems indispensable. However, there is no sign of such considerations being taken. The author believes this is due to the insular nature of the nuclear village discussed in Section IV-6 that neglects sharing information with the outside world.

There are many possible methods for improving PR. The first step would be a collaboration between the professionals of communication and radiation as discussed above to devise logic and expressions that are easy for the citizens to understand. Following this, is it necessary to print an explanatory article based on these expressions as a preserved version and distribute it among the people of affected areas who are concerned about the radiation exposure? (Newspapers are already trying similar PR techniques). Furthermore, establishing a fair third party organization focused on PR, as discussed earlier, would also be effective. References that will be useful for learning the points to be careful and useful examples are abundant, including the ones by us. The author hopes they will be utilized by the relevant parties ${ }^{7,8,11,14-18)}$.

In addition, a related problem that is being discussed is the so-called reputational damage. The term reputational damage is a neologism by the media, and is a concept without any academic ground. Socio-psychologically, reputational damage is close to gossip or rumor. And it is impossible in principle to stop the emergence of gossip or rumor, including the reputation. However, there are many techniques to reduce its scale, and there have been several studies on this issue ${ }^{12,19)}$. The author omits a detailed discussion due to space limitations. 


\section{Conclusions}

Even though the Atomic Energy Society of Japan invited the author to contribute to their journal, the author is aware that it was highly presumptuous of a non-specialist to present an opinion about this Fukushima Nuclear Plant Accident. Although the author discussed how things appear from the outside perspectives of risk studies or social psychology, there may have been some misunderstandings or prejudices originating from a lack of knowledge. The author would like to apologize to the concerned people in advance.

However, if the author may offer an opinion, while many vague expressions such as "safety myth" or "unexpected" were used liberally around this accident, this in fact points to the possibility that the discussions based on the concepts of "safe/secure" are problematic to begin with because "safe/secure" are problematic concepts that sound pleasant but cannot be defined operationally ${ }^{13}$. The author omits the details of the debate around them, but what is required in the future is "risk", which is a logical expansion seen from the perspective of science. As Sugawara ${ }^{20)}$ suggested, the author believes that it is necessary to "stop being emotionally satisfied with words such as safe or secure; instead recognize that risks exist in every product and technology, and think of appropriate measures against these risks."

Finally, the author would like to conclude this paper by dedicating the utmost respect and gratitude to the technicians and workers who are still risking their lives in the fight against the accident at the site of the Fukushima Nuclear Power Plant.

\section{References}

1) Kinoshita T., Structure of risk recognition and its international comparison. Anzen-Kogaku (J of Japan Society for Safety Engineering). 2002;41(6):356-363. [in Japanese]

2) The Asahi Shimbun (Morning paper). Regular national opinion poll. 2011 Apr 18. [in Japanese]

3) Kinoshita T., Crisis management for earthquake disaster prevention-the case of local municipalities. Nihon-Risk kenkyu-Gakkai Shi (Japanese Journal of Risk Analysis). 1996;7(2):3-12. [in Japanese]

4) Kinoshita T., The Kashiwazaki nuclear power station disaster seen from the position of the risk science-disconcerting lack of comprehensive PR strategy. Nihon-Genshiryoku-Gakkai Shi (J of the Atomic Energy Society of Japan). 2007;49(10):654-655. [in Japanese]

5) Schinzinger R., Martin M.W. Introduction to Engineering Ethics. New York: McGraw-Hill; 2000. (Translation supervision: Nishihara H. Introduction to Engineering Ethics. Tokyo: Maruzen; 2002.

6) Hirai N., I want people to know what is nuclear power station, [in Japanese] Available from: http:// iam-k.com/HIRAI/pageall.html.

7) Kinoshita T., Rethinking of risk communication-toward the formation of integrated risk communication (3). Nihon-Risk kenkyu-Gakkai Shi (Japanese Journal of Risk Analysis). 2009b;19(3):3-24. [in Japanese]

8) Kinoshita T., Philosophy and technology of risk communication / what is the easily understood contents in communication? / learning from the know-how of risk communication. In: Shibata Y. (Ed.), Philosophy and Technology of Risk Communication-Toward the correct understanding of radiation risk, Global Strategy Base for Radiation Health Risk Control, Global COE Program, Nagasaki University. 2010; p.1-46, 47-79, 81-87. [in Japanese]

9) Editors of Sentaku Magazine. Nuclear village-difficulty of its dismantling. Japanese Sanctuary Series 440 Sentaku. 2011 May; Issue(435):111-114. [in Japanese]

10) Kawaugchi J., Hayabusa asteroid probe-“Tamatebako" was opened. Tokyo: Chuko Shinsho; 2010. [in Japanese]

11) Kinoshita T., Rethinking of risk communication-toward the formation of integrated risk communication (1). Nihon-Risk kenkyu-Gakkai Shi (Japanese Journal of Risk Analysis). 2008:18(2):3-22. [in Japanese]

12) Kinoshita T., Is it possible to control rumor?. The Japanese Psychological Association (Ed.), Psychology World-Issue No.50 Special Edition. Tokyo: Shin-yo-sha; 2011. 221-226. [in Japanese].

13) Kinoshita T., Safety and security-its truth and fiction. Human Security Science. 2009c;(4):1-30. [in Japanese] 
14) Kikkawa, Y., Risk communication-toward mutual understanding and better decision making. Tokyo: Fukumura Shuppan; 1999. [in Japanese]

15) Kinoshita T., Rethinking of risk communication-toward the formation of integrated risk communication (2). Nihon-Risk kenkyu-Gakkai Shi (Japanese Journal of Risk Analysis). 2009a:19(1):3-17. [in Japanese]

16) Nakayachi K., Risk measurement-is safe and careful life possible?. Tokyo: NHK Books, Japan Broadcasting Corporation; 2006. [in Japanese]

17) Shibata Y. (Ed.), Philosophy and technology of risk communication-Toward the correct understanding of radiation risk. Global Strategy Base for Radiation Health Risk Control, Global COE Program, Nagasaki University. 2010. [in Japanese].

18) Shibata, Y. (Ed.). Risk recognition and risk communication-toward the correct understanding of radiation risk. Global Strategy Base for Radiation Health Risk Control, Global COE Program, Nagasaki University; 2011. [in Japanese]

19) Kinoshita T., Reputational damage-in relation to the criticality accident at JCO Tokai Office. Isotope News. 2001:572:5-14. [in Japanese]

20) Sugawara T., Where is Japanese risk research heading? Nihon-Risk Kenkyu-Gakkai (Japanese Journal of Risk Analysis) News Letter. 2006;(4):1-3. [in Japanese] 


\title{
Impacts of Fukushima Daiichi NPP Accident through Atmospheric Environment -First Step Toward Grasping Comprehensive Overview of Environmental Impact-
}

\author{
Graduate School of Engineering, Nagoya University \\ Hiromi Yamazawa and Shigekazu Hirao
}

\begin{abstract}
Currently, measurements are conducted on the site to reveal the environmental impact of radioactive materials released during the accident. Meanwhile, there has not been any public explanation on the overall impact. At any stage of an accident, it is required for the off-site counter measures to grasp the overall accident scenario and communicate to the society about its serious environmental impacts.
\end{abstract}

\section{Introduction}

In the northwestern direction from Fukushima Daiichi Nuclear Power Plant, higher air dose rate than other areas continues to be detected at the point of early May 2011, when this paper was written. In the Kanto region, which is more than $100-200 \mathrm{~km}$ away from the accident site, increase in air dose rate was detected on March 15 and 16, 2011 and radioactivity was detected from tap water and agricultural products after March 21. In contrast, relatively lower air dose rate was detected in the coastal areas of Minamisoma even if it was relatively close to the accident site.

Although these measurements were published by organizations, such as the national government, raw data with different qualities are published as lists without temporal or spatial uniformity from several organizations. There has not been any public explanation about the overall influence of the accident even after two months. In particular, during the first two weeks after the accident, there has been virtually no information about the situation of the radioactive material release from the plant. Meanwhile, environmental contamination by the radioactivity released due to the unprecedented accident in Japan was constantly being detected in various locations. Combined with the strong reactions from other countries, starting from the United States, it is deemed that the fragmentary information in fact caused the speculation and social confusion. The situation was such that even the specialists in the field of environment had to gather the information from the websites of relevant organizations and media reports and carefully analyze them to merely obtain a vague understanding of the scale of the accident or how the environmental impact was progressing.

DOI : 10.15669/fukushimainsights.Vol.1.46

(C) 2021 Atomic Energy Society of Japan. All rights reserved.

Originally published in Journal of the Atomic Energy Society of Japan (ISSN 1882-2606), Vol. 53, No. 7, p. 479-483 (2011)

in Japanese. (Japanese version accepted: May 31, 2011) 
While the release of radioactive material into the ocean is also causing a major impact, this paper will focus on its release into the atmosphere and examine the environmental impact of the accident from an analytical perspective. Following are the important perspectives for considering the impacts of the accident for a short duration. (1) The types and quantity of the radioactive nuclides that were released from the accident facility and their time course. (2) The concentration of radioactive materials and the quantity of deposition on the ground surface in the affected areas (contamination of soil, water, and agricultural products) due to the atmospheric transport phenomenon. (3) External exposure through radiation from the radioactive materials in the atmosphere (cloud shine) and the internal exposure through inhalation. (4). External exposure from the nuclides deposited on the ground surface (ground shine). In this study, the impact of the accident on the atmospheric transport will be surveyed provisionally from these perspectives.

Further, the perspectives on the internal exposure caused by the resuspension of nuclides deposited on the ground or by transfer to agricultural products will be indispensable to consider their long-term impacts. Moreover, it is important to grasp the impacts of these accidents and to plan and implement the measures based on them in timely and appropriate manner. The aspects whether the results contributed toward securing the safety of the local residents, whether information was disclosed properly, whether it contributed to avoiding confusion among people in Japan and people in foreign countries. It is inevitable that lessons learned objectively and multilaterally should be introduced in the future. Although prediction should be avoided, since this manuscript was written when the information was not yet sufficiently organized, please note that there is a limitation in distinguishing between facts and predictions.

\section{Release into the Atmosphere from the Accident Facility}

It is clear that the total absence of information provided by the facility on the radioactive nuclides released into the atmosphere, its amount (rate), form of the release (position and whether it was continuous or intermittent), and the time course of these release source was the major obstacle in estimating the environmental impact outside the facilities and devising a response plan. It is imperative to fully examine whether the necessity and importance of these information for the emergency measures outside the facility was not sufficiently recognized. If it was recognized, why was the necessary information not collected? Or was the method or competence for gathering such information lacking? This chapter will outline how to estimate the release information based on the limited information, such as incomplete environmental monitoring, result in the situation where no information can be expected from the facility. This chapter also includes the estimation result published by the Nuclear Safety Commission.

\section{Monitoring Data of Facilities}

If the radioactive material is released via exhaust stack, the release rate can be estimated from the exhaust stack monitor. However for this accident, absolutely no information was obtained from the exhaust stack monitor; whether this was due to power loss is unknown. Moreover, there is also no measurement result of the air dose rate from the permanent monitoring post on the premises boundary. During March, only dose rate at every $10 \mathrm{~min}$ from generally one location (mainly the main gate or the west gate) by a monitoring car was obtained. 
Although measurers faced difficulty due to exposure and contamination, the information derived is insufficient for quantitative understanding of the release source information and its time course; thus, only the broad tendency of the release could be determined. Measurement was not conducted during the early stage of the accident, and during March 14 to 16, which is considered to be the crucial time for the impact assessment, the measurement location was reduced and not restored or expanded in the following two weeks when a large amount of release into the atmosphere were deemed to be continuing. After April, dose rate was measured at the monitoring post on the boundary of the premises. However, this monitoring at the time when the release rate is significantly lower and with its minimum value at $1 \mu \mathrm{Sv} / \mathrm{h}$ only confirms that no as substantial release was observed as was in March; this information cannot be used for estimating the scale of the ongoing release. Outside the premises of the facility, Fukushima Prefecture has more than 20 observation stations. However, no necessary information for planning measures against dose rate or weather was obtained from these, presumably due to the effect of the earthquake and blackout.

Figure 1 shows the measurement results of air dose rate at the premises boundary $(\sim 1 \mathrm{~km}$ from the reactor building $(\mathrm{R} / \mathrm{B}))$ published by the company operating the power plant ${ }^{1}$. The dose rate increased considerably before March 16. Particularly before the morning of March 15 , it corresponds with the phenomena that are deemed to be accompanied by release. In the figure, the period of time when the wind direction was toward the ocean was calculated based on the wind data measured along with the dose rate monitoring. The wind data was measured 2-3 $\mathrm{m}$ above the ground. Considering the uneven terrain, it is necessary to evaluate whether the measured wind direction represents the wind of the whole site. It shows that before the morning of March 15, there were many cases wherein the dose rate did not increase even during the period when the onshore breeze continued. Therefore, it is assumed that the release was intermittent and accompanied the phenomena that triggered release.

In contrast, frequent increase of dose rate during the time period with onshore wind direction was observed after March 16. The dose rate increase while plume is passing greatly differs depending on whether the center of the plume passes in the vicinity of the measurement point or is at a distance while passing. The measurement from the Tokaimura criticality accident clearly demonstrated this phenomenon. When this result is considered along with the fact that the wind direction near the ground surface constantly changes due to the fluctuation

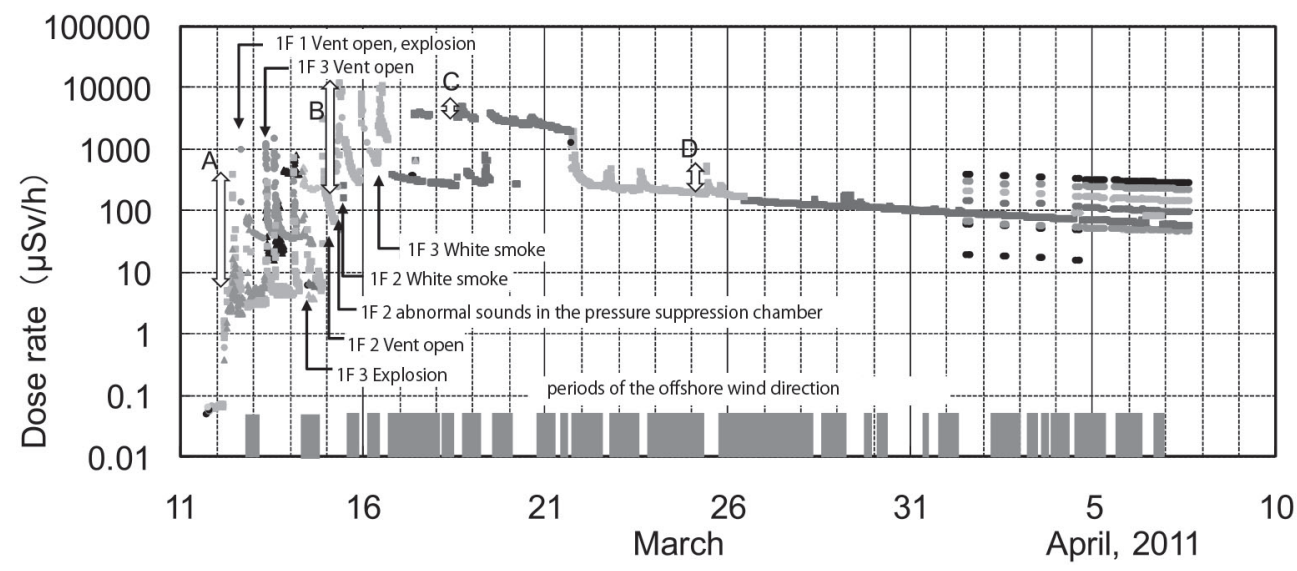

Figure 1 Monitoring results of the air dose rate around the premises boundary by the company operating the plant ${ }^{1)}$ 
of atmospheric turbulence and the changes in meteorological field through time, the shortterm changes in dose rate shows that the axis of plume crossed the measurement point (if plume is compared to a clock hand and the release point its fulcrum, then this phenomenon is similar for the sweeping second hand). By considering all these aspects, we fairly assume that the release continuously occurred after March 16 . The effect of the changes in wind direction is applicable to the measurements before the morning of March 15. Thus, the shape of dose rate transition does not necessarily represent the mode of release (the pattern of changes of release late through time).

Based on these discussions, it is assumed that although estimating the release mode from the dose rate data of the premises boundary is difficult, it is highly likely that the release rate at that point of time can be estimated from the amount of increase of dose rate determines. Figure 1 shows that if a timeline is obtained by picking up the size of each peak, then it's envelop can be regarded as the envelop of release mode at a good approximation. Although the analysis result based on this view is not considered herein, the release was relatively small until the evening of March 14, reached its peak on March 15, and gradually decreased throughout late March. At that point, the release was 3 or 4 orders of magnitude smaller than the maximum amount. However, the difference in the nuclide composition that contributes to the dose rate was not considered in this approximation. In the future, there is a possibility that other information about the release source could be obtained from the characteristics of dose rate change, such as the decrease of ground shine components or the ratio between sky and ground shine components.

\section{Estimation of Release Source Information Based on Remote Data}

On April 12, the Nuclear Safety Commission disclosed that the provisional estimation of I-131 and Cs-137 from the beginning of the accident to April 5 are $1.5 \times 10^{17}$ and $1.2 \times 10^{16} \mathrm{~Bq}$, respectively ${ }^{2)}$. Together with the estimations published by the Nuclear and Industrial Safety Agency (NISA) $\left(1.3 \times 10^{17} \text { and } 6.1 \times 10^{15} \mathrm{~Bq}\right)^{3)}$, these estimations became the basis for the provisional assessment of level 7 of International Nuclear Event Scale. This information from the Nuclear Safety Commission is available for the period until the date the information is published as an academic paper ${ }^{4}$. This paper will only discuss the outline. Please refer to the references for figures.

This estimation is obtained as the necessary release rate for reproducing the concentration of measured radioactive nuclide in the atmosphere via atmospheric diffusion calculation using SPEEDI and WSPEEDI. In other words, in atmospheric diffusion calculation, unit release is postulated (for instance, each nuclide is released at $1 \mathrm{~Bq} / \mathrm{h}$ ), and the release rate is obtained by dividing the concentration obtained from measurement by the concentration obtained from calculation (in this case equivalent to the dilution rate). However, the estimation on March 15 was conducted using the measurement and calculation of the ground shine dose rate of the deposited nuclide on the surface in the northwest direction from the accident facility because the atmospheric concentration that can be used for the release rate estimation was unavailable.

Thus, change in the release rate of I-131 was in the range of $10^{14} \mathrm{~Bq} / \mathrm{h}$ until March 14 , on the order of $10^{16} \mathrm{~Bq} / \mathrm{h}$ at a certain time in March $15,10^{14} \mathrm{~Bq} / \mathrm{h}$ until around March 24, and decreased to less than $10^{13} \mathrm{~Bq} / \mathrm{h}$ by March 27 . Then, the release rate increased once to $\sim 10^{14}$ $\mathrm{Bq} / \mathrm{h}$ by the end of March and decreased in the following few days to $10^{12} \mathrm{~Bq} / \mathrm{h}$. This tendency of change is similar to the aforementioned release rate variation estimated from the dose rate from the area around the boundary of premises. Although its ratio relative to I-131 increased as the time elapsed, the variation pattern of Cs-137 was almost similar. 
Estimations using similar methods were conducted previously. For instance, results that are consistent with the estimations made later with other methods were obtained for the Chernobyl Accident ${ }^{5)}$, the accidental release caused by burning medical Cs-137 in Europe ${ }^{6}$, and the JCO Accident ${ }^{7}$. It is a relatively robust method; although, performing a detailed estimation is impossible in principle.

However, there is a possibility that this estimation method may cause significant uncertainty. In atmospheric dispersion calculations, error originating mainly from the errors in wind field and atmospheric turbulence field is contained and the position of plume and its arrival time obtained from calculation do not necessary correspond to actual measurements. Moreover, the estimation accuracy is affected depending on whether the measurement captured the main part of the plume. In this case, since the number of atmospheric concentration measurement values is extremely limited, the accuracy of estimating the release rate and the details of grasping the time variation are limited. Thus, the published values should be regarded as provisional, and future examination is required to validate its accuracy.

From this perspective, the fact that little information on the concentration in the atmosphere was obtained via emergency monitoring during the early stage of the accident, combined with the lack of dose rate monitoring in the vicinity of the area as discussed earlier, is a serious shortcoming for comprehending the accident scale from the perspectives of release rate estimation and environmental impact, and more importantly, from the perspective of protecting local residents from internal exposure. For off-site countermeasures, it is difficult to understand why the measurement of the concentration in the atmosphere was not conducted for more than a week after the accident within the framework of emergency monitoring. There is a possibility that the measurement was conducted but data were not obtained; the authors cannot ascertain this presently.

\section{State of Atmospheric Diffusion}

\section{Outline}

The dose rate in the premises changes according to the changes in wind direction at the point of May; thus, it is inferred that release into the atmosphere is ongoing. However, its release rate is deemed to be small. Therefore, the atmospheric diffusion situation can be evaluated until around March 25 when the release rate is large, which mostly determined the environmental impacts. This paper only discusses that period; however, the impact of the release into the atmosphere during other periods cannot be ignored.

To facilitate easy understanding of the impact, it is categorized into the following three categories. (1) Contamination by diffusion and deposition within $20 \mathrm{~km}$ range (short-distance impact). (2) Impact on the areas several dozen kilometers northwest from the facility (northwestern-area impact). (3) Impact on large areas, including the central Fukushima prefecture, Tohoku region, and Kanto region.

Regarding the short-distance impact, sufficient monitoring information has not been disclosed; therefore, understanding the progress of contamination when large-quantity release was observed and the current state of contamination distribution are insufficient. The dose rate in the area within $20 \mathrm{~km}$ range was disclosed by the Ministry of Education, Culture, Sports, Science and Technology for the first time in April, and then several measurements were added ${ }^{8)}$ (mainly ground shine reflecting the soil contamination). The results showed that the high-contamination area with over $100 \mu \mathrm{Sv} / \mathrm{h}$ and the area with $<1 \mu \mathrm{Sv} / \mathrm{h}$, which are 
mainly around the shore on the north side of the site are mixed, showing strong localization of contamination, determined from the direction the plume extended from the accident facility, the release rate at that moment, and whether there was precipitation. Detailed measurement and analysis is required in the future to determine these factors.

\section{Contamination in Northwestern Direction}

In the coastal area, the land and sea breeze circulation becomes dominant when the barometric gradient of the general field becomes smaller. In the area of Fukushima Daiichi Nuclear Power Plant, the wind that was breezing toward the ocean in the evening turns to south in the early morning, followed by the direction changes to southwest, west, and then to northwest from afternoon to evening. Such clockwise wind direction change is frequent in that area. Moreover, this was combined with the valley wind along the slopes and valleys of the Abukuma mountain range to be considered to cause the transport toward inland. During the period with large release rate, such phenomena were considered to have occurred on March 15 and 20. Particularly on March 15, the release rate is estimated to be 1 to 2 orders of magnitude larger than those observed on other days. The transportation to the inland area by the sea breeze and the valley wind occurring at that time, and the stagnation caused by the weak wind at night are factors that influence the formation of contaminated area. However, the actual time when the radioactive materials that contributed to the northwestern contamination were released on March 15 is not understood so far.

Moreover, precipitation was observed from the evening of that day to the next day. A1though it was raining at the night of March 15 in Fukushima City, it snowed before the dawn of March 16 when the temperature lowered. It is likely that in the Abukuma mountain range at higher altitudes, it was snowing during the night of March 15. The deposition of radioactive materials when there is precipitation (wet deposition) causes significantly higher surface contamination than deposition without precipitation (dry deposition). Excluding the radioactive material in the form of large-size particle that can deposit due to the gravity, only the radioactive materials in the air that is in contact with the ground surface deposit in the dry deposition. Deposition of the radioactive material aloft must wait for the vertical transport by the atmospheric turbulence. Thus, in the dry deposition, the radioactive materials in the air close to the ground surface makes major contribution. In contrast, in the wet deposition, precipitation captures the radioactive material in the air and carries them down to the ground. Therefore, all the radioactive materials in the atmosphere, except for the noble gases, possibly contribute to the deposition.

Considering the time course of $\gamma$ ray dose rate caused by ground shine, it can be concluded that the contaminated area in the northwest direction were caused by the coincidence of the following three conditions, namely, the high release late on March 15, local wind circulation and precipitation. This contaminated area in the northwestern direction (ground shine caused by deposition) were understood at the latest by the early morning of March 16 as the result of SPEEDI calculation that considered the damage on Unit 2 pressure suppression chamber conducted by the Government Nuclear Emergency Response Headquarters (calculation No.41 by the secretariat to the Government Nuclear Emergency Response Headquarters) ${ }^{9)}$, and a spatial distribution that is close to the actual contamination situation was obtained. Moreover, SPEEDI calculation conducted at the dawn of March 15 allowed the Local Nuclear Emergency Response Headquarters to predict a high probability of diffusion toward northwestern direction in the afternoon of the same day (calculation No.3 of the Local Nuclear Emergency Response Headquarters) ${ }^{10)}$. 


\section{Large Area Impact}

The most conspicuous large area impacts during the period under discussion are the following: (1) Northward impact on March 12 (dose rate increase at Onagawa). (2) Impact on Kanto region and other regions between March 15 and 16. (3) Impact on the same area between March 20 and 22. This section will discuss the impact on Kanto direction of (2) and (3).

Figure 2 shows the result of atmospheric transport calculation of these two examples using a numerical model $^{7)}$. The analytical meteorological data JRA 25 by the Meteorological Agency and the Central Research Institute of Electric Power Industry were used as the input to calculate the three-dimensional distribution of wind and turbulence using the non-hydrostatic atmospheric model MM5 and the Lagrangian diffusion model to obtain the concentration field. The purpose of both calculations was to understand the outline of the atmospheric transport, and their calculation results of atmospheric concentration are provisional because the calculation only considered the atmospheric transport process without deposition; therefore, they may differ from the actual concentration distribution.
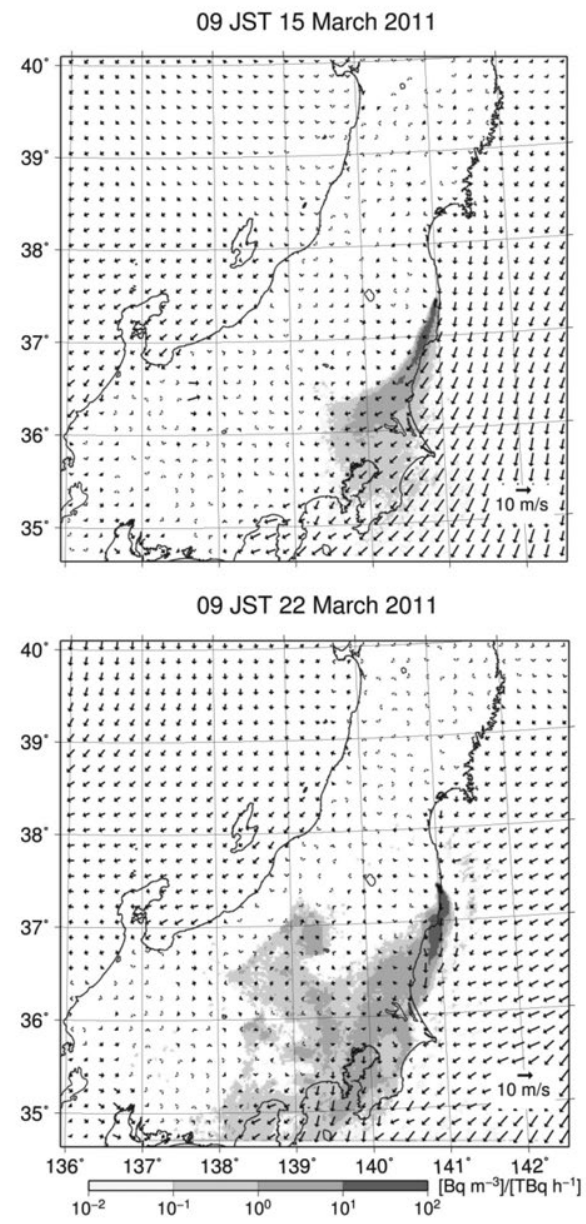

Figure 2 Example of calculation result of the surface atmospheric concentration with an assumption of continuous release of non-depositing radioactive materia at the rate of $1 \mathrm{TBq} / \mathrm{h}$. (Top: 09:00, March 15, 2011. Bottom: 09:00, March 22) 
It is well known that there often occurs a typical wind pattern at the Pacific coast on the eastern side of the Abukuma mountainous region located between the southern part of the Tohoku region and the northern part of the Kanto region, where Fukushima Daiichi Nuclear Power Plant is located. When there is a low or a stationary front on the south coast of Honshu causing a north-high pressure pattern, the Abukuma Mountains become a barrier for the wind system, in which a southward wind blows along the coast line in the lowest atmospheric layer with a depth of $0.5-1 \mathrm{~km}$. This wind turns into the northeastern wind at the area near Tokai mura, where the Abukuma mountain range ends and Kanto Plain opens out. As such wind is commonly accompanied by a maritime stable temperature stratification, it has a tendency to have less diffusive mixing and maintain high concentration. Moreover, another characteristic is that, in Kanto Plain, this wind system is frequently accompanied by precipitation caused by the depression or by the front.

Both the periods (2) and (3) occurred with this situation. During the period (2), precipitation was weak and occurred only in limited areas. Therefore, it is assumed that the impact of the wet deposition was less. The plume that affected the Kanto region on March 15 was considered from the travel time to be released in the late night of the day before and the early morning of the March 15. It is likely that its release rate was relatively small in comparison with the plume that affected the northwestern direction. WSPEEDI calculation result indicating such a situation was already obtained by the Ministry of Education, Culture, Sports, Science and Technology and the Japan Atomic Energy Agency at the point of March $15^{8}$, and its result was similar to the calculations made later by the authors. Thus, it is assumed that while the values of concentration contours were undetermined, the overview of distribution and its progress with time were almost identical the actual situation.

In contrast, during the period (3), transport by the aforementioned wind system continued for a long period. Moreover, strong rain continued during March 21 and 22, leading to the impact in a large area by the deposition of radioactive materials. Although the size of the impacted area and its level must be assessed based on field measurements, a comprehensive analysis where the actual measurement is supplemented by atmospheric transport calculations is necessary to cover the large-impact area.

\section{Further Concerns}

Regarding the impact of the radioactive materials released in the atmosphere following the accident, its quantitative and spatial details are still insufficiently understood. To comprehend these based on actual measurements in the future will be the first stage of environmental remediation.

First, it is the external exposure dose by cloud shine and internal exposure dose caused by inhalation during the passing of the plume. Judging from the dose rate measured throughout Japan and the concentration in the atmosphere, it is estimated that the impact in the large area is small. However, it is necessary to evaluate the radiological dose through calculation (dose reconstruction), such as one with SPEEDI, after determining the release rate and verify that that value is sufficiently small. Its necessity is particularly high for the early stage of the accident when there is less measurement data related to concentration in the atmosphere and the area near the accident facility.

Moreover, contamination of the ocean is a chief concern. The release of retained water in early April (no distinction of nuclides; $1.5 \times 10^{11} \mathrm{~Bq}$ ) and the leakage near the water intake of 
Unit 2 during the same period (total of main nuclides; $4.7 \times 10^{15} \mathrm{~Bq}$ ) are being evaluated as its cause. The impact of the contamination will be monitored for a long time. However, the release/leakage in aquatic form is not only the cause of the ocean contamination. We must consider the facts that the amount released in the atmosphere was 1-2 orders of magnitude larger than these amounts, the time the radioactive materials released in the atmosphere were moving toward the ocean was longer than that toward the land, and the radioactive materials in the atmosphere above the ocean will eventually deposit on the sea. It is clear that the true source of marine contamination in a relatively large area is the release into the atmosphere. Although we wish it is only the insufficient research by the authors, it is worrying that any public comment on this situation from a responsible organization cannot be found. If an undisclosed measurement results are revealed or the above mentioned problems are to be examined only according to the suggestion by a third party or a foreign agency, it cannot be seen as an attitude to faithfully understand the overall view of the environmental impact of the accident and it will be hard to regain trust from the researchers of the related fields and the members of academic societies.

\section{References}

1) Tokyo Electric Power Company Holdings, Inc. http://www.tepco.co.jp/nu/fukushima-np/f1/index-j. html. [in Japanese]

2) Nuclear Safety Commission. http://www.nsc.go.jp/info/20110412.pdf. [in Japanese]

3) Nuclear and Industrial Safety Agency. http://www.meti.go.jp/press/2011/04/20110412001/ 20110412001-1.pdf. [in Japanese]

4) Chino M, Nakayama H, Nagai H, Terada H, Katata G, Yamazawa H. Preliminary estimation of release amount of 131I and 137Cs accidentally discharged from the Fukushima Daiichi Nuclear Power Plant into the Atmosphere. J. Nucl. Sci. Technol. 2011;48:1129-1134.

5) Chino M, Ishikawa H, Yamazawa H, Moriuchi S. Application of the SPEEDI system to the Chernobyl reactor accident. JAERI-M 86. 1986;142.

6) Yamazaki H. Analysis of long distance diffusion of Cs 137 after its accidental release in Algeciras. Genshiryoku-Gakkai Shi (J. Atomic Ener. Soc. Japan.). 1999;41:114-116. [in Japanese]

7) Hirao S, Yamazawa H. Release rate estimation of radioactive noble gases in the criticality accident at Tokai-mura from off-site monitoring data J. Nucl. Sci. Technol. 2010;477:20-30.

8) Ministry of Education, Culture, Sports, Science and Technology. http://www.mext.go.jp/a_menu/ saigaijohou/index.htm [in Japanese]

9) Nuclear and Industrial Safety Agency. http://www.mext.go.jp/a_menu/saigaijohou/syousai/1305747. $\mathrm{htm}$. [in Japanese]

10) Nuclear and Industrial Safety Agency. http://www.nisa.meti.go.jp/earthquake/speedi/ofc/speedi_ofc_ index.html. [in Japanese] 


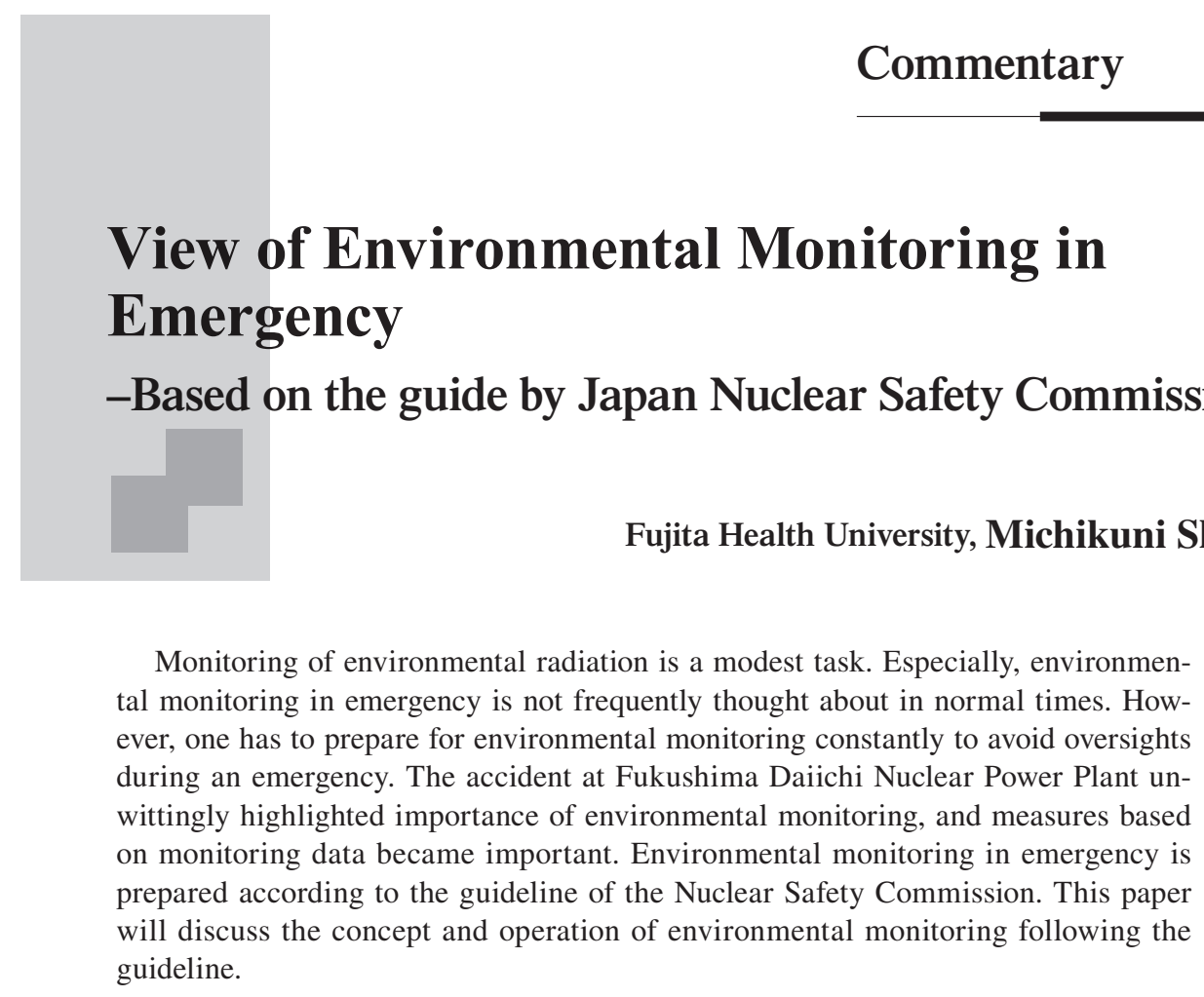

\section{Introduction}

Previously, monitoring of environmental radiation in emergency was differentiated from the monitoring of environmental radiation in normal times, and organized as a monitoring guideline of environmental radiation in emergency at the Nuclear Safety Commission. In March 2008, two guidelines were unified as part of the guideline review and newly positioned as "monitoring guideline of environmental radiation." The reason behind this change was that instead of having two separate guidelines existing independently, it is easier to operate when they are unified, because the improvement in the monitoring technology standard is common and unification will lead to a continuous/sustainable relation. Thus, the contents of the new guideline are a continuation of those of previous ones without much change.

Since the new guideline closely relates to environmental monitoring in normal times, this commentary introduces the differences in environmental monitoring in emergency from environmental monitoring in normal times, and how it is expected to be conducted, and the way of thinking, based on the environmental radiation monitoring guideline of the Nuclear Safety Commission (March 2008).

DOI : 10.15669/fukushimainsights.Vol.1.55

(C) 2021 Atomic Energy Society of Japan. All rights reserved.

Originally published in Journal of the Atomic Energy Society of Japan (ISSN 1882-2606), Vol. 53, No. 7, p. 484-488 (2011)

in Japanese. (Japanese version accepted: May 30, 2011) 


\section{Environmental Monitoring}

\section{Responses in Normal Times and Emergency}

During normal times, the priority of environmental monitoring is to protect the health and safety of the residents around nuclear facilities. Therefore, the monitoring is led by local public organizations, and the operators collaborate with them while conducting their own monitoring.

On the other hand, if there is an accident in the facility and unexpected leaking of radioactive material or radiation, or there is fear of leakage, the Japanese government, local public organizations, designated public corporations, and the business operator of the facility must take appropriate disaster prevention measures following the respective disaster prevention plans of each organization based on the Basic Disaster Management Plan (Basic Plan) published by the Central Disaster Prevention Council, as stipulated by the Disaster Countermeasures Basic Act and the Act on Special Measures (Act on Special Measures Concerning Response to Environmental Contamination by Radioactive Material Released from the Accident of the Nuclear Power Plant Caused by the Tohoku District-off the Pacific Ocean Earthquake). Environmental radiation monitoring is to be conducted as a part of this disaster prevention plan. In particular, the disaster prevention measures at nuclear facilities are to be conducted according to the separate guideline by the Nuclear Safety Commission, which corresponds to the 4th Chapter, Emergency Monitoring, of the environmental radiation monitoring guideline to be discussed. The guideline is structured in the following categories: "Monitoring in Normal Time," "Strengthening of Monitoring in Normal Time," and "Emergency Monitoring."

Note that the scope of this guideline includes nuclear reactor facilities, reprocessing plants, processing plants, usage facilities, waste treatment facilities, and waste management facilities.

\section{Monitoring in Normal Times}

The following four points are the concrete objectives and contents of environmental monitoring in normal times.

(1) Estimation of local residents' dose and its assessment.

(2) Understanding the accumulation tendency of radioactive materials in the environment.

(3) Early detection of unexpected release of radioactive materials and radiation from facilities and evaluation of its impact on the surrounding environment.

(4) Preparation of implementation system of environmental monitoring in case of emergency or abnormal situation.

To explain each point succinctly, (1) aims to estimate the dose that originates from radioactive materials or radiation attributed to the nuclear facility and to verify if it is sufficiently below the yearly dose limit; (2) aims to grasp the accumulation situation of radioactive materials released through the operation of the facility in the environment; (3) aims to detect abnormality in a nuclear facility at an early stage; and (4) aims to prepare for a smooth and prompt transition from monitoring in normal times to strengthened monitoring in normal times or environmental monitoring in emergency (emergency monitoring).

Table 1 shows the representative monitoring survey contents, and Figure 1 shows the flow of selections for measurement equipment. These correspond with monitoring in normal times, but can also be referred to during an emergency. 
Table 1 Representative Monitoring Survey Contents

\begin{tabular}{|c|c|c|c|c|}
\hline \multicolumn{2}{|l|}{ Category } & Survey Subject & Measurement Frequency & Notes \\
\hline \multicolumn{2}{|c|}{$\begin{array}{l}\text { Environmental gamma } \\
\text { Radiation }\end{array}$} & $\begin{array}{l}\text { Dose Rate } \\
\text { accumulative dose }\end{array}$ & $\begin{array}{l}\text { Continuously Measured } \\
\text { Measured Quarterly }\end{array}$ & $\begin{array}{l}\text { Possible to Calculate } \\
\text { from the Dose Rate }\end{array}$ \\
\hline \multirow{8}{*}{$\begin{array}{l}\text { Environmental } \\
\text { Sample }\end{array}$} & \multirow{7}{*}{$\begin{array}{l}\text { Land } \\
\text { Sample }\end{array}$} & Atmosphere & $\begin{array}{l}\text { Collect and measure continuously, } \\
\text { Collect continuously and measure } \\
\text { every } 1-3 \text { months }\end{array}$ & $\begin{array}{l}\text { Gas monitoring/dust } \\
\text { monitoring } \\
\text { Airborne dust, etc. }\end{array}$ \\
\hline & & Inland water & Collect and measure every quarter & Drinking Water, etc. \\
\hline & & Milk & Collect and measure when necessary & I131 Analysis \\
\hline & & Soil & $\begin{array}{l}\text { Collect and measure every half year- } \\
1 \text { year }\end{array}$ & Surface soil \\
\hline & & Agricultural products & $\begin{array}{l}\text { Collect and measure during the } \\
\text { harvest }\end{array}$ & $\begin{array}{l}\text { Greens, root vegetables, } \\
\text { rice, etc. }\end{array}$ \\
\hline & & Index organism & $\begin{array}{l}\text { Collect and measure every quarter- } \\
1 \text { year }\end{array}$ & $\begin{array}{l}\text { Artemisia princeps, pine } \\
\text { needles, etc. }\end{array}$ \\
\hline & & Fallout and precipitation & Collect and measure every month & Basin method, etc. \\
\hline & $\begin{array}{l}\text { Marine } \\
\text { Sample }\end{array}$ & $\begin{array}{l}\text { Seawater } \\
\text { Marine Soil } \\
\text { Marine Products } \\
\text { Index Organism }\end{array}$ & $\begin{array}{l}\text { Collect and measure every } 6 \text { months } \\
\text { Collect and measure every } 6 \text { months- } \\
1 \text { year } \\
\text { Collect and measure during the } \\
\text { fishing season } \\
\text { Collect and measure every quarter }\end{array}$ & $\begin{array}{l}\text { Surface water } \\
\text { Surface soil }\end{array}$ \\
\hline
\end{tabular}

(Note) When measuring the air dose rate, measure gamma-ray energy as necessary. Also, conduct nuclide analysis of the environmental sample as a rule.

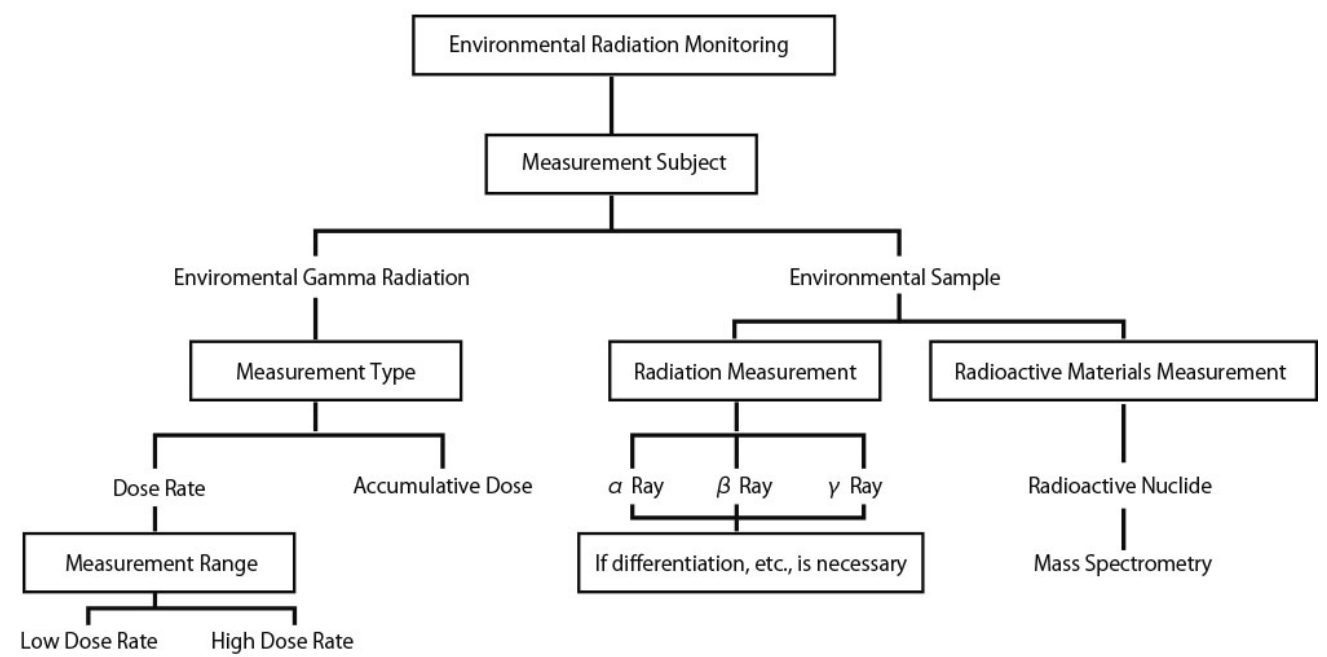

Figure 1 Measurement Equipment Selection Flow 


\section{Strengthening of Environmental Monitoring in Normal Times}

The purpose of strengthening the environmental monitoring in normal times is to take measures for the transitional situation. In other words, when there is an abnormal situation at the facility, it must quickly ascertain its scale and whether there is an impact on the local residents and surrounding environment, as well as clarify the cause and state of the situation and prepare for emergency monitoring.

Following are its concrete contents:

(1) Strengthening of ambient dose rate monitoring.

(2) Strengthening of monitoring of radioactive materials in the atmosphere.

(3) Strengthening of monitoring of meteorological observation.

(4) Strengthening of accumulative dose monitoring.

(5) Conduct moving survey.

It is not always necessary to conduct all of them. Instead, only the required action should be taken. In addition, when there is a possibility that a neutron ray is released, its measurement must also be conducted.

\section{Emergency Monitoring}

\section{Purpose}

"Emergency (environmental) Monitoring," which is the main subject of this paper, follows the aforementioned monitoring in normal times and its strengthening. Its main purpose is to collect necessary information for implementing measures for protection against radiation (sheltering, evacuation, food intake restrictions, etc.) enacted during an emergency, and to evaluate their impact on local residents.

\section{Role}

It is conducted by the national government, local public organizations, designated public corporations and the operator of the facility, and each of them must act according to the Basic Disaster Management Plan (Basic Plan) they prepared.

\section{Plan and Content}

Emergency monitoring would be pointless unless otherwise its system is immediately activated and implemented when an emergency situation occurs. It is therefore necessary to prepare the "emergency monitoring manual." This emergency monitoring manual must contain the preparation of the system, preparation of material and equipment, and the implementation method.

Emergency monitoring is divided into phase 1 monitoring and phase 2 monitoring. Following are their contents.

Phase 1 monitoring

A monitoring that is conducted promptly at the time of an emergency. It includes

(1) Grasping the ambient dose rate around the facility and the concentration of radioactive materials (radioactive noble gas, radioiodine, uranium, or plutonium) released in the 
atmosphere.

(2) Grasping the concentration of radioactive materials in the environmental samples that are deemed to have been influenced by the release of radioactive materials.

(3) Prompt estimation of the predicted dose to assist the protection measures.

Phase 2 monitoring

A monitoring for evaluating the overall impact on the surrounding environment. It includes

(4) Continuation of (1) and more detailed comprehension of the concentration of radioactive materials in the atmosphere, for instance, through increasing the subject nuclides.

(5) Continuation of (2) and more detailed comprehension of the concentration of radioactive materials in the environmental samples, for instance, through increasing the subject nuclides.

(6) Dose assessment of local residents who may have been exposed.

\section{Organization of National System}

At the time of an emergency, the national government establishes the "Government Nuclear Emergency Response Headquarters" and the "Local Nuclear Emergency Response Headquarters." At the Local Nuclear Emergency Response Headquarters, a "radiation team" responsible for having an oversight on the information for emergency monitoring would be set up.

The responsibilities of the radiation team include

(1) Collection and organization of emergency monitoring data.

(2) Instructing and advising the emergency response headquarters of local public organizations on emergency monitoring.

(3) Arrangement of necessary staff, material, and equipment for emergency monitoring.

(4) Exposure dose prediction using resources such as SPEEDI network system ${ }^{\mathrm{a}}$.

(5) Exposure dose assessment of local residents.

(6) Preparation for the implementation and cancellation plan for the sheltering/evacuation in the designated areas.

(7) Preparation for the implementation and cancellation plan for food and drink intake restriction in the designated areas.

(8) Summary for the plan for measures such as food and drink intake restrictions.

(9) Communication and coordination between respective group responsible for monitoring (e.g., monitoring center) of the Government Nuclear Emergency Response Headquarters and the emergency response headquarters of local public organizations.

(10) Preparation of documents for joint action council or press briefing related to emergency monitoring.

\section{System of Local Public Organizations}

On the other hand, setting up a monitoring center and a monitoring team working under it as an organization for precisely and smoothly conducting emergency monitoring work at local public organizations is considered to be effective.

The functions of the monitoring center include

${ }^{a}$ SPEEDI: System for Prediction of Environmental Emergency Dose Information

A system for quickly predicting the concentration of radioactive materials in the surrounding atmosphere or radiation dose

during an emergency, such as release of radioactive materials from facilities such as a nuclear power plant. 
(1) Preparing plans, instruction, and general management.

(2) Allocation of staff, material, and equipment.

(3) Collection and analysis of monitoring information and weather information.

(4) Report to the emergency response headquarters of local public organization.

(5) Report to the Government Nuclear Emergency Response Headquarters.

Meanwhile, the roles of the monitoring team include

(1) Conduct emergency monitoring.

(2) Report to the monitoring center.

\section{Implementation Method}

To implement emergency monitoring promptly and smoothly, it is desirable to prepare concrete plans as much as possible in advance, such as the measurement subjects, measurement locations, sampling location, and measurement method for each monitoring phase, while considering the exposure route. By following the concrete plans, effective monitoring is carried out.

Upon implementation, it is necessary to effectively use vehicles and portable monitoring posts to improve mobility, and furthermore, use boats and aircraft when required.

The detailed explanations of phase 1 and phase 2 are described below.

Phase 1 monitoring

As described above, phase 1 monitoring is conducted immediately after the occurrence of an emergency. Thus, the highest priority is speed, accuracy is in second. Results are used for the estimation of predicted dose in conjunction with the release source information, weather information, and information from the SPEEDI network system.

The measurement subjects include

(1) Air radiation dose rate.

(2) Concentration of radioactive materials (radioiodine, uranium, or plutonium) in the atmosphere.

(3) Concentration of radioactive materials (radioiodine, uranium, or plutonium) in the environmental samples (drinking water, green vegetables, raw milk, and rainwater).

(4) Accumulated dose.

The weather condition and the prediction result of the SPEEDI network system must be considered when the measurement location and sampling location are selected. These locations include

(1) The location where the maximum spatial radiation dose rate, as well as a few more locations nearby that point, is predicted to appear.

(2) The location where the maximum concentration of radioactive materials in atmosphere, as well as a few more locations nearby that point, is predicted to appear.

(3) A few locations that are in the area within approximately $60^{\circ}$ with the downwind direction, which pass the location where the maximum concentration of radioactive materials in the atmosphere is predicted to appear and run through the downwind axis.

(4) The number of measurement locations in the densely populated areas, settlements, evacuation facilities, etc., in the downwind direction should be decided according to the population distribution and other factors.

In addition, when measures such as evacuation are put into effect, environmental monitoring must also be conducted at evacuation facilities. 
Phase 2 monitoring

Phase 2 monitoring is started at the stage where the prediction of the accident state is certain and the release of radioactive materials or radiation begins to decrease. Thus, accuracy is more important than speed for this monitoring. To achieve this monitoring, it must be conducted in a wider area than that of phase 1 and its frequency should be daily or every few days after the release of radioactive materials or radiation is stopped. The results are used for understanding the dose assessment of residents and the radiation state of the environment, as well as for lifting various protective measures.

The measurement subjects include

(1) Ambient dose rate.

(2) Radioactive concentration in the atmosphere.

(3) Radioactive material concentration in the environment: Besides the monitoring samples of phase 1, soil, plants, agricultural products, water (rivers, water purification plants), seafood (when there has been release to rivers and the ocean).

Extra caution must be taken for samples that require tracking of how radioactive materials released in the environment change through time. They require sampling and measurements at certain intervals.

\section{Estimation and Evaluation of Dose}

At the time of an emergency, the first action must be to calculate the concentration of radiation of the surrounding environment and the predicted dose for the residents. This should be followed by the evaluation of the actual concentration of radioactive materials and dose based on the monitoring result. The predicted dose is the estimation of the dose a resident staying in a given area would receive when no protective measures are taken, based on the released amounts of radioactive materials and radiation, weather condition, etc. Needless to say, the predicted dose changes with the situation.

\section{Preparation of predicted dose distribution map}

The calculation methods for obtaining the information for the predicted concentration of radioactive materials and predicted dose include a detailed calculation method that uses a computer (SPEEDI network system) and a simple calculation method that uses diagrams.

The detailed calculation method receives weather data in real time and calculates the distribution of concentration of radioactive materials and dose distribution that move and diffuse through the atmosphere using various databases of information, such as topography prepared and stored in advance, and displays them as diagrams. In an emergency, the calculation can also be performed by speculating the release source information.

The simple calculation method prepares diagrams based on the calculation result of the atmospheric diffusion equation when online information of the SPEEDI network system is not available.

\section{Estimation of Predicted Dose}

From the perspective of taking protective measures, the predicted dose must be estimated quickly. As the situation differs depending on the type of facility, it is categorized into the following two cases. 


\section{In the case of nuclear reactor facilities}

The dose assessment of nuclear reactor facilities is mainly conducted from the effective dose of external exposure by using a radioactive noble gas and from the thyroid equivalent dose of internal exposure by radioiodine. This is because as a nuclear reactor is sheltered in multilayered protective walls, there is hardly any need for considering direct radiation and the possibility of solid or liquid radioactive material leaking to a large area is small. The radioactive materials that have high likelihood of leakage are the noble gases such as krypton and xenon, and radioiodine, which is volatile. In addition, aerosol accompanying them moves within the atmosphere, and thus, can be responded with the same measures as those mentioned above.

\section{In the case of nuclear fuel facilities}

At a nuclear fuel facility, release of uranium or plutonium in the form of aerosol due to fire, explosion, or leakage is assumed. In that case, direct release following an explosion and the amount of the release must be considered besides the release/diffusion in the plume form. Note that particles are deemed to settle relatively faster than gases.

Moreover, when there is a critical accident, exposure by neutron ray and $\gamma$ ray must also be considered. However, as the strength of radiation decreases mostly in proportion with the inverse square of the distance, the impact is limited to the short distance. Even during a critical accident, estimation of external exposure by a radioactive noble gas and thyroid equivalent dose by radioiodine is necessary depending on the type of accident.

\section{Points to be Cautious about When Estimating the Predicted Dose}

As promptness is required in the predicted dose, accuracy tends to be neglected. Following are the points that require caution when estimating the predicted dose.

(1) Obtaining and verification of the release source information (accurate released amount, composition of released nuclide, properties, and the time for which the release continued).

(2) Recognition and notification of the uncertainty of the calculation result based on insufficient release source information.

(3) Balance of speed and accuracy when preparing diagrams.

(4) Continuous adjustment of calculated value based on the monitoring value and complementation of the monitoring value using the calculation diagram.

(5) Addition of information related to the trustworthiness of the calculation result (date, information source, etc.).

These points can easily be overlooked at a busy emergency site, but must be followed with calm judgment and composed action.

\section{Conclusions}

This paper explained the view of environmental radiation monitoring in emergency and its implementation methods based on the guideline of the Nuclear Safety Commission.

When the emergency monitoring conducted after the Fukushima Daiichi Nuclear Power Plant Accident is studied, it shows that while most of the points/method discussed here were sufficient as the response to the accident, there were events that were beyond the preparation. 
For instance, the category of facilities itself did not fit the predicted categories. The facts that there was a meltdown of the nuclear reactor, the hydrogen explosion broke the multilayered protective walls of the nuclear reactor, and the radioactive materials were released from the spent fuel storage pool were phenomena that were not assumed in the environmental monitoring guideline.

Regarding individual responses, not enough information was provided quickly in the operation of the SPEEDI network system despite its praised prediction function. Suggested reasons for this include uncertainty of radiation source information. As it is the responsibility of monitoring to contribute to the safety of the residents, it is imperative to conduct thorough examination of both hardware and software and to promptly implement the necessary improvement. Moreover, it is regrettable that there were delays even though quick information disclosure is discussed in the monitoring guideline, regardless of the reasons for the delays. In addition, there are rumors that some information was not shared. The fact that there are such rumors at all is already a problem.

Though there are many problems, as discussed above, there is no doubt that environmental radiation monitoring in the emergency was somehow conducted by unifying the monitoring data measured by municipalities, universities, and various research institutes at the Ministry of Education, Culture, Sports, Science and Technology, which contributed to the disaster prevention activities. Needless to say, an appropriate, reliable, and accurate monitoring is required in a situation that is predicted to continue for a long time. In order to achieve this, it is necessary to quickly and resolutely improve the environmental radiation monitoring that were not adequate for this unprecedented accident.

\section{General References}

1) Nuclear Safety Commission. Environmental Monitoring Guideline. 2008 March. [in Japanese]

2) Ministry of Education, Culture, Sports, Science and Technology. Radiation Measurement Methods Series. [in Japanese]

3) Chino M. Study on nuclear energy and atmospheric diffusion. Nihon-Genshiryoku-Gakkai Shi (J. At. Energy. Soc. Jpn.). 1990; 32: 1080-1086. [in Japanese]

4) Yoshida H, Nagai H, Furuno A. Development of system for prediction of environmental emergency dose information (World Version) WSPEDI 2nd Version. Nihon-Genshiryoku-Gakkai- Wabun-Ronbun Shi (J. Jap. Papers of At. Energy Soc. Jpn.). 2008; 7: 257-267. [in Japanese] 


\title{
Recent Nuclear Policy Trends in Major Countries Post Fukushima Accident
}

\author{
The Institute of Energy Economics, Inc. Japan, \\ Tomoko Murakami
}

The accident at the Fukushima Daiichi Nuclear Power Plant led to discussions in many countries. While there are countries that are freezing new construction or extension of the operation of existing power plants, there are also other countries that are not planning to change their basic policy of nuclear energy promotion. In circumstances wherein severe attention is paid toward securing the safety of nuclear reactors, the actual state of future nuclear energy development is assumed to reflect the energy, environmental, economic, and industrial situation of individual countries.

\section{Categories of Nuclear Energy Development Trends of Each Country}

As of May 2011, nuclear power is used in 30 countries around the world. However, its position and development policy differs among these countries depending on the macro situation of their energy, economy, and industry.

Figure 1 shows the mapping of the capacity of existing nuclear power plants and the capacity of facilities of major countries (regions) around the world that are predicted to be newly built by 2035 . The horizontal axis represents the capacity of existing facilities by countries (region) as of the end of 2009, whereas the vertical axis represents the capacity of the facilities predicted to be newly built by 2035 .

The following is the categorization indicated by this map.

Countries that use/promote nuclear energy: Countries that have been actively developing nuclear power nationally and actively expanding internationally from the perspectives of improving the rate of energy self-sufficiency or strategic industrial growth. Though the necessity of new facilities of each country is different, they commonly position nuclear energy as their strategic industry.

(1) Nuclear energy high-growth countries: Countries that require large-scale construction of new facilities in the future due to the increase in energy demand.

(2) Countries considering the introduction of nuclear energy: Countries that were able to function without nuclear energy until now but considering its introduction in the future due to increasing energy demand and necessity of saving fossil fuel.

(3) Countries tending toward abandoning nuclear energy: Countries that already have

DOI : 10.15669/fukushimainsights.Vol.1.64

(C) 2021 Atomic Energy Society of Japan. All rights reserved.

Originally published in Journal of the Atomic Energy Society of Japan (ISSN 1882-2606), Vol. 53, No. 7, p. 489-490 (2011)

in Japanese. (Japanese version accepted: May 16, 2011) 


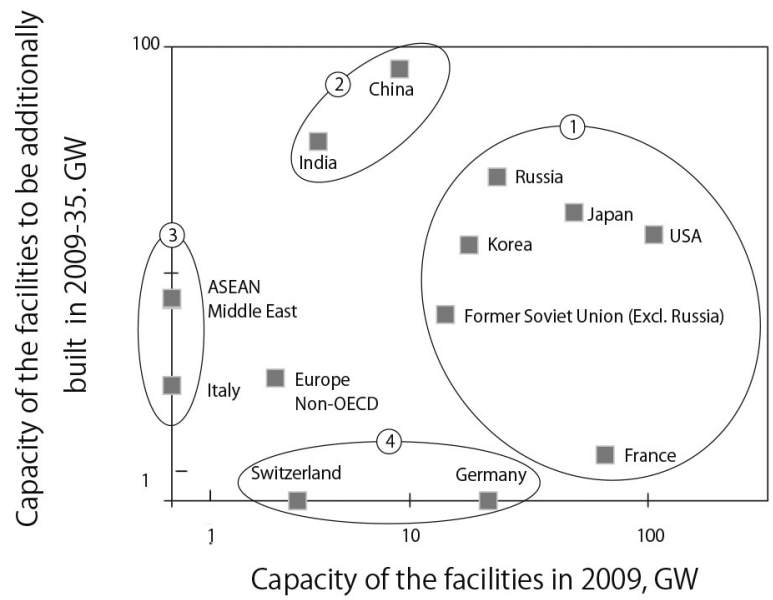

Figure 1 Current capacities of nuclear power plants in major countries around the world and the prediction of their new facilities by 2035

(Source), "Direction of International Nuclear Power Development 2010", Japan Atomic Industrial Forum, April 2010, and "Asia/World Energy Outlook," (Foundation) The Institute of Energy Economics Japan, October 2010

nuclear energy in their energy portfolio and do not need further expansion.

\section{Reaction of Other Countries to the Fukushima Daiichi Nuclear Power Plant Accident and the Current Status of Their Policy Responses}

\section{Countries Using/Promoting Nuclear Energy (the US, France, South Korea, and Russia)}

The United States Department of Energy made a statement on March 15, 2011 that said there will be no change in its basic energy policy that aims for the energy best mix toward low carbon. It also stated that it will learn many lessons from the accident in Japan and will continue to improve safety. Although there are construction projects of new power plants that are suspended due to the withdrawal of the business operators, they are caused not by the accident but by an increase in the construction cost and fund burden that were already causing problems even before the accident. The accident "is not considered to have reversed the renaissance."

In France, President Sarkozy immediately after the accident said that "it is impossible for France to abandon nuclear energy for its energy self-sufficiency" while promoting safety check of its nuclear energy facilities. President Putin of Russia instructed Sergey Kiriyenko, the director general of Rosatom, to conduct an inspection on the safety of nuclear reactors in Russia immediately after the accident. However, this was conducted with the premise of maintaining Russian nuclear energy. The South Korean government made a statement at the nuclear energy committee held on May 6 that safety of the design/operation of the nuclear reactor facilities within South Korea was verified after their safety inspection. Moreover, it also presented safety improvement measures in 50 points that enabled safe operation of 
nuclear power plant even during the worst natural disasters.

As seen above, there is no change in the basic policies of these countries, which positions nuclear energy as an important energy source while further improving its safety.

\section{Nuclear Energy High-Growth Countries (China and India)}

On March 16, the State Council of the People's Republic of China made a statement that said it will conduct inspection of Chinese nuclear reactor facilities in response to the accident in Japan and suspend its medium- and long-term plans, including the plans for new construction that are currently under consideration, until the completion of the inspection. Although this reduced the likelihood of achieving the "86 million $\mathrm{kW}$ by 2020 " plan that was progressing in high speed until then, there is no change in its policy to promote nuclear energy in the long term. As planned, the Ling Ao Nuclear Power Plant under construction is predicted to start its operation in June 2011. In India, on April 26, Prime Minister Singh restated the policy of the country to maintain its active development of nuclear energy and announced the preparation for establishing an independent organization for safety evaluation of nuclear power plants in India.

Thus, even though there is a possibility of slight slowdown due to safety verification, there is no change in the policy of both countries to promote long-term development due to the necessity for securing energy supply that meets the increased demand.

\section{Countries Considering the Introduction of Nuclear Energy (UAE, Turkey, Vietnam, Indonesia, etc. )}

There have been various reactions from the countries in this category. The minster of Abu Dhabi Water and Electricity Authority clearly stated that "nuclear energy is a technology that should be introduced to our country and there is no change in the plan to start the operation of the first unit in 2017" because "expansion of renewable energy alone will not be enough to satisfy the rapidly increasing demand for electric power" immediately after the accident. President Medvedev of Russia met the Prime Minister Erdoğan of Turkey on March 16 immediately after the accident and discussed the installation of Russian nuclear reactor in Turkey. On March 16, the ministries responsible for nuclear energy in Vietnam stated that "the construction plan in Ninh Thuan Province was approved by the government and there is no change in the plan" in the media briefing on the nuclear power introduction plans for the country and expressed their firm resolution to strictly enforce the safety measures concerning the nuclear energy introduction. During the Association of Southeast Asian Nations (ASEAN) summit held in Jakarta, Indonesia, on May 06-May 08, it was agreed to improve information sharing and transparency related to nuclear energy issues within the area while confirming the policy to employ the safety standards of the International Atomic Energy Agency (IAEA) for the development. The background of this agreement is the fact that there still are many countries intending to actively develop nuclear energy.

These trends show that among the countries considering the introduction of nuclear energy due to energy-related issues, e.g., increase in electric power demand, or countries that already have concrete construction plans, the basic intention is to pursue the existing plans while ascertaining safety. However, it is also true that countries that do not meet the aforementioned conditions are increasingly cautious about developing nuclear energy. 


\section{Countries Tending Toward Abandoning Nuclear Energy (Germany, Switzerland, etc. )}

Discussions on reconsidering nuclear energy in these countries are uniformly severe.

The country that responded most swiftly was Germany. On March 15, only three days after the accident, Chancellor Merkel announced moratorium of the extension of German Nuclear Power Plant operation that was approved by the cabinet only a year earlier and seven existing reactors were shut down immediately. Following this on May 30, the ruling coalition parties agreed to decommission every nuclear power plant in Germany by 2022. Switzerland also agreed on a national objective to decommission its five nuclear power plants by 2034 on May 25. The concern about the safety of existing nuclear reactors is spreading throughout Europe. On March 21, an emergency meeting of EU energy ministers was organized in Brussels; it was decided that safety stress test will be conducted at every nuclear power plant currently operating in the EU. On May 24, specifications that can withstand large-scale natural disasters as well as man-made phenomena were decided. However, European power companies have been conducting individual safety inspections prior to this.

The problem in the tough debate on abandoning nuclear energy is that the existing nuclear reactors are in operation with a considerable share in many major European countries. Early abandoning of nuclear energy is not realistic without securing alternative energy sources. The premise of the "safety verification" of existing reactors is the continuation of nuclear energy or it is unthinkable unless at least continuation is being considered. Even the countries Germany and Switzerland that promptly decided on total decommission are not in situation to immediately abandon the usage of nuclear energy due to the current situation. Moreover, instead of perceiving the accident as a direct trigger, it is more reasonable to view the freezing of new construction as a result of the ongoing argument over the cost competitiveness and the relative relation with other energy trends has been repeatedly progressing and retreating but is now in the trend of falling backward in response to the accident.

\section{Summary}

To summarize these points, while countries that position nuclear energy as an important part of their energy portfolio maintain the basic policy to value it, countries that were already cautious about nuclear energy increased its inclination toward caution. As the demand for countries around the world to learn lessons from this accident and secure the safety of nuclear power plants increases, a common important factor involves satisfying the strengthened safety standards. However, it is inferred that the fact that nuclear power is adopted (or not adopted) according to the energy/economic situation and cost competitiveness of each country is not going to change in the future. 


\title{
Lessons Learned from Fukushima Daiichi Nuclear Power Plant Accident
}

\author{
Atomic Energy Society of Japan, Special Committee on \\ "Nuclear Safety", Technical Investigation Subcommittee \\ Hisashi Ninokata and Koji Okamoto
}

\begin{abstract}
It is imperative to learn from the Fukushima Daiichi Nuclear Power Plants Accident and to reflect the lessons in the safety regulations of nuclear power plants operating in the world. Based on the publicly available information, Technical Investigation Subcommittee of Atomic Energy Society of Japan's "Nuclear Safety" Special Committee has analyzed the accident and its responses and summarized into 12 sections; the results were published on the society's website on May 9. We analyzed the accident from our own academic viewpoints and extracted new lessons such as design issues in the emergency cooling device and venting line. Moreover, we proposed improvement methods to the government, which has not published enough information not only immediately after the accident but also at the current stage; we expect more aggressive information disclosure. We believe that many of these lessons will be useful for both the field of nuclear energy and improvement in safety of general artificial systems.
\end{abstract}

\section{Introduction}

The Fukushima Daiichi Nuclear Power Plant Accident overturned the people's trust in nuclear safety to its core, and once again revealed the potential danger of nuclear power plants. The struggle to deal with the accident is still ongoing. It is important to learn our lessons from this accident and ensure that similar accidents never occur at any nuclear power plant operating across the world. Based on publicly available information, the Technical Investigation Subcommittee of Atomic Energy Society of Japan (AESJ)'s "Nuclear Safety" Special Committee summarized and analyzed this accident and its responses into 12 sections, compiled the lessons learned from them into 36 cases, and published this information together with proposed examples of possible countermeasures on May 9, $2011^{11}$.

The 12 items thus summarized are as follows: 1. Earthquake, 2. Tsunami, 3. Station blackout, 4. Total loss of cooling system, 5. Accident management, 6. Hydrogen explosion, 7. Spent fuel storage pool, 8. Safety research, 9. Safety regulation and safety design, 10. Organization/ Crisis management, 11. Information disclosure, and 12. Emergency safety management. Furthermore, 70 suggestions were made in total.

DOI : 10.15669/fukushimainsights.Vol.1.68

(C) 2021 Atomic Energy Society of Japan. All rights reserved.

Originally published in Journal of the Atomic Energy Society of Japan (ISSN 1882-2606), Vol. 53, No. 8, p. 540-545 (2011)

in Japanese. (Japanese version accepted: June 17, 2011) 
In addition, the government published a report for IAEA on June 7, 2011, which contained 28 lessons and corresponding countermeasures, and classified the divided sections into 5 groups $^{2}$. Although, many lessons present in the AESJ report are absent in the government report, and vice versa, roughly similar lessons are discussed in both. Herein, we present the lessons to be learned and the measures to be taken primarily based on the lessons discussed in the AESJ report, while also referring to the government report.

Moreover, in addition to the Fukushima Daiichi Nuclear Power Plant (hereinafter referred to as Fukushima Daiichi), we have also referred to the events that occurred at the Fukushima Daini Nuclear Power Plant (hereinafter referred to as Fukushima Daini), the Onagawa Nuclear Power Plant (hereinafter referred to as Onagawa), and the Tokai Daini Nuclear Power Plant (hereinafter referred to as Tokai Daini).

We believe that these lessons will be useful not only for safety improvement at nuclear power plants around the world, but many of them will also be useful for the safety improvement of general artificial systems besides of nuclear energy.

\section{Lessons Learned from the Earthquake Tremors}

\section{Seismic Resistant Design}

Following the revision of seismic resistance guidelines published on 2006 and related back-checks, design basis seismic ground motion Ss was reconsidered and seismic strengthening was conducted. The scale of this earthquake is considered to be approximately within the range of the design basis seismic ground motion Ss. Moreover, based on the facts that there was enough margin in the structure of equipments and the cooling was stable and continued for $1 \mathrm{~h}$ until the tsunami arrived, it is estimated that the important $\mathrm{S}$-class equipments were generally intact. Note that, however, detailed seismic resistance evaluation must be conducted in the future. On the contrary, it is considered that C-class piping equipment of low importance was partially damaged. Detailed evaluations and investigation on the effect of the damages must be conducted in the future.

\section{Seismic Resistance of the Power Supply System}

The importance of power supply systems was rediscovered in this accident from the shaking of overhead wires, damages on pylons, and resulted loss of external power supplies caused by the earthquake. Moreover at Onagawa, a power panel with low importance caught fire due to the earthquake ${ }^{3)}$. Reviewing the seismic resistance importance of external power supplies and power panels is also necessary.

\section{Lessons Learned from the Tsunami}

\section{Estimation of the Tsunami}

Tsunami ( $\sim 15 \mathrm{~m}$ high) that far exceeded the design estimation ( $\sim 5 \mathrm{~m}$ high) hit the power plant. This indicates that the scale of the tsunami considered during the design stage was inadequate. 
Based on this finding, reviewing the design basis of the tsunami estimation method is necessary; however, incorporating a risk assessment method and reviewing the method of predicting the tsunami, instead of blindly determining its estimated height, is also required. Note that the tsunami height to be estimated here is not the highest imaginable tsunami; rather it is the height of the tsunami to be assumed during the design stage. Hence, this assumed height must be decided rationally while considering potential risks.

\section{Damages Caused by the Tsunami to Equipment Important for Safety}

As will be shown below, the absence of the layer for defense in depth against the tsunami that occurred in reality led to this major accident. Due to the destruction of seawater pumps and tanks installed on the side of the ocean that was expecting a tsunami of $\sim 5 \mathrm{~m}$, station blackout occurred after the seawater cooling-type emergency diesel generator (D/G) stopped. Moreover, the function of the seawater-cooling system was lost, leading to a total loss of the cooling system, which will be discussed later. Note that at Fukushima Daini, the effect was slightly mitigated owing to its seawater pump building. Furthermore, because the flooding defense of the building installed around $10 \mathrm{~m}$ from sea level was insufficient, and because shutters were destroyed by the powerful tsunami, many equipments that were important for safety were flooded. In particular, as the power panel was flooded and thus damaged owing to the tsunami, recovering the electricity system became difficult.

Thus, to protect important equipment from being damaged during a tsunami, implementing hardware measures such as preventing seawater from flooding buildings containing such equipment important for safety is necessary. Moreover, considering the fact that flooding occurred through trenches and narrow gaps in the building of Onagawa, ensuring adequate water-tightness is also necessary.

Specifically, these measures include sealing doors and strengthening the sealing of cable trays and conduits. Moreover, it is believed that underground structures and buildings such as trenches do not consider water-tightness during design; hence, strengthening their water-tightness is necessary to ensure efficient water-tightness of the building.

Moreover, equipment close to the sea such as seawater pumps should be protected with buildings and walls when necessary to avoid any direct effect of the tsunami.

Furthermore, severe accident measures that consider tsunamis exceeding the estimated levels should also be undertaken. For instance, draining methods should be considered when a tsunami rises over the tide embankment, measures should be undertaken for situations when flooding breaches a building's water-tightness, and situations should be predicted where the power supply system could be lost.

\section{Flooding of the Underground Structure}

When a large amount of seawater flooded underground structures such as trenches and pits, electric cables and electric equipment for the seawater-cooling system were flooded and, a large amount of contaminated water was generated when the floodwater was mixed with contaminated water following the core meltdown. The flooding of the underground structures by seawater and contaminated water prevents the recovery effort.

Even pits of low importance in terms of safety must be watertight if they are located close to the shore to prevent the tsunami from entering. If necessary, their seismic resistance should also be reviewed. 


\section{Lessons from the Station Blackout}

\section{Responsibility of Safety Review}

In the safety design guidelines of the Nuclear Safety Commission, the situation of station blackout is considered only for a short duration; thus, the guidelines were deemed inadequate. Overseas, station blackout accidents have already occurred, and design evaluations that consider a station blackout that lasts for a longer duration are being conducted. Important lesson was the fact that the regulatory authorities and the government were in a situation that prevented them from applying such latest knowledge to their regulation methods.

\section{Long-Term Station Blackout}

In addition to the loss of external power supply (AC power source) and emergency diesel power supply, the power panel also stopped functioning, making recovery difficult. Moreover, arranging power supply vehicles and connecting them took time, delaying the recovery of electricity supply. Although Unit 3 could use a DC power supply, this supply was eventually exhausted, and running the turbine-powered water supply system and various valves in addition to the control panel and measurement equipment became difficult. Thus, it was inferred that systems important for safety did not run efficiently. The impact of the loss of function of the power panel was particularly significant, and only limited systems have been recovered.

It is important to introduce diverse generators such as gas turbine generators as a measure against such a situation. Furthermore, not only system diversification but also diversification of positioning and installation sites, such as seismic isolation floors, is deemed important. Preparing an air-cooled generator that is independent of seawater cooling is also considered a part of the diversification. If required, the power panel should also be diversified; for instance, by preparing a spare power panel. Measures such as preventing the flooding of the high-voltage distribution panel or shutting down the control power source during an emergency must be planned. In addition, sufficient seismic resistance must be considered to prevent fire.

\section{Inability to Measure the Parameters Inside the Nuclear Reactor}

Sufficient information of the nuclear reactor or primary containment vessel (PCV) could not be obtained owing to the power loss of the measurement equipment. Hence, considering a situation where all AC power sources are lost, it is important to provide alternative electricity supply for important equipment as well as the monitoring system of the reactor core. The minimum amount of information necessary would be obtained through this measure. Additionally, the power supply capacity necessary for such a measure is quite small. Preparing in advance for such an electricity supply method for the measurement equipments and valves used in accident management measures that are considered for final severe accident measures, is especially important.

\section{Reconfirmation of the Importance of Power Supply}

If the power supply is partially available, the progress of the incident could be halted. The cooling of the nuclear reactors and fuel pools of Units 5 and 6 was possible because the aircooled diesel generator worked. At Fukushima Daini, the power supply was available, which enabled controlling the emergency cooling system, thus delaying the event sequence despite 
losing the seawater-cooling system. Meanwhile, the seawater-cooling system recovered, Units 5 and 6 went into the shutdown mode safely.

\section{Design Issues in the Emergency Cooling Device}

Following the power loss, we point out that the emergency cooling system's design needs improvement. The reactor core isolation cooling system, which is a steam turbine-powered core injection system, does not require a power source and was able to delay the core damage at Units 2 and 3. However, after having lost the DC power supply that was necessary for control, the turbine-powered pump also stopped working finally. While being turned by the steam turbine that uses the high pressure steam of the reactor core, the pump injects water into the core. By installing a small generator that utilizes the rotation energy of the turbine, it would be possible to charge the control batteries while the core injection is carried out. These batteries would enable the control of solenoid valves and other devices, thereby facilitating autonomous operation even after total loss of power supply sources for a long time.

In contrast, however, it is reported that the isolation condenser installed in Unit 1 mistakenly recognized the signal of the loss of DC power supply due to the tsunami as the signal for a pipe rupture, and closed the valve automatically. Accessing the isolation valve (motor driven valve) inside the PCV is not possible, and hence, opening the closed valve without electricity is not possible. The principle of Fail Close (close the valve while failure) is not wrong in itself when considering the loss of coolant accident. However, compliance with the regulations against the short-term station blackout considered in the safety evaluation should be respected. According to the analysis of Nuclear and Industrial Safety Agency (NISA), the damage on the fuel rods began within the first hour following the failure of the isolation cooling system. Thus, future examinations including the accident scenario of short-term station blackout in the safety evaluation are required, distinguishing between the pipe rupture signal and that of the loss of power supply in the logic circuit is considered to be possible.

\section{Lessons Learned from the Total Loss of the Cooling System}

\section{Seawater Cooling is Vulnerable to Tsunami}

The core heat removal function was lost at Fukushima Daiichi and Fukushima Daini because the seawater pump became inoperative. Currently, as seawater cooling is still difficult at Fukushima Daiichi, air-cooling is being considered as an alternative, and has been partially adopted.

On the contrary, because external power supplies were available at Fukushima Daini, stable and continuous water supply to the nuclear reactors was possible. Using this spare time to change or repair the seawater pump motors, the seawater pumps were restored and the reactors were cooled safely. Moreover, some of the seawater pumps used in the emergency diesel cooling system at both Onagawa and Tokai Daini were flooded and stopped by the tsunami. However, as either external power supplies or other emergency diesel cooling systems were functioning, the reactors at both locations were shut down safely.

Nuclear power plants across the world are built adjacent to coasts, rivers, and lakes to secure cooling water. It is important to incorporate a backup cooling system using a coolant 
other than the seawater to remove the decay heat. As the decay heat is relatively low, the air-cooling is deemed effective. From the viewpoint, although the Sizewell B Nuclear Power Plant in the UK normally utilizes seawater cooling, an emergency air-cooling device is also installed.

\section{Lessons for Accident Management}

\section{Good Practices of AM}

An alternative water injection system was readily available thanks to the accident management (AM) plan made in advance, which enabled freshwater/seawater supply through the fire engines and fire prevention pumps. It is believed that the accident would have been even more severe without this water supply system.

\section{Bad Practices of AM}

AM that considered the station blackout was insufficient. Heat removal through freshwater/seawater supply and prevention of PCV failure through PCV venting were supposed to be conducted; however, they were insufficiently performed. Specifically, opening the valve of the venting line took a long time owing to the power loss that caused a significant delay. This led to the leakage of hydrogen into the reactor building (R/B) and resulted in the hydrogen explosion. Even though the air compressor and solenoid valve necessary to open the valve of the venting do not require much power, securing the source for this small amount of power took time. Moreover, maintaining the energized state of the solenoid valve was not possible and it closed frequently. As the power source required for alternative water injection and venting is relatively small, securing it under any circumstance is imperative. To repeat, the insufficient functioning of parameter measurement inside the nuclear reactor and PCV due to the power loss is also deemed as a contributing factor toward the inadequate implementation of AM measures.

Design issues of the venting line are also pointed out. According to the report on the emergency plan of the Shimane Nuclear Power Plant submitted in April ${ }^{4}$, the venting line of the Shimane Unit 2 is connected to the air-conditioning system of the building, and the valve between them operates on the Fail Open principle (i.e., it opens when power supply or operational air is lost). Conversely, at Shimane Unit 1, the venting line and the air-conditioning system are separated during a blackout as the valve operates on the Fail Close principle. Therefore, at Shimane Unit 2, the valve between the venting line and the air-conditioning is closed by supplying the valve with electricity and air during venting.

However at Fukushima Daiichi, there was insufficient electricity and air pressure, and hence, the venting line closed frequently (due to the Fail Close principle). The risks at Shimane Unit 2 should be evaluated, and examining the necessity of measures such as switching its valve to the Fail Close is worth considering. Note that the design of the valve of the venting line of Fukushima Daiichi is hardly made open except for the partial disclosure made during a press conference.

Furthermore, the alternative water supply that was discussed as a good practice in the previous section also presents many issues to be addressed. The water supply was not provided in time, causing a delay. Securing the water source took time and mistakes were made owing to which the water supply had to be halted. These are some of the many issues that must be examined to stop further progress of the accident. It is important to reflect on these issues and 
structure a better accident management plan.

\section{AM Measures to be Implemented Following Core Damage}

During the accident, alternative water injection was provided and PCV vent was conducted after the core damage. Therefore, the dose in the building is extremely high, which poses a major obstruction to recovery. The dose of the main control room is particularly high, which severely limits the work. Hence, sufficiently evaluating the AM measures under the high radiation doses in advance is necessary.

Hydrogen explosion occurred in all units from Unit 1 to Unit 3 within 18 to $24 \mathrm{~h}$ after the isolation condensers or the reactor core isolation cooling system stopped, and cooling the reactor core became impossible. Therefore, the need for AM measures to prevent hydrogen explosion is obvious. However, it is necessary to fully understand the short availability of time. Conversely, there are $18 \mathrm{~h}$, and devising a mitigative measure that can be implemented $18 \mathrm{~h}$ in advance would be important.

Moreover, it is considered that there were issues to be discussed in the simultaneous AM measures for multi-reactor units built on the same sites. Hence, it is necessary to devise a system to manage several AM plans implemented in parallel, including the chain of command.

\section{Lessons Concerning Hydrogen Explosions}

\section{R/B Damaged by the Hydrogen Explosion}

Part of the containment function was lost, and debris with high radiation dose were scattered, disturbing the recovery work.

\section{Hydrogen Explosion Outside PCV was Not Considered}

Although several studies have been conducted on the hydrogen explosions inside the PCV, explosions inside the R/B were not considered. In addition, hydrogen recombiners and hydrogen densitometers were not functioning during the blackout. It is, therefore, recommended to install static catalytic recombiner that can recombine hydrogen without electricity.

\section{Leakage Caused by Overpressure/Overheating of PCV}

It is considered that the venting line leaked together with leakages from sealed parts such as the head flange and the hatch due to the overpressure/overheating of PCV; thus, future examination of the same is required. The result of examining this leakage should be reflected on AM measures. Obtaining important parameters such as the pressure and temperature of $\mathrm{PCV}$ is indispensable. Specifically, important parameters such as the pressure and temperature of PCV must have an independent power supply line to enable monitoring at all times, and hardware and software should be installed, which allows measures such as cooling and venting before the pressure and temperature become too high. 


\section{Lessons Concerning the Spent Fuel Storage Pool}

\section{Containment of Spent Fuel after the Building is Damaged}

The hydrogen explosion damaged the building and the spent fuel storage pool was directly exposed to the atmosphere. If spent fuels are damaged, there exists a high risk of radioactive materials being directly released to the atmosphere. For cooling, radiation shielding, and containment, securing the water level of the pool is of vital importance.

\section{Cooling after the Hydrogen Explosion}

The hydrogen explosion greatly damaged the installed pipes used for cooling the pool and other facilities. Though the cooling water is supplied using the concrete pump vehicles and other means, there are still issues with long-term cooling. Note that the cooling system using the air-cooling device was already established for the spent fuel storage pool of Unit 2, where the building was less damaged, and the pool is in a stable state of cold shutdown.

It is important to review the previously neglected AM-related issues for the pool. Specifically, measures such as facilitating water supply via fire engines immediately after the loss of power and installing a dedicated system such as a flexible hose in advance to make the use of water supply on the ground level easy should be considered. Moreover, cooling via air is deemed possible as the heat generated in the spent fuel storage pool is relatively low. By devising a natural circulation cooling system using temperature difference, removing the decay heat without power supply will be possible.

\section{Lessons for the Promotion of Safety Research}

\section{Severe Accident Research}

It took 2-3 months to estimate the extent of core damage using the severe accident analysis code (MAAP). Moreover the use of the emergency measures support system (ERSS) and System for Prediction of Environmental Emergency Dose Information (SPEEDI) was not fully employed as much as expected despite there being data shortage due to the power loss. The Japan Atomic Energy Agency (JAEA) excessively focused on the research of the future reactors. Accordingly, it has neglected research on the safety of the light water reactors; this imbalance is considered to have taken place partly due to the fact that the JAEA is under the control of the Ministry of Education, Culture, Sports, Science, and Technology (MEXT).

It is important to systematically foster human resources for safety research/safety design that includes severe accidents. Moreover, the modeling/simulation technology assures the advancement of nuclear safety, and promoting verification \& validation that assesses the quality of calculation results as a national strategy is important.

Furthermore, it is also important to produce an AM simulator and prepare a tool to evaluate behaviors of the reactor or fuel on real time for training the operation staff or directors.

\section{Wasteful Usage of the National Budget}

Projects that are researched and developed as national projects are often discarded upon completion as they are not allowed to be carried over for reasons other than their original 
purposes owing to budget reasons. Thus, such products/facilities cannot always be used when they are needed. It is necessary to predict their possible usages during disasters and maintain significant results for effective use.

\section{Lessons Concerning Safety Regulation and Safety Design}

\section{Safety Design against External Events}

There was inadequate preparation for extremely high consequences but extremely rare and unpredictable events such as the tsunami. Internal events that caused the common cause failure were mainly software problems and human factors. Research on these failure modes has greatly advanced since the Three Mile Island Accident. Moreover, the research sufficiently established the philosophy of defense in depth against internal events. Although this philosophy of multilayered defense against internal events has also been applied to external events, the common cause failure was not recognized adequately.

The hardware common cause failure could prevail in the primary external events. Moreover, external events have a much lower probability of occurrence, but with high uncertainties. In such cases, the traditional three-layer defense-in-depth is inadequate, and preparing for adequate measures that include AM of severe accidents as well as disaster prevention is important.

It is necessary to evaluate the external events through the probabilistic safety assessment (PSA), focused on quantitative risks. However, discussing the uncertainty of PSA is also important. After all, it is accident management that balances this uncertainty. Restructuring the safety logic of the nuclear power plants, including AM and disaster prevention, assuming various types of natural disasters, is also necessary. It is important to formulate effective AM countermeasures by applying the results of the quantitative risk assessment and to review safety importance and diversity/multiplicity based on the risk assessment.

\section{Issues Relevant to Japanese Safety Regulation}

These issues include the lack of structure to assess the current design of a plant, delay in the adaptation of PSA, and insufficient implementation of new knowledge.

Although the incorporation of the severe accidents into the framework of nuclear regulations was initiated already, it was too late. Moreover, the regulatory scope of the Reactor Regulation Act (Act on the Regulation of Nuclear Source Material, Nuclear Fuel Material and Reactors) was too narrow, and the accident immediately became the subject of the Nuclear Emergency Act (Special Measures Concerning Nuclear Emergency Preparedness).

The connection between the assessment of basic design (installation permit application) and operation management is weak, and the required changes are a formality defined as the changes in the main text. The changed installation permit application does not reflect the current state of the plant. Furthermore, the structural strength regulation has been mainly focused for installation permission, construction plan approval, and pre-operation inspection; performance function and analysis of PSA were undervalued.

The reflection of new findings such as safety research and regulatory trends to be adopted from other countries was delayed. Moreover, the regulation was considered infallible, which resulted in undue focus on precedents and generated reluctance toward reviewing the regulation, which should pursue always safety. Furthermore, both the regulators and business 
operators were side-by-side, creating an environment where it was difficult for an individual operator to independently pursue safety.

Therefore, reviewing the legal system and restructuring the safety regulation, such as unifying the Reactor Regulation Act (Act on the Regulation of Nuclear Source Material, Nuclear Fuel Material and Reactors) and the Electricity Business Act, is necessary. The purpose and permission standard of the Reactor Regulation Act must be changed to "the protection of citizens from radiation hazard," and severe accidents must be included in the regulatory scope of the Reactor Regulation Act. Moreover, the effectiveness of the AM process (organization, role, response to multiple units, process validity, feasibility, training, material, and equipment) must be secured. Comprehensive safety analysis manuals should be introduced to the installation permit, and the analysis that postulates the conditions of operation management should be focused on. In addition, it must be ensured that the changes in the plant are always reflected on the comprehensive safety analysis manual, which should always be an as-built document created by defining the change from the perspective of nuclear reactor safety. A private third-party certification system should be introduced to the construction plan permit together with pre-operation inspection and an integrated inspection system that inspects its enforcement and monitors observance of the comprehensive safety analysis report.

\section{Lessons Concerning Organization and Crisis Management}

\section{Issues of the System of Responsibility}

Owing to the vertically-divided administration, the staff with specialized knowledge in various fields of nuclear energy is spread across different departments; thus, there is no single person who is responsible. There is no specialized organization that supervises the whole due to the distribution of law systems. In particular, the organizations for radiation regulation and nuclear energy regulation are separated. Moreover, the specialists were not adequately utilized.

Therefore, unifying the system of responsibility and creating a specialized regulatory organization is important. For example, the Nuclear Safety Commission can be turned into an article 3 agency (independent organization), nuclear and radiation regulations divided between NISA and MEXT can be unified/integrated, and also organizations with specialized knowledge such as the Japan Nuclear Energy Safety Organization (JNES) and the Nuclear Material Management Center can be integrated into one to create a regulatory organization with advanced specialization that could be a Japanese version of the United States Nuclear Regulatory Commission (NRC).

\section{Issues Concerning Emergency Response}

Owing to the blackout and the problem of communication, smooth response to the emergency was not possible. For instance, there was a delay in contacting and gathering the emergency response staff. Moreover, the opinions of foreign countries are too dominant, which obstructed Japan's superior knowledge (for instance in robotics and water processing) from being used. The emergency response support system (ERSS) did not work because of the blackout. 


\section{Lessons Concerning Information Disclosure}

\section{Delay in Information Disclosure}

Information disclosure during the emergency was inadequate. Information release of SPEEDI was delayed. Moreover, the information disclosure is insufficient even after three months since the accident. For example, the website of NRC in the US offers information that is unavailable in Japan ${ }^{5}$. This situation led the people to believe that headquarters is hiding information, leading to a loss in trust.

In general, the technical explanation only lists data and the published information does not contain the evaluation of these data.

\section{Lack of Understanding of Role of INES}

International Nuclear Event Scale (INES) communicates the degree of seriousness of the accident to the local residents, the Japanese population, and foreign countries, initiates actions such as evacuation. The initial publication of low-level preliminary numbers such as level 3 and level 4 that do not necessitate emergency evacuation had no correspondence with the actual evacuation orders for the area within the 3,10, or $20 \mathrm{~km}$ radii. Moreover, the more realistic estimated level, which should have been promptly published when the accident occurred, was not published until two months after the accident. This caused unnecessary confusion and mistrust both in and outside Japan. This is a serious matter, and undoubtedly a result of negligence toward accurate understanding and usage of INES.

\section{Poor Explanation of Radiation and Nuclear Safety}

To begin with, the thought behind radiation safety and nuclear safety is complex and difficult to understand. Information regarding emergency and normal circumstances, dose rate and dose, and the view on the effects of radiation on human health influence were communicated poorly, leading to unnecessary confusion.

\section{Insufficient Cooperation with Local Municipality, for Instance in Setting the Evacuation Area}

Unclear explanations, such as deliberate evacuation area and voluntary evacuation, confused the local municipality. Moreover, as the US designated $80 \mathrm{~km}$ radius (50 miles) as the evacuation area, such different and contradicting information increased the confusion.

\section{Lack of Communication Between Local Municipalities and the Disaster Control Headquarters}

As many municipalities are affected, communication is believed to be inadequate. 


\section{Lessons Concerning Emergency Safety Management}

\section{Issues in the Unification and Sharing of Information about Radiation Dose within the Premises during Emergency}

It is considered that safety, personnel, and exposure controls for the staff/workers during the emergency were inadequate. Specifically, examples of this inadequacy include the exposure incident that occurred at a puddle during power supply recovery work in the turbine building of Unit 3 and the fact that in the initial phase of responses to the accident, individual workers could not carry a dosimeter on themselves. Attention should be paid more to safety while working in tight emergency.

\section{Delay in Response to Internal Exposure}

The inflow of radioactive materials was not included in the design conditions of the seismic isolated building. The concentration of radioactive materials inside the seismic isolated building was not measured for two weeks after the earthquake. The setting up of a buffer zone (where one takes off protective clothing) in the seismic isolated building was delayed, which exposed the female staff in the seismic isolated building and the operators of the main control room. Consequently, more staff suffered internal exposure than external exposure.

\section{Issues of the Emergency Work Environment}

There was inadequate awareness regarding the effects on the health of the staff/workers under emergency. Poor quality of clothing, food, and accommodation continued for a long time after the accident. Further, response to health problems (including mental health) was slow and inadequate.

\section{Conclusions}

Sharing the lessons learned from this accident both within Japan and with the world is important. In hindsight, it is clear that the state of "nuclear safety" was not in good shape. There was insufficient improvement in response to the regulatory review (IRSS) conducted by IAEA a few years ago, resulting in the same problems being highlighted again in this report. We would like to believe that, finally, improvement will be made following this accident. For such improvements, it is important to first think of the ideal "nuclear safety" instead of thinking about how to change the existing system. The existing system should be improved by comparing it to the ideal system, and what is lacking should be created anew. The key is to shift from "regulation for checking the safety" to "regulation for checking the risks". Moreover, it is important to work under the premise that "there will be an accident" and be able to respond, in addition to the premise of "prevent accidents from happening".

Furthermore, "diversification" is the key to hardware response. By diversifying various facilities, more options will be available to respond to an emergency. However, this will also increase the risk for mistakes during normal operation. It will increase the maintenance, and occasions for potential mistakes. Therefore, blind diversification is not an answer. Instead, it is important for the regulatory authorities and the operators to recognize that true safety is the 


\section{INSIGHTS CONCERNING THE FUKUSHIMA DAIICHI NUCLEAR ACCIDENT Vol. 1}

reduction of the total risk.

\section{References}

1) Atomic Energy Society of Japan. Lessons from the Fukushima Daiichi Nuclear Power Station Accident. "Nuclear Safety" Special Research Committee, Technical Analysis Subcommittee. http://www. aesj.or.jp/information/fnpp201103/chousacom/gb/gbcom_kyokun20110509.pdf. 2011 May. [In Japanese]

2) Japanese Government Report on the Nuclear Safety for IAEA Ministerial Meeting-On the Accident at Fukushima Daiichi Power Station of Tokyo Electric Power Company. http://www.kantei.go.jp/jp/ topics/2011/iaea_houkokusho.html. 2011 June. [In Japanese].

3) Tohoku Electric Power Co. Inc. On the state of Onagawa Nuclear Power Station after the Earthquake Off the Pacific Coast of Tohoku and the Following Tsunami. http://www.tohoku-epco.co.jp/news/ atom/1183294_1065.html. 2011 May. [in Japanese]

4) The Chugoku Electric Power Company, Inc.. Progress Report on the Emergency Safety Measures at Shimane Nuclear Power Station. http://www.energia.co.jp/atom/notice/110422a.pdf. 2011. April. [In Japanese]

5) NRC, Advisory Committee on Reactor Safeguards, Subcommittee on Fukushima. http://pbadupws. nrc.gov/docs/ML1114/ML11147A075.pdf. 2011 May. 


\title{
The Science and Technology Communication
} in a Post 3/11 World

\author{
-How Can the Public Have Trust in Nuclear Experts?-
}

Osaka University Center for the Study of Communication Design,

Ekou Yagi

Post March 11, many nuclear experts may be pondering, "what can be done to regain the society's trust?" However, irrespective of what we say now, we must rethink everything from the perspective that words alone cannot be trusted. Instead of thinking of nuclear energy from the perspective of expert-driven promotion of scientific and technological understanding, the problem of nuclear energy must be rethought as a "trans-science" problem that can be posed as a question to science, but which science alone cannot answer. Herein, we will add some comments from such a perspective based on trans-science.

\section{Statements Without Self-Examination and the Message They Send to the Society}

\section{Statement Issued by the Atomic Energy Society of Japan and the Sense of Commitment}

After the 2011 earthquake that occurred off the Pacific coast of Tohoku, many research communities (academic societies) issued statements concerning the disaster from their own perspectives. Similar to other societies, the Atomic Energy Society of Japan (AESJ) also published its statement on March 18, one week after the earthquake. The author of this paper read that statement as a member of AESJ, and could not help being uncomfortable, especially regarding the following lines.

(Omitted) Through these activities, we promote dialog with citizens and an understanding of nuclear energy. (Omitted) We will play the role that is asked of us while remembering that nuclear energy is an indispensable technology for solving the energy problem of humanity, and we will continue to contribute to the development of the society with renewed resolve. ${ }^{1)}$ (Underline by the author)

At that time, only one week after the earthquake, the memory of the hydrogen explosion at the Fukushima Daiichi Nuclear Power Plant was still fresh, and not only the Fukushima Prefecture but the entire country of Japan was watching the progress of the situation at the power

DOI : 10.15669/fukushimainsights.Vol.1.81

(C) 2021 Atomic Energy Society of Japan. All rights reserved.

Originally published in Journal of the Atomic Energy Society of Japan (ISSN 1882-2606), Vol. 53, No. 8, p. 546-549 (2011)

in Japanese. (Japanese version accepted: June 2, 2011) 
plant with bated breath. The people in the vicinity of the power plant were not only forced to evacuate without much preparation, but were also faced with serious concerns regarding the effects of exposure on themselves and their families. Moreover, many people had to make a difficult decision to surrender the search for missing family in order to evacuate. The abovementioned statement was issued under such circumstances. AESJ, which was considered to be equally responsible for this accident as the electricity company, definitely stated that "nuclear energy is an indispensable technology" even before the prospects for the resolution of the incident or a proper examination were made. Many reactions among academics stated that the authors of this statement lack consciousness in terms of self-responsibility. The author felt that such criticisms were warranted. Furthermore, these criticisms are still deserved currently, three months after the accident, when a prospect for the resolution of the situation is still missing.

\section{Experts Who Express the Sense of Their Responsibility}

Conversely, several academic societies expressed their responsibility as experts. For instance, the president of the Physical Society of Japan (JPS) stated in the text he published in the Society's journal on March $22^{2)}$ that:

Under such circumstances, the Physical Society must tackle a huge problem. First, either as JPS or as physicists we must engage with the problem at the Fukushima Nuclear Power Plant in a correct manner, even if only belatedly. The usage of nuclear energy was pioneered by physicists. Thus, our responsibility is grave. The danger at the Fukushima Power Plant is an ongoing problem. However, physicists must think of medium to longterm problems. Physicists tend to close their eyes to nuclear power generation. This is the moment for us to seriously reengage with it. (Underline by the author)

Moreover, in the joint emergency statement issued by the following three academic societies ${ }^{3)}$ : the presidents of the Japan Society of Civil Engineers, the Japanese Geotechnical Society, and the City Planning Institute of Japan, stated that:

This earthquake is said to be unprecedented and unexpected. When we use the word unexpected as experts, we should not use it as an excuse or justification. When facing such a great earthquake, we must fear the force of nature, as our ancestors did, and remind ourselves that it is important to have a perspective that not only focuses on hardware (disaster prevention facilities) but also combines it with software. (Underline by the author)

Naturally, every academic society is facing a different situation, and hence, they cannot be generalized. However, the important difference between the statement issued by AESJ and these two statements is that the latter two clearly express their reflection on their research or words. Furthermore, it is the difference in whether the reader can feel the regret and agony behind the words of the experts. In the post-3.11 era, "trustworthiness of nuclear experts" will become an important theme in both the remediation of the environmental impact of the Fukushima Daiichi Nuclear Power Plant Accident as well as social consensus on building for the future usage of nuclear energy. However, is it possible for the society to trust a group of experts who refuse to reflect on themselves even after experiencing such an unprecedented disaster?

One of the conclusions that the author arrived on, after many years of being involved in the "dialogs" between nuclear energy experts and the local citizens near the power station sites, is that without reflecting on past comments and sharing this reflection with people who are non-experts, it is unlikely that the experts will be trusted by the people in the true sense ${ }^{4)}$. Instead of the experts who know the unshakable truth and educate non-experts, experts who 
struggle with the society and search for a better existence of nuclear energy together with better technology are required even more after facing this unprecedented disaster.

Instead of forcing the belief on the society that "nuclear energy is an indispensable technology for solving the energy problem of humanity", and self-righteously defining one's role as "contributing to the development of the society", being humble enough to think that if necessary for the society, we will dedicate ourselves to helping the society with a whole-hearted spirit. After 3.11, such humility is probably the only possible starting point for any dialog between experts and citizens.

\section{Self-Protection of Experts and Its Social Appraisal}

Similar issues are not unique in the field of nuclear energy. The responsibility of the unprecedented damage caused by the 2011 Tohoku Earthquake is not attributed to the nuclear energy experts exclusively.

The joint statement issued by the 34 academic societies led by the Chemical Society of Japan (including the AESJ) ${ }^{5)}$ is as follows: "Japan will not stop the progress of scienceAcademic societies will build a hopeful future of Japan with students and young researchers." Consequently, the following three points were proposed: (1) support for students and young researchers; (2) support for early repair/recovery of universities and research facilities damaged by the earthquake and reestablishment of the educational and research system; (3) transmitting accurate information to prevent national/international reputational damage of nuclear power plants following the disaster. One can find the same problems here as those in the statement issued by AESJ. In this joint statement of the 34 academic societies, a group of experts with diverse domestic expertise not only failed to appropriately predict the occurrence of the 2011 Tohoku Earthquake but also failed to predict the tsunami it triggered and prepare concrete measures (including countermeasures for nuclear power plants). Moreover, they did not reflect on any of these failures. On the contrary, in points (1) and (2), the statement only discusses the necessity of social support for scientists, including young researchers and scientific researches. From the perspective of the readers of the published statement (the society), its contents are readily perceived as self-protection.

Naturally, repair/recovery of the environment for scientific research is one of the important issues. However, when the society is asking questions about the raison d'être, i.e., the reason for the existence of the research itself, such as "what is scientific research? How can it/did it contribute to our society?" Under such questioning, the social impact of making the first statement that focuses on self-protection without reflection is significant. At the very least this is not a proposal that should be prioritized. From the society's perspective, science and technology experts are on the same side as the government and administrative agencies, i.e., the side that caused this unprecedented natural disaster and man-made atomic power fatality. In a sense, the experts do not have the right to say, "Japan will not stop the progress of science (technology)" at instance. Rather, they should say "stop the progress of science (technology) for the time being" and ask themselves what science can do for the resolution of this situation and true restoration of the disaster-stricken area. Unless they are judged by the society, they cannot begin anew.

\section{Limiting the Knowledge Injection Model}

Another problem in the statement issued by the 34 academic societies lies in point (3): reputational damage. To begin with, what is "accurate" information dissemination under such 
a circumstance? Our society has seen information that was said to be accurate being overturned many times in the last three months. Moreover, there is no agreement on the question, "what is accurate knowledge," in terms of the effect of radiation exposure on human health influence even among the so-called experts.

The author has been repeatedly arguing since March 11 that while a certain level of nuclear knowledge is necessary, injecting " (purportedly) correct” knowledge alone cannot remove all the fear concerning radiation. Particularly, in a society where a nuclear power plant accident that has never been experienced by human beings became reality, to blindly believe the "correct" knowledge some experts try to unilaterally force upon the society is extremely difficult. In a situation where everyone tries to comprehensively judge the situation not only through official announcements but also through counter information (including warnings for danger), what is required of experts is not the offer of exclusively correct information but to the offer of information with detailed proofs that can be used as for a basis to judge what is correct. At one of the dialogs organized by the author between experts and the residents of the nuclear power plant sites, one of the residents said the following: "I think in the end, the opinion of an expert is neither right nor wrong, but it is just that person's personal view. And it is up to me to decide whether it is correct or not." ${ }^{4)}$ The people who were facing risks after 3.11 are probably selecting the comments made by experts and deciding what is correct themselves, with such an attitude.

An expert must possess enough knowledge and confidence in his/her expertise. However, this confidence can become a misconception by making that one wrong move which propagates that only science and technology (specialized knowledge) can derive "correct" answers for people and the only necessity is to enlighten people about correct knowledge. In a situation where enough information regarding the current state or progress does not exist and distrust toward experts is increasing, for instance, the situation around the Fukushima Daiichi Nuclear Power Plant, it is not possible to alleviate the concerns of the people through thought-injection of knowledge alone.

\section{Science and Technology Communication in the Post 3.11 Era}

\section{Experts Who Respond to the Social Context}

It has been a long time since the interaction between experts and citizens began to be considered important, and terms such as "communication," "dialog," and "interactive" began to be used, not only in the field of nuclear energy but in the whole area of science and technology. Particularly in the field of nuclear energy, this tendency accelerated after the $1995 \mathrm{Monju}$ accident and the 1999 JCO Nuclear Accident.

However, this communication always had "progress of science" as its main premise, and its focus has been on promoting people's understanding about science (nuclear energy), despite claims to emphasize on interactivity, as is symbolized in some of the statements the author has discussed thus far. Experts do not grasp the situation of the society and do not understand what the society wants from science. Indeed, they are even lacking in the basic attitude of "listening to the voice of the society and learning from it". In the statements issued by academic societies, critically discussed in this paper at least, such an attitude could not be felt.

One of the themes on which people with varying views on nuclear energy (pros and cons) 
disagreed most strongly during the dialogs on nuclear energy that the author has been involved in was exactly this ${ }^{6}$. While nuclear energy promoters proclaim that the importance of "development of society" or "pursuit of wealthy life" is self-evident, opponents and cautious people offer perspectives that "to begin with, changing the vision of a future that expects unlimited electricity and energy is necessary" and "instead of focusing on the growth model, we should rethink our understanding of wealth". After 3.11, such views have suddenly become widespread in the society.

\section{From PUS to PEST}

In this sense, it is necessary to rethink the term "science communication," which feels rather overused in the last 10 years.

The occasion when science communication, which had become an important trend since the end of Cold War particularly in Europe, faced an important turning point was what is now known as the "BSE Problem". Even though experts in public positions stated that there is no harm to humans when the problem first emerged, the variant Creutzfeld-Jakob disease was discovered a few years later and human infection became a reality. This led to loss of trust in the government and experts in the UK. Following this, science communication in Europe, led by the UK, shifted from "public understanding of science (PUS)," which aimed at injecting knowledge into non-experts, to "public engagement in science and technology (PEST)," which shares the risk of science and technology, including their uncertainty, through dialogs and emphasizes on the participation of citizens in social decisions concerning the introduction of science and technology to the society and its regulation. To regain the lost trust in science and technology, they began aspiring to the "democratization model of specialization" that emphasizes the conclusion drawn by the common sense of non-experts instead of the model where experts enlighten the citizens.

Even in Japan, it has been brought to attention that after 1995, when many major accidents/ incidents that shook the foundation of the society occurred (the Great Hanshin earthquake, the Tokyo subway sarin attack, and the Monju Accident), trust in experts also collapsed. Thereafter, the need for science and technology communication has also become important in Japan, and many activities have begun, as discussed earlier. However, science and technology communication in Japan tends to focus on positive aspects of science and technology such as their greatness or how fun they are. Furthermore, most public research and businesses in Japan tend to be one-sided and based on PUS, and it is undeniable that there was a deflection.

However, as it became obvious after 3.11, a promotion of the understanding of science and technology led by experts is not what is required of science and technology communication in the future. There are problems that we can question science with, but that science alone cannot answer. Methods of confronting such problems are known as problems of "trans-science."

Various problems relating to low dose radiation exposure being faced in the Fukushima Prefecture pose questions such as how should experts provide information about scientific problems that no one knows the correct answer to? Or what is the right answer to problems that have a wide-range of solutions? How can society read such diverse information among diverse arguments with a certain degree of overview? And how can society derive any solutions? These are the urgent questions for the society now. 


\section{Transfer from Citizen Participation That Follows "Nuclear Energy First" to "Nuclear Power as a Choice"}

Since March 11, the question "what is required of nuclear energy experts to regain the trust of the society" is often asked. Although it sounds too tough, the author believes that at least for now, the premise that "they cannot be trusted only by words alone" must be trusted.

Nevertheless, if nuclear energy experts still wish to be trusted, they must show a drastic change within themselves.

In Japan, since 2000, citizen participatory technology assessment (pTA) such as consensus conferences started to gain attention as ways to implement the aforementioned trans-science methods. It is an attempt to comprehensively evaluate the potentials and risks of science and technology through discussions among the members of public having diverse ages, professions, and senses of value when a new technology is being introduced to the society. In Europe, a framework to reflect its result on the real policy has been developed. In Japan, though the implementation and results are still relatively low, they are gradually increasing.

However, in the case of nuclear energy, the trying such an initiative was challenging. The main hurdle was that the position of the pro-nuclear camp whose premise is a society that uses nuclear technology as its infrastructure and the position of the anti-nuclear (prudent) camp that argues for zero nuclear energy as the starting point instead of taking it for granted do not meet at all, and it is impossible to even begin a discussion. This means that the fate of the subject of nuclear energy was that "upper assessment," which is an evaluation to be conducted at the beginning of development and an important point of pTA, was not possible.

If nuclear experts wish to converse with the citizens in order to regain their trust, their side (including the policy-makers involved in nuclear energy) must change their perspective of taking the need for nuclear energy for granted to seeing nuclear energy as only an option, and undertake such initiatives in citizen participation. In other words, it is important for the nuclear experts to return to the drawing board and seriously consider the possibility and practicality of the "abandoning nuclear energy" scenario. Naturally, discussions remain to be had on whether the result of pTA should directly influence policies. There are also many issues in the system of pTA itself. In that sense, this is not a quick solution. However, irrespective of whether our society continues to use nuclear energy or abandons it, it is not a decision to be made in haste. Currently, the nationwide controversy of which type of energy source to select, including the process of social decision-making, is the most urgent discussion.

Furthermore, nuclear energy experts must have the determination to honestly accept the conclusion of such a discussion, even if it is to "abandon nuclear energy". If that is not possible, the people's trust in them will fade further, regardless of what they claim.

\section{Conclusions}

In the last 10 years, the author has organized many events where people from all walks of life discuss the issue of nuclear energy at several places throughout Japan. The most important point at these events was for people with different opinions to converse instead of seeking direct resolution (whether to promote or oppose the construction of a nuclear facility at a given site).

After March 11, the author has a profound concern that this assertion has been too slow. Observing various miscommunications after the earthquake, she is often tormented by regret that she was too slow. However, she still believes that in order to decide how to handle nuclear 
energy in the society, it is now especially important for people who have seen different "facts" after 3.11 to converse among themselves in order to try to bridge the gap between them, with the premise that "it should be decided gradually, and a direct conclusion should not be hurried."

The author of this paper wrote in her book ${ }^{4)}$ that "it is important for people like us who try to create the situation for discussions to be criticized by both the promoters and the opponents, and in a sense, it is meaningful to be recognized as a nuisance. Those who organize discussions must always be distant from every opinion, and at the same time be close to every opinion. In that sense, I believe it is the responsibility of the person who approaches such a problem to take every criticism to heart from the perspective of communication." Upon concluding this paper, the author would like to reflect on this responsibility again and consider the importance of the criticisms she have received until now.

\section{References}

1) Atomic Energy Society of Japan, To Japanese People: On the nuclear emergency following the earthquake off the Pacific coast of Tohoku. http://www.aesj.or.jp/information/tohokueq 20110318.pdf (As of May 31, 2011). [In Japanese]

2) Nagamiya S. After Tohoku earthquake. Butsuri-Gakkai-Shi (J. Phys. Soc. Jpn.). 2011 March;66[5]:337. [in Japanese]

3) Joint emergency statement: the presidents of the Japan Society of Civil Engineers, the Japanese Geotechnical Society and the City Planning Institute of Japan. http://committees.jsce.or.jp/2011quake/taxonomy/term/74 (As of May 31, 2011). [in Japanese]

4) Yagi E. What is Communication Design?-To bridge the gap between science and society.: Osaka University Press; 2009. [in Japanese]

5) Joint statement by the presidents of 34 academic societies. Japan does not stop the progress of science-Academic societies build hopeful future of Japan with students and young researchershttp://www.ipsj.or.jp/03somu/teigen/seimei 20110427.html (As of May 31, 2011). [in Japanese]

6) Interactivity Symposium. What to do with high-level radioactive wastes. http://www.enecho.meti.go.jp/rw/rikai/hlw-sympo/index.html (As of May 31, 2011). [In Japanese] 


\title{
Behavior of Spent LWR Fuel Decay Heat
} -For Better Insight into Fukushima-Daiichi Accident-

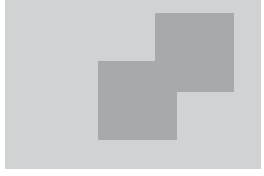

\author{
Tokyo City University, Tadashi Yoshida
}

The struggle with decay heat is considered to be a focal problem that can be attributed to the cold shutdown of the Fukushima Daiichi Nuclear Power Plant. The decay heat is broadly divided into the fission product (FP) decay heat accompanying the $\beta$-decay of the FP produced by nuclear fission and the actinide decay heat accompanying the $\alpha$-decay or $\beta$-decay of the actinide species, which are heavier than the uranium used as a nuclear fuel. There are several highly reliable methods that can be used to calculate the decay heat. Careful examination of the calculation method is necessary while performing the calculation for reasonably reproducing the situation of the nuclear reactor after its shut down.

\section{Introduction}

The most significant difference between nuclear fuel and fossil fuel lies in the fact that nuclear fuel continues to generate heat even after burning, i.e., even after the operation of the nuclear reactor has been terminated. Breakage or melting of the reactor core occurs if the nuclear fuel is not continually cooled. The heat remaining after reactor shutdown, which is caused by the delayed decay ( $\alpha$-and/or $\beta$-decay) of unstable nuclides produced during the operation of the reactor, is referred to as the decay heat. The time after reactor shutdown or the termination of burning can be referred to as the cooling time, which is the most important parameter related to decay heat. Decay heat is broadly divided into the fission product (FP) decay heat that accompanies the $\beta$-decay of the FP produced by nuclear fission and the actinide decay heat that accompanies the $\alpha$-decay or $\beta$-decay of the actinide nuclei, which are heavier than uranium, including plutonium, which is also used as fuel material.

\section{Fission Product (FP) Decay Heat}

\section{Origin and Characteristics of the FP Decay Heat}

A nucleus comprises both protons and neutrons. When the number of protons is expressed

DOI : 10.15669/fukushimainsights.Vol.1.88

(C) 2021 Atomic Energy Society of Japan. All rights reserved.

Originally published in Journal of the Atomic Energy Society of Japan (ISSN 1882-2606), Vol. 53, No. 8, p. 555-558 (2011)

in Japanese. (Japanese version accepted: May 30, 2011) 


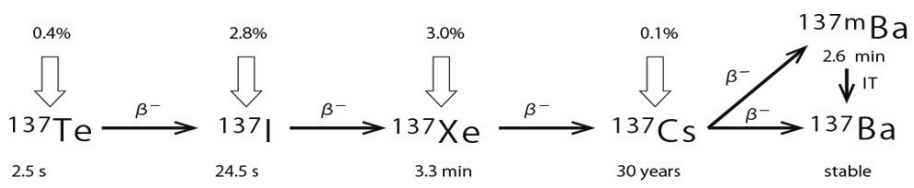

Figure 1 Example of $\beta$-decay chain (Mass number: 137)

as $\mathrm{Z}$ and the number of neutrons is expressed as $\mathrm{N}$, light nuclei often become stable at $\mathrm{N} / \mathrm{Z}=1.0$ (e.g., ${ }^{4} \mathrm{He},{ }^{10} \mathrm{~B}$, and ${ }^{12} \mathrm{C}$ ). As the atomic number $\mathrm{Z}$ of the nucleus increases, this $\mathrm{N} /$ $\mathrm{Z}$ ratio increases $\left(1.3\right.$ with ${ }^{93} \mathrm{Nb}, 1.4$ with ${ }^{133} \mathrm{Cs}$ ) and becomes $\mathrm{N} / \mathrm{Z}=1.6$ in case of uranium. Thus, heavy nuclei are observed to exhibit high ratio of neutrons. Therefore, when heavy ${ }^{235} \mathrm{U}$ undergoes nuclear fission and breaks up into two FPs having medium weight, both FPs are observed to contain excess neutrons. The FP that is unstable because of excess neutrons will repeat $\beta$-decay with time delay and move toward a stable nucleus while transforming neutrons into protons. Figure 1 depicts an example of this process. Because this process only transforms excess neutrons into protons, the mass number, $\mathrm{A}=\mathrm{N}+\mathrm{Z}$, does not vary. Further, such a $\beta$-decay chain can also be referred to as a mass chain.

This example depicts the situation in which the mass number is 137 . The white arrows in Figure 1 exhibit the generation of each nuclide due to nuclear fission; further, each number above them shows the generation rate of each nuclide (the numbers are relative to the ${ }^{235} \mathrm{U}$ thermal neutron fission). This rate is normalized at $200 \%$ and can be referred to as the independent yield. Each generated nuclide maintains its mass number, A, and continues its $\beta$-decay with the half-life that is written under the name of the nuclide until it reaches stable ${ }^{137} \mathrm{Ba}(\mathrm{N} / \mathrm{Z}=1.45)$. The total energies of the released $\beta$ - and $\gamma$-rays are considered to be the values of the decay heat. In case of FP decay heat, considering approximately 100 mass chains beginning from approximately $\mathrm{A}=75$ is necessary. The cumulative yield of ${ }^{137} \mathrm{Cs}$ that is frequently discussed is $6.3 \%$, which is the sum of the yields of the nuclides in the upstream (to the left of ${ }^{137} \mathrm{Cs}$ in the figure) and its own independent yield. This accumulated yield belongs to the largest category among all FPs. Though the energy of neutrinos, which inevitably accompanies the $\beta$-decay, is almost equivalent to those of the $\beta$ - or $\gamma$-rays, the neutrinos will still fly away to the outside of the universe without interacting with the substances around them. There are approximately 800 FP nuclides related to the FP decay heat. There are many FP nuclides having short lives that immediately contribute to the decay heat after shutdown; the number of FP nuclides contributing to the decay heat decreases with an increase in the cooling time.

\section{Summation of the FP Decay Heat}

The summation method is nearly an exclusive calculation method for calculating FP decay heat. The decay heat, $f(t)$, at cooling time, $t$, is obtained from

$$
f(t)=\sum_{i} \lambda_{i} \cdot\left(E_{\beta}{ }^{i}+E_{\gamma}{ }^{i}\right) \cdot N_{i}(t)
$$

This procedure is referred to as summation calculation because it utilizes the sum of all the FP nuclides. Here, $\lambda_{i}$ is the decay constant of nuclide $i$ and $N_{i}(t)$ is the abundance of nuclide $i$ at time $t . E_{\beta}{ }^{i}$ and $E_{\gamma}{ }^{i}$ denote the average energies of the $\beta$ - and $\gamma$-rays released when nuclide $i$ undergoes one $\beta$-decay. The FP decay data libraries, including the JNDC FP decay library ${ }^{1)}$, comprehensively include $\lambda_{i}, E_{\beta}{ }^{i}$, and $E_{\gamma}{ }^{i}$ together with detailed descriptions of their decay 
chains.

\section{The FP Decay Heat Time Behavior}

Figure 2 exhibits the FP decay heat of ${ }^{235} \mathrm{U}$. To simplify the explanation, we did not consider the effects of plutonium generation and combustion, which will be described later, and the minor actinide (MA) decay heat. The ratio of FP decay heat of ${ }^{235} \mathrm{U}$ after continuous burning for 2 years at constant power to the reactor operation power is shown. The recommendations provided by Japanese and USA institutions are observed to agree well each other. The FP decay heat observed immediately after shutdown is approximately $6.5 \%$ of the power while the reactor is being operated. Initially, the FP decay heat decreases rapidly and further continues to slowly decrease (note that it is a logarithmic axis.). It requires $8 \mathrm{~h}$ for the decay heat to become $1 / 10,4$ months to become $1 / 100$, and 3 years to become $1 / 1,000,000$ of the heat observed immediately after the shutdown. Furthermore, even after a decade of initiating burning shutdown, the level of FP decay heat is only 1/2,000 of the heat immediately after the shutdown. After a decade, even in case of uranium fuel, the heat emission from ${ }^{244} \mathrm{Cm}$ and ${ }^{238} \mathrm{Pu}$ in case of MA can no longer be ignored. This will be discussed later.

Finally, the influence of the difference in burning periods on the FP decay heat should be discussed. We observe that there are barely any differences between the decay-heat levels after a year of burning and after five years of burning; this can be observed immediately after the burning shutdown. However, their difference is observed to gradually increase by approximately two times after 120 days, approximately three times after a year, and more than four times after three years. Regardless, the decay heat level decreases along with an increase in the cooling time.

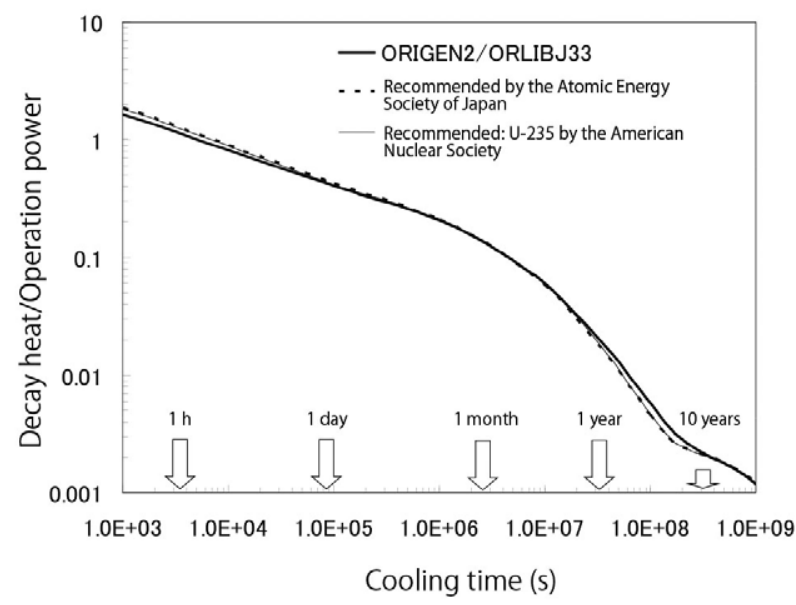

Figure 2 The FP decay heat of ${ }^{235} \mathrm{U}$ (after 2 year of operation)

\section{Behavior of the FP Nuclides and Decay Heat}

The number of the $i$-th nuclide $N i(t)$ that appears in equation (1) as a byproduct of the FP decay heat summation discussed in Section II-2 contains important information. Here, we present an example for this case in Figure 3, which depicts a comparison between the isotope 
number density ratio calculated using the cesium isotopic fractions in stagnated water from the Unit 2 turbine building of the Fukushima Daiichi Nuclear Power Plant released by Tokyo Electric Power Co., Inc. (TEPCO) in March, 2011 and the isotope ratio Ni ( $t$ ) calculated using ORIGEN2 code, which will be discussed later. The calculated and measured values are observed to agree well. Among these, ${ }^{137} \mathrm{Cs}$ is a typical FP nuclide that also appeared in Figure 1 ; however, ${ }^{134} \mathrm{Cs}$ exhibits completely different characteristics. The cumulative yield of ${ }^{134} \mathrm{Cs}$ from the ${ }^{235} \mathrm{U}$ thermal neutron fission is $7 \times 10^{-6} \%$, which is substantially equal to none. In truth, this isotope was generated by ${ }^{133} \mathrm{Cs}$ (cumulative yield 6.7\%), which was accumulated as the terminal stable isotope of the $\beta$-decay chain in the mass chain of $\mathrm{A}=133$ while the nuclear reactor was in operation, capturing the neutrons in the reactor. ${ }^{134} \mathrm{Cs}$ is generated as though "waking a sleeping dog," and it increases the FP decay heat by several dozens in percentage with 1-4 years of cooling time. There are several other nuclides that behave in a similar

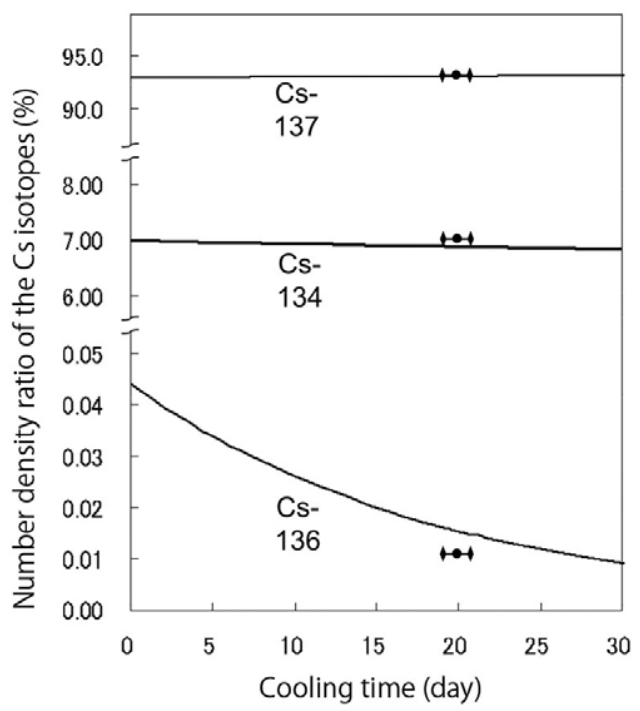

Figure 3 The Cs isotope number density ratio of the stagnated water in unit 2 turbine building (calculated by ORIGEN2/ORLIBJ 33)

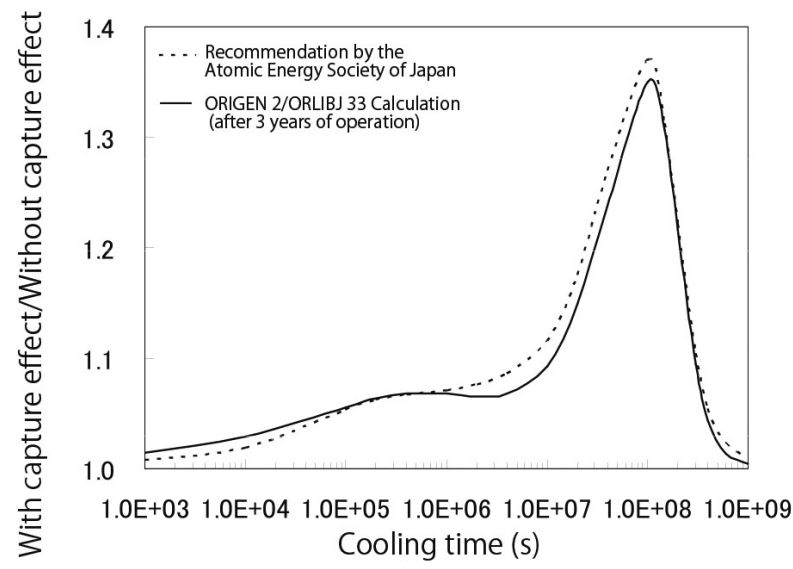

Figure 4 Neutron capture effect in the FP decay heat of ${ }^{235} \mathrm{U}$ 
manner. This effect can be referred to as the neutron capture effect. The large peak that appears at an approximate cooling time of $10^{8}$ s (approximately 3 years), depicted in Figure 4, can be attributed to ${ }^{134} \mathrm{Cs}$. This is observed to increase the decay heat by more than $30 \%$.

Table 1 presents the top ten nuclides that contribute to the FP decay heat of ${ }^{235} \mathrm{U}$ at Units 1 to 3 of the Fukushima Daiichi Nuclear Power Plant at the point of publication of this study (scheduled for August 1), which is approximately 140 days since the reactor shutdown (March 11, 2011). These nuclides correspond to the top ten nuclides of the sum of equation (1). Among them, only four types of nuclides, namely ${ }^{144} \mathrm{Pr},{ }^{95} \mathrm{Nb},{ }^{106} \mathrm{Rh}$, and ${ }^{95} \mathrm{Zr}$, produce $76 \%$ of the ${ }^{235} \mathrm{U}$ FP decay heat; further, the sum of the heats of all ten nuclides contribute to $96 \%$ of the heat. Note that the half-life of ${ }^{144} \mathrm{Pr}$, which is on the top of the list, is only $17.3 \mathrm{~min}$. A nuclide with such a short half-life continues to exhibit an effect even 5 months after the reactor shutdown because ${ }^{144} \mathrm{Ce}$, which has a long half-life of 285 days, is located immediately before ${ }^{144} \mathrm{Pr}$ in the mass chain having a mass number of 144 , which delays the generation of ${ }^{144} \mathrm{Pr}$.

Table 1 FP nuclides with largest contribution to the decay heat of ${ }^{235} \mathrm{U}$ (after 140 days of cooling)

\begin{tabular}{ccc}
\hline Ranking & Nuclide & Contribution $(\%)$ \\
\hline 1 & ${ }^{144} \mathrm{Pr}$ & 34.0 \\
2 & ${ }^{95} \mathrm{Nb}$ & 17.8 \\
3 & ${ }^{106} \mathrm{Rh}$ & 13.7 \\
4 & ${ }^{95} \mathrm{Zr}$ & 10.1 \\
5 & ${ }^{91} \mathrm{Y}$ & 4.9 \\
6 & ${ }^{134} \mathrm{Cs}$ & 3.7 \\
7 & ${ }^{144} \mathrm{Ce}$ & 3.0 \\
8 & ${ }^{89} \mathrm{Sr}$ & 2.8 \\
9 & ${ }^{103} \mathrm{Ru}$ & 2.0 \\
10 & ${ }^{90} \mathrm{Y}$ & 2.0 \\
\hline
\end{tabular}

\section{Actinide Decay Heat}

\section{Generation of Plutonium}

Even in case of a light-water reactor, the neutron capture reaction of ${ }^{238} \mathrm{U}$ continues while the uranium fuel is burning. The generated ${ }^{239} \mathrm{U}$ becomes ${ }^{239} \mathrm{Pu}$ after two steps of $\beta$-decay are completed in the following manner.

$$
{ }^{238} \mathrm{U}(n, \gamma){ }^{239} \mathrm{U}(23.5 \mathrm{~min}) \rightarrow{ }^{239} \mathrm{~Np}(2.36 \text { day }) \rightarrow{ }^{239} \mathrm{Pu}
$$

The times attached to both the nuclides denote their half-lives. Because these two $\beta$-decays are accompanied by a time delay, it is considered to be a part of the decay heat. The decay heat generated by this process can be referred to as U-Np decay heat to differentiate it from the MA decay heat that will be discussed in the subsequent section.

\section{Minor Actinide Decay Heat}

Even with a light-water reactor, MAs, including ${ }^{238} \mathrm{Pu}$, neptunium, americium, and curium, 


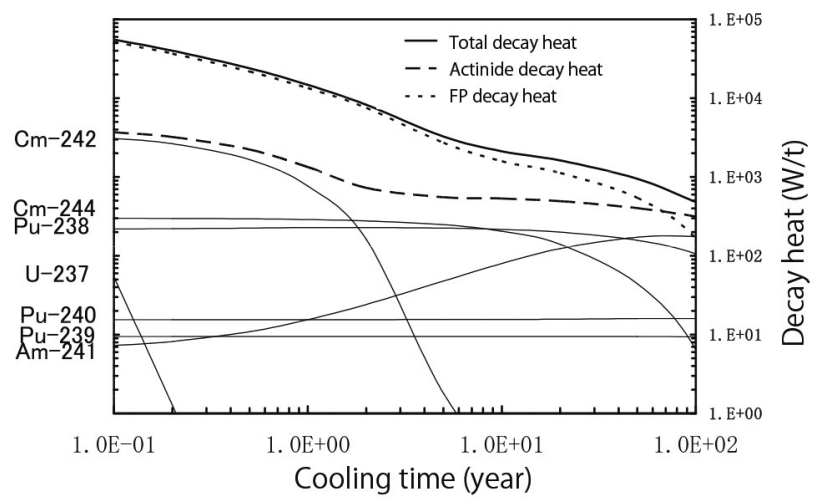

Figure 5 FP and actinide decay heats of uranium fuel after the shutdown of the operation

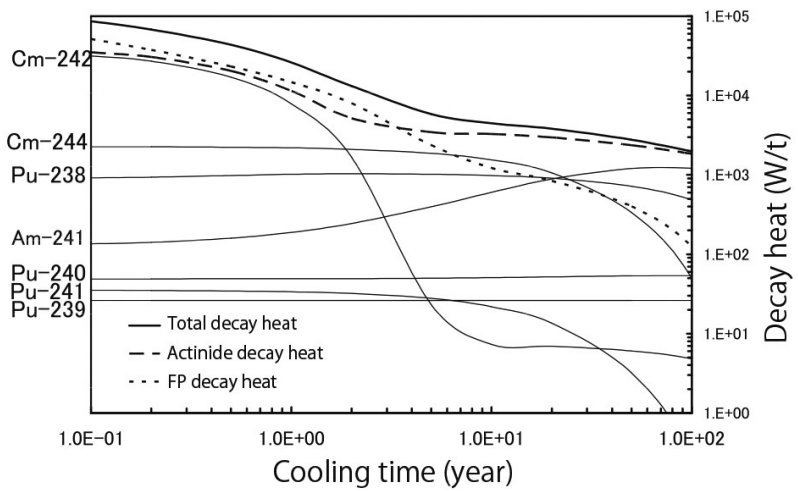

Figure 6 FP and actinide decay heats of MOX fuel after the shutdown of the operation

are accumulated after a long period of operation, and the MA decay heat that accompanies either the $\alpha$ - or $\beta$-decay of these nuclides can no longer be ignored. Figures 5 and $\mathbf{6}$ depict the contents of the FP and MA decay heats of uranium fuel decay heat and MOX fuel decay heat, respectively. As mentioned in the previous section, the U-Np decay heat is not included in these figures.

In case of the spent uranium fuel, the FP decay heat is observed to be dominant until a few years of cooling time, and the actinide decay heat is observed to decrease by approximately one decade. However, their positions in terms of size are reversed after a little less than a century of cooling time. In case of light-water reactor MOX fuel, their difference is observed to be small from the beginning; further, they become approximately identical after a few months of cooling time. The actinide decay heat is observed to become dominant after a few years.

\section{Calculation/Evaluation of the Decay Heat}

This chapter discusses the standard methods used to calculate/evaluate the decay heat. 


\section{Recommendations by Public Organizations}

(a) Recommendation by the Atomic Energy Society of Japan (AESJ) ${ }^{2)}$ : This is the recommendation by the "Nuclear reactor decay heat standard" special research committee of AESJ. The FP decay heat after instantaneous irradiation is expressed as an exponential polynomial (33 terms) with respect to the cooling time, $t$. The $66(33 \times 2)$ constant values that appear in the equation are assigned to each fuel nuclide and provided in reference 3 ). The decay heat after a given time of the operation with constant power can be obtained by integrating the decay heat of instantaneous irradiation with respect to time $t$; however, the result of this integration also becomes a simple exponential polynomial. Thus, it can be easily calculated, for example by using EXCEL. This is one of the advantages of the use of an exponential polynomial. For the neutron capture effect discussed in Section II-4, a correction factor is given, whereas an evaluation equation is given for the U-Np decay heat discussed in III-1. Furthermore, the MA decay heat must be separately calculated.

(b) Recommendation by the American Nuclear Society (ANS) ${ }^{4}$ : This is the result of consideration and evaluation of the summation result and the nuclear-fuel-sample irradiation experiment result by the ANS 5.1 working group of the ANS Standard Committee. The FP decay heat curve after instantaneous irradiation is expressed through exponential polynomials having 23 terms. This recommendation is reviewed and revised every few years and is well maintained. The treatment of the neutron capture effect, the U-Np decay heat, and the MA decay heat is the same as in the case (a) above.

\section{Appropriate Usage of the Summation Code and Attached Library}

(a) Usage of the OREGEN2 Code ${ }^{5}$ : The OREGEN2 code is extensively used worldwide because it is easy to use and highly useful owing to its clear input and comprehensive output. However, the calculation result may be altered because of the nuclear data library. The recommended usage of ORLJBJ-33 ${ }^{6}$ ) is based on the JENDL 3.3 nuclear data library, which has already been evaluated in Japan, and the JNDC FP decay data library ${ }^{1}$. Regarding the FP decay heat, the recommendation by AESJ discussed in IV-1 can be recreated by strictly matching the calculation condition using ORLJBJ-33. The MA decay heat, which cannot be easily evaluated using IV-1(a) and (b) methods, naturally enters the calculation. Additionally, during the late phase of burning the uranium fuel, the fission heat of plutonium becomes $30 \%-40 \%$ of the entire nuclear heat. Therefore, the situation for FP decay heat is observed to be different from the time when only ${ }^{235} \mathrm{U}$ contributed to the nuclear fission. OREGEN2 is also able to easily reflect this effect in the calculation.

\section{Measurement of the Decay Heat}

There are many data sets of directly measured decay heat. Typical examples include the measurements by Akiyama et al. of Tokyo University and by Dickens et al. of Oak Ridge National Laboratory in the USA. Both groups irradiated pure samples of ${ }^{235} \mathrm{U},{ }^{239} \mathrm{Pu}$, and so on, using neutrons in the experimental reactor core and removed; further, they measured the $\beta$-ray components using a plastic scintillator and the $\gamma$-ray components using a NaI (TI) scintillator and integrated them with energy to obtain the $\beta$ - and $\gamma$-ray components of the FP decay heat. These two sets of measured results, converted to those for time $t$ after a fission burst, were substantially referred to and reflected while preparing the recommendations by public 
organizations discussed in IV-1. Note that the Japanese and American recommendations are very similar, as depicted in Figure 2. These two recommendations were both independently evaluated. The fact that both were similar enhances the reliability of the recommendations. However, it must be remembered that both the recommendations are based on the same measurements, two of which were described above as examples. Therefore there exists a possibility that both may suffer from the same systematic error that originated from the measurements as part of their basis. Unfortunately, such sample-irradiation experimental data only exist up to $6 \mathrm{~h}$ of cooling time (measurement conducted by the Tokyo University). One of the few measurements required to ensure long-term cooling is the measurement at the fast experimental reactor, "Joyo," conducted by Aoyama et al. They sealed the reactor fuel assembly in a specially constructed calorimeter and directly measured the decay heat during 24-258 days after completing the burning. However, despite the detailed analytical calculation based on the JENDL 3.2 and JNDC FP decay data library, the measurement and calculation were not observed to satisfactorily agree. It is reported that the calculation exhibits an underestimation by approximately $10 \%^{7)}$. Regarding the calculated value of the decay heat, it should be understood that, after long-term cooling, a prediction error of approximately $10 \%$ should be expected for a while. However, the problem that the decay heat estimation of long-term cooling is excessively dependent on summation remains owing to the lack of actual measurement data.

\section{Conclusions}

Calculating the decay heat of a nuclear reactor is relatively easy. Additionally, the reliability of this calculation is guaranteed to a certain extent, and the error evaluation results are published. While evaluating or calculating the decay heat, it is necessary to carefully examine the calculation methods and verify whether they achieve the required accuracy. Are MA components included? How is the neutron capture effect of FP treated? In some cases, noble gas components, such as $\mathrm{Kr}$ or $\mathrm{Xe}$, or components that easily dissolve in water, such as I or Cs, may have already escaped from the fuel. Hence, ascertaining the condition of the nuclear reactor after shutdown is necessary while performing the evaluation.

Finally, I am deeply grateful to Mr. Hiroto Matsumoto, a 2nd year student of the master's course of the Tokyo City University who dedicated his time and cooperated in preparing this article.

\section{References}

1) Tasaka K. et al., JNDC Nuclear Data Library of Fission Products, JAERI 1287, 1983, Japan Atomic Energy Agency.

2) Special research committee of AESJ - Nuclear Reactor Decay Heat Standard, Nuclear Reactor Decay Heat and Recommendation for It, 1989, Atomic Energy Society of Japan. [in Japanese]

3) Special research committee of AESJ - Nuclear Reactor Decay Heat Standard, Decay Heat Recommendation and How to Use It, 1990, Atomic Energy Society of Japan. [in Japanese]; English translation available: Tasaka K. et al, JAERI-M 91-034, 1991, Japan Atomic Energy Agency.

4) American National Standard. Decay Heat Power in Light Water Reactors, 2005, ANSI/ANS-5.1-2005, American Nuclear Society.

5) Croff A.G., Nucl. Sci. Eng., 62, 1980, pp.335-250.

6) Katakura J. et al., JAERI-Data/Code 2002-21, 2002, Japan Atomic Energy Agency. [in Japanese]

7) Aoyama T. et al. Nihon-Genshiryoku-Gakkai Shi (J. At. Energy Soc. Jpn), 41, 1999, pp. 946-953. [in Japanese] 


\title{
Long-term Impact on the Marine Environment
}

\author{
-Simulation of the Marine Dispersion of Released \\ Radionuclides from Fukushima-Daiichi Nuclear Power \\ Plant and Estimation of Internal Dose from Marine \\ Products-
}

\author{
Japan Atomic Energy Agency, Masanao Nakano
}

\begin{abstract}
As a result of the accident at Fukushima Daiichi Nuclear Power Plant caused by the 2011 Off the Pacific Coast of Tohoku Earthquake and tsunami on March 11, radioactive materials were released into the environment. A global scale calculation of the long-term diffusion of radioactive materials in ocean using long-term assessment model for radioactivity in the oceans (LAMER), which is a calculation code developed by Japan Atomic Energy Agency, was conducted to estimate their concentration in seawater and the exposure dose caused by seafood ingestion.

When we postulate that $8.45 \mathrm{PBq}$ of ${ }^{137} \mathrm{Cs}$ has been released, the calculation of the ${ }^{137} \mathrm{Cs}$ concentration in seawater after April 2012 would be a maximum of $\sim 23$ $\mathrm{Bq} / \mathrm{m}^{3}$, which is $\sim 14$ times more than the concentration originated from atmospheric nuclear tests before the accident. The highest concentration continued to decrease after that point of time, and it will be of the same level as the concentration originated from the nuclear tests by 2023 . Moreover, internal exposure from ${ }^{131} \mathrm{I},{ }^{134} \mathrm{Cs}$, and ${ }^{137} \mathrm{Cs}$ caused by seafood ingestion was calculated to be a maximum of $1.8 \mu \mathrm{Sv} / \mathrm{y}$, which is approximately equal to the past yearly dose derived from the atmospheric nuclear tests.
\end{abstract}

\section{Introduction}

Fukushima Daiichi Nuclear Power Plant of Tokyo Electric Power Company Holdings, Inc. (TEPCO) suffered from a major tsunami caused by the 2011 Off the Pacific Coast of Tohoku Earthquake on March 11. This was followed by the release of radioactive materials into the environment, causing concerns about their effects on the environment.

Although the accident is yet to be resolved, this study will present the overview of the state of ocean monitoring, estimation of the amount of release into the ocean, and the state of marine diffusion simulation.

In particular, regarding the prediction of long-term environmental impacts in the future,

DOI : 10.15669/fukushimainsights.Vol.1.96

(C) 2021 Atomic Energy Society of Japan. All rights reserved.

Originally published in Journal of the Atomic Energy Society of Japan (ISSN 1882-2606), Vol. 53, No. 8, p. 559-563 (2011)

in Japanese. (Japanese version accepted: June 13, 2011) 
we conducted the global scale year-to-year marine diffusion calculation as well as estimated the concentration of radioactivity in seawater and the exposure dose caused by seafood ingestion using long-term assessment model for radioactivity in the oceans (LAMER) ${ }^{1}$, which is a calculation code developed by Japan Atomic Energy Agency (JAEA).

\section{Implementation Status of Sea Monitoring}

\section{Sea Monitoring}

The Ministry of Education, Culture, Sports, Science, and Technology and TEPCO have been sampling and analyzing seawater since March 21, 2011. TEPCO's facility has contributed to the detection of the following nuclides: ${ }^{58} \mathrm{Co},{ }^{99 \mathrm{~m}} \mathrm{Tc},{ }^{89} \mathrm{Sr},{ }^{90} \mathrm{Sr},{ }^{131} \mathrm{I},{ }^{132} \mathrm{I},{ }^{134} \mathrm{Cs},{ }^{136} \mathrm{Cs},{ }^{137} \mathrm{Cs},{ }^{140} \mathrm{Ba}$, and ${ }^{140} \mathrm{La}$. Among them, the concentrations of ${ }^{131} \mathrm{I},{ }^{134} \mathrm{Cs}$, and ${ }^{137} \mathrm{Cs}$ were relatively higher than the concentration limit provided by the dose notification in Table 1. Table 1 shows the highest concentration of radioactive materials in seawater obtained until the end of May. The concentration exhibited a tendency to decrease as the distance from the power plant increased. The ${ }^{137} \mathrm{Cs} /{ }^{131} \mathrm{I}$ ratio of the seawater concentration decreased further it went from the power plant. As the distribution coefficients at the coast (the ratio of concentration in seabed soil to that of seawater in equilibrium state) are 4,000 and 70 for cesium and iodine respectively, Cesium is selectively transferred to the seabed soil compared to iodine. Further, the ${ }^{137} \mathrm{Cs} /{ }^{131} \mathrm{I}$ ratio in the seawater concentration was increasing daily, resulting in the physical decay of ${ }^{131} \mathrm{I}$, whose half-life is eight days, thereby decreasing its concentration.

Table 1 Highest concentration of radioactive materials in seawater

\begin{tabular}{|c|c|c|c|}
\hline & & & Unit: $\mathrm{Bq} / \mathrm{cm}$ \\
\hline Location & ${ }^{131} \mathrm{I}$ & ${ }^{134} \mathrm{Cs}$ & ${ }^{137} \mathrm{Cs}$ \\
\hline $\begin{array}{l}\text { Near the Power Plant } \\
\text { (Excluding the extreme } \\
\text { proximity) }\end{array}$ & $\begin{array}{l}\sim 180 \text { (Near 1F South Water } \\
\text { Canal, March 30) }\end{array}$ & $\begin{array}{l}\sim 67 \text { ( North of Water Canal } \\
\text { of } 1 \text { F } 5-6, \text { April 7) }\end{array}$ & $\begin{array}{l}\sim 68 \text { (North of Water Canal } \\
\text { of } 1 \text { F } 5-6, \text { April } 7 \text { ) }\end{array}$ \\
\hline Coastal Area & $\begin{array}{l}\text { 3.8 (Near 2F North Water } \\
\text { Canal, March 28) }\end{array}$ & $\begin{array}{l}\sim 1.4 \text { (2F Near Iwazawa } \\
\text { Beach, April 5) }\end{array}$ & $\begin{array}{l}\sim 1.4 \text { (2F Near Iwazawa } \\
\text { Beach, April 5) }\end{array}$ \\
\hline $15 \mathrm{~km}$ off the Coast & $\begin{array}{l}\sim 0.18 \text { (15 km off Iwazawa } \\
\text { Beach, April 5) }\end{array}$ & $\begin{array}{l}\sim 0.31 \text { (15 km off Iwazawa } \\
\text { Beach, April 5) }\end{array}$ & $\begin{array}{l}\sim 0.32 \text { (15 km off Iwazawa } \\
\text { Beach, April 5) }\end{array}$ \\
\hline $30 \mathrm{~km}$ off the Coast & $\sim 0.161$ (Plant 4, April 15) & $\sim 0.166$ (Plant 4, April 15) & $\begin{array}{l}\sim 0.186 \text { (Location 4, April } \\
15 \text { ) }\end{array}$ \\
\hline $\begin{array}{l}\text { Concentration Limit in } \\
\text { Water defined by the } \\
\text { Notification }\end{array}$ & 0.04 & 0.06 & 0.09 \\
\hline $\begin{array}{l}\text { Concentration before the } \\
\text { Accident }\end{array}$ & Not detected & Not detected & $\begin{array}{l}0.0000017 \text { (2009 Average, } \\
\text { Off the coast of Fukushima) }\end{array}$ \\
\hline
\end{tabular}

\section{Marine Dispersion Simulation}

As of the end of May, the Ministry of Education, Culture, Sports, Science, and Technology (Japan Agency for Marine-Earth Science and Technology) and a French research group conducted dispersion simulation focused on the coastal area and published the results of their calculations on the Internet. Although there is a difference in the behavior at the initial stage of release, both are expected to disperse while moving in northeast to eastward direction. 


\section{Estimation of the Amount of Release into the Ocean}

\section{(1) Deposition from atmospheric release to sea surface}

After being struck by the tsunami, radioactive materials were released into the atmosphere from the power plant via venting and hydrogen explosion. According to the data released by Nuclear and Industrial Safety Agency (NISA) of the Ministry of Economy, Trade and Industry on June 6, the amounts released to the atmosphere between March 11 and March 16 were 160,18 , and $15 \mathrm{PBq}$ for ${ }^{131} \mathrm{I},{ }^{134} \mathrm{Cs}$, and ${ }^{137} \mathrm{Cs}$, respectively. Moreover, according to the distribution map of the estimates of intrathyroidal exposure dose by System for Prediction of Environmental Emergency Dose Information (SPEEDI) published on March 23 by Nuclear Safety Commission, the ratio of distribution of dose to the seaward direction and landward direction was 45:55. From these data, we inferred that 50\% of the total released amount to the atmosphere moved to the ocean and 80,9 , and $7.5 \mathrm{PBq}$ of ${ }^{131} \mathrm{I},{ }^{134} \mathrm{Cs}$ and ${ }^{137} \mathrm{Cs}$, respectively, deposited on the sea surface. Although quantitatively small, the release into the atmosphere continued even after March 16, albeit in small amounts.

\section{(2) Highly Contaminated Water}

According to the NISA report on April 2, 2011, it was found that highly contaminated water that exceeds $1 \mathrm{~Sv} / \mathrm{h}$ in the pit near the water intake of Unit 2 on the same day and it was being released into the sea. Moreover, extremely high concentrations of the inflow water to the Unit 2 screen were collected that day: $5.4 \times 10^{6}, 1.8 \times 10^{6}$, and $1.8 \times 10^{6} \mathrm{~Bq} / \mathrm{cm}^{3}$ for ${ }^{131} \mathrm{I},{ }^{134} \mathrm{Cs}$, and ${ }^{137} \mathrm{Cs}$, respectively. According to the TEPCO report on April 21, it was estimated that the release during the five days from April 1 to April 6 were 2.8, 0.94, and $0.94 \mathrm{PBq}$ for ${ }^{131} \mathrm{I},{ }^{134} \mathrm{Cs}$, and ${ }^{137} \mathrm{Cs}$, respectively.

Furthermore, according to the TEPCO report on May 21, $250 \mathrm{~m}^{3}$ of high-concentration water containing $3.4 \times 10^{3}, 3.7 \times 10^{4}$, and $3.9 \times 10^{4} \mathrm{~Bq} / \mathrm{cm}^{3}$ of ${ }^{131} \mathrm{I},{ }^{134} \mathrm{Cs}$, and ${ }^{137} \mathrm{Cs}$, respectively, was released from Unit 3 between May 11 and May 12. The released amount of ${ }^{131} \mathrm{I},{ }^{134} \mathrm{Cs}$, and ${ }^{137} \mathrm{Cs}$ was $0.85 \mathrm{TBq}, 9.3$, and $9.8 \mathrm{TBq}$, respectively.

Meanwhile, judging from the fact that around $100 \mathrm{~Bq} / \mathrm{cm}^{3}$ of ${ }^{131} \mathrm{I}$ had been continuously detected from the seawater collected near the water discharge port after March 25, there was a possibility that another highly contaminated water had been leaking into the sea during late March. Note that the concentration in the seawater continued to decrease after April 7 and April 8. By April 9, the concentrations of ${ }^{131} \mathrm{I}$ and ${ }^{137} \mathrm{Cs}$ were $\sim 10 \mathrm{~Bq} / \mathrm{cm}^{3}$. By the end of April, ${ }^{137} \mathrm{Cs}$ was $\sim 0.1 \mathrm{~Bq} / \mathrm{cm}^{3}$. However, there was no significant decrease in ${ }^{137} \mathrm{Cs}$ concentration in May.

(3) Low-Level Retained Water, etc.

According to the reports by NISA, between April 4 and April 10, 9,070 tons of low-level retained water was released from the integrated waste processing facility and $\sim 1,323$ tons of low-level ground water was released from the sub drains of Unit 5 and Unit 6 . The total released amount of low-level retained water was estimated to be $150 \mathrm{GBq}$. Compared to sections II-3 (1) and (2), it was $\sim 1 / 670,000$.

\section{Total Amount of Release into the Ocean after this Accident}

As of the end of May, there are three routes for the release of ${ }^{131} \mathrm{I},{ }^{134} \mathrm{Cs}$, and ${ }^{137} \mathrm{Cs}$ into the ocean as a result of this accident, which are listed on sections II-3 (1)-(3). The total of these is shown in Table 2. 
Table 2 Estimated amount of release into the ocean (As of June 6, 2011)

\begin{tabular}{lccc} 
& & & Unit: PBq \\
\hline Route & ${ }^{131} \mathrm{I}$ & ${ }^{134} \mathrm{Cs}$ & \\
\hline $\begin{array}{l}\text { (1) Released into atmosphere and deposited on sea surface. } \\
\text { (March 11-16) }\end{array}$ & 80 & 9.0 & 0.94 \\
(May 10-11) & 2.8 & 0.94 & 0.0098 \\
(2) High concentration contaminated water. (April 1-6) & 0.00085 & 0.0093 & 0.000042 \\
(3) Low level retained water, etc. (April 4-10) & 0.000066 & 0.000042 & 8.45 \\
\hline Total & 82.8 & 9.95 & \\
\hline
\end{tabular}

\section{Long-Term Marine Dispersion Simulation}

\section{Calculation Method}

\section{(1) Calculation Model}

The purpose of this prediction is to grasp the comprehensive view of the global scale diffusion in seawater after more than one year. As its purpose is not to predict the dispersion in the coastal area, LAMER wide-area model was used. The calculation conditions are listed in Table 3. The annual average of three-dimensional velocity field was obtained using a diagnostic method that uses ocean general circulation model (a method of restoring observation values of water temperature and salinity to successively calculated values). In the calculation of the concentration of radioactive materials in sea water, a particle diffusion model (a large number (150,000 particles for this calculation) of particles hypothetically having radioactive substances are advected in the flow velocity field and are diffused by random numbers) was used. Based on the result of seawater monitoring in II-1, the target nuclides were ${ }^{131} \mathrm{I},{ }^{134} \mathrm{Cs}$, and ${ }^{137} \mathrm{Cs}$.

Table 3 Calculation conditions for LAMER wide-area model

\begin{tabular}{|c|c|c|}
\hline Model & Item & Condition \\
\hline \multirow{2}{*}{$\begin{array}{l}\text { Ocean General } \\
\text { Circulation Model }\end{array}$} & Grid size & $2^{\circ}$ on latitude and longitude direction; 15 layers vertically. \\
\hline & $\begin{array}{l}\text { Water temperature/salinity } \\
\text { content/wind stress }\end{array}$ & Annual averaged data. \\
\hline \multirow{5}{*}{$\begin{array}{l}\text { Particle Diffusion } \\
\text { Model }^{1)}\end{array}$} & Surface mixed layer & $100-300 \mathrm{~m}$ depending on the latitude. \\
\hline & & $\left(200 \mathrm{~m}\right.$ at $\left.40^{\circ} \mathrm{N}\right)$ \\
\hline & Horizontal diffusion coefficient & $1.3 \times 10^{4} \mathrm{~m}^{2} / \mathrm{s}$ \\
\hline & Vertical diffusion coefficient & $3 \times 10^{-5} \mathrm{~m}^{2} / \mathrm{s}$ \\
\hline & Others & $\begin{array}{l}\text { Sedimentation on seabed, re-flotation from the seabed, and } \\
\text { adsorption/desorption are not considered. }\end{array}$ \\
\hline Overall Model & $\begin{array}{l}\text { Verification of validity using } \\
\text { atmospheric nuclear test data. }\end{array}$ & $\begin{array}{l}\text { In the case of }{ }^{137} \mathrm{Cs}, 82 \% \text { and } 93 \% \text { of calculated values } \\
\text { were included within } 1 / 2-2 \text { times and } 1 / 5-5 \text { times of the } \\
\text { observed values, respectively. Thus, when the calculated } \\
\text { value is multiplied by the safety margin (twice), } 90 \% \text { of the } \\
\text { observed value will be included within the calculated value. }\end{array}$ \\
\hline
\end{tabular}


In the coastal areas, cesium has a slightly larger distribution coefficient than in the ocean. Iodine and cesium dissolve relatively easily in seawater compared to heavy metal elements ${ }^{2}$. Therefore, scavenging process (process where radioactive materials in seawater adhere to suspended particles and are carried to deep sea due to gravity) and other processes were not considered. In the coastal areas, cesium may deposit and its concentration in seawater may increase in the future owing to re-suspension and dissolution. For this calculation, ${ }^{137} \mathrm{Cs}$, which is an artificial radioactive nuclide and has a long half-life, was chosen as the representative nuclide. The calculation timescale was set to 30 years because it represents the half-life of ${ }^{137} \mathrm{Cs}$. The concentrations of ${ }^{131} \mathrm{I}$ and ${ }^{134} \mathrm{Cs}$ in seawater were adjusted by considering their released amounts and physical decay. The details of the diffusion model are given in a previous report ${ }^{1)}$.

\section{(2) Amount Input into the 0cean}

From the results of the estimation of the amount of release into the ocean in section II-3, it was assumed that $82.8,9.95$, and $8.45 \mathrm{PBq}$ of ${ }^{131} \mathrm{I},{ }^{134} \mathrm{Cs}$ and ${ }^{137} \mathrm{Cs}$, respectively, were released to the ocean at once on April 1, 2011 off the coast of Fukushima Daiichi Nuclear Power Plant and used for the calculation. This ${ }^{137} \mathrm{Cs}$ input corresponds to $\sim 0.9 \%$ of ${ }^{137} \mathrm{Cs}$ that released onto the earth by the atmospheric nuclear tests until now $(948 \mathrm{PBq})^{4)}$.

In the real atmospheric route, the deposition on the sea surface occurs after the transportation to the Pacific by the atmosphere. In that case, the diffusion speed is considered to be faster than the result of this calculation. The horizontal distribution of the amount of descent from the atmosphere was not considered at this stage, and all the radioactive materials from the atmosphere were assumed to deposit on the place of direct input on the sea and treated as contaminated water.

\section{(3) Calculation of Internal Exposure Dose Caused by Seafood Ingestion}

Table 4 shows the concentration factor, ingestion amount and effective dose coefficient that are necessary for calculating the internal exposure dose caused by seafood ingestion.

Moreover, the seawater concentration of the part with the highest concentration in the ocean surface layer discussed later was used as the seawater concentration. The calculation of the concentration and dose of the period less than one year after the release was not considered because this model uses annual average field.

Table 4 Concentration factor, ingestion amount, and effective dose coefficient

\begin{tabular}{lcccc} 
& \multicolumn{2}{c}{ Daily Consumption $(\mathrm{g} / \mathrm{d})^{5)}$} & \multicolumn{2}{c}{ Concentration Factor $\left(\mathrm{Bq} / \mathrm{kg}\right.$ Fresh per Bq/kg Water ${ }^{2)}$} \\
\cline { 3 - 5 } & & ${ }^{131} \mathrm{I}$ & ${ }^{134} \mathrm{Cs}$ & ${ }^{137} \mathrm{Cs}$ \\
\hline Fish & 64 & 9 & 100 & 100 \\
Crustacean & 5.4 & 3 & 50 & 50 \\
Cephalopod & 5.5 & $-(3)$ & 9 & 9 \\
Shellfish & 3.5 & 10 & 60 & 60 \\
Seaweed & 10 & 10000 & 50 & 50 \\
\hline Effective Dose Coefficient $(\mathrm{Sv} / \mathrm{Bq})$ & & $2.2 \mathrm{E}-08$ & $1.9 \mathrm{E}-08$ & $1.3 \mathrm{E}-08$ \\
\hline
\end{tabular}

\section{Calculation Results and Discussion}

(1) Concentration Distribution in Seawater

Figure 1 shows the concentration distribution of ${ }^{137} \mathrm{Cs}$ for 30 years in the surface layer of 

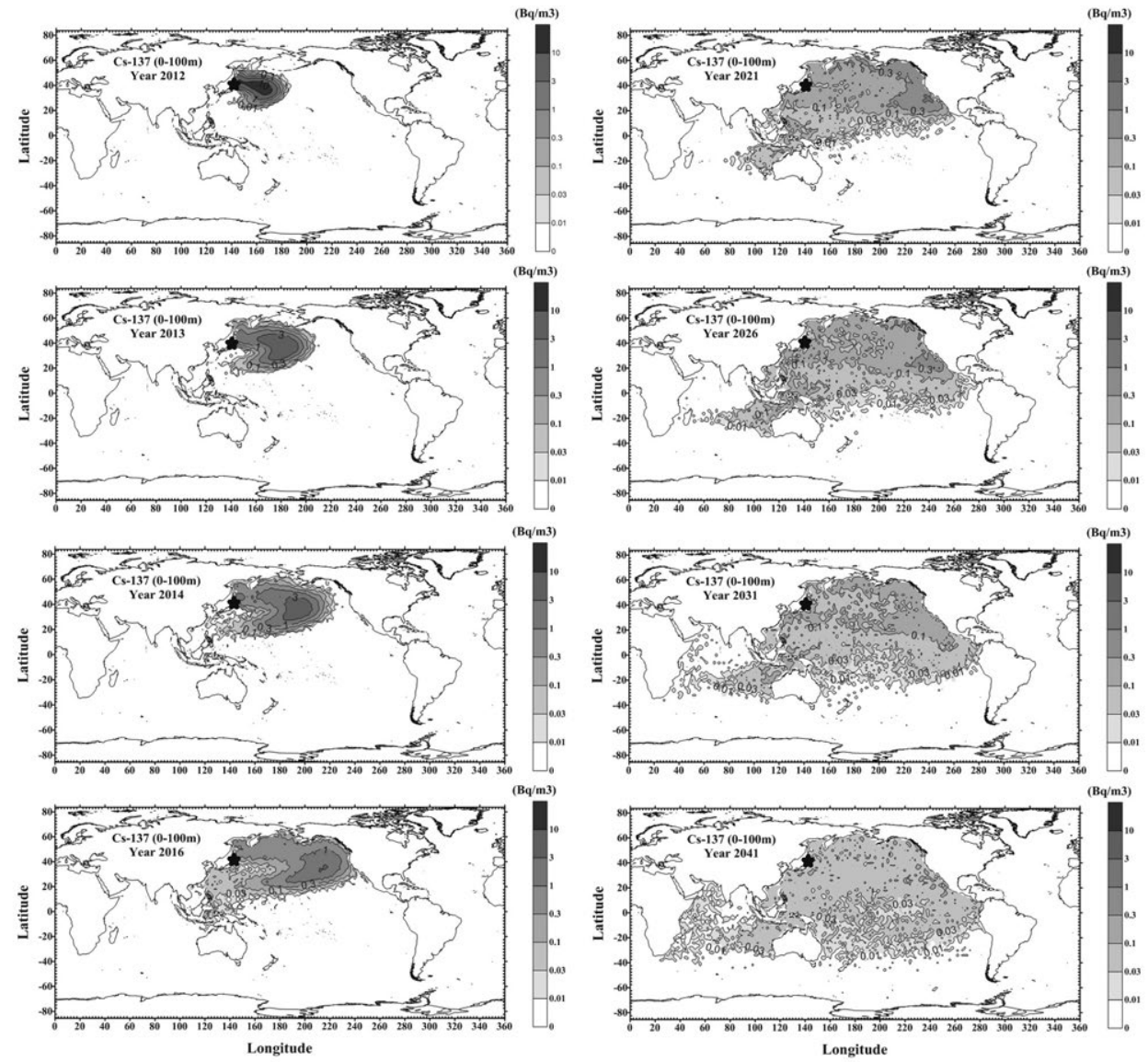

Figure 1 Concentration distribution of ${ }^{137} \mathrm{Cs}$ in the seawater surface layer 1-30 years after the release into the ocean (from 2012 (upper left) to 2041 (lower right))

seawater (0-100 m) on April 1 since its release (2012-2041). The ${ }^{137}$ Cs released off the coast of Fukushima Prefecture moved eastward and was carried away by the Kuroshio Current. The part having the highest concentration in the entire ocean surface will reach the west coast of North America in 5 years (2016). Following the subsequent diffusion, the concentration in the entire North Pacific will become almost uniform in 20 years (2031) and will not show noticeable difference in concentration.

According to the slide published by IAEA on May 5, it was predicted that ${ }^{137} \mathrm{Cs}$ will reach North America in 1 to 2 years. However, according to LAMER, ${ }^{137} \mathrm{Cs}$ will take $3-5$ years to reach the west coast of North America because the apparent current is slow due to the smoothing of local currents by the horizontal resolution $\left(2^{\circ}\right)$ of the ocean general circulation model. Although there is a possibility that a part of the water mass that contains ${ }^{137} \mathrm{Cs}$ will reach the west coast of North America in $1-2$ years, most ${ }^{137} \mathrm{Cs}$ will require 3-5 years to reach there.

Figure 2 shows the yearly change of the highest concentration in the entire ocean since 2012. The highest concentration in the surface layer after 2012 was calculated to be $\sim 23$ $\mathrm{Bq} / \mathrm{m}^{3}$. In contrast, the average concentration of ${ }^{137} \mathrm{Cs}$ in the seawater originated from atmospheric nuclear tests collected off the coast of Fukushima Prefecture was $1.7 \mathrm{~Bq} / \mathrm{m}^{3}$ according to the significant 43 data obtained from the environmental radiation database ${ }^{6}$. Thus, the 


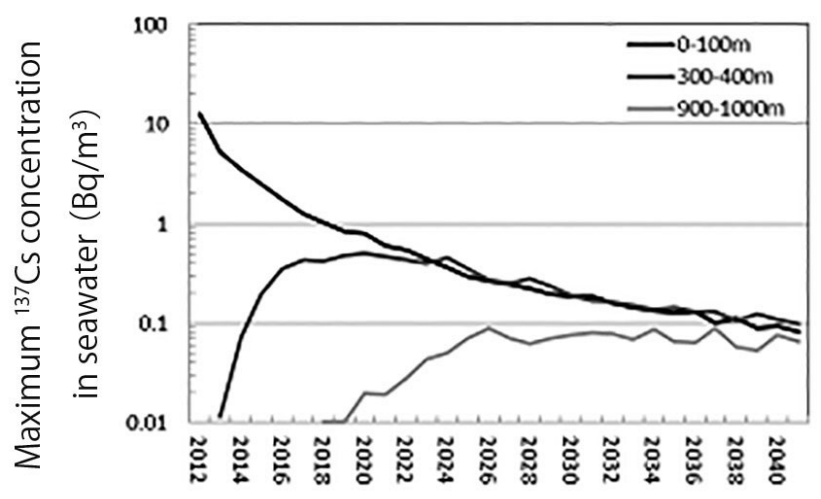

Figure 2 Chronological change of the highest concentration in the entire ocean

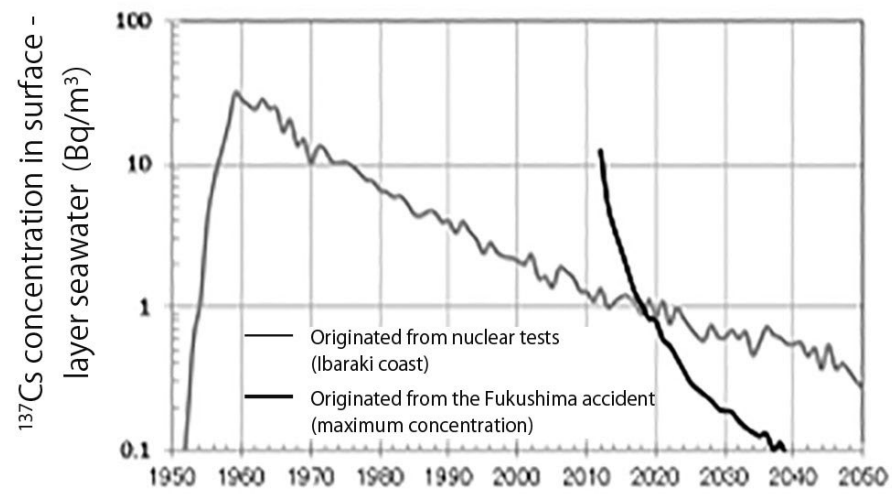

Figure 3 Comparison with the ${ }^{137} \mathrm{Cs}$ concentration in the surface of seawater originated from atmospheric nuclear tests

${ }^{137}$ Cs concentration from Fukushima as of April 2012 is $~ 14$ times that from the nuclear tests. Later, the highest concentration in the surface layer decreases. In 12 years (2023), the concentration will be $<1 \mathrm{~Bq} / \mathrm{m}^{3}$. At the same time, diffusion from the surface layer to the lower layers progresses. Therefore, the highest concentration of the layer at 300-400 m depth will slowly increase. Its concentration will be approximately similar to that of the surface layer in 10 years and then decrease, as was the case in the surface layer. At 900-1000 m, the concentration will slowly increase until 2026, and then change slightly. By 2041, after 30 years, all the highest concentrations from the surface layer to $1,000 \mathrm{~m}$ will be $\sim 0.2 \mathrm{~Bq} / \mathrm{m}^{3}$.

Figure 3 shows its comparison with the ${ }^{137} \mathrm{Cs}$ concentration calculation ${ }^{3)}$ in the seawater originated from atmospheric nuclear tests collected off the coast of Ibaraki. Although in $2012,{ }^{137} \mathrm{Cs}$ was $\sim 17$ times the concentration determined from the nuclear tests, it was about the same as the ${ }^{137} \mathrm{Cs}$ concentration determined from nuclear tests in around 1960 . The ${ }^{137} \mathrm{Cs}$ concentration from the accident decreases rapidly; it will decrease to about the same level by 2023 and to about half by 2031 .

Meanwhile, when the value obtained from dividing the input amount into the ocean $(\mathrm{Bq}$ input) by the highest concentration in the seawater $\left(\mathrm{Bq} / \mathrm{m}^{3}\right)$ is defined as the "minimum dilution rate," it becomes an index for indicating the minimum degree of dilution as it does not depend on the amount of release. Figure 4 shows the yearly change of the minimum dilution 
Table 5 Highest concentration in seawater of the entire ocean after one year

\begin{tabular}{lccc}
\hline & ${ }^{131} \mathrm{I}$ & ${ }^{134} \mathrm{Cs}$ & ${ }^{137} \mathrm{Cs}$ \\
\hline Maximum Concentration in Seawater $\left(\mathrm{Bq} / \mathrm{m}^{3}\right)$ & $4.7 \mathrm{E}-12$ & 20 & 23 \\
Concentration Limit of Water $\left(\mathrm{Bq} / \mathrm{m}^{3}\right)$ & 40000 & 60000 & 90000 \\
\hline
\end{tabular}

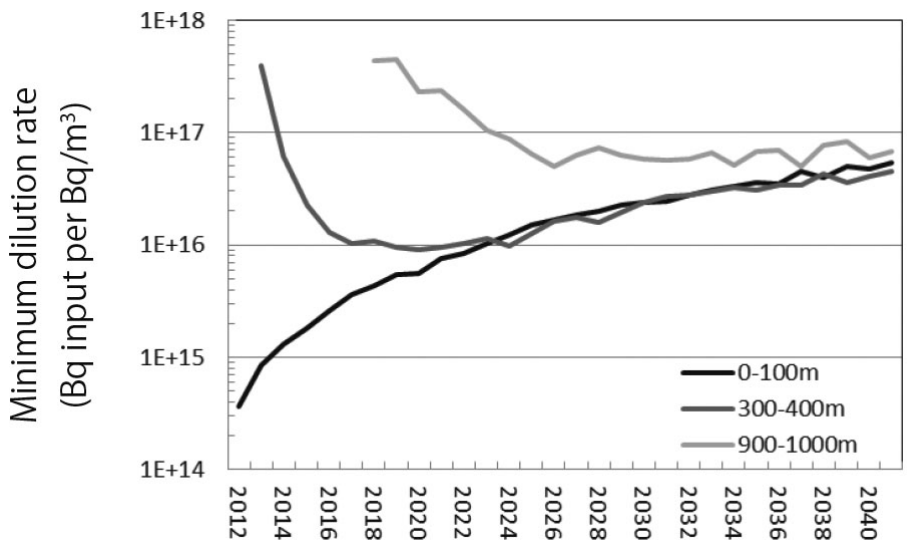

Figure 4 Chronological change of the minimum dilution rate in the entire ocean

rate. The minimum dilution rate in the surface layer is at its smallest level after one year at $\sim 3 \times 10^{14} \mathrm{~m}^{3}$. It continues to increase (dilute) after this point of time and becomes $\sim 5 \times 10^{16} \mathrm{~m}^{3}$ in 30 years. At deeper levels, ${ }^{137} \mathrm{Cs}$ initially has larger minimum dilution rate and it becomes approximately similar to that of the surface layer in 30 years.

The simulation result of the hypothetical release from Tokai reprocessing plant conducted in 2001 by Nakano et al. showed that when $6 \mathrm{TBq}$ of ${ }^{137} \mathrm{Cs}$, which is 100 times the yearly release limit of $55 \mathrm{GBq}$ stipulated in the reprocessing plants safety regulation, is hypothetically released, its maximum concentration is $<0.1 \mathrm{~Bq} / \mathrm{m}^{3}$ after one year. In this case, the minimum dilution rate is $>6 \times 10^{13} \mathrm{~m}^{3}$. The time was calculated by considering the horizontal diffusion coefficient obtained from literature, which was lower on the safety side than today $\left(2 \times 10^{3} \mathrm{~m}^{2} / \mathrm{s}\right)$; thus, its result was slightly smaller.

A realistic horizontal diffusion coefficient that matches the measurement was set later. ${ }^{3)}$ Then, release from Fukushima coast and Ibaraki coast after one year exhibit the minimum dilution rates. In other words, the highest concentration in relation to the unit release amount, displayed almost the same calculation result.

As discussed above, the highest concentration and the minimum dilution rate are numerical values taken from the place where the severest value in the world ocean is obtained at that time. Therefore, all other places have lower concentration and higher dilution rate. Table 5 shows the highest amount after one year obtained from the half-life adjustment of the calculation result of ${ }^{137} \mathrm{Cs}$ together with the concentration limit of water.

\section{(2) Internal Exposure Dose Caused by Seafood Ingestion}

Table 6 lists the internal exposure dose resulting from hypothetically eating only the seafood from the seawater that has the highest concentration of radioactive materials originated from Fukushima in the world (highest concentration shown in Table 5) for one year since April 2012. 
INSIGHTS CONCERNING THE FUKUSHIMA DAIICHI NUCLEAR ACCIDENT Vol. 1

Table 6 Internal exposure dose caused by seafood ingestion

\begin{tabular}{lcccc} 
& & & Unit: $\mu \mathrm{Sv} / \mathrm{y}$ \\
\hline Creature Type & ${ }^{131} \mathrm{I}$ & ${ }^{134} \mathrm{Cs}$ & ${ }^{137} \mathrm{Cs}$ & Total \\
\hline Fish & $2.1 \mathrm{E}-14$ & 0.89 & 0.70 & 1.6 \\
Crustacean & $6.1 \mathrm{E}-16$ & 0.037 & 0.030 & 0.067 \\
Cephalopod & $6.2 \mathrm{E}-16$ & 0.0069 & 0.0054 & 0.012 \\
Shellfish & $1.3 \mathrm{E}-15$ & 0.029 & 0.023 & 0.052 \\
Seaweed & $3.7 \mathrm{E}-12$ & 0.069 & 0.055 & 0.12 \\
\hline Total & $3.8 \mathrm{E}-12$ & 1.0 & 0.82 & 1.8 \\
\hline
\end{tabular}

The internal exposure dose of the sum of all seafood is $3.8 \times 10^{-12}, 1.0$, and $0.82 \mu \mathrm{Sv}$ for ${ }^{131} \mathrm{I},{ }^{134} \mathrm{Cs}$, and ${ }^{137} \mathrm{Cs}$, respectively, and the total exposure dose was $1.8 \mu \mathrm{Sv}$. Considering the average internal exposure dose among Japanese caused by seafood ingestion originated from atmospheric nuclear tests was $\sim 1.7 \mu \mathrm{Sv} / \mathrm{y}$ between 1963 and 1973 when it was the highest ${ }^{8)}$, the hypothetical released amount of this incident will cause about the same amount of internal exposure caused by atmospheric nuclear tests even at its highest estimation.

\section{Conclusions}

Ocean dispersion calculations on radioactivity released from Fukushima Daiichi Nuclear Power Plant using LAMER was conducted to predict the wide-area concentration distribution after one year until 2041, which is 30 years after the accident. Moreover, the internal exposure dose caused by seafood ingestion was estimated. Note that the concentrations of the coastal area during the first year from the accident were outside the applicability of LAMER.

When we postulate that $8.45 \mathrm{PBq}$ of ${ }^{137} \mathrm{Cs}$ have been released, it is calculated that the ${ }^{137} \mathrm{Cs}$ concentration in seawater after April 2012 will be highest $23 \mathrm{~Bq} / \mathrm{m}^{3}$, which is $\sim 14$ times the concentration in seawater originated from the atmospheric nuclear tests. This is however about the same concentration as the time around 1960. Later, the highest concentration continues to decrease and by 2023 , it will be about the same level as the concentration derived from the nuclear tests $\left(<1 \mathrm{~Bq} / \mathrm{m}^{3}\right)$.

Meanwhile, the internal exposure from ${ }^{131} \mathrm{I},{ }^{134} \mathrm{Cs}$, and ${ }^{137} \mathrm{Cs}$ due to seafood ingestion was calculated to be maximum at $1.8 \mu \mathrm{Sv} / \mathrm{y}$ after April 2012, which is about the same as the past dose from seafood ingestion derived from the atmospheric nuclear tests.

When the spatial and chronological distributions of the release input into the ocean are determined in the future, detailed evaluations of the radioactive nuclides concentration in the seawater and the dose of internal exposure caused by seafood ingestion will be possible. This may contribute to the future safety validation of marine products. In addition, estimating the released amount by reverse calculation using the measured concentration in seawater is possible to a certain extent via this simulation.

\section{References}

1) Nakano M. LAMER: Long-term Assessment Model for Radioactivity in the oceans. JAEA-Data/ Code 2007-024.2008. [in Japanese]

2) IAEA. Sediment distribution coefficients and concentration factors for biota in the marine environment. Technical Report Series. 2004; 422.

3) Nakano M. Long-term assessment model of radionuclides in the oceans (LAMER). Development 
and validation of the diffusion model in global oceans. Saikuru Kiko Giho (JNC Tech. Rpt.). 2004; 22:67-76. [in Japanese]

4) UNSCEAR, Annex C. Exposures to the public from man-made sources of radiation. Sources and Effects of Ionizing Radiation. 2000; 158.

5) Ministry of Health, Labor and Welfare. Report on study of the health/nutrition of the population, http://www.mhlw.go.jp/bunya/kenkou/eiyou/h20-houkoku.html. 2011 April. [in Japanese]

6) Ministry of Education, Culture, Sports, Science and Technology. Environmental Radiation Database, http://search.kankyo-hoshano.go.jp/. 2011 April. [in Japanese]

7) Nakano M. Radioactive Materials Movement Model for the Global Scale Marine Environment. Saikuru Kiko Giho (JNC Tech. Rpt.). 2001; 11. [In Japanese]

8) Nakano M. Calculation of Effective Dose Originated from Atmospheric Nuclear Tests through Seafood Ingestion. (Jpn. J. Health Phys.) 2007; 42:329-341. [in Japanese] 


\title{
Close Look at the Accident in Fukushima Dai-ichi Nuclear Power Plant and What-if
}

\author{
Osaka University, Akira Yamaguchi
}

This study discusses about the possible preventive measures that could have been taken to minimize the damage and effect of the Fukushima Daiichi Nuclear Power Plant Accident. The reports by the Japanese government and Tokyo Electric Power Company were published in June 2011. It may be too early to ask "What if?" at this stage. However, extensive crisis management and external event planning are crucial for damage control; therefore this study aims to clarify and analyze the situation of the site.

\section{Introduction}

On June 2011, the governmental report on the accident of Fukushima Daiichi Nuclear Power Plant ${ }^{1)}$ and the report on the situation immediately after the disaster by the Tokyo Electric Power Company ${ }^{2}$ (TEPCO) were published. The governmental report first discusses the structure of nuclear safety regulations in Japan, the damage caused by the 2011 Off the Pacific Coast of Tohoku Earthquake and the tsunami it triggered, and the reason for the occurrence of the accident at the Fukushima Nuclear Power Plants. It is then followed by the responses to the nuclear emergency, release of radioactive materials to the environment, and effects on environment such as the state of radiation exposure. The report then discusses the Government's collaboration with the international societies, communication about the accident, future measures for resolving the accident, followed by the experiences from this accident. The report by Tokyo Electric Power Company summarizes the situations and facts based on the information and testimonies obtained from the relevant parties available during its publication.

These reports were drafted when the accident was still unresolved; therefore, analysis and estimation were conducted using the verified facts, and for what was not yet clear, using the most probable assumption. In addition, the reports contained comprehensive lists of problems and lessons learned from findings within and outside of Japan. The fact checking regarding the progress of the accident is still ongoing. Above all, the accident is not yet resolved. Are the lessons listed necessary and sufficient? Can they offer realistic solutions? The solutions listed in these reports must be validated in order to use them as safety measures. Atomic Energy Society of Japan also presents the experiences from the accident ${ }^{3)}$ and it shares many points with the other reports. Japanese and international societies must be continuously

DOI : 10.15669/fukushimainsights.Vol.1.106

() 2021 Atomic Energy Society of Japan. All rights reserved.

Originally published in Journal of the Atomic Energy Society of Japan (ISSN 1882-2606), Vol. 53, No. 9, p. 610-616 (2011)

in Japanese. (Japanese version accepted: July 12, 2011) 
provided with the information on the resolution of the accident, remediation of the accident site, and various activities for ensuring nuclear safety.

In the progress and the response in the accident, we must consider the origin of watershed, its occurrence, and if it was intrinsic. In this study, the events will be arranged in chronological order based on the abovementioned reports and the situation at the accident site will be assessed. To practically reflect the experiences from the accident, it is inevitable to ask: What if? We believe that this study will serve such a purpose.

\section{Nuclear Reactor and Fuel Pool: Report on the First 13 Days after the Accident}

Immediately after the accident, the Local Nuclear Emergency Response Headquarters may have been under extreme confusion while trying to respond to the accident. "On 2011 earthquake off the Pacific coast of Tohoku" was published by the National Headquarters for Emergency Disaster Control from the time immediately after the earthquake occurred until March 12, and jointly by the Headquarters for Emergency Disaster Control and the Nuclear Emergency Response Headquarters from March 13. TEPCO also published press releases. In the press release as of 5 am on March 12, the company admitted for the first time that a monitoring car detected a radioactive material, namely iodine, inside the premises of the power plant, with concentration higher than the normal value. Further, at one monitoring post, the concentration increased above the normal value and suggested that the water injection situation by isolation cooling system was unknown. Nuclear and Industrial Safety Agency (NISA) has published 196 reports on earthquake damage information on July 11. In June, the previously mentioned governmental and Tokyo Electric Power Company reports were published.

The accident at Fukushima Daiichi Nuclear Power Plant that became extremely difficult to control was a rare and special occurrence. There are many speculations and interpretations about this accident. The interpretations in the series of the commentary articles published so far in this journal are based on published information, which are deemed accurate. However, many uncertain elements and new facts are yet to be discussed; thus, these articles may be revised in the future. Therefore, the available facts must be analyzed, for which we follow the time series of events occurring at the Fukushima Daiichi Nuclear Power Plant.

\section{March 11: Occurrence of Earthquake and Tsunami}

On 14:46, March 11, every nuclear reactor (Unit 1-Unit 3) operating at the Fukushima Daiichi Nuclear Power Plant stopped automatically. Although external power supplies stopped, emergency diesel generator $(D / G)$ continued to run. On 15:27, the first tsunami hit and the D/G of Unit 1 stopped at 15:37, followed by those of Units 3 and 4 at 15:38 and those of Unit 2 at 15:41, respectively. The power could not be supplied because no off-site power was available, and station blackout ensued. Moreover, all the reactors lost decay heat removal function and were unable to transfer the decay heat to the final heat sink (seawater).

Furthermore, Unit 1 lost DC power batteries due to the tsunami and the batteries of Units 2 and 3 discharged after a few hours, making it impossible to check the plant parameter. Then, the reactor water levels and water injection conditions of Units 1 and 2 could not be verified, leading to the issuing of Article 15 report at 15:36 (failure of water injection to the emergency core cooling device). Thus, an extremely severe accident occurred where the water levels of 
reactors and the water injection conditions could not be verified and lighting/communication systems were lost, which literally forced the staff to cope with the situation blindly in the dark.

Verifying the status of the reactor cores of Units 1 and 2 was set to the highest priority. Batteries and cables were collected from companies in the premise; the schematics were confirmed and connections were developed. As the DC bus of Unit 3 escaped from the flood, its isolation cooling system and recorder could operate for a long time using the backup storage battery. Thus, for Units 3 and 4, to maintain the battery for the isolation cooling systems and the high-pressure coolant injection systems (HPCI system), which can operate without AC power source, measures to shut down unnecessary electric load were taken. Power sources were important.

TEPCO was attempting to secure power supply vehicles immediately after the tsunami. At that point, the early recovery of external power supplies was unlikely and because the emergency diesel generators (d/c) were submerged, there was no other options left but to secure the power supply vehicles. All the power panels of Units 1 and 3 were also submerged, which was not known at that point, suggesting that it was not possible to connect power supply vehicles even if they arrived quickly. The power panels (power center) of Unit 2 were partially usable, and cable installation was undertaken to connect power supply vehicles on priority. It must have been recognized at this point that the situation was quite severe, particularly for Unit 1 .

The isolation cooling system of Unit 2 was started manually at 15:39. However, the reactor water level could not be verified. At 17:12, the water injection method using the fire-extinguishing system and fire engines, which were the accident management measures, was examined. The diesel-driven fire pump (D/D FP) was started following this; however, it stopped soon afterward. At 21:02, the injection situation could not be verified and the local headquarters were concerned about fuel exposure.

The insolation cooling system of Unit 3 was started manually at 16:03, and its cooling was secured. Temporary lighting was installed in the main control rooms of Units 1 and 2 at 20:49 and that of Unit 3 at 21:58. Moreover, the liquid level of Unit 1 was $+200 \mathrm{~mm}$ from the top of the fuel (at 21:19) and then $+550 \mathrm{~mm}$ (at 22:00), whereas that of Unit 2 was 3,400 mm (at 21:50). Thus, the reactor water level was maintained and reactor cores were being cooled.

According to the analysis conducted later, the fuel of Unit 1 was uncovered to air by the evening of March 11 (2-3 h after the earthquake). After $1 \mathrm{~h}$, core damage started and the melted core was dropped into the lower plenum. This conclusion is based on the analysis with the following assumptions: (1) The isolation condenser (IC) did not operate after the station blackout due to the loss of AC power. (2) Leaking hole of 3-cm diameter appeared on the primary containment vessel (PCV) $18 \mathrm{~h}$ after the earthquake, which expanded to 7-cm diameter after $50 \mathrm{~h}$. This is an assumption for approximating the PCV pressure with the actual measurement to a certain extent. The time series of the extent of the opening of the IC valve after the station blackout is unknown; therefore, the contribution of IC to the cooling cannot be determined. The analysis result does not correlate with the measured water level.

At 21:51, radiation dose of the reactor building (R/B) Unit 1 increased and entry was prohibited. At 23:00, the dose inside the turbine building increased to $1.2 \mu \mathrm{Sv} / \mathrm{h}$ in a short duration. By this point, it must have been recognized the reactor core was damaged and the radioactive materials were released. Thus the situation must have been tense, and methods, such as venting or seawater injection, became realistic undoubtedly.

From the midnight of March 11 to the dawn of March 12, power supply vehicles arrived in sequence. In the building, about 40 people installed more than one ton of cable using a labor-intensive method in darkness for $>4-5 \mathrm{~h}$. This was done amidst scattered obstacles where 
repeated evacuations occurred every time a major tsunami warning was issued. Connection to the power panels was also extremely difficult. At this time, communication facility could not be used. Further, communication with the power plant response headquarters was difficult.

At this point, the damage of the reactor core was recognized. The power source could not be recovered quickly. Next, venting was attempted without using electricity. The drawing was collected in the evening to check the type/structure of the venting valve. Thus, it was judged that manual venting was possible. However, at 23:50, March 11, when the battery was connected to the pressure gauge of the drywell (D/W), the PCV pressure of Unit 1 reached 1.5 times the design value $(600 \mathrm{kPa})$. The PCV pressure was not been published possibly because it could not be measured due to power loss. Thus, performing PCV venting was crucial.

\section{March 12: Hydrogen Explosion in Unit 1}

By 0:06 on March 12, examination of the mass of radioactive materials that would be released when the pressure decreased from 800 to $100 \mathrm{kPa}$ performed along with the instruction for the venting preparation of Unit 1. At 0:30, evacuation of the residents within $3 \mathrm{~km}$ was verified and the second issuing for Unit 1 of Act 15 (abnormal increase of PCV pressure) was made at 0:49. Attention was focused on PCV venting. The PCV pressure was continuously measured until 05:14. By 02:30, it reached $840 \mathrm{kPa}$, which was twice the design value. The work at the reactor building $(\mathrm{R} / \mathrm{B})$, or suppression chamber where radiation dose was extremely high, continued in darkness using flashlights. Several difficulties were encountered, including prohibition on on-site operation at 04:30 due to the possibility of tsunami caused by the aftershock. Note that after 04:15, decreasing tendency of pressure was reported. The monitoring of the power plant premises on 04:23 reported approximately ten-fold increase of radiation dose near the main gate compared to that recorded 20 min earlier. In other words, it was verified that radioactive materials spread rapidly outside the building.

Amidst the fear of tsunami, operation of isolation cooling system of Unit 2 was verified on site at 02:55. This led to prioritizing of response to Unit 1 over Unit 2 that was being cooled. There is no record of operation of Unit 2 for some time after this point.

The cooling of the reactor core of Unit 1 remained insufficient. At 05:46, alternative water injection using fire-extinguishing pumps started. At 06:50, an order to conduct venting manually was given by the Minister of Economy, Trade, and Industry. The director of the power plant instructed to conduct venting in $2 \mathrm{~h}$ at 09:00. At 09:15, the electric valve was manually set to $25 \%$ opening. However, the opening operation of the pneumatic operation valve connected in series could not be conducted because the radiation dose was high. At 10:17, the venting valve was operated assuming that there was residual pressure in the compressed air system for instruments; however, its result was unknown. At 14:00, a temporary air compressor was installed to conduct venting. At 14:30, the PCV pressure decreased and the venting was deemed successful. However, the aforementioned analysis could not reproduce the time series of PCV pressure and there are still unclear aspects. Due to the depletion of the water source, injection of fresh water to the reactor core was terminated at 14:53. 80 tons of water had been injected until that point. Then, the instruction to continue the implementation of seawater injection was issued. In the afternoon on March 12, the success of venting of PCV and preparation of alternative water injection was in progress. There might have been a misconception in the Local Nuclear Emergency Response Headquarters that the significant crisis has been averted, even though the radioactive materials had already been released.

Hydrogen explosion occurred (15:36) when the injection preparation from boric acid solution injection system was completed following the electricity recovery by the power supply 
vehicles. The reactor building(R/B) of Unit 1 was severely damaged. The hoses prepared for the electricity facility of the boric acid solution injection system or for seawater injection were also damaged. In the end, seawater injection from the fire-extinguishing system line using fire engines began at 19:04. Regarding the release of radioactive materials, the reports by Japanese government state that its contents are merely references as there are uncertainties in the analysis conditions, the analysis model, and the progress of events.

The hydrogen explosion damaged the reactor building $(\mathrm{R} / \mathrm{B})$ and brought the preparation for the convergence of the accident done up to that point to nothing. Moreover, it scattered debris that contained radioactive material, severely worsening the access of the workers. If there was no hydrogen explosion, the subsequent progress after that point would have been significantly different. The failure to prevent the hydrogen explosion was the primary watershed.

Due to the hydrogen explosion of Unit 1, the emphasis shifted to Units 2 and 3. After the hydrogen explosion of Unit 1, the power plant director instructed to conduct venting of Unit 2 at 17:30. To prevent the hydrogen explosion of Unit 2, its early venting was urgent.

The isolation cooling system of Unit 3, which was in operation, tripped at 12:36. At 11:35, the high-pressure system started automatically due to the low water level of the reactor core. Instructions to prepare for the venting of PCV of Unit 3 were also given at 17:30 assuming that the situation of Unit 3 was less urgent as its reactor core was being cooled. Nevertheless, its hydrogen explosion had to be prevented, similar to Unit 2.

\section{March 13: Difficulty in Securing Nuclear Reactor Cooling}

The wet venting line setting from suppression chamber for Unit 2 was completed at $~ 11: 00$ on March 13. However, the PCV pressure was lower than the working pressure of the rupture disc; therefore, venting was not possible. The monitoring of pressure had to be continued under all circumstances. At 12:05, the power plant director instructed to use seawater for venting.

The high-pressure injection system of Unit 3 stopped at 02:42, two days after Units 1 and 2. As injection into nuclear reactor core using the isolation cooling system was not possible, at 05:10, the nuclear reactor cooling function was deemed lost and Article 15 report was issued. At 05:15, the power plant director instructed to set up venting line and the setting was completed at 08:41. At 09:08, rapid decompression of the nuclear reactor using safety relief valve was conducted. This triggered the increase of PCV pressure and enabled venting, and the decrease of pressure in the reactor pressure vessel (RPV) enabled injection of water into the reactor with smaller driving pressure. At 09:20, pressure decrease of the drywell was verified, indicating successful venting. The fresh water injection using the fire-extinguishing system line started at 09:25. However, the amount of water was insufficient and the water level in the nuclear reactor continued to drop. The director ordered to collect seawater from backflush valve pit ${ }^{1}$ and inject it to the reactor at 10:30. Aftershock was still continuing, prompting evacuation each time, and preventing the preparation from progressing. Meanwhile, fire prevention water tank did not contain any fresh water at 12:20. The seawater injection by fire engines from the fire-extinguishing system line started one hour later, at 13:12.

\footnotetext{
${ }^{1}$ A pit in which a valve for back flowing the seawater in the capillary is installed when washing the condenser capillary. It is located between the turbine building and water intake facilities.
} 


\section{March 14: Hydrogen Explosion also occurred at Unit 3}

In addition, Unit 3 did not contain sufficient seawater. To supply the backflush valve pit with seawater, the injection was stopped at 01:10. The seawater injection from the backflush valve pit through fire engines at last resumed at 03:20. From dawn, PCV pressure started to slowly increase and wet venting from the suppression chamber was conducted at 05:20. Venting and seawater injection were conducted; however, the injection was approximately $>10$ tons per hour, which was insufficient. The damage of the reactor core was presumably worsening. The decisive event in the form of hydrogen explosion occurred at 11:01. The reactor build$\operatorname{ing}(\mathrm{R} / \mathrm{B})$ and waste processing building were heavily damaged, where 11 people were injured and complete evacuation was ordered. The fire engines and hoses were damaged, debris with high radiation dose were scattered, and the backflush valve pit was no longer usable. The fire engines were moved to near the landing, and the line to send seawater to reactors Units 2 and 3 was re-established. Seawater injection resumed at 16:30.

Following the hydrogen explosion of Unit 3, the interest on site shifted to Unit 2. The hydrogen explosion of Unit 3 had significant effect on Unit 2. The venting valve was closed and could not be opened. Moreover, the fire engines and hoses prepared for seawater injection were no longer usable. Thus, at 13:25 on March 14, $70 \mathrm{~h}$ after the tsunami, the reactor water level of Unit 2 started to drop and the nuclear reactor cooling function was deemed lost (issuing of Article 15). The venting valve could not be used immediately, and decompression of the reactor pressure vessel (RPV) using the safety relief valve for seawater injection was attempted at $~ 16: 00$. The batteries were gathered from the vehicles in the premises. The decompression finally succeeded at $\sim 18: 00$. The exposure of fuel started at 17:17; at 18:22, the fuel was exposed. At 19:54, seawater injection finally started and cooling was resumed. Thus, the seawater injection to all the reactors started at last.

Some claim that the hydrogen explosion of Unit 2 was prevented because the blowout panel of Unit 2 opened when Unit 3 exploded, but it is not certain if that is correct. Moreover, no report mentions this. White smoke from the fifth floor of Unit 2 was seen in the following day at 08:25 on March 15. At 09:16, opening the external wall panels of the reactor buildings of reactors Units 5 and 6 was discussed. Among the conflicting information, it is possible that the Local Nuclear Emergency Response Headquarters was thinking that way. TEPCO opened three holes each on the roofs of the reactor buildings(R/B) of Units 5 and 6 on March 19 as a measure for the hydrogen release from the fuel pool.

After seawater injection to Unit 2, the attention was shifted to venting because hydrogen explosion could possibly occur at Unit 2 . Although the reason was unclear, the blowout panel of the reactor building (R/B) of Unit 2 was opened, leading to the release of hydrogen leaking in the building to avoid hydrogen explosion. Venting line setup was completed by 21:00. The pressure in the suppression chamber was lower than the working pressure of the rapture disc, even though the pressure of drywell was rising, which prevented wet venting. Thus, the method to conduct drywell venting was adapted at $\sim 23: 35$.

On the third day of the accident, reactors Units 1 and 3 had already experienced core meltdown and hydrogen explosion. The measures for Unit 2 were urgent in the severe situation, where its reactor core was completely uncovered and the pressure of PCV was increasing.

\section{March 15: PCV Breakage of Unit 2}

At Unit 2, venting was conducted at 00:02 on March 15, but the pressure of PCV did not decrease beyond $750 \mathrm{kPa}$. Though injection to the reactor continued, the pressure of PCV 
remained high. At 06:00, a large impact sound that was interpreted as hydrogen explosion occurred in the suppression chamber. At this point, the pressure of the suppression chamber turned to $0 \mathrm{MPa}$.

In the end, explosion occurred at each operating unit during the earthquake and an abnormal situation progressed where the total control of cooling was not possible at every nuclear reactor. Then, it was necessary to cool the reactors without interruption. By 07:00, 650 staff members were evacuated temporarily to Fukushima Daini Nuclear Power Plant, leaving 70 staff members that were required for monitoring and operation.

Unit 3 also seriously impacted Unit 4, which did not have fuel loaded in its nuclear reactor vessel. Damage near the fifth floor roof of the reactor building (R/B) of Unit 4 was discovered after the hydrogen explosion, and damage on the building itself was discovered at 08:11. Fire started in northwestern corner of the third floor of the same building at 09:38. It extinguished by itself at $\sim 11: 00$. The incidents in the building of Unit 4 may be partly due to the shortage of the staff in the building at the time, but the details are unknown.

At 23:05, extremely high dose of $4,548 \mu \mathrm{Sv} / \mathrm{h}$ was detected near the main gate.

On March 11, cooling of the fuel pool was insufficient at Units 1, 2, 3, and 4 immediately after the station blackout. However, the staff was forced to divert most of the resources to the response to the reactors, and securing the cooling of the fuel pools was postponed. The first instruction was the water injection order to the pool of Unit 4 given by the Minister of Economy, Trade, and Industry at 22:00 on March 15. This was after the hydrogen explosion at Unit 3 at 11:01 on March 14, the explosion near the suppression chamber of Unit 2 at 06:00 on March 15, and the severe damage on the reactor building of Unit 4.

Large quantity of radioactive material was released from March 15 to 16. Its quantitative analysis was published. The evaluation of Unit 1 was conducted under the aforementioned conditions. The evaluation condition of Unit 2 assumed that a $10-\mathrm{cm}$ diameter hole appeared on the drywell $21 \mathrm{~h}$ after the earthquake occurred and that a 10-cm diameter hole appeared on the suppression chamber immediately after the impact sound. Unit 3 was analyzed assuming that the reactor water level matches with the measurement and the water level inside the fuel area was not maintained. The released quantity of radioactive material is an estimation based on these assumptions.

\section{March 16: Cooling of Nuclear Reactor Fuel Pools Starts}

The seawater was injected to Units 1, 2, and 3 continuously, and the condition of the nuclear reactors was stable. The cooling progressed smoothly. Cooling of fuel pools started on March 16. The first measurement was taken for Unit 3. Water was sprayed from the helicopters of Japan Self-Defense Forces (JSDF) to the fuel pool of Unit 3. The cooling of the reactors was stable, and response to the fuel pools, which was the source of concern, started. As this was the first light of the convergence of the accident, it can be recognized as the second watershed.

As shown in Table 1, the heat generation by the fuel stored in the fuel pool is sufficiently low and the time until the upper ends of the fuel rods are exposed is 12 days (shortest in Unit 4). It is 278 days in Unit 1, and there is no need to apply almost anything. Thus, no problem is encountered without cooling for $\sim 10$ days. First, we believe that it was a reasonable choice to focus on reactors from Unit 1 to Unit 3. Although the exposure of the fuel in the pool of Unit 4 was pointed out from the beginning, there was a testimony that the surface of the pool water was visible in the pool of Unit 4 by visual inspection from the helicopter, therefore, the cooling of Unit 3 pool, of which the building and ceiling appeared severely damaged and through 
Table 1 Spare Days for Fuel Pool Cooling

\begin{tabular}{|l|r|r|r|r|r|r|c|}
\hline & Unit1 & Unit 2 & Unit3 & Unit 4 & Unit 5 & Unit 6 & Common Pool \\
\hline Fuel Assembly (Piece) & 292 & 587 & 514 & 1331 & 946 & 876 & 6300 \\
\hline Water in Pool (m3) & 1020 & 1425 & 1425 & 1425 & 1425 & 1497 & 3828 \\
\hline Decay Heat (Mcal/h) & 60 & 400 & 200 & 2000 & 700 & 600 & 1000 \\
\hline Heat Removal Water (kg/day) & 2500 & 16300 & 8200 & 81500 & 28500 & 24500 & 40800 \\
\hline Spare Day (day) ${ }^{* *}$ & 278 & 58 & 117 & 12 & 33 & 41 & 63 \\
\hline
\end{tabular}

* Water temperature is set at $50^{\circ} \mathrm{C}$

** Days required for the water level to be reduced to $4 \mathrm{~m}$.

which water can be discharged, must have been prioritized.

\section{March 17: Stable Cooling of Unit 3 Fuel Pool}

From March 17, freshwater and seawater were discharged on Unit 3 from water trucks and fire engines. Considerable cooling effect was secured, and discharging continued for some time. From March 29 and April 26, seawater discharging from mobile concrete pumps and freshwater injection using fuel pool coolant purification system, respectively, were conducted.

\section{March 20: Prospect of Cooling Fuel Pools Becomes Clear}

Seawater injection using fuel pool coolant purification system to Unit 2 started on March 20. Freshwater injection started on March 29. From March 20, freshwater was discharged on Unit 4 from water trucks and fire engines. From March 22 and March 30, seawater injection from mobile concrete pumps and freshwater injection were conducted, respectively. From March 31, freshwater injection using mobile concrete pumps to Unit 1 started.

The reason for the delay of response to Unit 1 was the sufficient margin for time it had for cooling, as shown in Table 1. The seawater injection to fuel pools of Units 1-4 was stable; thus, the prospect of fuel pool cooling was clear. As the cooling of both nuclear reactors and fuel pools became possible, the risk of further release of large quantity of radioactive materials was averted. Although there were still many problems, the emergency was avoided.

\section{March 23: Stable Cooling of Nuclear Reactors Established}

Seawater injection to the nuclear reactors from Unit 1 to Unit 3 continued. Figure 1 shows the temperatures of the reactor of Unit 1 and around the PCV. By the dawn of March 23, the temperature of the RPV shifted to $<400^{\circ} \mathrm{C}$. The nuclear reactor pressure decreased to gauge pressure $0.2 \mathrm{MPa}$ and remained almost constant. If the fuel was submerged in water, the water temperature had to be approximately $100^{\circ} \mathrm{C}$ at this pressure. If the measurement was correct, then the injected water evaporated and heated by the exposed fuel. At 02:33 on March 23 , external injection of seawater using the seawater system started in addition to the seawater injection from the fire-extinguishing system using fire pump. This increased the injection amount from 2 to 18 tons per hour. The temperature decreased in an instant, down to $\sim 200^{\circ} \mathrm{C}$. 


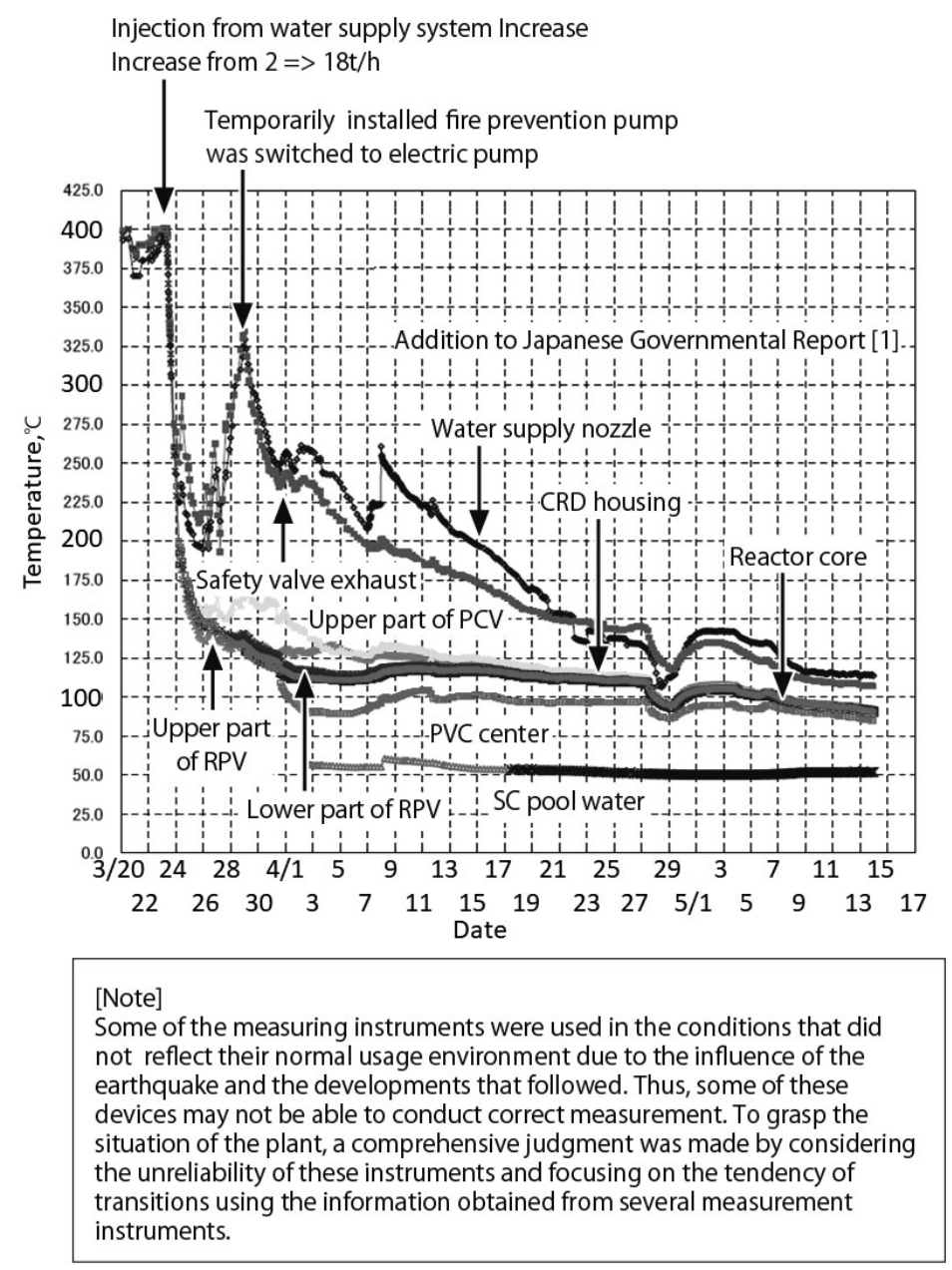

Figure 1 Temperature Transition of Nuclear Reactor of Unit 1 and Around PCV

At this stage, the staff on site may have recognized that all the nuclear reactors and fuel pools were stable. The responses after this point were steady and precise, and the situation gradually improved. Before the nuclear reactor temperature of Unit 1 decreased, the lighting of the central control room of Unit 3 recovered at 22:46 on March 22. Likewise, the lighting of the central control room of Unit 1 recovered at 11:30 on March 24. By March 26, the lighting of the central control room of Unit 2 recovered. On March 23, the third watershed occurred. From this point, main concern started to shift from cooling of nuclear reactors and fuel pools to the treatment of contaminated water.

\section{After March 24: Steps Toward Limiting Release of Radioactive Materials}

The cooling of nuclear reactors and fuel pools has been maintained since March 24. The water injection to nuclear reactors switched from seawater to freshwater for Units 1 and 3 on March 25 and for Unit 2 on March 26. Following this, the injection switched from seawater injection using the fire pump to freshwater injection using a temporary electric pump. In 
addition, transfer of the retained water under the turbine building started. On April 6, measures to prevent the high-level contaminated water leakage from the pit were taken. Nitrogen gas injection to Unit 1 started on April 7. The water of the fuel pool was analyzed, and most of fuel was judged to be in sound state. Moreover, hydrazine was injected to prevent oxidation.

The focus shifted to the secondary risk management, such as prevention of further hydrogen explosion or treatment of contaminated water. On April 17, the work schedule to the settlement of the accident was published by TEPCO. The most important task for the time being is the treatment of contaminated water. During this study, the system to decontaminate and circulate cooling water started its operation, allowing cooling without increasing contaminated water.

\section{Problems Pertaining to Disaster Prevention (INES Evaluation and SPEEDI)}

Several problems are encountered with respect to protection against radiation, evacuation of the residents, and providing accurate information. Nuclear and Industrial Safety Agency (NISA) has the responsibility of conducting an International Nuclear Event Scale (INES) evaluation. On March 11, they published that Units 1 and 2 were deemed impossible to cool, prompting issuing of INES level 3. On March 12, level 4 was issued in response to the venting of Unit 1 and the hydrogen explosion at the reactor building(R/B). On March 18, recognizing core damage at Units 2 and 3, the level was raised to 5 and level 3 was issued for the fuel pool of Unit 4 in response to its loss of water supply and cooling function. Thus, the accident was interpreted as the same level as the Three Mile Island Accident.

About a month later, on April 12, INES evaluation was raised to level $7^{4)}$. This was based on the analysis that the total released amount of radioactive materials from the nuclear reactors to atmosphere was $370,000 \mathrm{TBq}$ in iodine conversion. This was also judged to match with the result of the reverse calculation from the monitoring measurement result. The standard for level 7 is $50,000 \mathrm{TBq}$ in iodine 131 conversion, which the measurement exceeded. Thus, international community deemed this accident to be of the same level as the Chernobyl Accident. The reason for concluding that the released radioactive materials reached the standard of INES level 7 was the analysis based on aforementioned assumptions. However, the release from fuel pools and the release into the ocean were not evaluated. Meanwhile, the nuclear reactors are being stabilized and the release of radioactive materials is on decreasing trend.

In the introductory part of INES manual by the International Atomic Energy Agency ${ }^{5}$, it is stated that "INES standard must be used promptly and consistently to communicate the safety meaning of the event to the public from the view point of radioactive source." It then defines INES as a communication tool between specialists, the media, and the public. Thus, to avoid confusion among the media and the public on understanding the event, it is important to promptly issue INES Accident scale.

On the occasion of the Fukushima Daiichi Nuclear Power Plant Accident, evacuation orders were issued as follows.

On March 11, the evacuation area was $3 \mathrm{~km}$ and the sheltering area was $3-10 \mathrm{~km}$. On March 12, the evacuation area was $10 \mathrm{~km}$ and on the same day it was changed to $20 \mathrm{~km}$. Moreover, the sheltering area was set to $20-30 \mathrm{~km}$ on March 15. Thus, when the level was raised to 5 on March 18, the evacuation of the local residents was already complete. 
The issuing of INES level at the early stage could be considered prompt and appropriate in the light of the resident evacuation. In addition, the fact that it was raised at the point of March 18 was an effective message to communicate the seriousness of the radioactive materials release on March 15 and 16, even though the evacuation was already complete.

If INES is a communication tool, then it should utilize System for Prediction of Environmental Emergency Dose Information (SPEEDI). If the weather condition and the information of how the radioactive materials are spreading were published at the point of venting on March 12 and if each municipality (cities, towns, and villages) obtained those information quickly, understood them, and utilized them for disaster prevention measures in conjunction with the INES information, it must have greatly contributed to the protection against radiation.

We believe that the reevaluation to level 7 on April 12 was premature because there was no further release of radioactive materials. The INES manual states that the standard number of 50,000 TBq for level 7 itself is meaningless. Prompt evaluation should be made with a premise that INES scale is a standard for discussing the significance of accidents from the perspective of disaster prevention. In contrast, the evaluation of the safety engineering implications of an accident could be made after adequate analysis. As a consequence, INES scale may have triggered reputational damage. INES scale can be officially evaluated after the cause was determined and preventive measures against recurrence were established. It is possible to consider that following problems were revealed; consideration by specialists must be conducted from the viewpoint of radiation safety of the public, whether the INES level classification were appropriate for a severe accident, how it should be applied to an accident with multiple core damage, and how to consider the difference in release forms and compositions depending on the accident types (e.g., the power excursion type and the heat removal loss type).

\section{Learning from the Previous Lessons}

A method, known as Accident Sequence Precursor (ASP) Analysis, studies the precursor events for the previous serious accidents and analyzes what type of sequence would unfold if they lead to core damage. The U.S. Nuclear Regulatory Commission (USNRC) has been implementing the ASP program since 1979, providing important discussions and knowledge on the meaning of the abnormality and accidents that actually occurred for nuclear safety to the American Nuclear Industry. In conjunction with the development of probabilistic risk assessment (PRA), the ASP program matured. ASP and PRA are like the two wheels of a cart for learning lessons.

The first PRA study in the US was Reactor Safety Study (WASH-1400) conducted in 1975. To conduct crosscheck evaluation of WASH-1400, Lewis commission was established by USNRC. One of the many suggestions included in the 1978 report was to utilize operation data to the risk evaluation of nuclear power plants. It pointed out that when a potentially important accident sequence and its precursor events occur, they should be analyzed via comparison with the scenarios examined in PRA. Following this suggestion, the risk analysis department of USNRC started ASP in the summer of 1979. Coincidently, it was immediately after the Three Mile Island Accident. The first ASP report ${ }^{6}$ ) was published in 1982. The important point was the evaluations unique to plants. USNRC started to develop PRA models tailored for individual plants. 
Following is an example of external power supplies loss due to flooding ${ }^{7)}$. La Blayais power plant in France has 900 MWe PWR and located in the marshes near the mouth of the Gironde estuary northwest of Bordeaux. Extrapolating the records of flood water level from last few decades, its designed flood water level was set at $5.02 \mathrm{~m}$. At the time of the flood of December 27, 1999, Units 1, 2, and 4 were operating in rated power output and Unit 3 just had its fuel changed. The combination of strong wind and high tide caused the flood to far exceed the designed flood water level, and the external power supplies of Units 2 and 4 were lost between 19:30 and 22:20, and the nuclear reactors stopped. The flood started from 19:30, and the high tide occurred at 21:30. The water flooded from the northwest of the premises and caused severe damages to Units 1 and 2. The electricity room, the seawater pump room, and fuel building were flooded, as well as the decay heat removal function, the auxiliary machine cooling system, and the electricity system were lost.

For nuclear safety analyze precursor events and critical events (which could potentially be disaster) occurring in each country firmly must be analyzed to extract lessons and to consider what would happen if such events occurred in plants in Japan and evaluate it, having an attitude that proactively strengthen vulnerability if there is any chance of it.

\section{Conclusions}

The Local Nuclear Emergency Response Headquarters were doing considerable work in extreme conditions such as the measurement instruments failure and the loss of lighting/communication function due to the station blackout and the bad access due to the high radiation dose. The station blackout and the loss of heat sink could be considered inevitable after that tsunami. Examining the background of the accident, if there was a possibility for taking different measures, it was only in between the venting preparation instruction at 00:06 on March 12, and the successful venting at 14:30. As it was clear at the point of 02:55 that Units 2 and 3 were being cooled, all the resources could have been used for Unit 1. During this time, PCV venting and alternative water injection were attempted with no avail. Venting succeeded only at 14:00. Then, hydrogen explosion occurred at 15:36. We believe that this was the first watershed. If venting was conducted before hydrogen leaked to the reactor building (R\B), the explosion would not have occurred and many more measures could have been taken.

In the end, the response was always late until March 15. The nuclear reactors of Units 1, 2, and 3, and the fuel pools of Unit 1 to 4 were heavily damaged. In contrast, the cooling of the reactors with seawater injection using fire pump was established by March 16. The cooling of fuel pools also started. This was the second watershed. Following this, stable cooling of the fuel pools was possible by March 20. The final watershed was on March 23. With the nuclear reactor temperature still being high, further release of radioactive material was possible. Sufficient cooling was secured by increasing the amount of water injection from the water supply system. The reactor temperature dropped immediately. The desperate situation during the 13 days after the tsunami finally improved. Conducting What if analysis of what would have happened if different measures were taken is possible, but the situation at the accident site was extremely difficult.

The possible watershed of the development of this accident were March 12 (deterioration after the hydrogen explosions), March 16 (maintaining reactor core cooling) and March 23 (stable cooling of reactor cores and pools). If venting was conducted promptly at Unit 1 and the hydrogen explosion was prevented, it would not have reached this situation. However, it 
is not clear whether that would have been possible when there were no electricity, lighting or communication, debris were scattered and aftershock or tsunami warnings were constantly issued. One could only say that the force of tsunami is incredible.

There was severe release of radioactive materials in this accident. We believe that for the appropriate and prompt evacuation of the local residents, utilization of INES Accident scale and SPEEDI is essential. However, INES Accident scale did not necessarily effectively function. Japan is expected to provide remedial measures for such issues. Moreover, information, such as SPEEDI, was not fully utilized and maintaining the cooperative system between the national government, private businesses, and local municipality was not possible. Effective policies must be discussed.

If we search among the international experiences of operation, similar critical experiences (which could potentially be disaster) will certainly be found. It is important to remember the importance of learning from experiences, and a system to reflect them on the safety improvement should be constructed. No matter how many safety measures we take, scenarios that go beyond our imagination will continue to occur. However, they will appear firstly as precursor events and critical events (which could potentially be disaster). Problems that appeared this way should be properly analyzed while they are still in their early stages, run these scenarios at each plant to find out their individual vulnerabilities, and conduct risk management. Such steady efforts are important and is a realistic and effective approach.

\section{References}

1) The Government Nuclear Emergency Response Headquarters. Japanese Government Report on Nuclear Safety for IAEA Board Meeting, On the Accident at Fukushima Daiichi Nuclear Power Station of Tokyo Electric Power Company. 2011 June. [in Japanese]

2) Tokyo Electric Power Company. On the Response Situation Immediately after the Disaster at Fukushima Daiichi Nuclear Power Station. [in Japanese]

3) Atomic Energy Society of Japan. http://www.aesj.or.jp/information/fnpp 201103/chousasenmoniinkai. html

4) Ministry of Economy. Trade and Industry press release. On the Application of INES (International scale for evaluating international nuclear power/radiation phenomena). 2011 April. [in Japanese]

5) INES. The International Nuclear and Radiological Event Scale User's Manual 2008 Edition.

6) Precursors to Potential Severe Core Damage Accidents : 1969_1979. A Status Repor (NUREG/CR2497, Volume 1). 1982 June;

7) Gorbatchev A, et al. Report on flooding of Le Blayais power plant on 27 December 1999. 


\title{
Remediation of Contamination from
} Radioactive Material by the Fukushima Daiichi Nuclear Power Plant Accident

\author{
"Nuclear Safety" Investigation Committee Clean-up Subcommittee \\ Tadashi Inoue, Fumiaki Takahashi and Muneo Morokuzu
}

The clean-up subcommittee under "Nuclear Safety" Investigation Committee, which aims to propose environmental remediation methods from radioactive material contamination in the areas outside the power plant, has proposed an early establishment of the radiation monitoring and the environmental remediation centers and development of the environmental remediation strategy and environmental remediation technology program with cooperation from the local residents. Moreover, this study introduces the knowledge gained from the Chernobyl Accident, which experienced similar contamination of the surrounding area, from the perspective of the environmental remediation. On the contrary, the environmental remediation faced problems, including the inability of the legal system to treat the contaminated debris and other wastes as industrial waste and the absence of the safety standard in environmental radiation for lifting the evacuation order.

\section{Activities and Proposals of Clean-up Subcommittee}

\section{Activities of Clean-up Subcommittee}

The clean-up subcommittee of "Nuclear Safety" investigation committee was established for analyzing the decontamination and environmental remediation of the areas in and around the Fukushima Daiichi Nuclear Power Plant (hereafter power plant) contaminated by the radioactive materials that were released after this accident, examining the problems, and suggesting proposals toward their solutions.

Regarding the power plant premises, the medium/long-term perspective, which includes 1) identification of the problems related to the removal of melted fuel and its processing/disposal and 2) analysis of the contaminated water processing and types and quantity of contaminated waste as well as the identification of problems related to processing/disposal of radioactive waste, is required, and the subcommittee will propose an environmental remediation plan when required.

Regarding the area outside the premises of the power plant, we plan to conduct identification and analysis of the contamination, identify the problems related to the removal

DOI : 10.15669/fukushimainsights.Vol.1.119

(C) 2021 Atomic Energy Society of Japan. All rights reserved.

Originally published in Journal of the Atomic Energy Society of Japan (ISSN 1882-2606), Vol. 53, No. 9, p. 617-622 (2011)

in Japanese. (Japanese version accepted: July 1, 2011) 
and processing of radionuclides from a vast and diverse amount of contaminated materials in the environment, and explore the comprehensive environmental remediation strategy. Through these, we will suggest proposals about the remediation activities and propose technical programs for feasible remediation processes involving the entire stakeholders. Moreover, we already provided four proposals, as mentioned below, on the environmental remediation policies that will be required in future, including the necessity of the environmental radiation monitoring center and the environmental remediation center in the contaminated area.

\section{Proposal 1: Early Establishment of "Environmental Radiation Monitoring Center" and "Environmental Remediation Center"}

(1) Establishment of "Environmental Radiation Monitoring Center"

Since the measurement data for the environmental radiation that is conducted individually by each organization has different settings in measurement condition or unit depending on the purpose of each measurement, it is difficult for the general public to understand these data. Therefore, we suggest that establishing an "environmental radiation monitoring center," where these data are consolidated and comparison of measurement points or changes over time are comprehensively analyzed, will be effective. Moreover, monitoring requires cooperation with the relevant local municipalities to obtain and collect the detailed data, and in turn, it is important to promptly explain the collected data and the analysis results to the residents through the municipalities. In addition, considering the severe anxiety among the people in areas around the disaster zone about the effect of radiation on human body or the future prospect regarding the radioactive materials released into the environment, establishing a regular explanation system for the local residents by the specialists of radiation protection in parallel with the establishment of this radiation monitoring center is urgently needed.

(2) Establishment of "Environmental Remediation Center"

Establishment of an "environmental remediation center," which can engage with the environmental remediation of both the areas in and around the premises the power plant, is proposed. Currently, the electric companies and the Japanese government are focusing on the stabilization of the situation after the accident inside the power plant premises. This subcommittee plans to evaluate these plans and the implementation policies and will be offering suggestions when required. In addition, we will examine and offer proposals on the technical policies of the melted fuel removal and the processing/disposal of the vast amount of contaminated water, which are short and long-term problems.

The preparation of a unified plan for the future and its implementation are urgently required in the environmental remediation of the area outside the power plant. In response to this situation, the environmental remediation center must first prepare a comprehensive strategy ${ }^{1}$ for the environmental remediation, present applicable technologies, and specify the implementation plan and policies. Moreover, this strategy must include a remediation plan for the removal of soil, water, and dust that contain radioactive material using existing technologies. That is because the time of evacuation is getting prolonged due to the release of radioactive material in the area outside the power plant premises, and it is causing severe anxiety to the local residents for their future. Additionally, a rational and effective radioactive material

\footnotetext{
${ }^{1}$ Comprehensive strategy refers to a total environmental remediation strategy for the large areas in and outside of the nuclear power plant based on the importance of the lives of the local residents, proposing applicable technologies and their implementation method that includes the processing and disposal method of the secondary waste as well as preparing an effective decontamination plan.
} 
removal technology must be developed because there is no guarantee that the existing technologies will be enough for the complete removal of the radioactive materials.

On the contrary, it is important to quantitatively understand its effect in advance while conducting the actual radioactive materials removal work. Therefore, establishing a practical test site in the disaster zone for examining the effectiveness of removal technologies used in the remediation as well as for verifying the problems in the actual work is an important role of the environmental remediation center.

As mentioned above, we propose to establish an "environmental remediation center" in the disaster zone for planning strategies for environmental remediation, presentation of technologies, and comprehensive implementation of practical tests and technology development. The clean-up subcommittee aims to actively collaborate with its establishment and operation.

\section{Proposal 2: Preparation of Environmental Remediation Strategy toward the Removal of Radioactive Materials}

\section{(1) Preparation of Environmental Remediation Plan Based on Radiation Measurement}

Maps of air dose rate or radioactive material concentration in soil are necessary for preparing an environmental remediation plan. Moreover, the environmental remediation plan must be based on the usage of the land and facilities considered in the plan as well as the practically achievable removable effect of radioactive materials. On the other hand, it is assumed that the environmental remediation will require a long period of time. Therefore, it is necessary to set stepwise goals when required and conduct remediation with steady and continuous effort.

(2) Priority Determination in Environmental Remediation Based on 0bjective Indicators

While there are facilities being used by many people in the areas that are targets of environmental remediation, such as hospitals and schools, among the other public buildings, there are places where hardly which are not visited regularly such as mountains and forests. Further, for the case of farmlands in mountain areas, environmental remediation itself may not be sufficient as there is a possibility of the long-term effects from mountains and forests on the farmlands. Therefore, it is important to consider the impact of the radiation on the people living and working in the area, and the implementation of environmental remediation requires setting priorities based on a comprehensive examination. We consider that determining the actual priority of environmental remediation based on objective indicators of the concentration of radioactive materials in the target facility and location as well as the environmental factors, i.e., mode of usage, frequency of usage, among others, is fair and effective.

\section{(3) Adaptability Evaluation of Rational Environmental Remediation Technology}

It is predicted that, as a result of environmental remediation work, a large quantity of waste containing concentrated radioactive materials will be generated. Moreover, secondary wastes will also be generated as a result of various works. Therefore, it is important to examine the processing and disposal policies while grasping their quantity, types, and the concentration of radioactive materials properly. Meanwhile, quantitative evaluation of the exposure risk of the environmental remediation workers and the examination of protection plans are indispensable factors during the preparation of environmental remediation strategies. 


\section{Proposal 3: Early Presentation of Environmental Remediation Technology Program}

(1) Early Presentation of its Final Appearance and Stepwise Goals

It is necessary to clearly indicate the achievable final target figures of the reduction of the exposure dose rate and radioactive material concentration through environmental remediation together with the time scale in advance. Moreover, if achieving the final target requires a long time, presenting the stepwise goals (exposure dose, environmental remediation area, among others) for each time period will be an important indicator for the local residents.

(2) Identification of Definitely Achievable Environmental Remediation Effect

Presentation of existing candidate technologies applicable to the target areas and land categories together with a quantifiable efficiency of environmental remediation is required for the early start of remediation work. While selecting the applicable technologies, the types and characteristics of wastes must be taken into consideration, in addition to their expected environmental remediation effects. Meanwhile, while the development of a new technology is necessary, it is required to identify the problems and start developing the technology promptly. Moreover, it is desirable that relevant Japanese organizations cooperate with each other and bring together their knowledge to implement and develop technologies for environmental remediation. (Currently, each organization works in isolation and there is no unified effort.) The clean-up subcommittee of the Atomic Energy Society of Japan wishes to evaluate the expected environmental remediation effects and the applicability to the environmental remediation plan of the various technological policies that will be proposed in future and to collaborate with the main body of environmental remediation and providing easily-to-understand information to the local residents.

\section{Proposal 4: Importance of Local Residents Participation}

It is important to always conduct the selection of environmental remediation policies and discussion on the priorities of their implementation with the local residents and local municipalities. For this, it is necessary to establish many occasions and places where questions of the local residents, such as the meaning of radiation monitoring data, effects, and issues of environmental remediation work, or the future prospects based on a technological reasoning, are responded with honesty and explained in a clear manner.

\section{Future Plan}

We have presented the proposals made by the clean-up subcommittee related to the remediation of the environmental contamination caused by the accident at the power plant. Following is our future action plan. In addition, we wish to plan international conferences and symposiums on environmental remediation in collaboration with other academic societies.

(1) Embody the roles and functions of the Radiation Monitoring Center and Environmental Remediation Center.

(2) Advise the preparation of environmental remediation comprehensive strategies.

(3) Present concrete technological program for stepwise implementation policy and evaluate the various technologies to be proposed in the future.

(4) Actively conduct activities to reflect the opinions of local residents.

(5) Cooperate with international organizations and collaborate with their reviews. 


\section{Environmental Remediation Following the Accident of Chernobyl Nuclear Power Plant}

When planning environmental remediation programs for areas outside the premises of the power plant in future, the knowledge gained from the experience of the Chernobyl Nuclear Power Plant Accident, which caused major radiation contamination, could be useful. International Atomic Energy Agency (IAEA) published a report (STI/PUB/1239) that collected the environmental influence and remediation measures in 2006. We investigated the measures examined and implemented after the Chernobyl Nuclear Power Plant Accident and the results obtained with this IAEA report as the main source. In addition, we compared the local characteristics and contamination situations and will present the important perspectives for future environmental remediation.

\section{Comparison of Contamination Situation and Land Usage Situation}

The amounts of I-131 and Cs-137 released in the atmosphere during the Chernobyl Nuclear Power Plant Accident were $1.8 \times 10^{18}$ and $8.5 \times 10^{16} \mathrm{~Bq}$, respectively. Meanwhile, the released amounts of I-131 and Cs-137 after the Fukushima Daiichi Nuclear Power Plant Accident, as published by the Nuclear Safety Commission on April 12, 2011, were $1.5 \times 10^{17}$ and $1.2 \times 10^{15}$ $\mathrm{Bq}$, respectively (approximately one-twelfth (1/12) and one-seventh (1/7) of the Chernobyl Accident).

Regarding the land usage of the area around the accident sites, the Republic of Belarus as a whole, which was affected by the Chernobyl Accident, include $43 \%$ farmland, 39\% forest, and $2 \%$ rivers, lakes, and marshes. Meanwhile, the areas where the soil contamination concentration by Cs-137 after the Fukushima Daiichi Nuclear Power Plant Accident were $300 \mathrm{kBq} / \mathrm{m}^{2}$ or more were used as $<5 \%$ urban area, $<10 \%$ paddy field, and $<10 \%$ other types of farmland. The remaining $>75 \%$ was forest and mountains (Japanese average is $67 \%$ ).

\section{Environmental Remediation after the Accident of Chernobyl Nuclear Power Plant}

\section{(1) Environmental Remediation of Urban Area}

At residential settlements, the radioactive materials on the surfaces of roads, buildings, and soils became the source of the radiation exposure of the residents. Between 1986 and 1989, measures such as washing of buildings, cleaning and washing of roads, and removal of contaminated soil were implemented at about 1000 settlements and tens of thousands of houses and buildings, in three countries in the former Soviet Union (Ukraine, Belarus, and Russia). During this time, kindergartens, schools, hospitals, and other frequently visited buildings were prioritized for decontamination. During the decontamination, contamination level of the soil near the wall of the washed building increased.

Table 1 summarizes the decontamination target, measures, and achievable effects discussed in the IAEA report. The decontamination effect obtained by RISO laboratory in Denmark obtained is also shown. It was clarified that measures with decontamination effect of $>100$ involve the removal of contaminated surfaces, such as changing roofs. The decontamination effect of each measure is mostly above 2. During the Chernobyl Accident, dose rate decreased for about 1.5 to 15 factors in different measurement points depending on the adapted method. However, high cost prevented their application in wider areas, leading to only a 
Table 1 Environmental Remediation Technology for Urban Area

\begin{tabular}{|c|c|c|c|c|}
\hline \multirow{2}{*}{ Contaminated Surface } & \multicolumn{2}{|c|}{ IAEA STI/PUB/1239 ${ }^{1)}$} & \multicolumn{2}{|c|}{ RISO- R- $828^{2)}$} \\
\hline & Method & DRRF $^{* 1}$ & Method & $\mathrm{DF}^{* 2}$ \\
\hline Wall & Sandblasting & $10-100$ & $\begin{array}{l}\text { Sandblasting } \\
\text { Changing wall paper }\end{array}$ & $\begin{array}{l}4,5 \\
100\end{array}$ \\
\hline Roof & Spraying Water, Sandblasting & $1-100$ & $\begin{array}{l}\text { High-pressure water Spray } \\
\text { Changing Roof }\end{array}$ & $\begin{array}{l}2.2 \\
100\end{array}$ \\
\hline \multirow[t]{2}{*}{ Garden and Field } & Digging up & 6 & Digging up & $4-15$ \\
\hline & Removing surface soil & $4-10$ & Removing surface soil & $4-10,28$ \\
\hline \multirow{2}{*}{ Road } & Sweeping & $1-50$ & Vacuum Cleaner & 1.4 \\
\hline & Lining & $>100$ & Crushing and Removal & $>100$ \\
\hline
\end{tabular}

*1 Dose Rate Reduction Factor: Comparison of dose rate on the target surface before and after the decontamination.

*2 Decontamination Factor: Comparison of contamination concentration on the surface or inside of the target before and after the decontamination.

yearly decrease in the radiation exposure of $10 \%$ to $20 \%$ in average. Even among the infants and school children who were prioritized, it was $30 \%$. On the contrary, secondary contamination was not observed in the decontaminated areas.

\section{(2) Agricultural Measures}

During the first few months after the Chernobyl Accident, contamination by direct adhesion to agricultural crops and contamination of raw milk occurred. Contamination by Cs radionuclide was the most significant contamination at the stage after the early phase. In comparison to the first year, the radiation concentration of grains decreased in the second year. After 1987, high radiation concentration of radioactive Cs was detected in meat and raw milk. Therefore, reduction measures in the radioactive material in livestock products were conducted at collective farms of three former Soviet Union countries.

These measures were mainly: (i) Root improvement through soil cultivation, re-seeding and supply of inorganic fertilizer (nitrogen, phosphorus, potassium), and lime. (ii) Growing rapeseed, which absorbs less Cs, and use it for livestock feed. (iii) Clean-feeding which feeds livestock with less contaminated feed and grass. (iv) Giving Cs binding agent, which reduces the Cs absorption in the digestive organ, to the livestock by mixing it to the feed. Soil treatment, such as root improvement, showed the greatest effect for the first time, and it was influenced by the quality of the soil and its fertility situation. Usage of less contaminated feed showed constant effectiveness. Several types of Prussian blue, used to promote excretion at the time of ingestion of radioactive Cs nuclide, were used as Cs binding agents. In areas, such as Ukraine, where they were not available, clay minerals were used instead.

\section{(3) Measures for Forest and Water Area}

In forests, a large quantity of radioactive materials settles due to the filtering effect of the trees, and it is a characteristic that Cs amount in flora and fauna is difficult to reduce due to the recirculation within the ecosystem. Its environmental remediation methods can be roughly categorized into management-based measures through restricted usage and technology-based measures using machines and chemicals.

After the Chernobyl Nuclear Power Plant Accident, following management-based measures were taken. (i) Restriction on entry to the forests. (ii) Restriction on collecting food (mushrooms, berries, and game meat) and firewood. (iii) Warning to avoid hunting during the season when the games are eating contaminated plants. (iv) Preventive measures against the forest fire to prevent secondary contamination to the environment. Besides the three former Soviet Union countries, some of these measures were taken in Scandinavian countries. 
However, three former Soviet Union countries faced problems, where restrictions on collecting mushrooms and other restrictions in these areas were not socially acceptable and were ignored by the public. The technology-based measures were deemed unrealistic due to its enormous cost.

The water contamination immediately after the accident was caused by the effect of short half-life nuclide such as I-131. This decreased after time through dilution, decay, and deposition on the soil. In long-term, the outflow of Cs-137 and Sr-90 from the soil and movement of contaminated sediment are slowly continuing. The internal radiation of fishes decreased due to a decay in radionuclides. However, the Cs concentration increased afterward due to the food chain of the creatures in the water system.

The method to collect contaminated soil to prevent the transferring of radionuclides to the water system was not only expensive and ineffective but also caused the radiation exposure of the workers. Moreover, an experiment to spray lime or potassium in lakes to reduce the Cs intake of fishes, as was done in the agricultural measure, was conducted. However, due to the problem of the retention time of chemical substances in water, there was no long-term effect. As a result, it is deemed that there is no effective measure other than the intake restriction of contaminated water and freshwater fishes. Furthermore, no direct measure for irrigation water was taken, and there is no evidence of a request for or application of measures for seawater system because the accident site was far from the Black Sea or the Baltic Sea.

\section{Precautions for Considering Environmental Remediation Measures for Fukushima Daiichi Nuclear Power Plant Accident (Through Comparison with Chernobyl)}

Among the environmental characteristics, it is necessary to consider the difference in the ratio of the water area that influences the behavior of deposited radioactive materials and areas of forests and mountains where long-term exposure dose reduction policy is important. Regarding agriculture, the habits such as the use of irrigated water for rice farming vary significantly. Moreover, the huge amount of debris and damaged infrastructure due to the earthquake and tsunami, which caused the accident, is a specific problem of this accident. On the contrary, the low-level waste processing, the time required for remediation work, and the costs associated with the protection of the workers from the radiation dose, among others, which were problems also after the Chernobyl Accident, are the issues to be examined and evaluated for the future implementation of the remediation measures.

\section{Issues of the Legal System in Implementing Environmental Remediation}

We will specify the legal issues related to the clean-up of the surrounding area after the Fukushima Daiichi Nuclear Power Plant Accident.

\section{Radioactivity Released During the Accident and its Impacts}

First, what was the amount of radioactivity released during the accident? The estimation of the released radioactive iodine and radioactive cesium published by the Nuclear Safety 
Commission on April 12, 2011, was 160 thousand terabecquerel $\left(16 \times 10^{16}\right.$ becquerel).

Following are the main impacts of this released radioactive materials that have been verified so far, and legal measures against them.

(1) High level of radiation was detected in tap water, vegetables, and seafood.

The Ministry of Health, Labor and Welfare set a provisional regulation value for the Food Sanitation Law on March 17, 2011, and restricted the consumption of products that exceeded this standard. On April 5, the provisional regulation value for the radioactive iodine in seafood was added.

(2) Restriction associated with rice plantation in the evacuation area, deliberate evacuation area, and evacuation-prepared areas in case of emergency.

The Ministry of Agriculture, Forestry, and Fisheries instructed to refrain from planting rice in the evacuation areas, deliberate evacuation areas, and evacuation-prepared areas in case of emergency during 2011 FY. The Chief of the Government Nuclear Emergency Response Headquarters (Prime Minister Kan) presented the upper limit of cesium in the soil, stating that the amount of cesium in the plantation may be less than $5000 \mathrm{~Bq} / \mathrm{kg}$.

(3) High radiation was detected also in pasture grass.

The Ministry of Agriculture, Forestry and Fisheries instructed the standard for radioactive materials in a coarse feed to livestock farmers.

(4) Radiation was detected in the wastes.

Neither processing method nor standard limits are set yet.

\section{Where the Problem is Located (1) : Waste}

The current major problem is the fact that the debris and other wastes contaminated by radioactivity cannot be treated as industrial wastes.

According to the law on industrial wastes ("Waste Management and Public Cleansing Act"), the definition of waste excludes the radioactive materials and objects contaminated by them.

Reactor Regulation Act (Act on the Regulation of Nuclear Source Material, Nuclear Fuel Material and Reactors) sets the standard for when an object does not have to be treated as a radioactive waste (clearance level). However, disaster wastes are not wastes produced by nuclear facilities, and therefore inappropriate to apply this standard to them.

This absence of processing method and technological standard for the wastes is becoming a major issue.

The vast quantity of debris and other wastes will be generated. It is estimated that the debris alone will reach approximately 2.9 million tons. In addition, agricultural products, grass, and in some cases, contaminated soil with radioactivity level exceeding the standard limits will also be treated as targets.

\section{Where the Problem is Located (2) : Environmental Radiation}

The next problem is the absence of a safety standard for environmental radiation for lifting the evacuation order. On April 19, 2011, the Government Nuclear Emergency Response Headquarters provided a provisional standard of $3.8 \mu \mathrm{Sv} / \mathrm{h}$ for determining the usability of school buildings and schoolyard in the Fukushima Prefecture. This was set so as not to exceed 
$20 \mathrm{mSv} / \mathrm{year}$, which is the upper limit of the intervention dose standard of $1-20 \mathrm{mSv} /$ year at the convergence stage of an accident set by International Commission on Radiological Protection (ICRP). Later, the Ministry of Education, Culture, Sports, Science and Technology provided an estimation that stated the maximum radiation dose school children can be exposed to be about $10 \mathrm{mSv} / \mathrm{year}$. Note that, due to the many measures are taken afterward, the hourly average radiation dose of each schoolteacher from 55 schools between April 27 and July 3 was $0.2 \mu \mathrm{Sv} / \mathrm{h}$. If we assume the exposure to be $8 \mathrm{~h}$ per day and 200 days per year, it would amount to $0.3 \mathrm{mSv} / \mathrm{year}$. This was reported on July 21 by the Ministry of Education, Culture, Sports, Science and Technology to the Nuclear Safety Commission.

Currently, the standard for the setting of evacuation areas is $20 \mathrm{mSv} / \mathrm{year}$, which is the lower limit of the recommended amount of 20-100 mSv/year during an accident set by ICRP. In other words, areas where the estimated amount of accumulated dose until March next year based on the observed amount until now exceed this standard are designated to be deliberate evacuation areas.

\section{Current State of Waste}

The following emergency measures were taken collaboratively on May 2, 2011, by the Ministry of Health, Labor and Welfare, the Ministry of Economy, Trade and Industry and the Ministry of the Environment based on the advice from the Nuclear Safety Commission. (cf. 2011.5.2 the Ministry of the Environment document: "Provisional measures for disaster wastes in Fukushima Prefecture")

- Regarding the evacuation areas and deliberate evacuation areas.

Meanwhile, transportation and processing of disaster wastes have not been launched in these areas. The future actions will be considered in response to the specific situations of the evacuation areas and other areas.

- The waste in the Hamadori and Nakadori regions (excluding the evacuation areas and deliberate evacuation areas).

For the time being, collect wastes in temporary storage without processing. The processing of the contaminated disaster wastes will be considered based on the result of the field study.

- Wastes in the Aizu region.

The disaster wastes in the Aizu region will be processed systematically similar to that before the accident.

- Household wastes and a small quantity of common industrial wastes will be processed with the usual method. Moreover, objects left outside will be treated usually as long as it was not placed there between the accident and late March.

Note that the definition of "disaster waste" is waste that was generated by the tsunami or earthquake. The disaster waste that will be generated in Fukushima Prefecture is estimated to be approximately 2.9 million ton. Measures such as prevention of inhaling dust will be taken for the workers dealing with the disaster waste. Moreover, regarding the collection of disaster wastes, the Ministry of the Environment is scheduled to conduct environmental monitoring of the area around the temporary storage site and will take measures to reduce effects on the surrounding areas as much as possible, such as entry restriction and prevention of dispersion.

\section{Wastes to be Generated in Future}

A large quantity of radioactive waste is expected to be generated through contamination protective measures in the long-term contamination areas. The source will include cleaning of 
buildings and improvement of soil and plants. There are areas where cleaning of schoolyards of elementary schools is already being conducted. If contaminated soil is simply buried in the corner of each facility, there is a possibility of secondary calamity during medium to longterm usage of the land. The government must present options for processing methods and safety standard for each method urgently.

\section{Issues to be Solved}

(1) Protection of Residents Living in the Long-Term Contamination Areas after the Accident.

This will signify the beginning of the reconstruction phase after the accident. Determining the protection standard after the accident will provide people with protection against the potential health effects of radiation and sustainable living condition that includes a stable lifestyle and means of livelihood.

The 2009 ICRP recommendation (Pub 11) brought together the knowledge on this problem globally ${ }^{3)}$.

It contains not only the protection against radiation but also the ways of thinking that considers every aspect of daily life, such as environment, health, economy, society, psychology, culture, ethics, and politics, among others. It is especially important that it should be simultaneously conducted with providing the information on environmental remediation or the future policy on measures to be taken such as partial restriction of the lives of the residents and warnings on their daily lives, among others, after sufficient discussion with the relevant parties.

(2) Issues to Consider Regarding the Legal Measures to be taken after the Accident.

It is necessary to shift the management to a collegial system aiming to take individual situation into consideration and to rationally reduce the exposure as much as possible, where the Emergency Response Headquarters make decisions under the strain of urgency after the accident.

It is not appropriate to uniformly estimate the exposure when people are living and working in a contaminated area. The exposure level is mainly determined by individual actions and therefore differs greatly from person to person. Thus, the protection policy should be planned for each individual. It is the national government's responsibility to guarantee the welfare of the society and individuals when approving a group to stay within the contaminated area. It is extremely important for the decision-making on the protection policy to ensure the participation of relevant parties, providing all the important information to the relevant parties and leaving the record of the decision-making process in writing.

\section{Conclusions}

The two legal problems related to the clean-up discussed in this study are closely connected to the safety standard of radiation. The environmental radiation standard is especially required to accelerate the early return of the evacuated residents.

The 2009 ICRP recommendation (Pub 11) brought together the knowledge on this problem globally. It is effective to receive advice from specialists who are familiar with ICRP (Pub 111) and to share important information with relevant parties, especially with the residents of the contaminated areas. 
Through this, it is essential to plan concrete protection policies, set rationally achievable protection standard, and propose and execute concrete roadmap toward the lifting of the evacuation order. It is required for a specialist to prepare waste processing method and safety standards along with this plan.

\section{References}

1) IAEA, STI and PUB and 1239. 2006.

2) RISO, RISO R 828 EN. 1995.

3) International Commission on Radiological Protection (ICRP) Recommendations (Pub 11). 2009. 
Mental Health in the Atomic Energy

Research Institution

-From the Viewpoint of Occupational Physician-

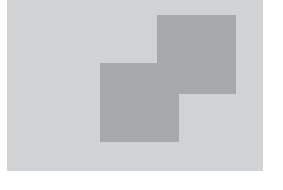

University of Tsukuba,

\author{
Yusuke Tomotsune and Ichiyo Matsuzaki
}

From the perspective of an occupational physician in the Japan Atomic Energy Agency, we observe the work environment and employee stress caused by changes in the environment and introduce necessary ideas and activities in the agency for maintaining psychological health and high motivation in a difficult environment. Further, we discuss the effect of the Great East Japan earthquake on the Japan Atomic Energy Agency and its employees.

\title{
I. Introduction
}

We have been working as occupational physicians in the Nuclear Fuel Cycle Engineering Labs (NFCEL) at the Japan Atomic Energy Agency (JAEA) since 2003. The NFCEL carries out research and development on nuclear fuel manufacturing and reprocessing and geological disposal of the spent fuel. Many might think that the main role of occupational physicians at such workplaces is providing healthcare for harmful jobs such as radiological processes (I was one of them at first). However, just like any other workplace, the mental health of employees affects the workplace and half of our time is spent on addressing mental health issues.

An article on mental health in a nuclear science and engineering journal might seem slightly out of place; however, as an occupational physician in the nuclear power industry, we think mental health issues cannot be ignored in order for the nuclear power industry to play its expected role in Japan and around the world. We hope that this article will contribute to the improvement of workers' mental health in these industries.

\section{Stress of Workers in the Nuclear Power Industry}

\section{Characteristics of Stress}

What are the characteristics of stress among employees in the nuclear power industry? A general concern is the fact that the employees work near radioactive materials with a risk of

DOI : 10.15669/fukushimainsights.Vol.1.130

(C) 2021 Atomic Energy Society of Japan. All rights reserved.

Originally published in Journal of the Atomic Energy Society of Japan (ISSN 1882-2606), Vol. 53, No. 10, p. 693-697

(2011) in Japanese. (Japanese version accepted: August 9, 2011) 
exposure to radiation. However, apparently, since the frequency of nuclear emergencies is not very high, the risk of exposure is not a direct cause of stress. Here, we discuss three major stresses among employees that are raised when interacting with them every day.

The first is "increasing work with limited human resources and budget," which is common in other workplaces as well. The second involves the physical and psychological stress caused by a drastic change in the quality of work expected for an employee in the past few years. The third involves the stress associated with the strict management standards and rules that are in place because any abnormal event or accident can cause serious damage to the residents and the surrounding environment.

\section{Limited Human Resources, but Increasing Work}

This issue is not limited to the nuclear power industry but is also the case in other workplaces. The members of our research group are occupational physicians in various workplaces such as educational research institutes in Tsukuba Science City. All workplaces have problems in dealing with mental health issues despite increasing workloads and limited human resources and budgets. We think that there has been some knowledge in this regard based on previous research results.

One such example is the large-scale epidemiological survey regarding stress in the workplace held once every five years for educational research institutes in Tsukuba Science City. The Tsukuba Science City hosts many governmental educational research institutes, and the number of researchers is exceptionally high compared to those in other communities in Japan.

This study revealed an interesting result in comparing employees in administrative jobs with those in research jobs in particular. While the workload of quantity and quality are a major burden on those in the research field, they felt a sense of accomplishment and discretion, indicating that they were in a better mental health condition than those in administrative fields. A covariance structure analysis revealed that stress-revealing factors such as discretion and fulfillment had three times as much of an effect on psychological health indicators as stress-causing factors such as quantitative and qualitative burdens. In other words, providing a sense of fulfillment has three times the power in terms of reducing stress as reducing work.

Since the way to provide discretion and a sense of fulfillment varies depending on the workplace and job category, this method cannot be generalized. However, as a key, being aware of the effort-reward imbalance model, personnel should be managed such that effort and reward are balanced. Stress occurs when there is an imbalance between "reward" and "work demand" or "effort." Work demand pertains to the difficulty in work and level of responsibility and burden. Even if one has work with a high burden, subjective stress can be reduced if reward meets effort. In contrast, stress is felt when an insufficient reward is given compared to the effort. One example is a case wherein many labor hours are wasted due to a change in the direction. Reward in the effort-reward imbalance model includes not only monetary and carrier rewards but also recognition from superiors, colleagues, and external organizations as well as the "mental reward" gained from having challenging and meaningful work. Therefore, it is extremely important to work out a way to evaluate not only the results of work but also the process of making effort.

\section{Rapid Change of Expected Work}

The second factor is that the quality of work expected from employees has been rapidly changing in the past few years. The NFCEL deals with operations related to nuclear fuel 
manufacturing and the reprocessing of the spent fuel as part of the national policy. This means that there are many employees who manage and operate the processes on factory lines, i.e., on-site jobs. However, with the technology transfer to private companies, research and development has been required for future generations and employees spend more time at their desks thinking over what their own value is.

In addition, the seismic resistance of facilities has recently become an issue. Many employees have said that "we have always been working on operational duties, but now we have to perform unfamiliar work, such as seismic resistance inspections and safety standards examinations." Due to this, the quality of work has changed significantly, causing much stress among employees, and then not a few of them were physically damaged. Work that requires a high level of expertise and confidentiality, such as that concerning nuclear power, requires workers to be in a specific field for a long period. In other words, it is not that employees have low ability to adapt. The very nature of the work makes the adaptation to other environments difficult.

Also, there are no existing standards in nuclear safety, which causes a qualitative burden in terms of responding to ever-changing conditions. It is desirable that occupational physicians understand the work environment and employee's problems and provide advice based on their aptitude and background in a way that the overall productivity of the workplace will improve. However, such environmental adjustment is difficult if the work has multiple aspects. It is irritating that occupational physicians can only promote communication between the employee and the workplace and support them so they can understand each other's problems and are more motivated in their jobs.

\section{Stress Specific to the Nuclear Power Industry}

The third stress involves various events that occur in the workplace, but can actually be caused by the atmosphere at the workplace. It is understandable that "accidents" cause stress, but there is a reason that we use the word "events." In the world of nuclear power, there is an atmosphere to not even induce "events" that would rarely lead to serious accidents, as the effect of an "accident" is so serious.

Of course, there are not frequent occurrences of events or accidents, and such occurrences should be avoided, but such atmosphere is inevitable considering the possible effect of a nuclear emergency. However, we once had the impression that some employees who work with possible danger feel like they "should not feel the stress to security and safety" and unconsciously suppress their stress. This is not desirable from the viewpoint of occupational psychology. When common stress exists in a group, it is very important for the individuals to recognize it and share the recognition of the cause of stress in order to maintain their psychological health.

The mutual understanding of each other's stress leads to mutual trust. Not knowing what others think and feel prevents one from building relationships with them and has a negative effect on their psychological health. Of course, the cause of stress cannot be solved simply through mutual recognition among those involved. Yet, anybody may have experienced their mind clearing up after sharing their problems or feeling stress relief after finding out that others have the same issue. In organizations as well, recognition and discussion of stress factors among the employees not only improves their stress resistance and maintains their mental health but also clarifies the weakness of the organizations and prevents trouble.

Recently, there has been active effort toward risk communication. We hear that anxiety can be reduced by not only explaining safety to the surrounding residents but also by actively 
discussing the risks. Feeling safe is an emotional issue that requires not only the knowledge and observation of effort but also the establishment of trust among those involved.

Regardless of their job type (administration, technology, or research), most workers in the nuclear power industry exert themselves in their roles in fulfilling the role expected of nuclear power in the world. Hence, while each individual has a strong sense of mission and responsibility, they might unconsciously feel like they cannot show weakness. However, resemble as risk communication within the surrounding residents, we feel the necessity of small-scaled risk communication within the workplace in order to establish mutual trust.

\section{Effort in Maintaining Motivation}

Under such difficult circumstances, there are new activities conducted by the staff from human resources departments and industrial health for employees so that they can maintain psychological and physical health and perform with high motivation. This is not a conventional mental health effort as part of illness countermeasures but an effort to actively improve motivation.

The central concept of this activity is sense of coherence (SOC). This concept is the opposite of the pathogenetic idea that asks "why one becomes ill," and originates from the salutogenetic idea that asks "why one remains healthy."

This is a concept born from research by a Jewish American health/medical sociologist Aaron Antonovsky (sociology) and Jewish people, who have had extremely harsh experiences in concentration camps, as subjects. He studied women who maintained their psychological health even under the ultimate stress caused by a possible massacre in a gas chamber and used the experience as an opportunity to grow as a human and to live a positive life. He studied how they were able to deal with such stress under a harsh environment.

Given a certain cause of stress, SOC consists of a sense of meaningfulness, a sense of comprehensibility, and a sense of manageability. A sense of meaningfulness is the ability to face events positively, without which one tends to not work seriously and rather to work passively when not understanding the meaning of one's job. In contrast, a high sense of meaningfulness enables one to work even on tasks in which one is not interested, with the mindset that it will be useful someday. A sense of comprehensibility is the ability to understand the situation one is facing and predict the consequences. A low sense of comprehensibility causes one to focus on the issue itself with a mindset that the problem will persist forever. A high sense of comprehensibility enables one to see through the situation and subjectively and objectively reduce the effect of current and future stresses with mindsets such as "it will be better next week" and "I will seek advice now since I am busy next month." The sense of manageability is the ability to think that it will be fine, even in situations where the future is not certain. A low sense of manageability causes one to have low esteem in their past accomplishments, with mindsets such as "I have just been lucky" and "I am not sure if I can do it in the future." A high sense of manageability enables one to understand what can and cannot be done using previous experience and what preparation and effort are needed.

There is active research in a sense of coherence, and individuals with a strong sense of coherence can not only reduce risk of mental and physical malfunction but also maintain sociological health.

Such a sense is particularly important for employees in the nuclear power industry. As mentioned above, since it is difficult to find the meaning in one's job in the nuclear power 
industry and long-term commitment sometimes blinds one to the situation one is in or in regard to how to proceed with the given task, it is important to understand whether work is referred to and employees are educated based on the sense of coherence.

In general, to increase the sense of meaningfulness, it is effective to work by feeling a sense of purpose through the meaning and significance of work and its prospect. The sense of comprehensibility can be raised by presenting the outline of work and grasping the whole scope of work. The sense of manageability can be raised by sharing words of support such as "you accomplished this much last time" and "this time, you can make this kind of effort."

This activity has just started, and we are both hopeful and uncertain about it, but we aim to make it effective through trial and error.

\section{Changes Brought by the Great East Japan Earthquake}

\section{Environment of the Employees}

In writing an article about nuclear power, one cannot avoid mentioning the tremendous earthquake that occurred on March 11, 2011. At first, Ibaraki prefecture was not recognized as a disaster area, and the conditions were not accurately reported in the news. We went over to the site shortly after the earthquake and felt the magnitude of the damage caused by the earthquake when we witnessed the conditions in Ibaraki (damage varied largely throughout Ibaraki). Like many, our thinking process also changed after the earthquake. After the earthquake, our way of thinking has greatly changed so that they would not think of before the earthquake, such as traffic conditions or whether related companies will correspond as usual, which prevents appropriate decision-making. Of course, the damage caused to the facility and infrastructure of JAEA was tremendous, and all the effort was given toward protection and management of the facilities under our jurisdiction. Even a few months after the earthquake, there were facilities and projects that needed restoration.

As for the issues related to the nuclear power plant in Fukushima, JAEA is a designated public corporation with expert knowledge in nuclear power that has been providing various means of support (Fukushima support) after the earthquake, which has been causing new sources of stress. Therefore, we have started organizational activities besides individual consultation in order to provide appropriate healthcare management.

Based on consultations with the employees, we gathered the impression that the employees feel like "we cannot prioritize ourselves in a difficult situation," "this is the time JAEA fulfills its mission," and "the effects on us are lighter than those on the residents heavily affected by the earthquake." This shows that the employees have a high sense of motivation, but could also mean that they are suppressing their stress and working without recognizing the sacrifice they are making.

Even under normal operations, during the time after late April to early May (Golden Week) and during June, many workers show the signs of fatigue that have accumulated since the new year as well as mental and physical illness. Therefore, following the earthquake, we increased the opportunities for healthcare consultations with employees, but surprisingly, there were not so many voluntary requests for consultations at the end of June. It could have been that the employees maintained their motivation and kept working on their tasks in high mental and physical health, but once we talked to them, many started to share the stress that had been accumulating. They might have been related to the feelings described above, wherein they thought that "we should not make complaints." 
Such a mentality is necessary for overcoming acute phases, but it is almost impossible to maintain such tense conditions for a long period of time. In fact, a week or two after the earthquake, we recognized signs of psychological and physical fatigue and gathered the impression that the quality of work also decreased. During such stressful events, psychological states vary since the workers have difficult conditions and roles to play with both work and family. Also, there are many who focus on their task, ignoring the stress. As a result, workers are concerned with the earthquake, but nobody is willing to talk about it. We would like to discuss the risk caused by suppressing one's feeling, through a case study (see below).

\section{Case study}

After the earthquake, a 40-year-old male came for a consultation about his family. During the earthquake, he worked in department of safety and health, and after the earthquake, he was assigned to the emergency headquarter, which prevented him from going home for several days. His workplace was damaged, but the damage to his house was also significant, and the electricity, water, and phone lines were disconnected. He could not contact his family (his wife and child in elementary school) for several days, but he prioritized his work given his position at work. Three days after the earthquake, he found out through his colleague that his family had fled to a nearby evacuation center, and one week later, he reunited with them, and his wife broke into tears.

Even after returning home, he was too busy with work and could not help with domestic chores. His wife has to face the fear of aftershocks on a daily basis, wondering "what to do if another strong quake occurs."

The situation is slowly returning to normal, but his wife sometimes cries after she sees him or the child off. He wonders "how to comfort her" or "what to say to her".

This is likely a case where an emotional distress occurred due to the inability to share the anxiety and fear from the earthquake with the family and due to suppressing such emotions. His wife was experiencing mental and physical stress from the fear of earthquakes, the uncertain safety of her husband, and the inconvenient evacuation to protect the child. She was likely relieved to find that her husband was safe and able to return home. After she resumed a normal life of sending off her husband and child, she likely suffered the fear of not seeing them again due to an earthquake, resulting in her crying. We let the employees take their time and talk about their feelings, such as "It must have been really difficult for you after the earthquake" and "It's back to normal now, but it's scary to think that another earthquake can separate us from family, isn't it?" After they were mentally calm, we advised them to make specific measures for emergencies such as communication methods and setting meeting places.

There will likely be demand for individual consultations from the employees. It might also be necessary for industrial health staff members to hold a small-scale lecture for each workplace, where employees can share what is causing them stress.

\section{Responding to Changes in Expected Roles}

Support for Fukushima involves phone consultations, on-site environmental monitoring, delegation of human resources for the government, coordination of temporary return to home, and lectures on nuclear power in communities. However, the situation is changing every day.

Phone consultations involve answering phone calls from outside, just like a customer 
service center in a company. The questions range from open-ended questions such as whether their location is safe or what to do to specific ones such as a request for a radiation measurement in their house, and whether the food is safe. They also include emotional expressions such as "how you are going to take responsibility" and "hold consultations on the site." The number of consultations increases following TV reports on certain food and communities, and the quality of questions increases with residential knowledge regarding nuclear power. Many consultations end with words such as "I am relieved" or "thank you" when the concerns are heard and addressed based on the person's background. However, the operators cannot hang up the phone, some consultations last for a few hours, and some employees take the client's emotions personally, which results in significant psychological stress, headaches, insomnia, and depression. Workers who take on this task have broad knowledge about nuclear power, and have to suspend their own work, which is highly limiting. Departments with facilities need several workers for protection management, even during machine down time. Also, there are employees who have knowledge and experience regarding radioactive materials but have a difficult time addressing the various questions from the residents. Therefore, certain employees take on most of the tasks, increasing psychological stress, and need psychological and mental support.

The NFCEL regards the Fukushima support as a "task that needs healthcare management," and the organization has started to provide support. Specifically, before and after Fukushima support tasks, the department and industrial health staff carry out health checks via questionnaires in an attempt to detect health issues. Since it is impossible to draw conclusions simply by using questionnaires, industrial health staff and departments communicate in regard to this initiative, make individual risk assessments, and develop activities for Fukushima support (days of service, number of services, and necessary follow-up system).

Even amid writing this paper, employees are receiving new requests one after another, indicating that the expected tasks can change in the future. In the past, JAEA had to validate its significance, but following the earthquake, the public has expectations from the agency. This, in part, has a positive effect on employee motivation. However, support for Fukushima will likely be a long-term effort, and the voluntary nature of the current support tasks will not sustain employees' motivation. Under such circumstances, many do not spare cooperation but struggle with finding what they can do, and it is necessary to examine how to engage them. In fact, some employees cannot work on their original assignments, and are concerned with how long the situation will last and wonder when they can start working on their original assigned work. The Fukushima support office that was newly established in May, 2011 became one of the duties of JAEA. This necessitates the continuous motivation of the employees.

\section{Conclusions}

Here, we have provided a summary of the environment of JAEA and its changes from the viewpoint of occupational physicians. The environment surrounding the employees varies due to many factors, which requires them to adapt to rapid changes, causing significant stress. However, what has been written in this paper is not just contained in our minds. We have started to communicate our opinions to managerial personnel and employees and hold necessary discussions. In closing, we promise to continue taking proactive steps to invigorate the employees in the field of nuclear power from the viewpoint of occupational physicians. 


\section{General references}

1) Antonovsky A. Solving the mystery of health.: Yushindo; Tokyo, 2001. [in Japanese]

2) Matsuzaki I, Sasahara S. Mental health in universities and research institutes. Rinsho-Seishin-Igaku (Clin. Psych.). 2004;33:869-875. [in Japanese]

3) Tomotsune Y, et al. Characteristic and changes of mental health among workers in Tsukuba Research Park City-From a Large Scale 5-Year Cross Sectional Study. (J. Phys. Fitness, Nutrition Immunol.) 2008;18:195-204. 
The Circumstances of Severe Accident Measure Implementation and "The Residual Risk"

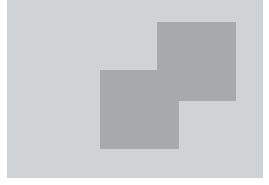

\author{
Tokyo City University, Mitsumasa Hirano
}

The examination of the direct factor(s), cause(s), and root cause(s) of the Fukushima Daiichi Nuclear Power Plant Disaster are the responsibility of the "Hatamura Committee" (Investigation Committee on the Accident at the Fukushima Nuclear Power Plants of Tokyo Electric Power Company, Chairman: Dr. Yotaro Hatamura), but it is clear that there were insufficient measures taken regarding the tsunami. Following this unprecedented and major accident, examinations are being undertaken in regard to revising the safety design guidelines and severe accident (SA) measures as regulated requirements. This study revisits the course and changes in the SA measures, implemented as voluntary protection under governmental guidance, including the introduction of "residual risk" in the seismic resistant design examination guidelines that were aimed toward the expansion and completion of the SA measures. The author believes that the lessons learned from this study will help improve safety in nuclear power facilities in the future.

\title{
Introduction
}

The Fukushima Daiichi Nuclear Power Plant Disaster caused catastrophical damage, and the restoration activity is still in progress. Some opinions hold that the cause and effect of the disaster are different from those of the former Soviet Union's Chernobyl Accident, but as one of the personnel involved with nuclear power, the author feels remorse and has significant concern for the people who had to evacuate and give up their residences, agricultural lands, and farms and for the damage caused to agricultural crops and livestock products in areas far from the plants. The examination of the direct factor(s), cause(s), and root cause(s) of this unprecedented accident are the responsibility of the Hatamura Committee, but it is clear that there were insufficient countermeasures taken in regard to the tsunami; therefore, this commentary aims to learn lessons as a staff member involved in this severe accident (SA) measures, including those related to "residual risk."

DOI : 10.15669/fukushimainsights.Vol.1.138

(C) 2021 Atomic Energy Society of Japan. All rights reserved.

Originally published in Journal of the Atomic Energy Society of Japan (ISSN 1882-2606), Vol. 53, No. 11, p. 748-754 (2011)

in Japanese. (Japanese version accepted: August 22, 2011) 


\section{Course of Establishment of SA Countermeasures}

Based on the lessons learned from the Three Mile Island Reactor 2 (TMI-2) Accident (March 1979) and Chernobyl Accident (April 1986), many countries have implemented countermeasures for severe accidents (SA), which lead to serious core damage that is the dominant risk factor in nuclear reactor facilities, and have studied how to reduce risks by preventing the occurrence and mitigating the impact of SA.

(1) The Nuclear Safety Commission extracted lessons (52 items) based on the investigation of the cause of TMI-2 Accident, including (i) reinforcement of education and training of operators, (ii) review of accident management procedures, (iii) establishment of a power plant emergency countermeasures office, and (iv) establishment and reinforcement of measurement instruments, and reflected the same in the nuclear safety policies in Japan.

(2) After the Chernobyl Accident, which caused radiation damage beyond the border, it was concluded that there was no lesson to be immediately reflected in the European-style light-water reactor in term of facility aspect, since the causes were mainly RBMK reactor design faults such as a positive void reactivity coefficient and a positive scram besides deviations from regulations and the operation plan. With the advent of safety culture, however, international attention has been focused not only on correct plant operation but also on the systems and organizations that prioritize safety.

(3) Based on the recognition of the importance of SA prevention measures and impact mitigation measures in case of SA in terms of improving safety, the Nuclear Safety Commission established a common problems conference and examined SA countermeasures, SA research, probabilistic safety assessments (PSAs), etc. A common problems conference report states, "Assuming that the safety of a nuclear reactor facility has been secured through safety activities corresponding to design basis events and that the risk of radiation to the surrounding public by reactor facility is sufficiently low, appropriate SA countermeasures (accident management: AM) based on PSA will significantly reduce the possibility of SA and alleviate its impact on the public, hence the risk will eventually be further reduced, even if SA or an event leading to SA occurs in the nuclear reactor facility." 1)

(4) Based on this report, the Nuclear Safety Commission published a decision in May 1992 with the following points. ${ }^{2)}$

1) Nuclear reactor installers should voluntarily prepare effective AM to improve the safety of nuclear reactor facilities, and ensure an appropriate implementation of management in case of emergency.

2) The administrative agency should identify its role in terms of the promotion and preparation of AM and continuously conduct specific examinations.

3) As a temporary measure, the following matters should be reported by the administrative agency.

i) An AM implementation plan prior to fuel installation for new nuclear reactor facilities (facility specifics, preparation of manuals, staff education and training, etc.)

ii) A future AM implementation plan for nuclear facilities in operation or construction

iii) A PSA to be implemented in i) and ii)

4) It is necessary for related organizations and nuclear reactor installers to continuously study SA. The Nuclear Safety Commission tracks the results of the above effort and conducts necessary investigations.

(5) Based on the decision of the Nuclear Safety Commission, the Ministry of International Trade and Industry made the following request (July 1992) for SA countermeasures to electric utilities and established an SA countermeasures meeting to use expert opinions for evaluating 
the validity of the AM proposed by the companies ${ }^{3)}$.

1) Implementation of PSA and corresponding preparation of AM

i) Implement Level 1 and Level 2 PSAs, understand the characteristics of each nuclear power plant, and investigate the candidate AM by the end of FY 1993. In addition, investigate the technical requirements of AM, such as primary containment vessel (PCV) measures including a PCV venting system and hydrogen control, an operation manual, and staff training.

ii) Strategically and quickly prepare the necessary AM based on the investigation results.

iii) Evaluate the validity of the above AM in the periodic safety reviews (PSRs), etc.

2) Others

i) Electric utilities will implement shutdown PSAs (Level 1 PSA) within a year in representative nuclear power plants, and take appropriate actions based on the results.

ii) Electric utilities will continue to improve the accuracy of PSA methods, conduct research to expand its scope, and develop the database with information such as instrument malfunction probability.

Below are some points that the government discussed with electric utilities in regard to the topic of voluntary safety.

a) It is agreed that Level 1 and Level 2 PSAs required from individual plants are Level 1 and Level 1.5 PSAs (up to the failure of the PCV) during power operations of the internal event, which was based on the PSA technology development status in Japan at that time.

b) Initially, the primary containment vessel countermeasures such as the PCV venting system and hydrogen control were required, regardless of the PSA results, but it was decided that the decision is made by efficacy evaluation with PSA.

c) The PSA implemented during shutdown is also carried out on representative reactors; if required, the appropriate response is sought out. Furthermore, based on the recognition of the significant risk of earthquakes in this country, electric utilities are requested to conduct research and development on PSA for external events such as earthquakes, i.e., expanding the scope of the research.

Item 1) c) is expected of electric utilities, but the government is to follow up. (See PSR in Chapter III)

(6) Posterior events

In March 1994, electric utilities reported the PSA results and the candidate AM to the Ministry of International Trade and Industry. The Ministry of International Trade and Industry and The Nuclear Safety Commission verified the validity of the same, and the electric utilities began preparation of AM on existing reactors with a goal of completion by 2000 .

Electric utilities reported the completion of AM preparations on existing reactors in May 2002 and submitted the results of a quantitative efficacy evaluation of AM based on individual plant PSA by March 2004. The Nuclear and Industrial Safety Agency (with technical support from the Japan Nuclear Energy Safety Organization (JNES)) and the Nuclear Safety Commission reviewed them based on the basic requirements of AM preparation (April 2002) and deemed them to be valid.

\section{Prepared SA Countermeasures}

Figures 1 and $\mathbf{2}$ show an example of the procedure of the extraction of AM measures. 
The procedure identifies an accident scenario in which core damage or PCV damage occurs, and prepares a system to replace the major loss of safety functions being a major cause of above accidents, and accident countermeasure procedures, which were most systematic among the SA countermeasures in many other countries.

This commentary does not mention the specific details of AM countermeasures; however, as Figure 2 indicates, the AM countermeasures for station blackouts caused by internal events

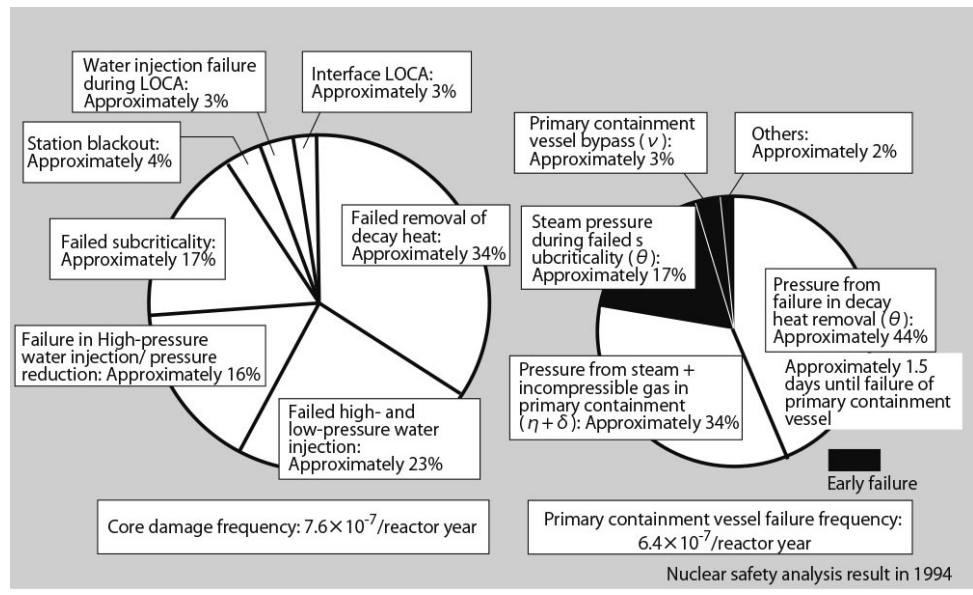

Figure 1 PSA example of Plant BWR5 (internal event, during output)

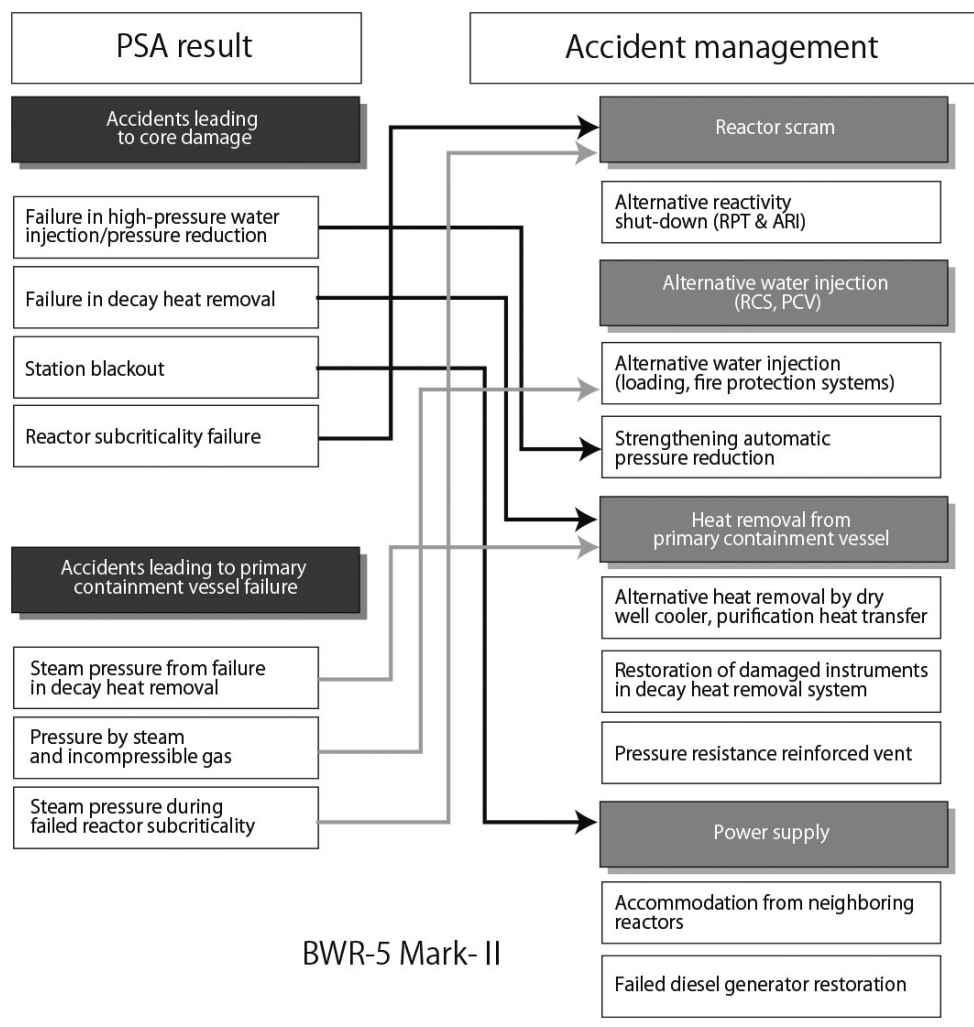

Figure 2 Extraction of accident management measures 
involve the restoration of the damaged emergency diesel generator (D/G) and accommodation from adjacent reactors. This explains the lack of a complete implementation of cooling by alternative water injection and the PCV vent, which have been heatedly debated in Fukushima Daiichi Nuclear Power Plant. However, AM is a "knowledge-based" treatment based on technical knowledge of the electric utilities, and it is desired that AM be carried out based on such knowledge and the situation in a flexible fashion. This makes research necessary for expanding its scope, as previously mentioned.

Preparation of AM on new reactors and a review of its validity by the government have been continued, and a review on Shimane Plant 3 was recently carried out in 2010. The SA countermeasures for the new reactors are basically the same as those proposed in 1994, and reflections of latest knowledge by SA research and expansion of the scope of examination, as mentioned in 4) in (4) and 2) in (5), were not made, except for the fact that the instrument malfunction probability used in PSA was based on the national data prepared with the standard set by the Atomic Energy Society of Japan.

\section{Periodic Safety Review (PSR)}

Following a request by the Ministry of International Trade and Industry around the time of the request for SA countermeasures ${ }^{4)}$, a PSR for the overall evaluation (in terms of the points below) of the safety of existing nuclear power plants was initiated as part of electric utilities' efforts toward quality assurance, based on new technical knowledge accumulated over approximately 10 years. The following points were taken into consideration:

1) A holistic evaluation of operational experience, 2) understanding and reflecting latest knowledge and planning necessary countermeasures, and 3) implementing PSA, understanding the efficacy of SA countermeasures, and establishing necessary countermeasures.

The result was to be evaluated by the administrative agency, who established a PSR committee based on expert opinions and conducted an evaluation in regard to the condition of the preparation of SA countermeasures as part of item 3). In fact, this evaluation involved verification of the condition of the SA countermeasure facility and operator education and training at the site, improved the stand-by exclusion facility configuration management procedures, and added the instrument for it, for PSA at the time of shutdown (after March 2001) considering the SA countermeasures based on the PSA during power generation. Furthermore, there was a preliminary agreement with the fire PSA during the following fiscal year, followed by discussion with the earthquake PSA, which slowly but steadily expanded and reinforced the SA countermeasures expressed by research for expanding its scope.

Following the incident inappropriately described by Tokyo Electric Power Company (the so-called shroud issue, August 2002), the regulations on commercial reactors were revised (October 2003), which made the PSR a requirement by law as a safety requirement. However, there was not enough technical knowledge regarding item 3) (related to PSA) to make a legal requirement, which remained a voluntary requirement with no evaluation by the administrative agency. Due to this, efforts aimed toward the periodic assessment of the condition of the preparation of SA countermeasures and expansion of the scope of SA countermeasures practically stopped.

Following this, experts in this country concerned with the risk of earthquakes introduced the idea of "residual risk" in the revision of seismic resistant design review guidelines, as a step aimed toward enhancement and expansion of SA countermeasures. 


\section{Background and Course of the Revision of Seismic Resistant Design Guidelines}

Since 1981, when the previous seismic resistant design guidelines were established, valuable knowledge has been accumulated regarding fault activity behavior, earthquake-motion characteristics, and seismic resistance of buildings from the results of survey research, in particular that conducted for the earthquake in south Hyogo in 1995 (Great Hanshin earthquake). In contrast, citizens requested a more transparent explanation regarding seismic safety for nuclear power plants due to the occurrence of large earthquakes, whose hypocenters have not necessarily been identified preliminarily, and the measurement of earthquakes of a scale beyond the expectations of the previous seismic resistant design guidelines that occurred at some sites.

Based on the domestic and international trends in terms of seismic safety, the seismic resistant design subcommittee established by the Nuclear Safety Commission worked on the following three points: categorizing the matters to be investigated and discussed into 23 items; establishing a basic WG (basic ideas aimed at ensuring seismic safety), a facility WG (facility design method), and earthquake/earthquake-motion WG (evaluation method of design basis seismic ground motion); and surveying and organizing the up-to-date knowledge regarding the said items. Based on the reports from each WG, the revised seismic resistant design guidelines (new seismic guidelines) were established on September 19, 2004, after 5 years and a few months of investigation and discussion.

\section{Characteristics and Significance of the New Seismic Guidelines}

Compared to the previous guidelines, following are the characteristics of the new seismic guidelines:

(1) They are based on a reliable geological and ground survey and decisions regarding design basic seismic ground motion Ss that incorporate uncertainty, and refer to exceedance probability.

(2) It does not deny the possibility of earthquake motions larger than Ss, recognizes the "residual risk," and minimizes the risk reasonably.

For decisions regarding design basis seismic ground motion Ss in above (1), besides considering uncertainty (variance) appropriately in the decision process, exceedance probability is also considered. This is from the perspective that it is desirable to consider using it for understanding and reducing "residual risk" and to understand to what extent the decided response spectrum of Ss corresponds to exceedance probability.

Introduction of "residual risk" in (2) is an innovative revision for SA countermeasures, given the fact that regardless of the definitions and expressions in the previous guidelines, which assumed that there would not be a seismic ground motion of a scale beyond design basis seismic ground motion $\mathrm{S} 2$ based on maximum probable earthquake.

This is because the framework of the revised seismic resistant guidelines with the proposed risk by the basic WG was almost accepted after many discussions. The following section shows the outline of these ideas. 


\section{Characteristics of Events Induced by Earthquake}

In general, the safety of nuclear reactor facilities is achieved through deterministic measures and evaluations based on the principles of defense in depth. Events induced by earthquakes have different features from internal events (events induced by instrument malfunction and human error, etc.).

(1) Earthquakes and ground motion are natural phenomena that cannot be controlled by humans.

(2) Even with the up-to-date technology acquired after the earthquake in south Hyogo (Great Hanshin earthquake), it is difficult to accurately estimate, with small uncertainty, the scale, frequency, and characteristics of earthquakes and ground motion.

(3) Large ground motions can cause simultaneous damage to important systems, instruments, and buildings, disabling the multiple layered protection.

\section{Basic Framework}

There are various guidelines for "preventing disasters" as written in the Reactor Regulation Act (Act on the Regulation of Nuclear Source Material, Nuclear Fuel Material and Reactors). Figure 3 shows the positioning of the seismic guidelines.

(1) The nuclear reactor site review guidelines include the following points:

A. A nuclear reactor must be designed, constructed, operated, and maintained in a way that prevents accidents.

B. Considering the events around the facility site, reactor characteristics, and safety protection facilities, it should be ensured that the surrounding public is not affected by radiation, even assuming that a serious accident can technically occur in the worst case (SA).

C. Furthermore, it should be ensured that the surrounding public is not affected significantly by radiation, even if an inconceivable accident (virtual accident) beyond SAs, which cannot be considered from technical perspectives occurs (e.g., emission of radioactive materials corresponding to a malfunction of some of the safety protection facilities during a SA).

The guidelines require the subject facility to limit the influence on the surrounding public

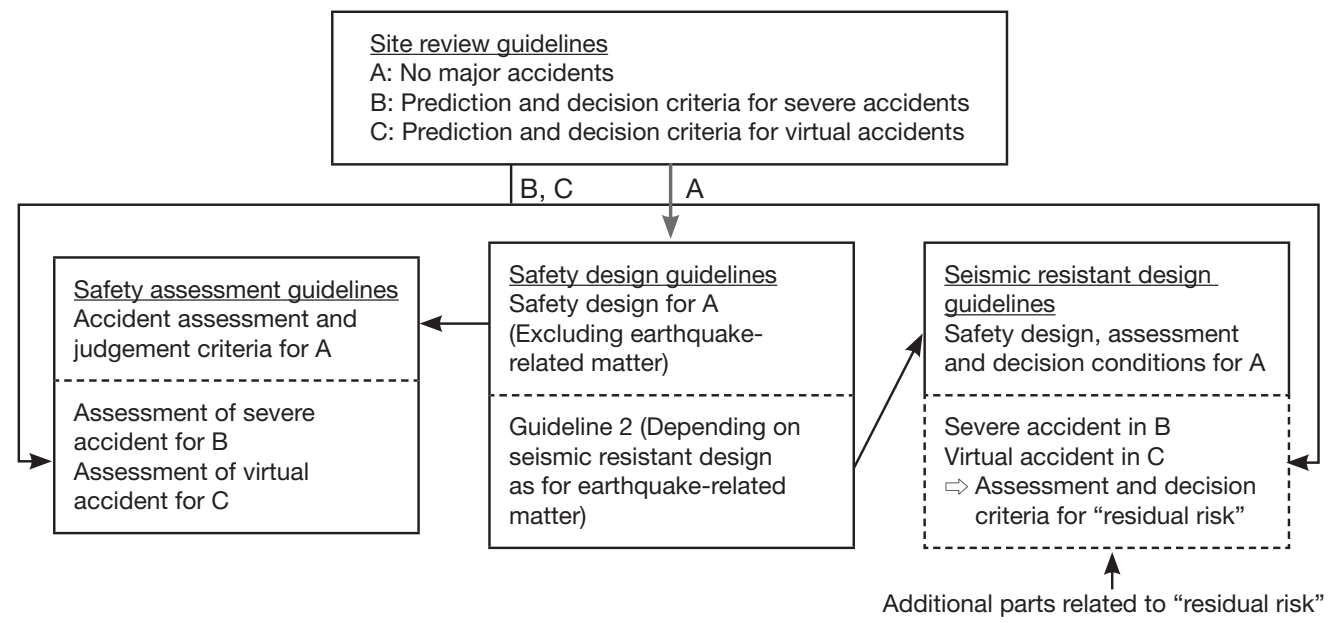

Figure 3 Role of seismic resistant design guidelines 
for each of the three conditions with different occurrence probabilities.

It is commonly recognized that $\mathrm{B}$ and $\mathrm{C}$ are regulations for $\mathrm{SA}$ beyond the design basis event.

(2) The safety design guidelines require safety design so as to satisfy condition A, but the explanation of section 1 of guideline 2 expects the seismic resistant design guidelines to specifically ensure seismic safety. In other words, it expects the design measures for A in the seismic resistant design guidelines.

(3) The safety assessment guidelines specify the method of safety assessment in regard to $\mathrm{B}$ (SA) and $\mathrm{C}$ (virtual accident) in addition to that for the design basis event for the validity of design (A), but clearly assumes internal events and not earthquakes.

(4) Therefore, the seismic safety that is deemed valid by the seismic resistant design guidelines should be congruent with the "relationship between occurrence probability and damage" allowed by guidelines such as nuclear reactor site review guidelines, and the congruency should be prescribed clearly.

There have been many discussions on the basic framework, which finally led to the introduction of "residual risk."

\section{Concepts for New Seismic Guidelines to Maintain Safe Functions}

The new seismic guidelines (1) account for the prevention of disasters listed in the Reactor Regulation Act by deciding on the design basis seismic ground motion Ss with consideration given to uncertainty and designing the important systems, instruments, and buildings in such a way that safety functions are maintained. As a result, (2) they request that the "residual risk" will remain low in addition to implementation of necessary countermeasures. "Residual risk" is a provision in a commentary, but Supreme Court case precedents show that it is often as binding as main text in regard to ensuring safety.

It is necessary to understand the "residual risk" by using methods such as seismic PSA in order to ensure that "residual risk" is small.

\section{Handling of "Residual Risk"}

\section{Definition and Requirement of "Residual Risk"}

"Residual risk" involves ground motion exceeding design basic seismic ground motion Ss extending to facilities so that 1 ) event(s) involving serious damage to the facility occur(s), 2) a large amount of radioactive materials is emitted, and 3) the surrounding public is exposed to radiation, which leads to disaster. Efforts should be made to understand the existence of the "residual risk" and make it as low as reasonably achievable.

\section{Assessment Method and Decision Indicator of "Residual Risk"}

The PSA method, which was developed and prepared in Japan's research institutions, regulatory support organizations, and industries, and used for analysis of commercial plants, is the implementation standard at the Atomic Energy Society of Japan, as shown in Figure 4. In particular, the seismic PSA implementation standards have been explained several times in the seismic resistant design subcommittee. Given that Japan is an earthquake-prone country, 
IAEA, NRC, and other organizations have deemed this method to be the most advanced globally.

It is valid to use the safety goals (draft) and performance goals (draft) established by the Nuclear Safety Commission as the judgment criteria. However, there is an increasing trend in the international community toward further reducing the risk of nuclear power plants, and it is necessary to review the performance goals.

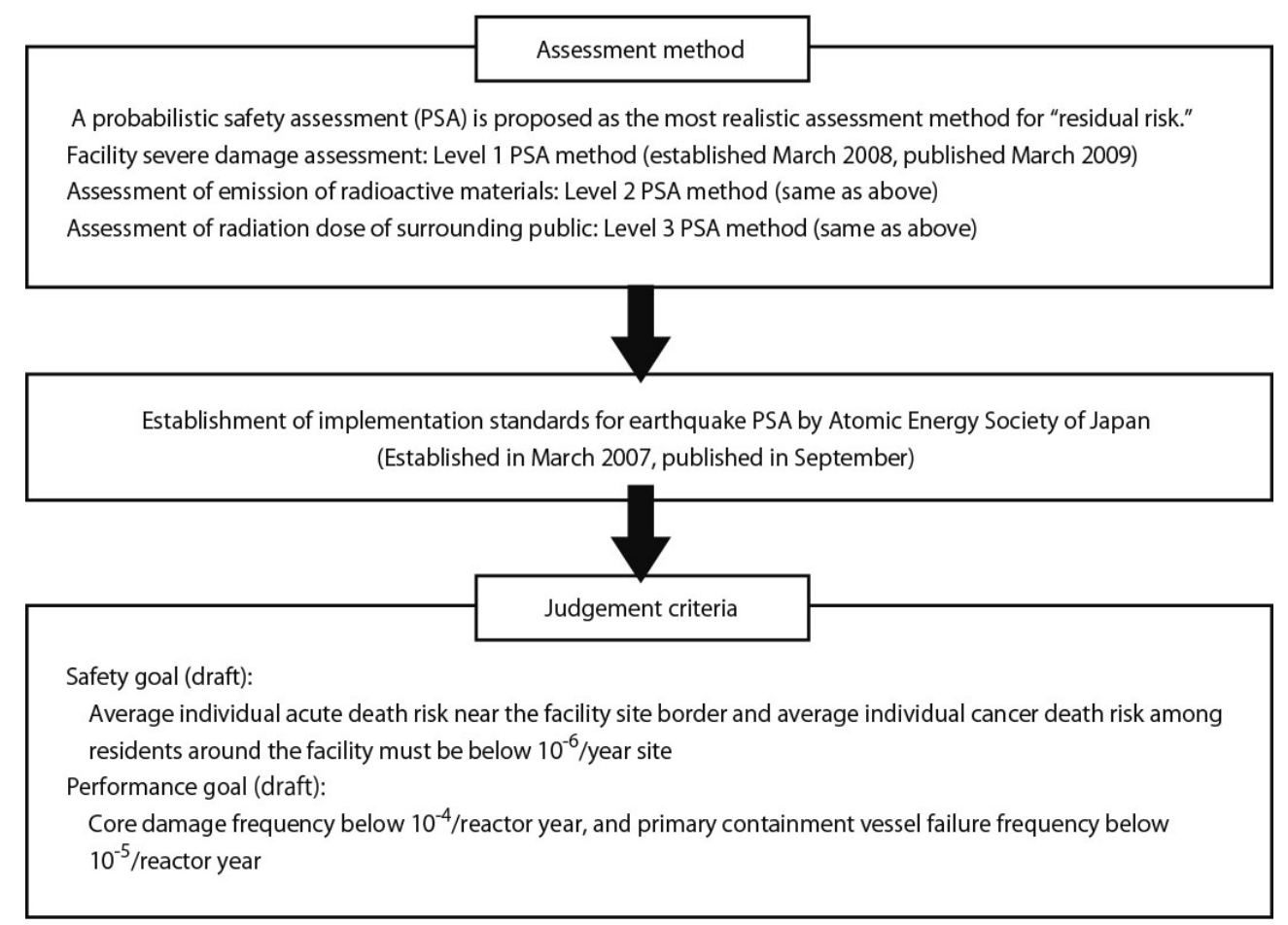

Figure 4 Assessment method and judgment indicator of "residual risk"

\section{Information from Seismic PSA and Reduction of "Residual Risk"}

(1) High transparency and explanatory power, clearly indicating assessment conditions, assessment models, used data, and assessment results.

(2) Enables obtaining and using the following information important for seismic safety.

- Appropriate seismic resistance importance classification for structures and instruments from the perspective of core damage frequency (CDF).

- Understanding of common-cause failure where multiple instruments are damaged during ground motion.

- Understanding of system redundancy and efficacy of multilayer protection by understanding the system and accident sequence important to CDF.

- Understanding the scale of ground motion leading to cliff edges such as core damage and damage in PCV.

- Comparisons among "residual risk" and safety goal, performance goal, and international standards.

In other words, the seismic PSA enables focus on buildings, instruments, and systems 
that considerably impact on $\mathrm{CDF}$, and executes improvements in seismic safety with plant remodeling and SA countermeasures aimed at reducing "residual risk." For example, reinforcement of structures involves strengthening support structures (basic anchor bolts and piping supports) for static parts such as tanks and pipes, and reduction in response by damping and isolating structures for dynamic instruments such as pumps and electric boards.

\section{Seismic Resistance Back Check}

(1) The Nuclear Safety Commission (September 19, 2006) concluded that the seismic safety of nuclear power facilities is secured not only through basic design but also detailed design, a construction process based on such design and appropriate operation management. The commission decided that it would receive reports from the administrative agency in regard to the assessment of seismic safety, including "residual risk," in addition to safety review.

(2) The Nuclear and Industrial Safety Agency ordered a seismic resistance back check to electric utilities (September 20, 2006).

Stage 1 (Swift implementation)

- Decisions on Ss considering uncertainty and safety assessments of buildings and instruments

- Decisions on tsunami formulation considering uncertainty and safety assessments of buildings and instruments.

\section{Stage 2 (After preparation)}

Table 1 Status of seismic resistance back check

\begin{tabular}{|c|c|c|c|c|c|}
\hline Company & Facility & $\begin{array}{l}\text { Discussion } \\
\text { status }\end{array}$ & Company & Facility & $\begin{array}{l}\text { Discussion } \\
\text { status }\end{array}$ \\
\hline Hokkaido Electric & Tomari & $\triangle$ & \multirow{2}{*}{$\begin{array}{l}\text { Kansai } \\
\text { Electric }\end{array}$} & $\begin{array}{c}\text { Ooi } \\
\text { (Reactor 3, 4) } \\
\end{array}$ & (C) \\
\hline \multirow{2}{*}{$\begin{array}{l}\text { Tohoku } \\
\text { Electric }\end{array}$} & $\begin{array}{l}\text { Onagawa } \\
\text { (Reactor 1) }\end{array}$ & (9) & & $\begin{array}{c}\text { Takahama } \\
\text { (Reactor 3,4) }\end{array}$ & (2) \\
\hline & Totsu & $\triangle$ & Chugoku Electric & $\begin{array}{c}\text { Shimane } \\
\text { (Reactor 1,2) }\end{array}$ & () \\
\hline \multirow{4}{*}{$\begin{array}{l}\text { Tokyo } \\
\text { Electric }\end{array}$} & $\begin{array}{c}\text { Kashiwazaki kariwa } \\
\text { (Reactors 1, 5, 6, 7) }\end{array}$ & $\begin{array}{c}\text { ( } \\
\text { (Final Report) }\end{array}$ & Shikoku Electric & $\begin{array}{c}\text { Ikata } \\
\text { (Reactor 3) }\end{array}$ & (2) \\
\hline & $\begin{array}{l}\text { Fukushima Daiichi } \\
\text { (Reactor 3) }\end{array}$ & $\diamond$ & \multirow{2}{*}{ Kyushu Electric } & Genkai (Reactor 3) & (C) \\
\hline & $\begin{array}{l}\text { Fukushima Daiichi } \\
\text { (Reactor 5) }\end{array}$ & (2) & & Sendai (Reactor 1) & (2) \\
\hline & $\begin{array}{l}\text { Fukushima Daini } \\
\text { (Reactor 4) }\end{array}$ & (2) & \multirow{2}{*}{$\begin{array}{c}\text { Japan Atomic Power } \\
\text { Company }\end{array}$} & Tokai Daini & $\bigcirc$ \\
\hline $\begin{array}{l}\text { Chubu } \\
\text { Electric }\end{array}$ & Hamaoka & $\begin{array}{c}\triangle \\
\text { (Final Report) }\end{array}$ & & Tsuruga & $\triangle$ \\
\hline Hokuriku Electric & $\begin{array}{c}\text { Shiga } \\
\text { (Reactor 2) }\end{array}$ & (2) & \multirow{2}{*}{$\begin{array}{c}\text { Japan Atomic Energy } \\
\text { Agency }\end{array}$} & Monju & $\begin{array}{c}\stackrel{(}{\text { (Final report) }} \\
\end{array}$ \\
\hline \multirow[t]{2}{*}{$\begin{array}{l}\text { Kansai } \\
\text { Electric }\end{array}$} & $\begin{array}{l}\text { Mihama } \\
\text { (Reactor 1) }\end{array}$ & (2) & & Reprocessing & $\triangle$ \\
\hline & & & $\begin{array}{c}\text { Japan Nuclear Fuel } \\
\text { Limited }\end{array}$ & Rokkasho & $\begin{array}{c}\bigcirc \\
\text { (Final report) }\end{array}$ \\
\hline
\end{tabular}

(): Verified by NSC $\bigcirc$ : Discussed by NISA and under discussion by NSC $\triangle$ :Under discussion by NISA $\diamond$ : Specially treated and verified by NISA

NSC: Nuclear Safety Commission NISA: Nuclear and Industrial Safety Agency

※ Except for the final report, the interim report is used for discussion, which does not include assessment of the tsunam 
- Quantitative assessment of "residual risk" using seismic PSA.

Table 1 shows the advancement status of the seismic resistance back check in stage 1 .

The plan was that the electric utilities would begin implementation within three years of request from the government. However, the floor response was accelerated by two times the design floor response based on the previous seismic resistance guidelines in Kashiwazaki-Kariwa Nuclear Power Plant buildings due to Chuetsu offshore earthquake in July 2005. Mainly due to this event, Stage 1 took a long time and there was a delay in laterally, reflecting new knowledge from the cause analysis (ground motion amplification and building floor flexibility, etc.) to each site and plant. In addition, the assessment of ground motion was prioritized, and there were discussions on the Jogan tsunami (the 869 Sanriku earthquake) in association with earthquake motion at the Fukushima Daiichi site. However, most interim reports do not include assessment of the tsunami. There are also no reports by electric utilities regarding "residual risk."

The results are difficult to predict, but the delay in the seismic resistance back check is deeply regretted, given the seriousness of the accident at the Fukushima Daiichi Nuclear Power Plant.

\section{Conclusions}

There are 28 lessons learned from the accident in the report by the Japanese government published in June $2011^{5)}$. The lessons directly related to SA countermeasures include group 1 (8 items: reinforcement of severe accident prevention measures) and group 2 (7 items: severe accident countermeasures), but many of them are related to SA, and this country needs to take the matter seriously.

This commentary discusses the earthquake/tsunami that is the direct cause of the accident and the safety culture, which forms the basis for accident response.

\section{Lesson 1: Reinforcement of earthquake/tsunami countermeasures}

The summary is stated as follows: "The earthquake was extremely large with multiple hypocenters, but the seismic resistant design assumed 120,000-130,000 years for the active period of the active faults of concern and appropriately considered the re-occurrence of large earthquakes. As a result, there was no significant damage recognized in important facilities and instruments for safety (further inspection is needed. The seismic resistance back check has not been completed at the Fukushima Daiichi site). The tsunami was $14-15 \mathrm{~m}$ in height, exceeding the predicted height $(5.7 \mathrm{~m})$ based on lore/clear traces of the previous tsunami by the tsunami design, indicating that the tsunami countermeasures were not sufficient.

Future plans include deciding on the tsunami design with a predicted occurrence frequency and height of re-occurring tsunamis as well as formulating a safety design of buildings for preventing inundation. We shall also recognize the existence of the risk of tsunami of scales larger than the tsunami design reaching the facility (residual risk), and plan countermeasures to maintain the important safety functions."

A ground motion larger than the design basis seismic ground motion S2 predicted by the maximum probable earthquake of the previous seismic resistance guidelines was observed in some sites. In the Kanazawa District Court decision which ordered the suspension of Unit 2 of Shiga Nuclear Power Plant, it has been pointed out there was not enough consideration given to the danger of active faults, which made the calculation method less valid. Given the above observations, there was insufficient discussion on tsunami, though there was an urgent 
need for revision of seismic resistance guidelines.

However, the new seismic guidelines state the following about tsunamis as by-products of earthquakes and it is important for related personnel involved in design and review to recognize that "there is little possibility of significant damage to safety functions of facilities, even by tsunamis that are extremely rare occurrences with finite probability during the operation period of the facility," which is the same requirements to the primary requirements for seismic ground motion.

\section{Lesson 28: Establishing Safety Culture}

The summary of the Japanese Government Report also stated as follows. "“Nuclear safety culture' is 'the integrated recognition, mindset, and attitude that organizations and individuals should have in order to ensure that important matters are prioritized in regard to safety issues concerning nuclear energy'. It is the starting point, duty, and responsibility of staff responsible for nuclear energy to internalize such culture. For organizations and individuals involved in nuclear industries and nuclear regulation, it is important not to neglect the slightest doubts about safety and to seriously reflect if they sensitively and swiftly respond to new knowledge.

Hereafter, the following points are expected: nuclear safety staff shall return to a basic understanding of the importance of pursuing defense in depth for nuclear safety, and learn expert knowledge regarding safety, repeatedly seek for improvement in safety, and establish a safety culture."

The root cause of the accident is not so much the insufficient setting of the design basis events and guidelines and standards for unexpected events as the lack of safety culture among the persons who design, construct, operate, review and regulate. For example, the seismic resistant design guidelines request that efforts be made to reduce the "residual risk" due to seismic ground motion of magnitudes higher than the design basis seismic ground motion Ss. Those engaged in nuclear safety must have this view regarding tsunamis, which are by-products of earthquakes. It is necessary to understand and reduce the "residual risk" while considering both seismic ground motion and tsunami.

In retrospect, the implementation of the first individual plant PSA in early 1990s by our predecessors and the development of SA countermeasures were not inferior when compared to international standards in terms of SA research and the maturity of risk assessment technology. Japan's new seismic guidelines, including the introduction of "residual risk," are considered to be the most advanced in the world and referred to in IAEA safety requirements and guidelines.

Points to reflect upon are not only that the following generation did not hold governmental review of PSRs but also that there was no implementation of an expansion of the scope of SA countermeasures based on SA research and new knowledge in PSA technology, and that the seismic resistance back check was not implemented as planned.

In the future, there will likely be revisions of guidelines and standards as well as regulated requirements for SA countermeasures. In addition to the establishment of a sound framework, more important is a safety regulation system based on a high safety culture in both industries and regulators who will accomplish and improve the framework.

\section{References}

1) Common problem conference. Examination report on severe accident management as severe accident measures -- focus on countermeasures for primary containment vessels 1992 March. [in Japanese]

2) Nuclear Safety Commission. On accident management as severe accident countermeasures for light-water nuclear power reactor. 1992 May (partially revised in 1997 October). [in Japanese]

3) Ministry of International Trade and Industry. On future advancement of accident management 


\section{INSIGHTS CONCERNING THE FUKUSHIMA DAIICHI NUCLEAR ACCIDENT Vol. 1}

countermeasures. 1992 July. [in Japanese]

4) Ministry of International Trade and Industry. On the implementation of a periodic safety review. 1992 June. [in Japanese]

5) The Government Nuclear Emergency Response Headquarters. Report from Japanese government for cabinet meeting of IAEA regarding nuclear safety -- Accident at the Tokyo Electric Power Fukushima Nuclear Power Plant. 2011 June. 


\title{
Waste Contaminated with Radioactive Material from the Fukushima Dai-ichi Nuclear Power Plant Accident
}

\section{-Relation between Amount of Radioactive Material in Waste and Related Laws-}

\author{
Japan Radioisotope Association, Shoji Futatsukawa
}

\begin{abstract}
In the Fukushima Daiichi Nuclear Power Plant Accident, a considerable amount of unplanned radioactive materials were emitted into the environment, creating waste contaminated by radioactive materials. To address this situation, the "Act on Special Measures for Debris Management" was established on August 26th 2011, paving way for managing waste and soil contaminated by radioactive materials. However, specific management and disposal methods have not been clearly defined. Waste management planning is steadily advancing, which will likely lead to reasonable and realistic methods for restoration. This commentary explains the relation between the waste contaminated by radioactive materials in the Fukushima Daiichi Nuclear Power Plant Accident and the related laws as they stand today.
\end{abstract}

\section{Generation of Waste}

On March 11th 2011, the unprecedented Great East Japan earthquake caused Tokyo Electric Power's Fukushima Daiichi Nuclear Power Plant accident (referred to as the Fukushima Nuclear Plant Accident), which led to a considerable amount of unplanned radioactive materials being emitted into the environment. These materials were deposited over a wide range of areas depending on the topographical and meteorological conditions, contaminating soil, crops, and water and creating various wastes contaminated by radioactive materials. Before the Fukushima Nuclear Plant Accident, an emission of such a large amount of radioactive material outside of the radiation facility was not anticipated and there were no laws for regulating it. On August 26th 2011, the first law regarding management of environmental pollution due to nuclear accidents, the "Act on special measures for managing environmental pollution by radioactive material released by Nuclear Power Plants Accident" (hereinafter, the Act on Special Measures for Debris Management), was established, paving way to manage debris and soil contaminated by radioactive material; however, specific management and disposal methods have not been clearly defined.

DOI : 10.15669/fukushimainsights.Vol.1.151

(C) 2021 Atomic Energy Society of Japan. All rights reserved.

Originally published in Journal of the Atomic Energy Society of Japan (ISSN 1882-2606), Vol. 53, No. 12, p. 813-816 (2011)

in Japanese. (Japanese version accepted: September 12, 2011) 


\section{The Waste Management Act and Disaster Waste}

The law regarding general waste management is the "Waste Management and Public Cleansing Act" (hereafter, the Waste Management Act). This law defines "waste" as "garbage, over-sized garbage, cinder, sludge, human waste, waste oil, waste acid, waste alkali, animal carcass, and other garbage and worthless materials in solid and liquid forms (excluding radioactive materials and materials contaminated by the same)," and as such, "radioactive waste" is excluded from the subjects of regulation of this act. The Waste Management Act designates "general waste," which must be treated by the local municipality, and "industrial waste," which must be treated by companies, but treatment of industrial waste is often entrusted to waste management companies. If industrial waste forms majority of waste, which includes small amounts of general waste, it is treated as "industrial waste," and in the opposite case, it is treated as "general waste."

Waste generated by disasters, e.g., earthquakes, tsunamis, and floods (which is left outside), including debris and wood chips from destroyed buildings, concrete, and metal pieces, is called "disaster waste." The management responsibility of it is held by the municipality in which the disaster occurred. In the Han-Shin Awaji Earthquake disaster in 1995, more than 8 million tons of disaster waste was generated, leaving the many issues to be solved, such as securing of disposal sites and transportation routes and inter-municipality collaboration. The management of disaster waste incurs tremendous costs, making it difficult for the affected municipalities to take on the full responsibility. Thus, it was necessary for the government and community as a whole to manage the issue.

Furthermore, since the Waste Management Act is a general law, wastes subject to the regulation of a special measures law are managed according to special regulations.

\section{Radioactive Waste}

Radioactive waste is generated from the use of nuclear energy in Nuclear Power Plants and nuclear fuel cycle facilities as well as from the use of radioisotope in universities, research facilities, and hospitals. "High-level radioactive wastes" refers to vitrified high-level radioactive liquid waste generated from reprocessing of spent nuclear fuel, while other types are called "low-level radioactive waste." Radioactive waste is primarily regulated by Act on the Regulations of Nuclear Source Material, Nuclear Fuel Material and Reactors (hereafter, the Nuclear Reactor Regulation Act), and Act on Prevention of Radiation Hazards due to Radioisotopes, etc. (hereafter, the Radiation Hazard Prevention Act).

\section{Contaminated Waste Generated by Radioactive Materials from Fukushima Nuclear Plant Accident}

Table 1 shows the waste contaminated by radioactive material from the Fukushima Nuclear Plant Accident, categorized by generation type.

Radioactive waste within Tokyo Electric Power's Fukushima Daiichi Nuclear Power Plant is generated as a by-product of the operation of the Nuclear Power Plant and is regulated by the Nuclear Reactor Regulation Act. The Act on Special Measures for Debris Management requires that the management plan for waste generated in restricted areas and planned evacuation areas and contaminated by radioactive materials to such an extent must be set by the Minister for the Environment and that the waste must be managed by the government. Waste beyond the criteria of radiation level generated outside the restricted and planned evacuation 
areas is also managed by the government. Other low-contamination waste contaminated by radioactive materials is managed according to the Waste Management Act. In other words, such waste is managed by the municipality or the related companies themselves. According to the Act on Special Measures for Debris Management, the low-contamination radioactive waste generated inside the radiation facility due to the Fukushima Nuclear Plant Accident can be treated by the Act on Special Measures for Debris Management, but there is no clear definition of the act.

Table 1 Waste contaminated by radioactive materials from the Fukushima Nuclear Plant Accident

\begin{tabular}{|c|c|c|}
\hline Location & Subject waste & Regulation \\
\hline Inside nuclear power plant & Radioactive waste & Nuclear Reactor Regulation Act \\
\hline $\begin{array}{l}\text { Inside restricted area and } \\
\text { planned evacuation area }\end{array}$ & $\begin{array}{l}\text { Waste potentially contaminated to an extent that } \\
\text { requires special management }\end{array}$ & $\begin{array}{l}\text { Act on Special Measures for Debris } \\
\text { Management }\end{array}$ \\
\hline $\begin{array}{l}\text { Outside restricted area and } \\
\text { planned evacuation area }\end{array}$ & Waste exceeding certain criteria of radiation level & $\begin{array}{l}\text { Act on Special Measures for Debris } \\
\text { Management }\end{array}$ \\
\hline Unspecified & $\begin{array}{l}\text { Low-contamination waste from Fukushima Nuclear } \\
\text { Plant Accident }\end{array}$ & Waste Management Act \\
\hline Radiation facility & $\begin{array}{l}\text { Low-contamination waste from Fukushima Nuclear } \\
\text { Plant Accident }\end{array}$ & $\begin{array}{l}\text { Nuclear Reactor Regulation Act or } \\
\text { Radiation Hazard Prevention Act (no } \\
\text { definition in Act on Special Measures for } \\
\text { Debris Management) }\end{array}$ \\
\hline
\end{tabular}

\section{Radionuclide and Concentration in Waste}

\section{Radionuclide from Fukushima Nuclear Plant Accident}

According to the "Report of Japanese Government to the IAEA Ministerial Conference on Nuclear Safety" created in June 2011 by the Government Nuclear Emergency Response Headquarters, the total activities of radionuclides emitted into the atmosphere from the Fukushima Nuclear Plant Accident were $1.6 \times 10{ }^{17} \mathrm{~Bq}$ for ${ }^{131} \mathrm{I}$ and $1.5 \times 10^{16} \mathrm{~Bq}$ for ${ }^{137} \mathrm{Cs}$; in addition, after the beginning of April, the emission activity of ${ }^{131} \mathrm{I}$ reduced to $10^{11} \mathrm{~Bq}-10{ }^{12} \mathrm{~Bq}$.

At that time, the major issue was the surface contamination of crops by radioactivity due to rain and snow. The subject radionuclide was ${ }^{131} \mathrm{I}$, which has a high level of emission. However, the half-life of ${ }^{131} \mathrm{I}$ is 8 days and the current subject radionuclides of issue are ${ }^{134} \mathrm{Cs}$ and ${ }^{137} \mathrm{Cs}$. The contaminated materials are leaves, soil, and sewage in areas with a relatively high concentration of radionuclides and incinerated ash with concentrated radionuclide from incinerating general waste. On August 29, 2011, the Ministry of the Environment published a report "On the management of waste potentially contaminated by radioactive materials in general waste incineration facilities," which contains a "Table of measurement results of radioactive cesium concentration in incinerated ash in general waste incineration facilities in 16 prefectures" up to August 24, 2011, which shows that the maximum ${ }^{134} \mathrm{Cs}$ and ${ }^{137} \mathrm{Cs}$ concentrations in the prefectures ranged widely from 196 to $95,300 \mathrm{~Bq} / \mathrm{kg}$. Based on the report, the number of cases with higher than $8,000 \mathrm{~Bq} / \mathrm{kg}$ and with higher than $100,000 \mathrm{~Bq} / \mathrm{kg}$, and a maximum concentration in 16 prefectures are shown in Table 2. The management of soil with concentrated radioactive materials due to decontamination of top soil is also an issue. Table $\mathbf{3}$ shows the radioactive cesium in agricultural soil in the prefectures shown in the report "Making a distribution map (radioactive cesium concentration map in soil) of radiation by the Ministry 
of Education, Culture, Sports, Science and Technology" announced by the Ministry of Education, Culture, Sports, Science and Technology on August 30, 2011.

Table 2 Radioactive cesium concentration in incinerated ash in general waste incineration facilities (number of cases and maximum concentration)

\begin{tabular}{l|c|c|c} 
& \multicolumn{2}{c}{$\left({ }^{134} \mathrm{Cs}+{ }^{137} \mathrm{Cs}\right)$} \\
\hline Prefecture & Over $8,000 \mathrm{~Bq} / \mathrm{kg}$ (cases) & Over $100,000 \mathrm{~Bq} / \mathrm{kg}$ (cases) & Maximum $(\mathrm{Bq} / \mathrm{kg})$ \\
\hline Iwate & 0 & 0 & 30,000 \\
\hline Miyagi & 0 & 0 & 196 \\
\hline Akita & 0 & 0 & 7,800 \\
\hline Yamagata & 23 & 0 & 95,300 \\
\hline Ibaraki & 10 & 0 & 31,000 \\
\hline Tochigi & 3 & 0 & 48,600 \\
\hline Gunma & 2 & 0 & 8,740 \\
\hline Saitama & 0 & 0 & 5,740 \\
\hline Chiba & 8 & 0 & 70,800 \\
\hline Tokyo & 1 & 0 & 12,920 \\
\hline Kanagawa & 0 & 0 & 3,123 \\
\hline Niigata & 0 & 0 & 3,000 \\
\hline Yamanashi & 0 & 0 & 813 \\
\hline Nagano & 0 & 0 & 1,870 \\
\hline Shizuoka & 0 & 0 & 2,300 \\
\hline Total & 0 & 0 & \\
\hline Basa & 0 & 0 & \\
\hline
\end{tabular}

(Based on "Management of waste potentially contaminated by radioactive materials in general incineration facilities")

Table 3 Analysis of value of radioactive cesium in agricultural soil (Concentration of radioactive cesium corrected on June 14)

\begin{tabular}{l|c|c}
\hline & Number of measurement subjects & Bq/kg( $\left.{ }^{134} \mathrm{Cs}+{ }^{137} \mathrm{Cs}\right)$ \\
\hline Miyagi & 65 & ND-27,981 \\
\hline Fukushima & 361 & ND-632 \\
\hline Ibaraki & 62 & ND-3,971 \\
\hline Tochigi & 48 & $55-688$ \\
\hline Gunma & 13 & $19-777$ \\
\hline Chiba & 30 &
\end{tabular}

(From "Making of a distribution map (radioactive cesium concentration map in soil) of radiation by the Ministry of Education, Culture, Sports, Science and Technology")

ND: "no detection" but not zero. This report does not indicate the detection limit. 


\section{Regulated Concentration}

The Radiation Hazard Prevention Act defines radioisotopes as "those with the quantity and concentration exceeding that specified by the Ministry of Education, Culture, Sports, Science and Technology." In cases involving multiple radioisotopes, they become subjects of regulation if the sum of the ratio of their quantity to the specified quantity exceeds 1 . The subject quantity is the total quantity in one facility. For various scenarios, the regulation values are set such that public exposure dose becomes less than $10 \mu \mathrm{Sv} /$ year under normal operations and $1 \mathrm{mSv} / \mathrm{year}$ for accidents. Each regulation concentration (exemption level) of ${ }^{134} \mathrm{Cs}$ and ${ }^{137} \mathrm{Cs}$ is $10 \mathrm{~Bq} / \mathrm{g}$.

According to "Ideas for the future treatment of by-products such as the water supply and sewage from which radioactive materials were detected" proposed by the Government Nuclear Emergency Response Headquarters on June 16, 2011, "Points to be cautious about storage, temporary storage, and transporting dehydrated sludge" include abiding by the related regulations on Regulation on Prevention of Ionizing Radiation Hazard (Ionizing Radiation Regulation). In the Ionizing Radiation Regulation, the regulation concentrations of both ${ }^{134} \mathrm{Cs}$ and ${ }^{137} \mathrm{Cs}$ are $10 \mathrm{~Bq} / \mathrm{g}$.

Radioactive waste exempted from the regulation include those contaminated by nuclides for positron computerized tomography (PET-nuclides), or the so-called PET wastes. Waste contaminated only by PET-nuclides whose half-lives are between 2 and $110 \mathrm{~min}$, such as ${ }^{15} \mathrm{O}$ and ${ }^{18} \mathrm{~F}$, can be removed from radioactive waste when the number of atoms of the subject nuclides is below 1. According to the Radiation Hazard Protection Act, "PET-nuclides and radioactive wastes contaminated by PET-nuclides after 7 days of storage are not regarded as radioactive wastes." In this case, radioactive wastes can be removed from regulation subjects only through decay storage at storage facilities.

The Reactor Regulation Act has a clearance policy which states that radioactive waste can be removed from subject waste if the quantity of activity in the radioactive waste goes below a certain threshold due to decay and decontamination. The clearance policy makes it possible to recycle radioactive waste, or if recycling is not reasonable, dispose of the same as waste for which there is no need for considering radiation protection. The clearance standards are set such that, no matter how the materials are reused and disposed, the level does not exceed the annual exposure dose for public of $10 \mu \mathrm{Sv}(1 \mathrm{mSv}$ for scenarios with a low probability of occurrence). Each clearance concentration of ${ }^{134} \mathrm{Cs}$ and ${ }^{137} \mathrm{Cs}$ is $0.1 \mathrm{~Bq} / \mathrm{g}$. According to the Reactor Regulation Act, to implement clearance, it is necessary for the nuclear company to determine that the radiation concentration of the waste materials does not exceed the clearance standard and for a regulatory organization such as the government to verify (verification evaluation system). In other words, verification for execution of clearance requires decisions by both the nuclear company and regulatory organization such as the government. A similar clearance policy will be implemented for the Radiation Hazard Prevention Act as well.

Standard concentrations related to the Fukushima Nuclear Plant Accident include the temporary standard value for radioactive cesium in food. With an annual exposure dose of $5 \mathrm{mSv}$, the sum of ${ }^{134} \mathrm{Cs}$ and ${ }^{137} \mathrm{Cs}$ is $200 \mathrm{~Bq} / \mathrm{kg}$ for drinking water, milk, and dairy products and 500 $\mathrm{Bq} / \mathrm{kg}$ for vegetables, grains, meat, egg, fish, and others. In addition, the index for the transfer of radioactive cesium from paddy soil to rice is 0.1 and the maximum allowed value of radioactive cesium concentration in soil for planting is 5,000 Bq/kg. Table 4 shows the regulation concentrations of ${ }^{134} \mathrm{Cs}$ and ${ }^{137} \mathrm{Cs}$ and those related to the Fukushima Nuclear Plant Accident. 
Table 4 Comparison of radioactive cesium concentrations

\begin{tabular}{|c|c|c|c|}
\hline & & ${ }^{134} \mathrm{Cs}$ & ${ }^{137} \mathrm{Cs}$ \\
\hline Radiation Hazard Prevention Act & Regulated concentration & $10 \mathrm{~Bq} / \mathrm{g}$ & $10 \mathrm{~Bq} / \mathrm{g}$ \\
\hline Ionizing Radiation Regulation & Regulated concentration & $10,000 \mathrm{~Bq} / \mathrm{kg}^{* 1}$ & $10,000 \mathrm{~Bq} / \mathrm{kg}^{* 1}$ \\
\hline Reactor Regulation Act & Clearance standard & $0.1 \mathrm{~Bq} / \mathrm{g}$ & $0.1 \mathrm{~Bq} / \mathrm{g}$ \\
\hline \multirow{5}{*}{ Food temporary standard } & Drinking water & \multicolumn{2}{|c|}{$200 \mathrm{~Bq} / \mathrm{kg}^{* 2}$} \\
\hline & Milk & \multicolumn{2}{|c|}{$200 \mathrm{~Bq} / \mathrm{kg}^{* 2}$} \\
\hline & Vegetable & \multicolumn{2}{|c|}{$500 \mathrm{~Bq} / \mathrm{kg}^{* 2}$} \\
\hline & Grains & \multicolumn{2}{|c|}{$500 \mathrm{~Bq} / \mathrm{kg}^{* 2}$} \\
\hline & Meat/fish & \multicolumn{2}{|c|}{$500 \mathrm{~Bq} / \mathrm{kg}^{* 2}$} \\
\hline Soil allowed for planting & Maximum & \multicolumn{2}{|c|}{$5,000 \mathrm{~Bq} / \mathrm{kg}^{* 2}$} \\
\hline Radiation Hazard Prevention Act & Removal standard of PET waste & \multicolumn{2}{|c|}{$\begin{array}{c}\text { Number of atom below } 1 \\
\text { (only for PET-nuclides, e.g., }{ }^{15} \mathrm{O} \text { and }{ }^{18} \mathrm{~F} \text { ) }\end{array}$} \\
\hline
\end{tabular}

"From "Ideas for future treatment of by-products such as water supply and sewage from which radioactive materials were detected." ${ }^{* 2}{ }^{134} \mathrm{Cs}+{ }^{137} \mathrm{Cs}$

\section{Waste Disposal}

According to the "Ideas for future treatment of by-products such as the water supply and sewage from which radioactive materials were detected," the following guidelines have been established. Waste such as dehydrated sludge with the total concentration of ${ }^{134} \mathrm{Cs}$ and ${ }^{137} \mathrm{Cs}$ below $100,000 \mathrm{~Bq} / \mathrm{kg}$, which are buried under the condition that an appropriate long-term dispersal plan will be established and the site will not be used for residence will cause annual exposure dose for public near the burial site to be below $10 \mu \mathrm{Sv}$. Because a site where burials of different conditions were created needs long-term management and it is the necessity for examination of environmental conservation, waste such as dehydrated sludge with the total concentration of ${ }^{134} \mathrm{Cs}$ and ${ }^{137} \mathrm{Cs}$ below $8,000 \mathrm{~Bq} / \mathrm{kg}$, for which the calculation shows that the annual exposure dose of the operators of the disposal of it will not exceed $1 \mathrm{mSv}$, can be buried with an appropriate disposal plan for placement of soil layer and waterproof measures (disposal in a control-type landfill site). Until the safety of use of the site will be secured, the management of the site should involve necessary treatments, such as monitoring of radiation and facility management.

Dehydrated sludge with a total concentration of ${ }^{134} \mathrm{Cs}$ and ${ }^{137} \mathrm{Cs}$ higher than $8,000 \mathrm{~Bq} / \mathrm{kg}$ and lower than $100,000 \mathrm{~Bq} / \mathrm{kg}$ is to be temporarily placed in a control-type landfill site at a certain distance from the site boundaries depended on the concentration until safe disposal can be secured. However, according to "Management of waste potentially contaminated by radioactive materials in general incineration facilities," as of August 2011, such treatment has not been reported to be appropriately implemented.

The report "On the maximum radiation concentration limits for burial disposal of low-concentration radioactive solid waste" put forth on May 21, 2007, by the Nuclear Safety Commission requires that the maximum concentration limits be set for each disposal method of low-concentration radioactive waste, which can be disposed by burial. The concentrations are set for three types of methods (trench disposal, pit disposal, and subsurface disposal) for low-concentration radioactive waste with different nuclides. The threshold dose for burial disposal is $10 \mu \mathrm{Sv} / \mathrm{year}$. The verification of contents such as nuclides and their quantities in radioactive waste to be dispersed and monitoring after burial are necessary. Table $\mathbf{5}$ shows the maximum concentrations limits in trench burial and pit burials, which are obtained in a 
relatively near-surface ground, as well as the concentration in the treatment of water purification waste soil.

Table 5 Comparison of ${ }^{137}$ Cs concentrations for disoposal

\begin{tabular}{l|l|c}
\hline \multicolumn{2}{|c|}{} & ${ }^{137} \mathrm{Cs}$ \\
\hline \multirow{2}{*}{ Maximum concentration limit ${ }^{* 1}$} & Trench disposal & $1 \times 10^{8} \mathrm{~Bq} / \mathrm{t}$ \\
\cline { 2 - 3 } & Pit disposal & $1 \times 10^{14} \mathrm{~Bq} / \mathrm{t}$ \\
\hline \multirow{3}{*}{$\begin{array}{l}\text { Treatment of water purification } \\
\text { waste soil }{ }^{* 2}\end{array}$} & Stored in a facility capable of radiation shielding & $>100,000 \mathrm{~Bq} / \mathrm{kg}^{* 3}$ \\
\cline { 2 - 3 } & Temporal storage in control-type landfill site & $\leqq 100,000 \mathrm{~Bq} / \mathrm{kg}^{* 3}$ \\
\cline { 2 - 3 } & Burial disposal at control-type landfill site & $\leqq 8,000 \mathrm{~Bq} / \mathrm{kg}^{* 3}$ \\
\hline
\end{tabular}

Based on "On the maximum radiation concentration limits for burial disposal of low-concentration radioactive solid waste"

"2 From "Ideas for future treatment of by-products such as water supply and sewage from which radioactive materials were detected."

${ }^{* 3} \quad{ }^{134} \mathrm{Cs}+{ }^{137} \mathrm{Cs}$

\section{Future Prospects}

Considerable radioactive material was emitted into the environment due to the Fukushima Nuclear Plant Accident, and considerable various waste was generated, including disaster waste contaminated by radioactive material. The conventional laws were not established assuming these events that can generate such waste. As such, various measures were planned and implemented during the emergencies during the accident as well as after matters were settled. As for the future disposal of waste contaminated by radioactive materials, however, the main subject nuclide is ${ }^{137} \mathrm{Cs}$, which requires long-term management. From the perspective of radiation protection, it is necessary to ensure consistency between the management of "radioactive wastes" and management of waste contaminated by nuclide emitted from the accident, which will lead to the understanding of citizens. Thus, reasonable and effective waste measures are needed.

\section{References}

1) Horiguchi M. Waste management methods-answer book: Nikkei BP. 2010. [in Japanese]

2) Ministry of Environment. Management of waste potentially contaminated by radioactive materials in general incineration facilities 201129 th August. [in Japanese]

3) The Government Nuclear Emergency Response Headquarters. Ideas for future treatment of by-products such as water supply and sewage from which radioactive materials were detected 2011 16th June. [in Japanese]

4) Nuclear and Industrial Safety Agency. On the clearance policy at nuclear facilities. 2001 August (revised in May 2009). [in Japanese]

5) Nuclear Safety Commission. On the maximum radiation concentration for burial treatment of low-concentration radioactive solid waste. 2007 21th May. [in Japanese] 


\title{
Lessons Learned from the Initial Response to Nuclear Disaster caused by Fukushima Nuclear Power Plants Accident
} -Monitoring and Use of Radiation Information-

\author{
Fukuyama University, Itsumasa Urabe
}

\begin{abstract}
The results of actual environmental radiation monitoring and the series of responses to accidents and disasters have been examined in a parallel fashion to investigate how the understanding of the radiation information was made via environmental radiation monitoring and a System for Prediction of Environmental Emergency Dose Information (SPEEDI) during the initial stage of the accident at the Fukushima Daiichi Nuclear Power Plant. It was discovered from the discussion that a significant amount of time was required for establishing the emergency monitoring system of the Government Nuclear Emergency Response Headquarters and that the proposition of plans and execution of emergency monitoring could have been significantly improved by examining emergency monitoring performed by the Tokyo Electric Power Company and Fukushima Prefecture as well as the SPEEDI results.
\end{abstract}

\section{Introduction}

Based on the experience attained from the JCO accident, the government has reinforced the disaster protection function of the system by enacting the Act on Special Measures for Nuclear Emergency Preparedness and reviewing the Basic Disaster Management Plan (the nuclear emergency response version) to enforce a swift initial disaster response as well as collaboration between the government and local public bodies. In particular, with regard to the emergency response measures for preventing damage escalation, the government has placed importance on the following aspects and has been working to improve the effectiveness of these aspects: implementation of emergency monitoring; an emergency response support system (ERSS) for monitoring the nuclear reactor condition; preparation of a System for Prediction of Environmental Emergency Dose Information (SPEEDI), which predicts the behavior of radioactive materials in the atmosphere; and collection of accident information and radiation information in nuclear power plants via by inspections for the operational safety program.

The nuclear accident at the Fukushima Daiichi Nuclear Power Plant on March 11, 2011 was one of the largest accidents in the world, which exceeded the predictions, and it is important

DOI : 10.15669/fukushimainsights.Vol.1.158

(C) 2021 Atomic Energy Society of Japan. All rights reserved.

Originally published in Journal of the Atomic Energy Society of Japan (ISSN 1882-2606), Vol. 53, No. 12, p. 821-825

(2011) in Japanese. (Japanese version accepted: September 14, 2011) 
to examine how the nuclear disaster response system in this country functioned to understand its effectiveness and improve current response system, which assumed that "accidents can happen." Even today, there are various protective measures in place for the areas surrounding the facility, which is under a state of emergency. While it might be premature to investigate the protective system as a whole since various protective actions are in progress under the emergency declaration, it is important to examine the radiation information collected as well as the measures taken during a nuclear emergency wherein considerable amounts of radioactive materials are emitted to the environment during the initial stage to understand the actual condition of the nuclear disaster.

During the accident, radiation information monitoring was required to be performed during station blackout as well as during the ensuing aftershocks, which caused many difficulties. In this commentary while taking the difficult operation conditions into consideration, the author identifies the actions taken by the Nuclear Emergency Response Office after the onset of the accident and the operated emergency monitoring and attempts to clarify the relations between these conditions for the effective monitoring of initial radiation information during such a disaster.

\section{Monitoring of Emergency Radiation Information}

\section{Emergency Monitoring}

Monitoring of radiation information is done as a basis for planning protective measures such as evacuations at the time of declaration of a state of emergency as well as for evaluating the effect of radioactive materials and radiation on surrounding residents ${ }^{1)}$. The implementation method is divided into two phases according to the importance of these phases when deciding the protective measures during the initial stage: phase 1 is initiated immediately after the onset of emergency, whereas phase 2 is initiated when the emission of radioactive materials and radiation has been certainly reduced; this phase is intended to monitor the effect on the surrounding areas. Speed is of importance during phase 1, while accuracy is important during phase 2 . The measurement items, locations, sample collection locations, and measurement methods for each phase are detailed in the environmental radiation monitoring guidelines. During the monitoring conducted during phase 1, measurements of the following are made: (a) air dose rate of radioactive noble gases, (b) radioiodine concentration in the atmosphere and environmental samples, (c) uranium and plutonium concentration in the atmosphere, and (d) concentration or $\alpha$-ray surface contamination density of uranium and plutonium in environmental samples.

In the monitoring conducted during phase 2 , the following additions are made to the measurement items, for which the concentrations of radioactive materials in environmental samples are measured: soil, crops, livestock, raw water (rivers and purification plants), and fish (in case of leakage into the rivers and oceans). Emergency monitoring is conducted stepwise according to the phases by specifying the target radioactive materials; for this purpose, the efficiency and swiftness of emergency actions during disaster responses is taken into consideration.

\section{SPEEDI Network System}

During an emergency, protective measures are taken based on the expected concentrations 
of radioactive materials and exposure dose rates of residents' in the surrounding areas. The prediction results obtained using the SPEEDI and the measured values monitored at several points in the surrounding areas are considered. SPEEDI has been installed and maintained by the government and local public bodies as a method to obtain information regarding the concentrations of radioactive materials and predicted doses in the surrounding area. For the sake of swiftly deciding upon protective measures, the environmental radiation monitoring guidelines hold that during a nuclear emergency, it is one of the duties of radiation protection groups in the government's nuclear emergency countermeasure office and local countermeasure offices to use this system for estimating dosages of residents; however, it is often difficult to quantitatively determine the information about emission sources during the early stages of a disaster. In such cases, it is advisable to work on the emergency monitoring plan, which includes the predicted figures for a unit amount of emission in terms of direction and location where monitoring should be reinforced as well as the monitoring items. Furthermore, since the calculation of SPEEDI is not always appropriate due to the differences between the predicted and actual meteorological conditions, the guidelines mention the need for repeated verification of the results based on the actual meteorological data.

\section{Environmental Radiation Monitoring at the Early Stage of a Disaster}

\section{Environmental Radiation Monitoring by Companies}

Figure 1 shows the change in the air dose rate measured using a monitoring car (MC; operated by the Tokyo Electric Power Company) since the onset of a disaster ${ }^{2)}$. The air dose rate shows the background (BG) level from the arrival of a tsunami until the early morning of March 12, which slowly increased during the early morning of the 12th and reached its first peak of $386 \mu \mathrm{Sv} / \mathrm{h}$ at 10:30 am near the main gate. After that, the air dose rate continued to vary by approximately a few hundred $\mu \mathrm{Sv} / \mathrm{h}$, reached a high dose rate of approximately $12 \mathrm{mSv} / \mathrm{h}$ in front of the main gate on March 15 at 9:00 am, and measured approximately $11 \mathrm{mSv} / \mathrm{h}$ after being measured again on 16th at 12:30. Such abrupt changes in the air dose rate around the facility boundaries have been examined in relation to (a) the plant phenomenon

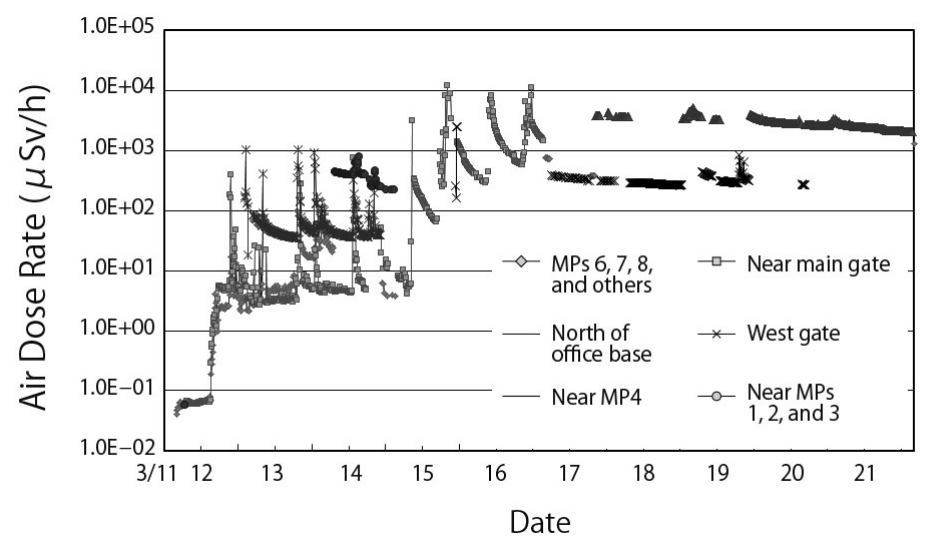

Figure 1 Change in air dose rate near the plant facility boundaries ${ }^{2)}$ 
after the earthquake and (b) meteorological conditions. In addition, the measurement results in Figure 1 show a change in the air dose rate in multiple directions around the same time period. For example, on March 14, the air dose rates at monitoring posts (MPs) 2 and 4 and at the main gate changed at the same time, indicating the possibility that radioactive materials scattered in multiple directions. This indicates the possibility that pollution caused by radioactive materials advanced at the same time over a wide range near the facility boundaries.

\section{Environmental Radiation Monitoring in Fukushima Prefecture}

Figure 2 shows the environmental radiation monitoring results obtained from seven locations in Fukushima ${ }^{3)}$. The results show measurements of approximately $20 \mu \mathrm{Sv} / \mathrm{h}$ in Minamisoma City at around 21:00 on March 12, and $24 \mu \mathrm{Sv} / \mathrm{h}$ as measured in Iwaki City at around 4:00 on March 15. The former measurement is likely to be due to south winds early evening on the 12th and the latter due to the north winds that had been blowing since the previous day (the 14th). Later, the air dose rate in Shirakawa City increased, followed by an abrupt increase in Koriyama City and Fukushima City. These changes are likely due to the east winds that were blowing during the daytime on the 15th, which then changed into southeast and south-southeast winds. After 16th, the air dose rate began to indicate a downward trend apart from Minamisoma City and Iwaki City, where large changes were observed.

\section{Disaster Countermeasure Office Response}

Table 1 summarizes the response measures after the earthquake, abnormal phenomenon in the nuclear power plants, and environmental-radiation-monitoring-related items ${ }^{4}$. Table 1

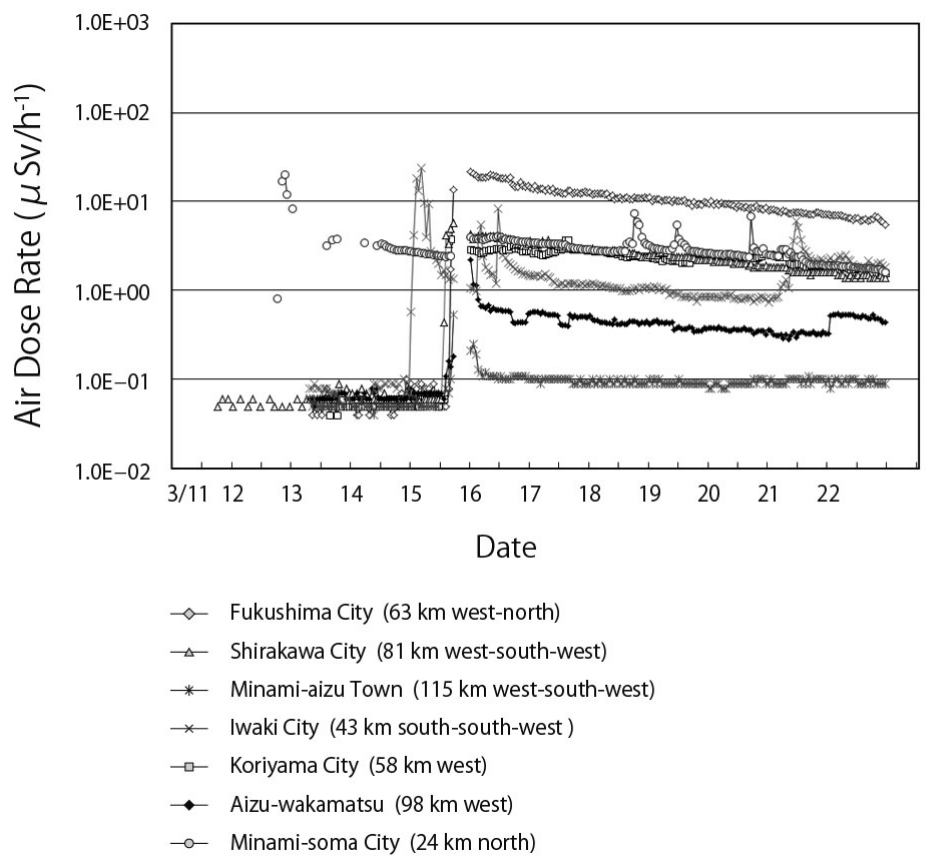

Figure 2 Environmental radiation monitoring results at seven locations in Fukushima Prefecture ${ }^{3)}$ 
also indicates that the function of MPs at the facility boundaries was maintained immediately after the earthquake, but the monitoring function was lost after the station blackout due to the tsunami. In addition, the loss of ERSS functionality after the earthquake meant that the act of conducting quantitative calculations using SPEEDI became more difficult. Later, a state of emergency was declared and the Government Nuclear Emergency Response Headquarters and the Local Nuclear Emergency Response Headquarters were established, but the air dose rate around the facility was at approximately the BG level. In the early morning on the 12th, the staff of the prefecture, the Japan Atomic Energy Agency (JAEA), and the National Institute of Radiological Sciences (NIRS) gathered at the Fukushima Nuclear Center (Okuma Town), but the assembling rate of the ministries and government offices was low and onsite delegation of Nuclear Safety Commission members was not made. At this time, the Local Nuclear Emergency Response Headquarters, which was temporarily moved to another location, returned to the emergency countermeasure office base facility (OFC), but the air dose rate around the facility boundaries was several times as high as BG. On the afternoon of the 12th, a hydrogen explosion occurred at Unit 1 and the air dose rate at this time exceeded 100 times as high as BG. In the evening of the same day, the air dose rate exceeded 1000 times as high as BG and an evacuation order was issued to the residents within a radius of $20 \mathrm{~km}$ from the nuclear power plants.

Table 1 Disaster response implemented immediately after the earthquake and environmental radiation monitoring ${ }^{4)}$

\begin{tabular}{|c|c|c|c|}
\hline $\begin{array}{l}\text { Date and } \\
\text { time }\end{array}$ & Countermeasures & Abnormal phenomenon at facility & Environmental radiation monitoring \\
\hline $\begin{array}{l}11 \text { th } \\
14: 46\end{array}$ & Onset of earthquake & $\begin{array}{l}\text { Reactor shutdown; emergency } \\
\text { response support system (ERSS) } \\
\text { fails to function }\end{array}$ & $\begin{array}{l}\text { No abnormality at monitoring posts } \\
\text { (MPs) in surrounding monitoring } \\
\text { areas }\end{array}$ \\
\hline $15: 30$ & Arrival of tsunami & $\begin{array}{l}\text { Subsequently, station blackout } \\
\text { occurs }\end{array}$ & \\
\hline $15: 42$ & $\begin{array}{l}\text { Establishment of Ministry of } \\
\text { Economy, Trade and Industry } \\
\text { Nuclear Emergency (onsite) } \\
\text { countermeasures office }\end{array}$ & $\begin{array}{l}\text { MPs do not function; measurement } \\
\text { performed using monitoring cars } \\
\text { (MCs) }\end{array}$ & $\begin{array}{l}\text { In total, } 23 \text { out of } 24 \text { MPs in the } \\
\text { prefecture did not function }\end{array}$ \\
\hline $\begin{array}{l}16: 36 \\
17: 00\end{array}$ & $\begin{array}{l}\text { Establishment of countermeasures } \\
\text { office in official residence } \\
\text { Vice Minister of Ministry of } \\
\text { Economy, Trade and Industry departs } \\
\text { for Emergency countermeasures } \\
\text { office (OFC) }\end{array}$ & $\begin{array}{l}\text { Impossible to pour water using } \\
\text { the emergency core-cooling } \\
\text { system (ECCS) ; inability to } \\
\text { make quantitative prediction } \\
\text { using the System for Prediction of } \\
\text { Environmental Emergency Dose } \\
\text { Information (SPEEDI) }\end{array}$ & \\
\hline $19: 03$ & $\begin{array}{l}\text { Declaration of state of emergency, } \\
\text { establishment of the Local Nuclear } \\
\text { Emergency Response Headquarters } \\
\text { (onsite), appointment of a person as } \\
\text { the acting director general }\end{array}$ & $\begin{array}{l}\text { Blackout; malfunction of emergency } \\
\text { power supply causes the inability to } \\
\text { communicate from OFC, so directors } \\
\text { move to the prefecture nuclear center } \\
\text { (Okuma Town) }\end{array}$ & \\
\hline $20: 50$ & $\begin{array}{l}\text { Evacuation order by the governor for } \\
\text { residents within the } 2-\mathrm{km} \text { radius }\end{array}$ & & \\
\hline $21: 23$ & $\begin{array}{l}\text { Evacuation order for those within the } \\
3-\mathrm{km} \text { radius and sheltering order for } \\
\text { residents within the } 10-\mathrm{km} \text { radius }\end{array}$ & Difficulty in cooling Unit 1 & \\
\hline $\begin{array}{l}12 \text { th } \\
00: 00\end{array}$ & $\begin{array}{l}\text { Vice minister arrived at the } \\
\text { prefecture nuclear center (Okuma } \\
\text { Town); staff of JAEA and National } \\
\text { Institute of Radiological Sciences } \\
\text { also arrived }\end{array}$ & $\begin{array}{l}\text { Low initial assembly rate of staff } \\
\text { of related organizations; no onsite } \\
\text { delegation of emergency response } \\
\text { measure officials }\end{array}$ & \\
\hline $03: 20$ & $\begin{array}{l}\text { The Local Nuclear Emergency } \\
\text { Response Headquarters returns to } \\
\text { OFC }\end{array}$ & $\begin{array}{l}\text { Emergency power supply recovers } \\
\text { in OFC; satellite communication } \\
\text { system is enabled }\end{array}$ & \\
\hline
\end{tabular}




\begin{tabular}{|c|c|c|c|}
\hline $\begin{array}{l}\text { Date and } \\
\text { time }\end{array}$ & Countermeasures & Abnormal phenomenon at facility & Environmental radiation monitoring \\
\hline \multirow[t]{2}{*}{ 05:44 } & $\begin{array}{l}\text { Evacuation order to residents within } \\
\text { the } 10-\mathrm{km} \text { radius }\end{array}$ & $\begin{array}{l}\text { Increase in pressure in primary } \\
\text { containment vessel (PCV); } \\
\text { difficulty in use of plant information, } \\
\text { ERSS, and SPEEDI at OFC }\end{array}$ & $\begin{array}{l}\text { Increase in air dose rate near facility } \\
\text { boundaries }\end{array}$ \\
\hline & & $\begin{array}{l}\text { Government office of Minamisoma } \\
\text { City, acting as OFC facility, cannot } \\
\text { be used due to earthquake and } \\
\text { tsunami response }\end{array}$ & \\
\hline $15: 36$ & & Hydrogen explosion at Unit 1 & \\
\hline $18: 25$ & $\begin{array}{l}\text { Evacuation order to residents within } \\
\text { the } 20-\mathrm{km} \text { radius. }\end{array}$ & $\begin{array}{l}\text { Consideration of disasters caused } \\
\text { due to accidents in other reactors }\end{array}$ & $\begin{array}{l}\text { At 20:00, air dose rate increases in } \\
\text { Minamisoma City }\end{array}$ \\
\hline 13 th & & & $\begin{array}{l}\text { First emergency monitoring } \\
\text { information }(>30 \mu \mathrm{Sv} / \mathrm{h}) \text { in some } \\
\text { areas) }\end{array}$ \\
\hline $\begin{array}{l}14 \text { th } \\
07: 30\end{array}$ & $\begin{array}{l}\text { Announcement of monitoring } \\
\text { information by Nuclear and } \\
\text { Industrial Safety Agency }\end{array}$ & 11:01 Hydrogen explosion in Unit 3 & $\begin{array}{l}\text { MC dispatch } 1 \text { (three cars) and } \\
\text { dispatch } 2 \text { (four cars) }\end{array}$ \\
\hline \multirow[t]{2}{*}{15 th } & Removal of staff from OFC & $\begin{array}{l}\text { Explosion at Unit } 4 \\
\text { Explosive activity at Unit } 2\end{array}$ & $\begin{array}{l}\text { Detection of high concentration of } \\
\text { radioiodine and cesium from surface } \\
\text { soil and plants }\end{array}$ \\
\hline & $\begin{array}{l}\text { Establishment of overall } \\
\text { countermeasures office for the } \\
\text { Fukushima Nuclear Power Plant } \\
\text { Accident }\end{array}$ & & $\begin{array}{l}\text { Measurement by } 15 \text { MCs (Ministry } \\
\text { of Education, Culture, Sports, } \\
\text { Science and Technology, JAEA, } \\
\text { Fukushima Prefecture, National } \\
\text { Police Agency, Ministry of Defense, } \\
\text { and electric companies) }\end{array}$ \\
\hline 11:00 & $\begin{array}{l}\text { Sheltering order to residents within a } \\
\text { radius between } 20 \text { and } 30 \mathrm{~km} \text {; } \\
\text { the Local Nuclear Emergency } \\
\text { Response Headquarters moves to the } \\
\text { Fukushima government office }\end{array}$ & & $\begin{array}{l}\text { Collection of soil and plants } \\
\text { (insufficient monitoring at the } \\
\text { Local Nuclear Emergency Response } \\
\text { Headquarters due to earthquakes) }\end{array}$ \\
\hline $20: 40$ & & & $\begin{array}{l}\text { Measurement of } 330 \mu \mathrm{Sv} / \mathrm{h} \text { at three } \\
\text { points near Namie Town }\end{array}$ \\
\hline \multirow[t]{2}{*}{ 16th } & $\begin{array}{l}\text { Announcement of dose rate } \\
\text { measurement results near Namie } \\
\text { Town by Ministry of Education, } \\
\text { Culture, Sports, Science and } \\
\text { Technology } \\
\end{array}$ & & $\begin{array}{l}\text { Start of emergency monitoring in the } \\
\text { prefecture }\end{array}$ \\
\hline & $\begin{array}{l}\text { Organization of roles within the } \\
\text { government (Ministry of Education, } \\
\text { Culture, Sports, Science and } \\
\text { Technology and Nuclear Safety } \\
\text { Commission) }\end{array}$ & & $\begin{array}{l}\text { Start of radiological survey of raw } \\
\text { milk and radiological survey of tap } \\
\text { water }\end{array}$ \\
\hline 17 th & $\begin{array}{l}\text { Daily announcement of } \\
\text { environmental monitoring by } \\
\text { Ministry of Education, Culture, } \\
\text { Sports, Science and Technology }\end{array}$ & & $\begin{array}{l}\text { Start of radiological survey on } \\
\text { vegetables }\end{array}$ \\
\hline 18 th & $\begin{array}{l}\text { Request for the introduction of } \\
\text { integrating dosimeters or for the } \\
\text { increase in measurement frequency }\end{array}$ & & $\begin{array}{l}\text { Collection and analysis of dust, } \\
\text { environmental samples, and soil }\end{array}$ \\
\hline 20th & & & $\begin{array}{l}\text { Contamination verified in soil and } \\
\text { weeds in areas } 40 \mathrm{~km} \text { northwest }\end{array}$ \\
\hline 21 st & $\begin{array}{l}\text { Ministry of Education, Culture, } \\
\text { Sports, Science and Technology } \\
\text { "Establishment of monitoring } \\
\text { planning for areas } 20 \mathrm{~km} \text { or more } \\
\text { from Fukushima Daiichi Nuclear } \\
\text { Power Plant" }\end{array}$ & & Soil plutonium analysis \\
\hline $23 \mathrm{rd}$ & & $\begin{array}{l}\text { Announcement of SPEEDI } \\
\text { calculations }\end{array}$ & Start of sea area monitoring \\
\hline
\end{tabular}


On the 13th, radiation monitoring was performed by the Local Nuclear Emergency Response Headquarters. The measurements exceeding $30 \mu \mathrm{Sv} / \mathrm{h}$ were made in some areas and were reported by the Nuclear and Industrial Safety Agency in the early morning on the 14th. This was the first time that the values related to environmental radiation monitoring were announced by the Government Nuclear Emergency Response Headquarters. At this point, an air dose rate of approximately $0.9 \mathrm{mSv} / \mathrm{h}$ was measured near the facility boundaries. From that day onward, the Government Nuclear Emergency Response Headquarters prepared several MCs to enhance the environmental radiation monitoring. On the 14th and 15th, explosions occurred at Units 3, 4, and 2 in succession and radiation measurements performed using many MCs (15 cars) and as well as measurements of soil and plants were initiated. On the 15th, soil and plants were collected for emergency monitoring, but the monitoring activity by the Local Nuclear Emergency Response Headquarters was insufficient due to the effect of the earthquake and other disasters ${ }^{4}$. Moreover, a dose rate of $330 \mu \mathrm{Sv} / \mathrm{h}$ was measured in Namie Town on the early evening of the 15th. Following this, allocation of roles in terms of environmental radiation monitoring was made within the government on the 16th and the Ministry of Education, Culture, Sports, Science and Technology was placed in charge of implementing and directing emergency monitoring and announcing the related reports. On the 21st, the Ministry of Education, Culture, Sports, Science and Technology finalized and announced the "Fulfillment of the monitoring plan for areas $20 \mathrm{~km}$ beyond the Fukushima Daiichi Nuclear Power Plant." Based on the above series of events, the establishment of an emergency monitoring system was attempted around this time, though the process still lacked a solid system in terms of selecting the measurement locations and items.

\section{Discussions and Lessons}

\section{Time Lag until Emission of Radioactive Materials}

So far, it has been thought that when an abnormal event occurs in a nuclear power plant, there is a certain amount of time lag until an abnormal emission of radioactive materials and radiation into the surrounding areas occur. The monitoring data obtained this time indicate that the air dose rate started to increase around the facility boundaries from approximately 4:00 am on the 12th, $\sim 13 \mathrm{~h}$ after the onset of the earthquake, and the dose rate of a few $\mu \mathrm{Sv} /$ $\mathrm{h}$ continued at the same measurement location, occasionally reaching a value of several hundred $\mu \mathrm{Sv} / \mathrm{h}$. This indicates that there was a time lag between the establishment of the precautionary office due to the abnormality notification and the emission of radioactive materials in the facility. However, from the perspective of implementing protective measures, it is important to accurately correlate the phenomenon inside the reactor to the increase in the air dose rate around the facility boundaries in the relatively early stages before the explosion at Unit 1. This is crucial to determine the possibility for regulating the phenomenon inside the reactor, which can affect the surrounding areas as well as the examination of effective disaster countermeasures.

\section{Initiation of Emergency Monitoring}

In nuclear disaster prevention, decisions during an emergency are made based on (1) radiation dose rate near the facility boundaries and (2) observed phenomena (onset of events at nuclear power plants and nuclear-related facilities indicating a large emission to the outside 
areas). This time, the declaration of a state of emergency was made based on the criteria regarding the latter aspect. When declaring a state of emergency, the heads of the assigned governmental organizations and local governmental organizations have the responsibility to implement emergency countermeasures. This was the case even for the accident this time in which the air dose rate was as low as BG near the facility boundaries. Therefore, in the case of an emergency, the Government Nuclear Emergency Response Headquarters and the Local Nuclear Emergency Response Headquarters need to immediately organize an emergency monitoring system and implement it. From an observation of the series of events from such a perspective, even when dose rates of several tens of $\mu \mathrm{Sv} / \mathrm{h}$ (occasionally $\mathrm{mSv} / \mathrm{h}$ ) were measured near the facility boundaries on the 13th (Figure 1) and dose rates of several $\mu \mathrm{Sv} / \mathrm{h}$ were measured in Minamisoma City (Figure 2), it is not necessarily the case that emergency monitoring was planned and implemented to evaluate the effect of the radioactive materials and radiation from the nuclear facility on the surrounding residents until 13th from countermeasures mentioned in Table 1.

Figures 1 and 2 and Table 1 show that the initial results of emergency monitoring were obtained in the early evening of the 13th; the measured values of Fukushima environmental radiation monitoring abnormally increased around the same time of the 15 th (a few $\mathrm{mSv} / \mathrm{h}$ were observed around noon near the boundaries of the facility), and a measurement of $330 \mu \mathrm{Sv} / \mathrm{h}$ was made in Namie Town in the evening of the same day, indicating an abrupt change in the situation. The government attempted to establish an emergency monitoring system under such conditions (the roles of related governmental organizations in emergency monitoring was determined on the 16th, and the Ministry of Education, Culture, Sports, Science and Technology finalized and announced the "Fulfillment of the monitoring plan for areas $20 \mathrm{~km}$ beyond Fukushima Nuclear Power Plant"), but a clear direction was established approximately 10 days after the declaration of a state of emergency. The reasons for the delay in establishing an emergency monitoring system under a state of emergency include the loss of local infrastructure, the loss of OFC function due to the loss of means of communication caused by the earthquake and tsunami, and the continuous aftershocks; however, the reason could also be found in the possibility of human cognitive characteristics (normalcy bias), which prevented an immediate recognition of a state of emergency despite the abnormally high levels of radiation observed in Fukushima area environmental radiation monitoring results and those near the power plant. In the future, it will be necessary to examine the emergency monitoring from such perspectives.

\section{Implementation of Radiation Monitoring in Phases}

Emergency monitoring is conducted in two phases to clarify its meaning. The radiation monitoring implemented around the 21st was effectively equivalent to phase 1 of the emergency monitoring. There is no indicator for distinguishing phase 1 from phase 2; however, by setting the boundary as the time at which it became possible to stably cool the reactor, the duration of phase 1 can be said to have lasted as long as several months in this case. However, phase 2 of emergency monitoring was implemented even before stable cooling of the reactor was achieved. This indicates the necessity of reviewing the conventional boundary between monitoring in phase 1 and phase 2 from a different perspective based on the progress of the disaster as well as necessary information.

Furthermore, it is not appropriate to limit the target isotopes to be monitored in phase 1 to rare gas, radioiodine, uranium, and plutonium to estimate residents' dose and the scale of the disaster. In this case, information on radioactive isotopes that are not part of the target 
isotopes for the early stage of radiation monitoring, i.e., radioactive cesium, is necessary. Furthermore, it is not appropriate to consider residents' dose as an evaluation item in phase 2 due to the indivisible relationship between radiation monitoring and resident dosages. In particular, the accuracy of the dose due to inhalation of radioactive material before the implementation of protective measures largely depends on the radiation information learned during the early stages, so it is necessary to implement emergency monitoring for dose assessment during the early stages. In other words, emergency monitoring can be classified into situations wherein (a) it is difficult to regulate the release of radioactive materials from the facility and (b) the uncertainty of the emission of the radioactive materials is significantly reduced; it is necessary to make plans and to conduct emergency monitoring for each situation to implement protective measures and dose assessments.

\section{Effective Use of SPEEDI Information}

During the initial stages of an emergency, SPEEDI plays an important role, together with environmental radiation monitoring, in estimating the resident doses and applying proper countermeasures. However, in this earthquake disaster, the ERSS functionality was lost immediately after the earthquake, making quantitative evaluation of the system impossible. Furthermore, there were less records of use of the system as part of the countermeasures during the initial stage. The environmental radiation monitoring guidelines indicate an expectation that SPEEDI should be utilized applying assumed amount of emission source for emergency monitoring and protective measures, even when there is no information about the emission source. The values in the monitoring results near the facility boundaries were extremely high around the noon on March 12. An abrupt change was also indicated in the monitoring results in Minamisoma City in the early evening on the same day. Based on the radiation monitoring results made after the 12th, proper interpretation using SPEEDI on the radiation monitoring results, even ex-post evaluation of the emission would have enhanced the understanding of the dynamic behavior of the radioactive materials over a wide range far from the facility and helped in improving the planning and execution of emergency monitoring plans.

In situations wherein the condition of a disaster can only be estimated through limited radiation monitoring, obtaining information about the emission source is important for understanding the scale and characteristics of the disaster and smoothly and effectively executing not only the immediate countermeasures but also the disaster response in general. There is no indication of consideration given toward estimating the information about the emission source via SPEEDI during the initial stages. The environmental radiation monitoring guidelines do not clearly specify the use of SPEEDI, as mentioned above, but the use of the advanced technology in addition to those in the response manual must be taken into consideration in uncertain emergency situations. Emergency countermeasures must encompass such use. The first dose map based on SPEEDI calculations, which was later announced by the Nuclear Safety Commission, was made with assumed emission rate values based on deductions from the radiation monitoring results. Errors were inevitable in the results, but the estimation results were effective in clarifying the whole picture with regard to the effect of emitted radioactive materials and determining the subsequent protective measures. 


\section{Conclusions}

The following results summarize the examination conducted herein:

(1) There was a time lag between the onset of abnormal phenomena in the nuclear facility and the emission of radioactive materials into the environment. However, from the perspective of disaster prevention, it is important to relate the phenomena inside the reactor to the increase in the air dose rate around the boundaries of the facility during the early stages.

(2) It took a significant amount of time after the declaration of a state of emergency to establish an emergency monitoring system. This delay was caused due to the effect of compound disaster and because of the delay, which may be caused by the normalcy bias - a characteristic in human recognition, during the initial stages of the disaster.

(3) The current environmental radiation monitoring guidelines do not clearly define the duty for evaluating the information about the types of radioactive materials and resident doses during the initial stages. It is necessary to consider the initial stages of a disaster as an emergency radiation exposure situation, as defined by international organizations, and systematically review the actions of obtaining radiation information, dose assessments, and execution of protective measures.

(4) SPEEDI has an important role in understanding the outline of nuclear emergencies in a spatial and temporal manner. When planning for emergency monitoring, it is indispensable to include SPEEDI information to supplement the radiation monitoring information, i.e., the actual measurement information of monitoring points. The SPEEDI system should be sufficiently flexible to utilize, including the estimation of source term.

\section{References}

1) Nuclear Safety Commission. Environmental radiation monitoring guidelines. 2008 March (partially revised in 2010 April).

2) Monitoring condition of Fukushima Daiichi Nuclear Power Station (March 11 - 21). Tokyo Electric Power Company home page.

3) Environmental radiation measurement results in 7 areas in the prefecture. Fukushima Prefecture home page.

4) The Government Nuclear Emergency Response Headquarters. Report from the Japanese government on IAEA cabinet meeting regarding nuclear safety--Accident in Tokyo Electric Power's Fukushima Nuclear Power Station. 2011 June. 


\title{
Requirement for Qualification and Expertise of Nuclear Regulatory Body
}

\section{-To Prevent the Recurrence of the Fukushima Daiichi Nuclear Power Plant Accident-}

\author{
NuFact Associates, Ltd., Toshio Morimoto \\ Tokyo Institute of Technology, Tetsuo Sawada
}

\begin{abstract}
Based on the lessons learned from the accident at the Fukushima Daiichi Nuclear Power Plant in March 2011, the Japanese government is considering the establishment of the Nuclear Safety Agency as an external bureau of the Ministry of Environment. Changes in the formation of the nuclear regulatory agency are not urgent in Japan. Urgent matters are challenges related to internal matters, especially the improvement of the expertise of its senior managers. It is necessary to appoint the director general and senior managers of the Nuclear Safety Agency based on their competencies and to establish their tenure at a level similar to that in the European and American countries. Receiving the IAEA review again will also be effective to upgrade the nuclear safety regulations of Japan to the international level.
\end{abstract}

\section{Lessons from SKI in Sweden}

\section{Unexpected Phenomenon at Barsebäck Nuclear Power Plant}

In July 1992, a safety relief valve was inadvertently opened due to an event at the Barsebäck Nuclear Power Plant. The ejected steam broke the insulator, which led to partial blockage of the strainer on the inlet of emergency reactor cooling pump. At that time, the occurrence and the results of such a phenomenon were not considered in safety review of nuclear power plants in any country.

However, the director of SKI (the Swedish nuclear regulatory agency at that time), who had implemented the safety review for construction of the plant, seriously considered the failure to address such a possibility previously and made a strong request to the Swedish government for the review of the competency of SKI by an international committee. As a result, the Swedish government convened domestic and international experts and formed a review team to identify deficiencies regarding the safety review capability of SKI. The appointed team members included the former executives of NRC, individuals involved in nuclear regulations in countries such as France and Finland, and those in aircraft safety review in Sweden. The

DOI : 10.15669/fukushimainsights.Vol.1.168

(C) 2021 Atomic Energy Society of Japan. All rights reserved.

Originally published in Journal of the Atomic Energy Society of Japan (ISSN 1882-2606), Vol. 53, No. 12, p. 826-830

(2011) in Japanese. (Japanese version accepted: October 15, 2011) 
review was conducted from 1994 to 1995 and pointed out that "though the regulatory activities of SKI are of high quality and are appropriate, there exist many undocumented procedures." This led to the development of the quality management system (QMS) of SKI.

\section{Lessons from Sweden}

The phenomenon in Barsebäck did not lead to a disaster. However, the director of SKI seriously took the insufficient review, received an external review on its review capability, and implemented the given advices. Japanese government should take a leaf from Swedish style mentioned above that the executive took the lead in humbly learning these lessons and implementing improvements.

Japan's Nuclear and Industrial Safety Agency (NISA), the nuclear regulatory agency, received IAEA's Integrated Regulatory Review Service (IRRS) with regard to its regulatory systems in $2007^{1)}$. However, the scope of the review was limited and the follow-up review by IAEA has not applied by Japanese government yet. Humbly receiving IAEA's review on nuclear safety regulations under the governance of the Nuclear Safety Agency is an international obligation as well as the foundation for restoration of trust.

\section{Lessons for Japan}

The main cause of the accident at the Fukushima Daiichi Nuclear Power Plant (Fukushima Accident) in March 2011 was the insufficient postulations of tsunamis and station blackouts (SBOs). The prime responsibility to maintain the safety of nuclear power plants within the licensed conditions rests with the operators. However, the responsibility to determine and revise the licensed conditions must rest with the regulatory agency, NISA. Therefore, the authors think that in-depth but primary responsibility for the Fukushima Accident mainly attributed for the Japanese regulatory agency. It is possible to argue that Tokyo Electric Power Company (TEPCO) also had a responsibility based on the current laws. However, honest self-reviews based on objective facts by regulatory agencies, especially NISA, are required. Furthermore, the insufficient recognition of issues by the Nuclear Safety Commission, an advisory agency, should not be overlooked. The agency had poor recognition of safety important issues and failed to provide clear directions to NISA on matters such as SBO.

We assume there are at least three root causes of the Fukushima Accident, as follows.

(1) Delayed Action on New Regulatory Issues: There was no clear regulatory position in Japan with regard to matters, such as the predicted level of tsunamis and protective measures for safety systems and buildings in the case of site flooding. Even if NISA had definitely determined its position on tsunamis based on recent knowledge about tsunami and countermeasures against tsunami taken in foreign countries, it is not clear whether the tsunami at Fukushima site of this time was postulated and whether effective measures were taken in place. In Japan, actions against new regulatory issues were often delayed. The speedup of such actions is crucial now more than ever. If this improper regulatory attitude is not improved, the trust in the regulations will not be restored in Japan. When there were only a few nuclear power plants in Japan, it might be inevitable that regulatory actions were taken based on individual basis. However, currently, there are more than 50 rectors in Japan and it is indispensable for Japanese regulatory agency to present regulatory policies on generic basis for each unresolved regulatory issues to ensure stable regulation and establish a consensus among 
the people.

(2) Delayed Periodic Review of Existing Guides for Safety Regulations: In Japan, the Regulatory Guide for Reviewing Safety Design of Light Water Nuclear Power Plants was revised in 1977 to consider short term (approximately 30-min) SBOs. Later, in 1988, in the U.S, longer term SBOs were required and all nuclear power plants in the country became capable to endure SBOs longer than $4 \mathrm{hr}$. After that, in Japan, the suitability of regulatory requirements of SBO endurance time was discussed, but considering the high levels of reliability of off-site power supplies in Japan, among others, SBO endurance time was not revised, and consideration of extended SBOs was left as a voluntary action of electric power companies.

Later, the importance of the SBO measures to prevent core damage was recognized around the world, and IAEA stated in its guide for the design of emergency power systems ${ }^{2)}$ that the possibility of SBO should be taken into consideration, even with high levels of off-site power and emergency power supplies (clause 2.14).

The Fukushima Accident may not have been prevented even if the measures for extended SBO were formally required and not left as voluntary actions. However, suitable operator actions against the SBO at Fukushima Daiichi Nuclear Power Plant could have been more secure.

A system for periodic revision of established safety regulation guidelines could have brought NISA to stricter regulation on SBO. This could have in turn led to more appropriate inspections of accident management procedures for SBO.

(3) Lack of a Formal Review Process for Differing Professional Opinions: With regard to the current postulated tsunami conditions, it has been said that some experts raised objections. If NISA had a formal process to review differing opinions expressed by experts of nuclear safety regulations, it could have led to a prompt revision of the design conditions for tsunamis.

\section{Future Regulatory Actions}

This chapter proposes corrective actions to eliminate the three root causes discussed in Chapter II, considering good practices in foreign countries.

\section{Systematic Approach to New Regulatory Issues}

According to an IAEA guide for regulatory review (clause 3.24), regulatory agencies are required to collect information from a broad range, including operational experience at nuclear power plants and results of research and development ${ }^{3)}$, when they are trying to establish regulatory requirements. In Japan, similar to other countries, the regulatory agency, NISA, collected various types of information, including the current activities of regulatory organizations in foreign countries, and reviewed them. However, the collection and review have largely relied on the individual efforts of NISA staff and were not systematically organized by NISA.

As occurred in the US after the Three Mile Island Nuclear Plant (TMI) Accident, in Japan, after the Fukushima Accident, many safety related countermeasures will be proposed. The importance of such countermeasures will vary widely and many of them would have overlapping effects. The US NRC developed Generic Issues Program (GIP) that systematically consolidated new safety issues with old unresolved safety issues that were identified prior to the 
TMI Accident. In this program, NRC prioritized these issues based on the safety benefit and cost of each issue, and gradually established regulatory policy or position of each issue ${ }^{4)}$. In GIP, NRC staff project teams are founded for important safety issues. From the initial stages of projects, these teams involved staff in charge of legal issue. The review status of GIP was periodically reported to the US Congress. It would be helpful for Japanese nuclear regulatory agency to learn good practices of project-based approach, which would avoid adverse impact of frequent staff shift, and to learn the merit of legal staff involvement from the initial stages in the project team. It would be also important for the agency to report the status of each project to the Diet periodically, in order to ensure the continuous progress of each project.

\section{Periodic Review of Existing Regulatory Requirements}

It is necessary to review the existing regulatory requirements based on the operational experience and new knowledge. In the US, NRC has set numerous regulatory guidelines, which are basically reviewed every five years ${ }^{5)}$. Periodic review of existing safety regulations is indispensable to ensure that they are effective and reasonable. In Japan, NISA did not have such a periodic review system formally. It preserved old requirements if they did not conflict with new requirements. It was lazy and wrong attitude for sound regulations. Periodic review of existing regulatory requirements is crucial to the scrap-and-build of existing regulatory requirements. Blind increase of safety requirements by nuclear regulatory agency causes unnecessary burdens on the staff of nuclear power plants, decreases their trust in the regulatory requirements, and finally degrades the safety culture at the plants. The staff of the nuclear safety regulatory administration should engrave on their heart and never forget this harmful effect to the safety culture at nuclear power plants.

\section{Establishment of Formal Process to Review professional Differing Opinions}

In the US, NRC has an official process to discuss and consider professional opinions of NRC staff differing from current NRC regulations ${ }^{6}$. NRC staff who have differing opinions first submit his or her differing professional opinion (DPO) to the director of office of the submitter via a written document, upon which a DPO review panel directed by the director reviews the validity and acceptability of the DPO. If the submitter is not satisfied with the review result, he/she can submit the DPO to the NRC committee or the Executive Director for Operations and the DPO is examined again. The result of reviews is made public upon the submitter's request. In DPO document, a submitter is required to describe the differences between his or her opinion and NRC's regulation as well as the supposed consequences in cases wherein his or her opinions are not accepted. One of the criterion to acknowledge a DPO as professional opinion is that it must not be based on a shallow consideration.

The nuclear safety assessment requires a high level of expertise, and there might be disagreements among the experts. Even when the experts' opinions are not uniform, the regulatory agency often has to make administrative decisions. In such cases, it is important to accumulate the arguments related to and the rationale for the administrative decision, for the sake of stability and transparency of the regulations. The Japanese nuclear regulatory agency should learn good practices from NRC regarding this point. In addition, administrative decisions have to be made based on legal grounds. Therefore, it is urgent for Japanese nuclear regulatory agency to establish a concrete regulatory framework for safety goals that will bring basis for nuclear safety regulations. 


\section{Acquisition of Human Resources}

\section{Expected Competency}

The corrective actions discussed in Chapter III pertain to regulatory policies and require continuous efforts to be made. The director and full-time executives of the regulatory agency play important roles in implementing the actions, and they must have sufficient expertise to carry out their duties. Expert knowledge regarding nuclear safety is a prerequisite for those who work on nuclear safety regulation, however, mere knowledge is insufficient. It is important for them to have sound personalities as well as leadership with regard to solving problems and competency in terms of management.

SKI in Sweden evaluates the competency of the staff based on the following five points ${ }^{7)}$ :

Expertise: Expertise in nuclear reactor physics, hydrothermal dynamics, PSA, etc.

Individuality: Ethical judgment, creativity, strong sense of responsibility, etc.

Sociability: Cooperation with colleagues, ability to form networks, etc.

Strategic characteristics: Ability to make decisions with holistic and long-term perspectives Functionality: Ability to execute duties reflecting multiple dimensions altogether

Among these points, expertise is the most important, while the remaining four are considered to be supplementary. SKI staff is required to have the above characteristics, and the higher the position one has, the higher the level of such characteristics one is expected to possess. Director of offices are required to have ${ }^{7)}$

(a) Good knowledge and experience in the field of nuclear safety : Competency not only with regard to technical aspects but also as a generalist who works with people and organizations.

(b) Knowledge about how government authorities function.

(c) Knowledge about international developments in the field of nuclear safety.

(d) Good performance as a manager and leader of scientifically/technically highly competent professionals.

In addition, desirable leadership competencies include the following:

- Ability to motivate and provide feedback to staff,

- Make use of and develop staff competence,

- Administrative skills such as planning, prioritizing, and evaluation,

- Ability to develop holistic views and see long-term strategic perspectives,

- Analytical skills,

- Sound judgment, inspiring confidence, possessing a high degree of personal integrity, non-pretentious,

- Ability to make decisions based on facts and without unnecessary delay.

There are few who meet all of the above criteria; the weak points are communicated to the directors as room for improvement, when they are appointed.

\section{Relationship with Advisory Agencies}

IAEA has the following requirements regarding the relationship between the regulatory agency and advisory agency and/or external consultants ${ }^{8)}$.

"The regulatory body must have experienced experts who can evaluate the quality and results of work done by external consultants" (clause 4.3).

"The regulatory body shall not solely depend on safety evaluations by external experts and other evaluations by private companies. Therefore, the regulatory body shall have full-time 
staff capable of either performing reviews and evaluations according with regulations or evaluating the appropriateness of the evaluations performed by external experts" (clause 4.8).

IAEA also requires that advisory agencies and technical support organizations shall not relieve the regulatory body of its responsibility for making decisions ${ }^{8)}$ (clause 4.4 and 4.9).

To compensate the poor expertise in the Japanese regulatory agency, Japanese government appointed many university academics for Nuclear Safety Commission (NSC) and for various nuclear safety related advisory committees, and accepted recommendations from them. In the safety review by NISA, usually, most of them directly depended ${ }^{9)}$ on various NSC's guides that were prepared by NSC for its safety reviews independently performed from NISA. This curious situation is partially due to some historical matters. The authors do not know such inefficient safety review process in the European and American countries. To make more efficient, and timely decisions, and to improve the ability to explain its decisions for public, the regulatory agency of Japan should increase the number of full-time staff who have sophisticated expert knowledge with regard to nuclear safety.

\section{Tenure and Appointment Process of the Executives}

To implement the corrective actions discussed in Chapter III steadily with a consistent policy, Japanese nuclear regulatory agency should avoid frequent changes of its director general. In the IAEA requirements or guides, there is no particular provision regarding the appointment of the director general of the regulatory agency. The following are the current regulations about the appointment of director generals of regulatory agencies in the European and American countries.

\begin{tabular}{|c|c|c|c|}
\hline $\begin{array}{l}\text { Agency/ } \\
\text { Country }\end{array}$ & $\begin{array}{l}\text { Director } \\
\text { General }\end{array}$ & Tenure & Number \\
\hline NRC U.S. & $\begin{array}{l}\text { NRC } \\
\text { Committee }\end{array}$ & 5 years & $\begin{array}{l}\text { In total, five members are appointed by the President with an agreement } \\
\text { with Congress. }\end{array}$ \\
\hline ASN France & $\begin{array}{l}\text { ASN } \\
\text { Council }\end{array}$ & 6 years & $\begin{array}{l}\text { In total, five members, three members are appointed by President, one by } \\
\text { National Assembly chairman, and one by Senate President. }\end{array}$ \\
\hline STUK Finland & Director & Life-long* & *Until age 67. \\
\hline SKI Sweden & Director & $\begin{array}{l}7 \text { years } \\
\text { (avg.) }\end{array}$ & $\begin{array}{l}\text { Highest decision-making body is the board of trustees consisting of eight } \\
\text { members. Chairman is the SKI director. In } 2005 \text {, three were members of } \\
\text { Congress, of which one was supreme court judge. Average term of board } \\
\text { members is } \sim 6 \text { years. }\end{array}$ \\
\hline
\end{tabular}

Executives of these countries stay for a long term. On the contrary, the director generals of the NISA, the Japanese nuclear regulatory agency, changed frequently as follows;

\begin{tabular}{|c|c|r|}
\hline Succession & Name & \multicolumn{1}{c|}{ Appointed } \\
\hline 1st & Yoshihiko SASAKI & January 2001 \\
\hline 2nd & Kazuo MATSUNAGA & June 2004 \\
\hline 3rd & Kenkichi HIROSE & September 2005 \\
\hline 4th & Yasuhisa KOMODA & July 2007 \\
\hline 5th & Nobuaki TERASAKA & July 2009 \\
\hline 6th & Hiroyuki FUKANO & August 2011 \\
\hline
\end{tabular}

As can be seen above, the director generals of NISA were replaced approximately every two years, which is a great difference from the cycle in European and American countries. Japan, which needs to quickly catch up with international standards with regard to safety 
regulations, can no longer allow the repetition of such a short-term cycle for executives in regulatory agencies.

Currently, the government is planning to abolish NISA and establish the Nuclear Safety Agency as an external bureau of the Ministry of Environment (MOE). Director general of external bureaus is usually appointed by the minister of the corresponding ministry, in Japan. To ensure political neutrality and stability, the appointment of director general of the Nuclear Safety Agency should be approved by the National Diet, and a board of directors (or a council) should be created within the agency to support the director general, similar to nuclear regulatory agencies in France and Sweden.

\section{Appointment Process for Chief Managers}

The chief managers of U.S. NRC, such as the director of NRR (Office of Nuclear Reactor Regulation), are appointed by the chairman of the NRC commission with the agreement of the commission ${ }^{10)}$. According to our survey taken in 2005, the term in office of the previous four directors of NRR ranged from 3 to 7 years; and all of them had more than 20 years of experience in the field of nuclear safety ${ }^{7}$.

To execute the corrective actions discussed in Chapter III in a stable manner, it is necessary to appoint appropriately competent individuals as chief managers of the Nuclear Safety Agency, and they should stay in their positions for at least five years. To this end, the term in office of the director general or the chairman who has a power to appoint chief managers, also should be more than five years, as in the case of European and American countries. The appointment of chief managers should not be rotated according to mere formality.

\section{Implementation of Direct Hiring by the Nuclear Safety Agency}

An IAEA safety guide ${ }^{11)}$ recommends that "the regulatory agency should have the responsibility and authority to recruit staff with technical expertise" (clause 2.9). The regulatory agencies in the U.S., Sweden, and Finland directly hire individuals who seek to work in nuclear safety regulations. As external bureaus are authorized to hire competent staff by themselves directly, the Nuclear Safety Agency should hire its staff directly from those who passed the civil service examination and not to select staff from persons who are hired by the MOE. This should be a basic policy for preservation and improvement of its expertise. People who are hired by the MOE may not want to engage in nuclear safety regulations. Appointing staff from such people is not only undesirable in terms of the development of expertise at the Nuclear Safety Agency but also leave the staff unfulfilled.

\section{Preventing Expert Staff from Outflowing to Other Agencies}

Many members of the NISA would move to the new Nuclear Safety Agency to maintain the continuation and consistency of regulatory administration. It is inevitable that some of them, particularly those who do not seek to become experts in nuclear safety regulations, will return to their mother ministries, e.g., the Ministry of Economy, Trade and Industry (METI). IAEA requires the nuclear regulatory agency to be effectively independent from organizations and groups that promote nuclear technology ${ }^{8)}$ (clause 2.2). To maintain and improve the expertise of the staff of the Nuclear Safety Agency and to meet IAEA requirements, the managers of the Nuclear Safety Agency should not be hired from other ministries or agencies. 
In general, supplementation of the managerial staff must be done within the Nuclear Safety Agency. In addition, it is important not to allow the staff members in managerial positions to return to their mother organizations, in general.

Such a rule, i.e., the no-return rule, was applied between the Financial Control Agency (now the Financial Services Agency) and the Ministry of Finance based on the "principle of separation of finance and fiscal" when the former was established. This time, based on the "principle of separation of nuclear safety regulation and development," such a rule should be placed between the Nuclear Safety Agency and nuclear promoting ministries such as METI.

\section{Acquiring Human Resources from the Private Sector}

Direct hiring and development of those who passed the civil service examination is fundamental, but it should be necessary to hire experts from the private sector without requirement of passing the examinations to acquire experts immediately. Such unusual employment is allowed by the Article 36 of National Public Service Act, and ruled in detail by National Personnel Authority's rule 1-24 Special cases of employment of human resources from the private sector for the development of official affairs. In addition, the Act on Special Measures of Employment and Remuneration of Officials with Fixed Term of Office in the Regular Service would be useful to proceed such employment. It should be important for the Nuclear Safety Agency to employ experts from private sectors, applying these acts and rules. And in such cases, it is important to eliminate the discrimination between those who passed the civil service examination and those who did not, and to assign experts from private sectors to the position of chief managers based on their competencies. This should be necessary to secure human resources of the agency and vitalize it.

\section{Establishment of a QMS of the Nuclear Safety Agency}

To ensure the progress of corrective actions discussed in Chapters III and IV, it is important for the Nuclear Safety Agency to establish and implement a quality management system (QMS). In the QMS, the mission of the Nuclear Safety Agency will be described in detail and the strategies to achieve the missions and the policy to secure and improve necessary human resources will be determined. Self-assessment and third-party assessment of the implemented status are required, and necessary corrective actions will be implemented. IAEA also requires regulatory agencies to establish QMS in its safety guide ${ }^{11)}$ (clause 3.9).

Upon the review by IAEA in 2007, NISA received advice from IAEA with regard to the continuation of NISA efforts to establish QMS ${ }^{1)}$. (Recommendation R10). The establishment and implementation of QMS by the Nuclear Safety Agency is one of the necessary conditions for bringing the level of Japanese nuclear safety regulations to the international level.

\section{Comprehensive Review by IAEA}

As discussed in Chapters I and V, NISA received Integrated Regulatory Review Service (IRRS) by IAEA in 2007, but its scope was limited, and the follow-up review is not yet applied by Japanese government. This should have earned frowns from the member countries of IAEA and increased the mistrust in nuclear safety regulations of Japan. Following the case in 
Sweden discussed in Chapter I, the Nuclear Safety Agency and its staff should be humble and indispensably apply IAEA for the follow-up review of IRRS.

\section{Conclusions}

Today, Japanese government is considering to establish the Nuclear Safety Agency as an external bureau of the MOE to improve nuclear safety regulations. From the viewpoint of the separation of regulation and development of nuclear industry, this organizational change is important, but more important is to improve the level of expertise and the quality of it. Even if the organizational framework is renewed, a personnel system based on loaned employment from other government organizations and short term periodic shifting of personnel will impair the efforts to obtain sufficient expertise of the executives of the renewed regulatory agency. The nuclear regulatory agencies in European and American countries have high levels of expertise of executive staff, and it is rare to rely on external experts to make expert decisions. The principle of nuclear safety regulations in Japan is to "no hindrance to the prevention of the hazard by reactors etc.," but there are no specific developments or interpretations of this vague principle. The new Nuclear Safety Agency should establish concrete safety principles such as safety goals, and make administrative decisions on individual safety issues based on expertise of its own staff. It would be a fundamental matter to improve the stability, timeliness, efficiency, and transparency of Japanese safety regulations.

This commentary was written with a hope that it could be useful for the government's discussions to establish the new Nuclear Safety Agency. There should be some assertions that do not have firm arguments. The authors would appreciate any comments and opinions of the readers in this regard.

\section{References}

1) INTERNATIONAL ATOMIC ENERGY AGENCY, Integrated Regulatory Review Service (IRRS) to Japan, IAEA-NSNI-IRRS-2007/01, IAEA, Vienna (2007).

2) INTERNATIONAL ATOMIC ENERGY AGENCY, Design of Emergency Power Systems for Nuclear Power Plants, IAEA Safety Standards Series No. NS-G-1.8, IAEA, Vienna (2004).

3) INTERNATIONAL ATOMIC ENERGY AGENCY, Review and Assessment of Nuclear Facilities by the Regulatory Body, Safety Standards Series No. GS-G-1.2, IAEA, Vienna (2002).

4) U.S. Nuclear Regulatory Commission, Generic Issues Program, NRC Management Directives MD 6.4, Washington, D. C. (2009).

5) U.S. Nuclear Regulatory Commission, Regulatory Guides, Management Directives MD 6.6, Washington, D. C. (2011).

6) U.S. Nuclear Regulatory Commission, Differing Professional Views or Opinions, Management Directives MD 10.159, Washington, D. C. (1999).

7) Sawada T. et al., Study on the methods to evaluate the value of whistle-blowing in nuclear power plants. (Final report), Japan Nuclear Energy Safety Organization (2006). [in Japanese]

8) INTERNATIONAL ATOMIC ENERGY AGENCY, Legal and Governmental Infrastructure for Nuclear, Radiation, Radioactive Waste and Transport Safety, Safety Standards Series No. GS-R-1, IAEA, Vienna (2000).

9) Nuclear and Industrial Safety Agency, Internal manual for safety review for the construction permit of nuclear reactor installation. Tokyo (2006). [in Japanese]

10) U.S. Federal Government, Energy Reorganization Act of 1974, Washington, D. C. (1974).

11) INTERNATIONAL ATOMIC ENERGY AGENCY, Organization and Staffing of the Regulatory Body for Nuclear Facilities, Safety Standards Series No. GS-G-1.1, IAEA, Vienna (2002). 


\title{
Why was Introduction of Station Blackout Regulation Late?
}

\section{-Failure to Apply Knowledge of Possible Major Tsunamis to Protect the Fukushima Daiichi Nuclear Power Plant-}

\author{
Former employee of the Japan Atomic Energy Research Institute, \\ Yasuhiko Miyasaka
}

\begin{abstract}
The severe accidents that occurred at the Fukushima Daiichi Nuclear Power Plant, which is operated by the Tokyo Electric Power Company (TEPCO), warrant a thorough examination and validation of factors such as the response and applicable regulations. To begin with, what were the reasons behind the belated regulation of station blackouts (SBOs) at nuclear power plants? Why did seismic regulations not reflect the possibility of earthquakes and tsunamis adequately despite the earlier warnings from experts? In Japan, seismic measures for safeguarding nuclear facilities were introduced in earnest a few years after the Great Hanshin Earthquake of 1995. A major revision of the Regulatory Guide for Reviewing the Seismic Design of Nuclear Power Reactor Facilities was announced in September 2006 in the wake of another major earthquake in Niigata. Regrettably, this revision took too long. It is high time Japan restructured its regulatory system giving due consideration to the importance of safety-related research. An independent agency is postulated as a part of this restructuring. However, the first step must be to examine the earthquake responses taken to date.

This commentary has been written with reference to the flood-induced loss of external power supplies, the tsunami-induced loss of cooling pump functionality, and other events that offer important lessons. It also presents the state of severe accident regulations in the United States and France before providing recommendations for the regulatory measures to be taken in Japan.
\end{abstract}

\section{Events that Teach Important Lessons}

The Blayais Nuclear Power Plant experienced a shutdown of its four pressurized water reactors (PWR; 900 MWe $\times 4$ units) when it lost a $225 \mathrm{kV}$ external power supply at 7:30 pm. on December 27, 1999. Units 2 and 4 also lost their $400 \mathrm{kV}$ power supply lines, but they were replaced by emergency diesel generators to supply power. Units 1 and 2 were flooded when the tide wall facing the Gironde River (designed to withstand a water level rise of up to $5 \mathrm{~m}$ ) was overwhelmed by a combination of the incoming tide and exceptionally high winds. The

DOI : 10.15669/fukushimainsights.Vol.1.177

(C) 2021 Atomic Energy Society of Japan. All rights reserved.

Originally published in Journal of the Atomic Energy Society of Japan (ISSN 1882-2606), Vol. 54, No. 1, p. 32-35 (2012) in

Japanese. (Japanese version accepted: October 28, 2011) 
submersion of the pumps and power distribution equipment led to functional losses of the safety systems and the cooling systems. However, the resultant power plant emergency was resolved owing to the cooling of the reactor cores with steam generators, the recovery of the essential service water system (ESWS) in the afternoon of December 30, and the successful resumption of the operation of Unit 4 to supply power in the early morning of December 30 after its warm shutdown. Unit 3, which was affected immediately after its fuel had been replaced, could not be operated due to problems experienced during an attempted restart after due preparations had been made ${ }^{1,2)}$.

On December 26, 2004, Unit 2 of the Madras Nuclear Power Plant (PHWR; 200 MWe) in India experienced a shutdown due to external flooding when the tsunami triggered by the Indian Ocean Earthquake (M 9.1) submerged the motor for the essential process pump in the pump house ${ }^{3)}$.

Such events are rarely mentioned in journals of the nuclear energy-related societies in Japan, reports, and other materials, which raises questions concerning the seriousness of subsequent surveys and discussions to learn from them. Obviously, demonstration tests cannot be conducted with respect to station blackouts (SBOs), so it is vital for on-site engineers to learn from near SBO events experienced at actual power plants. The regulatory authorities and utilities must become able to detect important information on such events and respond to it.

\section{Severe Accident Regulations and Measures Taken in the United States and France}

After the accident that occurred at Three Mile Island (TMI)-2 in March 1979, the United States experienced four short-term SBO events ${ }^{4)}$ from 1984 to 1990, as shown in Table 1. According to regulatory guidelines enacted in 2003 entitled NUREG-1776 ${ }^{5}$, the country has experienced four near SBO events up to 1998 due to disasters such as hurricanes and tornadoes.

In response to these events, SBO regulations were discussed as an urgent matter. The resultant regulations, which were close to being finalized in 2003, require an ability to withstand including long-term SBOs and restore external power supplies.

In accordance with the Mark I Containment Long-Term Program Safety Evaluation Report (July 1980), NUREG-0661 required the installation of pressure-tight venting systems. Later, the NRC established Rule 10 CFR 50.63 "Loss of all alternating current power" (July 1988) and Regulatory Guide (RG) 1.155 "Station Blackout" (August 1988). In the same year, the power utilities and plant manufacturers jointly established NUMARC-8700, which stipulates more detailed evaluation methods than RG 1.155 does. The NRC has approved this private standard.

Mark-I analysis results based on an analysis code (MELCOR) have also been reported with regard to the escalation of a severe accident that was caused by a long-term SBO (NUREG/ CR-5850; May 1994). The assigned condition for Peach Bottom 2 (MARK-I; ca. 3,300 MWt) was cooling for only 6 hours with batteries after the reactor shutdown and subsequent SBO and the failure of the emergency cooling system. According to this analysis, the water level in the reactor core dropped to the tops of the fuel region in about 15 to 17 hours. Approximately 120 minutes later, a core meltdown began and then escalated into a core collapse and damage to the reactor pressure vessel ${ }^{6)}$.

In France, the SBO regulations were tightened in 1977 because the policy target of restricting the possibility of events with an unacceptable impact to $10^{-6}$ per year was deemed 
Table 1 Examples of SBO and near SBO events experienced in the United States up to the 1990s ${ }^{4,5)}$

\begin{tabular}{|c|c|c|}
\hline Date occurred & Plant Name & Overview of SBO or near SBO events \\
\hline July 26, 1984 & $\begin{array}{l}\text { Susquehanna } 2 \\
\text { (BWR; } 1,140 \mathrm{MWe})\end{array}$ & $\begin{array}{l}\text { Short-term SBO event: Four emergency diesel generators (EDGs) failed to start up for } \\
17 \text { minutes during a simulated loss of external power supplies in a test operation with an } \\
\text { output of } 30 \% \text {. Cause: Operational mistake by an operator. }\end{array}$ \\
\hline November 20,1985 & $\begin{array}{l}\text { San Onofre } 1 \\
\text { (PWR; } 450 \mathrm{MWe})\end{array}$ & $\begin{array}{l}\text { Short-term SBO event: A condenser was under repair due to a seawater leakage while } \\
\text { the plant was operating at an output of } 60 \% \text {. After a connection to an external power } \\
\text { supply was established, a grounding fault alarm was issued for a safety bus leading } \\
\text { from an auxiliary transformer. The power supply from the bus was lost after various } \\
\text { procedures had been conducted to investigate the cause. This loss resulted in a short- } \\
\text { term SBO event. The external power supply was restored in } 4 \text { minutes despite four } \\
\text { failed attempts being made due to a failure to remember to press the reset button. }\end{array}$ \\
\hline February 20, 1990 & $\begin{array}{l}\text { Alvin W. Vogtle } 1 \\
\text { (PWR; } 1,150 \mathrm{MWe})\end{array}$ & $\begin{array}{l}\text { Short-term SBO event: A truck carrying fuel oil hit a } 230 \mathrm{kV} \text { power line pole near the } \\
\text { switching station while the reactor was shut down. The power line was grounded during } \\
\text { the inspection of EDGs. The unit tripped immediately after the remaining EDG (1A) } \\
\text { was activated. It began operating after the third attempt. The SBO lasted for } 36 \text { minutes. } \\
\text { The temperature of the primary circuit increased from } 36^{\circ} \mathrm{C} \text { to } 60^{\circ} \mathrm{C} \text {. A site emergency } \\
\text { was announced. Cause: Defective temperature sensor led to failed EDG startup. }\end{array}$ \\
\hline March 21, 1991 & $\begin{array}{l}\text { Zion } 2 \\
\text { (PWR; 1,040 MWe) }\end{array}$ & $\begin{array}{l}\text { Near SBO event: A deluge valve was opened by mistake during a surveillance test of } \\
\text { the fire water system for the reactor in operation. A large amount of spray water caused } \\
\text { the tripping of a generator. One EDG was being serviced, so it was not available for use. } \\
\text { The power supply was restored in } 60 \text { minutes by using an off-site source. }\end{array}$ \\
\hline August 24, 1992 & $\begin{array}{l}\text { Turkey Point } 3 \text { and } 4 \\
\text { (PWR; } 700 \mathrm{MWe})\end{array}$ & $\begin{array}{l}\text { Near SBO event: Five EDGs became inoperative when the switchgear connecting them } \\
\text { to a safety system became wet during a hurricane that lasted for } 6 \text { and half days. The } \\
\text { plant was remodeled in accordance with the SBO regulations. }\end{array}$ \\
\hline February 6, 1996 & $\begin{array}{l}\text { Catawba } 2 \\
\text { (PWR; } 1,130 \text { MWe) }\end{array}$ & $\begin{array}{l}\text { Near SBO event: The loop was stopped for } 330 \text { minutes due to inadequate insulation. } \\
\text { One of the two EDGs became operative after the battery charger had been repaired. } \\
\text { However, the recovery was delayed by an improper procedure. }\end{array}$ \\
\hline June 2, 1998 & $\begin{array}{l}\text { Davis-Besse } \\
\text { (PWR; } 910 \mathrm{MWe})\end{array}$ & $\begin{array}{l}\text { Near SBO event: A tornado damaged the power supply equipment and one EDG failed } \\
\text { to operate. }\end{array}$ \\
\hline
\end{tabular}

impossible to achieve. In 1978, the regulatory authority SCSIN requested installation modifications to reduce risks and the development of procedures to cope with severe accidents. It also requested measures for SBOs by revising the basic safety rules (1985) and quoting guidelines $(1983)^{4}$. By 1989, the installation of sand bed filtered containment venting systems had been completed in all power plants. Moreover, the aforementioned functional loss of a safety system caused by flooding at the Blayais Nuclear Power Plant prompted Électricité de France (EDF) to prolong the duration of SBOs in its scenarios from 1 day to 3 days and conduct the evaluation again to reinforce measures against flooding (e.g., tide embankments and various equipment) ${ }^{2)}$.

Regulatory authorities in the United States and France are clearly taking measures against severe accidents by establishing requirements for dealing with long-term SBOs based on the many findings that they have gained.

\section{Regulation of Severe Accidents in Japan}

Studies of severe accidents have been conducted since the establishment of the Severe Accident Research Laboratory in the former Japan Atomic Energy Research Institute (JAERI) in 1984, which was prompted by the accident that occurred at TMI-2 in March 1979. However, this laboratory was merged into Thermal Hydraulic Safety Research Laboratory as early as 2001.

Discussions on measures against severe accidents began in 1987, almost 8 years after the TMI-2 Accident. These discussions were conducted by the Council on Common Issues set up by the Expert Committee on Reactor Safety Standards under the Nuclear Safety Commission 
(NSC).

Subsequently, the former Regulatory Guide for Reviewing the Safety Design of Nuclear Power Reactor Facilities, which had been established in 1977, was revised in August 1991. Guideline 27 ("Design consideration against the loss of power supplies") of this guide requires reactor facilities to be designed to ensure that they shut down safely and that the reactors are then cooled properly in the event of any short-term total loss of AC power supplies (SBO). Guideline 27 simply carries over the provisions of Guideline 9 from the former guide without revision. The commentary for Guideline 27 provides the following explanation: "Long-term total loss of AC power supplies need not be considered because the power lines can be restored or the emergency AC power supply equipment can be repaired. The design does not need to anticipate a total loss of AC power supplies if the emergency AC power supply equipment is highly reliable either in its configuration or operation (e.g., constantly kept operational)." At present, the Subcommittee on the Regulatory Guide for Reviewing the Safety Design of Nuclear Power Reactor Facilities is discussing a revision of Guideline 27. According to their documentation, consideration of long-term SBOs was formerly deemed unnecessary while the design was required to "ensure the safe shutdown and subsequent cooling of reactors in the event of a short-term SBO (at least 30 minutes)."

In May 1992, the abovementioned Council recommended measures to prevent severe accidents and mitigate their impact in its report entitled "Management of Severe Accidents at Commercial Light-water Reactors." The Council strongly recommended that utilities voluntarily implement measures against severe accidents.

The NSC set up a working group on station blackouts under the Review Panel on the Analysis and Evaluation of Accidents and Failures at Nuclear Facilities. On June 11, 1993, the group issued a report on station blackouts at nuclear power plants ${ }^{4}$. This report describes short-term SBO events and the like in the United States and other countries and explains its judgment that the probability of an SBO occurring in Japan is lower owing to its reliable power supply systems. The escalation of an SBO to a severe emergency is considered very unlikely because external power supplies can be quickly restored. At the same time, the report points out the following key facts and observations.

- The United States and France have imposed regulatory requirements against long-term SBOs.

- Training must be conducted to enhance safety with respect to SBOs and ensure that operators remain familiar with the requisite procedures.

- New findings must be properly incorporated into the design, operation, maintenance management, and procedure manuals.

- Specific probabilistic safety assessments (PSA) must be conducted at each plant to estimate the core damage frequency due to SBOs and implement accident management measures.

These comments were completely forgotten, and nothing was done about them to prevent the Fukushima Daiichi disaster.

In October 1994, government ministries and agencies submitted a report on the results of their discussions on measures against severe accidents. Having received this report, the NSC examined the validity of the relevant measures in the newly established Comprehensive Investigation Committee on Reactor Safety. The validated results were issued in December 1995 (White Paper on Nuclear Safety, 1995).

Less number of reports regarding severe accidents in Japan have almost certainly been published by researchers since 1995, but the author has been unable to identify any reports on the relevant regulations.

Japanese regulations do not reflect any of the relevant regulations developed in the United 
States and France or any of the knowledge gained in those countries. Regrettably, Japan did not go any further than the recommendations made by researchers for the clear regulation of severe accidents.

Reports such as those mentioned earlier are worthless if the information that they provide is shelved without any follow-up. The need for a regulatory system that carefully selects and applies the relevant information to regulations is being keenly felt.

\section{Reason for the Failure to Apply Knowledge of the Major Tsunami Discussed in the Interim Reports on Seismic Assessments by TEPCO}

An article published in the April 2011 issue of Nikkei Business (a major weekly magazine in Japan) mentioned that TEPCO had been aware of the possibility that a large tsunami could occur. This surprising fact prompted the author to investigate the reason why such knowledge had not been leveraged.

As mentioned above, the Nuclear Safety Commission issued a major revision to the Regulatory Guide for Reviewing the Seismic Design of Nuclear Power Reactor Facilities on September 19, 2006, and the following describes the situation that prevailed thereafter.

The Nuclear and Industrial Safety Agency (NISA) submitted a written request (Nuclear and Industrial Safety Agency Issue No. 6, dated September 19, 2006) for nuclear power utilities to investigate and evaluate seismic safety (including tsunami measures). In response, Tokyo Electric Power Company (TEPCO) submitted the following interim reports to NISA in March 2009.

- Joint Report W32-2-1: "Interim Report on an Evaluation of the Seismic Safety of Unit 5 at TEPCO's Fukushima Daiichi Nuclear Power Plant Following the Adoption of the Revised Regulatory Guide for Reviewing the Seismic Design of Nuclear Power Reactor Facilities"

- Joint Report W32-2-2: "Interim Report on an Evaluation of the Seismic Safety of Unit 4 at TEPCO's Fukushima Daini Nuclear Power Plant Following the Adoption of the Revised Regulatory Guide for Reviewing the Seismic Design of Nuclear Power Reactor Facilities".

In response to the above interim reports, the Joint Working Group on Earthquake, Tsunami, Geology, and Ground Foundation (under the Seismic and Structural Design Subcommittee, Nuclear and Industrial Safety Subcommittee, Advisory Committee for Natural Resources and Energy) held the following notable discussion on June 24, 2009.

An expert member of the working group began the discussion by saying, "In 869, Japan was struck by the extremely large Jogan Tsunami. Why did the report not mention this tsuna$\mathrm{mi}$ at all despite the availability of investigation findings on it?"

TEPCO replied by saying, "There was not much sign of damage. Although we consider this tsunami to be a topic for research, a representative example of an earthquake that should be taken into account in seismic designs is the Shioyazaki-oki Earthquake (1938; M 7.5; estimated height: $5.7 \mathrm{~m}$ )." In response to TEPCO's comment, a member of the working group pointed out that the Jogan Earthquake was estimated to have had a magnitude of around 8.5 based on the model developed by the National Institute of Advanced Industrial Science and Technology (AIST). For the Jogan Tsunami, it estimated that over 1,000 people died, as recorded in the Nihon Sandai Jitsuroku (an historical record of ancient Japan). The method used by the AIST, which involves estimating the time of an earthquake based on analysis of sand 
and other sediment that have been carried inland, is adopted by the Japanese Government's Central Disaster Prevention Council. The NISA Secretariat managed to smooth things over for the time being by saying, "The Jogan Tsunami shall be taken into account in the final report" as the AIST and Tohoku University have knowledge about this tsunami (Summary based on the meeting minutes and other relevant sources of information).

A bulletin published by Gakushikai (an alumni community of major Japanese universities) explains the Jogan Tsunami as follows ${ }^{7)}$ : "The earthquake is estimated to have had a magnitude of 8.4 or more, and the area of distribution for the deposits caused by the Jogan Tsunami that followed is almost the same as the area inundated by the tsunami that followed the Great East Japan Earthquake in March 2011. Going forward, we will report the results of our detailed investigation."

The above opinion was, however, put to one side and omitted in the interim reports. On July 21, 2009, the NISA commission validated these reports. In addition, the NSC endorsed the views presented in these reports. There is no record of the NSC having discussed this issue with respect to the same earthquake.

On August 25, 2011, the Asahi Shimbun (a major newspaper in Japan) essentially reported that "according to an evaluation conducted in 2002 by the Headquarters for Earthquake Research Promotion of the Japanese government, TEPCO estimated that an earthquake off the coast of Boso with a postulated magnitude of M 8.3 would direct a tsunami wave with a height of $10.2 \mathrm{~m}$ toward Units 5, 6 and another with a height of between 8.4 and $9.3 \mathrm{~m}$ toward Units 1 to 4. This finding was reported to TEPCO's upper management in June 2008. In September 2009, TEPCO orally informed NISA personnel of the possibility of a tsunami with a height exceeding $6 \mathrm{~m}$, but NISA did not provide any special instructions. Moreover, 4 days before the earthquake, TEPCO reported the risk of a tsunami with a height exceeding $10 \mathrm{~m}$ to NISA." On October 3, NHK disclosed the report requested from NISA. It is extremely regrettable to find that, despite the findings and actions described above and the fact that the high risk of a tsunami had already been identified in an estimate produced by the Japan Nuclear Energy Safety Organization (JNES), a serious accident occurred due to a failure to implement appropriate measures. An investigation must be conducted to determine whether NISA passed this information on to the Nuclear Safety Commission to be properly double-checked. Poor communication between the JNES, which had essential knowledge, and NISA, as the executive branch for regulation, has already been identified.

Furthermore, it is debatable whether there is truly no need to implement guidelines for protective measures against tsunamis for Japanese plants located along the coast, especially when the United States has put in place RG 1.102 "Flood Protection for Nuclear Power Plants" and RG 1.59 "Design Basis Floods for Nuclear Power Plants."

\section{Conclusions}

In hindsight, it is clear that useful information could have been provided concerning proper measures against tsunamis in Iwate, Miyagi, Fukushima, Ibaraki, and other prefectures if the nuclear communities had begun discussions on findings related to earthquakes and tsunamis in 2009 at the latest, and had opened for public.

Clear regulatory requirements for measures against severe accidents must be introduced in place of the voluntary safety measures currently adopted by utilities. In particular, efforts to learn from SBO and near SBO events must be required to ensure that proper training is conducted. Human resource must be developed to cultivate broad views and keep track of 
findings from studies on SBOs around the world as well as information on topics such as reactor safety systems, earthquakes, tsunamis, structures, and regulations.

The author sincerely hopes that the nuclear power utilities will go back to basics and re-evaluate their technologies, actively engage in the development of technologies to ensure safety, and enhance their site management to disseminate clear and adequate information from the site.

As of the time of writing, the media is reporting on the possibility of integrating NISA and the NSC into the Nuclear Safety Agency to address the inadequate regulatory system in place today. The obsession with details that prevails under the current regulations is an obstacle to transitioning to risk-oriented regulations and the proper adoption of lessons learned from the practices, accidents, and troubles experienced in other countries. Moreover, a transition from emphasizing inspections of structural strength to conducting inspections of system functions has yet to be made. The Reactor Regulation Act still needs to be unified with the Electricity Business $\mathrm{Act}^{8}{ }^{8}$. The regulations have not adequately addressed the issues that were identified in the Integrated Regulatory Review Service conducted by the IAEA in $2008^{9 \text { ). }}$

In recognition of these lessons learned, active discussions must be facilitated by adopting the latest findings in order to build a transparent regulatory system.

In closing, it is worth mentioning that the Nuclear Safety Division of the Ibaraki Prefectural Government noticed and reported that the level of flooding at the Tokai Daini Nuclear Power Plant indicated by the tsunami disaster prevention map was higher than that postulated in the design. This led to a valuable experience that subsequent discussions among stakeholders prompted the implementation of various measures based on the information provided in the map and ensured the operation of cooling pumps at the plant.

\section{References}

1) Safety-related Backup System Failure Due to Flooding at the Blayais Nuclear Power Plant in France [in Japanese], Nucleonics Week (Japanese Edition), 2000.1.6.

2) J. M. Mattei, E. Vial, V. Rebour, H. Liemersdorf, and M. Turschmann: Generic Results and Conclusions of Re-evaluating the Flooding in French and German Nuclear Power Plants, Eurosafe Forum 2001, published 2001.

3) Safe Shutdown of Kalpakkam 2 in India Prompted by the Infiltration of Seawater into the Pump House, INES Case No. 0802-00.

4) Station Blackouts at Nuclear Power Plants [in Japanese], Working Group on Station Blackouts, Review Panel on the Analysis and Evaluation of Accidents and Failures at Nuclear Facilities, June 11, 1993.

5) Regulatory Effectiveness of the Station Blackout Rule, NUREG-1776, August 2003.

6) Analysis of Long-Term Station Blackout Automatic Depressurization at Peach Bottom Using MELCOR (Version 1.8), NUREG/CR-5850, May 1994.

7) Y. Okamura: Prediction of Massive Earthquakes and Tsunamis [in Japanese], Gakushikai Kaihou No. 890 (2011-V).

8) Y. Nishiwaki: Issues and Discussions on the Regulation of Nuclear Power Plants [in Japanese], Journal of the Atomic Energy Society of Japan, 51 (8), 616 (2009).

9) IAEA: Integrated Regulatory Review Service (IRRS) to Japan, (6/2008). 


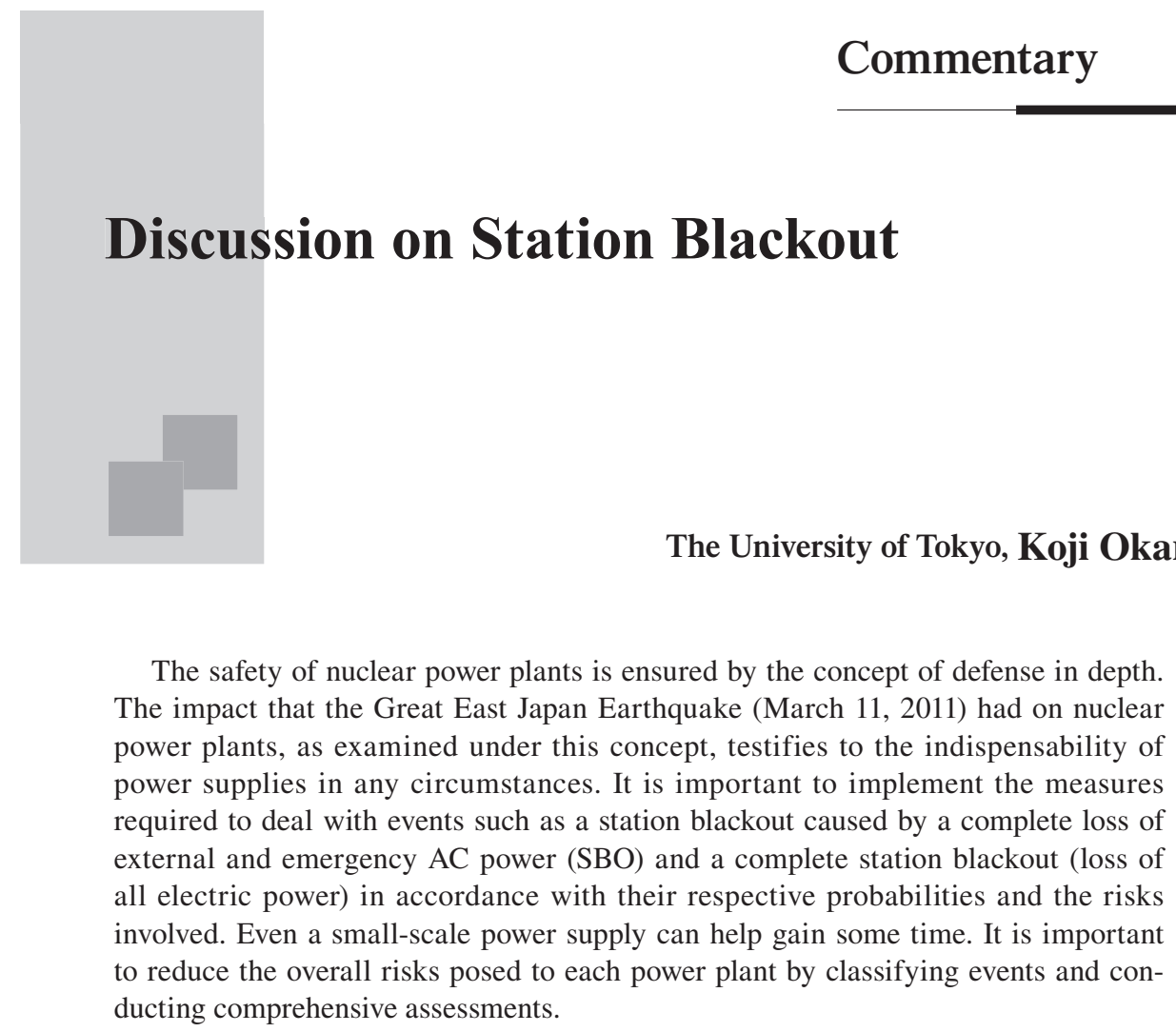

\section{Introduction}

Nuclear power plants produce a large amount of radioactive materials in return for a large amount of energy through nuclear fission. These radioactive materials contain nuclei resulting from the fission of uranium nuclei. Some of these fission products stabilize themselves instantly, while others may take 30 years or even longer to do so. During this process, the unstable fission products emit hazardous radiation such as gamma rays, thereby resulting in a continuous release of heat.

Nuclear safety is primarily aimed at protecting human health and the environment from such hazardous radiation ${ }^{1)}$. Defense in depth -or multi-level protection- has been incorporated as a concept to achieve this purpose. IAEA NS-R-1 defines the five levels of defense as follows ${ }^{2)}$.

(1) Prevent abnormal operations

(2) Prevent the escalation of abnormal operations

(3) Mitigate the impact of abnormal operations and prevent them from escalating into severe accidents

(4) Ensure suitable measures against severe accidents

(5) Protect human life even in the event of a failure to respond properly to a severe accident

The concept of defense in depth advocates the protection of human health by assuming

DOI : 10.15669/fukushimainsights.Vol.1.184

(C) 2021 Atomic Energy Society of Japan. All rights reserved.

Originally published in Journal of the Atomic Energy Society of Japan (ISSN 1882-2606), Vol. 54, No. 1, p. 27-31 (2012) in

Japanese. (Japanese version accepted: November 14, 2011) 
that the preceding level of defense may fail. For example, Level 2 is intended to prevent deviations from escalating if the defense provided under Level 1 fails, while Level 3 is intended to mitigate the impact of any failure of the defense provided under Level 2. Similarly, Level 4 prepares for severe accidents to prevent them from escalating and mitigate their impact, while Level 5 seeks to protect human life from any radioactive materials that may be released in the event of a severe accident.

The Great East Japan Earthquake affected 14 units at nuclear power plants located along the Pacific coast: three units at the Onagawa Nuclear Power Plant, six units at the Fukushima Daiichi Nuclear Power Plant, four units at the Fukushima Daini Nuclear Power Plant, and one unit at the Tokai Daini Nuclear Power Plant. At the Fukushima Daiichi Nuclear Power Plant, which is operated by the Tokyo Electric Power Company (TEPCO), an enormous amount of radioactive materials was released after its defense in depth was overwhelmed by the magnitude 9.0 earthquake and the subsequent tsunami.

The Fukushima disaster underlines the importance of reliable power supplies ${ }^{3,4}$. This commentary discusses station blackouts while also considering them in relation to defense in depth.

\section{Defense in Depth and Station Blackouts}

\section{Level 1: Preventing Abnormal Operations}

With the exception of Fukushima Daiichi Units 4, 5, and 6, which were being subjected to a regular inspection, all of the 14 reactor units mentioned above were in operation. Onagawa Unit 2 had just entered startup mode when the earthquake triggered an automatic cold shutdown. The full-output operation of the remaining ten units was automatically interrupted by the insertion of control rods to stop nuclear fission reaction.

Many external power supplies were rendered inoperable by the earthquake. The major reason for this was the damage that the seismic shaking caused to the insulators, etc. Each power station is equipped with multiple external power supply systems. At the Fukushima Daiichi Plant and the Tokai Daini Plant emergency diesel generators were employed to supply power when their external power supplies were lost. At both the Onagawa Plant and the Fukushima Daini Plant, one external power supply system remained operable although a few other systems were damaged.

External power supplies tend to be relatively unreliable. On September 8, 2011, for example, the San Onofre Nuclear Power Plant lost its external power supplies during a major blackout in California. Based on the lessons learned from an earlier large-scale blackout in New York, the station was designed in anticipation of a possible loss of external power supplies, so its emergency generators were automatically activated to supply electric power.

Owing to this emergency power, the pumps were able to release the decay heat from the reactor into the ocean. In Fukushima Daiichi Units 2 and 3, isolation cooling systems were employed to remove this heat. They supplied water to the reactors by operating turbines with the steam generated by the reactors. This heat was ultimately released into the ocean by using heat exchangers and seawater pumps, which was exactly how the Kashiwazaki-Kariwa Nuclear Power Plant had responded to the Chuetsu Offshore earthquake. The operators presumably expected the continued cooling to remedy the deviations and safely return the reactors to their normal cold shutdown conditions.

At Fukushima Daiichi Unit 1, the decay heat was removed using an isolation condenser 
that cooled the steam generated by the decay heat from the nuclear reactor through natural circulation before releasing the steam into the atmosphere.

Challenge: Ensuring reliable power supplies

The large pumps needed for the cooling process used at nuclear power plants are designed to operate with multiple external power supply systems and emergency generators. The necessary power supply remains intact as long as at least one of them is operational. All of the emergency generators operated properly to at least ensure a reliable power supply. In any assessment, external power supply systems should be assumed unreliable during emergencies. During the disaster, two external power supply systems (Fukushima Daini and Onagawa) remained intact to mitigate the risks.

Notably, an aftershock that occurred on April 7, 2011, led to a station blackout (SBO) at the Higashidori Nuclear Power Plant caused by both the shutdown of emergency generators and the loss of external power supplies. Greater reliability for external power supplies should certainly be pursued to some extent, but enhancing the overall reliability of power supply systems, including emergency generators, is more important.

\section{Level 2: Preventing the Escalation of Abnormal Operations}

A fire broke out at Onagawa Nuclear Power Plant Unit 1 when a power panel was damaged by the shaking. This regular power panel was not important to safety, but the resulting fire made it difficult to enter the building. Efforts were made to extinguish the fire and implement the necessary response. The emergency power panel was intact and did not compromise safety.

Incidentally, a fire also broke out at the Kashiwazaki-Kariwa Nuclear Power Plant when a transformer was damaged by the Chuetsu Offshore earthquake. The fire posed no threat to safety, but the substantial media coverage gave rise to harmful rumors.

Challenge: Protecting power supply systems from earthquake-induced fires

With respect to preventing the escalation of abnormal operations, one of the lessons that have been learned is that sufficient consideration must be given to the risk of earthquakes causing fires. Responses to fires can be hampered by problems with equipment that is not crucial for ensuring safety. Measures to prevent earthquake-induced fires will prove particularly effective with power supply systems.

\section{Level 3: Mitigating the Impact of Abnormal Operations}

About an hour after the earthquake, a massive tsunami hit four nuclear power plants. The wave height marked at each station $-13 \mathrm{~m}$ at the Onagawa Nuclear Power Plant, $14 \mathrm{~m}$ at the Fukushima Daiichi Nuclear Power Plant, $7 \mathrm{~m}$ at the Fukushima Daini Nuclear Power Plant (run-up height: $14 \mathrm{~m}$ ), and $6 \mathrm{~m}$ at the Tokai Daini Nuclear Power Station- was greater than the level postulated in the respective station designs. This tsunami triggered various different types of abnormal circumstances at these stations.

Tables 1 - $\mathbf{3}$ compile how the tsunami affected the power supply systems, which comprised external power supplies, emergency power supplies, power panels (metal-clad switchgear and power centers), and DC power supply. A circle indicates complete availability, while a cross indicates complete unavailability. Any partial availability was indicated by recording how many of the total number of systems were available. 
The Onagawa Nuclear Power Plant sunk $1 \mathrm{~m}$ due to earthquake-induced subsidence. However, the station was not directly affected very much because it was still about $1 \mathrm{~m}$ above the tsunami. Inadequate measures led to water leaking through trenches, thereby rendering two emergency generators unusable for Unit 2. Fortunately, the resulting abnormality was not a serious one.

Similarly, inadequate measures at the Tokai Daini Nuclear Power Plant led to water leaking and rendering one of the seawater pumps unusable for cooling an emergency generator. As a result, one of the emergency generators could not be used in addition to the external power supplies having failed. Safe cooling could be continued using the two remaining emergency generators in combination with the still functional and available seawater pumps, power panels, and other electrical systems.

Challenge: Ensuring that the power supply systems are watertight

One of the lessons that have been learned is that channels by which water may infiltrate power panels and emergency generators must be eliminated, since electrical systems are incompatible with water. Sufficient water-tightness must be ensured to protect the seawater pumps. Air-cooled emergency generators must be deployed alongside the implementation of

Table 1 Conditions at the Fukushima Daiichi Nuclear Power Plant immediately after the tsunami

\begin{tabular}{|l|c|c|c|c|c|c|}
\hline & $\# 1$ & $\# 2$ & $\# 3$ & $\# 4$ & $\# 5$ & $\# 6$ \\
\hline External power supply & $\times$ & $\times$ & $\times$ & $\times$ & $\times$ & $\times$ \\
\hline $\begin{array}{l}\text { Emergency diesel generator } \\
\text { Air cooling system (A/C) } \\
\text { *Damage to cooling pump }\end{array}$ & $\begin{array}{c}\times \\
\times\end{array}$ & $\begin{array}{c}\times \\
\text { A/C }\end{array}$ & $\begin{array}{c}\times \\
\times\end{array}$ & $\begin{array}{c}\times \\
\times^{A / C}\end{array}$ & $\begin{array}{c}\times^{*} \\
\times^{*}\end{array}$ & $\begin{array}{c}\times^{*} \\
\mathrm{O}^{\text {ACC }} \\
*^{*}\end{array}$ \\
\hline $\begin{array}{l}\text { Metal-clad switchgear } \\
\text { (emergency) }\end{array}$ & $\times$ & $\times$ & $\times$ & $\times$ & $\times$ & $3 / 3$ \\
\hline $\begin{array}{l}\text { Metal-clad switchgear } \\
\text { (regular) }\end{array}$ & $\times$ & $\times$ & $\times$ & $\times$ & $\times$ & $\times$ \\
\hline Power center (emergency) & $\times$ & $2 / 3$ & $\times$ & $2 / 3$ & $\times$ & $3 / 3$ \\
\hline Power center (regular) & $\times$ & $2 / 4$ & $\times$ & $2 / 2$ & $2 / 4$ & $\times$ \\
\hline DC power supply & $\times$ & $\times$ & 0 & $\times$ & 0 & 0 \\
\hline Seawater cooling pump & $\times$ & $\times$ & $\times$ & $\times$ & $\times$ & $\times$ \\
\hline
\end{tabular}

Table 2 Conditions at the Fukushima Daini Nuclear Power Plant immediately after the tsunami

\begin{tabular}{|l|c|c|c|c|}
\hline & $\# 1$ & $\# 2$ & $\# 3$ & $\# 4$ \\
\hline External power supply & 0 & 0 & 0 & 0 \\
\hline $\begin{array}{l}\text { Emergency diesel generator } \\
\text { Air cooling system (A/C) } \\
\text { *Damage to cooling pump }\end{array}$ & $\begin{array}{c}\times \\
\times \\
\times\end{array}$ & $\begin{array}{c}x^{*} \\
x^{*} \\
x^{*}\end{array}$ & $\begin{array}{c}x^{*} \\
0\end{array}$ & $\begin{array}{c}x^{*} \\
x^{*} \\
0\end{array}$ \\
\hline $\begin{array}{l}\text { Metal-clad switchgear } \\
\text { (emergency) }\end{array}$ & $1 / 3$ & 0 & 0 & 0 \\
\hline $\begin{array}{l}\text { Metal-clad switchgear } \\
\text { (regular) }\end{array}$ & 0 & 0 & 0 & 0 \\
\hline Power center (emergency) & $1 / 3$ & $2 / 3$ & $2 / 3$ & $2 / 3$ \\
\hline Power center (regular) & $6 / 7$ & $4 / 5$ & $7 / 7$ & $4 / 5$ \\
\hline DC power supply & 0 & 0 & 0 & 0 \\
\hline Seawater cooling pump & $\times$ & $\times$ & $1 / 2$ & $\times$ \\
\hline
\end{tabular}


Table 3 Conditions at the Onagawa Nuclear Power Plant and the Tokai Daini Nuclear Power Plant immediately after the tsunami

\begin{tabular}{|l|c|c|c|c|}
\hline \multirow{2}{*}{} & \multicolumn{3}{|c|}{ Onagawa } & \multirow{2}{*}{$\begin{array}{c}\text { Tokai } \\
\text { Daini }\end{array}$} \\
\cline { 2 - 4 } & $\# 1$ & $\# 2$ & $\# 3$ & $\times$ \\
\hline External power supply & 0 & 0 & 0 & $\times$ \\
\hline $\begin{array}{l}\text { Emergency diesel generator } \\
\text { Air cooling system (A/C) } \\
\text { "Damage to cooling pump }\end{array}$ & 0 & 0 & 0 & 0 \\
Metal-clad switchgear & 0 & $\times$ & 0 & 0 \\
(emergency) & 0 & 0 & 0 & 0 \\
\hline Metal-clad switchgear & $\times$ & 0 & 0 & 0 \\
(regular) & 0 & 0 & 0 & 0 \\
\hline Power center (emergency) & 0 & 0 & 0 \\
\hline Power center (regular) & 0 & 0 & 0 & 0 \\
\hline DC power supply & 0 & 0 & 0 & 0 \\
\hline Seawater cooling pump & 0 & 0 & 0 & 0 \\
\hline
\end{tabular}

other necessary measures in anticipation of any possible failure of the seawater pumps.

\section{Level 4: Countermeasures Against Severe Accidents}

Abnormal conditions that cannot be mitigated may lead to a severe accident. Even if the lines of defense in the design have been broken up to Level 3, all of the resources available at a station must be utilized to prevent the occurrence of a severe accident or mitigate the impact of a severe accident. Such measures are collectively referred to as "accident management (AM)."

In accordance with existing design guidelines, this commentary classifies short station blackouts (SBOs) as Level 3 (design basis) and long SBOs as Level 4 (beyond design basis).

(1) Loss of ultimate heat sink with available power supplies

This section discusses the loss of ultimate heat sink (LUHS) in Level 4, which is an event that is closely related to SBOs even though it is not actually classified as one. At the Fukushima Daini Nuclear Power Plant, a seawater pump in the cooling system was damaged by the tsunami. One of the seawater pumps for removing decay heat from Unit 3 could still be used, along with some of the pumps for the cooling emergency generators used for Units 3 and 4. The power panels for Units 1 to 4 were still operational, although part of the power panel for Unit 1 was damaged. The power supply systems could be operated normally because the external power supplies, the emergency generators for Units 3 to 4, and the power panels for all of the units were still available for use.

The damage suffered by the seawater pump for Fukushima Daiichi Unit 6, which was shut down at the time, led to the loss of ultimate heat sink. Fortunately, the power supply systems were still available because no damage was sustained by the air-cooled emergency generator deployed high above the ground and by the emergency power panel inside the reactor building.

As a result, both the Fukushima Daini Nuclear Power Plant and Fukushima Daiichi Unit 6 managed to avoid a station blackout. Despite the loss of ultimate heat sink, the power supplies enabled accurate monitoring of the conditions inside the reactors. Prearranged proceduresnamely, the depressurization of reactors and alternative water injections into the reactors and 
primary containment vessels-were conducted to gain some time. The cooling system was successfully restored three days after it had been struck by the tsunami while in operation, thereby allowing the Fukushima Daini Plant to be safely shut down. This experience demonstrates that power supplies can provide a gain margin of about three more days.

\section{(2) Station blackouts (SBOs)}

Station blackouts have already been experienced around the world. This section takes as an example an SBO experienced in 2001 at the Maanshan Nuclear Power Plant (Taiwan) ${ }^{5}$. On March 17, 2001, Unit 1 was in a hot standby condition after its operation had been stopped due to salt-bearing sea fog. About one day later at 0:35 am on March 18, the station's external power supplies were lost when both power lines suffered an insulation degradation due to the salt-bearing sea fog. Under the station's design, such a problem should have prompted the automatic activation of the two emergency diesel generator systems (A and B). However, System A failed to supply any power because its bus had been damaged by a ground fault in the distribution panelboard, while System B could not supply any power either as the emergency diesel generator failed to activate. The resultant station blackout led to the core being cooled using the auxiliary feedwater system and other such means.

In Taiwan, nuclear power plants had been backed up by a swing diesel generator in order to increase the reliability of power supplies, since the reliability of external power supply system had been poor. Two reactor units shared such a generator, which was also referred to as the fifth diesel generator. At 2:47 am, the fifth generator was connected to System B, which was still electrically intact, to end a station blackout that had lasted for nearly two hours. The temporary loss of ultimate heat sink caused by the station blackout did not trigger a major problem as the recovery took only two hours and the reactor had been shut down a day earlier.

This accident is a good example of an SBO being caused by damage to a bus or a power panel even though the generators and external power supplies are intact. It also demonstrates that the reliability of power supply system can be enhanced by the adoption of backup generators (i.e., generator redundancy). The DC power supply system also proved important as its availability ensured the proper functioning of the measurement control systems as well as the cooling of the core using the auxiliary feedwater system and other such means.

\section{(3) Station blackout and loss of power panels}

Fukushima Daiichi Unit 5 suffered a station blackout when its external power supplies were lost due to the earthquake and its emergency generators failed to operate after the tsunami. Furthermore, both of the emergency power panels were damaged by the tsunami. Fortunately, DC power supplies could still be used to operate the measurement control systems properly. Nonetheless, the batteries could last eight hours at most even with disconnected loads. On March 12, the batteries for Unit 5 were charged as an accident management measure by connecting its power panel to the undamaged emergency power panel for Unit 6, which still had one functional emergency generator. The power panel for Unit 5 was badly damaged, but it was charged by using a small part that had escaped damage. On March 13, temporary cables from the power panel for Unit 6 were connected to the standby gas treatment system and make-up water system for Unit 5 to supply power. On March 18, power was supplied directly to the seawater pump from a power supply vehicle and to the pump for removing decay heat through a temporary cable from Unit 6 so that the necessary cooling operation could be performed. These accident management measures proved effective. Fortunately, the reactor had been shut down for a periodic inspection, so it reached a cold shutdown state safely owing to the relatively small amount of decay heat. 
Challenge: Protecting power supply hubs and power panels from damage

Crucial task for ensuring the redundancy and independence of AC power supplies Crucial task for charging DC power supplies

In contrast, Fukushima Daiichi Unit 3 suffered not only an SBO, but also total damage to its power panel. Fukushima Daiichi Unit 5 experienced the same problem. In both cases, part of the measurement control systems still functioned properly using the only available DC power supplies. However, unlike for Unit 5, the batteries for Unit 3 could not be charged and a large amount of decay heat remained because the core shutdown had taken place only an hour before the station blackout. Measurement control systems could no longer be used when the batteries were depleted and the DC power supply was lost. The resultant core damage led to a hydrogen explosion that released a large amount of radioactive materials into the environment.

\section{(4) Station blackout, loss of power panels, and loss of DC power supplies}

When Fukushima Daiichi Units 1 and 2 were struck by the tsunami, they lost their DC power supplies (125 V) in addition to suffering SBOs and losing their power panels. Although the facts have yet to be ascertained, DC power supplies with voltages of $250 \mathrm{~V}$ and $24 \mathrm{~V}$ were presumably rendered inoperable. These units experienced complete station blackouts with absolutely no power supplies remaining operable. The resultant core damage led to a hydrogen explosion that released a large amount of radioactive materials into the environment.

The two most serious challenges posed by the loss of power supplies are the resultant failure to control the cooling systems and to operate the measuring instruments to gain key information from the reactor cores. Adequate control of a cooling system can gain some time until the core suffers any damage. Any available measuring systems can help keep track of the core conditions so that appropriate measures can be implemented. These systems do not require much power. It is vital to ensure a continued supply of power to important measuring and control systems.

Challenge: DC power supplies are the last bastion

If DC power supplies are lost, it is extremely likely that the core will be damaged and a massive release of radioactive materials will occur.

\section{Counter Measures for Complete Station Blackouts}

As explained above, SBOs occur on various levels. The pace of escalation into a more serious problem also depends on the amount of decay heat; in other words, the time between the core shutdown and any subsequent SBO. This chapter classifies the approaches to be taken in the event of an SBO.

\section{Station Blackouts}

A station blackout is defined as a failure to supply power to emergency equipment due to the loss of external and emergency AC power supplies (power generation units, such as emergency generators). An emergency power supply consists of multiple (usually two) independent systems to enhance its reliability. It is assumed that the power panel and the bus of at least one system will always be available for use. This type of SBO is considered most likely 
considering the dense fog and other such factors that cause it. Therefore, reliable measures should be implemented in advance to reduce the risk of this SBO.

If we take the Maanshan Plant as an example, we can see that the preparation of an extra power supply facilitates the necessary recovery. Various options are available for restoring power generation units, such as the restoration of external power supplies, the restoration of emergency generators, the establishment of a connection to an alternative emergency generator, and the establishment of a connection to a power supply vehicle. These options commonly enhance the reliability of power generation units. Given that the time constraints are increased by a larger amount of decay heat, reliability can be enhanced by preparing alternative power generation units in advance.

\section{Complete Loss of AC Power Supply Systems}

This condition is defined as a failure to supply power to emergency equipment due to the complete loss of the buses or power panels (metal-clad switchgear or power centers) for emergency power supplies with multiple lines. Due to the loss of power lines, power cannot be supplied even if external power supplies or emergency generators are available. For this reason, the power supply is lost regardless of the availability of power generation units. Similarly, the power supply will be disabled even if one type of power panel (e.g., power center) is still available downstream as long as another type (metal-clad switchgear) is unavailable upstream. In general, it is highly unlikely that multiple lines will suffer simultaneous damage due to a common cause. Therefore, it is not reasonable to deploy any permanent equipment in an attempt to prevent such a problem. Instead, accident management measures should be prepared in advance. It is important to adjust the design to enhance the independence and diversity of power supplies to eliminate any chance of failures resulting from common causes. Possible common causes include earthquakes, tsunamis, and other natural disasters, and terrorism.

In such an event, alternative emergency generators and the like cannot be expected to help because the power supply buses for the connected systems are damaged. Given the need to prepare for many kinds of triggering events, it is not realistic to eliminate common causes, although reliability could possibly be enhanced by preparing independent buses and power panels for alternative emergency generators.

Instead, accident management measures can be implemented to gain the necessary time. More specifically, DC power supplies should be used to remove the decay heat, while cables should be prepared to connect alternative emergency generators and power supply vehicles to the chargers for the DC power supplies in order to ensure that they are charged properly in the event of an emergency. It is also important to prepare the necessary temporary cables and organize regular training. Furthermore, it is necessary to estimate the possible duration of the cooling operation and make sure that it can last longer than the time required to restore the power supply lines.

\section{Complete Station Blackouts}

This condition is defined as the complete loss of AC power supply systems compounded by the unavailability of DC power supplies. Fukushima Daiichi Units 1 and 2 experienced this immediately after they were struck by the tsunami, as was Unit 3 after its batteries ran out. Similar to the complete loss of AC power supply systems, a complete station blackout is triggered by common causes of failures. The implementation of accident management measures 
is crucial, but this type of blackout is deemed slightly less likely to occur than a complete loss of AC power supply systems.

Possible accident management measures involving the use of equipment include enhancing the reliability, redundancy, and diversity of DC power supplies. For example, alternative DC power supplies or dedicated charging equipment could be deployed. In addition, backup power supplies could be prepared for measurement control systems and venting systems, both of which play essential roles during a severe accident.

\section{Combinations of Different Types of Station Blackouts}

The conditions involved in a station blackout, a complete loss of AC power supplies, and a complete station blackout are sometimes more complex than the simple definitions given above might suggest. For example, alternative AC power supplies may fail to activate during a station blackout. The necessary response should be taken by assessing the probabilities and risks of different combinations. It is generally believed that these different combinations can be enveloped by complete station blackouts. Nonetheless, further detailed assessments are probably required.

\section{Conclusions}

The safety of nuclear power plants is ensured by the concept of defense in depth. In practice, the crucial tasks involved in the shutting down and cooling of reactors, and containment of radioactive materials must be performed. Fail-safe designs enable reactors to be shut down and contained to a certain extent even without power supplies. However, a supply of power is essential for the cooling operation, so it is vital to ensure that one is available in any circumstances. Even a small amount of power can gain some time. Appropriate measures must be considered for each level of defense in accordance with the relevant occurrence probabilities and risks. The overall risks for nuclear power plant should be reduced by classifying possible events and assessing them in a comprehensive manner. A scalded dog may understandably fear even cold water, but excessive caution can do more harm. The situation that we face today requires a clear-headed response and a comprehensive assessment.

\section{References}

1) IAEA Safety Standards Series No. SF-1: Safety Fundamentals. Retrieved from https://www-pub.iaea. org/MTCD/publications/PDF/Pub1273_web.pdf.

2) IAEA Safety Standards Series No. NS-R-1: Safety of Nuclear Power Plants: Design. Retrieved from https://www-pub.iaea.org/MTCD/publications/PDF/Pub1099_scr.pdf.

3) Briefing on the Disaster at TEPCO's Nuclear Power Stations in Fukushima [in Japanese]. Retrieved from icanps.go.jp/2011/07/13/0708 touden4.pdf.

4) Additional Report of the Japanese Government to the IAEA: The Accident at TEPCO's Fukushima Nuclear Power Stations (Second Report). Retrieved from https:/www.meti.go.jp/english/earthquake/ nuclear/iaea/iaea_110911.html.

5) The Station Blackout Incident of the Maanshan NPP Unit 1. Retrieved from https://www.aec.gov.tw/ webpage/UploadFiles/report_file/1032313985318Eng.pdf. 


\title{
For Promoting Remediation of Contaminated Area; Principle of Remediation Methods
}

\section{-From Tests at Date-city and Iitate-mura in Fukushima Prefecture-}

\author{
Radiation Safety Forum (NPO), Zenko Yoshida
}

\begin{abstract}
The decontamination of areas affected by the disaster that occurred at the Fukushima Daiichi Nuclear Power Plant will gather momentum with the full enforcement of the Act on Special Measures concerning the Handling of Pollution by Radioactive Materials on January 1, 2012. This work must be carried out swiftly to help evacuees return to their homes as soon as possible. Although some technologies still need to be developed, the basic decontamination methods have been established based on earlier demonstration tests and the like. This commentary explains the principles of the main decontamination methods based on tests conducted mainly by the Radiation Safety Forum, a Japanese non-profit organization.
\end{abstract}

\section{Introduction}

The Great East Japan Earthquake triggered a disaster at the Fukushima Daiichi Nuclear Power Plant. As a result, a large amount of radioactive cesium and other such radionuclides was released into the environment, thereby contaminating vast areas. The inevitable first step that is required to help restore the lives of evacuees is the removal of radioactive cesium from their living areas. No other options are available. In late August 2011, the Japanese government enacted the Act on Special Measures concerning the Handling of Pollution by Radioactive Materials. The decontamination work will gather momentum with the full enforcement of this act on January 1,2012. The work must be carried out swiftly to help evacuees return to their homes as soon as possible. To this end, optimal decontamination methods must be chosen by taking into consideration various factors, including not only the type, amount, properties, and radioactivity level of the intended target, but also the desired efficiency, the amount of resultant waste, the necessary costs, the duration, and the safety of workers.

Since May 2011, the Radiation Safety Forum, a Japanese non-profit organization, has conducted decontamination tests on radioactive cesium in Date City and Iitate Village (Iitate mura), Fukushima Prefecture, in partnership with the Japan Atomic Energy Agency (JAEA), local governments, private companies, and other organizations. The entire village of Iitate has been 
designated as a deliberate evacuation area. Decontamination tests were conducted by about 60 experts over the course of 4 days (May 19-20 and 26-27) mainly on houses and farmland in the Nagadoro District, which had a particularly high air dose rate in Iitate. In addition, from early July to the end of September, tests were conducted on schools, settlements, peach orchards, community forests, and other parts of Date City, given that it has over 100 households in specific spots recommended for evacuation in the districts of Shimo-oguni and Tsukidate. Notably, the decontamination of a primary school and a preschool in the Tominari District that took place over the course of 11 days (July 2-17) was carried out by school employees, local stakeholders, parents, and many other volunteers as well as 370 experts.

This commentary presents the optimal decontamination methods identified based on previously conducted tests. It then explains the principles of these methods to facilitate the selection of the appropriate decontamination method in practice.

\section{Principles of Decontamination Methods}

\section{Scraping of Surface Soil}

The predominant decontamination target is the surface soil of this vast extent of land. The intended use of this land is diverse, ranging from residential, industrial, agricultural land and land designated for public facilities to forests and so on. Regardless of the various different land uses, radioactive cesium is commonly concentrated in the top part of the contaminated soil. This commonality has significant implications for the decontamination methods described in this section.

More specifically, the radioactive cesium that was deposited on the ground surface in midMarch 2011 was immediately captured when it bonded with the clay minerals present in the surface soil. Once captured, the cesium became extremely stable, so it remained near the ground surface without migrating inside the soil or dissolving into water as cesium ions. This stability is a result of the strong bonding of positively charged cesium ions in the cavities and layers of negatively charged clay minerals. The bonding strength is increased because the sizes of these cavities and layers are similar to the size of cesium ions in an aqueous solution (diameter: approx. $5 \times 10^{-8} \mathrm{~cm}$ ).

Figure 1 presents data on the vertical distribution of radioactive cesium in the surface soil of a pasture located in the Nagadoro District of Iitate Village (sampled and analyzed on May 19 and 20,2011). Almost all of the radioactive cesium is concentrated in an area ranging from the ground surface to a depth of approximately $3 \mathrm{~cm}$. This finding was not unique to pastures. A high concentration of radioactive cesium at a depth ranging from a few to five centimeters has also been confirmed for not only farmland used for greenhouses and paddies in the same district, but also land used for primary schools and orchards in Date City.

Given the behavior of cesium in soil, the most efficient way to decontaminate soil is to scrape off the surface soil. Scraping must be performed carefully to remove as thin a layer as possible and thereby minimize the amount of waste produced. Ideally, the scraping work should be carried out manually using hoes or shovels. For instance, the decontamination of grassland and gravel roads at a primary school in Date City was carried out by many parents, local residents, and volunteers using this equipment. This labor force enabled the decontamination work to be performed quickly throughout the vast school premises. To prevent this manual work from stirring up sand or dust, the PIC method (to be explained later) can be employed or other measures can be implemented to at least suppress any sand or dust scattering 


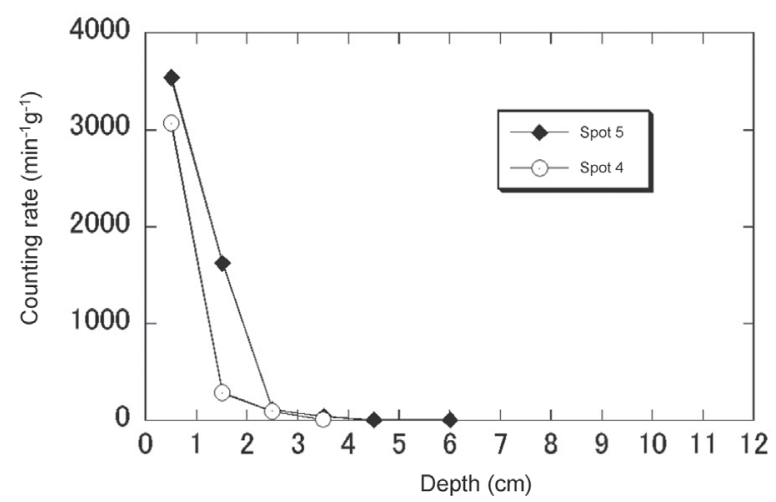

Figure 1 Vertical distribution of radioactive cesium in the surface soil of a pasture ${ }^{1)}$

(e.g., by sprinkling water).

As an alternative to the manual approach, a power shovel was deployed to remove the surface soil on the premises of a private house located in Date City. This highly efficient means of scraping off over $10 \mathrm{~cm}$ of surface soil produced double the amount of soil waste. For this mechanical approach to be employed, the machinery would have to be modified or developed so that it could scrape off a much thinner layer of surface soil.

However, heavy machinery can prove exceptionally effective in certain places. For instance, specialized machines for removing grass in a pasture probably offer a more effective means of decontaminating places with a relatively even growth of grass.

Scraping of the surface soil was also tried in another test conducted in a peach orchard located in Date City. While the surface soil is being removed in an orchard such as this, special attention must be paid to avoid hurting any tree roots that may extend near the surface. Ideally, this should be done by performing manual scraping so that as thin a layer as possible can be removed with precision. The combined use of a vacuum suction unit and a gardening shovel to remove surface soil with a thickness of $2 \mathrm{~cm}$ and $5 \mathrm{~cm}$ achieved a decontamination efficiency of around $40 \%$ and $80 \%$, respectively. Considering how vast the target area is, specialized machinery probably needs to be developed for scraping off the surface soil in orchards.

The polyion complex (PIC) method ${ }^{1)}$ was tried for the removal of a thin layer of surface soil. This method involves spraying an aqueous solution of a mixture of polymer cations and polymer anions on the ground surface and allowing it to soak into soil before solidifying into polyion complexes (PICs). These PICs and the surface soil are then scraped off together. One advantage of this method is that a relatively small amount of PIC (e.g., 2 wt $\%$ of soil) is sufficient to soak into the soil and solidify the surface layer. Figure 2 shows slices of surface soil that was solidified using the PIC and then scraped off from farmland covered by a greenhouse. Another advantage of the PIC method is its ability to prevent dust from being stirred up while the surface soil is being scraped off. In a test conducted on relatively dry dust-producing farmland for greenhouses, the adoption of the PIC method reduced the level of airborne soil dust to half or even less than one-third the usual level.

The effectiveness of the PIC method was also demonstrated in tests conducted on private houses and farmland in Iitate Village and an assembly hall in Date City. These tests all proved that the PIC method provides an efficient means of removing radioactive cesium from the ground surface.

As an example, the results from the decontamination tests conducted using the PIC method 


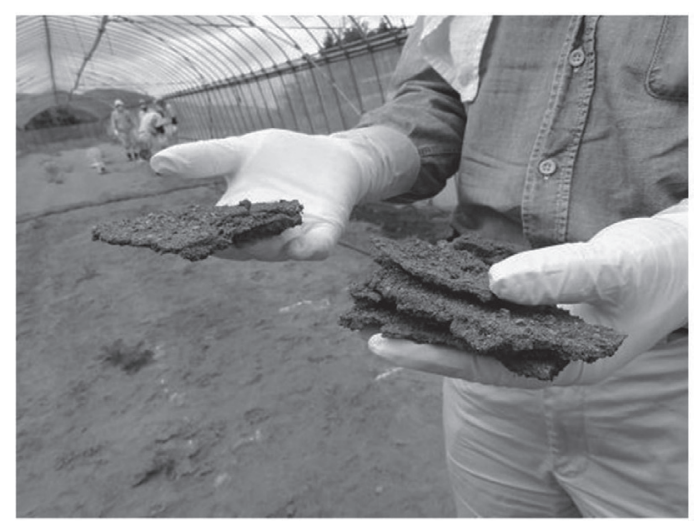

Figure 2 Slices of soil scraped off at farmland for greenhouses after being solidified using polyion complexes for decontamination ${ }^{1)}$

on farmland in Iitate Village are presented below. Before the decontamination, the radioactivity concentration measured using GM survey meters on pastures, paddies, and farmland for greenhouses stood at $1.7 \times 10^{4} \mathrm{cpm}, 4.3 \times 10^{4} \mathrm{cpm}$, and $1.6 \times 10^{4} \mathrm{cpm}$, respectively. At all of these test sites, between 80 and $95 \%$ of radioactive cesium was removed by scraping off the surface soil using the PIC method.

Many other methods have also been proposed as alternatives to scraping off the surface soil, such as employing adsorbents or extractants to elute the cesium contained in the soil into an aqueous solution in the form of ions. As mentioned earlier, however, it is generally difficult to dissolve the cesium in the soil into an aqueous solution because the cesium is extremely stable. Hot acids or aqueous solutions can hasten the cesium elution from soil of course, but that is not a realistic method for decontaminating a vast area of land.

\section{Removal of Thin Slices of Concrete and Asphalt Surfaces}

Radioactive cesium that has contaminated concrete or asphalt surfaces bonds tightly with the clay mineral particles contained in these base materials. For this reason, radioactive cesium is concentrated near the surface. As is the case when it is present in soil, the radioactive cesium does not migrate very much inside the concrete or asphalt and it does not dissolve into an aqueous solution. For this reason, the best decontamination method involves slicing off a thin layer from the surface of the concrete or asphalt with a thickness of $1 \mathrm{~mm}$ or less by using specialized machinery.

Various machines have been tried for the decontamination of asphalt and concrete by slicing off thin layers from the surface. Of these machines, a shot blast, which chips away the surface of the target by bombarding it with iron balls that have a diameter of around $1 \mathrm{~mm}$ at a high speed (Figure 3), proved to be the most effective option. Tests demonstrated that this machine could chip away a layer with a thickness of between 0.1 and $0.2 \mathrm{~mm}$ from the asphalt surface in one sweep, thereby enabling about 85 to $90 \%$ of the radioactive cesium to be removed. When two sweeps were performed, the removal performance exceeded $90 \%$.

However, the removal performance of a shot blast was reduced to between about 50 and $70 \%$ in cracks of various sizes on asphalt roads. A higher performance can be gained by using a shot blast in combination with a vacuum suction unit to remove the sediments and impurities present in these cracks. It is also desirable to inject filler into the decontaminated cracks to prevent any recontamination. 


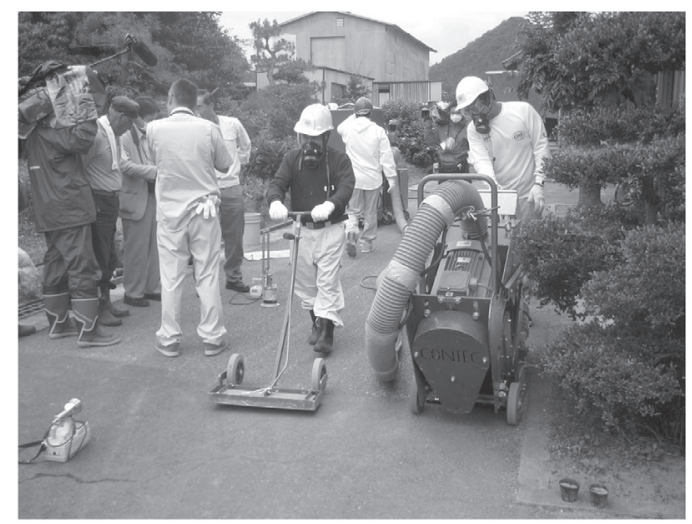

Figure 3 A shot blast for chipping away the surface of asphalt and concrete (photo courtesy of ATOX Co., Ltd.)

Shot blasts also offer an effective means of decontaminating concrete surfaces. Grinders (also known as "concrete shavers") are useful for decontaminating targets in narrow spaces, such as concrete stairs. A sufficient removal performance could be achieved by grinding away a thin layer (thickness: approx. $0.5 \mathrm{~mm}$ ) from the surface of the concrete. During any blasting operation, a dust collector should be connected to the shot blast to prevent the scattering of concrete particles.

As an example, the results of tests conducted using a machine to grind away layers from the surface of asphalt and concrete in a primary school located in Date City are presented below. Before the decontamination, the air dose rate was within the range of 5 to $8.5 \mu \mathrm{Sv} / \mathrm{h}$ on an asphalt slope leading to the school building, 0.7 to $1.6 \mu \mathrm{Sv} / \mathrm{h}$ in the asphalt square located in front of the school building, and 1.2 to $1.8 \mu \mathrm{Sv} / \mathrm{h}$ on the concrete stairs leading from the square down to the ground. After the decontamination, the air dose rate was reduced in almost all of the test spots. For instance, the asphalt slope leading to the school, which had the highest air dose rate prior to decontamination, registered a significant drop to 0.6 to $1.0 \mu \mathrm{Sv} / \mathrm{h}$ in all of the test spots.

Aside from the mechanical chipping of asphalt surfaces, various chemical decontamination methods were also tested with the aim of dissolving the radioactive cesium by using various acid or salt solutions. However, even the most effective methods -which involved using hydrochloric acid $(1 \mathrm{~mol} / \mathrm{L})$, nitric acid $(1 \mathrm{~mol} / \mathrm{L})$, or sodium citrate solution $(1 \mathrm{~mol} / \mathrm{L})-$ were only able to remove a maximum of $20 \%$ of the radioactive cesium (Naganawa et al., private communication).

\section{Water Blast Cleaning}

Radioactive cesium tends to be loosely deposited as dust on the roofs and walls of buildings. Blast cleaning of roof tiles, gutters, and wall surfaces with pressurized water is a relatively simple means of washing away radioactive cesium along with the dust. This method is an effective option for decontaminating large areas, and it is the best option for performing decontamination work in elevated places. In many cases, however, the radioactive cesium becomes firmly adsorbed by the tile surface once it has been deposited, so blast cleaning alone cannot remove the radioactive cesium sufficiently well. Consequently, the surface must be brushed with a cleaner or undergo another special treatment, especially if a high concentration 
of radioactive cesium has been deposited on tiles. During any cleaning operation, additional measures must be taken to minimize the scattering of misty droplets containing radioactive cesium and to prevent the radioactive cesium from dispersing by managing the channels of wastewater.

Water blast cleaning proved an effective means of decontaminating the rooftops and balconies of school buildings. For instance, nearly $90 \%$ of the radioactive cesium was removed by washing away moss, sludge, and fallen leaves from the balconies.

In addition, water blast cleaning removed over $90 \%$ of the radioactive cesium from the rubber mats located along the sides of pools after a commercially available acidic cleaner had been applied and they had been brushed using a scrubbing brush, polisher, and the like. Water blast cleaning also proved an effective means of decontaminating swimming pool gutters after the moss, sediment, dead leaves, and the like had been removed using a vacuum suction unit.

However, water blast cleaning combined with the application of various cleaners and the scrubbing of the surface with a polisher did not prove sufficiently effective for the decontamination of road surfaces paved with asphalt or concrete.

\section{Direct Removal of Contaminants}

If feasible, the most effective and reliable decontamination method is to remove the radiation sources directly. Numerous examples of the application of this method are available. The results from some decontamination tests conducted in Iitate Village and Date City are presented below to provide examples.

Prior to decontamination carried out in a test at a private house in Iitate Village, the state of the radiation sources was examined. The radiation sources were found to mainly meet the following conditions: (1) deposited on roof tiles and building surfaces; (2) deposited on the ground surface at the premises; (3) deposited in the sludge that had piled up in the gutter; (4) concentrated in the soil around a water collecting pit leading from the gutter; (5) deposited on fallen leaves from cedar and other trees as well as on the leaf mulch in the backyard; and (6) deposited on the surface of leaves from evergreens, such as cedar and fir trees, around the house. The best decontamination method for radiation sources (3) to (6) is their direct removal.

As much as possible of any sediment in a gutter or sludge in a water collecting pit should be removed. For instance, such work removed between 75 and $90 \%$ of the radioactivity from the gutter (the radioactivity concentration on the gutter surface as measured with a GM survey meter dropped from between $4 \times 10^{4}$ and $5 \times 10^{4} \mathrm{cpm}$ to less than $1 \times 10^{4} \mathrm{cpm}$ after the removal). To prevent the sediment and sludge being stirred up as dust, it is desirable to solidify them using the aforementioned PIC method before their removal.

Fallen leaves from cedar and other trees should also be removed from the backyard. The radioactivity concentration was relatively high (between $1.5 \times 10^{4}$ and $3 \times 10^{4} \mathrm{cpm}$ in one spot) in the backyard and the slope beside it where weeds were growing on the leaf mulch. In this area, between 60 and $80 \%$ of the radioactivity was removed by the complete removal of leaf mulch and weeds, followed by the scraping of the surface soil.

In the backyard of a private house in Iitate Village, leaves were sampled from a fir tree. Autoradiography was performed to check for the presence of radioactive cesium in the sample and examine its distribution. The distribution results are shown in Figure 4. The darker black areas indicate a higher concentration of radioactive cesium. The results indicated an almost homogenous deposition of radioactive cesium on leaves and branches (see Reference 2 for 


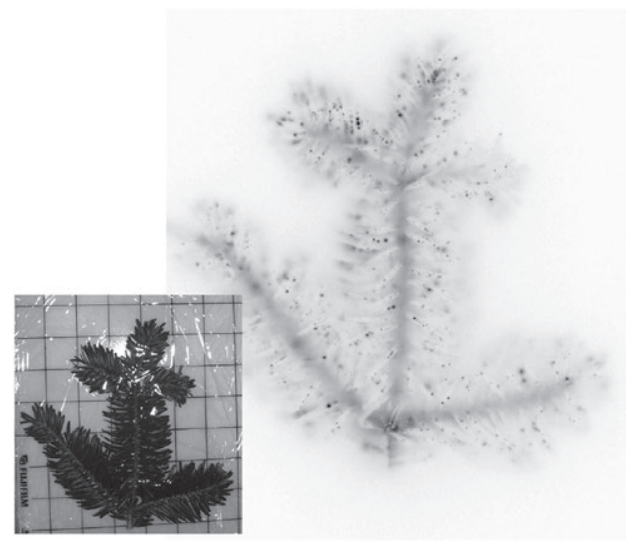

Figure 4 Autoradiography of fir leaves ${ }^{2)}$

Black spots in the image indicate the deposited radioactive cesium.

details). The radioactive cesium deposited on the surface of leaves from evergreens, such as cedar and fir trees, becomes firmly bonded, so it cannot be removed simply by washing it away with water and the like. Consequently, pruning and felling must be performed to reduce this radioactivity.

Prior to the performance of a decontamination test at a private house in Iitate Village, the dose rates were measured at nine spots, including the entrance to the main building, a Japanese-style room, the kitchen, and a corridor. The measured dose rates were significantly high across the board within the range of 4 to $10 \mu \mathrm{Sv} / \mathrm{h}$. Especially, the relatively higher measurements that were obtained around the external walls of the room facing the backyard $(6.5-9.6 \mu \mathrm{Sv} / \mathrm{h})$ suggest that sources in the backyard made a large contribution. In addition, a high dose rate was observed around the corridor near the water collecting pit leading from the gutter. Measurements obtained inside the main building demonstrated that decontamination reduced the dose rates in the room facing the backyard and the corridor near the rainwater collecting pit from their previously high levels. The dose rates in all of the nine spots converged to a level between 3.0 and $4.3 \mu \mathrm{Sv} / \mathrm{h}$. However, further decontamination must be carried out because this outcome is not yet sufficient. A further reduction in the dose rates could possibly be made by felling a wide range of cedar and fir trees around the house (e.g., within $50 \mathrm{~m}$ of the house).

The results of a decontamination test conducted in a community forest located in Date City are as follows. In mid-March 2011, the leaves on deciduous trees had not yet emerged, so most of the fallen radioactive cesium was deposited on the fallen leaves from last autumn or the leaf mulch. As of autumn 2011, the most effective method for decontaminating deciduous trees was the removal of the fallen leaves from last autumn and the leaf mulch. The decontamination test conducted in October 2011 in a community forest in Date City verified that simply clearing fallen leaves removes between 30 and $60 \%$ of the radioactivity. This decontamination performance could be further enhanced by scraping off the soil underneath the fallen leaves and the leaf mulch. Meanwhile, the leaves that emerged on deciduous and broadleaved trees after spring 2011 do not require decontamination because almost no radioactive cesium adhered to them.

In contrast, the decontamination performance of simply removing fallen leaves from evergreens (mainly in cedar forests) was as low as 10\%. It turned out that scraping off a layer with a thickness of around $5 \mathrm{~mm}$ from the surface of the soil was necessary to boost the performance 
to nearly $90 \%$. As mentioned earlier, leaves on evergreens are highly contaminated, so they require pruning, felling, or similar measures.

\section{Water Purification and Discharge}

Swimming pools at schools were filled with water from the previous autumn (2010). The bottoms of the pools were full of piles of dust and sludge from fallen leaves and the like. In the water, blue-green algae were flourishing. The radioactive cesium that had fallen on the water of these swimming pools was deposited in either the sludge or the algae, causing them to bond, or formed free ions in the water (Figure 5). Taking the swimming pool at the Tominari Elementary School in Date City as an example, the average radioactive cesium concentration (of the sampled nearly homogenous water with the radioactive cesium having combined with the entire pool after stirring the water) was found to be about $650 \mathrm{~Bq} / \mathrm{kg}$. The measurements taken revealed that about $70 \%$ of the radioactive cesium had been deposited in the sludge, about $10 \%$ had been deposited on the algae, and about $20 \%$ had dissolved in the water as cesium ions.

An effective way to treat the water in swimming pools ${ }^{3)}$ is to purify and drain away the upper portion that contains mainly both algae and free cesium ions before collecting the sludge on the bottom. The purification method used for the upper portion can be explained as follows. First, the upper portion of the water in the swimming pool is pumped into a polyethylene tank with a capacity of one ton. A small amount of zeolite powder is added, followed by an appropriate amount of a coagulant (polyaluminum chloride solution) to coagulate and precipitate the sedimentation of the algae and the zeolite powder. Once the water from the supernatant in the tank has been pumped away, the deposits are collected by filtration using a hemp sack or the like and the filtrated water is drained. After that, the sludge on the bottom of the pool is collected and filtrated using a hemp sack or the like, and finally the decontaminated water is drained away.

After the water had been treated using the above method, the swimming pools were filled

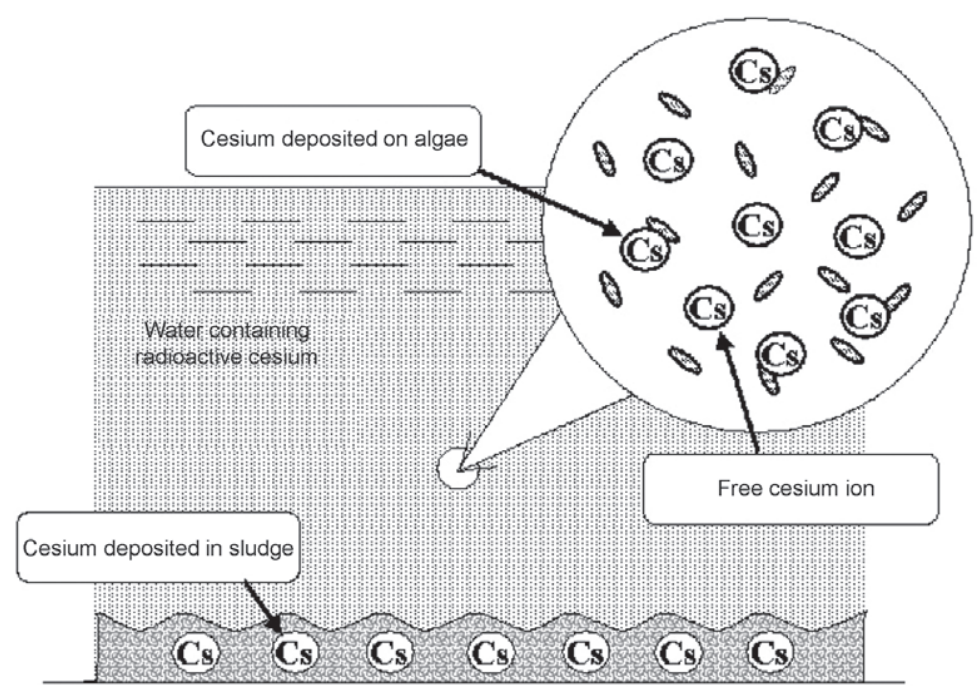

Figure 5 Chemical forms of radioactive cesium in the water of a swimming pool 
with tap water for 1 or 2 days. Subsequent measurements of the water verified that the radioactivity concentration had been reduced to under the detection limit (ca. $10 \mathrm{~Bq} / \mathrm{kg}$ ). The decontamination of the sides of the pools reduced the air dose rate from between 2 and $8 \mu \mathrm{Sv} / \mathrm{h}$ to between 0.7 and $0.8 \mu \mathrm{Sv} / \mathrm{h}$, thereby enabling the swimming pools to be used.

This water treatment method can be applied not only to swimming pools, but also to any kind of puddles. The same method was employed for the decontamination of a lotus pond next to the school building at Tominari Elementary School. This method can probably be applied in the decontamination of holding ponds scattered around farming areas.

\section{Conclusions}

This commentary explains the principles of basic decontamination technologies. The appropriate method must be employed according to the intended target. Some technologies and machines must be developed urgently. These development needs should be addressed immediately to keep pace with decontamination efforts. The waste produced from the decontamination work should be managed and disposed of in an appropriate manner. On October 29, 2011, the Ministry of the Environment presented the basic concept for interim storage facilities. It is hoped that the construction of temporary waste storage yards and interim waste storage facilities will be promoted, and then it will hasten the decontamination work in affected areas.

The content of this commentary is based on the results of decontamination tests conducted in Date City and Iitate Village under the coordination of Dr. Shunichi Tanaka, Vice President of the Radiation Safety Forum. The author would like to extend his gratitude to the many people who helped conduct these tests, including the following: Mr. Tatsuya Fukuda, Mr. Junichiro Tada, and their colleagues from Chiyoda Technol Corporation; Mr. Kaoru Kashima, Mr. Hiroshi Saito, and their colleagues from ATOX Co., Ltd.; Dr. Noriyuki Kumazawa (Ibaraki University); Dr. Hirochika Naganawa, Dr. Toshihiko Ohnuki (JAEA), and their fellow research group members; employees of the Date City Office; members of COOP Fukushima; members of the local community; and volunteers from many different parts of Japan.

\section{References}

1) H. Naganawa, N. Kumazawa, H. Saito et al.: Removal of Radioactive Cesium from Surface Soil Solidified Using Polyion Complex as a Solidifying Agent-Rapid Communication for Decontamination Tests at Iitate-mura in Fukushima Prefecture [in Japanese], Transactions of the Atomic Energy Society of Japan, 10, 227-234 (2011).

2) F. Sakamoto, T. Ohnuki, N. Kozai et al.: Local Area Distribution of Fallout Radionuclides from Fukushima Daiichi Nuclear Power Plant Determined by Autoradiography Analysis [in Japanese], Transactions of the Atomic Energy Society of Japan, 11, 1-7 (2012).

3) Guide for the Decontamination of Swimming Pools at Schools [in Japanese], JAEA website (http:// www.jaea.go.jp//fukushima). 


\title{
Distribution of Dose-Rates and Deposition of Radioactive Cesium by the Airborne Monitoring Surveys
}

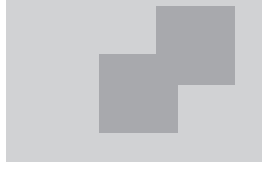

\author{
Japan Atomic Energy Agency, \\ Tatsuo Torii, Yukihisa Sanada and Takeshi Sugita \\ Japan Map Center, Kei Tanaka
}

To survey the impact of radioactive cesium emitted into the atmosphere and deposited into the ground surface as a result of the accident at the Tokyo Electric Power Company's Fukushima Daiichi Nuclear Power Plant, wide-range radiation monitoring via aircraft (hereinafter, airborne monitoring) was conducted in eastern Japan. An advantage of airborne monitoring is that it provides a "surface"-based understanding of air dose rates and deposition amount distributions of radioactive cesium by rapidly measuring gamma rays across a wide range, from urban areas to mountain forests, and the data are visually easy to understand. Through this airborne monitoring, in addition to the spatial dose rates and distribution of deposition amounts of radioactive cesium in each area of eastern Japan, we also gained an understanding of the air dose rate distribution of natural nuclides in eastern Japan, for which there have been no detailed measurement results until now. An overview of the wide range of airborne monitoring results in eastern Japan and the issues faced moving forward are explained herein.

\section{Introduction}

To evaluate the range of impact of radioactive substances that were emitted and diffused by the accident at the Fukushima Daiichi Nuclear Power Plant (hereinafter, the power plant), caused by the massive tsunami that hit the Pacific coast of Japan as a result of the Great East Japan Earthquake of March 11, 2011, Japan's Ministry of Education, Culture, Sports, Science and Technology (MEXT) and the United States Department of Energy conducted joint airborne monitoring and understood the air dose rates at a height of $1 \mathrm{~m}$ above ground and the status of radioactive cesium contamination at the ground surface within a range of $80 \mathrm{~km}$ from the power plant. Next, the group continued to conduct monitoring, including that of the surrounding area, and implemented airborne monitoring of the entire eastern Japan area (one metropolitan area, 21 prefectures) from Aomori Prefecture to Aichi Prefecture, including every prefecture surrounding Fukushima Prefecture, and understood the spatial dose rate distribution in the area and the contamination due to radioactive cesium on the ground surface ${ }^{1)}$.

DOI : 10.15669/fukushimainsights.Vol.1.202

(C) 2021 Atomic Energy Society of Japan. All rights reserved.

Originally published in Journal of the Atomic Energy Society of Japan (ISSN 1882-2606), Vol. 54, No. 3, p. 160-165 (2012)

in Japanese. (Japanese version accepted: January 7, 2012) 
In Japan, as indicated by the Environmental Radiation Monitoring Guidelines, airborne monitoring techniques were developed for use in the event of an accident at a nuclear power facility, but this experience of implementing large-scale measurements was the first of its kind. The U.S. Department of Energy provided guidance and advice regarding details such as measurement methods, and a measurement plan was devised while referencing various documents and groping about for additional information; sensitivity testing in regard to detection devices was conducted and airborne monitoring was conducted while developing analysis techniques. In this paper, we explain the knowledge that was gained through the airborne monitoring of the entire eastern Japan area implemented thus far, as well as the issues that remain.

\section{Details of Airborne Monitoring}

(1) Within a Range of $80 \mathrm{~km}$ from the Power Plant

As described below, primary to quaternary airborne monitoring was conducted in the area surrounding the power plant.

- First-stage Monitoring: The U.S. Department of Energy (hereinafter, "U.S. DOE") equipped a U.S. military aircraft (C-12, UH-1) with a large NaI detector (hereinafter, the DOE detector) and monitored an area within a radius of $60 \mathrm{~km}$ from the power plant (Figure 1). In addition, MEXT (The Nuclear Safety Technology Center, hereafter, NUSTEC) attached an NaI detector (hereinafter, the NUSTEC detector) to the outside of a helicopter and conducted similar measurements within a radius of $60-80 \mathrm{~km}$. (Implementation Period: April 6-29)

- Second-stage Monitoring: MEXT (NUSTEC) implemented measurements in an 80$100 \mathrm{~km}$ radius (up to $120 \mathrm{~km}$ for the southern part of Ibaraki Prefecture) using the NUSTEC detector. (Implementation Period: May 18-26)

- Third-stage Monitoring: The Japan Atomic Energy Agency (hereafter, JAEA) and NUSTEC equipped a helicopter (UH-60J) of the Japan Air Self-Defense Force with a DOE detector and conducted monitoring within a $40 \mathrm{~km}$ radius from the power plant. In addition, the Nuclear Safety Technology Center conducted monitoring using the NUSTEC detector within a 40 to $80 \mathrm{~km}$ radius. (Implementation Period: May 31 to July 2)

- Fourth-stage Monitoring: The distribution of radiation after being affected by the rainy season and typhoons was measured with the same system as that in the third-stage

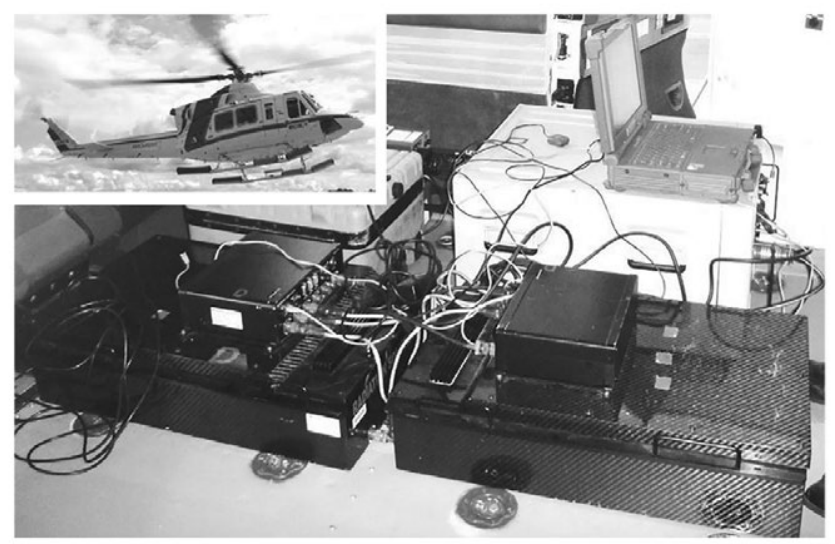

Figure 1 DOE detectors (two in the front), measuring instrument, batteries, and helicopter equipped with these instruments 
monitoring.(Implementation Period: October 24 to November 5)

\section{(2) Implementation in Entire Eastern Japan Area}

To understand the status of diffusion of radioactive substances beyond the $80 \mathrm{~km}$ radius of the power plant, airborne monitoring was conducted in one metropolitan area and 21 prefectures-from Aomori Prefecture to Fukui, Gifu, and Aichi Prefectures. To prevent any shielding of deposited radiation by snowfall, the goal was to complete the monitoring by mid-October and a decision was made to conduct monitoring with four helicopters including those equipped with the DOE detector and the NUSTEC detector and helicopters equipped with detectors obtained through the cooperation of two other companies (Oyo Corporation, Japan and FUGRO Co. Ltd. Australia). Details of the devices that were used are shown in Table 1.

Table 1 Detectors Used in Airborne Monitoring of the Entire Eastern Japan Area

\begin{tabular}{|c|c|c|c|c|c|}
\hline Detector Name & Loading Method & $\begin{array}{l}\text { Detector Size } \\
\text { (inches), Quantity }\end{array}$ & Energy Range & $\begin{array}{l}\text { Number of } \\
\text { Measurement } \\
\text { Channels }\end{array}$ & $\begin{array}{l}\text { Altitude } \\
\text { Measurements }\end{array}$ \\
\hline DOE Detector & Inside aircraft & $16 " \times 4 " \times 2 "$, qty. 6 & $0.02-3 \mathrm{MeV}$ & $1,024 \mathrm{ch}$ & GPS \\
\hline NUSTEC Detector & Outside aircraft & $16 " \times 4 " \times 4 "$, qty. 4 & $0.05-3 \mathrm{MeV}$ & $256 \mathrm{ch}$ & Laser \\
\hline OYO Detector & Outside aircraft & $16 " \times 4 " \times 4 "$, qty. 8 & $0.2-3 \mathrm{MeV}$ & $256 \mathrm{ch}$ & Radio waves \\
\hline FUGRO Detector & Inside aircraft & $16 " \times 4 " \times 4 "$, qty. 4 & $0.05-3 \mathrm{MeV}$ & $256 \mathrm{ch}$ & GPS \\
\hline
\end{tabular}

\section{Airborne Monitoring Method}

The monitoring was conducted on a prefecture unit beginning with the prefectures adjacent to Fukushima Prefecture. In addition, an airborne monitoring team for measuring the respective prefectures using four helicopters; an aboveground monitoring team for measuring the air dose rates at an altitude of $1 \mathrm{~m}$ and radioactive cesium concentration at the ground surface using in situ Ge detectors, and an analysis team for analyzing the dose rates at an altitude of $1 \mathrm{~m}$ from the airborne monitoring data, comparing and confirming with ground data, and mapping the data on maps were established. Through this, the air dose rates and deposition amounts of radioactive cesium were determined.

\section{Airborne Monitoring Devices and Measurements}

The large NaI detector shown in Table 1 was mounted either inside or outside of a helicopter; around two operators boarded each helicopter and the wave height distribution data for 256 or 1,024 channels was measured along with the total count rate [cps] every 1 s. Simultaneously, a GPS or another type of altimeter device was used to measure the positional information of the helicopter. To measure the altitude above ground, we used a method in which the altitude was either measured directly by a laser altimeter or a GPS altimeter was used to measure the flight altitude, and the difference from 90-m-mesh numeric map data (DEM: digital elevation model) was found and used as the altitude above ground.

Initially, in the measurements with the DOE detector for which the measuring instrument was installed inside the helicopter, one model of the helicopter was designed with the fuel tank installed under the cabin floor, but this required consideration of shielding by the fuel tank. Therefore, as a helicopter that used a detector that was installed inside the aircraft, a helicopter model without a fuel tank under the floor was selected for all helicopters.

To convert and evaluate the spatial dose rates at a height of $1 \mathrm{~m}$ from the total count rate 
obtained at the measurement altitude, a comparatively flat location at which the helicopters could be linearly flown for about $3 \mathrm{~km}$ was selected in advance as a test line. The helicopter was then flown in the skies above that level, with the altitude being changed every $150 \mathrm{~m}$ from an altitude above ground of $150 \mathrm{~m}$ (500 feet) to around 1,000 $\mathrm{m}(3,000$ feet) ; in this way, the effective air attenuation coefficient $\mu$ of radiation from aboveground was determined. In addition, the aboveground monitoring team conducted dose rate measurements (approximately five measurements were taken at each location, and the average value was calculated) at about 30 points using an NaI survey meter in an area with a width of $600 \mathrm{~m}$ and length of $3 \mathrm{~km}$ directly below the test line, and these measurements were compared with the airborne monitoring data to calculate the dose rate conversion coefficient [cps/ $(\mu \mathrm{Sv} / \mathrm{h})]$. Furthermore, cosmic rays and other such background compounds were identified by flying at an altitude near $300 \mathrm{~m}$ (above the water line) as a reference altitude above seawater (Figure 2).

As shown in Figure 3, in actual monitoring, flights were conducted in a series of parallele survey lines while maintaining an altitude of around 150 to $300 \mathrm{~m}$ above ground. The

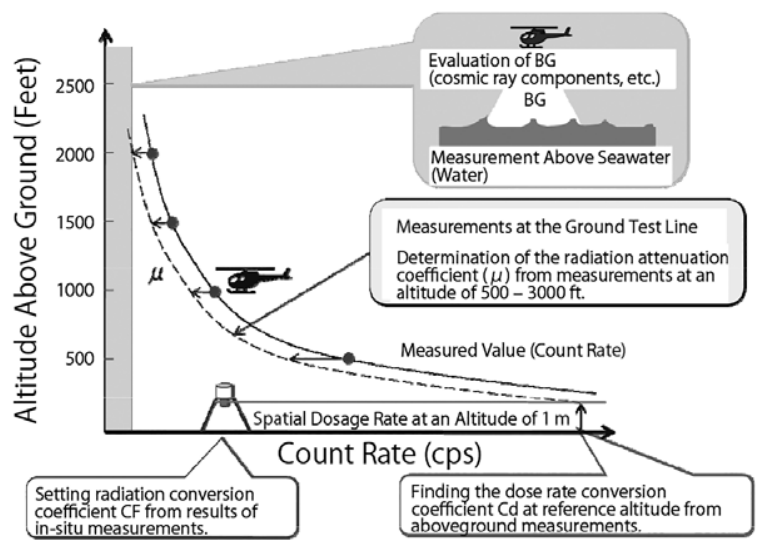

Figure 2 Measurement of radiation attenuation coefficient $\mu$ at the test line and that of the dose rate and conversion coefficient of radioactive cesium

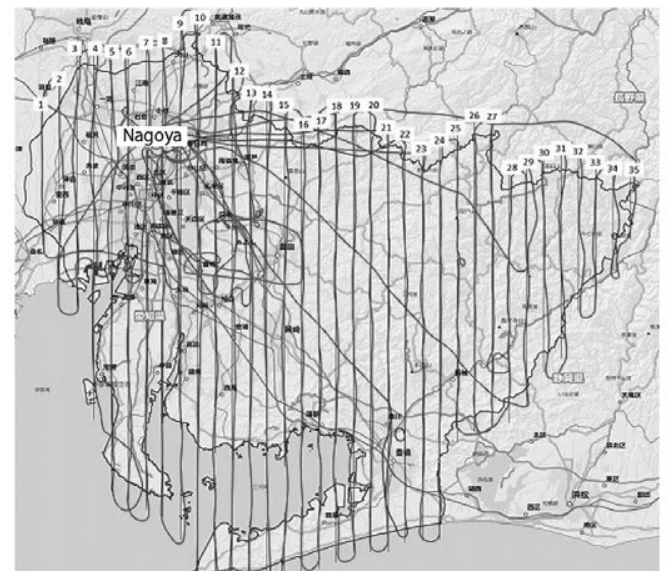

Figure 3 Flight Path Map in Aichi Prefecture Data obtained during movement from the airport and circling were not used and only data during linear flights were used in the analysis. The flight line spacing was $3 \mathrm{~km}$. 
measuring instruments loaded in the helicopters were not collimated, and gamma rays emitted from within a circle of the ground surface directly below with a radius that was about the same as the altitude above ground were measured. The flight line spacing within an $80 \mathrm{~km}$ range from the power plant was about $1.8-2 \mathrm{~km}$ (flights were partially conducted at a narrow survey line spacing with a width of $300 \mathrm{~m}$ ), and in other areas, as a general rule, measurements were conducted at around $3 \mathrm{~km}$. The flight path taken in Aichi Prefecture is shown in Figure 3.

\section{Analysis Method}

In the airborne monitoring conducted in this study, the energy spectrum data from gamma rays was collected, and to conduct a simple comparison with the aboveground air dose rates, the count rate in the entire energy area was used in the analysis. First, from the above-described air attenuation coefficient $\mu$ found at the test line, the dose rate conversion coefficient $C d[\mathrm{cps} /(\mu \mathrm{Sv} / \mathrm{h})]$ was found from a ratio of the count rate analysis value at a height of $1 \mathrm{~m}$ and the dose rate at a height of $1 \mathrm{~m}$ actually measured at ground level directly below the test line. This dose rate conversion coefficient $C d$ was then used to find the dose rate $D_{1 \mathrm{~m}}$ at a height above ground of $1 \mathrm{~m}$ from the airborne monitoring count rate and the altitude above ground $h$ using the following equation:

$$
D_{1 \mathrm{~m}}[\mu \mathrm{Sv} / \mathrm{h}]=e^{-\mu \mathrm{h}}\left(C_{\text {measured altitude }}[\mathrm{cps}]-B G_{\text {cosmic rays, etc. }}[\mathrm{cps}]\right) / C d
$$

Next, the concentration $V_{\mathrm{Cs}-134 / 137}$ of radioactive cesium (Cs-134, Cs-137) deposited on the ground surface was calculated by determining the conversion coefficient $C F\left[\left(\mathrm{kBq} / \mathrm{m}^{2}\right) /\right.$ $(\mu \mathrm{Sv} / \mathrm{h})]$ for the deposition of radioactive cesium on the ground surface with respect to the air dose rate from measurements using an in-situ Ge detector directly under the test line, and then subtracting the background dose rate contributed by natural nuclides (the background dose rate at the contaminated areas is unclear, and therefore, an average value of the spatial air dose rates for the past four years (2005 to 2008) obtained by radiation level surveys for the entire eastern Japan area was used) from the spatial dose rate at a height of $1 \mathrm{~m}$ (the data are presented in reference 2).

$$
V_{\mathrm{Cs}-134 / 137}=C F\left(D_{1 \mathrm{~m}}[\mu \mathrm{Sv} / \mathrm{h}]-B G_{\text {natural nuclides }}[\mu \mathrm{Sv} / \mathrm{h}]\right)
$$

\section{Method for Subtracting the Contribution Portion of Natural Nuclides}

As described above, in airborne monitoring, the dose rate at an altitude of $1 \mathrm{~m}$ was found from the total count rate, and the radioactive cesium deposited at the ground surface was calculated. As a result, as with the mountainous region of Niigata Prefecture, regardless of not detecting a significant energy spectrum for radioactive cesium, in areas for which the contribution of natural nuclides such as potassium, uranium, and thorium was higher than the average background dose rate ${ }^{3)}$, sites that were displayed on the map as if having a significant presence of radioactive cesium were observed on the map. Therefore, in airborne monitoring in Niigata Prefecture, the surrounding energy spectra were confirmed to be centered on sites where the spatial dose rates were high, measurement results for areas where a significant energy spectrum of radioactive cesium was not detected were not used, and the deposition amounts of radioactive cesium were corrected and mapped. However, while advancing with 
monitoring, there was a wide range of areas where a significant energy spectrum of radioactive cesium was not detected, such as Nagano Prefecture, Shizuoka Prefecture, Gifu Prefecture, and Toyama Prefecture, and therefore, it was difficult to identify areas where significant energy spectra of radioactive cesium were not detected using the same technique that was used when the airborne monitoring results were prepared for Niigata Prefecture. Therefore, for each measurement helicopter and each measuring instrument, techniques were examined for identifying areas where significant energy spectra were not detected for radioactive cesium.

Regarding areas where significant energy spectra of radioactive cesium were detected and those where they were not detected, as indicated by the following equation, the count rates were compared for energy areas that contained radioactive cesium energy spectra (areas with a gamma ray energy of $450 \mathrm{keV}$ or greater) and gamma ray energy areas attributed to natural nuclides containing almost no radioactive cesium (areas with energy of $900 \mathrm{keV}$ or greater).

$$
\text { Spectrum Index }=\frac{\text { Count Rate of } 450 \mathrm{keV} \text { or greater }}{\text { Count Rate of } 900 \mathrm{keV} \text { or greater }}
$$

The count rate ratio (hereinafter, spectrum index) of these areas differs depending on the presence or lack of radioactive cesium, and this difference was used to examine whether an area for which a significant energy spectrum of radioactive cesium was not detected could be identified.

Here, $450 \mathrm{keV}$ was selected as an energy level with minimal fluctuation because peaks of gamma rays emitted from Cs-134 and Cs-137 (Ba-137m) are not present, gamma ray peaks derived from natural nuclides are not visible; $900 \mathrm{keV}$ was selected because it is an energy level that is not affected by Cs-134 gamma ray peaks (796 keV).

As a method for evaluating low-contamination areas, the U.S. DOE developed the Man Made Gross Counts (MMGC) method ${ }^{4}$, and as the energy range for evaluating natural nuclides, this method uses a range at or above $1,400 \mathrm{keV}$. In this area, the count rate is low; therefore, the detection lower limit value is high, and because considerable data for non-contaminated areas are necessary, and due to issues with evaluating the deposition amounts, a method that uses the spectrum index was selected for this analysis rather than the MMGC method.

As a result, from a histogram of the spectrum index in areas where a significant radioactive cesium energy spectrum was not detected, it was confirmed that, while differences exist in the spectrum index average values and in the standard deviation thereof depending on the helicopter and type of measuring instrument that was used in the measurements, the data were distributed in a normal distribution centered on the average value. Figure $\mathbf{4}$ shows a case involving a prefecture for which the impact of radioactive cesium was large and a case involving a prefecture for which the impact was small. This image clearly shows that in prefectures where the cesium impact is large, in many areas, as the count rate increases, the spectrum index also increases; in contrast, in prefectures where the cesium impact is small, an almost normal distribution is observed (Figure 4, left).

Therefore, to specify areas where a significant energy spectrum of radioactive cesium was not detected, a reference value (average value $+3 \sigma$ ) for the spectrum index was established for each type of helicopter and measuring instrument used in the measurements, and it was determined that radioactive cesium gamma rays were significantly detected only for cases in which this index exceeded the reference value.

For comparison, data for Niigata Prefecture prior to correction and for which this 
technique was not used, as well as analysis data for which this technique was used, are shown in Figure 5. From the results, in areas such as the northern part of Niigata Prefecture, through the application of this technique, it was determined that much of the radiation was due to the contribution of gamma rays from natural nuclides, and it was determined that, in most areas, significant radioactive cesium was not deposited $\left(\leqq 10 \mathrm{kBq} / \mathrm{m}^{2}\right)$.

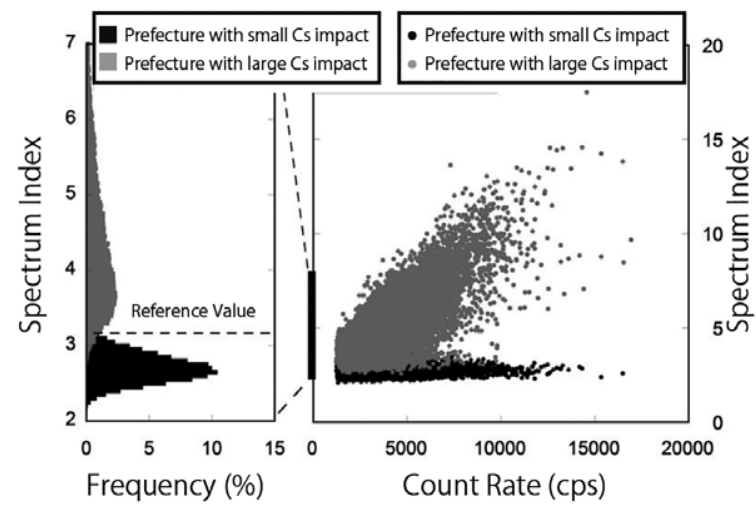

Figure 4 Difference in Spectrum Indexes of Measurement Data Based on Magnitude of Radioactive Cesium Impact

(Left: Frequency Distribution, Right: Correlation with Count Rate)
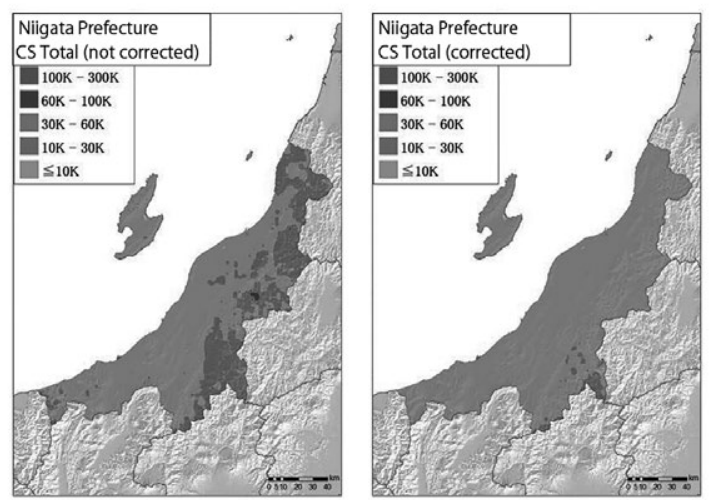

Figure 5 Total Radioactive Cesium Deposit Amount in Niigata Prefecture

Left is a map calculated from dose rates before correction, and the right shows results analyzed using the spectrum index.

\section{Results}

\section{Air Dose Rates and Deposition Amount of Radioactive Cesium}

The helicopters flew at a speed of about 130-148 km/h (70-80 knots), and sampled data every second; therefore, the measurement point interval was several tens of meters. Since the flight spacing was around $3 \mathrm{~km}$, it significantly exceeded the range of measurement obtained 
by the measuring instruments. Thus, it became necessary to find the air dose rates and "surface" distribution of the contamination due to radioactive cesium by interpolating the measurement results. To this end, the measured values for 180 points near the area that were to be analyzed were extracted and the inverse distance weighted method was used for evaluations, assuming that the weighting decreased as the distance from the point increased. A map of the air dose rate distribution for the entire eastern Japan area obtained through this technique is shown in Figure 6 (left). The results clearly show that areas with high spatial dose rates expand in the northwest direction from the power plant and expand from near the city of Fukushima to Gunma Prefecture in the southwest direction. In addition, from the southern parts of Iwate Prefecture and Ibaraki Prefecture to the northern part of Chiba Prefecture, a region with relatively high air dose rates of $0.1-0.2 \mu \mathrm{Sv} / \mathrm{h}$, thought to be due to the deposition of radioactive cesium, was observed. Furthermore, areas with relatively high spatial dose rates were also found scattered throughout areas such as Gifu Prefecture and Toyama Prefecture; however, many of these areas coincide with geological data thought to be granite, and are therefore thought to be due to the impact of natural nuclides. Therefore, as a result of examining the spectrum indexes, in most of these areas, the index is at or below the reference value, and thus, majority of the air dose rates are attributed to natural nuclides. Furthermore, as shown in Figure 6 (right panel), the deposition amount of radioactive cesium is $10 \mathrm{kBq} / \mathrm{m}^{2}$ or less.

\section{Map Usage Method}

A map of the air dose rates and radioactive cesium deposition amounts is always posted on the MEXT homepage ${ }^{1)}$. This is visually easy to understand, and therefore, can be used for
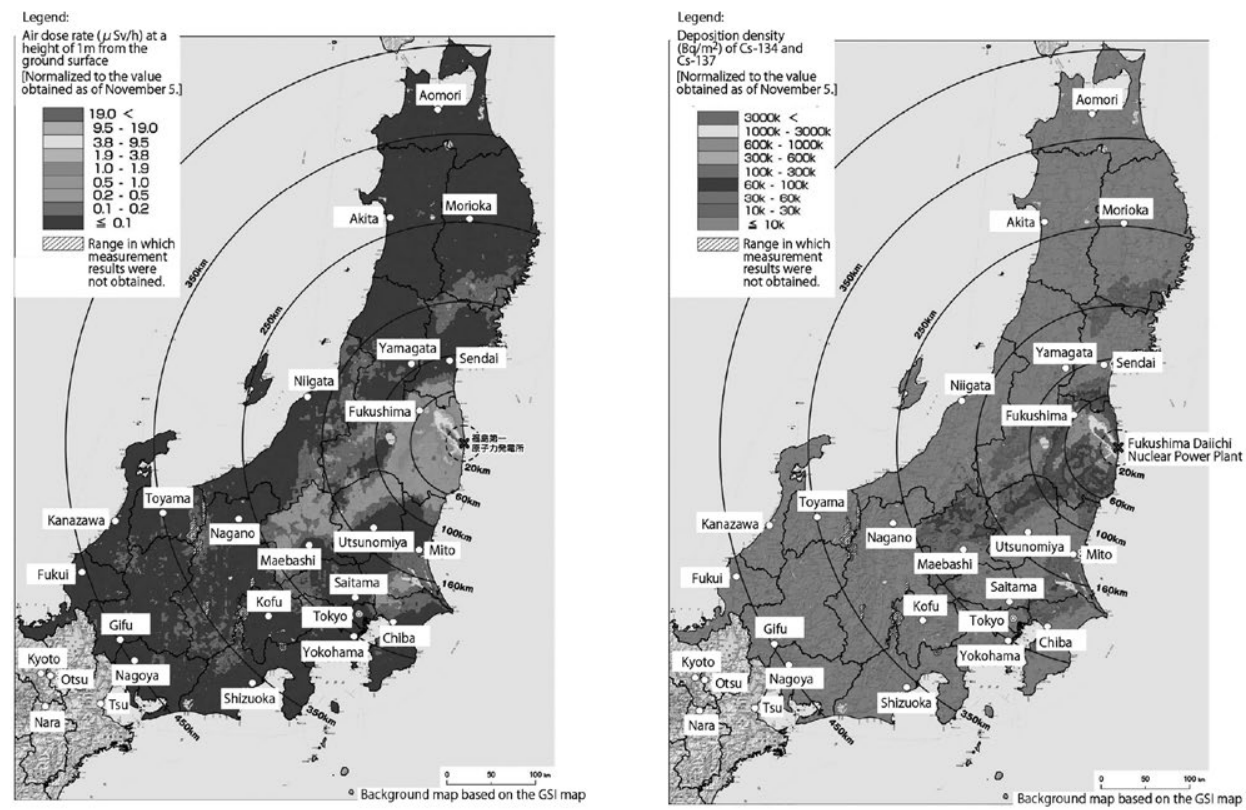

Figure 6 Analysis Results of Wide-Area Monitoring in Eastern Japan Area Reflecting Quaternary Monitoring in $80 \mathrm{~km}$ Range

Air dose rates at height of $1 \mathrm{~m}$ (left) and total amount of deposition of radioactive cesium (Cs-134, Cs-137) at ground surface (right). 


\section{INSIGHTS CONCERNING THE FUKUSHIMA DAIICHI NUCLEAR ACCIDENT Vol. 1}

various purposes.

For example, it can be used for producing an anticipated dose rate map after several years based on the physical half-life of radioactive cesium (Figure 7). In fact, in addition to physical decay, attenuation and fluctuation due to natural causes and decontamination are anticipated, and therefore, monitoring must be continued in the future and changes must be monitored by mapping the obtained data.

Moreover, attention can be focused topographically on the deposited amounts of radioactive cesium, and three-dimensional distributions can be created. As shown in Figure 8,
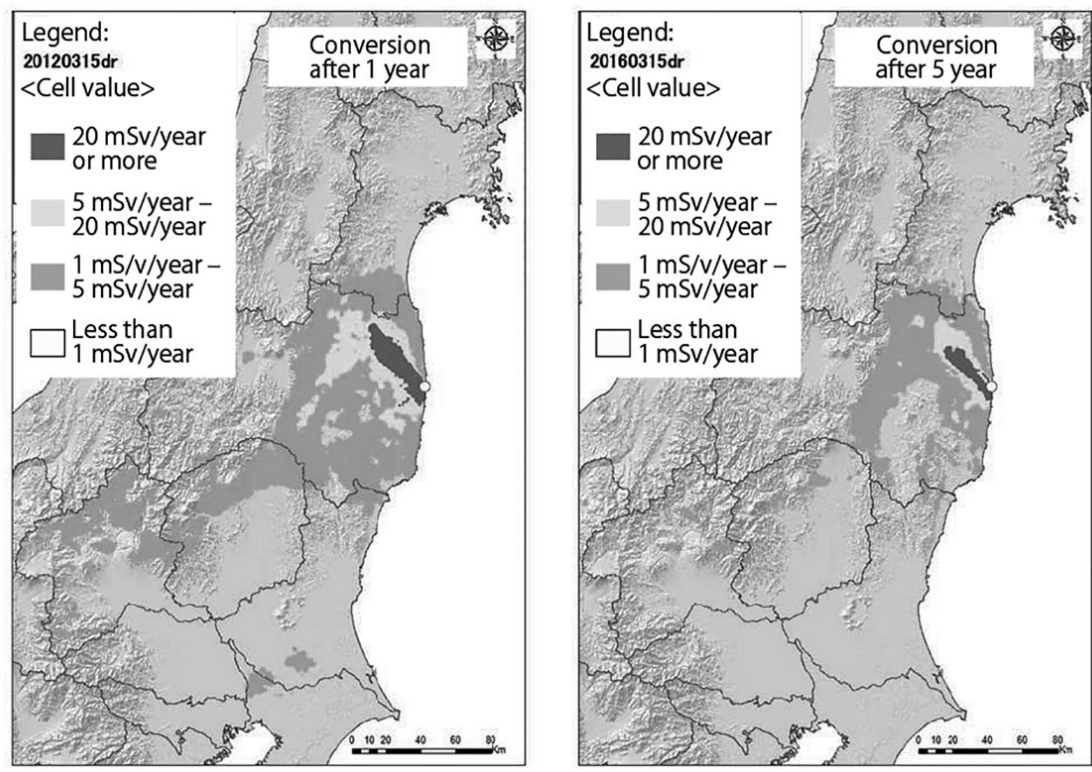

Figure 7 Dose Rate Maps (after 1 year, after 5 years) Corresponding to 1-20 mSv/year or Greater, Converted from Airborne Monitoring Results
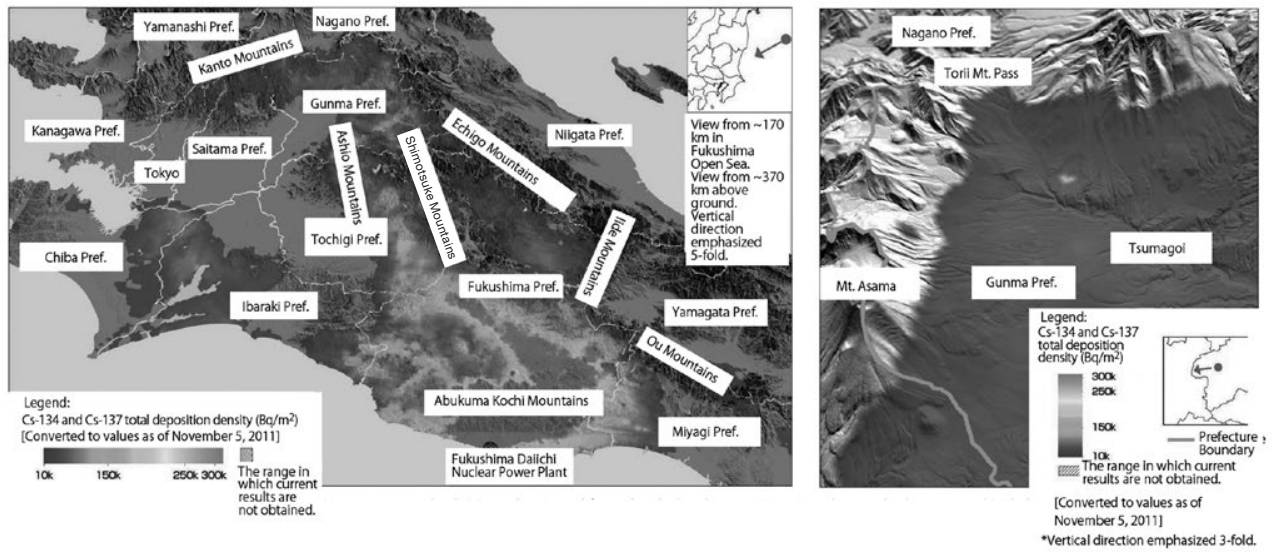

Figure 8 Bird's-eye View of Radioactive Cesium Deposit Amounts (Left: View from Open Sea at Fukushima Prefecture, Right: Near Borders of Gunma and Nagano prefectures)

※The topographical relation of measurement values for which the radioactive cesium deposition amount is $10 \mathrm{kBq} / \mathrm{m}^{2}$ or less is not depicted in order to the relation be easily confirmed. 
radioactive cesium emitted into the atmosphere is diffused and deposited along the Ou Mountain Range, the Iide Mountains, the Echigo Mountain range, the Shimotsuke Mountains, and the Kanto Mountains. In addition, the main deposition locations have an elevation that is lower than $1,000 \mathrm{~m}$, and therefore, it is inferred that the deposition did not exceed high elevations such as that of the Torii Mountain Pass with an elevation of 1,400 m for the most part.

\section{Future Issues}

This is the first study in which airborne monitoring was implemented over a wide range of eastern Japan; as a result, the distribution of surface radiation was made clear and the status of air dose rates and distribution of deposition amounts of radioactive cesium in each region thus far was confirmed. In addition, through these measurements, we confirmed the effects of natural nuclides in eastern Japan, for which detailed measurement results did not exist until now.

However, during the implementation of this monitoring, several issues, including the method for subtracting natural nuclides, became clear.

\section{Altitude Above Ground and Topographical Effects}

The airborne monitoring results confirmed a close match between data of approximately 2,200 points obtained by aboveground measurements within a range of $80 \mathrm{~km}$ from the power plant ${ }^{5)}$ and those from approximately 100 points of aboveground measurement results in the entire eastern Japan area. While there was some deviation with ground measurement results in mountainous areas and valleys, the ratio of ground measurements and airborne monitoring measurement results was generally within a range of $0.5-1.5$, indicating good agreement.

However, a large portion of Japan comprises mountainous areas, and in steep terrain, radiation is measured not only from directly below the measurement point but also from an inclined direction. In valleys, there is significant contribution from the inclined direction as well from a distance and surface area perspective, and in such locations, it is possible that the air dose rates were analyzed on the high side.

Therefore, moving forward, in order to increase the precision of airborne monitoring, the impact of topographical effects must also be evaluated.

\section{Impact of Cosmic Rays}

The dose rates with airborne monitoring were evaluated upon subtracting the contribution from cosmic rays. Here, the contribution portions of the cosmic rays were determined by an above-water line not affected by gamma rays from aboveground, and the value thereof (constant value) was subtracted. However, the amount of contribution from cosmic rays changes depending on the flight altitude, and in mountainous areas with high elevations, such as Nagano Prefecture and Gifu Prefecture, the ground air dose rates might be evaluated somewhat on the high side. Therefore, to improve precision, an evaluation method must be developed in the future. 


\section{Conclusions}

Airborne monitoring was conducted by JAEA as work commissioned by the MEXT FY 2011 Radiation Measurement Survey Committee for a "Survey of the Status of Radioactive Substance Diffusion Using Aircraft for Wide Range Environmental Monitoring," and the results were compiled. Over 80 people from various organizations and private companies including JAEA, NUSTEC, the Japan Map Center, and the Oyo Corporation participated in this effort by riding in helicopters to conduct measurements, conduct aboveground air dose rate measurements and in-situ measurements, and analyze and map the acquired data. In addition, cooperation for flights around the nuclear power plant was obtained from the Hyakuri Air Rescue Squadron of the Japan Air Self-Defense Force, and that for flights around Miyagi, Yamagata, Tochigi, Gunma, and Ibaraki prefectures was obtained from the disaster prevention flying corps from each prefecture and from Aero Asahi and Nakanihon Air Service. We express our sincere gratitude to all those who participated in this monitoring. We are also deeply grateful to MEXT Nuclear Emergency Countermeasures Support Headquarters Monitoring Team Leader Shuichiro Itakura and Daichi Saito, who planned and encouraged this monitoring project.

\section{References}

1) Airborne Monitoring Results by MEXT (Including cooperation by the U.S. Department of Energy) (http://radioactivity.mext.go.jp/ja/monitoring_around_FukushimaNPP_MEXT_DOE_airborne_monitoring/). [in Japanese] present web site is http://radioactivity.nsr.go.jp/en/list/307/list-1.html released by Nuclear Regulation Authority, Japan

2) Environmental Radiation Database (http: //search.kankyo-hoshano.go.jp/servlet/search.top). [in Japanese]

3) Hata S. Ground Surface Gamma Ray Dose Rate Distributions in Japan Chigaku-Zasshi (Journal of Geography).2006;115(1), 87-95. [in Japanese]

4) Hendricks T.J. et al. An Aerial Radiological Survey of the Nevada Test Site 1999;DOE/NV/11718 324.

5) Preparation by MEXT of Distribution Maps of Radiation Amounts, Etc. (Dose Measurement Maps) (http://radioactivity.mext.go.jp/ja/distribution_map_around_FukushimaNPP/0002/5600_080218.pdf). [in Japanese] 
Difficulties in Treatment of Contaminated Water in Fukushima-1 Nuclear Power Plant and Disposal of its Secondary Waste -Proposal of Countermeasures with Focus on Disposal-

\author{
Japan Atomic Energy Agency, Isao Yamagishi \\ Tohoku University, Hitoshi Mimura \\ Kyushu University, Kazuya Idemitsu
}

\begin{abstract}
The completion of a cold shutdown state (step 2), in response to the efforts to resolve the Fukushima Daiichi Nuclear Power Plant Accident, was declared in December 2011. The temporarily installed water treatment system is being operated for circulating water cooling, which supports the cold shutdown state of the nuclear reactors. However, the installation of the permanent water treatment system, and efforts to deal with the storage, processing, and disposal of secondary wastes generated by the contaminated water treatment are also required. In this commentary, we outline the current status of contaminated water treatment, and explain the adsorbent performance as well as technical issues regarding future processing and disposal.
\end{abstract}

\title{
I. Issues of Contaminated Water Treatment
}

When the accident occurred at the Fukushima Daiichi Nuclear Power Plant, several hundred tons/day of water was continuously poured into the plant to cool the reactor core, and large amounts of contaminated water containing high concentrations $\left(\sim 10^{6} \mathrm{~Bq} / \mathrm{cm}^{3}\right)$ of radionuclides such as cesium were produced in a short period, making it difficult to secure a storage location. However, there are no examples of previous measures taken for dealing with large volumes of highly radioactive water containing seawater. In step 1 of the path for resolving the accident, the water treatment system for decontaminating water by removing radionuclides such as cesium (Cs) and iodine (I) was installed, and the circulating water cooling (Figure 1), which reuses the decontaminated water as cooling water, was initiated in June $2011^{1,2)}$. Through this, stable cooling of the nuclear reactor became possible, and in December of the same year, a cold shutdown state (step 2) of the nuclear reactor was achieved ${ }^{3)}$.

DOI : 10.15669/fukushimainsights.Vol.1.213

(C) 2021 Atomic Energy Society of Japan. All rights reserved.

Originally published in Journal of the Atomic Energy Society of Japan (ISSN 1882-2606), Vol. 54, No. 3, p. 166-170 (2012)

in Japanese. (Japanese version accepted: January 10, 2012) 


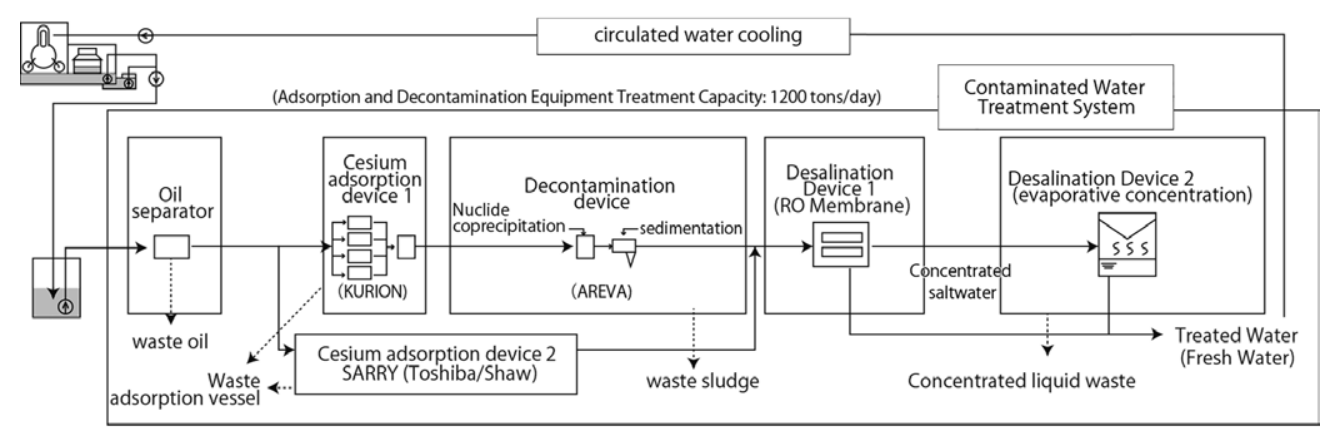

Figure 1 Contaminated water treatment system supporting circulating water cooling ${ }^{1,2)}$

\section{Contaminated Water Treatment System ${ }^{1-3)}$}

\section{(1) Oil Separation Device}

Highly contaminated water is transferred from No. 1-4 reactor turbine buildings, etc., to a centralized waste treatment facility, and is treated by the water treatment system. Turbine oil that was mixed owing to the tsunami hinders decontamination, and is therefore removed by an initial oil separator.

\section{(2) Radionuclide Removal Device}

The nuclides subject to decontamination include Cs-134 (half-life of two years) and Cs-137 (half-life of 30 years), which emit strong gamma rays. Serial operation of a cesium adsorption device from U.S.-based KURION with a treatment capacity of 1,200 tons/day and a decontamination device from France-based AREVA was started on June 17, 2011, and the Cs-137 concentration was reduced from $1 / 10^{5}$ to $1 / 10^{6}$ of the concentration before decontamination. The KURION adsorption device sends contaminated water into adsorption vessels (4 series) filled with herschelite, which is a kind of zeolite with a high $\mathrm{Cs}^{+}$ion-exchange capacity, and removes $99 \%$ or more of the radioactive Cs. The AREVA decontamination device is based on a sedimentation method that adds chemicals and adsorbs $\mathrm{Cs}^{+}$in a fine powder of ferrocyanide, which is then bonded to grains of sand with an organic polymer and rapidly precipitated. The sand is reused, and therefore, waste sludge (precipitate) containing Cs is generated as secondary waste. However, owing to the problems associated with the handling of the waste sludge and device corrosion by the chemicals, the AREVA decontamination device was shut down on September 13, 2011.

SARRY, the second cesium adsorption device from Toshiba/Shaw, has two series of adsorption vessels, and was added in August 18, 2011. After Cs is roughly removed with synthetic zeolite, it can be decontaminated with titanium silicate to at or below the Cs detection limit $\left(1 / 10^{6}\right)$. With the KURION and SARRY devices, the waste adsorption vessels become high-dose secondary waste.

\section{(3) Desalination Device}

Contaminated water from which $\mathrm{Cs}$ has been removed is first separated into fresh water and concentrated saltwater by using a reverse osmosis (RO) membrane, and the concentrated saltwater is further subjected to evaporative concentration and separated into fresh water and concentrated liquid waste (secondary waste). 


\section{Contaminated Water Treatment Results and Secondary Waste Generation Amount ${ }^{4)}$}

The cumulative treatment amount by the radionuclide removal device has reached $195,860 \mathrm{~m}^{3}$, and following operation of the SARRY device, the storage amount (contaminated water level) in each building has been undergoing a decreasing trend. As of January 3, 2012, the injection amount of treated water (fresh water) into the No. 1-3 reactors is $588 \mathrm{~m}^{3} /$ day, and thus, a margin remains with respect to the actual treatment amount of approximately $1,000 \mathrm{~m}^{3} /$ day over a period of 6.5 months by the water treatment system.

The amount of secondary waste generated is shown in Figure 2. The graph shows waste sludge of $581 \mathrm{~m}^{3}$, the number of waste adsorption vessels (290 KURION vessels and 28 SAR$\mathrm{RY}$ vessels), and concentrated liquid waste of $5,452 \mathrm{~m}^{3}$. The SARRY device has treated a volume of $77,210 \mathrm{~m}^{3}$, and the generation amount thereof is one digit less than that by KURION.

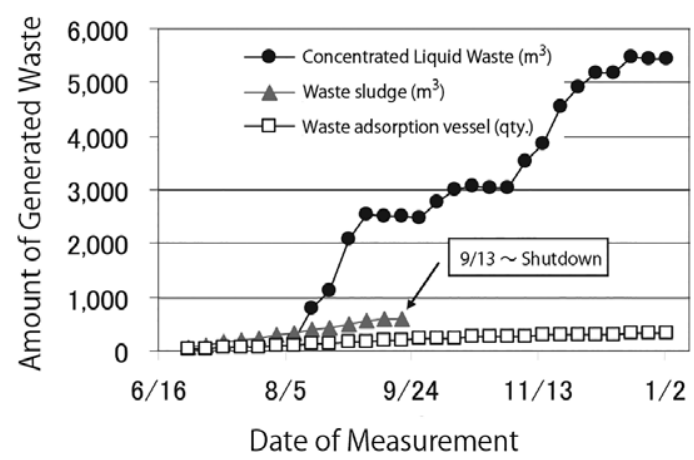

Figure 2 Amount of waste generated in contaminated water treatment (through Jan. 3, 2012) ${ }^{4)}$

\section{Issues with Contaminated Water Treatment}

(1) Increase in the Volume of Contaminated Water due to Groundwater Inflow

Table 1 shows the water volume, including that of contaminated water, in the treatment. After RO membrane desalination, the concentrated saltwater that has not yet been subjected to evaporative concentration is the largest, with the total volume reaching $44 \%$ of the total $200,000 \mathrm{~m}^{3}$. The inflow of groundwater into the buildings has been indicated as a primary cause for the increase of $80,000 \mathrm{~m}^{3}$ compared to $120,000 \mathrm{~m}^{3}$ immediately before the operation of the water treatment system ${ }^{3}$. The system is operated to maintain a water level that is lower than the level of ground water so that contaminated water does not leak externally, and therefore, urgent groundwater countermeasures are being sought.

\section{(2) Long-Term Stable Storage of Secondary Waste}

Almost all radioactive Cs is concentrated in the waste adsorption vessels, and therefore, evaluations and countermeasures from a safety perspective, such as the generation of hydrogen through water radiolysis, are desired. Stabilization of waste sludge and evaluation of the corrosion of waste adsorption vessels and concentrated liquid waste storage tanks owing to salt content, are also important. 
Table 1 Total Volume Including that of Contaminated Water in Treatment (As of Jan. 3, 2012) ${ }^{4)}$

\begin{tabular}{lcc}
\hline \multicolumn{1}{c}{ Contaminated Water, Treated Water } & Water Volume $\left(\mathrm{m}^{3}\right)$ & $(\%)$ \\
\hline No. 1-4 Reactor Buildings & 80,250 & 40 \\
Centralized Waste Treatment Facility & 15,540 & 8 \\
Saltwater (After Cs Decontamination) & 2,474 & 1 \\
Concentrated Saltwater (After RO Membrane) & 87,029 & 44 \\
Concentrated liquid waste (after evaporation) & 5,452 & 3 \\
Treated Water (Fresh Water) & 8,552 & 4 \\
\hline Total Volume & 199,297 & 100 \\
\hline
\end{tabular}

\section{(3) Contaminated Water Treatment Moving Forward}

Through the operation of desalination devices, the removal of calcium and other such seawater salt content is advancing; therefore, a water treatment system that takes the removal of Sr-90 (half-life of 30 years) contamination, which has been difficult thus far, is now desired.

\section{Decontamination Adsorbents}

\section{Adsorbent Selectivity}

In the area of selective adsorbents for radionuclide decontamination, there are numerous reports on primarily inorganic ion exchangers ${ }^{5}$. Highly contaminated radioactive water is limited to the use of highly radiation-resistant inorganic ion exchangers. The Cs ion exchange and adsorption characteristics of many inorganic ion exchangers are being examined, and an indicator (ion-exchange free-energy change, $\Delta \mathrm{G}^{\circ}$ ) that indicates the selectivity of ion-exchange adsorption has been reported. This value serves as a significant standard when comparing Cs adsorption capacities. With regard to the $\Delta \mathrm{G}^{\circ}$ value for inorganic ion exchangers that exhibit high selectivity for Cs, the selectivity for Cs increases as the negative value increases, and therefore, inorganic ion exchangers can be ranked as insoluble ferrocyanides $>$ heteropoly acid salts $>$ zeolite groups. When the Cs partition (distribution) coefficient values $\left(K_{d}\left(\mathrm{~cm}^{3} / \mathrm{g}\right)\right.$, the concentration ratio of $\mathrm{Cs}$ in a solid phase and a liquid phase) from a high-concentration $(5 \mathrm{M}) \mathrm{Na}$ salt solution and a high-concentration (3M) nitric acid solution are measured, insoluble ferrocyanide (KNiFC, KCoFC) and heteropoly acid salts (AMP, AWP) exhibit $K_{d}$ values of $10^{3} \mathrm{~cm}^{3} / \mathrm{g}$ or higher ( $90 \%$ or higher as an adsorption rate). However, these highly selective adsorbents are fine powder particles as is, and are difficult to handle, and therefore, a granulation method must be developed and numerous inorganic porous body (silica gel, zeolite, etc.) -bearing composites are being researched ${ }^{5)}$. However, zeolites exhibit a high adsorption characteristic toward $\mathrm{Cs}$ even from a Na salt solution (seawater-based), are abundantly produced in Japan, and can be used as a packed column, and therefore, they excel as adsorbents for Cs decontamination at the local site.

\section{Adsorbent Structure}

Adsorbents having high selectivity for ${ }^{137} \mathrm{Cs}$ have channels with openings that are close to that of the ionic radius of $\mathrm{Cs}$, the structure is stabilized by ion exchange with exchangeable cations, and many exhibit an "ion sieve action" of removing other cations having large 
hydrated ion radii. For example, all high decontamination adsorbents (crystalline silicotitanate (CST), Ni-based insoluble ferrocyanides, Figure 3) used to treat highly contaminated water at the Fukushima Daiichi Nuclear Power Plant have narrow channels with openings that are close to that of the ionic radius of Cs. Within the nuclear plant sites, CST is used as a packed column and insoluble ferrocyanides are used for sedimentation treatment.

The zeolite group can be classified into zeolites having a three-dimensional basket structure and those having a "beehive"-type tunnel structure. The Si/Al ratio is from 1 $\infty$, and the $\mathrm{Cs}$ and $\mathrm{Sr}$ adsorption characteristics vary significantly. In particular, "lantern-shaped" chabazite and "beehive"-shaped mordenite exchange, adsorb, and stabilize Cs inside narrow fine holes (Figure 4). Note that with regard to Sr adsorption, A and X types, which have three-dimensional basket structures, a small $\mathrm{Si} / \mathrm{Al}$ ratio, and a large cavity (super cage) internally, exhibit high selectivity ${ }^{6}$.
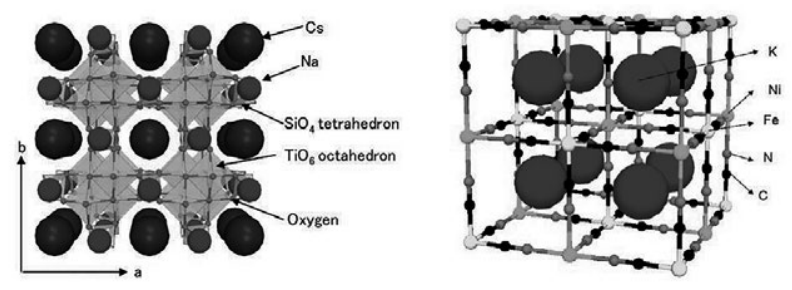

Figure 3 Structures of Adsorbents for High Cs Decontamination (CST (left), KNiFC (right), provided by the JAEA Center for Computational Science \& e-Systems)
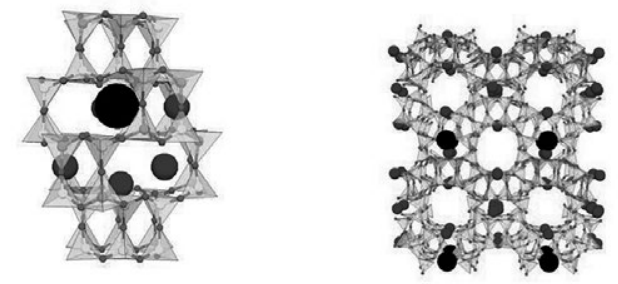

Figure 4 Schematic of Zeolite Structure (chabazite (left), mordenite (right), provided by the JAEA Center for Computational Science \& e-Systems)

\section{Selective Removal of Cs and Sr from Seawater}

After the TMI Accident, the necessity for building a system for treating highly contaminated water was advocated in Japan, and the decontamination of radioactive Cs and Sr through inorganic ion exchangers was evaluated ${ }^{7)}$. Examples of selective removal of Cs from seawater through each type of zeolite powder are shown in Figure 5. Chabazite, mordenite, and clinoptilolite exhibit $K_{d}$ values that are close to $10^{3} \mathrm{~cm}^{3} / \mathrm{g}$ (around $90 \%$ as an adsorption rate). In addition, the selective removal of $\mathrm{Cs}$ and $\mathrm{Sr}$ from simulated highly contaminated water using a mixed zeolite column was evaluated ${ }^{8)}$.

Following the Fukushima Daiichi Nuclear Power Plant Accident, the characteristics of granular inorganic ion exchangers for adsorbing $\mathrm{Cs}$ and $\mathrm{Sr}$ from seawater were evaluated by a voluntary team from the Atomic Energy Society of Japan (including Hokkaido University, Tohoku University, Tokyo Institute of Technology, Kyoto University, Kyushu University, and JAEA), and adsorption evaluation data on over 600 points were disclosed with regard to data 


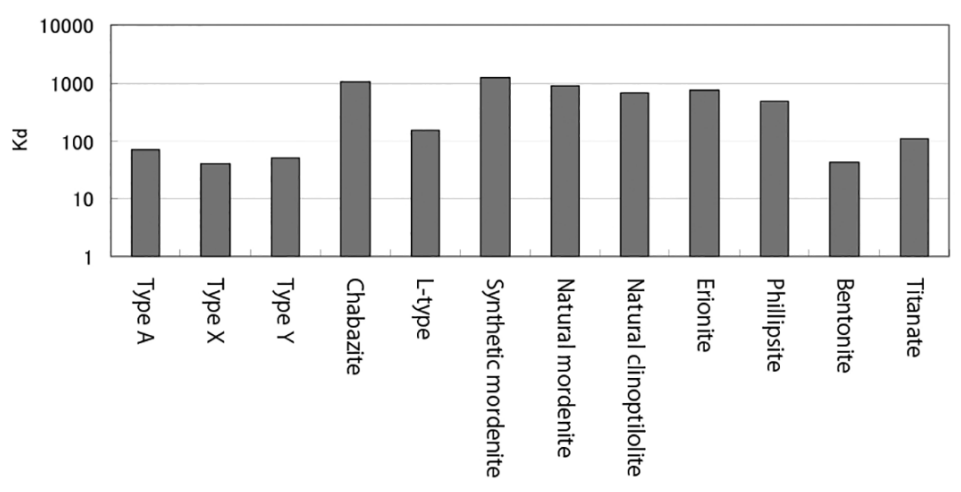

Figure 5 Comparison of $K_{d}$ Values of Cs from Seawater through Various Zeolite Powders

such as adsorption rate, adsorption characteristics from concentrated seawater, and adsorption volume $^{9)}$. In the tests, Cs was added to actual seawater in a reaction vessel, a liquid phase was sampled after every certain amount of time, the concentration was measured, and the change over time in Cs adsorption ( $K_{d}$ value) was examined.

The $K_{d}$ values exhibit an increasing trend with the passage of time, and a near-equilibrium state is approached with the zeolites after $24 \mathrm{~h}$. The ranking of the adsorptivity (ranking of the $K_{d}$ value for Cs) is insoluble ferrocyanides $>$ mordenite, chabazite $>$ clinoptilolite $>$ A, $\mathrm{X}$, and thus, corresponds closely to the ranking of Cs selectivity. Of the zeolites, mordenite and chabazite have a $K_{d}$ value of around $800 \mathrm{~cm}^{3} / \mathrm{g}$ (approximately $90 \%$ adsorption) after 24 $\mathrm{h}$ and approach the value of powdered zeolite. The ${ }^{137} \mathrm{Cs}$ radiation concentration in actual seawater does not change after filtration by a Millipore filter $(0.45 \mu \mathrm{m})$, and even when the $\mathrm{pH}$ is adjusted with hydrochloric acid (to 2.4), there is almost no change in the adsorption results; therefore, as a chemical species, the ion-exchange adsorption as $\mathrm{Cs}^{+}$is dominant. With Cs adsorption into mordenite from concentrated seawater (double and triple concentrations), compared to actual seawater, the $K_{d}$ value exhibits a decreasing trend in accordance with the concentration of seawater at double concentration, $K_{d}=197$, and at triple concentration, $K_{d}=$ 146.

On the other hand, in the case of insoluble ferrocyanide-carrying resin and CST resin, high $K_{d}$ values of $10^{3}$ or greater are maintained even in concentrated seawater. The adsorption isotherm of Cs into zeolite from seawater is an upward projection, and suggests high selectivity of Cs. The adsorption form was Langmuir-type adsorption and the saturated adsorption amount was $0.72 \mathrm{meq} / \mathrm{g}(9.5 \mathrm{wt} \%)$. Note that the Cs content percentage at the Cs concentration region (around $1.5 \mathrm{ppm}$ ) anticipated for seawater is estimated to be $0.0845 \mathrm{wt} \%$. Figure 6 shows the relation between the partition coefficient and adsorption rate constant (relative value) of Cs for various adsorbents in a seawater system. As is clear from the graph, the adsorbents are generally classified into highly selective insoluble ferrocyanides and CST and a zeolite group. The zeolite group has partition coefficient values in the range of $10^{2}-10^{3}$, but a large difference in the adsorption rate is observed. As is observed in mordenite produced in Ayashi, Japan, the difference in the particle diameter significantly impacts the adsorption rate.

Figure 7 shows the relation between the partition coefficient and the adsorption rate constant (relative value) of $\mathrm{Sr}$ for various $\mathrm{Sr}$ adsorbents in a seawater system. The partition coefficient is lower than the case for Cs, but the type A and type X zeolites having a three-dimensional basket structure exhibit a $K_{d}$ value of $10^{2}$ or greater. Note that the ranking of divalent 
Isao Yamagishi et al.

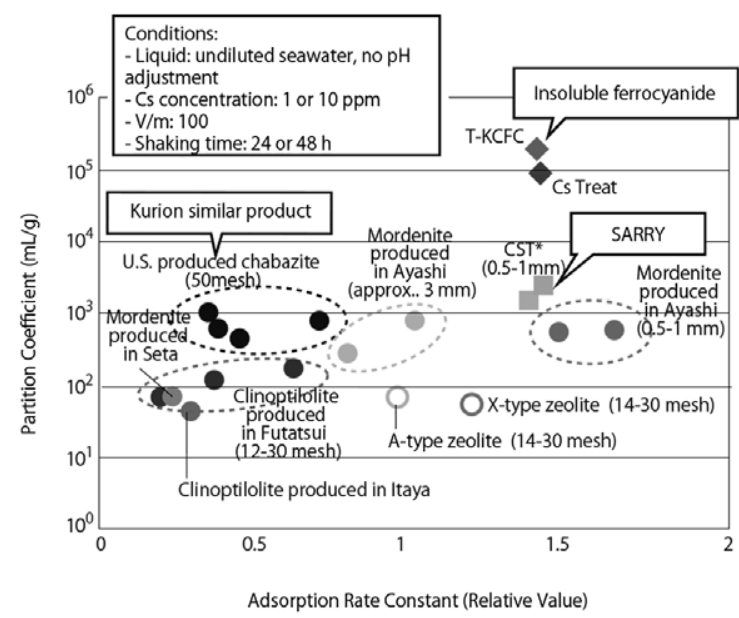

Figure 6 Relation between the Partition Coefficient and Adsorption Rate Constant (Relative Value) of Cs of Various Cs Adsorbents

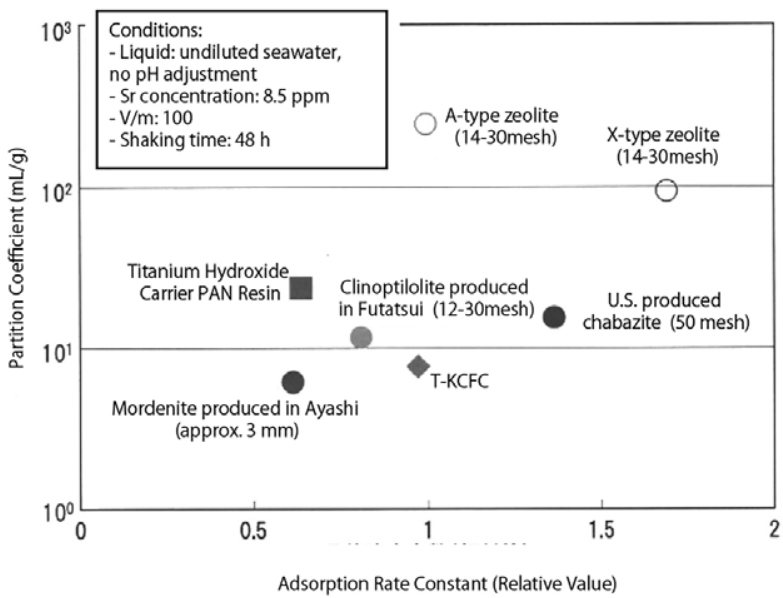

Figure 7 Relation between the Partition Coefficient and Adsorption Rate Constant (Relative Value) of $\mathrm{Sr}$ for Various Sr Adsorbents

cation selectivity in A-type zeolites is as follows.

$$
\mathrm{Zn}>\mathrm{Sr}>\mathrm{Ba}>\mathrm{Ca}>\mathrm{Co}>\mathrm{Ni}>\mathrm{Cd}>\mathrm{Hg}>\mathrm{Mg}
$$

Moving forward, the construction of a $\mathrm{Sr}$ decontamination system based on these zeolites is conceivable.

\section{Adsorbent Evaluations and Issues}

The partition coefficient and adsorption rate of the adsorbents are significantly affected by physical and chemical properties such as purity, cationic form, surface form, and macro 
cavities, and therefore, the characterization must be carefully evaluated. When selecting and using an adsorbent, the adsorbent must be determined through a comprehensive evaluation that includes not only these adsorbent properties but also factors such as stability and solidification treatment.

\section{Disposal of Solid Waste Generated by Contaminated Water Treatment}

\section{Definition of Disposal}

Methods for treating and disposing of not only radioactive materials but also toxic substances can be summarized as the following two types. If waste can be diluted to a safe concentration or less, it can be diluted and discharged into the environment. If dilution is not possible, the volume of the waste is reduced as much as possible and the waste is then isolated into tight containers. Both methods are designed to eliminate any negative impact on the environment. Disposal is an act of making the wastes safe without any type of treatment after the act (after disposal), and treatment is the act of processing waste into a form that is suited for disposal and storage. The above-described adsorption treatment reduces high-concentration liquid waste to a concentration that can be discharged into the environment, and is a method of trapping radioactive substances and transferring them to durable solids.

Radionuclides have a half-life, and if the toxicity can be reduced to a safe level during the period in which the radionuclides are fully isolated, safety can be ensured. However, if the radionuclides have a very long half-life, a fully sealed state cannot be maintained until the toxicity is reduced to a safe level.

In this case, a restriction method is used so that the discharged concentration can be diluted. For example, methods of solidifying waste in concrete and melting waste and forming it into glass are used to treat waste and convert it into a chemical form that is not easily dissolved in water to thereby dissolve the waste slightly at a time until it is at or below an amount that can be dissolved or is at or below a safe concentration. In addition, providing a barrier material such as clay around the solid body and delaying the translocation thereof is a technique for reducing the concentration that is discharged into the environment. Rocks and soil also have a retardation effect on the translocation of radionuclides, and therefore, the depth of the disposal site also has an effect of reducing the concentration discharged into the environment.

\section{Classification of Disposal Methods}

The Specified Radioactive Waste Final Disposal Act of Japan classifies disposal methods into the following four types (Figure 8).

(1) Trench disposal (simple landfill near the ground surface)

(2) Pit disposal (burying underground in a concrete structure)

(3) Subsurface disposal (disposal at a depth of $50 \mathrm{~m}$ or greater with the use of barrier materials)

(4) Geological disposal (disposal at a depth of $300 \mathrm{~m}$ or greater with the use of barrier materials)

The type of disposal method to be used for disposing different types of wastes is determined by performing a safety evaluation so that public radiation exposure becomes $10 \mu \mathrm{Sv}$ or 


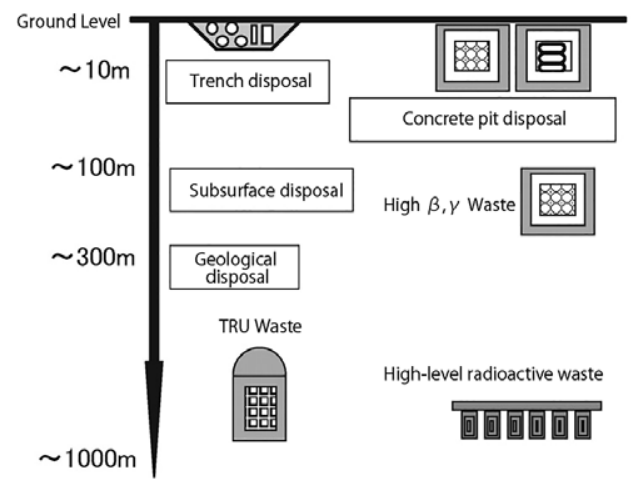

Figure 8 Classification of Underground Burial Disposal Methods

Table 2 Upper Limit Recommended Values According to Disposal Method ${ }^{8)}(\mathrm{Bq} / \mathrm{t})$

\begin{tabular}{|c|c|c|c|c|c|}
\hline \multirow[b]{2}{*}{ Nuclide } & \multicolumn{2}{|c|}{ Trench Disposal } & \multicolumn{2}{|c|}{ Pit Disposal } & \multirow{2}{*}{$\begin{array}{c}\text { Subsurface } \\
\text { Disposal and } \\
\text { Geological Disposal } \\
\text { Classification Value }\end{array}$} \\
\hline & $\begin{array}{l}\text { Recommended } \\
\text { Upper Limit } \\
\text { Concentration }\end{array}$ & $\begin{array}{l}\text { Evaluation Value of } \\
\text { Classification Value } \\
\text { Dependency }\end{array}$ & $\begin{array}{l}\text { Recommended } \\
\text { Upper Limit } \\
\text { Concentration }\end{array}$ & $\begin{array}{c}\text { Evaluation Value of } \\
\text { Classification Value } \\
\text { Dependency }\end{array}$ & \\
\hline $\mathrm{C}-14$ & - & $10^{10 \dagger 1}$ & $10^{11}$ & - & $10^{16}$ \\
\hline $\mathrm{Cl}-36$ & - & $10^{7}-10^{8}$ & - & $10^{11 \dagger 1}$ & $10^{13}$ \\
\hline Co-60 & $10^{10}$ & - & $10^{15}$ & - & - \\
\hline $\mathrm{Ni}-63$ & - & - & $10^{13}$ & - & - \\
\hline Sr- 90 & $10^{7}$ & - & $10^{13}$ & - & - \\
\hline Tc-99 & - & $\begin{array}{l}10^{5}-10^{6 \dagger 1} \\
10^{4}-10^{5 \dagger 2}\end{array}$ & $10^{9}$ & - & $10^{14}$ \\
\hline $\mathrm{I}-129$ & - & $10^{4}$ & - & $10^{10 \dagger 2}$ & $10^{12}$ \\
\hline Cs-137 & $10^{8}$ & - & $10^{14}$ & - & - \\
\hline$\alpha$-nuclide & - & $10^{9}$ & $10^{10}$ & - & $10^{11}$ \\
\hline
\end{tabular}

${ }^{\dagger 1}$ : Value estimated from relative concentration with respect to $\mathrm{Co}-60$.

${ }^{2}$ : Value estimated from relative concentration with respect to Cs- 137.

less per year. However, waste can be generally classified by the concentration of radioactive substances contained in the waste (Table 2) ${ }^{8)}$. The values shown in the table indicate the maximum concentration at which disposal is possible with each of the disposal methods, and are set 10 to 100 times higher than the concentration that satisfies the yearly $10 \mu \mathrm{Sv}$ amount (10 times for $\alpha$ nuclides and trench disposal, 100 times for all others). Therefore, the average concentration in the waste to be disposed becomes $1 / 10$ th to $1 / 100$ th or less than the figures shown in the table.

\section{Issues with Contaminated Water Treatment Waste Disposal}

The following points must be considered with regard to the disposal of solid waste generated from the treatment of contaminated water in the Fukushima Daiichi Nuclear Power Plant.

(1) Contained nuclides (radiation amount, half-life)

(2) Amount of heat generated

(3) Solidification form 
(4) Accompanying substances

The type and concentration of the contained nuclides are important when determining which disposal method (depth) to use for disposal. This time, the waste contains an overwhelmingly large amount of cesium, but ${ }^{137} \mathrm{Cs}$ has a half-life of 30 years, and because this is relatively short, subsurface disposal and geological disposal classifications are not mentioned for cesium. Therefore, when determining the disposal depth, the concentrations of nuclides other than ${ }^{137} \mathrm{Cs}$ become important. Measurement is easy with $\gamma$-ray nuclides, but with regard to other nuclides, the concentration measurements or information for estimating the concentration is necessary.

Information regarding the amount of heat generated is necessary at the design stage of the disposal site. When the amount of heat generated is large, the removal of heat underground becomes a problem when waste is disposed, and to maintain the temperature at or below the heat resistance temperature of the barrier material, considerations such as leaving an interval between the wastes must be made. Nuclides that generate considerable heat have a relatively short half-life, and therefore, intermediate storage until disposal is also conceivable.

Another important issue is processing the adsorbing material into a form that is suited for disposal. With regard to ferrocyanide sedimentation in particular, there is a possibility of chemical degradation in a reducing environment; therefore, the material must be changed into a suitable form. It is thought that disposal sites can be designed for the disposal of zeolites in their current form. If converted into glass or compressed bodies, a unique treatment facility becomes necessary. In the case of high-temperature treatment, the adsorbed cesium might undergo volatilization and move into exhaust gas, and additional waste is then generated in the exhaust gas treatment system. From the perspectives of the heat resistance temperature of concrete and the generation of hydrogen through radiation decomposition of the contained moisture, the concrete solidification method cannot be easily selected for cases in which the concentration is high.

Ample consideration must also be given to accompanying substances. When contaminated water is treated, the water contains oil content and salt content, and therefore, the interaction between these and the barrier materials must be examined. There is a concern that the salt content can cause issues such as corrosion of metal vessels, a decrease in the strength of concrete structures, and a decrease in the swelling force/water cutoff performance of clay. When oil (organic substance) is contained, there is a concern about the generation of hydrogen or other gases through radiation decomposition, and therefore, incineration, acid digestion, or other such treatment becomes necessary.

Therefore, the disposal method is determined according to each solidified body while paying attention to the abovementioned points.

\section{References}

1) Radioactive Stagnant Water Collection and Treatment Team Document. May 16, 2011. [in Japanese]

2) High Level Stagnant Water Treatment System Diagram. TEPCO Press Release Document. July 14, 2011. [in Japanese]

3) TEPCO Report on the Completion of Step 2 in Path to Recovery from Fukushima Daiichi Nuclear Power Plant. December 16, 2011. [in Japanese]

4) [Status of Storage and Treatment of Stagnant Water Containing High Concentration Radioactive Substances at the Fukushima Daiichi Nuclear Power Plant (Reports 1 28) ]. TEPCO Press Release Document. (through January 5, 2012) [in Japanese]

5) Mimura H. Nihon-Ion-Koukan-Gakkai Shi (Jpn. Soc. Ion Exchange). 2008;19(2) :127-140. [in Japanese]

6) Mimura H, Kanno T. J. Nucl. Sci. Technol. 1985;22:284-291. 
7) Mimura H, Yamagishi I, Akiba K. Research Report of the Laboratory of Nuclear Science 1988;21:6470. [in Japanese]

8) Radiation Concentration Upper Limit Values with Regard to Buried Underground Disposal of Low Level Radioactive Solid Waste. Nuclear Safety Commission, May 21, 2007.

9) Collection of Fundamental Data for Technology to Treat Contaminated Water in the Fukushima Daiichi Nuclear Power Plant. At. Energy Soc. Jpn., Backend Subcommittee HP. 2011. [in Japanese] 


\title{
Crisis Communication at the Fukushima Accident and the Concept of Crisis Management
}

\author{
-What is the information dissemination for?-
}

\author{
Kansai University, Shoji Tsuchida
}

\begin{abstract}
This commentary discusses the crisis communication that took place during the severe accidents experienced by the Tokyo Electric Power Company at its Fukushima Daiichi Nuclear Power Plant in the aftermath of the 2011 Great East Japan earthquake. Crisis communication is conducted to exchange information between the actors who are responding to a crisis and the public. The commentary first defines the term "public" in this context and explains why crisis communication is necessary. After that, it identifies problems that occurred in relation to crisis communication during the Fukushima Nuclear Accident according to the idea that safety, rather than security, is the top priority when responding to a crisis.
\end{abstract}

\section{Introduction}

The 2011 Great East Japan earthquake that occurred on March 11 and the subsequent tsunami ravaged parts of east Japan. In addition, a complete loss of external and emergency AC power at the Fukushima Daiichi Nuclear Power Plant operated by Tokyo Electric Power Company (TEPCO) resulted in severe accidents (hereinafter referred to as the "Fukushima Nuclear Accident"). With more than seven months having passed since the accident was triggered, this commentary discusses the initial crisis management in retrospect, with a particular focus on crisis communication.

\section{Crisis Communication}

(1) What is crisis communication?

Putting details aside, the Fukushima Nuclear Accident was literally a crisis involving severe accidents. Crisis communication is the exchange of information with the public in response to a crisis (severe accidents). One of the most difficult tasks to perform during a crisis is to perceive the reality of the situation accurately based on proper assessments. The difficulty involved in taking on-site measurements is not the only reason. Under difficult circumstances, people's perception of reality is also distorted by human (psychological) factors. For instance,

DOI : 10.15669/fukushimainsights.Vol.1.224

() 2021 Atomic Energy Society of Japan. All rights reserved.

Originally published in Journal of the Atomic Energy Society of Japan (ISSN 1882-2606), Vol. 54, No. 3, p. 181-183 (2012)

in Japanese. (Japanese version accepted: November 27, 2011) 
on the first day of a war, $80 \%$ of reports from the battlefront are said to provide incorrect information.

For this reason, crisis communication is not limited to the actors who are directly responding to a crisis simply reporting the on-site situation to the public. Essentially, the public need to communicate with these actors to ensure that the latter perceive the reality of the situation and make on-site judgments objectively.

(2) Who are the public in relation to crisis communication?

As a counterpart in the exchange of information with the actors directly responding to a crisis, the public can be classified as follows in relation to crisis communication.

(1) General public: By definition, the term "public" refers to people in general.

(2) Press: As the mass media is well developed today, the press represents the general public by serving as an interface for information exchanges between them and the actors responding to a crisis.

(3) Administrative bodies: Administrative bodies exercise authority in various fields on different levels on behalf of the general public. The central (national) government, prefectural governments, and municipal governments on local levels work closely together. It is important to note, however, that these bodies are separate counterparts in relation to the actors responding to a crisis and they each require an adequate amount of individual information exchanges.

In the case of the Fukushima Nuclear Accident, TEPCO and the Nuclear and Industrial Safety Agency (NISA) seem to have, in their capacity as the on-site actors, exchanged information with the Prime Minister's Office, which was ultimately responsible for the response to the accident. However, it seems likely that little information was exchanged with the prefectural and municipal governments. The adequacy of the information that the national government exchanged with prefectural and municipal governments has yet to be verified.

(4) Affiliated companies and industry peers: Nuclear power in Japan is not carried out entirely by the utility companies alone. Their operations are sustained by their partners, second-tier and third-tier contractors, and so forth. Needless to say, information exchanges among these companies are vital during any crisis. Moreover, a large part of the resources and capacity that would normally be expected becomes unavailable during a crisis. To make up for this loss, information must be exchanged among otherwise unfamiliar affiliated companies and industry peers.

(5) Research and development institutes (and relevant professionals) involved in other fields: A crisis is an abnormal situation that would not normally be expected to occur. Naturally, research findings from other fields may prove effective in helping to deal with such a crisis. A situation that is abnormal for actors in one field may be usual or expected for actors in another field. The more abnormal a given situation is, the more effective exchanges with research and development institutes from other fields may prove to be.

(6) Overseas counterparts of the abovementioned stakeholders ((1)-(5)): In today's global society, crisis communication regarding nuclear accidents must be conducted with other countries no differently to how it is conducted in our own country.

Media coverage of the Fukushima Nuclear Accident suggests that TEPCO, as the primary actor, actively sought to engage in crisis communication with supervisory administrative bodies. Perhaps in line with instructions issued by these bodies, TEPCO formally engaged in crisis communication to a certain degree with the press, as well. Nevertheless, the extent and effectiveness of the crisis communication that TEPCO conducted directly with local residents, municipalities and other local administrative bodies that deal closely 
with residents, affiliated companies, industry peers, research and development institutes from other fields, and the public in other countries has yet to be verified.

\section{Why is Crisis Communication Necessary?}

Crisis communication must be conducted by the actors responsible for responding to a crisis for the following reasons.

(1) To fulfill moral obligation: The actors are held accountable for having caused an accident and disturbance in society. Naturally, they have an obligation to explain the situation to the public. Crisis communication is carried out solely out of moral obligation if the resulting crisis can be contained by the actors. Crisis communication becomes crucial for the reasons described below in any crisis that grows beyond the control of the actors to cause extensive damage and impact.

(2) To gain the public's understanding: To prevent harmful rumors and ensure that public opinion is shaped based on reasoning that withstands criticism, the public should be asked to understand a crisis based on an adequate amount of accurate information. To this end, the actors must provide the public with the information necessary to gain a proper understanding as well as respond to any feedback from the public regarding the information provided.

(3) To save the public: If the crisis also affects the public, information on hazards and evacuation requirements must be swiftly disclosed to the public. The actors must also swiftly accept and respond to any information shared by the public regarding possible hazards associated with the crisis.

(4) To request the public's support: A serious crisis can no longer be handled solely by the actors directly responding to it. In such a situation, support must be sought from the wider public (the whole country or even all of humanity). During such crisis communication, it is important to specify the form of support that is being requested from the public while providing clear information to the intended recipients.

In the crisis communication prompted by the Fukushima Nuclear Accident, TEPCO solicited support only from the national government as their legal superordinate decision-making body. According to media coverage, TEPCO did not solicit support from anyone else. The operations required to deal with a crisis are not envisaged in routine work. The actors must be open to the possibility that others may have superior skills and knowledge in relation to handling such extraordinary operations. Crisis communication can prove effective in helping to overcome a crisis when the form of support being requested is specified. For instance, support could be requested from smaller companies, research and educational institutes, and a wide range of other potential partners to locate heavy machinery that is resistant to a specified level of radiation so that remote operations can be performed without any of its electronic units malfunctioning.

\section{The Issue of the "Unexpected": Two Dimensions of Safety Measures}

During the initial phase of the Fukushima Nuclear Accident, the actors directly responding to the accident and other concerned experts often described the accident as "unexpected." The problems inherent in describing a crisis as something unexpected are pointed out based 
on the two interrelated concepts of security and safety.

\section{Security and Safety}

The Japanese word "ANZEN" carries at least two meanings ").

One meaning is "security," which can be defined as the minimized probability of accidents and disasters. Basically, the focus is placed on the prevention of these undesired events.

The other meaning is "safety," which can be defined as the minimizing of damage from any accidents and disasters that take place.

Prior to the Fukushima Nuclear Accident, nuclear ANZEN measures in Japan had been excessively focused on security. Safety measures aimed at the mitigation of severe accidents may have neglected what needed to be done if a severe accident took place. In other words, these measures would inevitably be criticized for neglecting safety. Such neglect is symbolized by the fact that the term "unexpected" was used during the crisis.

\section{Any Party that Resorts to Saying "That Was Unexpected" Is Incompetent}

Tomio Kinoshita classified unexpected circumstances into the following five categories ${ }^{2}$ : (1) meteorite impacts and other extremely rare events; (2) circumstances that are considered likely only by the minority in a relevant discipline; (3) circumstances subjectively deemed unlikely by directly involved actors due to their overconfidence or the like; (4) circumstances classified as unexpected as a result of a tradeoff with costs, political considerations, and other external factors; and (5) circumstances whose likelihoods were unnoticed by directly involved actors due to a lack of diligence or imagination. Kinoshita concludes that, in the proper sense of the word, unexpected events only belong to Category (1) and that the rest do not qualify. In any case, the most important issue is the reality that severe accidents took place. The expression "unexpected" only has worth as an indication that the security side of ANZEN measures failed. It is useless in dealing with severe accidents that actually take place. As an illustration, imagine a commander who says during a war that an enemy's operations were unexpected. Such a remark would only serve as an acknowledgement of incompetence as the reason for the commander's resignation.

In response to a crisis that actually takes place, safety-oriented measures are necessary to minimize the resultant damage. Consequently, safety-related information must be shared in crisis communication.

Security-related information, including the question of what matters were genuinely unexpected, is only relevant after the end of a crisis during discussions concerning necessary future measures and who should be held responsible. Such information is utterly irrelevant in crisis communication during an ongoing crisis.

\section{What Type of Information Needs to be Shared and to What Extent in Crisis Communication?}

In crisis communication and other forms of communication, the type and extent of information to be shared depends on the ability of the intended recipients to comprehend the information. In other words, crisis communication is impossible without first assessing the comprehension capabilities of the intended recipients. To achieve the intended goal of crisis 
communication as described earlier, useful information must be shared with the intended recipients by inferring what they want to know and estimating their comprehension capabilities.

Any incomprehensible information that is shared will not reach the intended recipients properly. Worse still, such information is likely to be interpreted as an attempt to cover-up something or regarded as insincere or untrustworthy.

During the Fukushima Nuclear Accident, TEPCO and NISA probably did try to convey facts accurately by sharing information intended for media coverage. Nonetheless, it is apprehensive that the information was not even comprehensible to the journalists themselves. Communication requires adequate training and skills to enable information to be shared in accordance with the comprehension capabilities of the intended recipients. Unfortunately, there is a dire shortage of such talented personnel among entities dealing with nuclear energy.

\section{General References}

1) Emiko Kanoshima: Review concepts of safety, security, ANZEN (a Japanese word) and other relating words [in Japanese], Journal of Societal Safety Sciences, 1, 153-177, 2011.

2) Tomio Kinoshita: The Fukushima Nuclear Accident Discussed in Terms of Risk Sciences [in Japanese], Journal of the Atomic Energy Society of Japan, 53 (7), 465-472, 2011.

- H. Hirakawa, S. Tsuchiya, and T. Tsuchiya: Theory of Risk Communication [in Japanese], Osaka University Press, 2011.

- $\quad$ A. M. Howitt and H. B. Leonard (eds.): Managing Crises: Responses to Large-Scale Emergencies, CQ Press, 2009. 


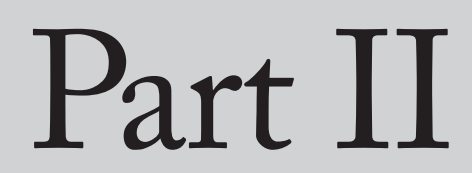

Effects of Radiation

(Published from April 2012 to 2016) 



\title{
New Standard Limits for Radionuclides in Foods
}

\author{
Institute for Integrated Radiation \\ and Nuclear Science, Kyoto University, \\ Tomoyuki Takahashi
}

\begin{abstract}
Examination of a new standard limits for radionuclide concentration in food to replace the provisional regulation value set immediately after the accident at Fukushima Daiichi Nuclear Power Plant of Tokyo Electric Power Company (Inc.) caused by the 2011 Earthquake off the Pacific Coast of Tohoku was conducted by the Committee on Countermeasures against Radioactive Materials established within the Food Safety Commission of the Pharmaceutical Affairs and Food Sanitation Council of the Ministry of Health, Labour and Welfare. The new standard limits came into effect on April 1, 2012. This paper outlines the timeline until the establishment of the new standard limits and the views on the derivation of the new standard limits.
\end{abstract}

\section{Introduction}

The accident at Fukushima Daiichi Nuclear Power Plant of Tokyo Electric Power Company (TEPCO) caused by 2011 Tohoku earthquake off the Pacific Coast of Tohoku led to release of a large quantity of radionuclides into the atmosphere and the ocean. As this accident had a possibility of causing high-concentration radionuclides to accumulate in food, the Ministry of Health, Labour and Welfare (MHLW) set provisional standard limits for intake restriction of radionuclides in food and drink in "On disaster prevention measures for nuclear facilities" 1) (Hereinafter referred to as "Nuclear Emergency Preparedness Guide") of the Nuclear Safety Commission and notified local municipalities to restrict intake of food according to Article 6-II of the Food Sanitation Act on March 17, 2011 2). Following this, examination of new standard and criteria to replace the provisional regulation value was conducted by the Committee on Countermeasures against Radioactive Materials established within the Food Safety Commission of Pharmaceutical Affairs and Food Sanitation Council of the MHLW (hereinafter referred to as the Committee on Countermeasures against Radioactive Materials), and on April 1, 2012, these new standard limits came into effect. This paper outlines the timeline until the establishment of the new standard limits and the views on the derivation of the new standard limits.

DOI : 10.15669/fukushimainsights.Vol.1.231

(C) 2021 Atomic Energy Society of Japan. All rights reserved.

Originally published in Journal of the Atomic Energy Society of Japan (ISSN 1882-2606), Vol. 54, No. 9, p. 602-605 (2012)

in Japanese. (Japanese version accepted: May 8, 2012) 


\section{Thought on the Index Value of Food and Drink Intake Restrictions in the Nuclear Emergency Preparedness Guide}

The index value for the food and drink intake restrictions specified in the Nuclear Emergency Preparedness Guide used as the provisional regulation limits in the Food Sanitation $\mathrm{Act}^{3)}$ set the thyroid equivalent dose of radioactive iodine to be $50 \mathrm{mSv}$ per year and effective dose of radioactive cesium (including contribution of radioactive strontium) to be $5 \mathrm{mSv}$ for its dose level. The guide uses this index value as the basis for judging whether its preventive measures should be taken or not (hereinafter referred to as "intervention dose level"). The guide derives radionuclide concentrations in food equivalent to this intervention dose level (hereinafter referred to as "inductive intervention concentration") and set them as the index value. In addition, uranium and major Trans-Uranium nuclides have their index values set.

Among these, ${ }^{89} \mathrm{Sr},{ }^{90} \mathrm{Sr},{ }^{134} \mathrm{Cs}$, and ${ }^{137} \mathrm{Cs}$ are considered as the assessment subject nuclides for deriving the inductive intervention concentration of radioactive cesium. The nuclide composition for the assessment, ${ }^{90} \mathrm{Sr}$ and ${ }^{137} \mathrm{Cs}$, are estimated to be 0.1 from the soil surface atmosphere concentration ratio at the Chernobyl Nuclear Power Plant Accident, and for ${ }^{89} \mathrm{Sr}$, ${ }^{90} \mathrm{Sr},{ }^{134} \mathrm{Cs}$, and ${ }^{137} \mathrm{Cs}$, the representative proportion of formation in the case that the specific burn-up of the fuel of light-water reactor is 30,000 MWd/t. Moreover, food was divided into the following five categories of "drinking water," "milk/dairy," "vegetables," "grains," "meat, egg, fish, others," and $1 \mathrm{mSv}$ per year was allocated for each category. Here, 0.5 is used as the ratio between the yearly average concentration and the peak concentration. In addition, people were divided into three age groups of adults, children, and infants, and assessment was conducted for each age group. "Vegetables," "grains," "meat, egg, fish, others" are unified at the same value as "vegetables," which had the lowest inductive intervention concentration. As a result, it was inferred that the index value for the food and drink intake restrictions of radioactive cesium were $200 \mathrm{~Bq} / \mathrm{kg}$ for "drinking water" and "milk/dairy," and $500 \mathrm{~Bq} / \mathrm{kg}$ for "vegetables," "grains," and "meat, egg, fish, others."

In Food Safety Basic Act, it is stipulated that preparation of policies related to ensuring the safety of food requires a food health impact assessment of food. However, the provisional regulation value set on March 17 were established without a health impact assessment of food by the food safety commission because "it is so urgent to prevent or suppress the adverse effect on human health and there is no time to assess the health impact of food in advance." Therefore, on March 20, after the notification, the MHLW requested the chairman of the food safety commission to conduct a food health impact assessment, and the chairman submitted "urgent summary on radioactive materials" to the minister on March 20. In this summary, it was stated that, with regard to radioactive iodine and radioactive cesium, "extensive safety measures are required to prevent radiation exposure from food," and "appropriate measures should be evaluated when necessary from the perspective of risk management." Moreover, it stated that "it is necessary to continue the food health impact assessment."

Note that on April 4, high concentration of radioactive iodine was detected in seafood. As the Nuclear Emergency Preparedness Guide did not specify an index value for radioactive iodine concentration in seafood, the regulation value was not set at this point. Therefore, the MHLW decided to apply the provisional regulation values of radioactive iodine used for vegetables to seafood, which is 2,000 Bq/ $\mathrm{kg}$, on April 5 .

On April 8, the first meeting of the Committee on Countermeasures against Radioactive Materials was held. At this meeting, it was decided that the provisional regulation values should be kept for the time being and it is necessary to build a system for continuous analysis/ assessment of various data toward the future examination of the standard limits. 


\section{Thought on Setting the Regulation Standard ${ }^{3)}$}

As discussed above, the new standard limits were mainly examined by the Committee on Countermeasures against Radioactive Materials. Note that the new standard limits were decided to be according to Article 11 of the Food Sanitation Act. The thought on the new standard limits (hereinafter referred to as "the standard limits") will be discussed as follows.

\section{Intervention Dose Level}

The food safety commission reported the results of the food health impact assessment of the radioactive materials contained in food to the minister of MHLW on October 27. Its main points are as follows:

- The food health impact assessment of food considers that the possibility of human health influence by radiation arises when the additional accumulated effective dose over lifetime is $\geq 100 \mathrm{mSv}$.

- There is a possibility that children are more sensitive than adults (thyroid cancer or leukemia).

- It is difficult to comment on the human health influence of dose $<100 \mathrm{mSv}$ according to currently available knowledge.

In response to the above, it stated that, "considering the fact that the evaluation result is shown in the additional accumulated dose through lifetime into account, future risk management should be according to the detection situation of radioactive materials from food and the current state of Japanese food consumption habit." These values postulate that the additional exposure was given only from food. Moreover, these values are considered to be applied to the additional effective exposure dose based on the monitoring data for ingestion of food that contains radioactive materials, and not to the administrative limits for decreasing the exposure from food, also known as the intervention dose level.

According to this report from the food safety commission, on October 28, the MHLW stated that they would lower the yearly acceptable dose of radioactive cesium in food from $5 \mathrm{mSv}$ per year to $1 \mathrm{mSv}$ per year by April 2012, with the basic consideration for the new standard limits.

The Committee on Countermeasures against Radioactive Materials had already estimated the committed effective dose based on the monitoring result, and as a result, the effective exposure dose for the case of continuously ingesting food with median concentration (deterministic method) is estimated to be approximately $0.1 \mathrm{mSv}$ per year in committed effective dose. Moreover, from the safety side estimation, even in the case of ingesting food with 90 percentile concentration ( $90 \%$ concentration from the lower end), the dose is estimated to be approximately $0.2 \mathrm{mSv}$ per year. Thus, it was considered to be sufficiently low. However, according to the principle to maintain the dose as low as reasonably achievable, it decided that lowering the intervention dose level to $1 \mathrm{mSv}$ per year is reasonable. This decision was according to the perspective to ensure the safety and security of the citizens still further, and on the fact that Codex Alimentarius Commission, which is an intergovernmental organization for setting the international standard of food, uses $1 \mathrm{mSv}$ per year as the "intervention exemption level" that does not require intervention. 


\section{Regulated Target Nuclides}

Regarding the regulated target nuclides in the setting of the standard limits, as the standard limits correspond to the long-term situation since April 2012, when over 1 year has passed since the accident, the nuclides with relatively long half-life by which long-term impact needs to be considered, should be targeted. Thus, the nuclides with half-lives of $\geq 1$ year among the nuclides whose estimated values of release amount are published by the Nuclear and Industrial Safety Agency (NISA) ${ }^{5)}$ were selected for consideration. That is, ${ }^{134} \mathrm{Cs},{ }^{137} \mathrm{Cs},{ }^{90} \mathrm{Sr}$,

${ }^{106} \mathrm{Ru},{ }^{238} \mathrm{Pu},{ }^{239} \mathrm{Pu},{ }^{240} \mathrm{Pu}$, and ${ }^{241} \mathrm{Pu}$ are the regulated target nuclides. Considering that those other than radioactive cesium among them are expected to require a long time for their measurement, setting a regulation value to each of them and monitor their concentration in food is not realistic. Therefore, it was decided to set the limits that do not go beyond $1 \mathrm{mSv}$ per year, which is the intervention dose level, by estimating the ratio of the concentration of these nuclides and the concentration of radioactive cesium (sum of ${ }^{134} \mathrm{Cs}$ and ${ }^{137} \mathrm{Cs}$ ) and then adding the dose of these nuclides.

Note that ${ }^{131} \mathrm{I}$ whose half-life is 8 days was not included in the limits as it has not been discovered in food since July 15, 2011. Moreover, the nuclides that are not considered in this evaluation were judged to be unnecessary to set limits for them at this point as they are deemed to contribute little to the dose.

\section{Estimation of Concentration Ratio of Radionuclides in Food}

To derive the limit of concentration in food equivalent to the intervention dose level, it is necessary to estimate the ratio of nuclides other than radioactive cesium to radioactive cesium in food. The route of radionuclides released from a nuclear facility into the atmosphere to move into agricultural products is dominated by the "direct deposition pathway" caused by the direct deposition of radionuclides in the atmosphere on agricultural products, immediately after the accident. Note that this direct deposition route includes the route that the radionuclides deposited on the surface of leaves or on a tree and then absorbed into the body of the plant/tree moves into the edible part of that plant/tree. Meanwhile, at the point of time when the release from the nuclear facility is almost converged and the deposition amount from the atmosphere has decreased, the "root uptake pathway" that the radionuclides deposited on the soil of cultivated land are absorbed into the body of a plant through its roots and then move into the edible part becomes dominant. From the long-term perspective, it is important to assess this root uptake pathway.

Regarding livestock products, as is the case with the agricultural products, radionuclides are transferred to the grass or forage crop through either the direct deposition pathway or the root uptake pathway and then ingested by the livestock as their fodder.

The possible transfer pathways to the freshwater system, such as rivers, lakes, and marshes, include direct deposition from the atmosphere to the water of rivers, lakes, and marshes immediately after the accident or the radionuclides settled on the catchment area flowing into the water later. The radionuclides transferred into freshwater through these pathways are absorbed by the freshwater organisms in these rivers, lakes, or marshes.

Moreover, the pathways to seafood include the radionuclides either in the waste water generated in the facility during the emergency measures against the accident, released directly into the ocean, or in the radionuclides, released into the atmosphere. The latter component diffuses toward the ocean and gets deposited on the sea surface, which is later transferred to seawater then being absorbed by the marine organisms living in either the seawater or in the 
marine soil.

As these standard limits correspond with the long-term situation over a year after the accident, the root uptake pathway from the soil is deemed to be dominant among the transfer route of radionuclides to agricultural products (including the forage crop). Therefore, the nuclide concentration ratio in agricultural products can be estimated by multiplying the nuclide concentration ratio in the soil with the soil to agricultural products transfer coefficient ratio. For this concentration ratio in the soil, the concentration ratio for cesium rounded to the safety side is used for the nuclides whose concentration ratio in the soil are obtained in the radiation dose map prepared by the Ministry of Education, Culture, Sports, Science and Technolo$\mathrm{gy}^{6}$, and those whose concentration ratios are not obtained were estimated using the ratio of release estimate by NISA. Moreover, for the nuclide concentration ratio in freshwater used for estimating the nuclide concentration ratio of drinking water and freshwater products, the nuclide concentration ratios rounded to the safety side were used for ${ }^{90} \mathrm{Sr}$ and ${ }^{137} \mathrm{Cs}$ whose actual measurements are obtained in the radiation dose map ${ }^{6}$, and it was estimated from the estimation of the concentration ratio in the soil and the solid-liquid distribution coefficient ratio for other nuclides. Note that transfer coefficient from the soil to agricultural products (including forage crop), transfer coefficient from fodder to livestock products, transfer coefficient from freshwater to freshwater products and solid-liquid distribution coefficient were used as the environmental transfer parameters of this evaluation. Regarding these parameter, according to the data acquired in Japan and the International Atomic Energy Agency report, the values on the safety side, that is, the value for which the concentrations of other nuclides are highly evaluated was selected, so that the concentration ratios of radioactive cesium to other nuclides are not underestimated.

However, the information on the quantity or composition of the radionuclides released directly from the power plant site to the ocean was scarce, and an evaluation using a detailed environmental monitoring data akin to that for the land is difficult. Therefore, the evaluation of radionuclide concentration ratio in seafood was conducted by assuming that the contributions made by the dose from other radionuclides and those made by radioactive cesium to be equivalent, i.e., by considering the total dose to be the double of the dose from radioactive cesium.

\section{Food Category}

Food was divided into the following four categories: "drinking water," "food for infants," "milk" and other "general food." The reason why food for infants and milk are in different category is that the comment by the food safety commission that was stated that "The possibility that children are more susceptible than adults" was taken into consideration.

Moreover, no detailed categories were used for general food so as to minimize the effect of variations in individual eating habits, to make the limits easier to understand for the general public, and to make it consistent with the international views, such as that of Codex Alimentarius Commission.

The scope of these categories was also examined. For instance, the limit of tea leaves was set at $500 \mathrm{~Bq} / \mathrm{kg}$ in the provisional regulation value but in the standard limits, the regulation standard of drinking water at the drinking stage after production and processing was applied. Moreover, for food whose ingredients were dried and normally ingested after being soaked in water among the general food, it was deemed appropriate to apply the limit for general food at the stage of original ingredients and at the stage of ingestion. 


\section{Age Category, etc.}

Although three categories of age group were used for deriving the provisional regulation value, more precise age categories of " $<1$ years," "1-6 years," "7-12 years," "13-18 years" and ">19 years" were used for setting the standard limits. Moreover, the difference in the amount of food ingestion between male and female was also considered for all the categories other than " $<1$ years." In addition, pregnant women were considered to be in a separate category, making the total number of categories ten.

The food ingestion used for calculating the radionuclide concentration equivalent to the intervention dose level (hereinafter referred to as "the limit value") was set by referring to the research result of the national average. The intake of drinking water was set at $1 \mathrm{~L} /$ day for " $<1$ years" and 2 L/day for all other categories according to the World Health Organization (WHO) guideline.

\section{Setting of the Regulation Standard Values}

First, $10 \mathrm{~Bq} / \mathrm{kg}$, which is the guidance level of radioactive cesium in WHO drinking water quality guideline, was adopted as the regulation standard value for drinking water. This guidance level is sufficiently conservative, and although water exceeding the guidance level would trigger a follow-up research, it does not necessary mean that the water is unsafe to drink. This value is considered to be applied as the normal everyday operation condition for providing existing or new drinking water ${ }^{2}$.

The yearly dose allocated to food was obtained by subtracting the dose equivalent to this drinking water concentration (including contributions from other nuclides) from $1 \mathrm{mSv}$ per year which is the intervention dose level. The limit value of food was derived using this yearly dose allocated to food, radionuclide concentration ratio in food, yearly intake of each food, internal exposure dose coefficient of each nuclide, and the contamination rate of food in distribution. The contamination rate of food in distribution was assumed to be $50 \%$ according to the actual measurement obtained from monitoring examination, etc. and the fact that much imported food is contained in the food distribution. Moreover, the same limit value was set for "milk" and "food for infants," and $1 / 2$ of $100 \mathrm{~Bq} / \mathrm{kg}$ limit for general food was adopted as their limit value, as the value that would not be influenced even if every food in distribution were contaminated. The nuclide concentration ratio in food was calculated by considering the physical radioactive decay of radionuclides, and the value at the point that the limit value becomes the smallest was obtained.

The category that has the smallest limit value after such a calculation was " $13-18$ year-old (male)" at $120 \mathrm{~Bq} / \mathrm{kg}$ (note that the 3rd digit was rounded down to the safety side). According to these results, the Committee on Countermeasures against Radioactive Materials agreed on adopting the following as the standard limits of radioactive cesium during the meeting held on December 22, 2011: $100 \mathrm{~Bq} / \mathrm{kg}$ for general food, which rounded down the smallest number of the derived limit value to the safety side, and $50 \mathrm{~Bq} / \mathrm{kg}$ for food for infants and milk, which is $1 / 2$ of $100 \mathrm{~Bq} / \mathrm{kg}$ limit for general food. Moreover, transitional measures in some areas were required during the transition to the new standard limits to avoid confusion in the market.

The estimated value of actual exposure dose from radioactive cesium based on these new regulation standard values was $0.043 \mathrm{mSv}$ per year when using the median concentration, and $0.074 \mathrm{mSv}$ per year when using 90 percentile concentration. Thus, it was verified that the values are sufficiently low compared to the intervention dose level. 
The new standard limits plan was submitted to the Radiation Council by the Minister of MHLW on December 27 and deliberations were held. The Radiation Council reported on February 16, 2012 regarding this standard limits plan: "there is no objection to formulate it as a technical standard from the viewpoint of the basic policy stipulated by Act on Technical Standards for Prevention of Radiation Hazard," however, they stated that "it is important to prepare the system for maintenance of measurement equipment and securing/training the staff to use them for the appropriate operation of the standard limit for food" "7). Further, this report included the following opinions; setting new standard limits is unlikely to significantly improve the effectiveness of protection against radiation because the risk originating from food is already smaller than $1 \mathrm{mSv}$ per year, the opinions of the stakeholders (people who are involved in this issue from various perspectives) should be taken into consideration as much as possible, it is important to appropriately conduct the risk communication that recognizes the fact that the upper limit of the risk is minute even when the limit is slightly exceeded, and enough consideration to children in protection against radiation is already taken even if special standard limits were not set for "food for infant" and "milk."

Moreover, public comments were accepted via Internet from January 6 to February 4, 2012, and 1,877 opinions were received. Among them, 1,449 opinions called for more strict limits, 819 demanded more consideration to be given to children, and 55 regarded the new standard limits to be too strict ${ }^{2}$.

Following these steps, a joint meeting between the Committee on Countermeasures against Radioactive Materials and the Food Safety Commission was held on February 24, and the standard limits plan without a modification from the original plan was then adopted and decided to come into effect from April 1.

\section{Conclusions}

The standard limits came into effect on April 1, 2012. It was reported in the media that radioactive cesium concentration in some foods exceeded $100 \mathrm{~Bq} / \mathrm{kg}$ and their distribution was regulated. To obtain the safety and security of the general public in food regulation, it is important to pursue further improvement of examination system, prompt and sufficient information disclosure of examination results, continuous dose assessment of internal exposure, investigation and research on the transfer of radionuclides into food, and informing people about the thought on the regulation standard in the future.

\section{References}

1) Nuclear Safety Commission. On disaster prevention measures at nuclear facilities, etc., Nuclear Safety Commission. (Final Revision 2008). [in Japanese]

2) http://www.mh lw.go.jp, Accessed 6 May 2012.

3) Nuclear Safety Commission, Department of specialized disaster prevention measures for the surrounding area of nuclear power station, Environmental working group. On the index for intake restrictions food and drink. Nuclear Safety Commission 1998. [in Japanese]

4) Food Safety Commission. Assessment Report: Radioactive materials contained in food. Food Safety Commission 2011. [in Japanese]

5) Nuclear and Industrial Safety Agency. On the evaluation of the state of reactor cores of Unit 1, Unit 2 and Unit 3 related to the accident at Fukushima Daiichi nuclear power station of Tokyo Electric Power Company Holdings, Inc.,. (June 6, 2011 [Revised at October 20]). 2011. [in Japanese]

6) http://radioactivity.mext.go.jp/ja, Accessed 6 May 2012.

7) Radiation Council. On the ministerial ordinance to partially revise the ministerial ordinance 


\section{INSIGHTS CONCERNING THE FUKUSHIMA DAIICHI NUCLEAR ACCIDENT Vol. 1}

regarding the component regulation of milk and dairy products (Ministry of Health and Welfare, Ordinance Nr.52, 1951) and the partial revision of the standard limits of food and additive (Ministry of Health and Welfare, Announcement Nr. 370, 1959). (Report). 2012. [in Japanese] 


\title{
The Effects of the Nuclear Disaster at Fukushima Daiichi Nuclear Power Station on Local Governments
}

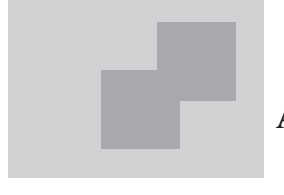

\author{
All Japan Council of Local Governments with Nuclear Power Stations, \\ Makoto Nakamura and Kinji Dake
}

\begin{abstract}
All Japan Council of Local Governments with Nuclear Power Stations (The Council) consists of 30 municipalities in total. They are 24 municipalities that are either the site of a nuclear power station or the planned site for one and their 6 neighboring municipalities. They collaborate with each other to solve problems arising at the site of a nuclear power station. The nuclear emergency that occurred at the Fukushima Daiichi Nuclear Power Station caused damage to our member municipalities and led to an unprecedented and severe situation that included "administrative function transfer" and "large-area evacuation," which went beyond the municipal areas that were not in the realm of our expectation. The Council established a working group to conduct a survey for the municipalities to verify this disaster and reflect the result on the nuclear energy administration, such as safety and disaster prevention measures. The obtained results were published as a report on March 2012. This paper will report on the outline of the survey and the direction for the engagement with the challenges that were revealed during the survey.
\end{abstract}

\section{Introduction}

The 2011 off the Pacific coast of Tohoku Earthquake and its accompanying tsunami caused a large-scale nuclear emergency with a radioactive material release at the Fukushima Daiichi Nuclear Station, which Japan has never experienced. The member municipalities affected by the disaster are still facing difficulties in the management of their administration due to the prolonged evacuation of their residents or the transfer of their administrative functions.

This disaster highlighted a vast number of problems such as the confusion in the initial response of the national government or the delay in the measures for recovery and reconstruction. It is necessary to conduct thorough research/examination of not only the cause of the accident but also the nuclear disaster prevention system including the initial response of the national government to conduct an urgent fundamental review of the crisis management flamework and disaster prevention system.

As the municipalities where nuclear power stations are located, we believe that we should examine the measures to protect the safety and security of our residents, and therefore

DOI : 10.15669/fukushimainsights.Vol.1.239

(C) 2021 Atomic Energy Society of Japan. All rights reserved.

Originally published in Journal of the Atomic Energy Society of Japan (ISSN 1882-2606), Vol. 54, No. 10, p. 647-652

(2012) in Japanese. (Japanese version accepted: July 10, 2012) 
decided to survey the disaster-stricken areas ourselves.

\section{System and Items for the Survey}

"The Nuclear Emergency Examination Working Group" comprising staff from 5 cities, 5 towns, and 3 villages among the member municipalities of the Council was established. They surveyed 6 member municipalities in Fukushima Prefecture that were affected by the disaster (Futaba, Okuma, Naraha, Tomioka, Minamisoma, and Namie) as well as the offices of the Nuclear Power stations that did not suffer nuclear emergency even though they were hit by the same earthquake and tsunami (Onagawa Nuclear Power Station and Tokai Daini Nuclear Power Station). Following are the subjects of the survey. Based on the results, extraction of issues and examination of the direction of measures were conducted.

$\circ$ Notification and information communication

Evacuation of the residents

$\circ$ Disaster prevention and response system

$\circ$ Management of the evacuation center

$\checkmark$ Others (Problems and challenges in measures against earthquake disaster, etc.)

\section{Survey Result}

Table 1 shows the situation of the communication report, as obtained from the operator. The first notification from the Fukushima Daiichi Nuclear Power Station was not recognized by any of the municipalities, and section 10 and section 15 of Act on Special Measures Concerning Response to Environmental Contamination by Radioactive Material Released from the Accident of the Nuclear Power Station caused by the Tohoku District-off the Pacific Ocean Earthquake (Act on Special Measures) also reached only some of the municipalities.

The hotlines between the nuclear power stations and the 4 towns had already been prepared. Especially the one to Fukushima Daini Nuclear Power Station was the type that could be used during a blackout. Thus, it was connected immediately after the earthquake. In addition, staffs of Tokyo Electric Power Company, Inc. (TEPCO) were dispatched there from the early stage and they also accompanied evacuation, thus the system for constantly providing information was in place. However, the information from Fukushima Daiichi Nuclear Power Station was extremely fragment and its contents were insufficient.

Meanwhile, at the neighboring Namie, and Minamisoma next to Namie, they did not receive any communication via phone and no TEPCO staff was dispatched there immediately after the disaster, meaning they could only collect information through a TV.

Table 2 shows the situation of dispatch communication from the national government or the prefectural government such as evacuation orders. Hardly any municipalities received communication from the national government or the prefectural government, and most of them did not even receive evacuation order. Naturally, there was no precise instruction on the evacuation destination or method.

Moreover, there was no communication between municipalities regarding the setting of the off-site center, and information sent from off-site center hardly reached there. Only Okuma could dispatch its staff. However, the function of off-site center itself was down, and therefore sufficient understanding of the situation was impossible. 
Makoto Nakamura et al.

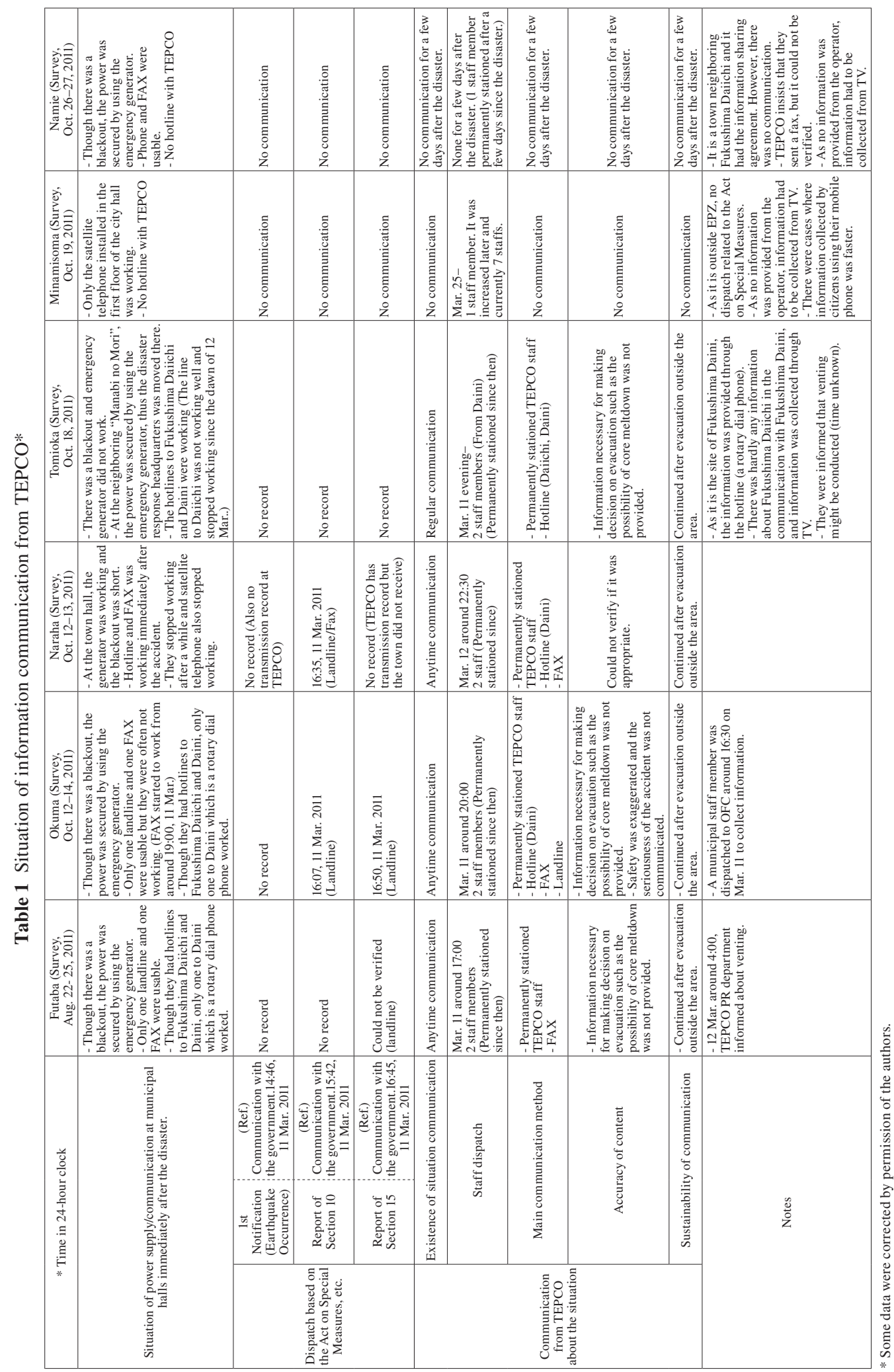


INSIGHTS CONCERNING THE FUKUSHIMA DAIICHI NUCLEAR ACCIDENT Vol. 1

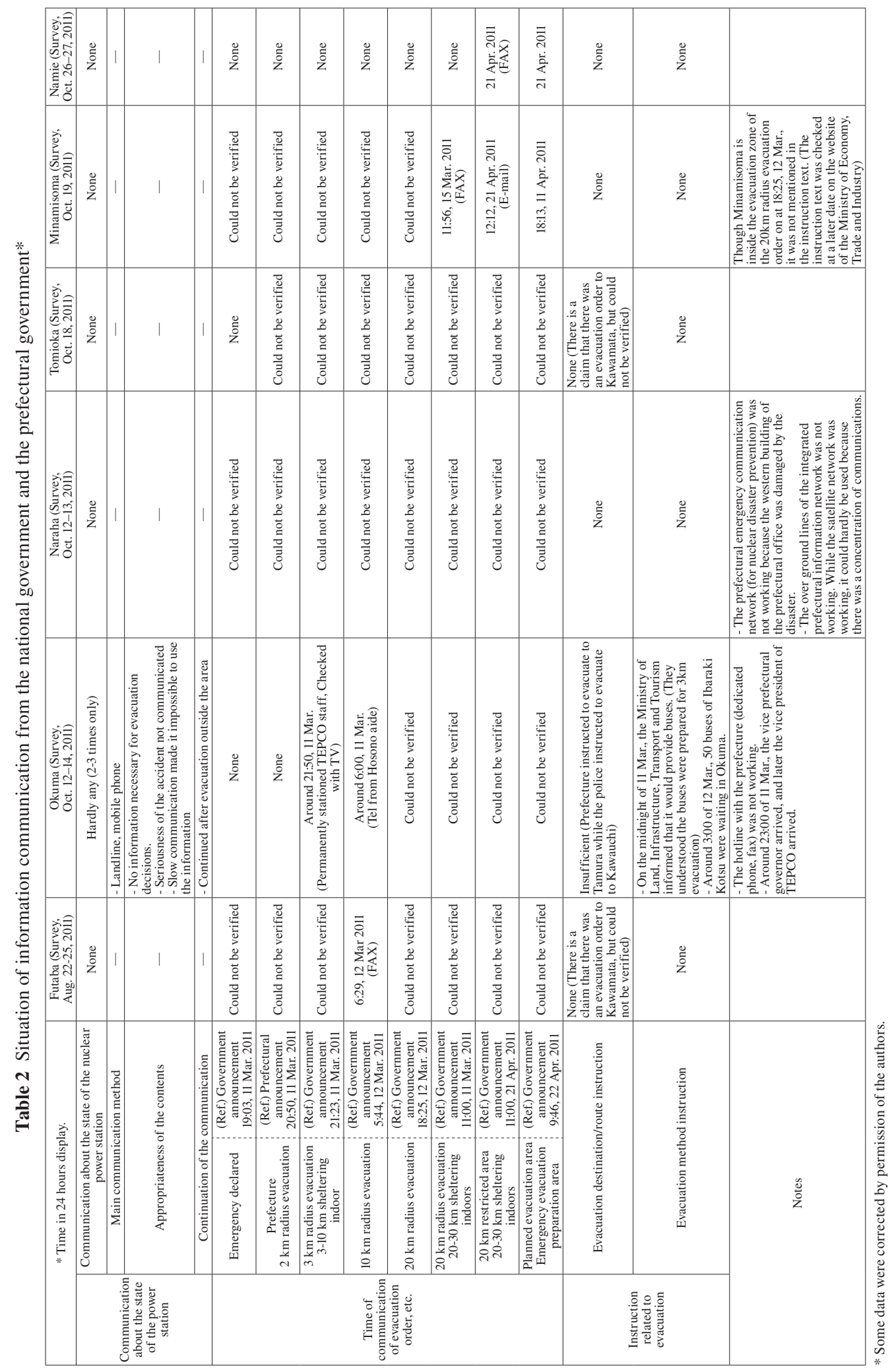


As the evacuation order from the national government or the prefectural government did not reach the local municipalities, residents had to make a decision about the evacuation on the basis of the information sources such as TV. Moreover, they also had to secure the evacuation site or evacuation method on their own. Though some municipalities used buses dispatched from the national government, most municipalities had to secure transport by themselves. However, it was extremely difficult to organize a transport, forcing many residents to use their own cars for the evacuation. The evacuation orders for the residents were spread using the emergency broadcast system installed in the municipalities, advertisement vehicles or patrols by the fire brigade and the municipal staff.

As the nuclear emergency spread, there were cases where people had to evacuate again from the place they were initially evacuated to. Moreover, since information from System for Prediction of Environmental Emergency Dose Information (SPEEDI) was not provided, there were municipalities that established their evacuation site within the high dose area. (See Figure 1).

Response to the people requiring assistance during a disaster or hospital patients was made with cooperation from the local people. For the immediate transportation of patients, the vehicles of the Self Defense Force, ambulance or the police vehicles were used in addition to the measures taken by the hospitals.

After issuing evacuation order within $20 \mathrm{~km}$ radius on March 12, the national government issued an order for those who were remaining within $20 \mathrm{~km}$ radius to take iodine thyroid blocking agent on March 16. However, this order was not precisely communicated to most of the municipalities. As the residents living nearby the power station sites had knowledge about

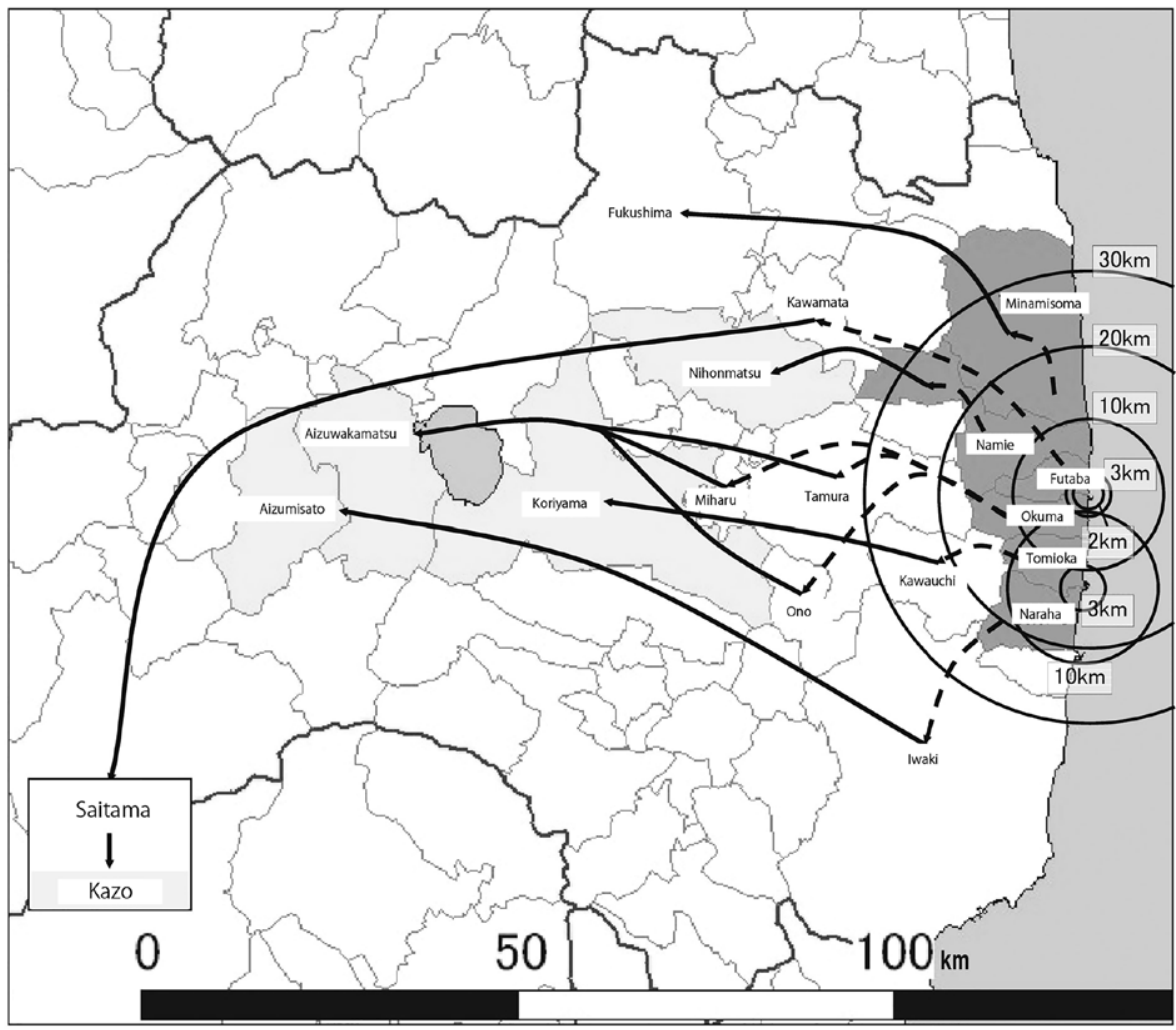

Figure 1 Main evacuation destinations of each municipality 
iodine thyroid blocking agent, and demand for its distribution was increasing in response to the hydrogen explosions at Units 1 and 3 of Fukushima Daiichi Nuclear Power Station, municipalities decided to distribute it on their own.

As it was a compound disaster that went beyond expectation and off-site centers were not functioning, the nuclear emergency response trainings in the past by all the municipalities were completely useless. Moreover, there was no preparation for a situation where the administrative function had to be transferred, which made response to the residents extremely difficult. As the evacuation became long-term and expanded to a wider area, the number of evacuation site also increased greatly and problems such as the inability to station staff at each site has occurred. Furthermore, since the distribution of goods was halted in a large area, the staff of the affected municipalities had to go and pick up the goods by themselves.

\section{Challenge/Problem and the Direction of Measures}

Based on the survey results, the challenges and problems were extracted from the perspective of municipalities and the direction of the measures was examined. Following are the main points.

\section{Information Communication/Public Relation with the Residents}

- There was hardly any information from the national government or the prefectural government, forcing people to depend on information from sources such as TV. In addition, confusion was caused because each organization issued different orders and acted differently.

- A thorough examination of the initial response to this accident should be conducted and a system that allows prompt information communication or ensures information sharing between various disaster prevention organizations should be constructed urgently.

- Due to the blackout or communication failure caused by the large-scale disaster, the communication networks of the national government, prefecture, cities, towns, and the operator was stopped and their functions were lost.

- Urgent strengthening and diversification of the communication networks through the installation of satellite telephone or the utilization of security telephone should be conducted to ensure information communication during a large-scale disaster or a blackout.

- The information provided by the national government or the operator was inappropriate and triggered doubt and distrust among many citizens. In addition, information was insufficient among municipalities and they could not provide enough information to the residents.

- A system where the national government directly dispatches a public relation officer who is responsible for a press release and PR with the residents should be constructed.

\section{Disaster Prevention System}

- There was no information or instruction from the national government and municipality had to make their own decisions. However, small towns and villages did not have staff who were specialized in nuclear emergency.

- The national government and the operator should create a legal framework for 
dispatching staff to the disaster response headquarters of municipalities that can provide necessary information and advice during a nuclear disaster.

- A compound disaster was not expected and nuclear disaster prevention measures did not function effectively.

- The national government should learn lessons from this disaster and urgently prepare a concrete guideline for nuclear disaster prevention plan review. Moreover, municipalities must examine a system that can effectively function during a compound disaster.

- The national government caused confusion by taking disaster responses that are not stipulated by laws such as setting up a joint response headquarters and planned evacuation preparation zone or emergency evacuation preparation zone.

- The national government should urgently examine the initial responses to this accident and fundamentally review the disaster prevention policy and crisis management framework.

- Long-term response in a wider area became inevitable, putting an excessive burden on municipal staff.

- The national government should construct a backup system such as a prompt dispatch of staff and specialists to municipalities.

\section{Off-Site Center}

- The function of the off-site center was lost due to the earthquake, and personnel was not assembled sufficiently. For example, it also did not function later as a base because of the necessity for evacuation.

- The reason why the off-site center did not function at all should be examined, and its structure including the staff assembling system should be reconstructed. Fundamental facility strengthening and securement of alternative facilities such as response to the power loss or dose increase and multiplexing of communication facility should be urgently examined.

\section{SPEEDI}

- The diffusion prediction information of SPEEDI was not provided to the municipalities.

- The reason why SPEEDI was not utilized should be investigated and examined, and the results should be published.

\section{Administrative Function Transfer}

- Transfer of the administrative function was an unexpected situation that was beyond the limit of municipalities' ability to respond, leading to the severe deterioration of municipal function.

- The national government or the prefectural government should construct a system for offering backup to municipalities such as securing the location for administrative function transfer.

\section{Evacuation Road Maintenance}

$\bigcirc$ Instructions from the national government and the prefectural government on evacuation 
destination, method or route were insufficient. They failed to secure buses for the evacuation, forcing many people to evacuate by their own cars. The roads thus became congested, which caused a long delay in the movement of people.

- The national government should take a responsibility to prepare roads that are ready for disasters by taking measures such as creating multiple lanes or removing sudden slope/ curves. Moreover, they should examine the state of traffic regulations and traffic control, and construct a system that enables prompt evacuation during a compound disaster.

\section{Evacuation of Residents}

- The situation required a large-area evacuation that goes beyond the boundaries of municipalities. However, initiatives from the national government and the prefectural government were lacking and no appropriate measures, such as evacuation order and communication of evacuation destination and method, were taken.

- The national government and the prefectural governments should construct a framework that presumes large-area evacuation in advance. Moreover, to protect the local community after the evacuation, it is necessary to devise a system that maintains the connection to the neighborhood.

- As information about radiation diffusion was not provided, some municipalities set up evacuation site within the high dose area.

- The national government and the prefectural governments should urgently construct a system that enables the precise instruction of evacuation destination and route using the monitoring results and diffusion prediction of SPEEDI. An emergency monitoring system, such as the installation of the measurement device or personnel distribution, should be strengthened to promptly obtain a radiation dose in the evacuation destination.

- Following evacuation using private cars, problems such as traffic jam and abandoned cars due to the depletion of fuel and shortage of parking space at the evacuation site occurred.

- A traffic simulation that takes evacuation with private vehicles into consideration should be conducted and a plan for prompt evacuation with private vehicles should be examined.

\section{Transport of Supporting Goods/Management of Evacuation Centers, etc.}

- Stagnated distribution in a large area caused problems with administrative operation and the lives of the residents. Moreover, there were cases where the staff of the affected municipalities had to go and pick up the aid.

- The national government and the prefectural governments should examine the system of transport of supporting goods in advance in order to avoid unnecessary burden on municipalities.

- As the evacuation destinations were widespread, it was not possible to station required staff and was difficult to respond to the needs of the residents. Moreover, the same evacuation site housed residents from several municipalities and therefore it was difficult to obtain the evacuees' information and to respond to an inquiry about safety confirmation of individual person.

- It is desirable to prepare for a nuclear emergency that would affect a large area and construct a support system of dispatching the municipal staff or the staff of the national government. The municipalities also must secure communication methods between 
evacuation sites or to the residents as well as examining the staffing system.

\section{Exposure of Residents}

- The handling of emergency monitoring by the national government, the prefectural government or TEPCO was insufficient, and prompt measurements on internal exposure was also not conducted.

- A whole body counter should be installed at every area around a nuclear power station site. Especially for children who are considered to be vulnerable to radiation, the national government should be responsible for their continuous health research.

\section{Distribution/Taking of Iodine Thyroid Blocking Agent}

- The national government did not give appropriate distribution/ingestion instruction.

- The chain of command/communication of this case should be examined thoroughly and measures should be taken urgently. Moreover, its storage and distribution method should be examined and a system that allows prompt distribution should be constructed.

\section{Conclusions}

Requests to address the issues that should be solved by the national government among the challenges extracted through this survey were sent to relevant ministries. The national government must recognize that unless they respond to these challenges with sincerity, the municipalities with nuclear power stations cannot have hope in local governance.

This survey was conducted only by the municipal staffs. In the course of this survey, the municipalities had to face difficult reality, but they were simultaneously able to examine the new direction of nuclear disaster prevention. There are many issues that require subjective engagement by the municipalities, and the Council is currently examining how to continue the working group this year and reflect its findings on the nuclear disaster prevention plan of each municipality. It cannot be denied that there is a limit to the measures that municipalities as host nuclear power station can take. Still, we are required to urgently devise truly indispensable disaster prevention measures for the local residents. The member municipalities of the Council will further strengthen our solidarity and wholeheartedly engage with the measures to secure safety and comfort of the residents.

\section{References}

1) Report of Nuclear Emergency Examination Working Group (March, 2012). (http://www.zengenkyo.org/houkokusyo/bousaihoukokusyo.pdf) [in Japanese] 


\title{
Present Situation of Radioactivity
}

Distribution

\author{
-Summary of Initial Activity Situation-

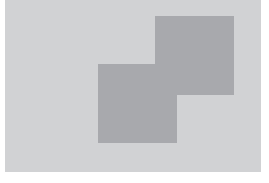 \\ Tohoku University, Takashi Nakamura \\ Japan Atomic Energy Agency, Takuma Momose \\ Nagoya University, Tetsuo Iguchi
}

\begin{abstract}
This paper outlines the issues discovered during the initial activities related to the monitoring of radioactive contamination during the Fukushima Daiichi Nuclear Power Plant Accident, individual exposure dose assessment, the radiation measurement in the environment by general public, as well as their future prospects.
\end{abstract}

\section{Radioactivity Distribution}

After the Fukushima Daiichi Nuclear Power Plant Accident, airborne surveys, radiation dose measurements, and sampling/analysis of soil were conducted to understand the contamination level of the soil. The items that were measured, analyzed, and assessed have been published in sequence by the Ministry of Education, Culture, Sports, Science and Technology (MEXT). As a part of this activity, an examination committee for producing the radiation dose distribution map was established at the MEXT in late May 2011. This committee held 10 meetings by September 30, 2011. They worked with over 400 collaborators from more than 90 organizations, including universities and research institutes, to conduct the following measurements twice from June 6 to June 13 and from June 27 to July 8.

(1) Conduct a survey of environmental dose rate using a vehicle called KURAMA developed by Kyoto University.

(2) Select a spot at every $2 \mathrm{~km}$ within $80 \mathrm{~km}$ radius of Fukushima Daiichi Nuclear Power Plant and at every $10 \mathrm{~km}$ within $80-100 \mathrm{~km}$ radius and the rest of Fukushima Prefecture. On each spot, collect five soil samples from a depth of $5 \mathrm{~cm}$ within the $3 \mathrm{~m} \times 3 \mathrm{~m}$ area. Measure the radioactive concentration by the nuclide of each sample using a Ge detector.

(3) Use a scintillation survey meter to measure the environmental dose rates of the spots where soil samples were collected.

(4) Conduct related research on the depth-direction radioactive materials distribution in the soil, study of the migration of radioactive materials accumulated on the soil surface, and the study of radioactive material in the rivers and ground water.

On August 2 and 12, the results of the airborne survey, the vehicle-borne survey, and the

DOI : $10.15669 /$ fukushimainsights.Vol.1.248

(C) 2021 Atomic Energy Society of Japan. All rights reserved.

Originally published in Journal of the Atomic Energy Society of Japan (ISSN 1882-2606), Vol. 54, No. 11, p. 743-746

(2012) in Japanese. (Japanese version accepted: August 17, 2012) 
fixed-point measurement were published first as a distribution map of environmental dose rate. On August 29, the soil concentration distribution maps of Cs-134 and Cs-137 and the result of in situ measurement with Ge detector were published. On September 13, the result of migration of cesium in forests was published. Following these, the soil concentration distribution map of I-131 was published on September 21. On September 30, the soil concentration maps of Sr-89, Sr-90, Pu-238, and Pu 239+240 were published. The distribution maps of other rare radioactive nuclides and the research result of migration to rivers and other waters are scheduled to be published in the future.

Due to limited space, we will only include one example from these published data. Figure 1 shows the soil concentration distribution map of Cs-137 (published on August 30, 2011). These results reveal that both the environmental dose rate measurements and the soil concentration distribution map of Cs-137 show the highest value in the northwestern direction from the nuclear power plant; higher values are observed toward the Nakadori region of Fukushima Prefecture. The general tendency of this distribution corresponds well with the result of the airborne survey. Moreover, it became clear that there is strong correlation between the environmental dose rate of each spot and the soil concentration distribution of Cs- 137 . This distribution map also corresponds well with the result of SPEEDI calculation and clearly shows that the distribution was dominated by the weather condition at that time. Thus, it is a highly valuable data for understanding the current soil contamination situation and devising the future environmental recovery; it is desirable to conduct a continuous monitoring in a wider area.

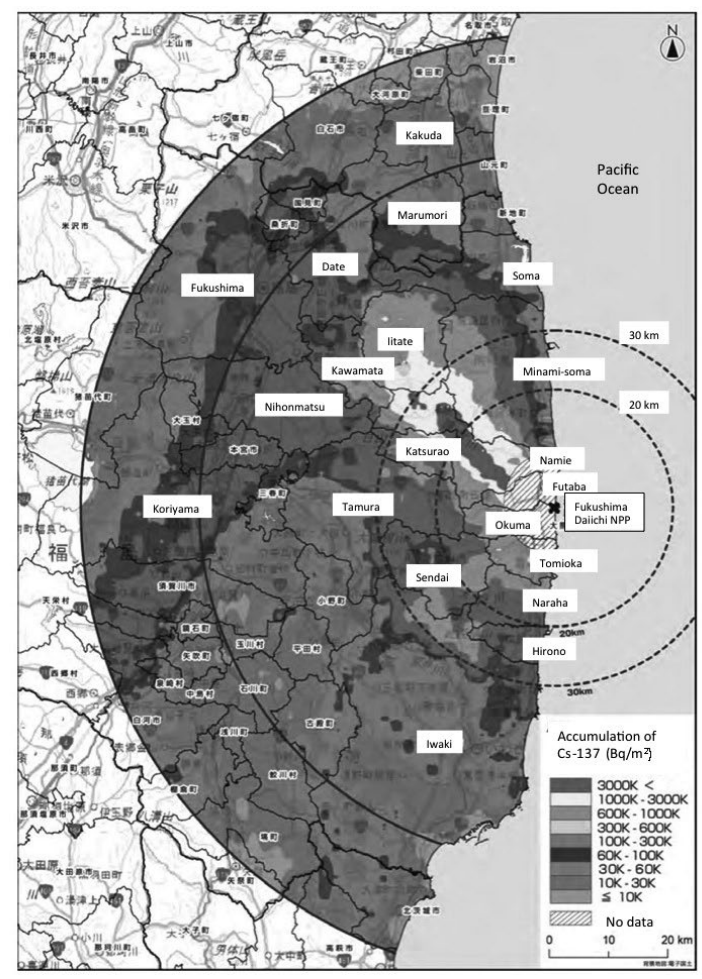

Figure 1 Soil concentration map of Cs-137 (http://radioactivity.mext.go.jp/old/ja/1910/2011/09/1910_0912. pdf (Appendix 4) 


\section{Individual Monitoring of Workers and Residents}

\section{Individual Monitoring of Workers}

The workers in the premises of Fukushima Daiichi Nuclear Power Plant were conducting their emergency work under a severe working environment with radiation during the early stage of the accident. The observed maximum environmental dose rate reached $12 \mathrm{mSv} / \mathrm{h}$ (March 15, 2011), and it became necessary for the workers to wear a mask not only outside but also inside the building for protection against internal exposure. Moreover, female workers who stayed in the important anti-seismic building and other buildings suffered from internal exposure by radioactive iodine and other materials and their exposures exceeded the dose limit for women. In addition, flooding by the tsunami made many individual dosimeters (APD) and its reading system unusable, causing the shortage of individual dosimeters. The wholebody counter (WBC) installed inside the power plant became unusable due to the increase in background and defects. Under such a circumstance, external exposure dose was initially measured using a method wherein each work group shares one dosimeter. After April, the necessary number of individual dosimeters was secured. For measuring internal exposure dose, the onboard WBC of Japan Atomic Energy Agency (JAEA) dispatched to Onahama was used. The workers whose internal exposure rate may have exceeded $20 \mathrm{mSv}$ according to this test underwent a measurement using the precision-type external measurement device with Ge semiconductor detector inside the 20 -cm-thick iron shield installed in the radiation infirmary of the nuclear fuel cycle engineering laboratory of JAEA.

The distribution of the effective dose, which is the sum of the external exposure and internal exposure of the workers engaged in the emergency work, has been published by Tokyo Electric Power Company. According to this, six workers exceeded the dose limit of $250 \mathrm{mSv}$ for an emergency work by late March and the maximum effective dose was $678 \mathrm{mSv}(88 \mathrm{mSv}$ for external exposure and $590 \mathrm{mSv}$ for internal exposure). The main cause of the exposure that exceeded the limit dose was internal exposure by radioactive iodine. The exposure management of the workers was strengthened after April, and there has not been any case wherein the exposure exceeded $50 \mathrm{mSv}$ since May.

\section{Individual Monitoring of Residents}

As a part of health management survey of Fukushima Prefecture, the activity survey of every prefectural resident after the earthquake is ongoing. Based on the result of this survey, external exposure dose assessment of each resident, considering the time course of the environmental dose rate due to $\gamma$ ray, differences in position and the shielding effect of buildings into consideration, will be conducted. Moreover, in some areas, individual dosimeters are given to school children to measure their individual external exposure doses in their living environment.

The residents within the restricted area or the deliberate evacuation area may have been significantly exposed to internal exposure mainly due to inhalation of radioactive materials in plume during the early stage of the accident. If there is a result of continuous monitoring of radioactive material concentration in the atmosphere, the internal exposure situation of the area by calculating the environmental dose rate. However, due to the blackout caused by the earthquake, monitoring data of radioactive material concentration in the atmosphere in the area around the nuclear power plant is scarce. Although there are measurement results of iodine or dust samples conducted around the power plant from March 12 to March 15 by the 
environmental monitoring team dispatched by the national government to the off-site center during the early stage of the accident, these data are not continuously monitored and because they have shortcomings such as the limited measurement points and period, they are difficult to apply to internal exposure dose assessment of the residents.

Examples of continuous monitoring include the continuous dust monitoring conducted form March 13 by the Nuclear Fuel Cycle Engineering Laboratory in Tokai village, Ibaraki Prefecture. Table 1 shows the actual measurement data of the radioactive material concentration data in the air by each nuclide. Based on this result, the internal exposure dose from March 13 to May 23 in the measurement point (outside) was assessed using the inhalation rate of general public. The result showed that the effective dose of an adult was $0.57 \mathrm{mSv}$ and the thyroid equivalent dose of a small child (one year old) was $15 \mathrm{mSv}$.

A study on internal exposure dose by Cs-134 and Cs-137 using WBC was conducted from July to late August by the National Institute of Radiological Sciences and JAEA for about 3,300 residents of Namie, Iitate, and Yamakiya areas of Kawamata. The measurement has continued since September by JAEA and other organizations for residents in seven municipalities of Futaba District. In all the measurements, numerical results that would affect health were not detected. A plan to organize WBC and start measurement in order at other areas of Fukushima Prefecture is being prepared. The result of the tests with WBC is planned to be registered in the health management survey database of Fukushima Prefecture.

Table 1 Concentration of radioactive materials in the atmosphere in Tokai, Ibaraki Prefecture

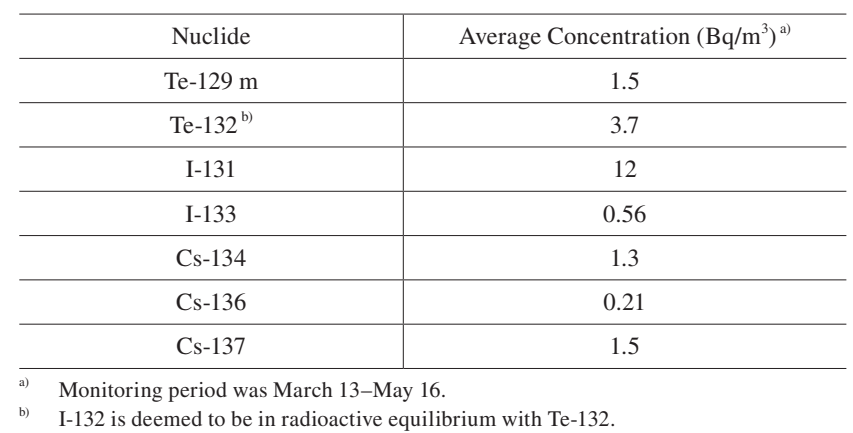

\section{Future Prospect}

For the reconstruction of the dose of residents, it is difficult to assess the internal exposure by materials, such as radioactive iodine, during the early stage of the accident. During late March this year, the pediatric thyroid examination was conducted on 1,080 children from Iwaki and other places. Its result showed that every child exhibited a screening level of thyroid equivalent dose $\leq 100 \mathrm{mSv}$. Thus, the contribution of internal exposure dose, including inhalation during the evacuation, is smaller compared to the external exposure dose from, for instance, the $\gamma$ ray of Cs-137 that deposited on the ground. However, sufficient evidence-based data is not available for proving this prediction. When focusing on the I-131/Cs-137 ratio of deposited dust within $30 \mathrm{~km}$ radius, while it was $0.31-5.83$ in the north to southwest direction, including the area around Iitate where the amount of radioactive material deposition was high, the ratio of I-131 was comparatively large at 13-26.5 in the south to southwest direction, where the amount of radioactive material deposition was relatively low. As can be seen in this case, the fact that I-131/Cs-137 ratio can be different depending on the direction or time also needs to be considered. When the detail of the concentration distribution on radioactive 
material in the atmosphere becomes clear in future via comparison with the vast environmental monitoring data and the calculation result of atmospheric distribution simulation of radioactive material using, for instance, SPEEDI, it is expected that the actual measurement of Cs-137 and other materials by WBC will be used as an individual index for assessing the internal exposure dose of inhalation of nuclides such as radioactive iodine.

\section{Points of Caution for Radiation Measurement}

\section{Introduction}

As the extent of release of large quantity of radioactive materials into the environment and their diffusion into a large area after the Fukushima Daiichi Nuclear Power Plant Accident became clearer, interests and concerns for radiation around us, for instance, in our living environment, food, drinks and everyday goods, are increasing. Currently, the MEXT and the Ministry of the Environment are leading the governmental initiative to gain a detailed understanding of radioactive contamination based on actual measurements. Meanwhile, people who are not specialized in radiation measurement are willing to post their measurements on websites and blogs or identify the spots with high dose rate and share the information with each other to actively take precautionary measures. To correctly understand these radiations around oneself as seen in these example (including the natural radiation that existed before the accident) will lead to in-depth understanding of various radiation risks and measures to reduce them. Therefore, we believe that the Atomic Energy Society of Japan should aggressively promote and support these movements.

However, measurement of radiation, particularly quantitative evaluation of exposure dose to human body or the radioactive concentration in articles, is one of the most difficult techniques among the measurement of various physical quantities (e.g. time, length, and weight). A variety of miscellaneous radiation measuring instruments are available on the market. However, to make effective use of the activities of radiation measurement of daily activities by general public, it is strongly desirable that they understand the characteristics specific to each measuring instrument and measured values, and the characteristics of radiation in the environment and target actually being measured.

Here, we will focus on the measurements of "environmental dose rate," "surface contamination of human body/articles," and "radioactivity concentration in food/drink" that are with high concern among the public. The discussion will be conducted from the following perspectives: (1) What does the instrument measure? (2) How to convert the measured data to dose rates or radioactivity concentrations. (3) To what extent do the measured results vary? From these three perspectives, we will present an overview of the points of consideration in the radiation measurement for the general public.

\section{What does the Instrument Measure?}

Almost all current radioactive materials in the environment originated from the Fukushima Daiichi Nuclear Power Plant Accident can be radioactive Cs (Cs-134 and Cs-137). From these radioactive Cs, $\gamma$ ray (photon) and $\beta$ ray (electron) are emitted. When they collide with materials, electric charge or light is produced. Radiation measuring instruments use gas, such as air or noble gases, or solid matter, such as transparent inorganic fluorescent materials or semiconductors, as sensing materials. For instance, common small radiation survey meter 
types often used for relatively low environmental dose rate in the surrounding area outside Fukushima Prefecture include Geiger-Mueller (GM) counter tube of the former type and scintillation detector of the latter type.

In the GM counter tube type, the electric charge generated in the filled gas per one radioactive substance that entered the counting tube is amplified by the discharge phenomenon to generate a pulse current (or voltage) of a substantially constant magnitude. Thus, by counting the number of current pulses, the intensity of the radiation can be measured. Meanwhile, the scintillation type normally combines material that generates fluorescence when hit by radiation, such as $\mathrm{NaI}(\mathrm{Tl})$ or $\mathrm{CsI}(\mathrm{Tl})$ crystals (scintillator), with photomultiplier tube or photodiode that converts light to electric current. As the intensity of fluorescence light or the magnitude of current pulse is almost proportional to the radiation energy absorbed by the scintillator, energy information can be measured together with the strength of radiation. By multiplying the electric signals obtained from these radiation measuring instruments with conversion factors based on calibration experiment or theoretical calculation, the radioactivity expressed in units of Becquerel (Bq) (the number of radioactive substance released per second) or Sievert ( $\mathrm{Sv}$ ) (equivalent or effective) dose (in the case of $\gamma$ rays and $\beta$ rays, equivalent to the amount of energy absorbed per $\mathrm{kg}$ of human body tissue) are obtained.

\section{Correct Measurement Method with Radiation Survey Meter}

First, the small radiation survey meters available on the market are electronic product that can be easily influenced by the surrounding although they are generally robust and easy to use. Thus, it is the most basic precondition to follow the instructions on the temperature, humidity, air pressure, vibration, shock, and electromagnetic induction, during measurement written in the manual. Moreover, it is extremely important to use a meter with an understanding of its basic performance as a radiation meter to achieve a correct interpretation of the measurement results. Here, we will discuss the main points of caution of small radiation survey meters available on the market from the perspective of detection sensitivity, energy dependency, and directional dependency.

\section{(1) Detection Sensitivity}

The minimum detection limit of hourly environmental dose rate with a small radiation survey meter available on the market is $\sim 0.1 \mu \mathrm{Sv} / \mathrm{h}$ with the GM counter type and $\sim 0.01 \mu \mathrm{Sv} / \mathrm{h}$ with the scintillation. Thus, it is desirable to choose the scintillation type to correctly measure the low dose rate in a normal environment. However, as discussed in section III-2, a high-precision standard radiation source and calibration under a strict measurement condition are required to convert the pulse counting rate (count/second) of the electric signal from the radiation measuring instrument outputs into dose rate $(\mu \mathrm{Sv} / \mathrm{h})$. A correct dose rate can only be obtained when the measurement is conducted under the same condition as that of the calibration. Moreover, the pulse counting rate that is equivalent to the minimum measurement limit is in the order of $\sim 0.1 \mathrm{cps}$. Unless a sufficient measurement time is given, the measurement result essentially exhibits variation. Considering this minimum measurement limit, it is extremely difficult to measure the weak radioactivity that is equivalent to the radioactive Cs in the regulatory limit $(\sim 100 \mathrm{~Bq} / \mathrm{kg})$ contained in food with a common radiation survey meter.

\section{(2) Energy Dependency}

Although to measure dose rate accurately, it is desirable for the energy dependency (detector response) of the detection efficiency to be equivalent to the energy dependency of $1 \mathrm{~cm}$ 
dose equivalent (exposure dose under $1 \mathrm{~cm}$ of skin), there is often a deviation. Among scintillation-type survey meters that can measure radiation energy, there is a model (energy-compensation type) that compensates the deviation by weighting the energy discrimination measurement. However, for the relatively inexpensive and small GM counter-type and scintillation-type survey meter, energy compensation is not performed, even though they devise means for compensation such as physically attaching a filter (cover). Thus, they have a tendency to improve the detection efficiency of $\gamma$ ray whose Cs-137 $\gamma$ ray energy is $\sim \leq 0.66 \mathrm{MeV}$. This means that even if it is calibrated by a Cs-137 $\gamma$ ray source, it can easily show higher measurement values when low energy $\gamma$ ray, which are scatter components, exist in a large amount in the environment.

\section{(3) Directional Dependency}

The directional dependency of the detection efficiency of radiation survey meter depends on the shape of the sensitivity area. Because the GM counter type is rod shaped, its detection efficiency is low at front and back and high on the sides. Moreover, the directional characteristic of the scintillation type is relatively isotropic. However, the detection efficiency of the direction where photoelectric conversion device is located tends to be lowered by $\sim 20 \%$. Thus, to conduct dose measurement accurately, it is necessary to always measure from the same direction and facing the same side of the measurement object as the calibration.

\section{(4) Statistical Properties of Counts from Radiation Measuring Instrument}

The counts from radiation measuring instrument have an essentially fluctuating property (the variation of the counts follow Poisson distribution or normal distribution). When the count value is $N$ counts, its fluctuation index, standard deviation $\sigma$, is known to be $\sqrt{N}$. Thus, the lower the sensitivity of the meter or the lower the dose being measured, the greater the fluctuation becomes. For instance, with a small GM counter-type survey meter available on the market, the detection sensitivity is $\sim 10$ counts per minute measurement for $\sim 0.1 \mu \mathrm{Sv} / \mathrm{h}$ environmental dose rate. Therefore, the fluctuation of the relative standard deviation $\sim \pm 30 \%$ $(10 \pm \sqrt{10}$ count) is expected. Note that the "Radioactive concentration measurement methods guideline" by the Ministry of Environment encourages to use three times the standard deviation of the average of multiple dose measurements as the index for the fluctuation.

\section{(5) Other Points of Caution}

When measuring the radiation dose of environment or goods with a small radiation survey meter available on the market, it is important to consider the presence of time variation of naturally existing radiation originating from the location or weather in addition to the indicated value originating from the characteristics of the meter itself. Among the natural radiation, the radiation coming from space has small influence on a small radiation survey meter because it has high energy and is difficult to detect. Meanwhile, for instance, $30 \mathrm{~Bq}$ of K-40 (half-life 1.25 billion years), which is an isotope of potassium (a necessary element for human body), is contained in $1 \mathrm{~g}$ of natural potassium, and it is widely distributed in soil or food. Moreover, if there is granite or other such material, the contribution of dose of thorium, uranium, or radioactive nuclide of their group (for instance, radioactive gas $\mathrm{Rn}-222$ released in the atmosphere and its daughter nuclides) contained in it cannot be ignored. Indeed in Japan, maximum 30\% fluctuation range due to the location or weather of natural radiation for about $\sim 0.1 \mu \mathrm{Sv} / \mathrm{h}$ environmental dose rate is expected.

Moreover, "time constant" is used as the standard for the response time of the meter in a radiation survey meter. Generally, unless the indicated value of dose rate is read after a time period of a few times the time constant has elapsed, underestimation or some deviation in the 
detection location of hotspot would occur.

In addition, when measuring the radioactive Cs of soil surface or goods surface using, for instance, a GM counter-type survey meter that possess sensitivity for both $\gamma$ ray and $\beta$ ray, because the sensitivity for $\beta$ ray is nearly two orders of magnitude higher than for $\gamma$ ray, a wrong dose rate value that is extremely high will be indicated unless the measurement is conducted shielding $\beta$ ray.

\section{General References}

1) Prime Minister's official residence. On the monitoring data of radiation. http://www.kantei.go.jp/ saigai/monitoring/index.html. [in Japanese]

2) JAEA-Review 2011-035. Special environmental radiation monitoring result related to the Fukushima Daiichi nuclear power station accident. [in Japanese]

3) Ministry of the Environment. Guideline relevant to waste material The fifth part Guidelines for method of measurement of radioactive concentration. 2011 December. http://www.env.go.jp/jishin/rmp/ attach/haikibutsu-gl 05_ver1.pdf (This link was not found as of July 26, 2017). [in Japanese] 


\title{
Application of Reference Levels in the Existing Exposure Situations
}

-Towards Stepwise Reduction of Radiation Dose Depending on Situations of Contamination-

\author{
Dependi \\ Central Research Institute of Electric Power Industry \\ Haruyuki Ogino, Nobuyuki Hamada and Daisuke Sugiyama
}

\begin{abstract}
Optimizing protection against radiation on the reference levels is important to restore the contaminated areas after an accident. Various steps, which are decided based on the contamination status, have to be performed to achieve normality by considering the balance between the health risks of radiation and the societal and economic effects. This study discusses the idea of reference levels that has been introduced by the International Commission on Radiological Protection (ICRP). Further, we will discuss three measures that have been introduced after the Fukushima Daiichi Nuclear Accident, namely the decontamination screening levels, provisional regulation values and new standard values of food, and target values for the management of radioactive contaminated substances, and consider the application of intermediate reference levels in phases.
\end{abstract}

\section{Concept of Protection against Low-Dose Radiation}

After the Fukushima Daiichi Nuclear Power Plant Accident, there were concerns and fears related to the effect of low-dose radiation on health and the concept of protection against radiation such as "why were the protection standards different after an accident?" and "given the fact that new standards were introduced for food, were the old standards dangerous?"

There is a considerable amount of scientific knowledge related to the human health effect of high-dose radiation. However, debates are observed to persist at an international level over the human health effect of low-dose radiation below $100 \mathrm{mSv}$. This is because of the difficulty in distinguishing the effect of radiation from the effect of other factors. There is some knowledge with regard to the range of effects of low-dose radiation. However, the impression that enough scientific knowledge is not known has led some people to consider the unknown to be dangerous, further increasing the fear among the public.

The International Commission on Radiological Protection (hereafter, the ICRP) maintains that, from the viewpoint of protection against radiation, even low-dose radiation is assumed to exhibit effects according to the dose and that actions should be taken to reduce the exposure

DOI : 10.15669/fukushimainsights.Vol.1.256

(C) 2021 Atomic Energy Society of Japan. All rights reserved.

Originally published in Journal of the Atomic Energy Society of Japan (ISSN 1882-2606), Vol. 55, No. 2, p. 106-110 (2013)

in Japanese. (Japanese version accepted: December 10, 2012) 
as low as reasonably achievable, economic and societal factors being taken into account. Due to this, there are different threshold values that separate "safe" and "dangerous" from tissue reactions (deterministic effects) such as skin erythema; further, there is no threshold for the probabilistic effects such as cancer. Therefore, reference levels have been introduced as restrictions to serve as countermeasures to reduce exposure.

Strict application of the standards (dose limit) after an accident, which are set for normal conditions, can cause massive evacuations and confusion during daily activities, which could affect the society and the economy. Therefore, ICRP introduced the basic concept of protection against radiation, which ensures balance with the health impact of radiation by temporarily increasing the allowed dose from the normal value to a "reference level" with an annual effective dose of $100 \mathrm{mSv}$ or less through which normality can be achieved in phases.

On July 19, 2011, the Nuclear Safety Commission (NSC), Japan decided that it was appropriate to apply the concept of reference levels that was introduced by ICRP in $2007^{1)}$ to serve as radiation protection as part of restoration. In future, it will be important to deepen our knowledge with regard to the reference levels and to reduce the exposure to restore the contaminated areas.

This study will examine the advice given by ICRP in $2007^{1)}$ with regard to reexamining the principles and rules of protection against radiation and will discuss the concept of reference levels. This study will also discuss three examples of measures that are introduced after the Fukushima Daiichi Nuclear Power Plant Accident, including the decontamination screening levels, provisional regulation values and new standard values of food, and target values for radioactive contaminated substances; further, this study will consider the application of intermediate reference levels in phases. In addition, you may refer to the lecture series of this journal that was released in 2010, "ICRP's new recommendation - new concepts and standards for protection against radiation" (8 installments), for the ICRP 2007 Recommendations ${ }^{1)}$.

\section{Principles and Rules of Protection against Radiation}

\section{Approach for the Radiation Sources}

Before the ICRP 2007 Recommendations ${ }^{1)}$, the ICRP 1990 Recommendations ${ }^{2)}$ stated that the contribution of a radiation source (explained in the subsequent chapter) is not related to that of other sources when an individual dose is sufficiently lower than the threshold value that is observed in case of deterministic effects. An individual can be exposed to multiple sources; however, to ensure protection against radiation, it should be possible to independently treat each source or source group, which will ensure that all the individuals who are potentially exposed by sources or source groups are considered. This procedure can be referred to as the "source-related approach," and the ICRP 2007 Recommendations ${ }^{1)}$ emphasized that this approach was the most important in terms of protection. Even though the source-related approach may not provide sufficient protection in case of multiple radiation sources, we observe that there is a dominant source in majority of the situations; therefore, an appropriate selection of the reference level will guarantee an appropriate level of protection.

\section{Definition of the Radiation Source}

While using the source-related approach, it is necessary to define the radiation source. In the ICRP 2007 Recommendations ${ }^{1)}$, examples of radiation sources included single physical 
sources (e.g., radioactive material and X-ray devices), facilities (e.g., hospitals, nuclear power plants), and physical sources with methods or similar characteristics (nuclear medical methods, backgrounds, or environmental radiation). If a facility emitted radioactive materials into the environment, the entire facility was considered to be a single radiation source. If radioactive materials were already scattered in the environment, partial collection of radioactive materials would be considered to be a radiation source. In addition, the definition of a radiation source was generally assumed to be associated with the selection of an appropriate protection strategy; therefore, a radiation source can be defined during the process of establishing countermeasures.

\section{Exposure Situations}

The ICRP 1990 Recommendations ${ }^{2)}$ adopted protection methods based on practice (human activity that increased individual exposure and the number of people who were exposed) and intervention (human activity for reducing the overall exposure). This concept was further developed in the ICRP 2007 Recommendations ${ }^{1)}$, and protection methods were adopted for three exposure situations (planned exposure situations, emergency exposure situations, and existing exposure situations). The definition of each exposure situation is given below.

A planned exposure situation involves intentional introduction and operation of radiation sources. This can cause expected exposure (normal exposure) as well as unexpected exposure (potential exposure).

An emergency exposure situation requires emergency countermeasures to avoid or minimize the effect of situations that are caused while operating planned activities; these situations may range from malicious intent to other unexpected situations.

An existing exposure situation is a situation that already exists when a decision on control has to be taken. A long-term exposure after the occurrence of emergencies is included in this situation.

\section{Principles of Protection Against Radiation}

The source-related principles, which are applied to all the exposure situations, include the justification and optimization of protection. The individual-related principles, which are applied in case of planned exposure situations, include the dose limit. The definition of each principle is given below.

Justification: Any decision that affects the radiation exposure situation will ensure that the advantage is greater than the disadvantage. By adding new radiation sources, reducing the existing exposure, and reducing the risk of latent exposure, individual or societal advantages that cancel out the damage caused by such risks will be observed.

Optimization of protection: The possibility of exposure, number of exposed individuals, and individual dose for such individuals should be kept as low as reasonably achievable, economic, and societal factors being taken into account.

The level of protection should be optimal under the general conditions; further, the extent to which the advantage exceeds the disadvantage must be maximized. To avoid the occurrence of unfair results using the optimization method, the dose constraint, the risk constraint, and the reference level should be set to restrict the doses from and the risks of specific radiation sources.

Dose restrictions: In planned exposure situations, except for medical-related exposures in case of patients, the total individual dose from any regulated source must not exceed the dose limit that is specified by ICRP. 


\section{Dose Limit and Reference Level}

To provide protection against radiation for the general public in planned exposure situations, individual exposure has been managed to ensure that the effective dose does not exceed $1 \mathrm{mSv}$ per year, except the natural radiation and medical exposures. To ensure that the general public is protected against the radiation under existing exposure situations, it is recommended that the reference level should be set to approximately 1-20 mSv per year; further, optimized protection should be implemented. Thus, we can infer that $1 \mathrm{mSv}$ per year can be considered to be the limit of individual exposure in planned exposure situations as well as the lower bound of the source-related reference level in the existing exposure situations.

What level of risk does the exposure to $1 \mathrm{mSv}$ per year exhibit? According to the ICRP 1990 Recommendations $^{2)}$, there were at least two objectives behind setting the dose limit at $1 \mathrm{mSv}$ per year. The first was the decision from the radiation risk estimation model that was based on the epidemiological studies that were conducted with the help of the survivors from the nuclear attacks at Hiroshima and Nagasaki. Using the multiplicative risk model (assuming that an increase in the ratio of the mortality rate due to radiation to the natural mortality rate continues for a lifetime) and by assuming that the dose and dose-rate effectiveness factor (determined using a decision for which the biological effect per unit dose at low doses and a low dose-rate is lower than that in high doses and a high dose-rate) is 2,75 years of exposure at $1 \mathrm{mSv}$ per year would result in the death of 95 out of 1 million people (not exceeding $10^{-4}$ ). The second objective was that the decision was made based on the range of variation in the natural background radiation. Except in the case of exposure to radon, which is easy to change, the dose from the natural background radiation is approximately $1 \mathrm{mSv}$ per year, and elevated areas exhibit doses that are more than twice this value.

Thus, the value of $1 \mathrm{mSv}$ per year has been chosen as the public dose limit in case of planned exposure situations after considering the radiation risk estimation models and the natural background radiation levels from various angles. The public dose is managed so that it is within the dose limit that is set by certain considerations; further, it is important to understand that the dose limit is not set as an indicator for safety and danger.

Once a nuclear accident or a radiation emergency occurs, the environment in which the radiation sources exist, which are assumed to ensure radiation risk management, changes. The characteristics of protection also change, and matters ranging from the deterministic effects on human health to effects on quality of life will be handled. Such situations that require emergency measures or emergency exposure situations lead to decisions that differ from regular decisions in which the dose limit is not applied; thus, the concept of a reference level emerges.

As time passes after the occurrence of a nuclear accident or a radiation emergency, the radiation measurements are performed by various bodies; further, the knowledge of the environment in which the radiation source exists is collected. Later, an existing exposure situation is observed in which long-term coexistence of manageable radiation sources and humans are taken into consideration. In an existing exposure situation, the dose limits are not applied; further, the objective is to ensure the optimization of protection against radiation based on the reference levels. To implement optimization, which is to keep the exposure as low as reasonably achievable, economic and societal factors being taken into account, the lessons learned from the Chernobyl Accident ${ }^{3)}$ indicate the importance of making decisions based on the inputs of the residents and the autonomous activities in individual living environments. 


\section{Discussion on the Application of Reference Levels}

Implementing the optimization principle is a source-related process, and an optimal protection strategy is selected for the given prevailing circumstances; further, the difference between advantage and disadvantage should be maximized. ICRP recommends that the reference level in the existing exposure situations should be $1-20 \mathrm{mSv}$ per year ${ }^{1)}$. The recommendations also indicate that the long-term objective of an existing exposure situation is to restore the dose level back to normal or equivalent to the normal level; as such, the reference level should be in the lower part of the $1-20 \mathrm{mSv}$ per year range ${ }^{3)}$. ICRP also recommends that the governmental regulatory agencies should consider the given prevailing circumstances, use the timing of restoration planning, and apply an intermediate reference level to improve the situation in phases. Based on experience, the representative value to restrict the optimization process in the long-term period after an accident is $1 \mathrm{mSv}$ per year. Here, $1 \mathrm{mSv}$ per year should be considered as the lower bound of the reference level for radiation sources in existing exposure situations in such a context.

The optimization process is to be applied to situations in which the protection strategy is justified; further, it requires judgments, which demand transparency. To make decisions based on sufficient explanations, transparency requires that all the related information should also be provided to stakeholders and that the traceability of the decision-making process should be appropriately documented.

The following is a discussion on the three examples of measures that are introduced after the Fukushima Daiichi Nuclear Power Plant Accident, such as the decontamination screening levels, provisional regulation values and new standard values of food, and target values for management of radioactive contaminated substances; further, we consider the application of intermediate reference levels in phases.

\section{Decontamination Screening Levels}

In case of regular radiation management, humans are observed to vacate the managed areas. When materials are to be taken out, the density of radioactive materials on the surface of the body or the materials must be lower than 1/10th of the surface density limit (i.e., $4 \mathrm{~Bq} / \mathrm{cm}^{2}$ for alpha-ray-emitting radionuclides and $40 \mathrm{~Bq} / \mathrm{cm}^{2}$ for non-alpha-ray-emitting radionuclides). At a site under regular radiation management, when significant contamination is detected, it is a general practice to decontaminate a reasonable area near the location and to eliminate the concerned material even while conforming to the standards that are defined in regulations such as the Radiation Hazard Protection Act.

However, the accident simultaneously contaminated humans and materials over a wide range of areas. Furthermore, decontaminating every person was impossible due to water shortages and blackouts after the disaster in Japan; additionally, the low temperatures made it difficult to remove clothes. In such a situation, it was not realistic to strictly apply the regular standards. It became necessary to use a scientific standard to classify individuals and materials based on their priorities for decontamination. This requires screening (sorting). Based on the perspective of emergency medical exposure, the screening level in Fukushima was set to $40 \mathrm{~Bq} / \mathrm{cm}^{2}$ (equivalent to $13,000 \mathrm{cpm}$ (counts per minute) measured by a GM survey meter, a general radiation meter). Given the aforementioned situation, the screening level was set to $100,000 \mathrm{cpm}$, which was the maximum reading of a GM survey meter, after March 14, 2011. $\mathrm{Cpm}$ is the number of measurements of the radiation meter per minute.

The authors assessed the whole-body effective dose and local skin absorbed dose ${ }^{4)}$ by 
assuming a case in which surface contamination of $100,000 \mathrm{cpm}$ was observed on a material and in which a similar amount of contamination was directly deposited on the skin. The results exhibited that the whole-body effective dose from the material was below $1 \mathrm{mSv}$ per year, which was the lower limit of source-related reference level, and that the local skin-absorbed dose was also lower than $1 \mathrm{mGy}$ per hour. By considering a realistic exposure time, the skin was observed to be protected from deterministic effects such as hair loss and ulcers (threshold is of the Gy order) ${ }^{4)}$.

On August 29, 2011, the NSC recommended that the screening levels should be reduced in phases to prevent further expansion of contamination by radioactive materials outside the evacuation areas (restricted areas). Based on this advice, the director-general of the Local Nuclear Emergency Response Headquarters set 13,000 cpm as the new screening level after September 16, 2011. In future, it will be important to consider the progress of the monitoring results and to flux in and out of evacuation areas (restricted area), to consider the connectivity with the regular standards, and to continue the efforts to reduce the screening levels in phases.

\section{Provisional Regulation Values and New Standard Values for Food}

The regulation of food contaminated by radioactive materials is important to reduce internal exposure. The NSC had set indicators before the accident so that disaster countermeasure offices will use them to initiate discussions with regard to whether food regulation was necessary; however, there were no regulation values in case of food regulation. Based on the indicator values, the Ministry of Health, Labour, and Welfare set the provisional regulation value for radioactive material in food on March 17, 2011; further, the shipping and intake of food, which violated the provisional regulation values, were regulated.

The authors sorted the reasons for setting food regulations and provisional regulation values that were implemented within the initial three months after the accident, extracted issues in food regulation, and proposed an improvement plan $^{5,6)}$. We also organized the food regulations that were implemented within the first year after the accident ${ }^{7)}$. We highlighted the issues in food regulation, including a lack of comprehensive indicator values for radioiodine in case of a variety of food, and the fact that the original objective for setting the indicator values was compromised when the provisional regulation values for seafood were added and when the provisional regulation values for drinking water and dairy were altered. Furthermore, we exhibited that social confusion had occurred since a similar indicator value was set (equivalent to an intervention dose level of $5 \mathrm{mSv}$ ) without distinguishing the emergency exposure situation and the existing exposure situation after the accident.

To improve upon such issues, the authors have proposed to implement the reference levels in phases ${ }^{5,6}$. This idea uses the difference in exposure based on the distance from the accident site, considers the effectiveness of the regulation values, and categorizes the periods between the emergency exposure situation and existing exposure situation during an early phase (phase 1), an interim phase (phase 2), and a later phase (phase 3) and reduces public exposure in phases by setting the reference levels for each phase. This concept also involves setting operational reference levels that are equivalent to the regulation values for each phase. The operational reference levels are set to be applied to all the food, radioactive isotopes, and age groups in such a manner that they do not extend beyond the reference levels in each phase. With regard to selecting the reference levels for each phase, we consider it appropriate to use $10 \mathrm{mSv}$ per year, which is 1/10th of the upper bound of the reference level during an emergency exposure situation (100 mSv per year), for an early phase, $1 \mathrm{mSv}$ per year, which is the 
lower bound of the reference level during an existing exposure situation, for the later phase, and $5 \mathrm{mSv}$ per year, which is somewhere between 10 and $1 \mathrm{mSv}$ per year, for the interim phase $^{5,6)}$.

On April 1, 2012, the Ministry of Health, Labour, and Welfare decided to further ensure food safety and set new standard values for food to replace the provisional regulation values and to prepare for long-term situations. The additional dose from contaminated food was reduced from 5 to $1 \mathrm{mSv}$ per year, and a standard value was established for radioactive cesium. This action can be understood to consider the contamination of food as one radiation source group using $1 \mathrm{mSv}$ per year, which is the lower bound of the reference value for the existing exposure situations.

\section{Target Values for Management of Radioactive Contaminated Substances}

After the accident, a significant amount of substances contaminated with released radionuclides, such as debris, waste matter, sludge, incinerated ash, and soil removed due to decontamination, among others, hereafter referred as contaminated substances, were generated over a wide area. It was decided that safety with regard to managing the contaminated substances should be based on the ideas provided in "ideas on immediate handling of by-products containing radioactive materials from drinking water and sewage treatment facilities" by the Nuclear Emergency Response Headquarters. This idea holds that the dose for the surrounding residents after the management period of the disposal facility should be lower than $0.01 \mathrm{mSv}$ per year under a scientifically probable scenario (likely scenario) and lower than $0.3 \mathrm{mSv}$ per year in case of variations of the likely scenario (less-likely scenarios). To ensure that the dose for the surrounding residents during the operational phase or for the operator is lower than $1 \mathrm{mSv}$ per year, the disposal of contaminated substances with a radioactive cesium concentration lower than $8,000 \mathrm{~Bq} / \mathrm{kg}$ is allowed, and contaminated substances with a radioactive cesium concentration lower than $100,000 \mathrm{~Bq} / \mathrm{kg}$ can be temporarily stored at facilities equivalent to a controlled landfill waste disposal facility for municipal wastes that do not contain radioactive materials in normal situation.

The aforementioned target values are based on the guidelines ${ }^{8)}$ for the management of radioactive waste in planned exposure situations. In addition, the value of $1 \mathrm{mSv}$ per year refers to individual dose limits in planned exposure situations. This can be interpreted as consideration that suitable management of contaminated substances was necessary in remote areas from the Fukushima Daiichi Nuclear Power Plant with low radioactive contamination.

However, while applying the aforementioned target values to environmental remediation (such as decontamination) in areas with environmental radiation of a few $\mathrm{mSv}$ to few tens of $\mathrm{mSv}$ per year due to soil contamination, management of contaminated substances and decontamination that leads to the generation of contaminated substances are restricted; further, strict management is required, which interrupts environmental remediation.

From the perspective of optimization principle, appropriate target values for waste management should be applied to various situations to achieve realistic progress in reducing the exposure. In an existing exposure situation with elevated environmental radiation level, the target values for waste management as the source related reference levels should be selected in the range of the dose band of 1-20 mSv per year indicated in the ICRP 2007 Recommendations ${ }^{1)}$, on condition that related information are adequately shared among the stakeholders. Practical and steady environmental remediation would be possible through continuous effort in selection of reference levels; a few $\mathrm{mSv}$ to few tens of $\mathrm{mSv}$ per year during the early phases and stepwise reductions of the reference level in phases as the environmental radiation level decreases ${ }^{9}$. 


\section{Conclusions}

Protection against radiation after a nuclear accident is beyond normality and affects the economics, government, environment, society, and public psychology. To ensure smooth implementation of the optimization of protection against radiation in the existing exposure situations, it is important to further understand the reference levels, consider a long-term coexistence with the manageable radiation sources in the environment, and reduce the exposure in phases. It is easier said than done; however, we hope that this study will help the reader to understand and contribute to restore the contaminated areas.

\section{References}

1) International Commission on Radiological Protection. The 2007 Recommendations of the International Commission on Radiological Protection. ICRP Publication 103. Ann. ICRP. 2007; 37: 1-332.

2) International Commission on Radiological Protection. 1990 Recommendations of the International Commission on Radiological Protection. ICRP Publication 60. Ann. ICRP. 1991; 21: 1-83.

3) International Commission on Radiological Protection. Application of the Commission's Recommendations to the Protection of People Living in Long-term Contaminated Areas after a Nuclear Accident or a Radiation Emergency. ICRP Publication 111. Ann. ICRP. 2009; 39: 1-67.

4) Ogino H, Ichiji T, Hattori T. Verification of screening for decontamination implemented after Fukushima nuclear accident. Radiat. Prot. Dosim. 2012 August; 151: 36-42.

5) Hamada N, Ogino H. Food safety regulations: what we learned from the Fukushima nuclear accident. J. Environ. Radioact. 2012 September; 111: 83-99.

6) Hamada N, Ogino H. Problems and improvement proposals for food safety regulations during the Fukushima Daiichi Nuclear Disaster. Report from Central Research Institute of Electric Power Industry. 2011 December; L11001: 1-28. [in Japanese]

7) Hamada N, Ogino H, Fujimichi Y. Safety regulations of food and water implemented in the first year following the Fukushima nuclear accident. J. Radiat. Res. 2012 September; 53: 641-671.

8) Nuclear Safety Commission, Japan. Basic Guides for Safety Review of Category 2 Radioactive Waste Disposal. 2010 August; NSCRG: F-RW-I.02. [in Japanese]

9) Sugiyama D, Hattori T. Radiological protection from radioactive waste management in existing exposure situations resulting from a nuclear accident. Radiat. Prot. Dosim. 2013 January; 153: 74-79. 


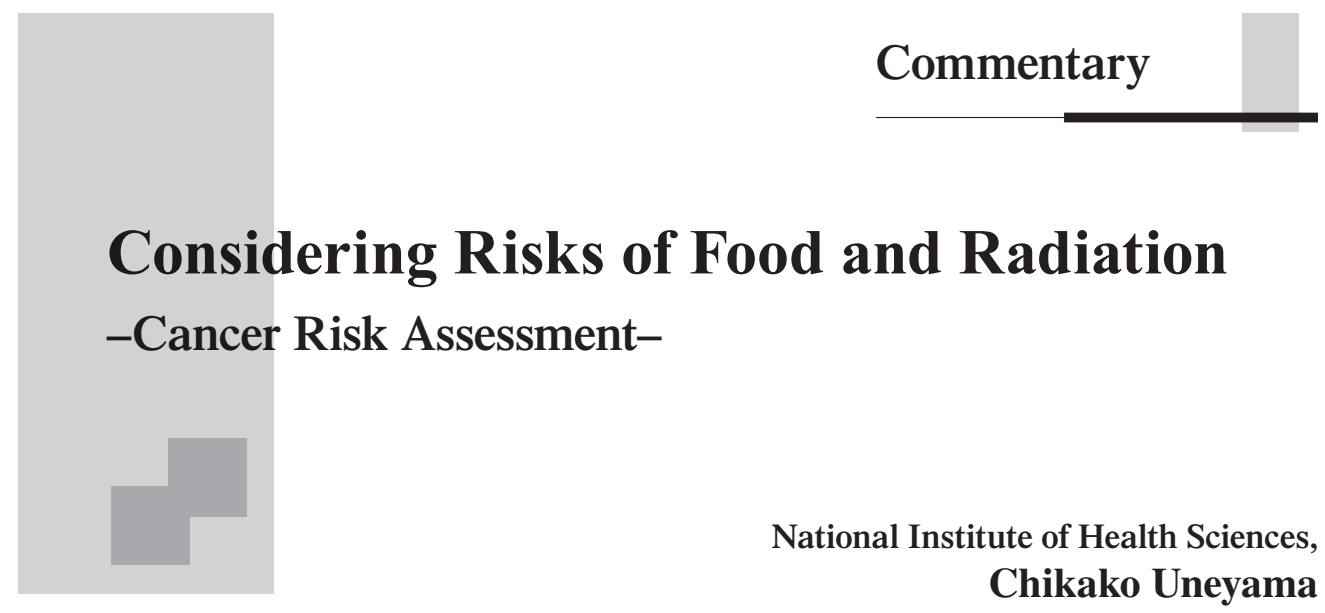

There have been many discoveries of genotoxic carcinogens in food, as with radioactive materials, which are considered "carcinogens with no threshold." This paper presents a simple commentary on how such risks have been assessed.

\section{Carcinogens in Food}

Foods are "objects with an unknown chemical composition," which humans have been eating with the understanding that doing so does not cause immediate harm. Food additives and agrochemical residues are often topics of "food safety," and there are standards for their use and residual amounts with enough room to maintain safety. This might seem obvious, but the safety of food is not necessarily guaranteed. There can be some identified risks, but unknown objects made up the majority exist in a gray area. Due to the idea that food should be perfectly safe, which is an impractical idea, the general public might have a different way of looking at the risks from that of experts (Figure 1).

Representative examples of toxic substances in food include plant alkaloids in potatoes such as solanine and chaconine. When the inedible parts or globefish and mushrooms are eaten, poisoning can occur.

Substances such as solanine are commonly contained in food, though usually in concentrations too small to cause poisoning. Most toxic substances would not cause harm as long as the amount ingested is low, so they are not usually concerning; however, there are many cases of food poisoning caused by a lack of proper risk management based on the misunderstanding that natural products are safe.

Among toxic substances in food, genotoxic carcinogens cannot simply be neglected as something harmless if the amount ingested is low. Genotoxic carcinogens can cause cancer by affecting substances responsible for genetic traits such as DNA and chromosomes (genotoxicity). Typical examples include radioactive material, fungal toxins such as aflatoxin, and plant alkaloids such as aristolochic acid. Like radiation, genotoxic carcinogens are treated as materials whose risk is not zero unless the amount ingested (dose) is zero, i.e., there is no ingestion threshold in which safety is guaranteed. Therefore, substances that are intentionally

DOI : 10.15669/fukushimainsights.Vol.1.264

(C) 2021 Atomic Energy Society of Japan. All rights reserved.

Originally published in Journal of the Atomic Energy Society of Japan (ISSN 1882-2606), Vol. 55, No. 10, p. 592-596

(2013) in Japanese. (Japanese version accepted: July 19, 2013) 
used, such as food additives and agrochemical residues, are basically not allowed if they are suspected to be genotoxic carcinogens. Substances contained in natural food should be managed "as low as reasonably achievable" (ALARA).

This ALARA principle was somewhat meaningful when the number of genotoxic carcinogens in food was relatively low. However, scientists have continued to discover dozens of new genotoxic carcinogens (including candidates), and it is no longer realistic to simply apply the ALARA principle. A decisive moment occurred in 2002, when it was discovered that food products containing starches and amino acids produce significant amounts of acrylamide when heated to temperatures higher than $120^{\circ} \mathrm{C}$. Acrylamide was a compound commonly known as an industrial chemical substance, but it was newly discovered that we ingest a significant amount of the substance on a daily basis. Acrylamide has been found to be carcinogenic due to animal experiments, and its mechanism is suspected to be genotoxicity. Acrylamide is not added to food but forms automatically during the cooking process, and food products constituting a substantial portion of diet have been found to produce the substance, including potato products, breads, cookies, coffees, and roasted green teas. It is impossible to "take as little as possible," and such an approach is inappropriate as it would make it difficult to maintain a healthy diet.

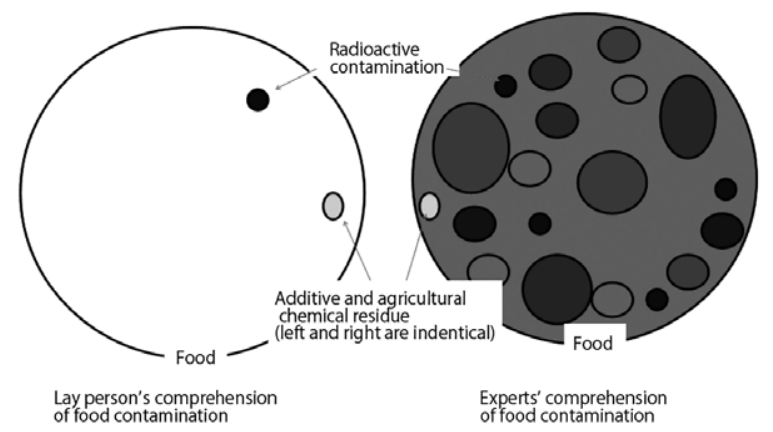

Figure 1 Views on food

\section{Food Safety Risk Analysis}

Food safety risk analysis has been used worldwide to ensure food safety ${ }^{1)}$. In 2003, the Food Safety Commission was established in Japan, and began conducting scientific assessments in regard to food safety independently from the Ministry of Health, Labour and Welfare and the Ministry of Agriculture, Forestry and Fisheries. Figure 2 shows three elements of the risk analysis.

The Food Safety Commission conducts "risk assessments," and based on these assessments, the Ministry of Health, Labour and Welfare and the Ministry of Agriculture, Forestry and Fisheries work on "risk management" such as by setting standards and monitoring products in the market. The most important part of this effort is "risk communication" throughout the system. Risk communication should be carried out among all related parties, from suppliers to consumers; this does not simply refer to "briefing sessions," wherein the government unilaterally explains new standards to consumers. It is obviously important to understand the basic matters of communication, such as the problems and solutions, but that is not enough. To ensure food safety, it is important for all parties, from the farm to dining table, to take 
responsibility and play their own roles (shared responsibility). For example, some food products are provided in edible form, and other products can be eaten safely only after cooking properly. Products such as raw meat can lead to health damages if the consumers do not appropriately store or cook them. Moreover, some food products might be safe as a single unit, but can lead to health damages when consumed in large quantities and for a long period. At the same time, few would argue that the government should determine the details in regard to when to eat, what to eat, and how much to eat, as done in animal experiments. Some countries and communities try to manage consumer selection by taxing food products with high sugar and fat contents. Risk communication involves a communication exchange among related parties to come up with the best solution for management methods. Consumers do not necessarily desire reinforced management because it can reduce options and increase consumer burden.

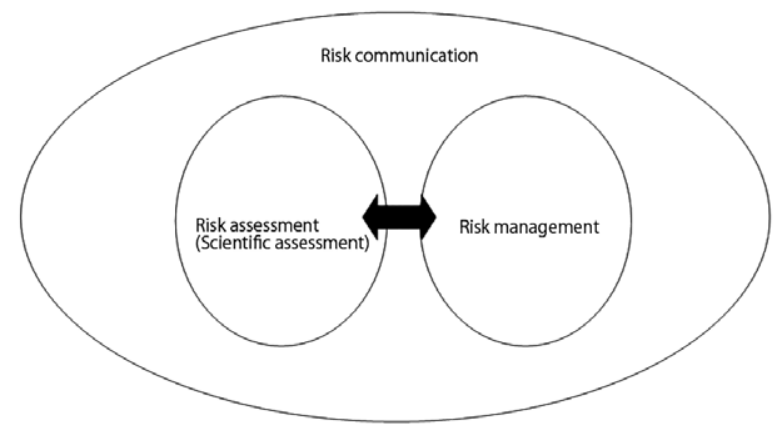

Figure 2 Conceptual map of risk analysis

\section{Margin of Exposure}

Risk communication is indispensable in food safety risk analysis. It is therefore necessary to educate the public on expert knowledge about the results of risk assessments and options regarding management methods. This task was particularly difficult for genotoxic carcinogens in food. In general, carcinogens are something to be avoided at any hand. Genotoxic carcinogens have been treated much like risk factors of radioactive materials; a linear non-threshold model has been used to extrapolate the results of carcinogenesis in humans and animals in the high dose range in order to create a slope factor (SF) (slope of the dose-response line), which is then used to calculate human lifetime cancer risk per exposure. In the field of setting environmental standards for chemical substances, a virtually safe dose is defined to range from $10^{-4}$ to $10^{-6}$, and this range is used for management goals. The default value for sterilizer by-products in water is $10^{-5}$ (however, a realistically achievable value is set for inorganic arsenic, which is a natural contaminant, since this value cannot always be achieved).

Such a method has been used by experts as an indicator for risk assessment. However, human cancer risk $10^{-5}$ is often interpreted by the public as "one in 100,000 people can get cancer" or "if the Japanese population is approximately 100 million, 1,000 would die from cancer." Given a lifetime cancer risk of $10^{-5}$, one out of 100,000 is not the predicted number of people who will develop cancer; however, this misinterpretation is unavoidable, given the number.

To tackle the situation, the concept of margin of exposure (MOE) has been used as an 
improved method for risk communication ${ }^{2-4)}$. This is calculated by dividing an indicator dose of toxicity such as no-observed effect level (NOAEL) or benchmark dose lower confidence bound $\left(\mathrm{BMDL}_{10}\right)$ by actual human exposure. The resulting value is equivalent to the safety factor. In other words, this indicates how the actual exposure compares to the dose level at which harmful effects barely appear. The higher the value, the safer, and vice versa. An MOE lower than 1 indicates that the possibility of a harmful effect cannot be denied. Even if this number is indicated independently, it is impossible to tell how many people will develop cancer. It is only when the value is compared to those of other substances that it is defined as high, low, or same as the others.

MOE is an indicator for ranking priority in risk management. MOEs for several compounds can help determine which of them should be prioritized. Table 1 shows the MOE values evaluated by the food safety organizations in countries across the world (a similar, though slightly different, table is shown in reference ${ }^{5}$.

When exposure varies among individuals, it is possible to prioritize risk management based on the person's exposure and then MOEs, which will help consumers start thinking about their highest priority risks. They would also understand that genotoxic carcinogens have quite varying risks. For genotoxic carcinogens with an MOE higher than 1 million, countermeasures can be postponed even with the ALARA principle.

Risk analysis involves a concept called an appropriate (health and hygiene) level of protection (ALOP). This value indicates the acceptable target level of risk, and though it may vary from community to community, it should be defined for each society. Ideally, risk management measures are implemented to meet ALOP, but in reality, it is difficult to quantify the values. For example, it is easy to set a goal of having zero deaths from food poisoning, but this would require sanitary management for entire foods at the level needed for space food, which is impossible to implement. However, it would not be easy for the public to accept a calculated annual death rate of 1 . From the viewpoint of risk psychology, it has been found that taking risks, even if it is negligible, is difficult. Risk ranking involves postponing goal setting and aims in order to deal with high or easy risks with a high cost-effect ratio, and subsequently if the task has achieved deal with the next risk in ranking. This is a practical method based on the risk-ranking measure. The protection standard of a country or community is set when such resources are depleted.

\section{Future Challenges}

Carcinogen risk assessments are usually about the development of cancer or death from cancer. However, with the average life expectancy rising, it is debatable whether, for example, death from cancer at the age of 100 is a serious issue. It is meaningless to aim for zero deaths from cancer, so human cancer measures often aim to reduce the number of people of age 75 or under who develop cancer. Strong carcinogens can cause cancer in animals in early stages, but some weak carcinogens have, after animal experiments and during autopsies, been found to be precancerous lesions that can cause cancer if left alone. It is more desirable to appropriately evaluate the time factor, which would defeat the purpose of cancer measures if we were to invest only in cancer prevention and not as much on securing the lives of seniors. For example, if the average life expectancy were 40, many cancer measures such as non-smoking would not be necessary. Cancer would also not be of a particular risk. Lead, added to the end of Table 1, causes issues not in terms of cancer but child intelligence. Which should we 


\section{INSIGHTS CONCERNING THE FUKUSHIMA DAIICHI NUCLEAR ACCIDENT Vol. 1}

Table 1 MOE of genotoxic carcinogens

\begin{tabular}{|c|c|c|c|}
\hline Substance & MOE & Condition & Organization, year \\
\hline Benz (a) pyrene & $130,000-7,000,000$ & Food source & COC, 2007 \\
\hline Hexavalent chromium & $9,100-90,000$ & Food source & COC, 2007 \\
\hline Chrome & $770,000-5,500,000$ & Drinking water & COC, 2007 \\
\hline 1,2- dichloroethane & $4,000,000-192,000,000$ & Drinking water & COC, 2007 \\
\hline Benz (a) pyrene & $17,000,000-1,600,000,000$ & Drinking water & COC, 2007 \\
\hline 1,2- dichloroethane & $355,000-48,000,000$ & Indoor air & COC, 2007 \\
\hline Benz (a) pyrene & $10,800-17,900$ & Food source & EFSA, 2008 \\
\hline $\mathrm{PAH} 2$ & 15,900 & Average intake group & EFSA, 2008 \\
\hline PAH4 & 17,500 & Average intake group & EFSA, 2008 \\
\hline PAH8 & 17,000 & Average intake group & EFSA, 2008 \\
\hline Urethane & 18,000 & Non-alcohol & EFSA, 2007 \\
\hline Urethane & $>600$ & Drinker of brandy and tequila & EFSA, 2007 \\
\hline Acrylamide & $78-310$ & Indicator for rat mammary tumor & JECFA, 2010 \\
\hline Urethane & 20,000 & Average intake group & JECFA, 2005 \\
\hline Urethane & 3,800 & High intake & JECFA, 2005 \\
\hline Acrylamide & $133-429$ & 2-6 year-old children in Netherland & RIVM, 2009 \\
\hline Aflatoxin B1 & $63-1,130$ & 2-6 year-old children in Netherland & RIVM, 2009 \\
\hline Furan & $480-960$ & Food source & JECFA, 2010 \\
\hline Arsenic in food & Not safe & Average European consumer (Notes 1 and 2) & EFSA, 2009 \\
\hline Arsenic in food & $1.1-33$ & Average French adult & ANSES, 2011 \\
\hline Arsenic in food & $0.8-27$ & Average French child & ANSES, 2011 \\
\hline Acrylamide & $419-721$ & Average French adult & ANSES, 2011 \\
\hline Acrylamide & $261-449$ & Average French child & ANSES, 2011 \\
\hline PAH4 & $113,409-230,041$ & French adult & ANSES, 2011 \\
\hline PAH4 & $72,433-150,509$ & French child & ANSES, 2011 \\
\hline Inorganic arsenic & $9-32$ & Average Hong Kong (Note 3) & CFS, 2012 \\
\hline Inorganic arsenic & $5-18$ & Hong Kong High intake & CFS, 2012 \\
\hline $\mathrm{PAH} 4$ & $27,600-15,500$ & Average food origin for all English people - 97.5 percentile & EFSA 2008 \\
\hline PAH8 & 45,606 & Adult & Spain, 2012 \\
\hline PAH8 & 40,078 & Child & Spain, 2012 \\
\hline Arsenic & $0.77-20.5$ (Note 4$)$ & Male & Spain, 2012 \\
\hline Arsenic & $0.32-8.6$ & Child & Spain, 2012 \\
\hline Acrylamide & $853-305$ (Note 5 ) & Younger than 1 year old & Health Canada, 2012 \\
\hline Acrylamide & $296-119$ & 1-3 years old & Health Canada, 2012 \\
\hline Acrylamide & $1,146-586$ & Older than 71 years old & Health Canada, 2012 \\
\hline Inorganic arsenic & 3 & Belgium adult & AFSCA, 2013 \\
\hline Inorganic arsenic & 68 & Belgium adult & AFSCA, 2013 \\
\hline Lead (Note 6) & $0.9-1.9$ & Infant drinking only breast milk & COT2012 (proposal) \\
\hline Lead & $1.6-10$ & Infant drinking only milk & COT2012 (proposal) \\
\hline Lead & $1.3-5$ & Milk and baby food & COT2012 (proposal) \\
\hline Lead & $1.9-6.3$ & Water & COT2012 (proposal) \\
\hline Lead & $0.2-0.9$ & Soil & COT2012 (proposal) \\
\hline Lead & $100-833$ & Air & COT2012 (proposal) \\
\hline Lead & 3 & Hong Kong, diet only & CFS, 2013 \\
\hline Lead & 6 & Hong Kong High intake, diet only & CFS, 2013 \\
\hline Lead & $1.8-4.8$ & Belgium adult & AFSCA, 2013 \\
\hline Lead & $0.5-1.2$ & Belgium child, 2.5-6.5 years old & AFSCA, 2013 \\
\hline Lead & 1 & Belgium infant, 3 months & AFSCA, 2013 \\
\hline
\end{tabular}

PAH2: benz (a) pyrene, chrysene PAH4: benx(a) pyrene, chrysene, $\quad$ COC: $\quad$ Scientific committee (England) for carcinogenicity of benz (a) anthracene, benz (b) fluoranthene PAH8: benz (a) pyrene, benz (a) anthracene, benz (b) Fluoranthene, benx (k) fluoranthene, benz (ghi) perylene, chrysene, dibenz (a,h) anthracene and indeno $((1,2,3-\mathrm{Cd}))$ pyrene

Note 1: Given $\mathrm{BMDL}_{01}$ intake of $0.3-8 \mu \mathrm{g} / \mathrm{kg}$ weight/day, the estimate intake is $0.13-0.56 \mu \mathrm{g} / \mathrm{kg}$ weight / day

Note 2: Given $\mathrm{BMDL}_{01}$ intake of $0.3-8 \mu \mathrm{g} / \mathrm{kg}$ weight/day, the estimate intake is $0.37-1.22 \mu \mathrm{g} / \mathrm{kg}$ weight / day.

People who eat seaweed might have $4 \mu \mathrm{g} / \mathrm{kg}$ weight/day, infants under 3 years old who eat rice have a value that is 3 times higher than that of adults

Note 3: POD used in Hong Kong was established in 2010 by JECFA. The inorganic arsenic intake in food in Hong Kong is half as much as that in Japan

Note 4: POD of 0.3 is used for small numbers and 8 is used for large numbers

Note 5: Average intake and 90 percentile value

Note 6: Not genotoxic, but there is no threshold for its toxicity environment

ANSES: French Agency for Food, Environmental and Occupational Health \& Safety (L'Agence nationale de sécurité sanitaire de l'alimentation, de l'environnement et du travail)

EFSA: European Food Safety Authority

FSA: $\quad$ Food Standards Agency

JECFA: Joint FAO/WHO Expert Committee on Food Additives

RIVM: National Institute for Public Health and the Environment

CFS: Hong Kong Centre for Food Safety

Spain: Catalan Food Safety Agency

BMDL: Benchmark dose limit 95\% lower confidence limit $\mathrm{BMDL}_{10}$ is BMDL for which cancer development increases by $10 \%$.

NOAEL: Quantity for no effect, maximum dose for which no negative effect is observed 
prioritize, cancer that develops in later ages or the lifelong effect on intelligence? Response to risk requires one to consider how to best distribute limited resources, including tradeoffs.

Finally, after the Great East Japan earthquake, I have had many opportunities to talk about carcinogens in food in front of individuals involved in nuclear power, and had the impression that they were not as aware of carcinogens in food as I expected. Nuclear power is a huge industry, and one can live entirely within this large bubble. If there had been measures in regard to natural carcinogens in food, on which there has been little research, by the wealth generated by nuclear power, the response after the earthquake would also have been different. Even very small effects of nuclear radiation are studied with huge funds in the nuclear community, but little is understood in regard to why substances known to be carcinogenic, such as inorganic arsenic, cause cancer in humans but not in animals. There is often no person who is clearly responsible for natural substances, and there is, therefore, no pressure in the form of attacking someone's responsibility. However, the improvement in human health and welfare is desired by all members of society, and thus, I would like as many people as possible to expand their views and think about the most pressing issues of all.

\section{References}

1) Hayashi Y. (Editor) Food Safety Risk Analysis (A guide for national food safety authorities. (FAO food/nutrient series).: Japan Food Hygiene Association; 2008. [in Japanese]

2) Uneyama C. Conceiving Reality of "Food Safety" -- Illusion of zero risk (DOJIN Anthology 28).: Kagaku-Dojin Publishing; 2009. [in Japanese]

3) EFSA Opinion of the Scientific Committee on a request from EFSA related to A Harmonised Approach for Risk Assessment of Substances Which are both Genotoxic and Carcinogenic. 2005. http:// www.efsa.europa.eu/en/efsajournal/pub/282.htm

4) Uneyama C. What is "safe food"? Conceiving radiation and risk of food.: Nippon Hyoron Sha; 2011. [in Japanese]

5) Uneyama C. Risk of intake of toxic substances through food -- Risk of intake of radioactive materials --. Shokuhin-Eisei-Gaku Zasshi (J. of Food Hygiene and Safety Science). 2013; Vol. 54, No. 2: 83-88. https://www.jstage.jst.go.jp/article/ shokueishi/54/2/54_83/_article/-char/ja/ [in Japanese] 


\title{
Preventing a Second Chernobyl
}

\section{-The Results of Efforts to Eliminate the Effects of Fukushima's Low-dose Radiation Contamination-}

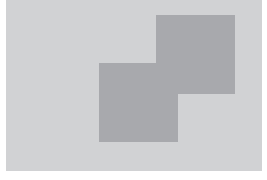

\author{
Louis Pasteur Center for Medical Research Foundation, \\ Kazuko Uno
}

\begin{abstract}
It has already been 3 months since I published the book "Overcoming Low-Dose Radiation" in late July, $2013^{1)}$. I am very happy with the feedback I have received such as, "The book made it easier to understand the lecture" or "It cheered me up" from people in Fukushima to whom I gave the book. Moreover, my senior colleagues, radiobiology and molecular biology professors at Kyoto University, commended me for the hard work undertaken to complete the book. The kind words from these professors emeritus, who are usually stern, were encouraging. In addition, I was surprised to receive emails and letters from people specializing in nuclear energy or material technology who agreed with the new perspectives in the book and offered their congratulations for its publication. I am surprised by the reaction to the book; I thought what I wrote was simple common knowledge in my field. This paper will discuss my intentions behind this book and what I learnt through the discussions with researchers in other fields while writing this book.
\end{abstract}

\section{Why were the Opinions of Scientists Divided?}

Looking back on 3.11, I was anxious for information about what to do while glued to the images of the earthquake, tsunami, and nuclear power plant accident. The biggest cause of concern was the risk of cancer stemming from radioactive substance from the Fukushima Daiichi Nuclear Power Plant. Moreover, many controversial public comments were rampant which exacerbated the fears in the affected areas. The general public, including scientists insisted that at the very least, children in Fukushima should be evacuated and those even in Tokyo should be moved to Kansai. As an immune researcher I believed that I could offer my knowledge to help ameliorate the fears regarding the risk of cancer. Many commentators on the Internet and television argued that mutant cells are created when humans are exposed to radiation. Since cells in the growth phase are more sensitive to radiation, children are over ten times more likely to develop cancer than adults. As such, these commentators predicted that one after another child in Fukushima would develop cancer within a few years. In a lecture on how to find motivation and meaning in life given to cancer patients I explained the mechanism of cancer and why radiation increases the risk of cancer. The lecture slides were

DOI : 10.15669/fukushimainsights.Vol.1.270

(C) 2021 Atomic Energy Society of Japan. All rights reserved.

Originally published in Journal of the Atomic Energy Society of Japan (ISSN 1882-2606), Vol. 56, No. 1, p. 15-18 (2014) in

Japanese. (Japanese version accepted: October 17, 2013) 
posted on the website of NPO Einstein, a volunteer group of scientist headed by Dr. Masako Bando, formerly the president of the Physics Society of Japan. My point of view is that the exaggeration of cancer risks on the Internet and in the media creates fear which weakens the immune system and increases the cancer risk. I believed I had a responsibility to speak out against it.

While radiation levels in Fukushima immediately after the nuclear power plant accident was indeed high, the consensus among medical/biological professionals around me was that the cancer risk of smoking tobacco was still higher than that associated with the radiation. In a mailing list distributed to many medical professionals, a doctor in Tokyo wrote that, "A patient of mine asked me to prescribe him sleeping pills for insomnia due to anxiety about radiation contamination. I wrote the prescription for him but was perplexed that he was quite concerned about radiation and yet he is a smoker" Indeed, one-third of cancer cases are caused by smoking. Another one third originates from dietary habits. Other causes include virus infection, work environment, and their living environment. The percentage of cancer cases attributed to radiation and ultraviolet rays is only about $2 \%$ of the total.

However, some of my colleagues who are physicists insist that it is inappropriate to consider the harm induced by tobacco and those by radiation as equivalent. It was difficult to convince them that tobacco and radiation both create oxygen radicals species (active oxygen species). I explained that a majority of DNA damage is caused by oxygen radicals that are generated when radiation breaks down water molecules. Oxygen radicals are created daily in an organism during respiration; it is used for bactericidal and other beneficial actions, however it also has harmful effects in the organism. Furthermore, I explained that living organisms have now developed a system for overcoming the harm related to oxygen radicals, and that most DNA damaged by radiation, ultraviolet ray, and breathing is repaired immediately. Thus, these physicists finally understood both radiation and smoking could be discussed in terms of oxygen radicals.

\section{Effects of Low-Dose Radiation and Ways to Overcome it}

\section{Cancer-Prevention Diet}

I believe that a diet that prevents cancer and adult diseases is effective to overcome the impact of low-dose radiation. Noteworthy examples of such diets include those presented in the McGovern Report and the Designer Foods Project. The McGovern Report published in 1977 in the U.S., stated that many chronic diseases originate from improper meat-based dietary habits and cannot be cured by drugs. The report pointed out that excessive consumption of fat, sugar, and salt are directly linked to life-threatening diseases such as heart disease, cancer, and stroke. The Designer Foods Project conducted by the National Cancer Institute in the U.S. researches plant-based compounds, such as phytochemicals, that they believe to be anti-carcinogenic. One of the aims of the project is to promote the consumption of these cancer-fighting foods that have phytochemicals and other compounds. Indeed, numerous compounds, which counters the harm inflicted by oxygen radicals, is contained in vegetables and fruits. Phytochemicals such as carotenoid, polyphenol, vitamin C, and vitamin E have particularly strong antioxidant effects that have been proven to aid in preventing cancer.

Fukushima Prefecture is an agricultural district that grows vegetables and fruits that are high in antioxidants. When I reflected upon the advice I can give to people of Fukushima, I came to the conclusion that "one should eat vegetables and fruits from Fukushima as much as 
possible when the measurement of their radiation dose shows no problem. Upon hearing this advice, a doctor from the Fukushima Japanese Red Cross Society commented that such a diet is quite similar to the adult-disease prevention diet that they were promoting. Indeed, not only does the antioxidant diet lead to cancer prevention, it also aids in preventing common adult diseases. Although Fukushima has a high rate of heart disease, it is possible that after ten years, residents in the prefecture can have a long life expectancy if salt intake is reduced and the anti-oxidant diet is implemented.

\section{Oxygen Radical is Keyword}

As was the case for my colleagues the physicist, the mechanisms of oxygen radicals and radiation can be understood once explained and can lead to a deeper mutual understanding of the topic. The influence of oxygen radicals is diverse. In the field of anti-aging medicine, oxygen radicals is reviled as the biggest cause of "rusting" or deterioration of the human body. It has been proven that oxygen radicals plays a role in many diseases that accompany aging, such as arteriosclerosis, myocardial infarction, Alzheimer's, cancer, diabetes, gastric ulcer, and cataracts. Recently, there is an abundance of supplements on the market designed to counteract oxygen radicals commonly referred to as free radicals. However, oxygen radicals should not be thought of as having only negative effects on an organism. The opposite is true; they are essential. For example, neutrophils and monocyte in white blood cells use oxygen radicals to kill bacteria, and this is one of their positive functions.

Biologists agree that when creatures started to live on land and breathe oxygen, they evolved to acquire a system to utilize this potentially dangerous oxygen radicals and overcome its harmful qualities. It is true that on a daily basis, organisms repair the damage inflicted by oxygen radicals that was produced by radiation, smoking, carcinogenic substances, or their own breathing. Based on this information, we can understand that radiation is not exceptional, but something that naturally occurs within our bodies and the environment.

\section{Natural Progression History of Cancer}

Cancers do not develop in overnight. Cells become carcinogenic only after several mutations. Moreover, it takes about 20 to 30 years for solid tumors to attain a clinically diagnosable size, with the exception of cancers such as leukemia or thyroid cancer. Cancer that is discovered one or two years after the nuclear power plant accident cannot be regarded as the consequence of the radiation from accident; it is more reasonable to think that the roots of such cancers were already present before the accident. After the nuclear plant accident, researchers who are not aware of the mechanism of cancer strongly predicted that 100,000 people living within a $100 \mathrm{~km}$ radius from Fukushima will have cancer in the next 10 years. These types of predictions caused unnecessary anxiety among many residents. However, this anxiety is detrimental, since the last defense against cancer cells in the human body is immune cells such as the natural killer cells. In fact, a vast majority of the mutant (carcinogenic) cells that humans produce daily is removed by natural killer cells and other immune cells. Fear, anxiety and other stressors reduce the function of these immune cells. Knowing this, I was concerned that exaggerated information about the effects of radiation would increase the risk of cancer in Fukushima residents due to increased stress. My hope was that my book would help to alleviate this anxiety, and offer a solution that would boost residents' immune system to mitigate the effects of stress and any exposure to low dose radiation. 


\section{Outreach Activities in Fukushima}

\section{1st Stage: 2011 Radiation Measurement by Japan Society for the Promotion of Science Volunteers}

Professor Ryuichi Shimizu of Osaka University, who attended my lecture in Kyoto in July invited me to Fukushima Projects. As a result, I joined and participated in a series of studygroup projects held between October to December, 2011 in Shirakawa city, Fukushima Prefecture. I participated as a member of the Industry-academia Cooperation Research Project of Japan Society for the Promotion of Science (JSPS) (commonly referred to as JSPS team for measuring and explain radiation). This is an outreach program organized by JSPS to assist Fukushima residents in overcoming the physical and emotional challenges they were facing due to the effects of the radiation. The outreach program was staffed mainly by volunteer researchers. JSPS team members measured radiation levels in the affected areas and offered explanations to residents. Shirakawa city created the study group so that researchers could give residents accurate information on how to guard their health from radiation. The meetings were held over three months, once in each of the eight districts of Shirakawa city from 6 p.m. to about 9 p.m. One of the main characteristics of our team was the fact that we walked around schools and other areas in the daytime before the meeting started and measured radiation levels. Radiation levels in the air measured between $0.1-0.7 \mu \mathrm{Sv} / \mathrm{h}$ and $0.2-0.5 \mu \mathrm{Sv} / \mathrm{h}$ on school playgrounds. This proved to us the effectiveness of decontamination, especially in school environments. (However, we noted that unlike schools in the cities, in schools surrounded by mountains, radiation levels increased slightly every time it rained). We were told that the contaminated soil taken from areas around the school was buried in the center of the school playground. It would be natural to think that the playground would have the lowest radiation levels and is safe, meaning that a common conclusion would be to let children spend as much time as they want on the playground. During the study-group lectures, the JSPS team reported the actual radiation levels around the city. On Google Map, displaying actual radiation levels and photographs of the areas where the measurements were taken such as an elementary school yard or hotspots under a drainpipe, made it easier for the residents to understand where actual elevated radiation spots were in their neighborhood. These lectures created a forum where residents could calmly express their concerns and receive factual feedback; this outreach program lead to our team receiving a certificate of appreciation from Shirakawa City.

\section{2nd Stage: 2012 Relaxation and Antioxidant Experiment}

Mothers with small children stood to benefit the most from the study groups. However, since the meetings were held in the evenings it was difficult for mothers to attend. This led me to think that it was necessary to have childcare available at the meetings. However, when I requested support this project to a female member of Fukushima prefectural assembly in April, she replied, "mothers in Fukushima are extremely stressed at the moment, so aromatherapy would be more welcomed than lectures by famous scientists." This reaction prompted me to introduce cosmetic therapy to the women in Fukushima. Using a sample of aged women, I had already demonstrated to the effectiveness of cosmetic therapy in activating natural killer cells and IFN- $\alpha$ production which are the index of a immune activity ${ }^{2}$. JSPS was a little reluctant to undertake the project. However, I was invited to a lecture organized by the Japanese Red Cross Society, and at the time, I proposed adding cosmetic therapy sessions to 
the study group in Fukushima. The team at Red Cross was already aware of the effectiveness of spa therapies such as footbaths and aromatherapy relaxation, so they agreed, saying they were onboard with anything that helps the disaster victims. Additional support for the cosmetic therapy project came from Naris Cosmetics, a company that had supported my prior cosmetic therapy research. Naris Cosmetics is located in Fukushima Ward, Osaka, and they assisted me with this project partly because their headquarters is located in Osaka, in a city that shares the same name as Fukushima. The company generously donated facial lotions and other cosmetics for 10,000 participants and this allowed the launch of the cosmetic therapy project. Hand massages with Naris lotions were offered during the study meetings and during these massage sessions, volunteers answering questions and offering more information helped the female participants to deepen their understanding of the lectures. I believe that this spa project helped to put not only the females but also males in the community at ease and so it was particularly unique to female researchers.

\section{3rd Stage: 2013 Training Peer Educators}

I believed that simply explaining that an appropriate cancer fighting diet is equivalent to generous amounts of fruits and vegetables high in antioxidants was not enough to convince Fukushima residents to change their eating habits. As a result, during the autumn of 2012, I introduced an experiment to demonstrate the antioxidant capacity of fresh fruits and vegetables to residents. It was a simple experiment wherein the juice of a vegetable or fruit was extracted and mixed with diluted isodine solution (it can be used as antiseptic solution and also for oxidation-reduction titration) to observe the change in color. It was easy to see the anti-oxidative effect: the brown isodine solution immediately turned transparent when green tea, garlic, or green pepper juice was added. The mothers in the study group were positively influenced by the experiment, and there was one mother who told her child to eat green peppers from now on.

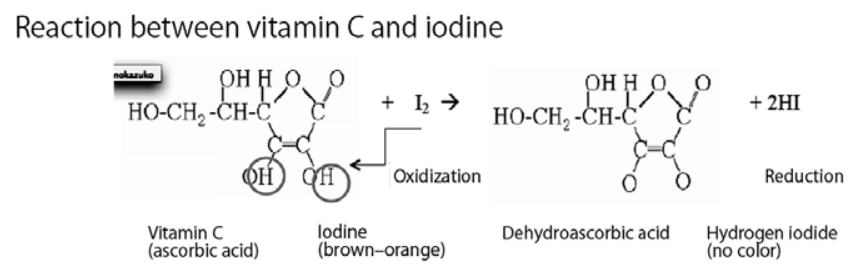

A representative of a group of affected residents who evacuated from Fukushima to Kyoto, visited NPO Einstein on June 2011. She requested our help for these evacuees to receive whole body counter test to determine their radiation levels and/or tests to check their thyroid function.

Whole body tests are performed free of cost in Fukushima by a mobile testing center housed in van. These evacuees were denied testing service because people who were physically in Fukushima were given priority and this mobile testing center could not come to Kansai Region anytime soon. We at NPO Einstein discovered that Kyoto University Research Reactor and Mihama Nuclear Power Plant have a whole body counter, and with their support, we visited both institutions with the Fukushima evacuees. Before undergoing the test, we had an orientation session in the chartered bus to explain the whole body counter, what the equipment measures, and how the results of the whole body counter in Fukushima fared. 
In addition, we also asked the staff from these institutions to give a talk. In addition to Einstein researchers, evacuees who already underwent radiation testing participated, and spoke about their experience to the evacuees who were being tested for the first time. Through this experience, we came to understand that people who were anxious about doing their amount of exposure got more comfort from explanations given by a fellow evacuee than explanations provided by researchers.

In 2012, I was requested by the Fukushima local government to hold several health workshops for public health workers and again in 2013 for both public health workers and public schools teachers. The primary goal was to enable workshop participants to interact with local residents with confidence. There are many Fukushima residents who are still anxious and even though I visit every month, there is a limit to the number of people I can council at any given time. My hope is that those fortunate to attend my lectures will confidently relay information to the people around them, and in this way, residents' concerns will slowly fade and be replaced with more optimistic thinking.

\section{Crisis Communication}

\section{The Power of Network}

I believe that one of the main issues underlying the inadequate response to the needs of Fukushima residents during this crisis was the poor communication of accurate, relevant information on the part of scientists. Personally, as a scientist, I was particularly disappointed in the barrage of misinformation surrounding the biological impact of low-dose radiation that was communicated during the early months after the accident. Researchers who attempted to reassure the public that at the current level there was no need to worry about radiation effects were accused of taking sides with the government. Several hackneyed theories about the impact of radiation were thrown around; these theories were based on experiments conducted in test tubes only, data that were several decades old, and exaggerated case reports. Those who sided with the opinion that "danger" existed tended to be recognized as being conscientious. During this time, I was attempting to verify the many theories about radiation that were circulating and trying to connect the theories with their original sources. We concluded that most of these exaggerated warnings were because: (1) mere sections of an entire paper were taken out of context and the risks magnified, (2) the original source were merely case reports that would not qualify for peer review and could hardly be considered as reliable academic publications, and (3) the results published in a single paper on epidemiological studies were likely treated as being typical example for the entire subject. We recognized that it was necessary to uncover if they were more reliable papers including those from other countries that reported similar impact.

As such, we created a discussion forum at NPO Einstein that included researchers from various fields including physics, radiobiology, medical science, and nuclear engineering.

\section{Role of Scientists}

Rapid, cutting-edge advances in the field of science has created the need for a new profession called scientific communicators who can relay complex scientific information in a way the general public can understand. However, these scientific communicators made very little worthwhile contributions during this crisis. As far as I know, they either exaggerated the 
impact of low-dose radiation based on their rather limited knowledge and caused confusion, or simply stayed silent. Meanwhile, I thought that even though there was very little support from these communication specialists from various fields, some citizens who are avid critical thinkers were able to better assess the situation and make more accurate judgments. One could find such people among the evacuees from Fukushima. The difference between these people and the science communicators is that the evacuees had a strong connected to, and history with Fukushima

During the disaster recovery period, retired researchers played a particularly important role. Many active researchers, due to their work obligations, either visited Fukushima very few times, or not at all. Additionally, they tended to have a narrower perspective compared to the older retirees who have the benefit of years of experience in their respective discipline. To overcome the dire situation in Fukushima, it is perhaps more effective to invest in programs in which retired researchers train peer educators (people who guide the sharing and propagation of appropriate knowledge/skill/action in their community) instead of training science communicators. In the field of AIDS study for example, the investment in developing peer educators is showing some results ${ }^{3)}$.

\section{Chernobyl vs. Fukushima}

An onslaught of books about Chernobyl was published after the Fukushima Accident, many discussing how children from Chernobyl are inflicted with many diseases. Reading these books would make an anxious person even more concerned. I found the methods to reduce radiation in vegetable and meat that was mentioned in the book "How to Protect you and your Children from Radiation" especially problematic, as these suggestions were meaningless unless the actions were taken immediately after the accident. More worrisome, is that the advice presented could also have negative health effects by decreasing the nutrients and microelements in these natural foods. Although Japan should learn from Chernobyl's system of testing the safety of their food chain, such a system is already in place in Fukushima, and instruments to measure radiation levels in locally grown produce and animal products are installed in local community centers and other locations. As such testing is not available in other prefectures; I expect that in the future, foods from Fukushima will be regarded as safer because they have been more carefully tested.

I am of the opinion that Fukushima will not be a second Chernobyl for the following reasons:

(1) The estimated radiation dose detected after the Fukushima Daiichi Nuclear Power Plant Accident was about 1/10th that of the Chernobyl Accident.

(2) In Fukushima, the distribution of milk contaminated by iodine was halted quite quickly after the accident.

(3) Unlike residents of other regions who are prone to have chronic iodine deficiency, Japanese tend to naturally consume healthy amounts of iodine in their diets through seaweed and other foods.

(4) From the results from Co-op Fukushima extra-meal research (households prepared an extra single serving for every meal the family ate over a two-day period; these meals were evenly rotated and their radiation levels were measured), we know that as long as residents rotate the food they consume, there is little need to worry about the accumulation of radioactive materials from foods.

(5) Unlike the areas around Chernobyl where it was difficult to obtain produce high in 
antioxidants in winter, these fruits and vegetables can be obtained far more readily year round in Japan.

(6) Published reports showed that the soil in areas affected by the Chernobyl Accident such as in Belarus and the prairie in Ukraine, were low on minerals, making them even more susceptible to contamination by radioactive materials ${ }^{4)}$. Moreover, while the addition of land-improvement agents succeeded in reducing the contamination level of agricultural produce, these agents also tend to reduce the absorption of microelements necessary to support healthy soil organisms, such as cobalt, zinc, copper, iron, manganese, and potassium. On the contrary, the soil composition in Fukushima is significantly different from in the Ukraine, and the food chain in Fukushima did not have the levels of radiation contamination that occurred in Chernobyl and the surrounding regions.

(7) In Fukushima, whole body counter did not detect a problematic amount of cesium in most people. However, in Chernobyl, 20-70 Bq/kg radiation doses are still being detected in many residents even 10-20 years after the accident.

\section{References}

1) Uno K. Overcoming Low-Dose Radiation Contamination. Shogakukan Shinsho; 2013. [in Japanese]

2) Uno K, Tani M, et al. Effect of Cosmetic Therapy on Old Women. Nihon=Sei-Kenkyukaigi Kaiho (J Japan = Sexuality Study Council). 2001; Issue 13: 11-19. [in Japanese]

3) Takamura S. Peer Counseling Manual to Support the Sexual Health of Puberty. Shogakukan; 2005. [in Japanese]

4) Shiraishi K. Radiation and Nutrition. Miyaobi Publishing; 2011. [in Japanese] 


\title{
The Reconsider Linear Non-Threshold (LNT) Hypothesis of Radiation Effect on Living Object
}

\author{
Osaka University, Yuichiro Manabe \\ Chinese Academy of Science, Issei Nakamura \\ Osaka University, Hiroo Nakajima \\ Kyoto University, Yuichi Tsunoyama \\ NPO Einstein, Masako Bando
}

\begin{abstract}
After Muller's experiment on drosophila, it was found that the risk of radiation depends on the total dose, and the linear-non-threshold (LNT) hypothesis became the basis of radiation protection. However, Russel et al. later showed the existence of the dose rate effect. We propose a mathematical model for integrating the results for different species and extrapolating them to humans. With scaling rule, the model can help interpret various data in a comprehensive manner. This would produce new knowledge in radiation risk assessment.
\end{abstract}

\section{Introduction}

The discovery of mutations by artificial radiation (Muller's experiment on drosophila) led to the conclusion that "The mutation rate is proportional to the total dose of irradiated radiation and that the proportional coefficient does not change for different dose rates (Linear-Non-Threshold, LNT)" " ${ }^{1)}$. It is understandable that the scientists at that time thought this way since it only requires the dose $(D)$ that causes mutation and the amount of mutation is a physical process. After this discovery, radiation protection was based on the LNT hypothesis.

Later, however, an experiment with 7 million mice at Oak Ridge National Laboratory (Russel's mega-mouse project) led to the discovery that the mutation rate changes with the dose rate ${ }^{2}$. Figure 1 shows the results. If there was thorough analysis of the implication of the mega-mouse project, the dose rate standard would have replaced the LNT hypothesis and the protection standards might have been corrected.

The important question is how the output, balanced with the input (determined by the dose rate), is different when the input is different. If the input and output are not related to the amount accumulated in the body, the balance is determined by the difference between the input and the output. However, if the output is proportional to the accumulated amount,

DOI : 10.15669/fukushimainsights.Vol.1.278

(C) 2021 Atomic Energy Society of Japan. All rights reserved.

Originally published in Journal of the Atomic Energy Society of Japan (ISSN 1882-2606), Vol. 56, No. 11, p. 705-708

(2014) in Japanese. (Japanese version accepted: August 20, 2014) 
certain accumulation will not allow further accumulation even with more input. Therefore, it is important to observe the change with time. Unfortunately, however, the impact of LNT hypothesis obtained by Muller's experiment persists, leading to a fixation on the idea that mutation (mutation frequency) depends on total dose, and the sole importance is placed on total dose. Therefore, Russel's discovery that the mutation rate drastically changes with low dose rates even with same total dose was considered to supplement the LNT hypothesis.

In fact, Russel also concluded that the slope of LNT is different between low dose rates and high dose rates and semi-forcefully explained the experiment data with two lines, introducing the ratio of the slopes as the Dose and Dose Rate Effectiveness Factor (DDREF) (See Figure 1).

Let us examine the details of Russel's data in Figure 1. The horizontal axis is the total dose, and the vertical axis is the mutation frequency. A rough idea of the relationship between the dose and the mutation frequency can be obtained since the plot has experimental data for Drosophilinae and Tradescantia are provided, which are well-referenced. With the same total dose, the difference between the slopes of mutation frequency for acute dose $\left(\sim 10^{1}(\mathrm{~Gy} / \mathrm{hr})\right)$ and chronic dose $\left(\sim 10^{-4}-10^{-3}(\mathrm{~Gy} / \mathrm{hr})\right)$ is larger than that between the errors, failing the explanation for experimental data with a single line. However, there has not been a formulation to quantitatively evaluate this difference in the dose rate.

Consider pouring water in a cylinder. When pouring $1 \mathrm{cc}$ of water per second, the total water accumulated in the cylinder matches the total water poured; however, if the cylinder has a hole at the bottom, water will not accumulate unless the input rate is higher than the output rate through the hole. With an increase in the pouring rate, water is accumulated. However, the water pressure increases, thereby increasing the output rate. Finally, the input rate and output rate are balanced, leading to constant accumulation of water. From this point onwards, the accumulated water will remain constant even if one continues to pour water. Members of the Atomic Energy Society is familiar with this phenomenon since it is the same as the concept that exposure does not keep accumulating when absorbing $1 \mathrm{~Bq}$ of radiation per day through food in Fukushima. Radioactive elements have two decays (consider these as outputs), a physical half-life and a biological half-life, and they decrease at a certain rate. For this reason, daily intake of a certain amount of radiation from radionuclides is balanced with the output, leaving the exposure constant. There are numerous examples of such balances in

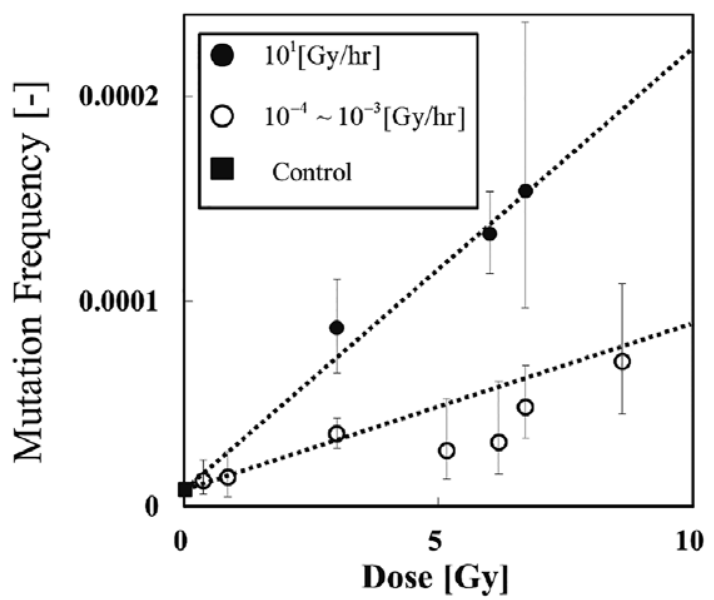

Figure 1 Experimental results of Russel's mega-mouse project 
natural phenomena, e.g., in the ozone layer, ozone is decomposed at the bottom of the layer while it is created at the top of the layer. Although it appears to have a constant thickness, the input and output are dynamically balanced.

\section{From Lea Target Theory to WAM Model}

From bacteria to humans, organisms are diverse, but the smallest unit of living beings is cells; multi-cell systems have common structures, in which they adapt to the environment and continue the cycle of metabolism and multiplication. Biologists are most interested in diversity, while physicists are interested in the unified picture and quantitativeness.

Let us consider a certain organ in a living organism as an n-body system composed of normal cells and mutated cells. Cells respond to external micro-stimuli, $\Delta$, in various ways. The changes in mutated and normal cells are mathematically expressed as follows.

$$
\begin{aligned}
\Delta N_{n} & \Leftrightarrow\left(T_{n n} N_{n}+T_{n m} N_{m}\right) \times \Delta \\
\Delta N_{m} & \Leftrightarrow\left(T_{m n} N_{n}+T_{m m} N\right) \times \Delta
\end{aligned}
$$

Here, $N_{n}$ and $N_{m}$ are the numbers of normal and mutated cells in the system, respectively. There is a significant difference between choosing time $(t)$ and dose $(D)$ for micro-variation. In the 1950s, Lea proposed the "target theory," which reproduces Muller's experimental results and provides a fundamental formulation of radiation biology ${ }^{3)}$. The formulation was based on the following differential equations,

$$
d N_{n}=-N_{n} \frac{d D}{D_{0}} \rightarrow N_{n}(D)=N_{0} e^{-\frac{D}{D_{0}}}
$$

In Lea's formulation, let us consider the simplest case, a 1-target-1-hit case. $D_{0}$ is the average lethal dose necessary for hitting the target (most receptive part of the cell). When the normal cells are dominant in the system, the mutation frequency $F$ is

$$
F(D)=\frac{N_{m}}{N_{0}}=\frac{N_{0}-N_{n}}{N_{0}}=1-e^{-\frac{D}{D_{0}}}
$$

As a physical process, this equation is consistent but neglects the contributions from an organism's repairing process, apoptosis, and mutant-cell death. Later, researchers made corrections, but the tradition of taking dose $D$ as the variable continued ${ }^{4,5)}$.

According to the description in Chapter I, time is intimately related to the repairing process. Here, we develop our work and consider the following equation ${ }^{6}$.

$$
\frac{d}{d t} F(t)=(\kappa+\gamma d)-(\alpha+\beta d) F(t)
$$

Here, $d$ is the dose rate. The first term is the mutation rate of normal cells, and the second term corresponds to the repairing process, which tends to reduce $F$. Note that each term includes parameters proportional to the dose rate (stimulation) as well as $\kappa$ and $\alpha$. This is because mutation of cells and repairing functions are present even without artificial irradiation. If $d$ is constant with time, the solution can be easily obtained, which is 


$$
\begin{gathered}
F(t)=F(\infty)\left(1-\mathrm{e}^{-(\alpha+\beta d) t}\right)+F(0) \mathrm{e}^{-(\alpha+\beta d) t}, \\
F(\infty)=\frac{\kappa+\gamma d}{\alpha+\beta d}
\end{gathered}
$$

This familiar form is a special form of the Richards differential equation, known as growth curve $^{7)}$

$$
\frac{d}{d t} W(t)=\eta\{W(t)\}^{m}-k W(t)
$$

In other words, our equation corresponds to Eq. (6), where

$$
m=0, W(t)=F(t), \eta=\kappa+\gamma d, k=\alpha+\beta d
$$

$m$ in Eq. (6) is called the geometry parameter, which stops the growth when the growth reaches the maximum. If $m=0$, the curve is a Logistic curve, and $m=1$ corresponds to a Gompertz curve. This is often used as a growth model for animals ${ }^{1}$. The growth curve is not a simple increasing function, and the growth slows down as $k t$ becomes of order 1 and $W$ approaches $W(\infty)$ as time passes.

Equation (5) reveals that the parameters such as $\eta$ and $k$ in (6) depend on external stimulation (radiation), i.e., the dose rate, and indicate that they explicitly regulate growth in response to stimulation, which is the feature of our formula. This term explains the difference in mutation frequency induced by the difference in the dose rate.

For the sake of comparison with the experiments, we devise the formulation so that species can be analyzed in a unified manner. We rearrange the solution of $F$ in (5) and define a screening function common to organisms.

$$
\Phi(\tau) \equiv \frac{F(t)-F(0)}{F(\infty)-F(0)}=1-\mathrm{e}^{-\tau}, \tau \equiv(\alpha+\beta d) t
$$

$\tau$ is the dimensionless time, and when this becomes of order 1 , restoration function and input are balanced and converge to a certain value with no dependence on species. We call the above model the Whack-A-Mole (WAM) model. The naming comes from the observation that organisms "whack" mutated cells in response to stimulation.

\section{Comparison with Experimental Data}

There are 4 parameters $(\kappa, \gamma, \alpha$, and $\beta)$ in the WAM model. The experimental data show the mutation frequency for irradiation with varying dose rates. Most studies in literature have given attention to the total dose, and only a few studies have emphasized the dose rate. Among those few studies, we applied our mathematical model to the data of five species of animals (mice and drosophila) and plants (maize, Tradescantia, and chrysanthemum) ${ }^{2,8-11)}$. With experimental subjects and the irradiation rate (assumed to be constant), we determined the 4 parameters via an $\chi^{2}$ test, convert data with different dose rates and the total dose to scaling functions, and compared with the experimental data. Obviously, sensitivity and recovery effect against radiation, reflected in the 4 parameters, vary depending on species, sex, and type of organ. Table 1 shows the parameter sets of the 5 species.

Figure 2 shows the experimental data for the mice, flies, maize, Tradescantia and

\footnotetext{
${ }^{1}$ In reality, geometric parameter $m$ varies due to body length and weight, so the growth curve of an animal is determined empirically. http://en.wikipedia.org/wiki/Generalised_logistic_function
} 
chrysanthemum along with the theoretical curve.

Figure 2 shows an cross-species experimental result and indicates that the predicted value based on our model matches well with the distribution of the experimental data. The time scale of the initiation of repair depends on the species and dose rate. However, expressing the dependency on species parameters and dose rate by a dimensionless time $\tau$ enabled a unified picture to be drawn.

Table 1 Parameter set for each species

\begin{tabular}{|c|c|c|c|c|c|c|}
\hline & & Mice & Dros-ophila & Maize & $\begin{array}{l}\text { Crysan- } \\
\text { themum }\end{array}$ & Tradescantia \\
\hline$\alpha$ & {$[1 / \mathrm{hr}]$} & $3.00 \mathrm{E}-03$ & $3.00 \mathrm{E}-04$ & $1.78 \mathrm{E}-01$ & 4.49E-03 & $6.94 \mathrm{E}-01$ \\
\hline$\beta$ & {$[1 / \mathrm{Gy}]$} & $1.36 \mathrm{E}-01$ & $0.00 \mathrm{E}+00$ & $0.00 \mathrm{E}+00$ & $0.00 \mathrm{E}+00$ & $1.61 \mathrm{E}-01$ \\
\hline$\gamma$ & [1/Gy] & $2.94 \mathrm{E}-05$ & $2.32 \mathrm{E}-03$ & $2.02 \mathrm{E}-03$ & $6.49 \mathrm{E}-03$ & $1.63 \mathrm{E}-01$ \\
\hline$\kappa$ & {$[1 / \mathrm{hr}]$} & $3.24 \mathrm{E}-08$ & $0.00 \mathrm{E}+00$ & $0.00 \mathrm{E}+00$ & $0.00 \mathrm{E}+00$ & $2.91 \mathrm{E}-02$ \\
\hline
\end{tabular}

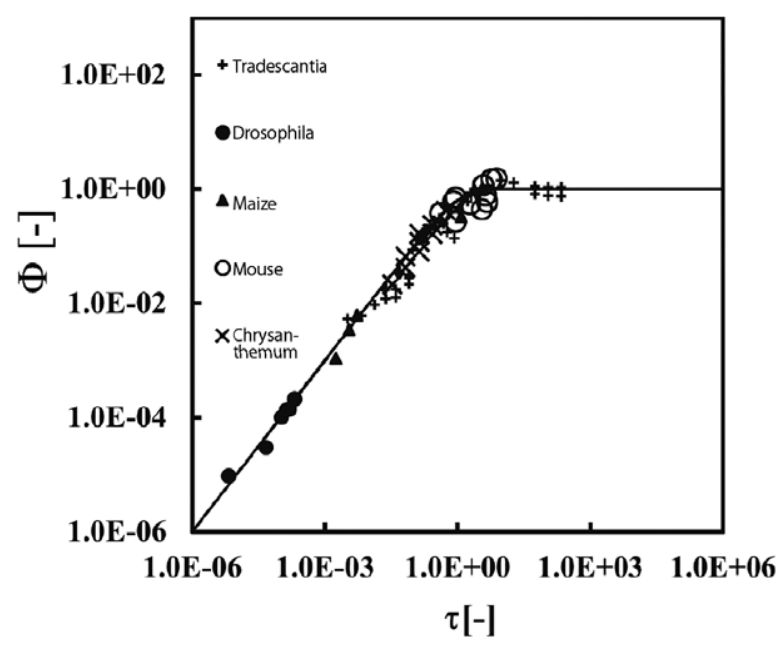

Figure 2 Reproduction of experimental data by scale function Vertical axis: value of screening function (common to organisms), Horizontal axis: dimensionless time.

\section{Spontaneous mutation}

We will now discuss the effect of mutation frequency on control data, i.e., without artificial irradiation. We focus on the parameters of the mouse, which is the closest to a human in terms of such modeling. Russell mentioned that the dose necessary to cause humans to have the same mutation rate as mice is $1 / 2$ of that required for mice; that is, humans are more receptive to such a dose ${ }^{2)}$. Note that this comparison is for reference purposes only. Organisms repeat metabolism and self-proliferation through interactions with the environment; such activities are one of the stimulations that occur in organisms. In fact, reactive oxygen species produced from such activities can damage DNA and cause replication error. We consider spontaneous mutation, which occurs because of stimulations other than artificial ones, as an equivalent stimulation and define 
$\kappa=\gamma d_{e f f}$

We can then obtain the following from the mouse data ${ }^{6}$.

$d_{\text {eff }}=1.11 \times 10^{-3} \mathrm{~Gy} / \mathrm{hr}$

Compared to the current dose rate in Fukushima, which is of the order of $\mu \mathrm{Sv} / \mathrm{hr}(\approx 1 \mu \mathrm{Gy} /$ hr), it is 1,000 times as high and does not even compare to the global average natural dose rate of $2.74 \times 10^{-7} \mathrm{~Gy} / \mathrm{hr}(2.4 \mathrm{mGy} / \mathrm{yr})$. According to the analysis by Tubiana et al., the equivalent dose rate for a spontaneous mutation rate in humans is $8.4 \mathrm{mGy} / \mathrm{h}$, which is consistent with the value for mice ${ }^{12}$.

\section{Summary}

This article introduced recovery mechanisms such as cell proliferation and apoptosis as well as the reparing function; death of normal cells and changes to mutated cells caused by radiation; and the "Whack-A-Mole model of destruction and repairing" for normal cells and mutated cells, with consideration for the death of mutated cells by radiation. Studying the functions of organisms means recognizing their strength for survival. LNT is only established when the recovery functions are weak. The dose rate effect could be observed for drosophila if we had low-dose data. With a high dose rate, repair could not catch up in a short time, and mutated cells rapidly increased, showing the symptoms of LNT in mice.

If we can understand the effect of radiation on organisms in a unified manner with the scaling rule, it will become the basis for estimating the same effect on humans. We can go beyond the qualitative assessment and possibly make a quantitative assessment. This will need to be verified through the use of epidemiology, biological experiments, and physical experiments.

After the Fukushima Daiichi Nuclear Accident, the "Committee on low-dose radiation effects" was established, wherein physicists and biologists engaged in heated debates. Bando used her experience in traffic flow theory to start the study, and Manabe, Kento Ichikawa, and Nakamura joined the research. We wanted to somehow quantify the effect of radiation by utilizing mathematical models and saw a hint in equations given in the "voices of the members" (Takashi Inamura: Journal of Physical Society of Japan, November 2011) ; on the basis of these factors, we developed this model. Later, Tsunoyama and Nakajima, with their expertise in plants and animals, joined, creating an interdisciplinary network. We received support from numerous individuals; from biology: Mitsuyuki Abe, Hiroshi Utsumi, Kazuko Uno, Shunichi Takeda, Ohtsura Niwa, Michiaki Kai; from the American Physical Society: Hanna M. Dobrovolny and Michael Ellis; and for advice on mathematical calculation: Takuya Matsuda and Hiroshi Isaka et al.

We held discussions across fields such as radiation biology, medicine, physics, and information science. This effort convinced us that serious exchange among diverse fields can lead to a new, fused field. The Fukushima Daiichi Nuclear Accident was no doubt a severe experience, but it served as an opportunity to re-examine the meaning of science. We wish to continue this pioneering work and expand our knowledge in new areas. We hope that doing so is a scientists'way of contributing to the rehabilitation of Fukushima. 


\section{Acknowledgment}

This research was partly supported by the Toyota Physical and Chemical Research Institute Scholars in 2014.

Added entries by author 24, July, 2018.

The later development of this research and its future prospects were presented at the "International Workshop on the Biological Effects of Radiation -bridging the gap between radiobiology and medical use of ionizing radiation-" (HP: https://www.rcnp.osaka-u.ac. jp/ ber2018/), which was held at the Osaka University Nakanoshima Center in March 2018. The content of this presentation is scheduled to be published in a Special Issue of the International Journal of Radiation Biology.

The other research activities of our group are published at https://www.rcnp.osaka-u.ac. jp/ manabe/project.html.

Moreover, this research requires interdisciplinary cooperation. Thus, we established Committees for Research Promotion in Specialized Areas on "multidisciplinary research on biological effects of radiation" at Japan Society for the Promotion of Science in October 2015, with Dr. Takahiro Wada from Kansai University as the chairperson. This committee supports multidisciplinary research based on purely scientific discussions, and its objective is to construct a common platform for promoting comprehensive studies on the impact of radiation through active exchange of opinions between the industry and academia. Though it is planned to cease operations in September 2018, we are currently exploring ways of continuing such activities. The aforementioned international conference was hosted by our committee, and we decided to work toward the construction of a platform for "multidisciplinary research on biological effects of radiation."

\section{References}

1) Muller HJ. Science. 1927; 66:84.

2) Kelly EM, Russell WL. Proc. Natl. Acad. Sci. 1982; 7(92) :542.

3) Douglas LE. Actions of Radiations on Living Cells. Cambridge University Press, 1954.

4) Chadwick KH, Leenhouts HP. Phys. Med. Biol. 1973 1(81):78.

5) Kellerer AM, Rossi HH. Radiat. Res. 1978; 75(3) :471.

6) Manabe Y, Ichikawa K, Bando M. J. Phys. Soc. Jpn. 2012; 81:104004. Manabe Y, Bando M. J. Phys. Soc. Jpn. 2013; 82:094004.

Manabe Y, Nakamura I, Bando M. J. Phys. Soc. Jpn. 2014 accepted.

7) Richards FJ. J. Exp. Bot. 1959; 10(2) : 290.

8) Spencer WP, Stern C. Genetics. 1948; 33(1):43.

9) Mabuchi T, Matsumura S. Jpn. J. Genet. 1964; 39:131.

10) Sparrow AH, Underbrink AG, Rossi HH. Science. 1972; 176(4037):916 Nauman HC, Underbrink AG, Sparrow AH. Radiat. Res. 1975; 62:79.

11) Yamaguchi H, Shimizu A, Degi K, Morishita T. Breeding Sci. 2008; 58(3) :331.

12) Tubiana M, Feinendegen LE, Kaminski JM. Radiology. 2009; 251(1):13. 


\title{
Low-dose Radiation Effects to Humans and the Importance of Eating Wisely
}

\author{
Louis Pasteur Center for Medical Research, Kazuko Uno
}

More than three years have passed since the Fukushima Daiichi Nuclear Power Plant Accident caused by the Great East Japan earthquake on March 11, 2011. Still, there are more than 120,000 evacuees who were forced to take refuge elsewhere, in and outside the prefecture. Immediately after the accident, residents were severely anxious about the health effects of low-dose radiation, especially on children. Some people are relieved that three and a half years later, there are no significant effects despite their original concerns. However, radiation is still a significant emotional burden on residents in Fukushima prefecture as many people are still uneasy about the possible long-term effects. This paper is based on a presentation "The effects of low-dose radiation on humans and the importance of eating wisely," that was geared towards women, and presented at the Atomic Energy Society of Japan Symposium. Although my expertise is in immunology and not radiology, being deeply involved in the radiation and other dire issues facing Fukushima from March 2011, has shaped my awareness of the complexities involved. Additionally, actively doing outreach activities with evacuees and other residents in Fukushima several times a month for the past three years combined with specialized knowledge has allowed the author to for focus on relevant subjects that other researchers do not touch upon. Some information in this article may overlap those from a previous article "My Reasons for Writing the Book, "Overcoming Low-Dose Radiation Contamination" which appeared in this journal last year.

\section{Importance of Thinking Scientifically}

\section{1, What is the Most Influential Factor for Cancer Risk? Does Fear Reduce Immunity and Increase the Risk of Cancer More Than Exposure to Low-Dose Radiation?}

From March 11, 2011, until now, I have been explaining the effects of low-dose radiation to concern citizens in Fukushima. If the main concern in regard to low dose radiation is the risk of cancer, then my prior research has led me to believe that the introduction of a lifestyle that improves the immune function might be effective. 
In my studies, I measured the immune function of several thousand of cancer patients, patients inflicted with diseases such as hepatitis and diabetes and healthy individuals. The immune function in the sample groups was measured using several parameters including interferon (IFN) -production ability. IFN production ability was measured by quantifying the IFN produced in patients blood sample against a viral infection simulated in a test tube ${ }^{1)}$. The activity of natural killer cells against cancer cells that they attack cancer cells appeared in the body almost every day was also measured. I also developed a method to assess whether or not an immune response occurred in a cancerous site in a patient, and found that the prognosis was better in patients with activated T cells and that the performance status (PS) and quality of life (QOL) of the patients were more important for the immune function (although the size and stage of the cancer surely influenced the same) ${ }^{2}$. PS is an approximation of cancer patients' general well-being and physical activity level in their daily life. A healthy and active cancer patient would be rated (PS0), up and about more than $50 \%$ of the day (PS2), and bedridden (PS4). These results became the contents of presentations I gave lecture exclusively to cancer patients; these presentations were also posted on the home page of "NPO Einstein," a volunteer group of scientists to which I belong just at the end of March, 2011.

Based on the aforementioned data, and other exhaustive studies done on radiation and the onset of cancer, I personally, even in 2011, did not believe that cancer risk would increase by a significant amount due to the radiation levels in Fukushima (except in the evacuated area where the radiation dosage was especially high). Rather, I believed that a decrease in immune function caused by people's excessive concern about the effects of the radiation and the stress associated with living as evacuees might increase their cancer risk. About a month after the accident I also become concerned about the high number of children in metropolitan areas who left vegetables from their school lunches uneaten because they were worried about radioactive contamination in the food. Hearing this, I have consistently warned that a lack of vegetables also increases cancer risk. I still talk about the relationship between cancer and immune function based on past studies, and try to introduce the foods and lifestyle that prevent cancer.

\section{Effects of Radiation and Reactive Oxygen Spaces}

So-called oxygen radical (reactive oxygen species), such as the superoxide and hydroxyl radical produced when radical hits water in the body, indirectly damaging a gene is more common than damage from radiation hitting a gene directly. This issue is an extension of my research specialty, and so I could play a role in explaining these effects. Recently, it has been shown that the effect of oxygen radical, namely those of oxidative stress, has been substantial in various so-called adult diseases including cancer. In the field of longevity and anti-aging medicine, oxidative stress is considered the chief culprit that causes rust in the body and has been found to be responsible for many age-related diseases, such as arteriosclerosis, myocardial infarction, Alzheimer's, cancer, diabetes, gastric ulcers, and cataracts.

Aging and inflammation was a topic of particular interest to me even before the Daiichi Accident. I believe that the accentuation of a particularly weak chronic inflammation was related to various diseases and many so-called adult diseases ${ }^{3)}$. In fact, it has been proven that IL-6, an inflammatory cytokine produced in the presence chronic inflammation, tends to increase as people age. Meanwhile, it was also found that this IL-6 had a dose-dependent, upward trend of exposure in atomic bomb survivors ${ }^{4}$.

Recent research has been probing into diseases other than cancer that may be influenced by radiation. Data accumulated on the aging population of atomic bomb survivors, show that the risk of circulatory diseases in particular, increases under the effects of radiation. The life 
expectancy survey conducted on the survivors of the atomic bombing in Hiroshima and Nagasaki, revealed that the effects of radiation are more increasingly apparent as the follow-up period increases. In other words, in the study done from 1950 through 1965, a dose dependency was not observed at 1 Gy or less; while in the study conducted from 1966 through 2003, a dose dependent relationship was observed between radiation and the severity of circulatory diseases even for survivors who were exposed to lower doses of radiation ${ }^{5)}$.

The excess relative risk of circulatory disease per $1 \mathrm{~Gy}$ of radiation exposure was 0.11 , which was not much larger than 0.47 for solid carcinoma. However, when we examined the cause of death of 50,620 people, who died between 1950 and 2003, the number of people who died of all types of solid carcinoma such as stomach cancer, colon cancer, and breast cancer (whole solid carcinoma), was 10,929 , while the number of people who died of circulatory system disease was 19,054 . This is approximately two times more than the total deaths from cancer. This excess dose dependency is still evident even at lower doses as the study period gets longer.

Recently, it has also been found that oxygen radicals which causes various diseases, is produced by not only ionizing radiation but also by smoking, obesity, various environmental factors, and repeated infections (Figure 1).

Reactive oxygen is not always bad for living organisms, on the contrary, it is essential. Many aerobic organisms produce reactive oxygen in a metabolic process using oxygen in the mitochondria to obtain the energy necessary to survive. This activated oxygen damages cells and may lead to cancer and other diseases including so-called adult diseases. On the other hand, living organisms also use oxygen radicals for sterilization and detoxification, and terrestrial organisms in particular, have developed a system that erases any damage caused by activated oxygen.

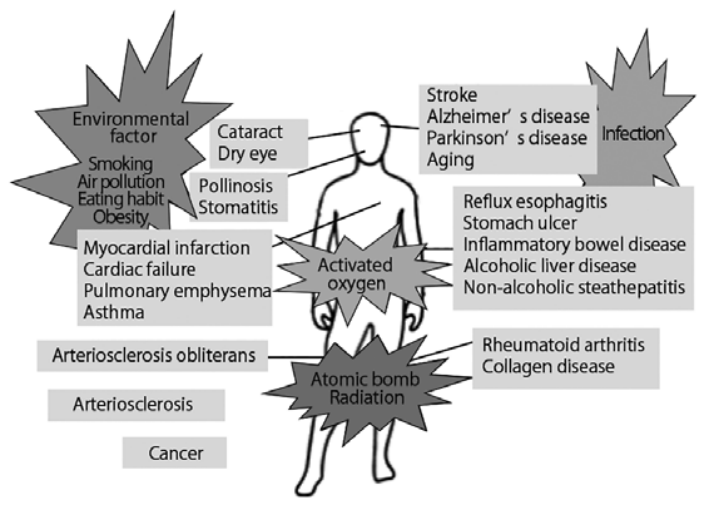

Figure 1 Activated oxygen and disease

\section{Understanding the Formidability of Living Organisms}

Since March 11, 2011, researchers, especially physicists, have begun to ascribe to the theory that "If the double-stranded of DNA (gene) is cut, it is permanently damaged; this damage accumulates, and cancer develops. I disagree with this notion and believe that it reflects a lack of understanding of the recent discoveries in biology. The fact is that cancer does not develop so easily or rapidly. In fact, even if there is some damage to double-strand chain DNAs, the majority is usually repaired.

Even if a genetic mutation occurs, it does not immediately become a life-threatening form of cancer in living organisms. The first defense system is an antioxidant, glutathione, and an 
anti-oxidative enzyme that living organisms have. These detect and detoxify the oxygen radicals. Next, the system that immediately assesses and restores the mutation when the gene is damaged operates. A representative tumor-suppressor gene, p53, plays an important role by checking whether the damage is too severe to repair and allows the cell to self-destruct. The mutant cells that pass through these processes are targeted and eliminated by immune cells. This process clearly functions like a multi-stage cancer protection system. Note, that organisms that breathe oxygen and live on land have acquired this system to protect them from the damage caused by leaking oxygen, rather than a system that has been acquired specifically to guard against radiation.

Biologists believe organisms can live on Earth because they have acquired this multi-protection system through an evolutionary process in which a dangerous substance must be removed; a gene must be repaired, if damaged; a cell must die if it cannot be repaired; and the same cell must be destroyed if none of the above works (Figure 2). The important principle for everyone to understand is that oxygen-breathing organisms are routinely damaged by reactive oxygen; therefore, human beings could not survive for 80 years if they could not self-repair after exposure to low dose radiation. After the Daiichi Accident, many medical doctors were reported in the media as saying that smoking has a higher cancer risk than exposure to radiation at the levels found in Fukushima. From my point of view, this was obviously true; however, physicists expressed their opposition to the notion, arguing that the effects of radiation and the effects of smoking cannot be compared. On the contrary, these effects are comparable. The effect of low-dose radiation is largely due to the reactive oxygen produced when radiation hits water, and smoking and various mutations can also generate oxygen radicals.

In regard to the evolution of the earth, there was no free oxygen during the initial stage of the birth of life. Oxygen became available with the emergence of photosynthetic organisms, and finally, oxygen-breathing organisms evolved. Since breathing oxygen is accompanied by oxidative damage, oxygen-breathing organisms also evolved and developed a system to overcome damage from oxygen radicals. Without this basic understanding that it is not necessarily catastrophic when a gene or cell is damaged, fear surrounding low-dose radiation cannot be overcome. Living organisms are repeatedly undergoing cycles of injury and repair.

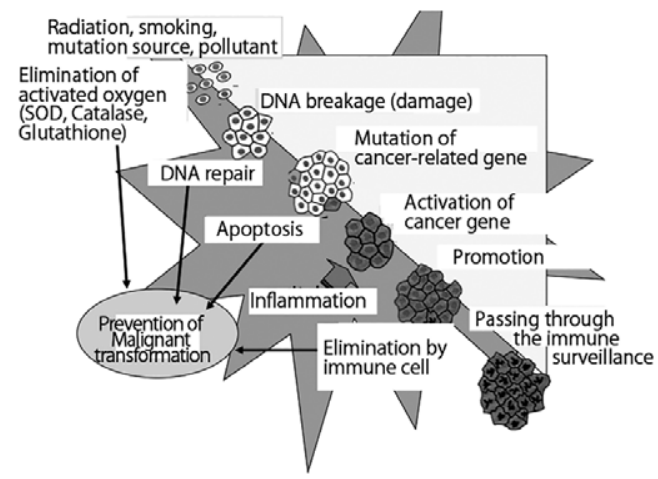

Figure 2 Malignant transformation process and multi-stage suppression mechanism

\section{Effects of Radiation and Ability to Defend}

It is generally believed that our body's response to radiation depends on the level of exposure. Specifically, the probability of an effect increases with dose. The effects of high dose 
radiation that exceeds a certain threshold are called deterministic; everyone exposed at these high levels will show the same negative symptoms. However, the effect that may occur as a result of low doses of radiation are considered probabilistic; meaning negative effects don't always occur, and when they do, the severity of these radiation-induced effects are different in each individual.

While this is an accepted theory, I do not believe these definitions should be used in health education. There are people who develop cancer and those who do not even though they are exposed to the same levels of radiation. Thus, it is also a fact that the outcome of radiation exposure cannot always be determined by probability. In reality, the balance among the amount of mutation source, the quality of the host defense system, the genetic background as well as the life style of the individual are very important factors that determine the effect of low dose radiation. Due to this, it is important to undertake a lifestyle that increases our natural defensive abilities. The way an individual lives from now on will change his or her life 20 or 30 years in the future.

When considering an appropriate lifestyle to improve immune ability, it should be noted that fear and stress worsen immune function, while a life lived with purpose and laughter improves it. In the previous studies, the activity of natural killer cells was enhanced in participants who were given cosmetic therapy. The same effect was found for image therapy, in which people imagined that their immune cells were attacking cancer cells. As an application of the cosmetic therapy, Fukushima residents who attended my lectures were given hand massages. The hand massage is warming and improves blood flow to the hands. Additionally, although these results are only preliminary, decreased amylase activity was observed in participants after the massage, indicating that stress was decreased. Above all, participants' mood softened. It seems that through these lectures, participants learned first-hand how they can better deal with the effects of low dose radiation by improving their immune system, rather than worrying a lot.

At this point (three and a half years since the accident), it is clear that the initial concern radiation contaminated food was unwarranted. This is evident from the results of the wholebody counter tests in residents and the testing of meals prepared by households in Fukushima by Co-op Fukushima (one extra meal was prepared for two days and sent to an inspection center to precisely measure the radiation dosage). I am convinced that there will be no significant health consequences due to low dose radiation in children in the near future if children are eating well. I believe there is a need for more people to eat meals that are high in antioxidants, so as to overcome any damage caused by radiation thus far, and as a way to prevent cancer and adult diseases in the future.

Instead of radiation, a more realistic problem in Fukushima in the near future is obesity in children and evacuees, which is a result of stress and lack of exercise.

\section{Moving Beyond Scientific Issues and the Effects of Low- Dose Radiation}

\section{Effects of Radiation and Crisis Communication}

It was shocking to see the graphical representation of evacuees moving out of Fukushima Prefecture. Since timely data on the evacuees were not compiled in March 2011, the actual situation immediately after the accident is unknown. However, it is apparent that the number 
of residents moving outside the prefecture increased around the summer of 2011 until early 2012 (Figure 3). The number of evacuees who moved to neighboring Yamagata Prefecture was particularly astonishing.

Looking back, the situation regarding the Fukushima Daiichi Nuclear Power Plant should have calmed down to a certain degree by the summer of 2011. It seems that the tense atmosphere that remained was affected by: (1) the comments by cabinet advisor Toshiso Kosako on April 29, 2011 that the radiation reference value of $20 \mathrm{mSv} / \mathrm{year}$ on a school ground was unacceptable and, (2) the testimony of Tatsuhiko Kodama, a professor at The University of Tokyo, at the Diet on July 27, 2011. Both had a big effect on the situation. However, when the author interviewed residents who evacuated not immediately after, but some time after the accident, they said that they decided to evacuate because they were skeptical about the government's statements when the decision was made to evacuate Iitate village one month after the accident. Many evacuees believed they could no longer trust the government because of the confusion caused when the evacuation order was issued one month after the accident, although just two weeks prior the government said that there was no immediate need to evacuate Iitate village. The reason why such an overwhelming number of Fukushima residents choose to evacuate out of the prefecture should be examined thoroughly in the future.

In addition, the effects of the dispute among scientists over the effects of low-dose radiation cannot be ignored. I noted that after the accident, researchers in the field of physics and biology/medicine who spoke out in the media had different perceptions of radiation from researchers in physics and biology/medicine in Kyoto. In times of crisis, it may be better to have a thorough interdisciplinary discussion among scientists to address differences in opinion and reach a consensus before speaking to the public.

This time, there were significantly different notions of "radiation" and "gene damage," especially among the researchers in the fields of physics and medicine/biology which seemed to cause confusion. The ALARA principle (As Low As Reasonably Achievable) has taken root among physicists, and there were strong sentiments against even the tiniest amount of radiation exposure that minimally exceeded the norm. On the other hand, researchers in the fields of medicine and biology understand that extremely high doses of radiation are used beneficially in cancer therapy and that genes are repeatedly damaged and repaired enabling humans to survive.

Three and a half years after the accident, the problems caused by excessive evacuation have also become clearer. Being over-cautious against every risk was the source of major confusion at the time of the crisis. Unlike short-term evacuation, the negative effects of long-term

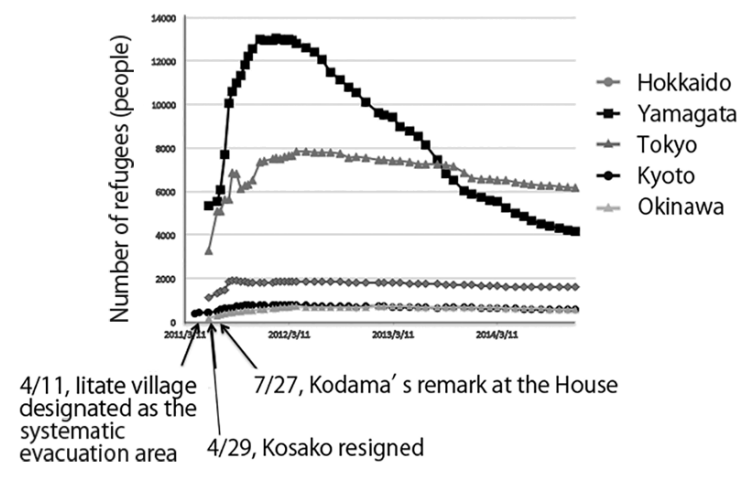

Figure 3 Movement of refugees from Fukushima to outside prefecture 
evacuation are blatant and cannot be ignored. In particular, the evacuation order based on the distance from the Fukushima Nuclear Power Plant brought miserable consequences to so-called "Weak evacuees", such as sick and elderly residents ${ }^{6}$. Currently the Japanese Red Cross Society is reviewing their guidelines for nuclear emergencies. Unlike other disasters, the protocol for nuclear disasters should be that residents remain where they are and evacuate only after deciding where to go; this will minimize the number of evacuees. Although countermeasures were implemented such as installing a filter unit to reduce the radiation leak from the nuclear power plant (based on the lessons learned from the Three Mile Island and Chernobyl disasters), what should be reflected upon is that there were no discussions about how to prepare for a nuclear emergency in Japan.

\section{Education about Radiation, Atomic Bombs, and Nuclear Power Generation}

Japan has experienced atomic bombs, and has stopped considering and arguing calmly about the effects of various doses of radiation. Having seen that atomic bombs and nuclear power generation were talked about with almost similar images on occasion, I felt a harmful influence in the past 40 years, during which we have not provided proper education about radiation. It is desirable to learn about the scientific side of radiation to limit education about radiation to the atomic bombs and nuclear disasters. The need to start with the commonplace, such as determining the dosage and scientifically evaluating it, will be increasingly called into question in the future.

\section{Issues That Cannot be Solved with Science}

The problem: the evacuation of Fukushima residents, which was meant to be only temporary, became prolonged and developed into a dire problem. The facts: houses that were intact with no major damage were located in 'no-go' areas and became breeding grounds for wild mice. These problems and facts weigh heavily on the hearts of the evacuees. In Minamisoma city, some residents commented that, "I do not grow the rice, if it cannot be sold. I have the compensation money anyway." Fukushima rice has very poor sales because it has developed a reputation for being unsafe. Food-service brokers took advantage of this, by demanding drastic price reductions, telling farmers, "The price difference would be compensated for with government reparations anyway." I realize that Fukushima residents have so many problems that cannot be solved by simply explaining low dose radiation and its scientific effects.

\section{References}

1) Uno K, Nakano K, Maruo $\mathrm{N}$ et al. The determination of IFN $(-\alpha)$ producing capacity in patients with various diseases and healthy persons using whole-blood cultures. J. IFN Cytokine Res. 1996; 16:911-918.

2) Uno K, Setoguchi J, Tanigawa $M$ et al. Differential interleukin 12 responsiveness for interferon gamma production in advanced stages of cancer patients correlates with performance status. Clin Cancer Res. 1998; 4:2425-2432.

3) Uno K. Anti-aging of immunity. Sogo-Rinsho (Clinic All-Round.) 2011;60:343-350. [in Japanese]

4) Kusunoki Y, Hayashi T. Long-lasting alterations of the immune system by ionizing radiation exposure: implications for disease development among atomic bomb survivors. Int. J. Radiat. Biol. 2008; $84: 1-14$.

5) Ozasa K, Shimizu Y, Suyama A, et al. Studies of the mortality of atomic bomb survivors, Report 14, 1950-2003: an overview of cancer and noncancer diseases. Radiat Res. 2012; 177:229-243.

6) Aikawa Y. Weak evacuee: Toyo Keizai Inc; 2013. [in Japanese] 


\title{
Radiation and Children's Health
}

\author{
Ichikawa Clinic, Yoko Ichikawa
}

Since the Tokyo Electric Power Co.'s Fukushima Daiichi Nuclear Power Plant disaster triggered by the Great East Japan Earthquake, the citizens of Fukushima Prefecture have lived with anxiety and rumors caused by the considerably confusing information regarding the health effects of the radiation exposure. The real nature of this anxiety can be summed up in two points: (1) the future being unclear and (2) not knowing what can be trusted. It is thought that most of the causes of such are due to having believed false information regarding the radiation and because of not being able to understand the right information correctly.

For the healthy growth of children in Fukushima Prefecture, it is indispensable that we, the adults, properly understand the correct information about the radiation, and we need to have the strength to raise our children in this place with resolute minds and confidence so as to not be defeated by anxiety and rumors. The author feels, based on the interactions with parents, that the misunderstandings and anxieties regarding radiation still remain and summarizes the kinds of ideas that are important in order to solve this issue.

\section{Past Developments}

Just after the nuclear power plant accident, the government's expression, "No immediate health effects" gave rise to negative speculation. The interpretation, "There must be some kinds of effects, which are not immediate, in the future" was spread as if it was true. The emergency measure, "Exposure to radiation that does not exceed $20 \mathrm{mSv}$ per year" also created a misunderstanding that people were forced to be exposed to radiation at that dosage. There were also conflicting opinions. One was that of the experts that there would be few long-term human health influence. The other, espoused by those who considered themselves to be knowledgeable, was that the health effects would certainly appear eventually, and that all children in Fukushima Prefecture should be evacuated. Furthermore, in the opinions of most in the media and on the Internet, the web of false information was confusing, and the experts, who advocated that there were little health effects, were criticized as being government-patronized scholars. The author has the impression that such criticism made many 
doctors in Fukushima Prefecture stay quiet. Moreover, the appropriateness of the use of nuclear energy and the human health influence of the radiation exposure because of this accident were discussed in the same context in some instances, and the general population in Fukushima Prefecture has lived in anxiety, making it unclear who or what to trust.

\section{Misunderstandings Regarding Radiation}

The author has been holding lectures regarding "Radiation and Children's Health" in various venues in Fukushima City since October 2011, with the aim of alleviating the anxiety of child-rearing parents, in cooperation with the Department of Health Promotion in Fukushima City and the Committee on Mother and Child Health of the Medical Association of Fukushima City. It was found, based on the questions received during those lectures and from daily outpatients, that there were several misunderstandings regarding the radiation.

\section{Does the Radiation Received Accumulate in the Body and Result in Health Damage?}

Understanding the cumulative amount of radiation received is important to understand the effects of radiation on the body. However, it has been found that more than a few people thought that they were exposed to radiation because this cumulative amount remained in the body or, in other words, because the external dosage remained in the body upon exposure. This misunderstanding was particularly common among elderly people. It is thought that the information about the dosage of $20 \mathrm{mSv}$ and such created this misunderstanding, "It is dangerous when it stays in the body." Internal exposure was confused with external exposure.

\section{Does Low-Dose Exposure have an Influence on Children in Fukushima?}

We can still find blog posts and tweets claiming that there are abnormalities in children in Fukushima due to the low-dose exposure. "Nose bleeding comics" caused controversy recently, and the magnitude of the misunderstanding was re-experienced. It is a clear misunderstanding that the number of children who experience nosebleeds increased in Fukushima Prefecture after the accident due to radiation exposure. Radiation exposure causes nose bleeding when one is exposed to high doses (500-2,000 mSv), which inhibits the hematopoietic functions of bone marrow. In other words, it is the manifestation of a deterministic effect (Figure 1). Such high doses of radiation could not occur in the areas in Fukushima where the general public lives, even during the time of the accident, and nose bleeds due to radiation exposure are medically inconceivable.

The health effects that one should be concerned with regarding the radiation exposure caused by this nuclear power plant accident are the existence of an increase in cancer and leukemia cases due to long-term low-dose exposure. This is a stochastic effect (Figure 2). It is becoming more and more clear that the possibility is extremely low based on past health surveys of citizens of the prefecture. Nevertheless, the deterministic effects and the stochastic effects are often confused. In fact, we can find such false information on the Internet regarding the health effects covered in Fukushima.

One of the reasons that there is no end to such a misunderstanding is because, "radiation damages genes." Therefore, it creates the perception that radiation is terrible, that the slightest 


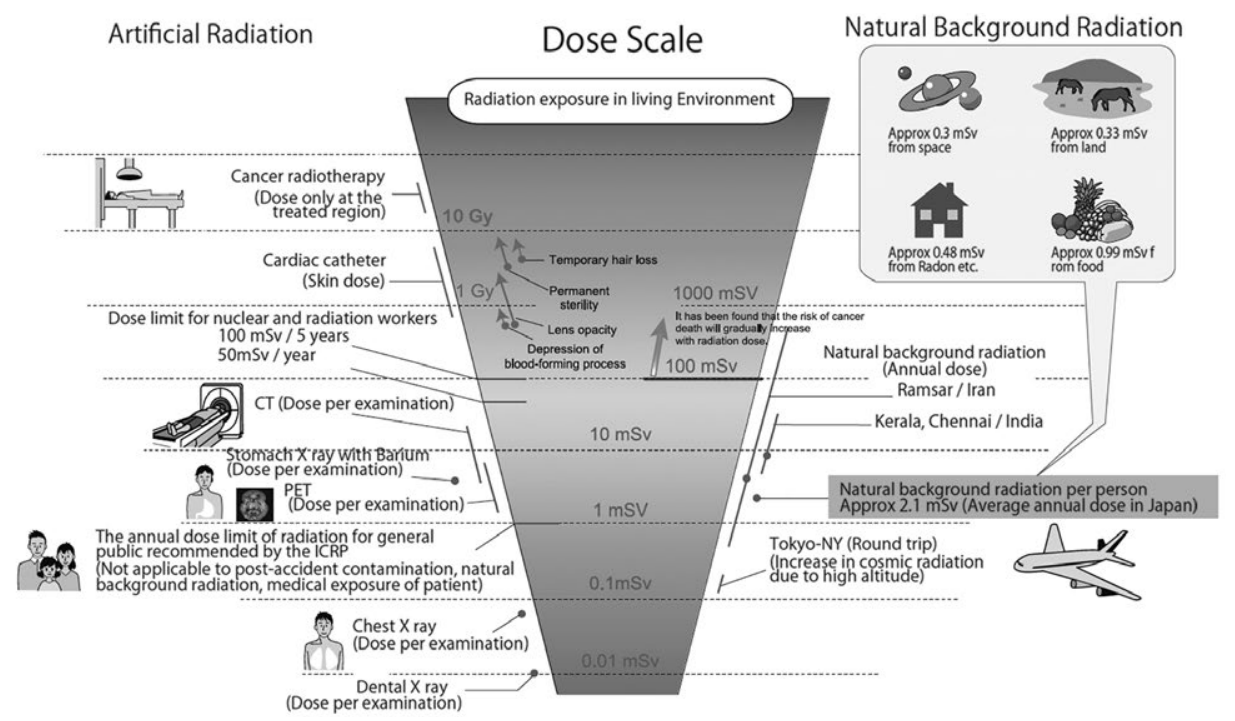

Figure 1 Comparison of Exposure Doses (Simplified Chart)

Retrieved from National Institute of Radiological Sciences web site.

Deterministic effect: Eliminate the effect by limiting the dose below the threshold

Stochastic effect: Assume that there is no threshold and lower the dose as much as possible to

make the probability that the effect appears to be at an acceptable level

* Threshold: The value at the boundary regarding whether a certain action induces a response

Deterministic effect (alopecia, cataract, etc.)

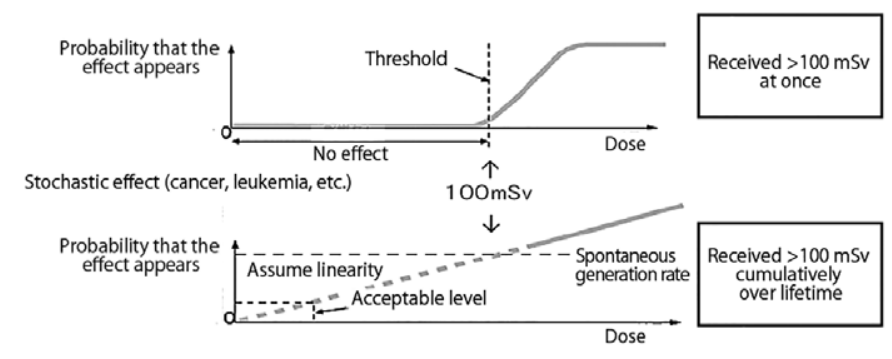

Figure 2 Thought process on radiation protection

Retrieved from "Committee on answering questions regarding radiation", Japan Atomic Energy Agency.

exposure can damage genes, and that the cells will become cancerous in the future. Speaking of the gene damage caused by radiation, radiation itself breaks down genes in around onethird of cases. Genes are more likely to be damaged by the activated oxygen generated by the radiation in the cell. Moreover, the factor that generates the activated oxygen is not limited to the radiation. It is known that the activated oxygen increases due to one's lifestyle, such as due to smoking, stress, etc., and the effects of one's mental condition. In this manner, genes in all cells are not only damaged by radiation. It is not widely known that approximately 70,000 genes in the cells are spontaneously damaged every day due to the activated oxygen generated in the body and repaired each time. 


\section{Are the Japanese Provisional Standards for Food too High?}

The provisional standards of radioactive cesium set by the government in fiscal year (FY) 2011 were: $200 \mathrm{~Bq} / \mathrm{kg}$ for drinking water, milk, and dairy products; and $500 \mathrm{~Bq} / \mathrm{kg}$ for vegetables, grains, meat, eggs, fish, etc., and food products exceeding these criteria were not allowed to be shipped. However, since not all bags of rice were inspected when they were shipped in this FY, rice having $>500 \mathrm{~Bq} / \mathrm{kg}$ was shipped from a part of the rice made in Fukushima. This made headlines and resulted in spurring on the damage caused by harmful rumors. If a Japanese adult eats rice with $500 \mathrm{~Bq} / \mathrm{kg}$ for 1 year (approximately $60 \mathrm{~kg}$ ), the internal exposure is calculated to be only $0.15 \mathrm{mSv}$ a year (Figure 3). Of course, this is a "hypothetical calculation" and does not mean that one can proactively eat rice with a higher radiation dosage than the provisional standards.

The standards have been further lowered since April 2012 and these continue to be used to this day. The current Japanese standards, including the provisional values, are considerably low, even when compared with the standards in the former Soviet Union at the time of the Chernobyl Nuclear Accident; countries such as Russia, Ukraine, etc., 5 years after the accident; and the EU (Tables $1 \& 2$ ).

The method used to determine the standards used by the Food Safety Commission is based on the determination, "The possibility of health effects becomes apparent when the cumulative dose exceeds $100 \mathrm{mS}$ as the lifetime additional exposure, except for dosages received during everyday life such as natural radiation (2.1 mSv/year in Japan), medical exposure, etc." The standards are then calculated so that the additional exposure received by ingesting food is within a range that does not exceed $1 \mathrm{mSv}$ a year.

In terms of cesium-137, it was also not generally known that the physical half-life and biological half-life in the body are different. The physical half-life of cesium-137 is 30 years,

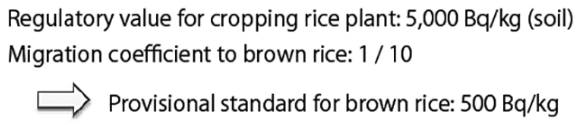

Because brown rice (particularly bran) contains a large amount of cesium, milling eliminates approx. $60 \%$ of cesium content.

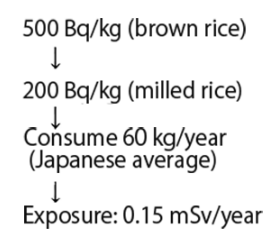

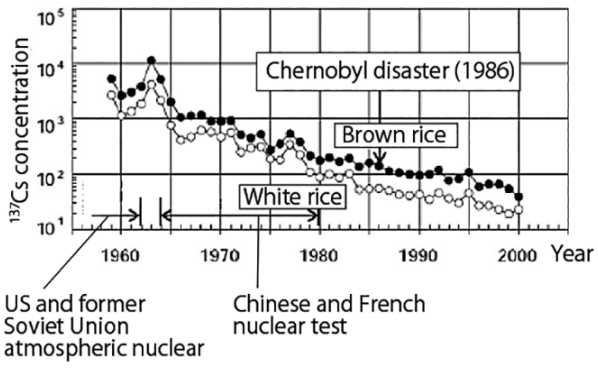

Cesium concentration in brown rice and white rice due to atmospheric nuclear test (time variation of national average)

Komamura, et al. Waga kuni no kome, komugi oyobi dojyō ni okeru 90Sr to 137C s nōdo no chōki monitaringu to hendō kaiseki [Long-term monitoring and variation analysis of $90 \mathrm{Sr}$ and $137 \mathrm{Cs}$ concentrations in rice, wheat, and soil in the country]. Nōkankenhō, 24: 1-21. (2006)

Figure 3 How about the effect of cesium contained in rice?

Retrieved from "Committee on answering questions regarding radiation", Japan Atomic Energy Agency. 
Table 1 Changes in the food intake tolerance level in the former Soviet Union-Russia, etc. Table: Action level for cesium in food $(\mathrm{Bq} / \mathrm{kg})$

\begin{tabular}{|c|c|c|c|c|c|c|c|c|}
\hline & Codex & $\mathrm{EC}^{*}$ & \multicolumn{3}{|c|}{ USSR, TPL } & Belarus & Russia & Ukraine \\
\hline & 1989 & 1986 & 1986 & 1988 & 1991 & 1999 & 2001 & 1997 \\
\hline Milk & 1,000 & 370 & 370 & 370 & 370 & 100 & 100 & 100 \\
\hline Baby food & 1,000 & 370 & - & 370 & 185 & 37 & $40-60$ & 40 \\
\hline Dairy products & 1,000 & 600 & 3,700 & $370-1,850$ & $370-1,850$ & $50-200$ & $100-500$ & 100 \\
\hline Meat & 1,000 & 600 & 3,700 & $1,850-3,000$ & 740 & $180-500$ & 160 & 200 \\
\hline Vegetable & 1,000 & 600 & 3,700 & 740 & 600 & $40-100$ & $40-120$ & $40-70$ \\
\hline Bread & 1,000 & 600 & 370 & 370 & 370 & 40 & $40-60$ & 20 \\
\hline
\end{tabular}

* Action level for imported food prompted by the Chernobyl disaster

April 24, 2007: The Japan Nuclear Safety Commission Retrieved from the Nuclear Safety Commission and "Q\&A for radiation and food," Consumer Affairs Agency.

\section{Changes in the standards for radioactive cesium intake limits in Japan}

\begin{tabular}{|c|c|c|c|c|}
\hline Drinking water & \multirow{2}{*}{200} & & \multicolumn{2}{|c|}{ After April 1, 2012} \\
\hline Milk, dairy products & & & Drinking water & 10 \\
\hline Vegetables & \multirow{3}{*}{500} & & Milk, baby food & 50 \\
\hline Grains & & & General food & 100 \\
\hline Meat, egg, fish, etc. & & $(\mathrm{Bq} / \mathrm{kg})$ & & $(\mathrm{Bq} / \mathrm{kg})$ \\
\hline
\end{tabular}

Table 2 Guidelines on radioactive substances in food around the world $(\mathrm{Bq} / \mathrm{kg})$.

\begin{tabular}{|c|c|c|c|c|c|c|c|}
\hline Nuclide & Japan & & Codex & & EU & & US \\
\hline \multirow{4}{*}{ Radioactive cesium } & Drinking water & 10 & & & Drinking water & 1,000 & \multirow{4}{*}{ All foods $\quad 1,200$} \\
\hline & Milk & 50 & & & Dairy products & 1,000 & \\
\hline & Baby foods & 50 & Baby foods & 1,000 & Baby foods & 400 & \\
\hline & General food & 100 & General food & 1,000 & General food & 1,250 & \\
\hline Upper limit for additional dose & \multicolumn{2}{|l|}{$1 \mathrm{mSv}$} & \multicolumn{2}{|l|}{$1 \mathrm{mSv}$} & \multicolumn{2}{|l|}{$1 \mathrm{mSv}$} & $5 \mathrm{mSv}$ \\
\hline $\begin{array}{l}\text { Estimated percentage of foods that } \\
\text { contain radioactive substances }\end{array}$ & \multicolumn{2}{|l|}{$50 \%$} & \multicolumn{2}{|l|}{$10 \%$} & \multicolumn{2}{|l|}{$10 \%$} & $30 \%$ \\
\hline
\end{tabular}

※ecause the standard values take the amount of consumption of foods, and estimated percentage of foods that contain radioactive substances, etc., into consideration, it is not possible to compare only the numerical values. The upper limits for additional doses from foods in the Codex, $\mathrm{EU}$, and Japan are the same at $1 \mathrm{mSv} /$ year.

whereas the biological half-life in the body is $9,38,70$, and 90 days in infants, children age $\leq 9$ years, individuals aged $\leq 30$ years, and individuals aged $\leq 50$ years, respectively. In other words, the biological half-life in the body is shorter in younger children, whose metabolism is faster. Even though the same quantity of food with the same $\mathrm{Bq} / \mathrm{kg}$ is taken in, children excrete it from the body more quickly than adults.

Most of the agricultural products currently distributed in Fukushima have a radiation level below the detection limit. Despite that, there is also a misunderstanding regarding internal exposure, because it is said that infants are more susceptible to radiation; it is regrettable that there are still people who are hesitant to consume agricultural products made in Fukushima. 


\section{Will There be Thyroid Cancer and Other Health Effects in Many Children in Fukushima in the Future?}

Self-proclaimed experts have actively voiced this idea since just after the accident, and many mothers and children voluntarily evacuated because of that. However, the fact that this concern is extremely low is becoming clear based on the health survey conducted on the citizens of the Prefecture described below as well as other surveys. In reality, however, due to this false information, the younger generation still secretly has anxiety as to whether or not they are allowed to get married, and regarding whether it will be all right for them to have children in the future.

Why, then, do such things have to be said about the children in Fukushima in this way? One of the major reasons may reside in the fact that thyroid cancer increased among children due to the Chernobyl Nuclear Power Plant disaster. The fact that the TEPCO Fukushima Daiichi Nuclear Power Plant disaster was classified as level seven on the International Nuclear Event Scale (INES)-the same as Chernobyl-1 month after the accident is also one of the factors. In other words, it ended up giving rise to speculation that the same thing that happened in Chernobyl would happen in Fukushima as well.

However, in reality, the magnitude of the accidents and the measures and steps taken by the governments just after the accidents were different (Table 3). Furthermore, the healthcare and the economical background as well as the lifestyles, including the food of inhabitants between the former Soviet Union (at the time of the accident) or Russia, Ukraine, and Belarus (thereafter), and current Japan were also different.

Because a thyroid hormone is made from iodine, iodine is always stored in the thyroid gland at a certain ratio. Although iodine is contained in seaweed in large quantities, the inhabitants of the inland area in the former Soviet Union do not have a custom of eating seaweed, and many suffer from chronic iodine depletion. Radioiodine can easily enter a thyroid gland that lacks iodine. It is also thought that a custom of consuming many mushrooms, which easily absorb radioactive materials, resulted in even more radioiodine being absorbed.

On the other hand, Japanese have a custom of consuming iodine-rich seaweed and have a tendency toward having a chronic surplus of iodine. Therefore, it is thought that radioiodine

Table 3 Comparison between Chernobyl and Fukushima

\begin{tabular}{|c|c|c|}
\hline & $\begin{array}{l}\text { Chernobyl } \\
\text { April 26, } 1986\end{array}$ & $\begin{array}{l}\text { Fukushima Daiichi } \\
\text { March 11, } 2011\end{array}$ \\
\hline Reactor type & Graphite-moderated pressurized boiling water & Boiling water \\
\hline Containment vessel & No & Yes \\
\hline First response & Control rod not inserted & Control rod inserted \\
\hline Amount of radioactive materials released & 5.2 million $\mathrm{TBq}$ & 0.57 million $\mathrm{TBq}$ \\
\hline Announcement after the explosion & $\begin{array}{l}\text { After three days } \\
\text { Official announcement by the President was } 10 \text { days later }\end{array}$ & Same day \\
\hline Maximum air dose just after the accident & $3,306 \mu \mathrm{Sv} / \mathrm{h}$ & $170 \mu \mathrm{Sv} / \mathrm{h}$ \\
\hline Milk contained radioactive iodine & Circulated & No Circulated \\
\hline $\begin{array}{l}\text { Radiation dosage from } \\
\text { radioactive iodine }\end{array}$ & $50-100 \mathrm{mSv} \sim 2,000 \mathrm{mSv}$ & $\begin{array}{l}0.01 \sim 0.1 \mu \mathrm{Sv} / \mathrm{h} \\
(45 \% \text { of } 1,149 \text { people) }\end{array}$ \\
\hline Thyroid cancer & $\begin{array}{l}6,848 \text { people } \\
\text { (Younger than } 18 \text { yo. at the time of accident) }\end{array}$ & ? \\
\hline Number of death due to thyroid cancer & 15 people $(0.22 \%)$ & $?$ \\
\hline
\end{tabular}


has a difficult time entering thyroid glands that have a surplus of iodine. Furthermore, in terms of the response by the government after the accident, in the case of the former Soviet Union, the truth was concealed for three days, and the general public continued to live normal lives during that time. In contrast, in Fukushima the inhabitants in the surrounding area evacuated that same day. Although some local residents lived with a slightly higher radiation dose, the dose was much lower than the environmental pollution caused by the Chernobyl Accident. A subsequent survey also showed that the dose was not high enough to cause any human health influence. Shipments of all agricultural and livestock products from Fukushima were also suspended.

It is a mistake to argue as if the health effects caused by the Chernobyl disaster and the Fukushima Daiichi disaster are similar without considering such differences. To do so only gives rise to anxiety and confusion among the general public, who have lived and continue to live in Fukushima.

\section{Health Survey of the Inhabitants in the Prefecture}

Based on the results of the health surveys conducted thus far, it is becoming clear that the future health effects, regarding both the internal and external exposure, are extremely low in children.

\section{External Exposure}

According to the survey on external exposure conducted in each municipality in the prefecture using the glass badge, $>90 \%$ inhabitants received less than $1 \mathrm{mSv}$ per year, which is the long-term target for acceptable additional exposure set by the government based on the International Commission on Radiological Protection recommendations. Although some inhabitants received more radiation at first in 2011 (but even that dosage was not high enough to cause any human health influence), they were all adults, and it was thought that this was due to engaging in farming in the open air for a long time.

\section{Internal Exposure}

A survey on internal exposure using whole-body counting (WBC) has been conducted in each municipality in the prefecture since FY 2011. According to the aggregate total of the examination results from each municipality, the committed effective dose of all 7,204 people examined in October 2014 was $<1 \mathrm{mSv}$. The committed effective dose is the integrated value of close to the lifetime's worth (50 years for adults, 70 years for children) of an effective dose for internal exposure caused by radioactive materials taken into the body. It is calculated as if those doses were received in the first year. Similar to the external exposure, although some inhabitants appeared to have slightly more internal exposure at first in 2011 (this was also not a level that actually causes human health influence), it is believed that this was due to the consumption of vegetables, wild boar, etc., which were not measured.

Figure 4 shows the results of the WBC performed for children living in Minamisoma City at the Minamisoma Municipal Hospital in 2011. When the results of 527 children examined in September and October in 2011 and the results of 386 children of the same group examined in January 2012 are compared, just under $60 \%$ of them were at less than the detection limit in 


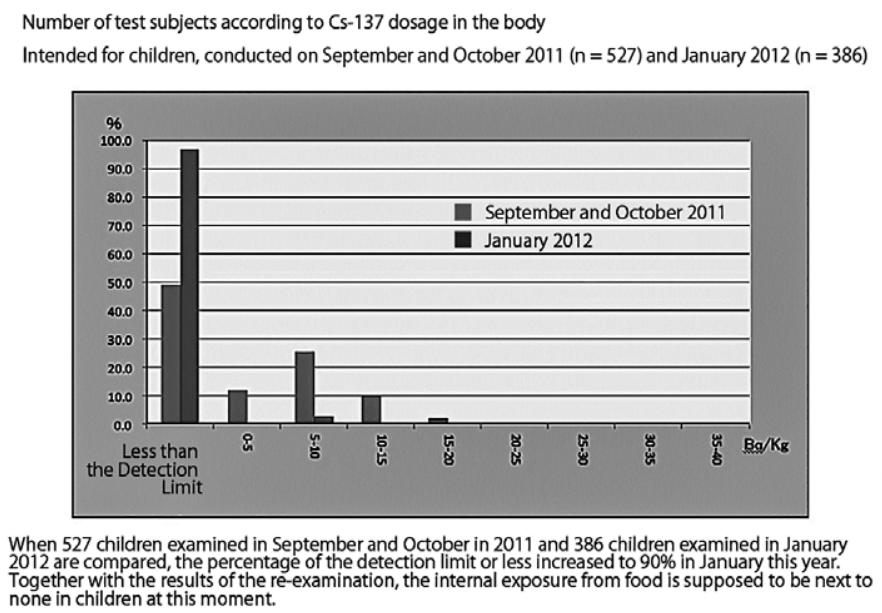

Figure 4 Internal exposure examination in Minamisoma City

Retrieved from Minamisoma Municipal Hospital website.

September and October, whereas the percentage increased to $90 \% 3$ months later in January, indicating the elimination of cesium from the body.

The consumers' cooperative Co-op Fukushima has been continuously measuring the radioactive materials contained in the food prepared with the cooperation of its members since November 2011 to confirm the safety of food and to eliminate the anxiety toward internal exposure. In the duplicate diet method, one more set of meals than those needed for the number of family numbers is prepared every time, and the radioactive materials contained in $1 \mathrm{~kg}$ of the 2 days' worth of meals are measured. Over $90 \%$ of the 100 households who participated in the survey used ingredients made in Fukushima.

In the second half of FY 2011, $\geq 1 \mathrm{~Bq} / \mathrm{kg}$ of cesium were detected in 10 households. If we assume that these households consume the same foods used for the measurement for 1 year and calculate the effective dose of cesium, it will only be approximately $\leq 0.02-0.14 \mathrm{mSv}$ per year. In the second half of FY 2013, $\geq 1 \mathrm{~Bq} / \mathrm{kg}$ of cesium were detected in four households out of 100. When we calculated the effective dose in the same way, it was $0.04 \mathrm{mSv}$ at the maximum. Most of that detected on the graph is potassium-40 (Figure 5).

Based on the observations above, it is assumed that the concern about human health influence due to internal exposure is next to none, even if people consume agricultural products from Fukushima.

\section{Thyroid Inspection}

In Fukushima Prefecture, thyroid gland examinations using ultrasound have been conducted for all children aged $\leq 18$ years in the prefecture, who were born at the time of the accident, since November 2011. The judgment of the results is done based on the criteria of the Thyroid Cancer Society as follows:

A: Considered to be within a normal range

A1: There are no cysts or tubercles

A2: Tubercles of $\leq 5.0 \mathrm{~mm}$, and/or cysts of $\leq 20.0 \mathrm{~mm}$

B: Tubercles of $\geq 5.1 \mathrm{~mm}$, and/or cysts of $\geq 20.0 \mathrm{~mm}$

C: A detailed examination appears to be required immediately

To compare this with other prefectures, similar examinations were also performed in three 
Cesium-134 Potassium-40

Cesium-137 Below determination limit (1 Bq/ $/ \mathrm{kg})$
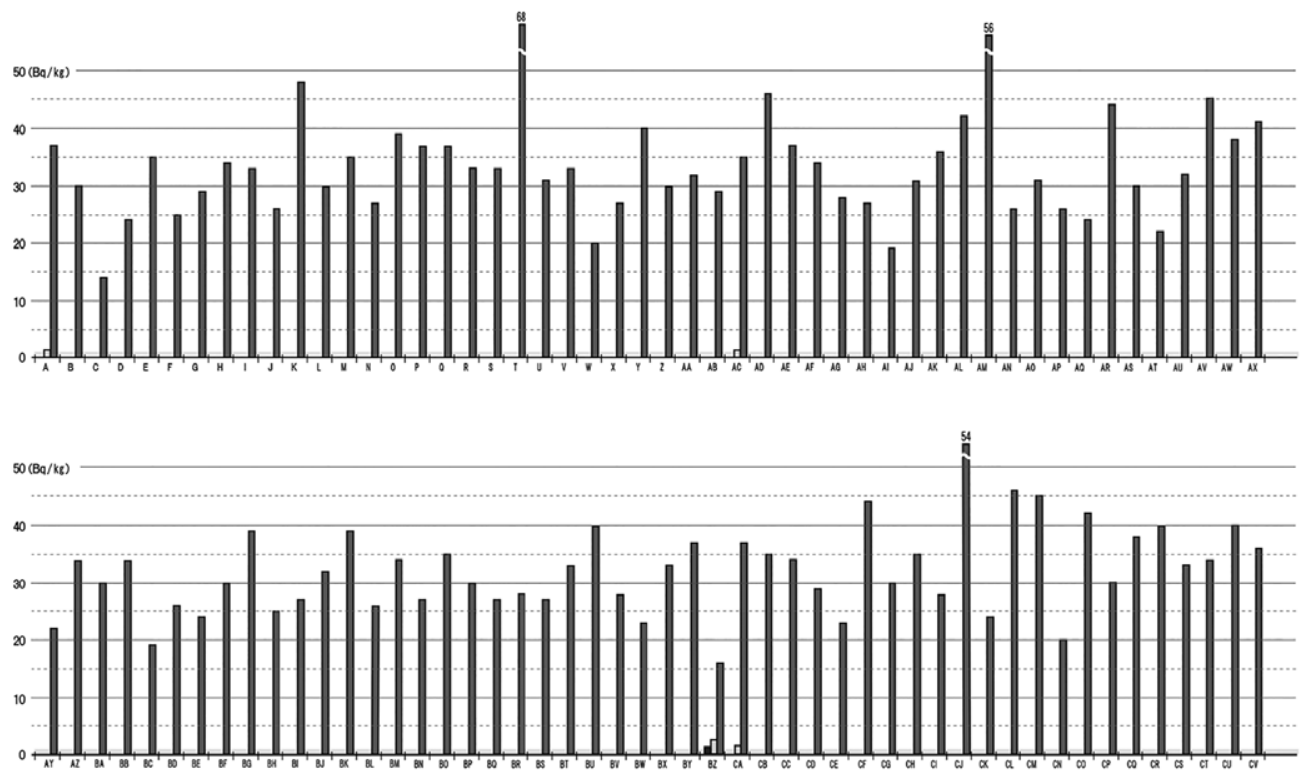

Figure 5 Duplicate diet method radiation dosage survey results (reported on Mardh 7, 2014) Retrieved from Co-op Fukushima website.

Prefectures: Aomori, Yamanashi, and Nagasaki. The results show that there was no difference in the percentages of A1 and A2 between Fukushima Prefecture and other prefectures (Figure 6).

In terms of the $\mathrm{B}$ and $\mathrm{C}$ verdicts, malignancy or possible malignancy totaled 109 people (Among them, 85 people were operated on. Breakdown: benign tubercle, 1; papillary cancer, 81; poorly differentiated cancer, 3 ) ; the ratio of male to female, 38-71; average age, 17.2 \pm 2.7 years (8-21 years; at the time of the earthquake, $14.8 \pm 2.6$ years (6-18 years) ; and average tumor diameter, $14.1 \pm 7.3 \mathrm{~mm}(5.1-40.5 \mathrm{~mm})$ as of November 11, 2014. It is said that thyroid cancer in children because the Chernobyl disaster increased beginning 4-5 years after the accident, and the primary ages of onset were babies and toddlers. On the other hand, most of the malignancy to possible malignancy cases were in their late teens according to the results of the thyroid inspection conducted in Fukushima (Figure 7).

If the thyroid cancer cases detected in the thyroid inspections currently being performed in Fukushima are occurring due to the exposure to radioiodine generated by the nuclear plant accident, the cases should be more detectable among local children in the area where the radiation dose was high, and in infants and toddlers said to be susceptible to radiation exposure. However, there have been no differences seen in the rate of onset among children in Hamadori District, the evacuation zone, Nakadori District, and Aizu District.

In addition, as shown in Table 3, the dosage in Fukushima was considerably lower than that in the Chernobyl disaster. Therefore, it is considered to be appropriate to assume that the thyroid cancer cases currently being detected are not due to the effects of radiation exposure, but something that already existed that is being detected early by the screenings.

The progress of thyroid cancer, and papillary cancer in particular is slow, and it is said 
First round thyroid examination: Comparison of Fukushima Prefecture and three other Prefectures

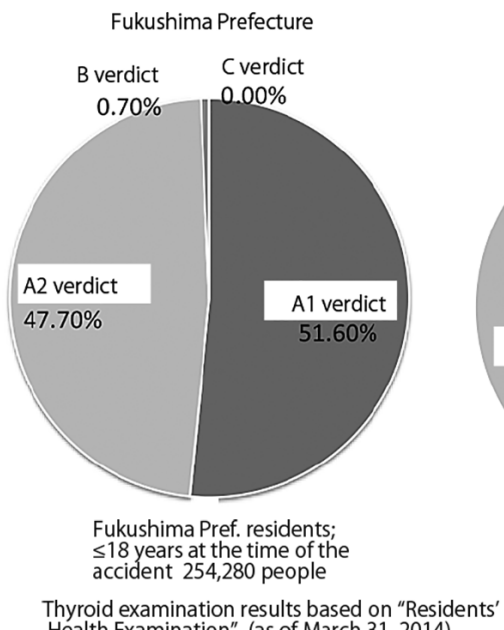

Thyroid examination results based on "Resident
Health Examination" (as of March 31, 2014)
Three other Prefectures

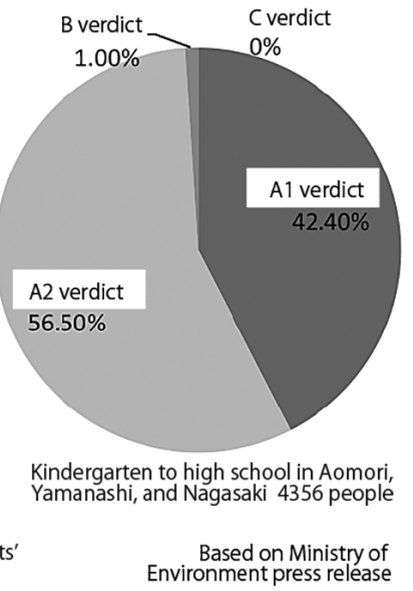

Figure 6 Comparison of Fukushima and three other Prefectures

Total from 2011-2013

- Malignancy to possible malignancy; 109 (operated, 85: benign tubercle, 1; papillary cancer, 81; poorly differentiated cancer, 3 )

- Male: female $=38: 71$

- Average age, $17.2 \pm 2.7$ years (8-21 years); at the time of the earthquake, $14.8 \pm 2.6$ years (6-18 years) - Average tumor diameter, $14.1 \pm 7.3 \mathrm{~mm}(5.1-40.5 \mathrm{~mm})$

Age and gender distribution of 104 people diagnosed as malignant or possibly malignant by biopsy

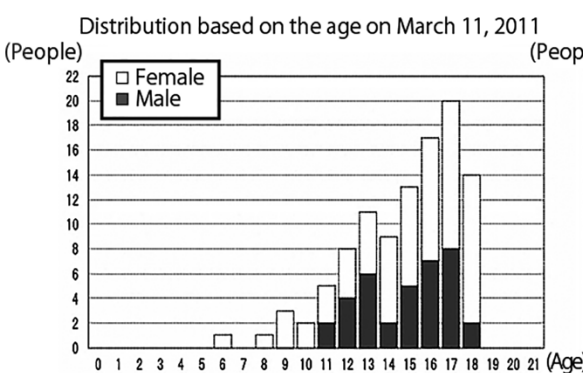

Distribution based on the age at the second-round examination

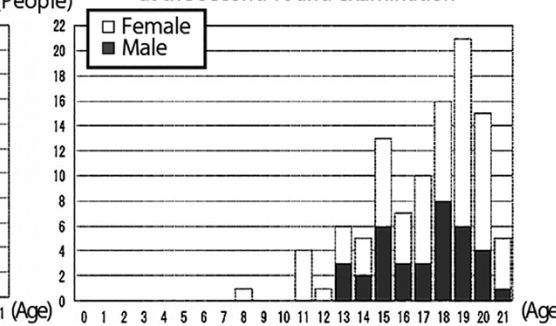

Figure 7 Overview of the results of thyroid examination in Fukushima Prefecture Retrieved from Fukushima Prefecture website.

that there is $3 \%-10 \%$ of latent thyroid cancer discovered during autopsies in cases where the victims died of another disease, and most of these are papillary cancers of $\leq 5 \mathrm{~mm}$ diameter. Thyroid cancer with a maximum diameter of $\leq 10 \mathrm{~mm}$ is classified as micro-cancer, and the majority of these are papillary cancers. It has been thought that it remains as latent cancer, because it does not develop into a clinically tangible thyroid tumor. With the recent rapid improvement in image analysis through ultrasound diagnosis, the detection rate of micro-cancers has also increased. It is well known that, when the ultrasound diagnosis of the thyroid gland is conducted in tandem with that of breast cancer in Korea, thyroid cancer 
increased. Similarly, there is a possibility that the detection rate of micro-cancers in thyroid inspection could increase as the number of cases inspected increases, which has been pointed out in Fukushima as well.

Following the first round of examinations conducted in 2011, the second round of examinations are being conducted as of April 2014. There was a report that thyroid cancer was found in four children on December 23rd of this year (2015). These four children are the ones with the A verdict in the first round. According to Fukushima Prefecture, the houses where those four children lived at the time of the accident does not have a tendency, and the dosage is much lower than that of Chernobyl; therefore, it is hard to imagine that there are effects from the Fukushima nuclear plant accident.

In Fukushima Prefecture, examinations are expected to be conducted every 2 years until the children reach 20 years of age and every 5 years thereafter. Some view these examinations as excessive. However, the author thinks that they are important for alleviating the anxiety of the citizens in the prefecture in the future to prove whether or not the radiation exposure has had any effect on the children in Fukushima Prefecture, and that the continuous follow-ups are required to protect the health of children in the future.

\section{Creativity in Life Going Forward}

The safety of all food products from Fukushima currently in the marketplace has been confirmed, and the local environmental radiation levels in the areas where the general public is living are considered to pose little to no human health influence. For the healthy growth of children in Fukushima in the future, one must nurture the five senses so as to understand the true taste and deliciousness of seasonal ingredients; engage in play using the body; and repeat experiences to directly feel the nature by touching soil, trees, plants, water, etc.

To that end, we the adults need to properly understand the meaning of becquerel and sievert and recognize that the current exposure dose that is added to the dose received from the natural environment poses almost no health effect in the future. It is also important to understand that most of the causes of cancer and other diseases are strongly affected by one's lifestyle such as smoking, alcohol consumption, an unbalanced diet, anxiety, stress, etc.; consider a lifestyle that minimizes these factors apart from the radiation; and raise children with strong hearts and serene love, while not being confused by anxiety-fomenting information.

\section{Summary}

Children, even the babies who do not yet speak, hear the conversations of adults and sense their unstable psychological conditions. That never has good effects on children's minds. The author thinks that, rather than living frightened by the slight risks that may or may not occur in the future, tidying up one's lifestyle and living every day with a bright and positive attitude leads to the healthy growth of children, which in turn plays a part in restoring normalcy.

\section{General References}

1) Japan Atomic Energy Agency. Committee on answering questions regarding radiation. [in Japanese]

2) Okazaki T. Emergency guidance on radiation exposure learned from the basics.: Iryōkagaku sha. 
2012. [in Japanese]

3) Vladimir M, Imanaka T. Overview of legal actions and studies on effect in Belarus. Radiation disaster caused by the Chernobyl accident-Report of the international joint study: Technology and humankind, October 1998. [in Japanese]

4) Consumer Affairs Agency. Questions and answers regarding foodstuffs and radiation.

5) Tashiro S. Human health influence of radiation on babies and toddlers. Nihon-Shōnikaikai Kaihō (J. of Jpn. Pediatric Assoc.). 2011; 42:51-54. [in Japanese]

6) Nakagawa K. Truth about radiation exposure and onset of cancer.: Best Shinsho; 2012. [in Japanese]

7) Takashima N. Clinicopathological study on latent thyroid cancer. Okayama-Igakukai Zasshi (J. of Okayama Medical Assoc.). 89(3\&4) :333-360 \& 1977-2004. [in Japanese]

8) Kinoshita S. Thyroid micro-cancer. Ehime-Kenritsu-Iryō-Gijyutsu-Daigaku Kiyō (Bulletin of Ehime Pref. Univ. of Health Sciences). 2010; 7(1) :1-3. [in Japanese]

9) Japan Health Physics Society. Questions and answers regarding radiation in life, July 2013.

10) Uno K. Beyond the low-dose radiation.: Shōgaku kan shinsho; 2013. [in Japanese] 


\title{
Radiation Dose Registration System for Decontamination Works and Dose Distribution of Workers
}

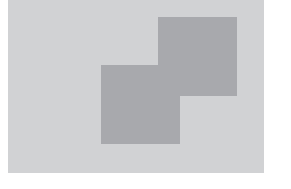

Radiation Effects Association, Kenjiro Miyabe, Atsuo Itoh, Tsuneo Yasutake and Tsubasa Ogawa

\begin{abstract}
A radiation dose registration system was established for workers engaged in decontamination and related works in areas contaminated by radioactive material discharged during the accident at the Fukushima Daiichi Nuclear Power Plant operated by the Tokyo Electric Power Co., Inc. The system has been operated by the managing body, the Radiation Dose Registration Center of the Radiation Effects Association, which periodically receive radiation dose records from the decontamination contractors. This paper reports an overview of the radiation dose registration system for workers engaged in decontamination and other works; the established work of the dose registration; and the statistics of the radiation dose of the workers based on the registered data.
\end{abstract}

KEYWORDS: Radiation dose, Decontamination worker, Dose registration system

\section{Introduction}

Decontamination and other related works have been implemented in areas contaminated by radioactive materials discharged during the Fukushima Daiichi Nuclear Power Plant Accident, which occurred after the Great East Japan earthquake. The radiation dose of the workers engaging in decontamination and other related tasks is managed by each contractor responsible for those tasks (hereinafter called "decontamination contractor") based on laws and ordinances. However, the workers often move from one contractor to another. Therefore, it is necessary to have one organization that centrally manages the radiation dose data recorded by each contractor so that the radiation dose of each worker can be easily controlled. In August 2013, the decontamination contractors established a "Committee for the Establishment of Radiation Dose Registration System for Decontamination and Related Works" and agreed to establish a system for decontamination works, similar to a "Radiation Passbook System" or a "Radiation dose registration system for nuclear workers" (hereinafter called the "nuclear worker registration system") implemented for the workers such as those in nuclear power plants. ${ }^{1)}$ As a result, the "Radiation dose registration system for radiation dose of workers

DOI : 10.15669/fukushimainsights.Vol.1.304

(C) 2021 Atomic Energy Society of Japan. All rights reserved.

Originally published in Journal of the Atomic Energy Society of Japan (ISSN 1882-2606), Vol. 57, No. 8, p. 523-526 (2015)

in Japanese. (Japanese version accepted: May 25, 2015) 
engaged in decontamination and other related works" (hereinafter called the "decontamination worker registration system") was established on November 15, 2013, to manage the radiation dose of the workers.

An overview of the implementation of the radiation dose registration system and the radiation passbook, which are combined into the nuclear worker registration system and the decontamination worker registration system, is shown in Figure 1.

In the decontamination registration system, the Radiation Dose Registration Center of the Radiation Effects Association (hereinafter called "RADREC") is the operating body. It is used to register the radiation dose and other information related to the workers engaging in decontamination and other related projects in the database, and stores and manages the data over a long term. The registered information is commonly used for inquiries related to the radiation dose and for other purposes by decontamination contractors who participated in the system, the radiation passbook issuing organization, and the nuclear operators (the radiation workers are defined as the workers who have engaged in the decontamination and other related work) to use worker-related radiation dose management.

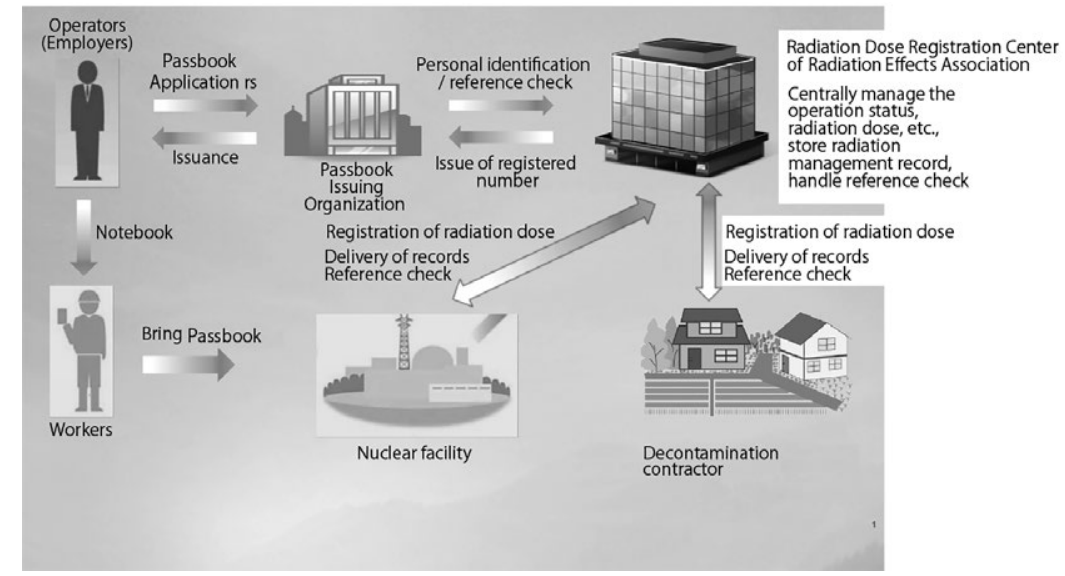

Figure 1 Implementation of the radiation dose registration management system and radiation management notebook

\section{Overview of the Decontamination Registration System}

To establish the decontamination worker registration system, the existing nuclear worker registration system was used as reference. The following features related to the decontamination and related work were also considered.

1) Since the decontamination and related works are performed by the contractors, who have little or no experience in radiation protection, it is important for the contractors to recognize the needs of the system and properly understand the implementation methods of the system.

2) Major construction companies have become the primary contractors for the full-scale decontamination projects commissioned by the national government, while small companies and joint ventures, etc., have become the original contractors for the projects ordered by the local government. Therefore, many companies are expected to participate in the system. 
3) The duration of the decontamination projects is relatively short (1 to 2 years), and there are cases in which the workplace is closed after the projects are completed. Taking this into consideration, it is necessary that the registration of radiation dose during the projects and the delivery of records after the decontamination and related work are securely performed.

4) Some workers engage in the decontamination and related projects while moving around to multiple contractors or workplaces, and some others go to, and come from, nuclear facilities and decontamination and related workplaces within a short period. Therefore, it is necessary to check the past records of the radiation doses at each movement.

\section{Scope of the System}

The decontamination registration system is intended for primary contractors engaging in the following work: "decontamination," "collection of the waste," and "handling designated contaminated soil and waste," as specified in paragraph 7 of Article 2 of the Ionizing Radiation Ordinance for Decontamination ${ }^{2}$; "works under the designated dose rate" in paragraph 8 of the Ionizing Radiation Ordinance for Decontamination; and the projects concerning the disposal of accident-derived waste, which is included in the "Radiation work" in paragraph 3 of Article 2 of the Ionizing Radiation Ordinance ${ }^{3)}$ (These operations are collectively known as "decontamination-related projects." The workers engaging in the decontamination-related projects are called "workers engaging in decontamination-related work.").

In the guidelines for the prevention of radiation hazard for workers engaging in decontamination projects, ${ }^{4,5)}$ the primary contractors shall designate a radiation protection manager and compile the radiation dose of the workers with the subcontractors (the employers working under the primary contractors). As the subcontractors are not always familiar with radiation works, the primary contractors are expected to participate in the radiation dose registration system for decontamination projects.

In the decontamination worker registration system, the primary contractors participating in the system shall perform the items listed in the right column of Table $\mathbf{1}$ depending on the classification of the project.

The following provision was specified for primary contractors in the aforementioned guidelines in accordance with the establishment of the decontamination worker registration system; "Participate in the Organization for Registration Control of Radiation Exposure Doses for Decontamination and Related Works to accurately determine the accumulated exposure

Table 1 Items to be implemented depending on the project classification

\begin{tabular}{|c|c|}
\hline Classification of decontamination operations, etc. & Items for participation in decontamination worker registration system \\
\hline $\begin{array}{l}\text { Decontamination-related projects in the special } \\
\text { decontamination area }\end{array}$ & $\begin{array}{l}\text { i) Acquisition and use of radiation passbook } \\
\text { ii) Project site registration, periodical dose registration (quarterly) } \\
\text { iii) Reference check (past radiation dose records, etc.) } \\
\text { iv) Submission of radiation dose and medical examination records for } \\
\text { ionizing radiation work (at the time of project completion) }\end{array}$ \\
\hline $\begin{array}{l}\text { Decontamination-related projects other than the special } \\
\text { decontamination area }\end{array}$ & $\begin{array}{l}\text { i) Submission of radiation dose and medical examination records for } \\
\text { ionizing radiation work (at the time of project completion) }\end{array}$ \\
\hline $\begin{array}{l}\text { Projects regarding the disposal, etc., of waste originating } \\
\text { from an accident (inside and outside of the special } \\
\text { decontamination area) }\end{array}$ & $\begin{array}{l}\text { i) Acquisition and use of radiation passbook } \\
\text { ii) Project site registration, periodical dose registration (every quarter) } \\
\text { iii) Reference check (past radiation dose record, etc.) } \\
\text { iv) Submission of radiation dose and medical examination records for } \\
\text { ionizing radiation work (at the time of project completion) }\end{array}$ \\
\hline
\end{tabular}


doses of workers and prevent exposure dose records from getting scattered or lost.

\section{Framework of the Decontamination Registration System}

\section{(1) Acquisition of Radiation Passbook}

The primary contractor of the decontamination projects and the subcontractor in charge of the management of radiation work shall implement the following: applying for issuance of radiation passbooks for workers engaging in decontamination work and recording the radiation dose on the radiation passbook.

\section{(2) Registration of Work Site and Periodical Dose}

The primary contractor shall register the name of the work site established for decontamination projects, the operation job name, and other such details into the decontamination worker registration system for each work site.

The primary contractor shall also register, on a quarterly basis, the following information (periodical dose registration) in the decontamination worker registration system within three months of the last day of the quarter:

a. Personal identification

b. Information about the project (the name of the project, start and end date of work, etc.)

c. Radiation dose (effective dose)

\section{(3) Submission of the Legal Record}

The primary contractors shall submit the radiation dose records and the ionizing medical examination records for the workers engaging in decontamination work, in accordance with laws and ordinances, to the decontamination worker registration system within three months of the end of the term of the decontamination projects.

The decontamination worker registration system stores the delivered records on the microfilm for a long time.

\section{(4) Personal History Inquiry and Disclosure Request}

The primary contractor can inquire about the radiation dose of the workers engaging in the decontamination work registered in the decontamination worker registration system and the content of the stored records. In this case, for data sharing, the primary contractor can also inquire about data and records regarding the radiation dose, etc., that other primary contractors participating in the decontamination worker registration system have registered.

The worker can also make a disclosure request about his or her own data and the record of the radiation dose, etc.

\section{(5) System Used for Registration}

In the beginning, when the decontamination worker registration system was established, a stand-alone PC was tentatively used to register the work site name, the project name, the periodical dose, and other related information. Starting on December 8, 2014, it is now possible to make, for example, online inquiries about the radiation dose of the workers engaging in decontamination work via the Internet from the exclusive terminal of the participating contractors using the system developed for the decontamination registration system.

\section{Cross Referencing with the Nuclear Worker Registration System}

The radiation dose registration system intended for workers engaging in radiation work 
in nuclear facilities started in November 1977, and the radiation dose has been centrally managed for more than 35 years along with the radiation passbook system.

Some workers often move between both nuclear facilities and decontamination project sites to engage in radiation work. Therefore, every time they start working in nuclear facilities or decontamination project sites, the radiation dose until that point (past dose record) and other related information should be confirmed.

For this reason, in order for the participating contractors in the decontamination worker registration system and the nuclear worker registration system to be able to confirm each respective information regarding the radiation dose and other such related information related to the workers, the following systems were established.

a. Using the terminal, nuclear operators can make inquiries about the information such as the radiation dose and other related information registered in the decontamination registration system, providing the information only about the workers engaging in radiation work in own nuclear facilities.

b. Using the terminal, decontamination contractors can enquire about the radiation dose and other related information registered in the nuclear worker registration system, providing the information only about workers engaging in radiation work at their own work sites.

c. The radiation passbook issuing organization can make inquires, using the terminal, about the information registered in the nuclear worker registration system and the decontamination worker registration system.

The relations between the decontamination worker registration system and the nuclear worker registration system are shown in Figure 2.

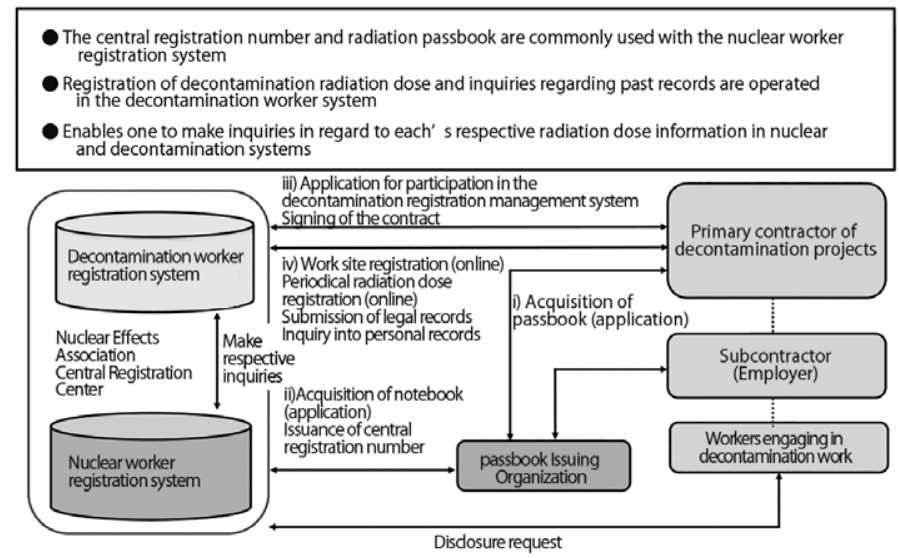

Figure 2 Relations between the decontamination worker registration system and the nuclear worker registration system

\section{Implementation of the Registration System}

The status of each registration and submission of the records in the decontamination worker registration system is shown in Table 2.

As of the end of March 2015, there were 160 operators participating in the decontamination worker registration system (operators registering the periodical doses and submitting the 
records: 49; operators performing submission only: 111).

In addition, the registration of the periodical dose is conducted on a quarterly basis in the decontamination worker registration system and the cumulative registration by the end March 2015 was 132,306 records.

Further, there were 11,226 submitted records, which were sequentially microfilmed from electronic images (records in paper-form were scanned to create the electronic image). These microfilms are stored as the original.

The information registered in the decontamination worker registration system and the nuclear worker registration system can be mutually inquired into, and there were 6,809 inquiries as of the end of March 2015.

Table 2 Status of each registration, etc., in the decontamination registration management system

\begin{tabular}{l|l|c}
\hline \multicolumn{2}{c|}{ Item } & Number of registrations, etc. \\
\hline \multirow{2}{*}{ Number of participating contractors } & Periodical dose registration and submission of records & $49^{\mathrm{i}}$ \\
\cline { 2 - 3 } & Submission of records only & $111^{\mathrm{i}}$ \\
\hline Project site registration & $154^{\mathrm{i}}$ \\
\hline \multicolumn{2}{l|}{ Registration of the name of operation } & $281^{\mathrm{i}}$ \\
\hline \multicolumn{2}{l|}{ Registration of periodical dose (quarterly basis) } & $132,306^{\mathrm{ii}}$ \\
\hline Submission of the records & $11,226^{\mathrm{ii}}$ \\
\hline
\end{tabular}

i Number of enrollments or registrations at the end of March 2015.

ii Cumulative number by the end of March 2015

\section{Radiation Dose of the Workers Engaging in Decontamination Work}

The radiation dose distribution and relevance to dose limit of workers engaging in decontamination work can be confirmed by statistical data using the periodical dose registered in the decontamination worker registration system.

\section{Data Processing Method}

\section{(1) Personal Data Processing}

The dose of each worker was processed based on their personal identification number (central registration number).

\section{(2) Dose Processing Method}

The radiation dose in 2011 was added to the 2012 statistics to create a dose distribution table in accordance with the treatment of the dose stipulated in the guideline by the Ministry of Health, Labor and Welfare ${ }^{4)}$ (The dosages received from March 11 to December 1, 2011, were considered as those received on January 1, 2012, and added) to compare with the dose limits prescribed in the Ionizing Radiation Ordinance for Decontamination.

\section{(3) Period of the Annual Dose}

The period of the annual radiation dose is from January 1 to December 31 of the corresponding year (calendar year). 


\section{Statistical Data}

The distribution of the annual radiation dose of the workers engaging in decontamination work from 2012 and 2013 is shown in Table 3.

In the 2012 statistical data, the total number of workers was 11,058, the average radiation dose was $0.5 \mathrm{mSv}$, the maximum dose of individual was $13.9 \mathrm{mSv}$, and the total dose was 5,226.0 man-mSv.

The radiation dose administered during the decontamination pilot project for the period of 2011-2012 is included in the dose statistics ${ }^{6}$. Note that $90.3 \%$ of workers'radiation doses were $1 \mathrm{mSv}$ or less.

In 2013, the total number of workers was 20,564 , the average radiation dose was $0.5 \mathrm{mSv}$, the maximum dose of individuals was $6.7 \mathrm{mSv}$, and the total dose was $10,719.8 \mathrm{man}-\mathrm{mSv}$. Note that $85.4 \%$ of workers' radiation doses were $1 \mathrm{mSv}$ or less.

Note that the annual radiation dose of the workers engaging in decontamination work in 2012 and 2013 was less than the dose limit (50m Sv/year) specified in the Ionizing Radiation Ordinance for Decontamination. Furthermore, the annual average dose was $0.5 \mathrm{mSv}$, which is less than half the average dose of the radiation workers in nuclear facilities in $2009\left(1.1 \mathrm{mSv}^{7}\right)$ before the accident at the Tokyo Electric Power Co., Fukushima Daiichi Nuclear Power Plant.

Table 3 Radiation Dose Distribution of workers engaging in decontamination work (Number of Workers and Percentage)

\begin{tabular}{|c|c|c|c|c|c|c|c|c|c|c|c|}
\hline Year & $\leq 1 \mathrm{mSv}$ & $\begin{array}{l}1<\text { and } \\
\leq 3 \mathrm{mSv}\end{array}$ & $\begin{array}{l}3<\text { and } \\
\leq 5 \mathrm{mSv}\end{array}$ & $\begin{array}{c}5<\text { and } \\
\leq 10 \mathrm{mSv}\end{array}$ & $\begin{array}{l}10<\text { and } \\
\leq 15 \mathrm{mSv}\end{array}$ & $\begin{array}{l}15<\text { and } \\
\leq 20 \mathrm{mSv}\end{array}$ & $\begin{array}{c}20 \mathrm{mSv} \\
<\end{array}$ & $\begin{array}{c}\text { Total } \\
\text { (Number of } \\
\text { Workers) }\end{array}$ & $\begin{array}{c}\text { Total } \\
\text { Dose } \\
\text { (man-mSv) }\end{array}$ & $\begin{array}{c}\text { Average } \\
\text { Dose } \\
(\mathrm{mSv})\end{array}$ & $\begin{array}{l}\text { Max } \\
\text { Dose } \\
(\mathrm{mSv})\end{array}$ \\
\hline \multirow{2}{*}{2012} & 9,989 & 738 & 169 & 130 & 32 & 0 & 0 & \multirow{2}{*}{11,058} & \multirow{2}{*}{$5,226.0$} & \multirow{2}{*}{0.5} & \multirow{2}{*}{13.9} \\
\hline & $90.3 \%$ & $6.7 \%$ & $1.5 \%$ & $1.2 \%$ & $0.3 \%$ & $0 \%$ & $0 \%$ & & & & \\
\hline \multirow{2}{*}{2013} & 17,569 & 2,787 & 168 & 40 & 0 & 0 & 0 & \multirow{2}{*}{20,564} & \multirow{2}{*}{$10,719.8$} & \multirow{2}{*}{0.5} & \multirow{2}{*}{6.7} \\
\hline & $85.4 \%$ & $13.6 \%$ & $0.8 \%$ & $0.2 \%$ & $0 \%$ & $0 \%$ & $0 \%$ & & & & \\
\hline
\end{tabular}

(Data registered by March 30, 2015)

\section{Summary}

Through the establishment of the decontamination registration system, the information that was previously managed by each primary contractors and subcontractor of the decontamination projects, such as the radiation dose of workers engaging in decontamination work, is now centrally registered and maintained in the RADREC database. The system has also made it possible to centrally manage each person's radiation dose together with the dose received in nuclear facilities and to handle inquiries. It is also possible to store and manage the radiation dose records and ionizing medical examination records for a significant period, which can prevent the loss of records.

To properly operate the decontamination registration system, it is necessary to spread awareness regarding the importance of the system, not only among the primary contractors participating in the system but also among the many subcontractors. It is also necessary to try to refine and improve the functionality and operability of the registration system so that the dose registration and delivery of records from the participating contractors are promptly and reliably performed. It is further necessary to make efforts to reliably operate the radiation passbook (issuance of the passbook; entry to the passbook; and return of the passbook to the 
worker when the project is completed, or he or she leaves the job).

In the decontamination projects, the radiation dose of the workers is managed based on the operational plan and the management regime of each project. However, the radiation dose of the workers in decontamination projects changes depending on the plan and goal of the project (reducing the dose), the form and the method of the operation, and environmental conditions (ambient dose rate). The statistical data regarding the radiation dose distribution and other parameters of the workers engaging in decontamination works will continue to be published in the future. The authors expect that the results will be reflected in the radiation management in the decontamination projects.

\section{References}

1) Radiation Effects Association. Interim report of the study meeting for the registration management system for radiation dose of workers engaged in the decontamination and other related works. November 15, 2013; Final report of the study meeting for the radiation dose registration management system of the workers engaging in the decontamination and other related works. December 26, 2013. [in Japanese]

2) Ministry of Health, Labor and Welfare. Ordinance on Prevention of Ionizing Radiation Hazards at Works to Decontaminate Soil and Wastes Contaminated by Radioactive Materials Resulting from the Great East Japan Earthquake and Related Works. Ministry ordinance of the Ministry of Health, Labor, 152. December 22, 2011.[in Japanese]

3) Ministry of Health, Labor and Welfare. Ordinance on the Prevention of Ionizing Radiation Hazards (amendment). Revised on 2013 July. [in Japanese]

4) Ministry of Health, Labor and Welfare. Guidelines on Prevention of Radiation Hazards for Workers Engaged in Decontamination Works(amendment). Standard, 1222-6, dated December 22, 2011. Revised on December 26, 2014. [in Japanese]

5) Ministry of Health, Labor and Welfare. Guidelines on the Prevention of Radiation Hazards for Workers. Engaged in (Nuclear) Accident-derived Waste Disposal (amendment). Standard, 0412-2, dated April 12, 2013. Revised on December 26, 2014. [in Japanese]

6) Asano T. Radiation Protection of Workers for Decontamination Pilot Project in the Contaminated Area of Fukushima Prefecture. Jpn. J. Health Phys. 2012;47(4) :241-246. [in Japanese]

7) Radiation Effects Association. http://www.rea.or.jp/ 


\title{
Sheltering or Evacuation? Role of Emergency Monitoring in Nuclear Disaster Control
}

\author{
Nagoya University, Hiromi Yamazawa \\ Aomori Prefectural Nuclear Power Safety Center, Hideki Kimura \\ Fukushima Prefecture Government, Yoshihiro Koyama \\ Tohoku University, Toshiki Iwasaki
}

\begin{abstract}
This report is a compilation of the planning session of the Health Physics and Environmental Science Subcommittee of the Atomic Energy Society of Japan that took place in the 2015 fall meeting. In addition to a lecture focused on the details and issues of monitoring required by the Nuclear Emergency Response Guidelines, lectures were conducted on the status of monitoring performed by the local prefecture at the time of the Fukushima Nuclear Power Plant Accident under the constraints of an enormous natural disaster, on lessons learned therefrom, and on the current status of reviews. In addition, the Meteorological Society of Japan, which specializes in atmospheric dispersion, conducted a lecture on the usefulness and limitations of predictive calculations and explained proposals made by the society after the accident. There are advantages and disadvantages to both the monitoring and atmospheric dispersion predictions. Therefore, overall, the session discussed that the complementary use of both will lead to a more effective disaster prevention scheme.
\end{abstract}

KEYWORDS: nuclear accident, environmental monitoring, emergency operation, emergency response scheme, atmospheric dispersion prediction

\section{Introduction}

The Nuclear Regulation Authority established the "Nuclear Emergency Response Guidelines" (hereinafter, referred to as the "guidelines") in 2012 to ensure smooth and reliable disaster responses by utility companies, government and local administrative organizations, and relevant public agencies in the event of a nuclear emergency; the current guidelines were set through the fifth process of revisions made in August 2015. The purpose of a disaster response is to prevent deterministic effects and minimize probabilistic effects of radiation. The enactment of and revisions to these guidelines were implemented based on a reflection upon numerous existing problems with regard to nuclear power disaster responses before the Fukushima Daiichi Nuclear Power Plant Accident e.g., lack of a resident-based viewpoint,

DOI : 10.15669/fukushimainsights.Vol.1.312

(C) 2021 Atomic Energy Society of Japan. All rights reserved.

Originally published in Journal of the Atomic Energy Society of Japan (ISSN 1882-2606), Vol. 58, No. 2, p. 115-120 (2016)

in Japanese. (Japanese version accepted: November 16, 2015) 
inadequate preparation of systems and materials, and the non-clarity of the decision-making process. As a basic idea, "countermeasures from a resident-based viewpoint," "continuous provision of information," and a "review for optimization" were clearly expressed in the preamble of the guidelines.

In these guidelines, the basic policy of determining the disaster response was established on the basis of the measured air dose rate, and mechanisms were established to enable decision making with regard to response measures based on clear judgment criteria. From the perspective of the ease of understanding, the guidelines are thought to be reasonable. However, it is important to clarify whether the purpose of the countermeasures based on these guidelines can be sufficiently achieved. Excluding the question of whether the judgment criteria are appropriate, the practicality of the scheme depicted by the guidelines heavily depends on how successful the emergency environmental monitoring is. The reasonability of the judgment criteria must be discussed separately. It would be worth pointing out here that determining plume countermeasures or restrictions of food and drinking water solely on the basis of air dose rates is difficult.

In the session, the primary topics of discussion included information that must be obtained through emergency monitoring to understand the environmental situation; this information serves as the basis for decision making, feasibility, and problems of monitoring. The session was configured to also include discussions on the capability of relevant atmospheric dispersion predictions. First, Hideki Kimura, Director of the Aomori Prefectural Nuclear Power Center, who participated in discussions related to monitoring when enacting the guidelines, discussed the key points and issues associated with the guidelines from the perspective of implementing monitoring. Next, Yoshihiro Koyama, Head of the Fukushima Prefectural Nuclear Power Safety Response Section at the time of the Fukushima nuclear power accident, who was in charge of controlling the response for the overall prefecture, discussed the current status and reflections. Furthermore, Toshiki Iwasaki, President of the Meteorological Society of Japan, conducted lectures on (a) recognition among research fields specializing in meteorology and atmospheric dispersion with respect to the capability and usefulness of atmospheric dispersion predictions in the event of a nuclear power accident and (b) proposals made thus far by the Meteorological Society regarding nuclear power disaster prevention.

Numerous discussions from the floor arose with regard to each of the lectures, and it is thought that the purpose of sharing the current status and problems of emergency monitoring and atmospheric dispersion predictions with all participating members was sufficiently achieved. I served as the chairman of the discussions, but due to my lack of skill in guiding discussions, summarization discussions of the overall session were not fully achieved for the most part. However, from the perspective of a chairman, it is evident that there exist respective advantages and disadvantages related to both monitoring and atmospheric dispersion predictions, and thus, an overall scheme utilizing both monitoring and atmospheric dispersion predictions in a complementary manner must be considered. I also pointed out my apprehensions about the weaknesses of the current scheme, which adopts only monitoring, as a rough conclusion of the overall session. In particular, it is unlikely that a nuclear emergency would occur alone, and therefore, we must seriously consider whether the current scheme is truly feasible and effective from the perspective of hardware and manning key personnel in a case of a nuclear power plant accident in conjunction with a major natural disaster, similar to the Fukushima nuclear power plant accident.

(Hiromi Yamazawa) 


\section{Monitoring Required by the Guidelines}

\section{Current Status of Environmental Radiation Monitoring}

Environmental radiation monitoring in Japan can be broadly classified into surveys of the impact of radiation on areas surrounding a nuclear power facility and surveys of environmental radiation levels throughout Japan. With regard to the former, the surveys are primarily conducted by the local government, where the nuclear power facility is located, along with the cooperation of the utility company. With regard to the latter, the surveys are conducted by 47 prefectures in Japan as projects commissioned by the Government of Japan. An advanced and specialized radioactivity analysis is conducted by the Japan Chemical Analysis Center. In both cases, the survey details include continuous measurements of air dose rates by monitoring posts and analysis and measurements of radioactive materials in environmental samples, e.g., atmospheric dust, drinking water, soil, seawater, and food products.

\section{Emergency Monitoring as per the Guidelines}

The idea of environmental radiation monitoring in the event of an emergency (hereinafter referred to as "emergency monitoring") was presented in the guidelines that were enacted in October 2012 and in supplementary reference documents based on the accident at Tokyo Electric Power Company's (TEPCO) Fukushima Daiichi Nuclear Power Plant that occurred in association with the Great East Japan Earthquake in March 2011.

In the initial response stage of an emergency situation, the guidelines classify emergency situations into three categories according to the status of the nuclear power facility: an alert, a site area emergency, and a general emergency. In addition, as zones in which response measures are devised with priority in the event of a nuclear emergency, in the case of a nuclear power plant, a precautionary action zone (PAZ) with a radius approximately $5 \mathrm{~km}$ from the nuclear power plant is established as a zone for the preparation of precautionary protection measures according to the emergency activity level (EAL) from the stage before the emission of radioactive materials into the environment. An urgent protective action-planning zone (UPZ) with a radius of generally $30 \mathrm{~km}$ from the power plant is established for the preparation of emergency protection measures based on the EAL and the operational intervention level (OIL).

In an alert, the Government of Japan, local governments, nuclear power utility companies, and relevant designated public institutions implement preparations for emergency monitoring. Emergency monitoring during site area emergency is primarily implemented by the Emergency Monitoring Center (EMC). If radioactive materials are emitted into the environment from the nuclear power facility, necessary measures are implemented based on the emergency monitoring results. As the judgment criteria thereof, the OIL is designated for measurable values, e.g., the air dose rates and the concentration of radioactive materials in environmental samples.

The purposes of emergency monitoring are as follows:

(1) Collect information related to the status of environmental radiation caused by a nuclear emergency.

(2) Provide materials that can be used to implement protection measures determined on the basis of the OIL.

(3) Provide materials for the evaluation of the impact of radiation on the environment and inhabitants caused by the nuclear accident. 
Among these, in the initial monitoring, priority is given to the materials required for the determination of protection measures.

Regarding monitoring for OIL1 (air dose rate of $500 \mu \mathrm{Sv} / \mathrm{h}$ ), as first priority, air dose rates continuously measured by fixed monitoring stations and portable monitoring posts are primarily used. As necessary, monitoring is implemented using monitoring cars and survey meters. The methods and locations of monitoring for an OIL2 (air dose rate of $20 \mu \mathrm{Sv} / \mathrm{h}$ ) are the same, but airborne monitoring is also conducted to supplement the measurements at the fixed observation stations.

Regarding monitoring for OIL6, which is a criterion for radioactive materials in foods and drinks, first, regions wherein the concentration of radioactive materials in foods and drinks must be measured (regions exceeding an air dose rate of $0.5 \mu \mathrm{Sv} / \mathrm{h}$ ) are identified through air dose rate measurements by the fixed observation stations and aerial monitoring. As for OIL6, initial settings of concentration are prescribed with regard to radioactive iodine, radioactive cesium, plutonium, alpha-ray emitting transuranium nuclides, and uranium targeting "drinking water, milk, and dairy products" and "vegetables, grains, meat, egg, fish, etc.," and analyses and measurements are performed thereon.

Regarding protection measures outside the UPZ, for which consideration was given to the impact of the radioactive plume emitted from the nuclear power facility, sheltering instructions are expanded to a certain range beyond the UPZ based on the conditions of the facility and the emergency monitoring results. When it has been confirmed that the radioactive plume has passed the said range, the instructions for sheltering are to be quickly lifted. To this end, information within the site and at the site boundary must be obtained, an overview of the path of the radioactive plume must be understood through monitoring using monitoring equipment within the UPZ, and mobile monitoring techniques, e.g., carborne monitoring and airborn monitoring, must be used to gather information that will contribute toward determining the passage of the radioactive plume in the expanded protection area.

\section{Future Issues and Outlook}

To correspond to the aforementioned monitoring process required by the guidelines, the system has been reinforced for measuring air dose rates and a system for publicizing the monitoring information has been developed. However, to further improve the effectiveness of monitoring, we must address the following issues.

With respect to measuring air dose rates, to cope with natural disasters, it is necessary to multiplex communication lines, increase the soundness of monitoring facilities, and establish a system for promptly enabling the replacement of devices and alternative measurements with spare devices. In addition, to gain an overall understanding of the radiation levels and estimate the path of the plume, efforts are needed to build an analysis methodology that combines measurements and numerical simulations.

To handle numerous environmental samples in the measurement of radioactive nuclides, it is recommended to develop a measurement system that transects the administrative field and establish pre-processing and measurement manuals that reflect the experiences gained through this accident. In addition, to evaluate the internal dose received by the inhabitants and understand the impact from the facility, a system for sampling and measuring radioactive nuclides in the atmosphere and a system for analyzing alpha-ray emitting nuclides (plutonium, etc.) and beta-ray emitting nuclides (strontium 90, etc.) must be reinforced.

Finally, going forward, continuing efforts are essential to "acquire data" through an effective and efficient monitoring system, to "utilize data" through the visualization of evaluation 
results and measures to notify inhabitants, and particularly to "raise personnel" by establishing a comprehensive monitoring education and support system for enhancing and reinforcing monitoring.

(Hideki Kimura)

\section{Initial Emergency Monitoring Response by Fukushima Prefecture in the Fukushima Daiichi Nuclear Power Plant Accident}

\section{Preface}

In the Fukushima Prefecture (hereinafter referred to as the "prefecture"), efforts were made to reinforce the preparation for natural disasters with respect to environmental radiation monitoring (hereinafter referred to as "emergency monitoring") in the event of a nuclear emergency. However, when the accident occurred at the Tokyo Electric Power Company's (TEPCO) Fukushima Daiichi Nuclear Power Plant (hereinafter referred to as "Daiichi Power Plant") on March 11, 2011 (hereinafter, the month and year will be omitted unless otherwise noted) due to the Great East Japan Earthquake, responses had to be implemented under major constraints, such as securing equipment, materials, and key personnel in general. In this section, I will present an overview of the status of the initial emergency monitoring activities in the prefecture.

\section{Status When the Earthquake Disaster Occurred}

\section{(1) Status of Damage to the Facility Due to the Earthquake and Tsunami}

The Fukushima Prefectural Nuclear Power Center (hereinafter referred to as "prefectural center") is located adjacent to the Fukushima Prefecture Nuclear Emergency Response Center (hereinafter referred to as "off-site center") within the town of Okuma located approximately $4.9 \mathrm{~km}$ to the west-southwest of the Daiichi Power Plant, and when the nuclear emergency occurred, the prefectural center was supposed to serve as an emergency monitoring center. Immediately after the earthquake, which exceeded a seismic intensity of 6 , the entire region suffered a power outage and a water outage due to the breakage of water pipes and public telephone lines. In addition, cell phone service became difficult to use for the most part and the function of these and other public infrastructures was lost. While significant damage to the building of the prefectural center itself was not observed and emergency power generators operated without any problems, printers, FAX machines, and other devices in the office and the measurement laboratory toppled over and additional damage was observed, such as dislocation of the shields of two of four germanium semiconductor detectors, resulting in an inability to perform measurements. Furthermore, with regard to the "environmental radiation telemetry systems" that performed focused monitoring at a total of 23 environmental radiation measurement stations installed in six towns around the nuclear power plant, four of the measurement stations were carried away by the tsunami. In addition, at around 4:42 pm on March 11, the designated wired communication line was interrupted. With the exception of one measurement station located on the site of the prefectural center, data could not be collected at the remaining measurement stations.

While in the midst of efforts to understand the damage status of the facility at the 
prefectural center (eight full-time personnel) and to restore the center, notification of the occurrence of an emergency situation based on the Act on Special Measures (Act on Special Measures Concerning Response to Environmental Contamination by Radioactive Material Released from the Accident of the Nuclear Power Plant Caused by the Tohoku District-off the Pacific Ocean Earthquake) was received and the team began advancing with emergency monitoring preparations.

Note that at that time, with regard to external communication with the prefectural center, email could be intermittently used until the early morning of March 12 but could not be used from that point onward. Even the designated communication lines prepared for use in the event of a disaster gradually became more difficult to use, and from the afternoon of March 12, satellite cell phones became the only means of communication for the most part.

\section{(2) Status of Gathering Key Personnel for Emergency Monitoring}

In the nuclear power disaster prevention plan of the prefecture, personnel from the prefectural center correspond the preparation and intensive monitoring as an intial respnse, then, an emergency monitoring team was to be organized from the personnel (total of 52 people) dispatched from local prefectural administrative organizations, local towns, and TEPCO, after which support was to be received from government agencies on a national level to enhance the system (total of 120 people). However, immediately after the earthquake, it became difficult to dispatch key personnel from the prefecture, the towns, and local organizations owing to the earthquake and tsunami response. From the early morning of March 12, i.e., the following day, key personnel dispatched from TEPCO (5 people), the Japan Atomic Energy Agency ( 7 people), and the prefecture ( 20 people) were gradually assembled and emergency monitoring activities, e.g., measuring outdoor air dose rates, were initiated. Furthermore, on March 13, personnel dispatched from the Ministry of Education, Culture, Sports, Science and Technology (MEXT) also participated. By March 14, emergency monitoring activities were being continuously implemented by approximately 30 personnel.

However, with the expansion of the evacuation range, the range subject to surveys also exceeded a range of $10 \mathrm{~km}$ from the power plant, which was the priority range for implementing emergency monitoring. Wireless communications between the prefectural center and the monitoring cars became difficult, and it was unclear how replacement personnel could be secured and how the vehicles could be refueled. These and several other issues gradually became obstacles to continuing the monitoring activities. Therefore, on the afternoon of March 14 , following discussions with the offsite center radiation team, the continuation of activities at the local site was discontinued. On the evening of the same day, the prefectural center was evacuated and the base for emergency monitoring activities was moved to the Fukushima city.

\section{Measurement Results Obtained via Emergency Monitoring}

\section{(1) Emergency Monitoring Results of the Prefectural Center}

On the early morning of March 12, the instructed evaluation range that had been within $3 \mathrm{~km}$ of the Daiichi Power Plant based on instructions issued at 9:23 pm the previous day was expanded to a $10 \mathrm{~km}$ range at 5:44 am and three survey teams for measuring air doses while traveling in monitoring cars were assembled for understanding the situation of the entire area within $10 \mathrm{~km}$ of the Daiichi Power Plant. Surveys were then conducted along National Highway No. 6 by primarily traveling in the north and south along the Pacific coast. The first survey on March 12 was conducted from 8 am to 9 am, and the second survey was conducted from 11:30 am to 1:30 pm. In each survey, air dose rates were measured at nine locations, 
atmospheric suspended dust was collected at three locations, and samples were brought back to the prefectural center, where they were analyzed for radionuclides. In the first survey, an increase in the air dose rate was observed to the north and northwest of the Daiichi Power Plant (the maximum value was $15 \mu \mathrm{Sv} / \mathrm{h}$ at a location $8 \mathrm{~km}$ to the northwest) and radioactive nuclides, e.g., iodine 131 (maximum of $166 \mathrm{~Bq} / \mathrm{m}^{3}$ of iodine 131), were confirmed from the samples of atmospheric suspended dust. In the vicinity of the main gate of the Fukushima Daiichi Nuclear Power Plant, the dose rate began to increase from around 4 am on March 12, but it was clear that the impact extended to a wide surrounding area.

At 5:39 pm on March 12, evacuation instructions were expanded to within a range of $10 \mathrm{~km}$ from the Fukushima Daini Nuclear Power Plant, and at 6:25 pm, the evacuation instructions were further expanded to within a $20 \mathrm{~km}$ radius. With a limited number of personnel and materials, deliberations regarding what type of emergency monitoring should be implemented were conducted with the off-site center radiation team. Then, on March 13, i.e., the next day, air dose rates were measured and atmospheric suspended dust samples were collected in a range from the city of Minamisoma to the city of Iwaki as well as from the Fukushima Daiichi Nuclear Power Plant to approximately $30 \mathrm{~km}$ to the north and south. The monitoring car of the Japan Atomic Energy Agency also traveled and conducted surveys from Minamisoma to Okuma and within $20 \mathrm{~km}$ in the northwest direction from the Daiichi Power Plant.

As a result, an increase in the air dose rate that exceeded $30 \mu \mathrm{Sv} / \mathrm{h}$ was confirmed in Minamisoma, the town of Namie, and the town of Futaba. Iodine 131 was also detected in the afternoon in the northern part of Iwaki.

These survey results were all reported to the radiation team of the offsite center, but the Nuclear and Industrial Safety Agency publicized only a part of them. As a result, it could not be said that the results were effectively utilized in formulating protection measures for the inhabitants, such as evacuation. In addition, in the prefecture, information sharing between the Nuclear Emergency Response Headquarters of the prefecture and the prefectural center was difficult and appropriate information was not provided to relevant organizations of the cities and towns in which evacuation was conducted. All measurement data obtained during March 11 to March 15 by the off-site center radiation team was disclosed on June 3.

Note that other than the four measurement stations that were washed away by the tsunami, four of the remaining 19 stations did not suffer power outages and the remaining 15 stations continued measurements until around March 15 when the fuel for the emergency power supply ran out. This fact became clear when data were collected later. These data were useful in analyzing the initial dispersion conditions of radioactive materials.

\section{(2) Monitoring Results Within the Prefecture}

To understand the radiation levels throughout the prefecture, independent of the surveys conducted by the prefectural center, when the nuclear emergency occurred, the prefecture decided to measure air dose rates using survey meters at local promotion bureaus established at seven locations within the prefecture. In addition, the results of the measurements initiated from March 11 to March 12 were summarized at the Nuclear Emergency Response Headquarters of the prefecture. The prefecture, with support from the monitoring organizations of other prefectures, deployed eight portable monitoring posts within a $20-50 \mathrm{~km}$ radius from the Fukushima Daiichi Nuclear Power Plant by March 13.

Through these surveys, air dose rate measurements were initiated immediately after $5 \mathrm{pm}$ on March 12 at the Prefectural Hamadori Local Promotion Bureau (Minamisoma) located approximately $25 \mathrm{~km}$ north-northwest of the Daiichi Power Plant and a dose rate increase of $20 \mu \mathrm{Sv} / \mathrm{h}$ was measured at $9 \mathrm{pm}$ on the same day. Dose rate increases were detected at the 
other six local promotion bureaus on the afternoon of March 15.

\section{Response Thereafter}

On and after March 16, from the government side, MEXT began coordinating the implementation of the environmental monitoring and publicizing the results. The prefecture set up a base for emergency monitoring at the Fukushima Branch (city of Fukushima) of the Prefectural Nuclear Power Center, and collaboration between the off-site center radiation team and the Nuclear Emergency Response Headquarters of the prefecture was finally secured. As a result, all efforts were devoted toward understanding the status of radioactive material contamination throughout the prefecture.

In addition, with regard to initial emergency monitoring activities, it was pointed out that, at prefectural headquarters, the handling of information from the System for Prediction of Environmental Emergency Dose Information (SPEEDI) and data from portable monitoring posts was inappropriate. Based on the lessons and experiences gained during the emergency phase of the earthquake, the prefecture is now endeavoring to revise the emergency monitoring system, with priority given to the following three points as initial response issues: "preparation of emergency monitoring resources and materials that can cope with natural disasters," "securing personnel for emergency monitoring in the event of a complex disaster," and "the public release of data when the off-site center is not functioning."

(Yoshihiro Koyama)

\section{Use of Numerical Prediction on Atmospheric Dispersion of Radioactive Materials Released from a Nuclear Power- Related Facility Accident (from a Working Group Report of the Meteorological Society of Japan)}

\section{Activities of the Meteorological Society of Japan}

After the accident at the Fukushima Daiichi Nuclear Power Plant (hereinafter referred to as the Fukushima Accident), the Meteorological Society of Japan established a "Working Group on Radioactive Material Dispersion in Association with an Accident at a Nuclear Power-Related Facility" (hereinafter referred to as the Working Group) to examine how to provide information when an accident involving the release of radioactive materials occurs. The Working Group concluded that a monitoring system must be established and dispersion predictions using numerical models must be used. On March 05, 2012, the Working Group announced the "Proposal on Countermeasures to Radioactive Material Dispersion in the Event of a Nuclear Power Facility Accident" under the name of the President of the Meteorological Society of Japan ${ }^{1)}$.

In the "Operation of SPEEDI" announced on October 08, 2014, the Nuclear Regulation Authority decided that "when determining protective measures, such as evacuations and temporary relocations in an emergency, calculation results through SPEEDI shall not be used" ${ }^{2}$. This differed from the opinion of the Working Group, and therefore, the Working Group assembled a "proposal related to reinforcing monitoring and prediction technology with regard to the atmospheric dispersion of radioactive materials in association with an accident at a 
nuclear power-related facility." As the Meteorological Society of Japan, the group proposed that a numerical model must be used ${ }^{3}$. At the same time, the Working Group announced a "plan for utilizing numerical prediction information related to the atmospheric dispersion of radioactive materials in association with an accident at a nuclear power-related facility" (hereinafter referred to as the "utilization plan") 4 .

From March 2015 to April 2015, the Nuclear Regulation Authority solicited public opinion regarding the guidelines (revision drafts) and the Meteorological Society of Japan submitted the opinion that numerical models should be used ${ }^{5)}$. The basic ideas of these proposals and the key points of the utilization plan assembled by the Meteorological Society of Japan and the Working Group thereof are presented below.

\section{Monitoring Data and Prediction Data}

Accurate ground level observations by monitoring posts are indispensable for monitoring actual conditions and should be proactively expanded. However, the following drawbacks should be acknowledged.

(1) The data represent currently existing conditions without lead time and their usefulness in planned evacuations are limited.

(2) The data are collected at ground level, and there is a possibility that contamination exists in regions wherein monitoring is not being implemented. Radioactive materials passing aloft might be overlooked.

(3) With accidents attributed to large-scale natural disasters, such as the Fukushima Accident, monitoring posts and communication networks will not necessarily function.

Atmospheric dispersion predictions of radioactive materials with a numerical model have a significant merit of being capable of issuing advance warnings (providing lead time). However, owing to estimation errors in source term and numerical calculation errors, the predicted absolute values have significant errors. Therefore, in the "utilization scheme," rather than absolute values, it is proposed to use the predicted values as relative indicators representing the spatiotemporal distributions of danger. The ability of numerical predictions to reproduce the approximate movement of radioactive materials in the air has been proven by the SPEEDI predictions ${ }^{6}$ that were implemented at that time as well as through the calculation model comparisons ${ }^{7)}$ made by the Science Council of Japan.

In a nuclear emergency, the monitoring data and numerical prediction data are in a mutually complementary relationship. Both should be maximally utilized to reduce damage.

\section{Key Points for Effectively Utilizing Numerical Predictions}

\section{(1) Forecasts Providing Lead Time and an Accurate Understanding of the Actual Conditions Are Both Necessary for Disaster Prevention}

Based on numerous experiences, disaster prevention systems for natural disasters have been established, in which situations are assessed by combining forecasts and actual conditions. In the case of typhoons, prediction information containing uncertainties, e.g., "tomorrow afternoon, strong typhoon winds will hit XX, and the winds could gain strength," and actual values, e.g., "today, at $3 \mathrm{pm}$, maximum wind speeds of $30 \mathrm{~m} / \mathrm{s}$ were recorded at XX," are both important disaster prevention details for reducing damage. Even in a nuclear emergency, all types of information should be used to build a scheme (disaster prevention system) for minimizing damage. 
(2) If Release Amounts are Unknown, Conduct Simulations with a Unit Amount of Release and Use the Results as Spaciotemporal Distribution of the Relative Risk

The assumption of a unit release corresponds to a worst case scenario, which may result in a false alarm, but will never fail to issue an alarm. This type of simulation also plays an important role in formulating emergency monitoring plans and in the evaluation of discrete monitoring data.

(3) The Suspension of Radioactive Materials in the Air near the Ground and the Wet Deposition are to be Separately Warned About; the Vertically Integrated Amount is used as the Potential Deposition Amount

In numerical predictions, the predicted amount of precipitation can be used to calculate the deposition amount, but prediction errors in precipitation amount distributions are large. As a result, they can cause deposition to be overlooked. Vertically integrated values for radioactive materials calculated without deposition are used as worst case scenarios (potential maximum deposition amounts) that do not overlook risk.

If a high concentration of radioactive materials is predicted in the air near the ground, issue a warning, e.g., "around the time of $\bigcirc \bigcirc$ near XX, there is a risk that the concentration of radioactive materials in the air near the ground could increase, and therefore, you must evacuate."

If a high potential deposition amount is predicted, issue a warning, e.g., "around the time of $\bigcirc \bigcirc$ near XX, there is a danger that the precipitation could Contain redioactive material." If rain has actually fallen, implement restrictions on water intake and circulation, and monitor the contamination status. If there is no precipitation, cancel the wet deposition warning.

(4) Considering the Uncertainty of Prediction Results, Assume Wider Potential Risk Areas in Terms of Time and Space

In the case of dispersion predictions for a nuclear emergency, it is important to assume worst case scenarios. It is important not to miss issuing warnings, even in the case of false alarms.

As described above, even if monitoring results are used in determining protection measures, e.g., evacuations and temporary relocations, numerical predictions can be used as forecasts for devising and evaluating monitoring plans. These predictions can also be used for avoiding unnecessary exposure during evacuation or other actions. In addition, as was learned from the Chernobyl Accident and the Fukushima Accident, even in regions relatively distant from the UPZ (radius: $30 \mathrm{~km}$ ), wet deposition can cause serious contamination. If the predicted value for the vertically integrated amount (potential deposition amount) and the values for actual precipitation conditions are used, regions with a high potential contamination can be significantly narrowed. It then becomes possible to efficiently specify the contaminated areas and implement countermeasures for food product screening in these areas. Numerical predictions provide various usage merits, and effective utilization of numerical predictions is anticipated.

(Toshiki Iwasaki)

\section{References}

1) Meteorological Society of Japan. Proposal Relating to Countermeasures to Radioactive Material Dispersion in the Event of a Nuclear Power Facility Accident. http://www.metsoc.jp/others/News/proposal_120305.pdf. 2012. [in Japanese]

2) Nuclear Regulation Authority. Operation of the System for Prediction of Environmental Emergency Dose Information (SPEEDI). http://www.nsr.go.jp/data/000027740.pdf. 2014. [in Japanese] 


\section{INSIGHTS CONCERNING THE FUKUSHIMA DAIICHI NUCLEAR ACCIDENT Vol. 1}

3) Meteorological Society of Japan. Proposal Relating to Reinforcing Monitoring and Prediction Technology with Regard to the Atmospheric Dispersion of Radioactive Material in Association with an Accident at a Nuclear Power-Related Facility. http://www.metsoc.jp/2014/12/17/2467. 2014. [in Japanese]

4) Meteorological Society of Japan Working Group. Plan for Utilizing Numeric Prediction Information Relating to the Atmospheric Dispersion of Radioactive Material in Association with an Accident at a Nuclear Power-Related Facility. http://www.metsoc.jp/default/wp-content/uploads/2014/12/teigen-201412.pdf. 2014. [in Japanese]

5) Meteorological Society of Japan, Board of Directors Meeting. Opinions Regarding Amendments to Nuclear Emergency Response Guidelines and Related Nuclear Regulation Authority Regulations. http://www.metsoc.jp/2015/03/31/3837. 2015. [in Japanese]

6) Chino M. Verification! prediction information provided by SPEEDI in Fukushima Nuclear Power Plant Accident - Information and timeliness, use in the future. J. Atomic Energy Society of Japan. 2013; 55:220-224. [in Japanese]

7) Science Council of Japan. Report. A Review of the Model Comparison of Transpotation and Deposition of Radioactive Materials Released to the Enviroment as a Result of the Tokyo Elecric Power Conpany's Fukushima Daiidhi Nuclear Power Plant Accident 103 pp. 